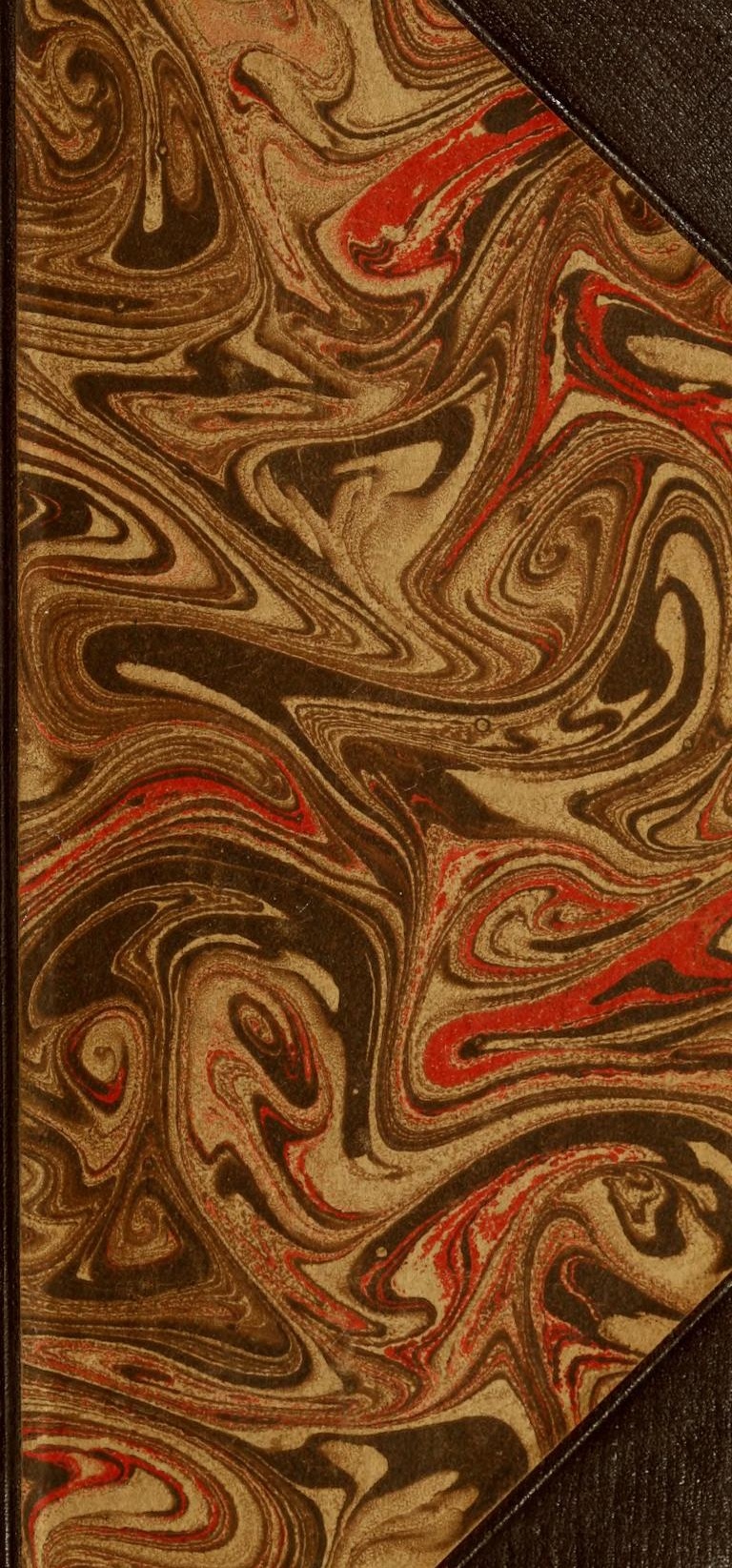





Sentiard Stejnegur 1874

COURS ELEMENTAIRE

D'IIISTOIRE NATURELLE. 


\begin{abstract}
คำ
PAKIS. IMPRIMÉ PAR BÉTIIUNE ET PLON
\end{abstract}

"बुल 


\title{
COURS ÉLÉMENTAIRE
}

\section{D'HISTOIRE NATURELLE}

A l'usage des Collégeses et des Maisons d'Bducation,

\author{
R É D I G É
}

Conformément au Programme de l'Université du 14 septembre 1840 ;

PAR

MM. MILne-EDWARDS, F.-S. BEUdANT, et A. DE JUSSIEU.

Adopté par le Conseil royal d'Instruction publique pour l'enseignement dans les Colléges.

\section{ZOOLOGIE.}

\section{PAR M. MILNE-EDWARDS,}

Membre de l'Institut, Professeur au Muséum d'Histoire naturelle et ì la Faculté des Sciences de Paris, etc

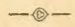

$$
\text { Are PARTIE. }
$$

Anatomie et Physiologie.

\section{PARIS.}

\section{LANGLOIS ET LECLERCQ,} Rue de la Ilarpe, \$1.
FORTIN, MASSON ET CIE, Place de l'École-de-Médecine, 1. 



\section{PROGRAMME}

POUR

\section{L'EISEGGIENEVIT DE L'HISTOIRE IITLRELL}

\section{DANS LES COLLÉGES,}

ADOPTÉ PAR LE CONSEIL ROYAL DE L'INSTRUCTION PUBLIQUE

(4 septembre 1840 )

PRE EMIELE IPATRIE

\section{STEINEGER}

\section{NOTIONS PRELLIMINAIRES ( ${ }^{2}$ ).}

1. Considérations générales sur les corps et sur la distinction à établir entre les corps bruts et les êtres organisés. - Caractères généraux de ces derniers, tirés $1^{\circ}$ de la composition chimique; $2^{\circ}$ de la structure; $3^{\circ}$ de la forme; $4^{\circ}$ de l'origine $5^{\circ}$ du mode d'existence (nutrition et accroissement); $6^{\circ}$ du mode de destruction.

Considérations sur la manière d'étudier les corps organisés. Anatomie. Physiologie. Classification. Mœurs. Distribution. Usages.

Division des êtres organisés en deux groupes: le règne animal et le règne végétal. Base de cette division: zoologie, botanique.

\section{REGNE ANIMAL.}

Caractères généraux des animaux. Notions préliminaires sur les tissus dont se compose le corps des animaux ; définition des mols organe, appareil, fonction. - Coup d'œil sur l'ensemble des phénomènes qui se manifestent chez les animaux vivants ; classification des fonctions.

II. Histoire des principales fonctions, considérées d'une manière com. parative dans toute la série animale. - Fonctions de nutrition. Absorption et exhalaison. - Digestion.

III. Sang et circulation.

IV. Respiration.

V. Assimilation. - Sécrétions. Excrétions; - Chaleur animale.

VI. Fonctions de relation. - Système nerveux. - Sensibilité; sens du toucher, du goùt, de l'odorat, de l'ouie, de la vue.

(i) La seconde et la troisieme partie de ce programme, ayant rapport à la Botanique et au Règne minéral, seront reproduites en tète des volumes consacrés à ces matières.

(2) Les chiffres romains indiquent la répartition du Programme en leçons. 
VII. Mouvements; organes moleurs (muscles); organes passifs, fo chez les animaux dépourvus de parties dures servant de leviers; 2 " chez les animaux renfermés dans un squelette tégumentaire; $3^{\circ} \mathrm{chez}$ les animaux pourvus d'un squelette intérieur. Notions sur le squelette; os ; leur structure, leur forme et leur mode d'articulation; description du squelette. (Exemple, Thomme.) - Mécanisme de la locomotion. Conformation des organes du mouvement : $1^{\circ}$ chez les animaux destinés à marcher sur terre; $2^{\circ}$ chez les animaux grimpeurs; $3^{\circ}$ chez les animaux desinés à nager; $4^{\circ}$ chez les animaux destinés à voler.

VIII. Facultés instinctives de l'homme et des animaux; Exemples. Notions sur la voix, la parole, eic.

IX. Notions générales sur le mode d'organisation des animaux. $1^{\circ}$ Rapport entre la complication plus ou moins grande de l'organisation et la perfection des facultés. - 20 Transformation des mèmes parties en instruments divers appropriés à des usages différents. - $3^{\circ}$ Coordination des organes divers réunis dans un mème organisme. Principe des harmonies organiques et de la subordination des caractères. - 40 Tendançe de la nature à ne modifier la structure des animaux que graduellement. Série zoologique ou échelle animale. Affinités naturelles des animaux.

X. Classifications zoologiques. - Application des notions précédentes à la distinction des animaux et à leur distribution méthodique. - Base de la classification des animaux : individus, espèces, genres, familles, ordres, classes, embranchemenis. Importance de la classification naturelle, comparée aux classifications artificielles. - Coup d'œil sur les grandes modifications introduites par la nature dans la conformation des animaux, et représentées dans la classification méthodique par les divisions du règne animal en embranchements et en classes.

XI. Notions sur l'organisation des animaux appartenant à chacune de ces classes, et sur les principales différences qu ils présentent dans leur structure, dans leurs fonctions et dans leurs moeurs. - Mammifères. Oiseaux.

XII. Reptiles. - Poissons.

XIII. Insectes. - Arachnides. - Crustacés et vers. - Mollúsques. Zoophytes.

XIV. Coup d'œil sur la distribution géographique des animaux. Régions zoologiques. Influence des circonstances extérieures sur la distribution des animaux à la surface du globe (température, végétation, configuration du sol, etc.). Tendance de la nature à représenter, par des esp ces distincles, les mèmes types organiques dans des régions zoologiques éloignées, mais ayant entre elles certains points de ressemblance. Exemple du mode de distribution géographique de quelques-uns des groupes précédemment étudiés et de quelques-uns des animaux les plus uliles a l'homme. 


\section{COURS HEEUENTIRE}

\section{DE ZOOLOGIE.}

\section{NOTIONS PRÉLIMINAIRES.}

S. fr. But et utilité de l'Histoire Naturelle. - On désigne sous le nom d'Historre Natrrele la seirne qui s'oreme de la strurture des corps répandus a la surface du globe, ou rémis pour en constituer la masse, desphénomenes dont ces corps soml le siego, des caracteres propres à les faire distinguer entre eux et du role qu’ils jonent dans l'ensemble de la Creation. Son domaine, eomme on le voit, est immense, et som importancene lecide pas a son étendue. (buelques hommes, peu familiers anx sciences, n'y aperenivent qu'un recueil de faits anecdotiques polus propres à piquer la curiosité qu’à exereer l’intelligence, ou bien line étude aride dr noms techniques et de classifications arbitraires; mais me pareille op)iniom ne peut avoir sa souree que dans l'ignorance, et quiconque possède les premieres notions de l'Histoire Naturelle ne peut se Pefuser ì en recomnaitre l'immense: milité. Le spertacle si grand et si harmonieux de la nature, en faisant voir combien le beau réd de la Création est au-dessus du beau idéal de's inventions humaines, éleve l'àme et ramène sans cesse l'esprit à de haules et salutaires pensées; la comnaissance de noms-mines ot des objels qui nous enfourent n'est pas faite seulement ponr salisfaire ce besom de savoir qui se développe toujours à mesure que l’intelligenee grandit; clle est une base nécessaire à bien d’antres chudes, elle est éminemment.

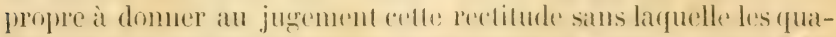
lités les plus hrillantes perdent lemr vateme, el, daus le comes de" la vie, ixarent plus somvent fluchles me romduisent ì un but utile.

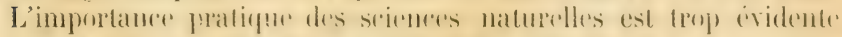

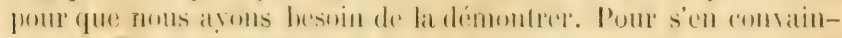

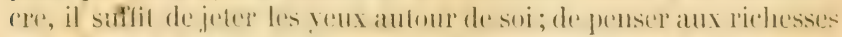

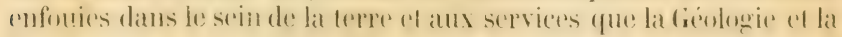

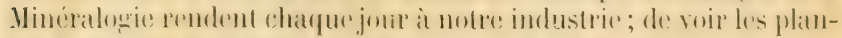
les si varues el si belles qui fommissent à mos hesolns aree mo si

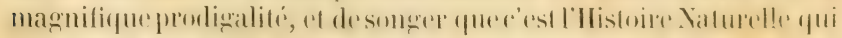

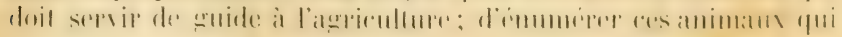


nous donnent la laine, la soie et le miel, qui nous prètent la force dont nous manquons, ou qui, loin de nous ètre utiles comme les précédents, détruisent nos récoltes; de se rappeler enfin la longue série d'infirmités dont la machine humaine est parfois affligée, et de se bien convaincre de cette vérité, que la médecine s’agite en aveugle toutes les fois qu'elle ne s'appuie pas sur l'étude scientifique de la nature de l'homme. L'importance pratique de ces études, nous le répétons, n’a pas besoin de preuves et se fait sentir, quelle que soit la carrière que l'on poursuit; mais leur utilité ne se borne pas là , et l'influence qu'elles peuvent exercer sur nos facultés ellesmèmes mérite aussi la plus sérieuse attention. En effet, les sciences naturelles, à raison de la marche qui leur est propre, accoutument l'esprit à remonter des effets aux causes, et en mème temps à soumettre sans cesse les résultats déduits des observations précédentes à l'épreuve de faits nouveaux : elle porte aux idées spéculatives les plus élevées, mais ne permet jamais à l'imagrination de s'égarer, car elle place toujours l'épreuve matérielle à coité de l'hypothèse. Enfun, mieux que toute autre étude, celle de l'Histoire Naturelle exerce l'intelligenceà la méthode, partie de la logique sans laquelle toute investigation est laboricuse, et toute exposition obscure.

L'Histoire Naturelle doit done constituer un deséléments de tout systeme libéral d'éducation; mais ce n'est pas à dire qu'il faille fairo de tout jeune homme un naturaliste. Une science aussi vaste, pour ¿̀tre approfondie, nécessiterait un temps dont les autres études classiques ne permettent pas de disposer, et comprend une foule de détails utiles seulement aux personnes qui veulent s'en vecuper d'une manière spéciale. Ce que tout homme éclairé doit savoir, ce n'esl pas le caractère à l'aide duquel on peut distinguer tel genre de plantes ou d'animaux de tel autre genre voisin, ni le trajet exact de chaque artìre ou de chaque nerf dans le corps de l'homme; en charger sa mémoire, serait l'assujettir à un travail qui ne laisserait de tracesni durables ni utiles; mais ce qu'il importe de lui donner, ce sont des notions justes sur les grandes questions dont les sciences naturelles cherchent la solution; sur la constitution du globe et les révolutions physiques qui se sont suecédé à sa surface; sur la nature des plantes et des animaux; sur la maniere dont s'exercent les fonctions de ces ères, et sur les principales modifications qui se remarquent dans leur structure, suivant le genre de vie auquel ils sont destinés. Cie sont là des commaissances qui une fois acquises ne s'oublient gruere, qui doivent servir de base aux études spéciales de quiconque veut devenir naturaliste, et qui suffisent aux hommes dont les oceupations ne se lient fas d'une manière intime aux 
sciences. Ce sont, jar conséquent, ces notions générales qu’on doit surtout chercher à graver dans l'esprit des élèves près d’achever le cours des études classiques. L'Université, dans son programme d'enseignement, a sanctionné cette marche; et dans le livre que nous publions ici, nous nous proposons de l'adopter.

\section{Division des corps naturels en trois Règnes. - L'Histoire} Naturelle, ainsi que nous l'avons déjà dit, s'occupe de tous les corps répandus à la surface du globe, ou rassemblés dans l’intérieur de la terre; et ces corps, comme chacun le sait, sont de deux espèces: les corps bruts ou minéraux, et les corps vivants ou organisés. Ces derniers se divisent à leur tour en deux groupes que personne ne peut méconnaitre: les végétaux et les animaux. Aussi dans la science, comme dans le langage ordinaire, distingue-t-on dans la nature trois grandes divisions ou RÉGNes, désignés sous les noms de Règne minéral, de Règne végétal et de Règne animal.

En abordant l'étude de l'Histoire Naturelle, on est donc nécessairement conduit à se demander en premier lieu sur quoi reposent ces divisions si évidentes, et à chercher quelles sont les différences fondamentales qui distinguent un corps brut d'un corps vivant, une plante d'un animal.

$\$ 3$. Différence entre les corps bruts et les êtres vivants. - Ces différences sont nombreuses et ressortent, quel que soit le point de vue sous lequel on compare entre eux les corps minéraux et les ètres organisés; l’origine, le genre d'existence, la durée, le mode de destruction, la forme générale, la structure intime, el jusqu’à la composition élémentaire, tout est dissemblable. Pour le démontrer, il nous suffira de quelques mots.

\$.'. Ainsi, le mode d'origine n'est pas le mème, disons-nous, pour les corps bruts et pour les ètres vivants. Effectivement, lorsqu'un corps minéral se forme, il naì immédiatement de l'union de dcux ou de plusieurs matieres qui, par leur nature, diffèrent essentiellement de la sienne, et quì se combinent entre elles à raison des affinités chimiques dont elles sont dotées. Un ètre vivant, au contraire, n'est jamais le produit de ces combinaisons spontanćes de la matiere; il ne peut se former que sous l'influence d'un corps vivant scmblable à lui, et la force vitale essenticlle à son existence se transmet far une succession non interrompue d'individus qui naissent les uns des autres, et qui se ressemblent entre eux. Le sel commun, par exemple, se formera toutes les fois que deux substances particulieres qui ne ressemblent en rien à ce produit, la soude et l'acide chlorhydrique, viendront à s'unir; et ces substances, pour se combiner ainsi, n’aurout nullement besoin de la présence 
l'un sel semblable i celui quielles vont former. Tine plante ou un animal, au contraire, n'est jamais creie ainsi de toutes pièes, et, pour se former, doit nécessairement participer d'abord à la vie d'un parent, cest-à-dire d'un corps vivant développé préalablement, et

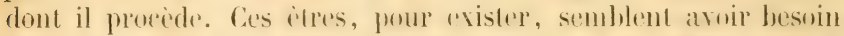
d'une impulsion étrangere; of cetle impulsion, ils ne peuvent la recevoir que d'un arops semblable à ec qu'ils seront eux-mèmes.

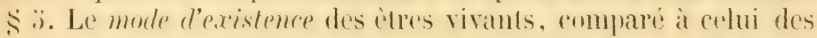
ilres inopaniques, est également caracteristique. Les erpos bruts, tels que les pierres of les mincraux, sont dans un itat premanent de repos intéricur; les molécules dont ils so composent ne se remonvellent pas; si leur volume augmente, rest semlement paree que d'autres corps semblables a eux viement se dínerser à leur surface: et s'ils perdent une partie de leur propre substance, éest aceidentellement, et par l'action dequelque forcengissant au dehors d'ens, et eomplétement independante de la cause de leur existence. Tout corps vivant est an comtraire le siege d'un monvement intérieur el incessant de composition, el de déeomposition moléculaire, par suife duypel une partie de la maliore dont il se compose se renouvelle insensiblement. Sanscesse il incorpore il sa propre substance des molécules étrangèeres qu’il puise an dehor's; et sans cesse aussi il abandome ef rend an monde estéricur une portion de sa matiere constitutive. Cette espece de tombillon constitue le phénomène de la mutrition, el sa continuite est une condition de vie pour tout ère organise. Cást aussi de ce monvement intérieur que dépendent les changements de volume que subissent les corps vivants; quand leur masse diminue, éest pare que la quantite de matieres espulsées recide celle des molécules nouvelles qu’ils s'assimilent; et quand ils s'aceroissent, éest par intussusception, el non par juxtuposition, comme chez les minéraux; catr les noteriaux monveaux ajoulés à leur masso ne se déposent pas sur leur surfare extériemer, mais pénetrent dans la profondeur de leur substane pour s'inlerposer entre les molicules deja existantes, en mène fempss qu'ils remplacent celles que le travail mutritif rejente at dehor's.

s. Enfin, aprés avoir eviste ainsi pendant un temps dont la limite extreme est determince pour chayue espere, lescorps vivants périssent infailliblement, tamelis que lescorps bruts, une fois formés, evistent lant qu'une force ctrangere ne vient pas les défruire; leur duréc n’a pas de limitr nécessaire, ef ils ne mortent en eux anem principe de destruction. Pour les ètres magunises, nous le répétons,

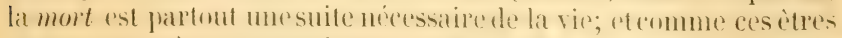

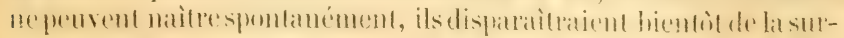




\section{NOTIONS PPELIMINAIRES.}

face de la terre, si, vulre la facultéde se mourrir, ils n'avatent aussi le pouvoir de se reproduire : mais cette propriété est ézalement accordie à tout corps vivant, et constitue aussi un des caracteres qui distinguent essentiellement les itres oromisés des corpes inorganiques.

5. Les différences qui se remarquent entre les corps bruts el les corps vivants, considerés sous le rapport de lrur forme et de leur volume, méritent aussi d'ètre signalíes. Tout comps vivant est en quelque sorte prédestiné à acquérir mo forme ginérale determince. yu’il n’offre pas lor'squ'il commence à exister, mais qui se developpe: peu ì peu; et cette forme n’a rien de la simplieité grometrique que: nous offrent les mineraux lorsque les moleroles de eeux-ci so réunissent en cristaux. Chatue ète vivant est assujeuti aussi à des limites de volume qu'il ne pent franchir, of une force interieure tend à déterminer son aceroissement, jusqu'à ce qu'il approrthe de ces limites, qui varient suivant les especes. Pour leseorplofuts, il en est tout autrement; leur masse n'a pas de limites nécessaires. In marbre, par exemple, pourra evister également bien sonis la forme d’un fragment microsenpique on d'une montagne lout entiere; une plante, un insecte, un oisean, ne pourra viver s'il n’alleint de's dimensions déterminces, et ne pourra jamais dépasser certaines limites que la nature a assignées à sa croissance. Un corps brut peut aussi ère tonjours divise mécaniquement, sans que pour cela les portions ainsi séparées changent de nature, et perdent leurs propriétés essentielles; les diverses parties d'une mème masse ne sont pas lices entre elles d'une maniere nécessaire, ef e'est par la pensée seulement quon peut admettre l'existence d'un individu minéral insécable. Chez les plantes et les animaus, an contratre, diverses parties réunies par la nature constituent un ensemble nicessaire à l'existence de charcune d'elles, mon seul tout, un être individuel distinct de ere qui l'envirnme, et ne ponvant itre mutile an delà d'un certain degré sans cesser d'exister.

š. D’autrescaractiones propres aux corps vivants somb fournis par leur strueture intime. Tonjours ils sont constitues par lateunionde parties solidesed do partirs liquides; cenles-ci sont repandues en pro-

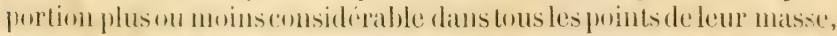
at les partios solides pour contenir ces liquides affectent la forme de lames mineres ou de filaments disposes de fareon it eireonserire des interstiens on ravites phus on moins rapporoches. Lne disposition

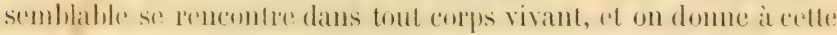
structure frencrale le nom d'oryanisation; mais, dans le Riegne. mineral, on me: voit jamais moe texture analogme. Ce mode de cont-

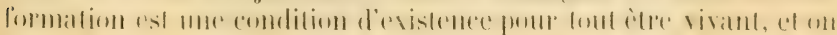


en comprendra facilement la nécessité si on réfléchit un instant à ce que nous avons dit du mouvement nutritif qui constitue le phénomène le plus constant et le plus caractéristique de la vie. En effet, pour assurer à ces corps une forme quelconque, il leur faliait évidemment des parties solides; et, pour faire pénétrer dans leur tissu intime les substances étrangères destinées à y ètre incorporées, et pour entrainer au dehors les particules qui devaient eesser d'y appartenir, il fallait aussi des fluides, car les fluides seuls offrent dans leurs molécules assez de mobilité pour se prèter à un pareil mouvenent. Ces fluides devaient pouvoir pénétrer partout où il y avait vie à entretenir, dans l'épaisseur des solides comme à leur surface, et par conséquent ces parties solides devaient nécessairement avoir une texture spongieuse et aréolaire. Il est donc impossible de concevoir l'existence d'un mouvement semblable au travail nutritif, sans un mode de structure tel que celui dont nous venons de parler, et comme nous l'avons déjà dit, l’observation apprend que cetteorganisation se retrouve dans tousles ètres vivants, dans les végétaux comme dans les animaux: aussi dome-t-on à ces ìtres le nom général de corps organisés, par opposition aux minéraux que l'on appelle corps inorganiques.

$\$ 9$. Enfin il n’est pas jusqu’à la composition élémentaire ou chimique de la matiere qui n'offre des différences importantes dans le Piegne ninéral comparé à la grande division des ètres vivants.

Un corps brut, tel qu'une pierre ou un minéral, peut ètre formé miquement par des molécules d'une mème substance simple ou élémentaire, le fer ou le soufre, par exemple, ou bien résulter de l'union de denx ou de plusieurs des éléments chimiques, dont la liste s'éleve maintenant à plus de cinquante. La Nature ne s'est imposé à cet égard aucune restriction, et, dans tout corps composé minéral, elle n’a associé les éléments constituants que dans des jroportions très-simples.

Pour les ètres vivants, il n'en est pas de mème; ils sont toujours d'une composition chimique tres-complexe, et, afin de se bien rendre compte de la nature des matériaux constitutifs de leurs corps, il faut rapporter ces matières à trois classes. En effet, parmi cessubstances, les unes se rencontrent aussi dans le Riegne minéral et n'offrent, chez les animaux et les plantes, rien de particulier; l'eau et divers sels sont dans ce cas el rentrent dans la classe des corps inorganiques. D'autres substances que l'on peut appeler des matières organiques, le sucre ef l'urée, par exemple, ressemblent beaucoup aux premicres par leur mode de constitution, mais ne se forment dans la nature que sous l'influence de la vie. Enfin d'autres encore, telles fue l'albumine, la fibrine et la cellubse, pour lesquelles, il convient de 
réserver le nom de matières organisées, ressemblent aux dernières par leur origine, mais s'en éloignent, ainsi quedes corps bruts, par des caractères chimiques d'une haute importance: elles résultent toujours de l'union de trois ou de quatre éléments déterminés; savoir le carbone, l'hydrogène et l'oxygène, soit seuls, soit combinés à un quatrième principe, l'azote; elles sont remarquablespar leur peu de stabilité et par la manière dont elles se détruisent en se putréfiant lorsqu'elles sont exposées pendant un certain temps à l'influence de l'air chaud et humide; enfin elles different des corps bruts par leur mode de constitution moléculaire, car, ainsi que la chimie nous l'apprend, tout atome d'une matière organisée résulte de l'union d'un trèsgrand nombre d'atomes des divers éléments rassemblés pour le former tandis que, dans le Règne minéral, chaque atome d'un corps composé nę contient qu'un très-petit nombre d'atomes élémentaires(1).

Or, ce sont ces matières organisées qui forment la base essentielle de toutes les parties vivantes des animaux et des plantes, qui en constituent, en quelque sorte, la trame, et les matières organiques ou minérales ne remplissent dans l'économie de ces ètres que des rôles plus ou moins secondaires. Tout corps vivant est, par conséquent, caractérisé chimiquement par la présence de ces composés particuliers de carbone, d'hydrogène et d'oxygène, ou bien d'azote uni aux trois éléments que nous venons de nommer; car, dans le Règne minéral, on ne connait pas de composé semblable.

$\$ 10$. Ainsi les corps vivants different des corps inorganiques par leur composition chimique, par leur structure intime, par leur conformation générale, par leur mode d'origine, par leur mode d'existence et par leur mode de destruction. Mais, pour les caractériser, il n'est pas nécessaire d'énumérer toutes ces différences; il suffit de dire que ce sont des étres qui senourrissent et se reproduisent; car cesont là les phénomènes les plus remarquables et lesplus généraux par lesquels la vie se manifeste.

Ce qui caractérise essentiellement les animaux.et les plantes considérés collectivement, c'est done la vie dont ces ètres jouissent, et la vie elle-mème, réduite à sa plus simple expression, c'est la faculté de se nourrir; mais, comme nous le verrons bientôt, elle ne se manifeste que rarement avec cette simplicité, et elle est en général, la cause d'une multitude d'autres phénomènes.

11. La science ne posside aucune donnée sur le principe de la

(1) Ainsi un atome dacide earbonique est forme par 1 atume de carbone uni a 2 atomes d'oxycene, tandis que 1 atome de l'espece de graisse comute sous le num de stiarine parait contenir 140 atomes de carbone, 134 atomes d'hodrogene et it atomes d'oxygène. 
vie, mais, de mime qu'en physique on persomilie en quelque sorle: la cause de la chaleur sous le nom de calorique, bien qu' n' n'en fommaisse pas la nature, de mème aussi, en physiologic, pour faciliter l'expression des faits, on admet l'existence d'une force speciale romme cause des phenomènes particuliers aux ètres vivants el inexplicables d'aprés les lois ordinaires de la chimie on de la physigue; refle foree, wn la désigne sous le nom de force vitale, mais on ignore: les lois qui la regrissent. On sait seulement qu'elle ne se développe que dans des corps organisés, ef que pour s'y manifister ces corps doivent eire placés dans certaines conditions d'existence deferminées. Ainsi une des cireonstane es indispensables a la manifestation des phenomenes vitaux, est la présence d’une certaine quantile d'eau dans le corps des ètres organisés. Il est des animaux el des plantes chez lesquels la vie est complétement suspendue par l'effet de la dessiceatlion, clsemontre de nouvean desque l'on rend à l'ètre en appatrenex mort l'humidite qui lui est necessaire; mais dans la plupart des cas cette privation d'eau entraime immédiatement la mort. Ene antre rondition d'existence pour les thes vivantsest l'influence d'une certaine temperature. Enfin tousont aussi besoin de l'influencedel'air.

$\$ 12$. Organes. - Du reste la foree vitale ne se manifeste que par l'intermédiaire desorganes ou instruments plus ou moins nombreux demb l'ensemble enstitue le eorps de l'ète vivant. Chacun des phénomienes qui se develnppent chez un animal ou vhez une plante, est le resultat de l'action d'une partie détermince de som corpls, of il existe toujours un rapport nécessaire entre la conformalion de cette partie et la nature des actes quivlle est rhargece d'evicuter. Ainsi l'homme ne pent evécuter des mouvenents que par l'interméliare de certains oryanes ou instruments appelís muscles, el ne peut avoir la connaissance de ce qui l'entonte que par l'intermédiaire des oryomes des sens, et la eonformation de chacun de ce's organes rarie suivant ses fonctions.

13. Rapports sous lesquels on étudie les êtres vivants. - li i lude der mode de comformation des oreanes d'un animal ou d'ume plante eomstitue la hranche de l'Histoire Naturelle eomme sous te mom d'analomie. Lidtade des fonctions de ces etres porte le nom de physiologie.

Lisitume col dome la scimere qui traite de la structure des corps

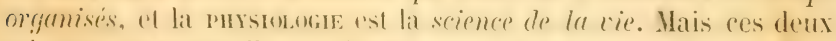
sciences onl entre olles les liatisons les phus cotroites, car la physiologie ne peut so passere de l'anatomie, et l'analomice à son tour perdrait

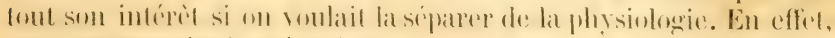

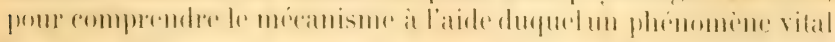


se produit, il faut avant tout eomnaitre la disposition materielle des organes qui en sont les instruments, ef, d’un autre còté, la connaissance de la structure de ces organes n'aurait que peu d'importance si on ne cherchait co mème tempes à en déconvir les usages.

L'anatomie et la physiologie constituent la base de l'Histoine Nafurelle des ètres organisés; mais ces denx sciences ne suffisent pas a la comnaissance desanimanx et des plantes, il faut aussi les étudier sous d'autres rapports. Ainsi, pour pouvoir distinguer entre ens tous ces corps dont le nombre est immense, il faut avoir recours à l'observation des particularitís qu'ils offrent, et dont on peut se servir comme de caractères, pour recommaitre avec certitude chacun d'entre eux. Il faut aussi, jour soulager la mémoire, les classer dr facon à faciliter ces distinctions, et les ranger de maniere à rendre significative la place que chacun d'en oceupe dans cette distribution, e'est-ì-dire les grouper d’après les divers degrés de similitude on de dissemblance qui se remarquent dans leur nature intime; car ì l'aide de classifications pareilles on résume en peu de mots lous les points les plus importants de l'Histoire des ètres vivants. La considiration du moele de répartition des animaux et des plantes a la surface du globe et des lois qui président à cette distribution offre égaiement de l’intérèt. Il en est de mème des usages auxquels nous employons ces corps si variés. Enfin l’Histoire Naturelle ne s'oc(upe pas seulement des ètres qui, aujourd'hui, vivent autour de nous, elle recherche les traces de ceux que le temps a détruits, et par l'examen des débris fossiles qu'ont laissés dans le sein de la terre ses antiques habitants, clle arrive ì la comnaissance de ce qui existail lorsque l'homme lui-meme n'existail pas eneore à la surfare du globe.

Cies ciludes variées se partagent naturellement en deux branches, suivant qu'elles ont pour oljet les animaux ou les plantes. On domme le $n o m$ de zoologie a l'Histoire du Regme animal, et celui de botınique à la science qui traite des régélaux. Dans ce livre nous n'aurons à nous oecuper que des animaux.

\section{Caractères yénéraux des animaux.}

1 \%. Différences entre les animaux et les plantes. - En ('om!parant les etresoreanisés aux corps bruts, nous avons fitit commiIre les caractires principaus qui distinguent le higne animal du Rigne miniral; mais ces cararteres appartiement aussi an Rienn vegretal, rat ils sont inherents a tomt ce qui vil, "l chl abordant l'hisloire des animans, ii nous faut aussi indipuer les diflépences qui les séparent des plantes. 
La limite entre le Règne animal et le Règne végétal n’est pas toujours aussi facile à reconnaitre qu'on le croirait au premier abord, car il existe des ètres d'une grande simplicité de structure qui semblent établir le passage entre ces deux groupes, et qui embarrassent quelquefois le naturaliste lorsqu'il cherche à les classer; mais dans l'immense majorité des cas, rien n'est plus facile que de distinguer un animal d'une plante, et les incertitudes dont nous venons de parler tiennent peut-ètre à l'imperfection de nos connaissances plutît qu'à la nature des choses; aussi ne convient-il pas de nous y arrèter ici, et pouvons-nous dire d'une manière grénérale que les animaux diffèrent des plantes par des caractères d'une haute imporlance tirés en mème tenps de la nature des phénomènes par lesquels la vie se manifeste chez ces ètres, de leur mode de structure, et de la composition chimique des principales matières constituantes de leurs corps.

$\$ 13$. Les actes que les végétaux exécutent ont uniquement pour objet la nutrition de l'individu ou la reproduction d'individus nouveaux. Chez les animanx, la vie se manifeste sous une forme plus compliquée: à la faculté de se nourrir et de se reproduire vient s'ajouter le pouvoir d'exécuter, sous l'influence d'un moteur intérieur, des mourements qui tendent à un but déterminé, el la faculté de sentir ou de receroir des impressions dı dehors et d'en avoir la conscience. De là est venu le nom d'êtres animés, que l'on donne aux animaux, par opposition aux végétaux, que l'on appelle des êtres inanimés.

Ainsi les végetacx sont des corps qui se nourrissent et qui peucent. se reproduire, mais qui ne sentent mi ne se meutent colontairement; les axmacx sont des corps qui se nourrissent, se reproduisent, sentent et se meuvent.

Il existe aussi des différences considérables entre la manière dont s'exercent les mèmes fonctions chez les animaux et les plantes: ainsi les actes à l'aide desquels s'effectue la nutrition ne sont pas tous les mèmes dans les deux grandes divisions des corps vivants; mais c'est seulement en itudiant ces fonctions que nous pourrons indiquer ces dissemblances, et nous y arrèter ici serait primaturé.

$\$$ 16. Cés différences dans les fonctions en entrainent de non moins considérables dans la conformation des organes ou instruments dont l'ensemble constitue le corps d'un animal ou d'une plante. Lesanimaux, flant doués d'un plus grand nombre de facultés que les végélaux, doivent nécessairenent avoir des organes plus variés, el offrir par conséquent dans leur organisation une complicatiom plus erande. Nais ce n'est pas seulement sous ce rapport que les animaux et les végritaux rlifferent anatomiquement; la structure: 
intime des tissus constitutifs de leurs organes n'est pas la mème. Les parties qui forment ces tissus, et qui sont pour ainsi dire les matériaux organiques d'un végétal, affectent essentiellement la disposition de cellules ou utricules pourvus de parois propres et creux à l'intérieur ; chez les animaux, iln'en est pas de mème; les tissus sont pour la plupart composés de filaments ou de lamelles qui s'entrecroisent de façon à circonscrire imparfaitement des lacunes, et à constituer des masses ou des membranes plus ou moins spongieuses, mais point divisées en une multitude d'utricules indépendants les uns des autres, comme chez les végétaux; souvent, il est vrai, les tissus animaux en voie de formation se montrent composés d'utricules; mais en général, cette structure qui est permanente chez les plantes, n'est que transitoire chez les animaux et ne persiste que dans les parties de l'économie où la vie est peu active, dans les membranes épidermiques, par exemple.

$\$$ 17. Enfin, aux caractères tirés des fonctions et de la structure des animaux et des plantes, il faut ajouter encore ceux fournis par la nature chimique de ces ètres. En effet, les matières organiscées qui forment la base des tissus vivants sont composées de carbone, d'hydrogène et d'oxygène seulement chez les plantes, tandis que chez les animaux ces substances résultent de l'union de l'azote avec les trois éléments dont il vient d'ètre question. Il existe bien chez les plantes des matières azotées, et chez les arimaux on trouve aussi des composés qui ne renferment pas d'azote; mais les matières organisées essentielles à la constitution des parties vivantes offrent dans les deux Règnes la composition chimique que nous venons d'indiquer.

Des tissus organiques des animaux et de leurs oryanes.

$\$$ 18. Nous avons déjà dit que diverses substances élémentaires, mais principalementl'azote, le carbone, l'hydrogène et l'oxycène, se combinent pour produire les matieres dont se compose le corps des animaux; et nous avons vu aussi que parmi les substanees ainsi constituées, il en est quelques-unes, designées sous le nom de matières organisees, qui forment la base essenticlle de toutes les parties solides animées par le mouvement vital. Ces matieres oronanisées sont moins variées quon pourrait le supjoser, car chez tous les animaux la trame de ces parties vivantes parait itre composéc prinripalement d'une substance nommée albumine, on de fibrine qui n'est probablement que de l'albumine légerenent modifice. Toutes les parties solides du corps animal se ressemblent aussi par la prisence d’une proportion considérable d'eau qui est interpenséc rutre leurs molécules, et qui contribue puissamment à leur donner la flexi- 
trilite, la mollesse et les antres proprictés physiques nécessaires pour qu'elle's remplissent les fonctions auxquelles elles sont destinées dams l'iconomie. Mais le mode de texture des solides ainsi constitués varic beaucoup, et on donne le nom de tissus organiques àces parties, qui ì leur lour se réunissent pour comstituer les organes, et qui en sont pour ainsi dire les matériaux.

19. Le's principaux tissus organiques des animaux somt au nombre de trois, savoir: les lissus musculaire, nerveux ef cellulaire.

Le tissu musculaire constitue ce que l'on nomme vulgairement la chair des animaux; il est l'agent producteur de fous leurs mouvements, et consiste toujours en filnes susceptibles de se raceourcir. Quelquefois ces fibres sont, pour ainsi dire, disséminées daus la subslance des organes; d'autres fois clles sont rassemblées en masses, et forment des muscles; mais quelle que soit leur disposition, on les distingue toujours par leur faculte contractile, ot dans le corps de l'homme, dememe quechez la plupart desamimaus, on les rencontre partout où il y a des mouvements à exécuter.

Le tissu nerreux est une matiere molle et ordinairement blanchatre, qui constitue le cerveau et les nerfs, et qui est le sieme de la faculte de sentir; en traitant des fonctions de relation, nous aurons l'oceasion d'en citudier les propriétés et les usages.

Enfun, le tissu cellulaire, que l'on nomme ainsi à cause de sa texfure areolaire et spongieuse est, de tous les matériaux constitutifs de nos organes, le plus universellement répandu. Dans quelques animaux des plus simples, il parait former la presque totalite du corps; et dansecurquiont, ainsi que l'homme, la structure la plus compliquee, ce tissu eviste en couche plus ou moins cpaisse entre tous les organes; il remplit les interstices queces parties laissent entre clles, et se rencontre aussi dans l'épaisseur de leur substance, où il sert a remir les diverses portions dont elles se composent, comme à leur surface il sert à mir les divers appareils de l'économie; il est en quelque sorte la gangue de tous les organes, et en se modifiant de diverses manieres, il domne naissance aux membranes el à me foule d'antres tissus: enfin, c'est toujours dans son épaisseur que se dépose la graisse. Ce tissu est une substance blanchàtre, demitransparente et tres-élastique, qui se eompose de filaments et de pedites lamellesplus ou moins consistants et réunis irrégulierement, de farom à laisser entre eux des lacunes ou cellules de grandeurs variables. Ces cellules n'ont que des parois incomplètes, et ne sont séparies les unes des autres que par une espece de feutrage spongiens; anssi communiquent-elles toutes ensemble, el livrent-elles un passage farcile ans lundes qui trudent at les traverser; enfin, 
elles sont toujours imbibées d'un liquide aqueux charge de partictiles alloumineuses et connu sous le nom de sérosité.

Les autres tissus organiques qui concourent aree les précédents it former les diverses parties du eorps des animaux, sont les membranes désignées par les anatomistes sous les noms de membranes séreuses et muqueuses, les diverse's varitités du tissu fibreux', les cartilages, te tissu ossenx, ete; mais, suivant toute apparence, ces tissus ne sont que des modifications du lissu collulaire, qui lantiit, eomme dans les membranes séreuse's, s'etend en grandes lamrs minces et lisses, tantit, comme dans le tissu osseux, se charge? de produits organiques particuliers, et se solidifie par le dépoit de matieres minérales dans les mailles de sa substance. Quant a l'útude plus approfondie de ces tissus, elle trourera sa place dans la suite de ce cours.

$\$ 20$. Ces tissus, diversenent combinés et affectant des formes particulières, constituent les différents organes ou instruments it l'aide desquels les facultés des animaux s'exercent.

Lorsque plusieurs organes concourent à produire un phénomène, on désigne cet assemblage d'instruments sous le nom d'appareil, ot l'on appelle fonction l'action d'un de ces organes isolé ou de l'un de ces apprareils. On dit, par exemple, appareil de la locomotion pour désigner l'ensemble des oryanes yui servent à transporter l'animal d'une place à une autre, et fonction de la locomotion pour' désigner l'action de loutes ces parties.

Ainsi que nous l'avons déja dit, la maniere dont un organe ou un appareil fonctionne dépend de sa conformation; en sorte que la structure des animaux varie autant que leurs facultés el leurs genres de vie. Chez ceux dont les facultés sont les plushornes, lesorganes, dont l'ensemble constitue le corps, présentent le moins de diversiti, tandis que chez ceux dont les fonctions sont plus variées, et chez lesquels la vie est, pour ainsi dire, plus parfaite, les organes se multiplient aussi, et le corps offere une structure plus compliquée.

\section{Classification des fonctions des animaux.}

21. Les fonctions des animaus se rapportent a deux ohjets, lit conservation de londividu et la conservation de sa race; mais. parmi les premieres, il est me distinction importante a ctablir : les

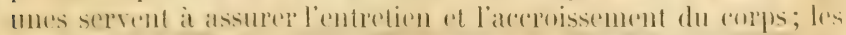
autres, it medre l'animal en relation aver les ctresquil'enviroment.

Il en resulte que les fonctions ou actes de ces itres peuvent se: diviserer en trois grandes classes, savoir: les fonctions de mulrition. les fonctions de redation al les fonctions de reprosduction. Las finte- 
lions de nutrition et de reproduction, ainsi que nous l'avons déjà vu, sont communes aux plantes et aux animaux; aussi leur donnet-on le nom collectif de fonctions de la vie végétative; mais les fonctions de relation n'existent que chez ces derniers et constituent ce que les physiologistes appellent la vie animale.

Chacune de ces grandes divisions physiologiques se subdivise à son tour en plusieurs séries de phénomènes qui tendent bien à un mème but final, mais qui sont plus ou moins distinctes entre elles; enfin,chacun de ces phénomènes est, en général, le résultat de l'action de plusieurs agents. Ainsi la nutrition d'un animal, par exemple, ne s'effectue que par le concours de diverses fonctions, telles que la digestion, la circulation, la respiration, ete.; le travail digestif à son tour se compose d'un nombre plus ou moins considérable d'actes distincts, la mastication, la déglutition, la transformation desaliments en chyme, la production du chyle ou extraction des parties essentiellement nutritives contenues dans le chyme, l'absorption dece chyle et l'expulsion du résidualimentaire désormais inutile dans l'économie: enfin cette mastication, cette dighlutition, et tous cesactes que nous venons d'énumérer sont eux-mèmes le résultat de divers phénomènes particuliers, tels que le mouvement musculaire dont dépendent le rapprochement et l'écartement alternatif des màchoires, et la production des sucs propres à modifier la constitution des aliments.

522 . Du reste, rien n'est plus varié que la manière dont les diverses fonctions des animaux s'exécutent, et comme la structure de leurs organes est toujours en harmonie parfaite avec les usagesauxquels la nature les a destinés, il existe aussi une variété étonnante dans le mode d'organisation de ces ètres. Chez les uns, les facultés sont des plus bornces et la structure est des plus simples; chez d'autres, cette structure offre une complication extrème et la vie se manifestepar les phénomines lesplus variés. A mesure que nousavancerons dansl'élude des fonctions des animaux, nous aurons à signaler cette diversité, et, si le temps nous le permettait, nous pourrions aussi, à chaque pas, domner de nouvelles preuves de l'accord admirable qui règne entre le mode d'organisation de chacun de ces ètres et son mode d'existence; mais c'estaprèsavoir passé en revue toutes les fonctions que nous nous arreterons sur ces comsidérations, car c'est alors seulement que nos jeunes Jecteurs pourront en saisir toute la portée.

Nous allons donc: aborder maintenant l'étude des principales fonctions des animanx, et mous mous ocemperons d'abord de celles qui ont pentr objet le maintien de la vie de l’individu, ćest-ìdire les fonctions de untrition. 


\section{HISTOIRE}

\section{DES PIINCIPALES FONCTIONS DES ANIMAU.}

\section{DES FONGTIONS DE NUTRITION.}

\$23. La nutrition des ètres vivants consiste, ainsi que nous l'avons déjà dit, dans l’introduction de certaines matières étrangères jusque dans la profondeur des tissus dont l'ensemble constitue le corps, de l'assimilation, la fixation et l'organisation des matières ainsi introduites; enfin dans l'expulsion des molécules qui se séparent des parties vivantes, et qui peuvent ètre comparées à des matériaux vieillis et mis hors d'usage dont l'économie a besoin de se débarrasser.

Il est donc évident que la première condition nécessaire à la production de ce phénomène intérieur de composition et de décomposition moléculaire est la faculté d'absorber les matières étrangères, c'est-à-dire de s'en laisser pénétrer, de les attirer du dehors et de les admettre jusque dans la profondeur des organes. L'absorption, en effet, est une fonction commune à tous les ètres vivants.

$\$ 24$. Chez les plantes, cette seule faculté suffit à l'introduction de toutes les matières nécessairesà la nutrition de ces ètres, et e’est directement qu'ils puisent autour d'eux tout ce qui doit pénétrer dans la substance de leurs organes; mais chez les animaux, il n'en est pas de mème. Ceux-ci admettent bien de la sorte une partie des matériaux nouveaux qu'ils doivent assimiler au tissu de leurs organes; mais ils ne trouvent pas autour d'eux la totalité de ces matériaux tout préparés, et ils ont besoin d'approprier à leur usage la plupart des matières nutritives avant que de les absorber. Ce travail préliminaire, cette préparation des substances alimentaires nécessaire à leur introduction dans l'économie animale par la voie de l'absorption, constitue le phénomène de la digestion et peut ètre signalé comme un des traits distinctifs des animaux comparés aux plantes.

$\$ 23$. C'est donc par absorption que les matières, puisées directement au dehors ou préparées par le travail digestif, sont admises dans l'intérieur de l'économie animale, où elles se mèlent aux humeurs du corps. Ces liquides les répandent ensuite partout où elles doivent pénétrer; quelquefois ce transport ne se fait qu'avec lenteur et ne s'effectue que par l'effet d'un phénomène intérieur analogue à celui qui a déterminé leur introduction dans le corjs, c'est-ì-dire l'absorption; mais, chez presque tous les animaux, la distribution rapide et réguliere des matieres nutritives dans toutes les parties 
de l'eronomic est assure par l'existence de commants qui parcourent sans cesse tout le corps el qui servent en mème temps à entrainer au foin les molécules éliminées de la substance des organes par lo travail mutritif. Ce mourement du fluide nourricier est déterminé par l'action d'un apjareil plus ou moins compliqué, et constitue une troisieme srande fonction de mutrition, celle de la circulation du sany.

$\$$ 2ti. Le fuide nourricier, en circulant ainsi à travers la substance des opranes, ne tarde pas it perdec la propricte d'y entretenie la vie; mais, pour retrouver sa qualité vivifiante, il lui suffic du contact de l'air. Par ce contact, il se charge d'un principe parliculier, l'uxygens, qui en modifie lesproprietés, et en mème temps il se débarrasse d'autres matieres dont la présence est nuisible at l'annomie. Ces rapports entre l'air et le fluide nourricier constifuent le phinumene de la respiration, et cette fonction, de mème yur labsmption el la digestion, est un des principaux actes de la vie végétalive chez les animaux.

$\$ 27$. La digestion, l’absorption, la respiration et la circulation sont des actes préparatoires pour le phénomène essentiel de la nuIrition; celui-ci consiste dans la fixation des molécules nouvelles dans la substance des tissus virants, l'assimilation de ees molérules à ceux dont la partic est déjà formée, leur organisation et leur participation à la vie commune de l'ensemble ainsi constitué. Ce travail est désigné par les physiologistes sous les noms d'assimilation ou de NUTRITION PropREMEXT DITE.

5 28. Enfin les matieres éliminées des tissus par suite du renonvillement de molécules inhérent au mode d'existence des ètres viVants; ces matieres, qui ne participent plus a la vie et qui sont devenues en quelque sorte étrangeres à l'économie, ne doivent pas Y demeurer, et, pour que leur sortie soit possible, il est évident que les animaus, de mème que les plantes, doivent ètre le siege d'un phinnmine inverse de l'absorption. C'est effectivement cequi a lien; mais la manièe dont les excrétions s'effectuent n'est pas toujours identique; tantiot est un simple passage, en quelque sorte mécatnique, des matieres les plus fluides des humeurs qui s'échappent an dehors; d'antres foris éest un travail chimique qui opere la sératration de liquidesparticuliers dont la nature differe essentiellement. de celle du fluide nomricier qui les fommit. On domme au premier.

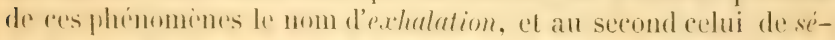

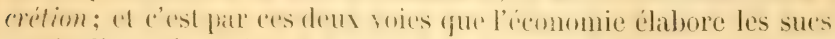

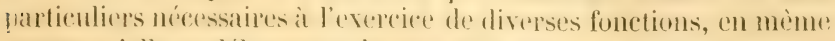

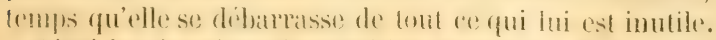

tinsi fes fonctions de mutrition consistent essentiellement dans 
l'alssorption, la digestion, la circulation, la respiration, l'assimilattion, l'exhalation et les séerétions. Ce sont, flar conséfuent, ces erands actes de la vie végétative que nous devons maintenant étudier successivement.

DE L' ABSORPTION゙.

$\$$ 29. L'absorption est l'acte par lequel les itres vivants pompent en quelque sorte, et font pénetrer, dins la masse de leurs humeurs, les substances qui les enviromnent, on qui sont déposées dans l'intérieur de leurs corps.

Pour constater l'existence decette facultíabsorbante, il suffit d'un petit nombre d'erpériences. Si l'on plonge dans de l'eau le corps d'une grenouille, de facon ì ce que le liquide ne puisse s'introduire daus la bouche de l'animal, on truuve néanmoins qu'au bout d'un certain temps son poids augmente: or, cette augmentation qui, dans des circonstances favorables, s'élève jusqu'au tiers du poids total de l'animal, ne peut évidemment déperidre que de l'absorption de l'eau par la surface exlérieure du corps.

Si l'on introduit une quantité connue d'eau dans l'estomae: d'un chien, et qu'à l'aide de deux ligatures on ferme toutes les ouvertures qui font communiquer la cavité de cet organe avec d'autres parties, le liquide n'en disparaitra pas moins au bout de pen de: temps, car il sera cibsorbé par les parois de l'estomac ot se melera ainsi au sang.

Il n'existe cependant, à la surface de la peau ou de l'eslomace ni pores (1) ni ouvertures quelconques qui conduisent directement dans les vaisseaux sanguins, el qui servent au passagedes liquidesabsorbés. Mais les tissus qui forment ces organe's, de mine que ceux de: toutes les autres parties du corps, ont une structure plus on moins spongieuse, et sont tous plus ou moins perméables aux liquides.

En effet, dans le corps vivant comme sur le cadavre, ces tissus s'imbibent toujours des fluides qui les baignent, et se laissent traverser par eux avec plus ou moins de facilité.

$\$ 30$. Mécanisme de l'absorption. - La perméabilití des partices solides des corps organisés suffit dija pour nous faire comprendre comment l'abserputiom est possible. A l'aide de celle propriete des

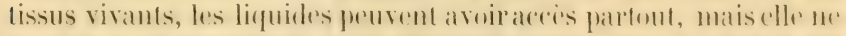

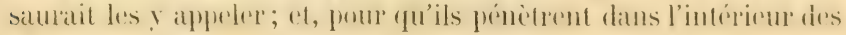

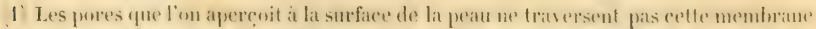

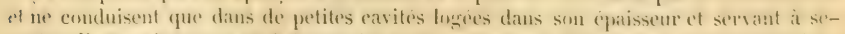

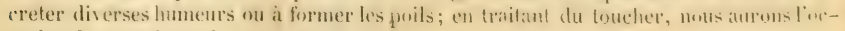
casion de revenir sur la structure de la peau. 
organes, il faut nécessairement qu’ils soient sollicités à le faire par une force quelconque.

L'attraction capillaire (1) contribue puissamment à produire cette imbibition; mais elle n'est pas la seule force qui agisse dans ce sens, et pour se former une idée exacte du mécanisme à l'aide duquel les liquides pénètrent dans la substance des tissus organiques, il est nécessaire de comnaitre un phénomène très-curieux, découvert il y a quelques années par II. Dutrochet, et désigné par lui sous le nom d'endosmose.

Ce physiologiste a constaté que, si l'on renferme de l'eau gom-

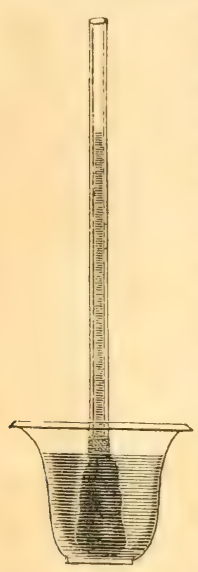

Fig. 1. mée dans un petit sac membraneux surmonté d'un tube et baigné par de l'eau pure (fig. 1), ce dernier liquide pénètre dans l’intérieur de l'appareil, et s'élève dans le tube à une hauteur considérable. Il y a done ici une véritable absorption, et la force qui la détermine agit souvent avec assez d'énergie pour faire équilibre à une colonne d'eau de plusieurs centimètres. En plaçant au contraire de l'eau gommée ou sucrée au dehors du sac memloraneux, et de l'eau pure dans son intérieur, le passage a lieu en sens inverse, et le sac, au lieu de se remplir, se vide.

Ce phénomène a la plus grande analogie avec l'absorption qui a lieu chez les ètres vivants, et l'explication en est facile à trouver. Nous avons vu que les membranes organiques, de mème que tous les corps spongieux ou poreux, se laissent traverser par les liquides; mais la facilité avec laquelle ce transport a lieu varie suivant que ces liquides sont plus ou moins fluides et mouillent plus ou moins facilement ces espèces de filtres. Si les deux liquides, placés dans l'intérieur et à l'extérieur de la poche membraneuse, pouvaient traverser avec la mème rapidité les parois de cette cavité, ils se mèleraient

(1) On donne en phỵsique le nom d'atlraction capillaire à l'attraction qui se manifeste entre les liquides et les parois d'un tube tres-etroit ou la surface d'un corps quelconque qui s'y trouve plonge en partie, et qui determine l'élévalion de la portion du liquide ainsi influence au-dessus de son niveau primitif ou bien son abaissement. Cette force devient surtout evidente dans linterieur de tubes de tres-petite dimension, et determine l'ascension du liquide toutes les fois que celui-ci peut mouiller les parois du tube et presente par conséquent, dans son interieur, une surface concave. C"est par l'effet de la capillarite que l'huile monte dans la meche d'une lampe et que l'eau se rupand rapidement dans toutes les parties d'm morceau de sucre dont la parlie inferieure senlement est plongee dans le liguide. 


\section{DE L'ABSORPTION.}

igalement, et le mème niveau s'établirait en dedans et au dehors de l'instrument. Mais sile liquide extérieur traverse plus facilement les parois du sac que le liquide intérieur, le courant du dehors en dedans sera plus rapide que le courant en sens contraire, et le liquide s'accumulera dans l'intérieur de l'appareil. Or, c'est ce qui a lieu quand il y a endosmose; l'eau qui baigne le sac renfermant l'eau gommée filtre facilementà travers les parois decette cavité, et lorsqu’elle est arrivée dans son intérieur, elle s'unit à la gomme, et forme ainsi un liquide nouveau dont le passage à travers ces mèmes parois est d'autant plus difficile, que la quantité de gomme est plus considérable: elle doit done s'y accumuler, et s'élever dans le tube vertical qui communique avec le réservoir membraneux.

$\S 31$. Les corps organisés qui absorbent du dehors les liquides dont ils sont entourés sont placés dans les mèmes conditions que le sac membraneux dont nous venons de parler; il est done à présumer que, dans tous les cas, les mèmes effets sont dus à des causes analogues, et que la force principale qui détermine le passage des substances absorbées à travers les membranes vivantes est la mème que celle dont dépend le phénomène de l'endosmose.

$\$ 32$. Organes de l'absorption. - Dans certains animaux des classes inférieures, ceux dont la structure est la moins compliquée et les facultés les plus bornées, l'absorption ne consiste que dans l'espèce d'imbibition dont nous venons de parler. C'est par le mème mécanisme que les substances étrangères traversent l'épaisseur des parties solides avec lesquelles elles sont en contact, pour aller se mèler aux liquides dont les aréoles de ces organes sont remplies; qu'elles se répandent ensuite dans le reste du corps, et qu’elles pénètrent dans la profondeur de tous les tissus. Chez les animaux dans lesquels il se fait une circulation régulière, l'absorption proprement dite, ou le passage des substances étrangères du dehors dans l'intérieur de l'économie, s'effectue toujours de la mème manière que chez les ètres moins parfaits; mais, dumoment où ces substances en traversant de la sorte les tissus pénètrent dans les vaisseaux, dont ceux-ci sont creusés, et qu'elles s'y mèlent aux sues nomrriciers du corps, les choses se passent tout autrement; car, au lieu de continuer ì se répandre de proche en proche dans les diverses parties par l'effet de l'imbibition, elles son' entrainées par des courants plus ou moins rapides, et distribuées immédiatement daus tous les points ou le sang lui-mème pénètre. On voit done que l'absorption de ces matières é leur transport dans l'intérieur de l'économie ne sont plus $11 n$ acte unique, mais se composent de deux séries de phénomenes parfaitement distincts: les unis, purement locaux, consistent dans l’imbibi- 
tion des tissus et dans le mélange des matieres absorbées avec les humeurs contenues dans les vaisseaux de ces parties; les autres, dépendant d’une circulation générale, consistent dans le transport do ces mèmes substances dans les parties éloignées de celles ou elles avaient d'abort pénétré.

$\$ 33$. Chez tous ces ètres, l'agent principal à l'aide duquel ce transport s'effectue est le sang qui traverse les organes où l'absorption a lieu, et qui retourne par les veines vers le cour, pour se porter ensnite de nouveau dans l'épaisseur des divers tissus. Il s'ensuit que chez les animaux pourvus d'un systeme circulatoire les veines jouent un rôle très-important dans l'absorption, et que, dans l'immense majorité des cas, c'est par leur intermédiaire que les liquides, dont un point circonscrit du corps est imbibé, se répandent dans toute l'économie.

\$3'. Chez un grand nombre d’animaux, c'est seulement par l'intermédiaire des vaisseaux sanguins que l'absorption s'effectue; mais, chez l'homme ef la plupart des autres animaux dont l'oreqanisation est la plus compliquere, il existe un autre systeme de canaux, qui servent an mène usage, ef qui paraissent ètrespécialement destinés it absorber certaines substances déterminces. C'est l'appareil des vaisseaux lymphatiques.

On domne ce nom ì des camanx qui naissent par des radicules extremement délies dans la profondeur des divers oreanes, et qui, après s'ètre réunis en trone's plus ou moins gros, ront enfin déboucher dans les veines. Leurs parois sont transparenteset d'unegrande délicatesse; ils communiquent fréquemment entre eux par des anastomoses $(1)$ et se rémissent successivement de facon à constituer des branches plus grosses, lesquelles se joignent à leur tour pour former des tromes d'un diamelre de plus en plus considérable. Chez l'homme et les autres mammiferes, on en trouve dans presque toutes les parties du corps, soit sous la peau, soit plus profondément, et la plupart de ces vaisseaux se terminent dans un gros trone nommé canal thoracique, qui remonte dans l'abdomen et le thorax au-devant de la colome vertibrale et va deboucher dans une grosse veine silué pres du corur, à sauche de la hase du cou, et applelie reme sous-clacière gauche; mais d'autress'ourrent isolément dans la veine du coite opposé du eou, on mème quelquefois dans dirers vaisseraux sanguins situés phus pros de leur origrine. Pendant leur trajet, on les roit passer à travers de petits organes irrégulierenent arrondis, ed silués aux aisselles, au pli de l'aine, au cou, dans la poitrine et dans

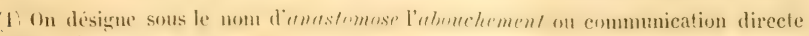
do deux vaisseans entre enx. 
l'abdomen (voyez fig. 26). La structure et les usages deces corps sont encore peu commus; on les appelle ganglions lymphatiques. Enfin. dans l'intérieur des vaisseaus lymphatiques, il existe un grand nomJre de replis iransversaux (fui remplissent les fonctions de valvules, et qui s'opposent an reflux du liquide contenu dans leur cavite.

On a constaté l'existence des vaisseaux lymphatiques rhez les oiseaux, les reptiles et les poissons, aussi bien que chez les mammiferes. Chez divers reptiles, tels que la grenouille, cetappareil offre mème une structure plus compliquée que chez les animaux supeirieurs, car les vaisseaux lymphatiques sont en communication avec un certain nombre de réservoirs contractiles qui battent d'une manière régulière, et qui peuvent ètre considérés comme des espèces de cours lymphatiques.

ร33. Le liquide contenu dans le systeme des vaisseaux lymphatiques porte le nom de lymphe. Lor'squ'il n'est pas mècé aux produits de la digestion, il est légèrement jaunitre el transparent; examiné au microseope, on y dícourre des globules incolores qui paraissent itre spheriques et qui sont plus pelits que les globules rouges dont nous aurons bientòt à signaler l'existence dans le sang; abandonné it lui-mème, il se eoagule à peu près comme ce dernicr liquide, mais avec moins de force; enfin, soumis à l'analy se chimique, il se montre composé d'eau, d'albumine, de fibrine el de divers sels.

On ne sait que peu de chose sur les mouvements de la lymphe dans l'intérieur des vaisseaux lymphatiques; ainsi que nous le verrons en étudiant la digestion, ce liquide remonte quelquefois avec beaucoup de force dans le canal thoracique, et en dernicr résultat il va toujours se mèler au sang dans les grosses veines siluées près du cour.

$\$ 36$. Rien n’est plus facile que de demontrer l'absorption qui a lieu dans certains organes par l'intermédiaire des vaisseaux lymphatiques; pour le faire, il suffit d'ouvrir l'alidomen d'un animal dont la digestion est en pleine activité, car on trouve alors tous les vaisseaux lymphatiques des intestins garorges d'un linguide lacté provenant des matieres alimentaires, landis que, chez un animal it jeun, ils paraissent presque vides et incolores.

L'absorption qui at lieu directement par les veines est également prouve par les exprériences faites sur les animaux vivants, ed on a meme comstate de lit sorte que e'est par l'intermédiaire de ces vaisseaux yue la plupart des matieres absorbees pénetrent dans l'éenomic; les vaissoam lymphatiques servent principaleme-nt it l'introducliondes produits nutritifs ćlabores par lat digestion, el prorbablement anssi at l'absomption du residu fourni par le travail motritif dams la profondeur de loutes les parties de l'éomomice. 
$\S 37$. Circonstances qui influent sur l'absorption. - D'après ce que nous avons dit du mécanisme de l'absorption, on comprendra facilement quelles sont les principales circonstances qui doivent influer sur la marche de cette fonction.

Ainsi, la première condition de toute absorption étant la perméabilité des tissus interposés entre la substance qui doit ètre absorbée et les liquides qui serviront à en effectuer le transport, il est évident que, toutes choses égales d'ailleurs, ce phénomène doit étre d'autant plus rapide, que ce tissu lui-même offre une texture plus lâche et plus spongieuse.

Un autre principe également facile à déduire des faits déjà exposés, c'est que, toutes choses égales d'ailleurs, la rapidité de l'absorption doit être en raison du degré de cascularité du tissu qui en est le siége.

En effet, la texture làche et spongieuse des solides organiques est, de toutes les propriétés physiques, celle qui doit faciliter davantage l'imbibition, et les veines étant la route principale par laquelle les substances absorbées se répandent au loin dans l'économie, l’influence du nombre plus ou moins grand de ces vaisseaux et de leur grosseur est trop évidente pour nécessiter aucun commentaire.

Dans la plupart des cas, ces deux lois suffisent déjà pour nous fournir l'explication des différences énormes quel'on remarque dans la rapidité avec laquelle l'absorption s'effectue dans diverses parties du corps; elles pourraient mème nous faire prévoir ces différences, d'après la seule considération de la disposition anatomique de nos organes.

Ainsi, les poumons, dont nous ferons connaitre plus tard la structure et les fonctions, sont, de toutes les parties de l'économie, celle dont la structure est la plus spongieuse, et dont le système vasculaire est le plus déreloppé. Il s'ensuit que l'absorption doit ètre plus rapide dans ces organes que partout ailleurs, et c'est effectivement le résultat auquel on est arrivé par l'expérience.

La substance molle et blanchàtre que l'on trouve entre tous les organes, et que l'on nomme le tissu cellulaire, est aussi très-perméable aux liquides, mais on y trouve bien moins de vaisseaux simguiins que dans le tissu du poumon: aussi l'absorption s y fait-elle avee moins de vitesse que dans ces organes, sans laisser cependant que d'ètre encore très-rapide.

La pean présente, au contraire, une texture très-dense, et sia surface est recouverte d'une espèce de vernis peu perméable formi par l'épiderme; en général, les vaisseaux sanguins y sont également petits et peu nombreux; et, comme on pouvait s'y attendre d'après 


\section{DE L'ABSORPTION.}

cette disposition anatomique, l'absorption ne s'y fait que très-difficilement. Le peu de perméabilité de l'épiderme nous explique aussi pourquoi on peut manier sans danger la plupart des poisons les plus violents, pourvu toutefois que la peau des mains soit intacte, car alors l'absorption est à peu près nulle; tandis que les accidents les plus graves peuvent ètre le résultat du contact de ces mèmes substances sur un point où la peau est entamée par une coupure, ou seulement dépouillée de son épiderme.

Une autre circonstance qui exerce aussi une influence très-considérable sur la rapidité de l'absorption, est l'état de pléthore (1) plus ou moins grand de l'animal.

La quantité de liquide qui peut ètre contenu dans le corps d'un animal vivant a des limites, de mème que le degré de dessiccation compatible avec la vie. Or, plus le corps approche de son point de saturation, plus les liquides éprouvent de difficulté pour pénétrer dans son intérieur.

Ainsi, que l'on administre à deux chiens des doses égales d'un poison, dont les effets ne se manifestent qu'après son absorption, et que, préalablement à cette opération. on diminue la masse des humeurs chez l'un de ces animaux au moyen d'une saignée copieuse, tandis que, chez l'autre, on augmente le volume des liquides contenus dans le corps, par l'injection d'une certaine quantité d'eau dans les veines: l'empoisonnement aura lieu chez le premier avec plus de rapidité que dans les cas ordinaires; et, chez le dernier, les symptômes qui dénotent l'absorption du poison ne se montreront qu'après un temps bien plus long.

Enfin, la nature des substances absorbées influe aussi sur la promptitude avec laquelle elles pénètrent dans l'épaisseur des tissus, et sont portées dans le torrent de la circulation. En thèse générale, on peut dire que, toutes choses égales d'ailleurs, l'absorption scra d'autant plus rapide, que les liquides sont moins denses et mouillent plus facilement les tissus; pour les solides, il faut tenir compte, en premier lieu, de leur degré de solubilité, et ensuite des propriétés physiques des dissolutions qu'ils forment.

DE LA DIGESTION.

\$38. Une des principales voies par lesquelles s'effectue l'absor'ption des matières nécessaires à la nutrition des animaux est unc cavité ouverte au dehors, et servant, en mème temps, à la prépat-

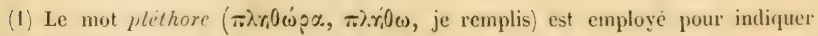
l'état de plénitude du système vasculaire. 
ration que diverse's de ces matieres doivent subir pour devenir propres à ètre aiusi absorbées. Ce travail préalahle constitue, comme nous lavons deja dit, le phénomène de la vigestrox.

$\$ 39$. Aliments. - On puurrait domner le nom d'aliments à toutes les substances qui, introduites dans le corps d'un ètre vivant, servent à son aceroissement, ou ì reparer les pertes quil iprouve continuellement; mais, en général, on restreint davantage le sens de ce mot, et on ne l'applique qu'aux matieres qui ne sont absorbees ot ne servent à la nutrition qu’apres avoir été digreres. Pour plus de clarté, nous ne l'emploierons que sotis cette derniere atception.

Les aliments ne sont pas moins nécessaires a l'entreticn de la vie que l'air que nous respirons, ou que l'ean que notie corps absorbe continuellement, soit à l'ital liquide el sous la forme de boisson, soit a l'eitat de vapeur. Lorsque les animaus en sont privés, on voit leur corps diminuer de volume, leurs forces s'affaiblir, et la mort survenir toujours apres des souffrances plus ou moins prolongées.

Le besoin d'aliments se fait d'abord commaitre par me sensation particuliere, qui a som siege dans l'estomate : la faim. Il est augmenté par l'exercice, par l’influence stimulinte d'un froid modéré, ef par l'action que certaines substances anceres, telles que le cachou, exereent sur l'estomate. An contraire, tout ce qui tend à ralentir le mouvement vital, l’immobilité, le sommeil, ete., tend aussi à rendre ce besoin moins imperiens. Les animaux qui s'engourdissent pendant l'hiver ne prennent aueun aliment pendant tout le temps que dure leur léthargie; et les animaux it sang froid, tels que les poissons ef les grenouilles, peuvent supporter une abstinence tres-lonsue, lorsque l'exercice de leurs diverses fonctions est ralenti par l'influence d'une température très-basse. Mais les animan dont le mouvement mutritif est tres-rapide, tels que l'homme et la plupart des mammiferes, périssent en général tres-promptement par le défaut d'aliments, ct les jeunesanimaux, dont lanutrition est bien plus active que celle des adultes (puisque le volume de leur corps augmentecontinuellement, au lirude rester stationnaire), meurent aussi de faim plus lit que cerus-ci. Ce que le Dante a décrit, avec des rouleurs si vives, dins le célichre épisode du comte Lgolin, est done bien réellement ce qui arriverait, si un homme déjà parvenu au terme de sa croissane, et des enfants en bas àge, se trouvaient privés en mème temps de toute espece de nomriture.

Les aliments sont tous fournis par le regne organique, et c'est toujours aux dépens de substanees qui ont elles-mèmes fait partie d'un ère vivant, que la vie est entretenue chez l'homme et chez tous les autres animaux. 
Du reste, toutes les substances alimentaires ne possident pas au mème degré la propriété nutritive, ct des expériences très-curieuses ont fail voir que, pour la plupart des animaux au moins, le concours d'un certain nombre de matières différentes était indispensable pour subvenir aux besoins de la vie. Ainsi, des lapins, nourris avec une seule substance, tel que du froment, des choux, de l'avoine ou des carottes, meurent, dans l'espace d'environ quinze jours, avec toute l'apparence de l'inanition; tandis que, nourris avec ces mèmes substances, données concurremment ou successirement it de petits intervalles, ces animaux vivent et se portent bien.

La diversité et la multiplicité des aliments sont done une régle importante d'hygiène; et en cela, les préceptes de la science sont parfaitement d'accord avee notre instinet et avee le's variations que les saisons apportent dans les substances alimentaires qui nous sont offertes par la nature.

On a constate anssi que les substances, telles que le sucre, lit gomme, l'huile et la graisse, dans la composition desquelles il n'entre pas d'azote, ne peuvent suftire pour la nourriture des animaux, mème lorsfuion les varie le plus. L'usage d'une certaine quantité d'aliments azotés, tels que la chair musculaire, le gluten, yui se trouve daus le blé de froment, l'albumine, ete., parail ètre indispensable à l'entretien de la vie de tous ces ètres. Du reste, ces diverses substances qui peurent servir d'aliments varient suivant la nature des animan, et ces différences, comme nous le verrons par la suite, sont toujours en rapport avec d'autres differences dans l'organisation.

$\$$ 40. Appareil digestif. - La digestion a pour whjet: 1" de siparer la partie nutritive des aliments d'aree les parties qui ne possèdent pas cette qualité et qui doiventère rejetées sous la forme de fèces; $2^{\circ}$ de transformer la partie nutritire de ces substances e'l un liquide particulier, propre is se mèler au sang jour nourrir lecorgs, et désigné par lesphysiologistes sous le nom de chyle.

Cette élaboration des matieresmutritives s'effectue principalement par l'action de certaines humeurs sur les aliments, el elle a tonjour's lieu dans une eaviti phus on moins valste gui renferme ces humenrs, et qui communique aussi an dehors, afin de peecroir dans son interieur les substances cestimies à elre digérées, ef de pousoir rejeder ensuite les feeps ou residu laisse par le travail digestif. Cefte "spreere

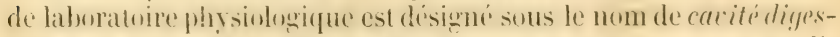

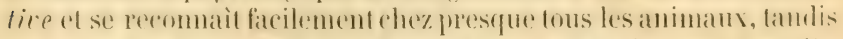
que chez les plantes qui nont jamais besoin de prefoarer les maliores mutritives avaut do les absorber, on me voit rien de semblialde. 
\$. Chez quelques animaux, la cavité digestive n'est qu'une

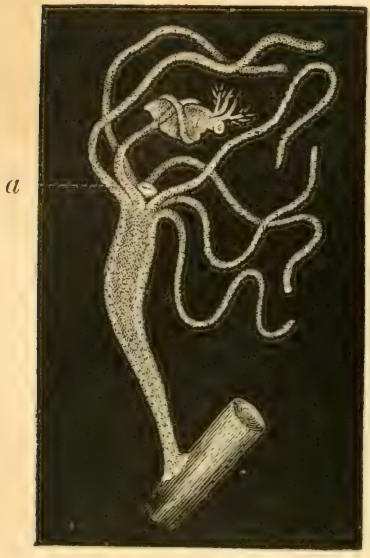

Fig. . Hydre ou Polype d'eau douce. anus, est spécialement destinée à livrer passage au résidu fécal.

La cavité alimentaire affecte alors la forme d'un tube ouvertà ses deux bouts, et ordinairement élargi vers le milieu, afin que les matièresnutritives puissent mieux s'y accumuler et y séjourner pendant le temps nécessaire à leur digestion (fig. 3). L'espèce de chambre formée par l'élargissement du tube alimentaire, et destinée à ètre le siége des phénomènes les plus essentiels de la digestion, est nommée estomac. Tantòt il existe une seule de ces grandes cavités digestives, tantòt deux ou plusieurs, et cette derniere disposition se remarque surlout chez les animaux herbivores, tandis que chez les animaux destinés à vivre de chair l'estomac est leplus ordinairement simple; et la raison de cette différence est facile à comprendre, car la viande, se digérant plus vite et plus facilement que l'herbe, n'a pas besoin de séjourner aussi longtemps dans les organes de la digestion.

$\$$ 42. La cavité digestive tout entière est tapissée par une membrane dite muqueuse qui, par sa structure, offre beaucoup d'analogie avec la peau dont elle est la continuation, mais qui en differe far sa texture plus molle, par l'absence presque complète d'épiderme, par une plus grande abondance de petits vaisseaux sanguins ef de pores sécréteurs. Autour de cette membrane muqueuse se trouve une tunique charnue formée par des fibres musculaires plus ou moins abondautes, et servant, par leurscontractions, soit à pousser les substances alimentaires de la bouche jusqu’à l'anus, soit à les 
arrèter dans leur marche et à les faire síjourner, pendant un certain temps, dans telle ou telle partie de l'appareil digestif. Enfin, dans une Glande maxillaire. Glande parotide.

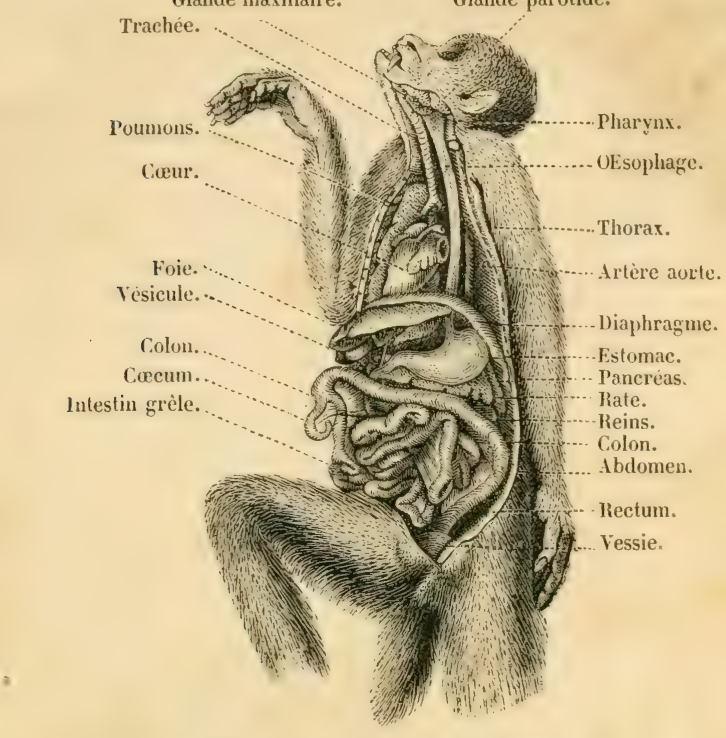

Trachée.

Fig. 5. Appareil digestif d'un Singe.

grande partie de son étendue, le tube alimentaire de lat plupart des animaux est encore enveloppé d'une membrane séreuse, mince et transparente, appelée péritoine, qui sert en mème temps à le fixer et à faciliter ses mouvements.

$\$$ 43. La digestion des aliments s'effectue principalement, avonsnous dit, par l'action de diverses humeurs dont ces sulsstances s'imbibent pendant leur séjour daus la cavité alimentaire. La production de ces sues digestifs est le résultat d'un travail de sécrétion, ayant son siege dans desoronanes particuliers, appelés d'une manière grenérale des glandes; aussi l'appareil de La digestion ne se composet-il pats seulement du tube alimentaire, mais aussi de divers organes grlandulaires situés à l'entour, el destinés à verser daus sa cavité des liquides particuliers. Le nombre de ces organes sécréteurs valrie chez les différents animaux, mais en général ils sont assez nombreux. Les plus importants sont les grlandes gastriques, le foie, le pancreas ef les glandes salivaires (fig. 3 ef 20 i). 


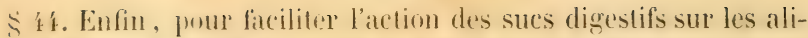
ments, il est utile que ces matières soient divisées mécaniquement. Chez la plupart des animaux les plus inférieurs, cette division ne sopère que d'ume maniere tres-imparfaite par suite de la compression qu'exercent sur les matieres en digestion les parois minces et faibles du tube alimentaire. Quelquefois l'estomac lui-mime aequiert assez de force pour pouvoir broyer les corps introduits dans sa catvilé ; est e qui se voil chez les crabes, les oiseaux ranivores, ele.: mais en grinéral la division mécanique des aliments est confice par la nature a des instrumentsparticuliers placés ver's l'entrée du tube digestif, el disposies de facon à pouvoir couper ou broser ces malieres; ces instruments sont les dents, et on domne le nom d'oryamis masticuteurs à ces dents ef aux parties qui servent à les metre en mouvement.

\$.;. D'apries ce que nous renons de dire on peut voir que si l'appareil digestif est d'une grande simplicité chez quelques animaux inférienrs, tels que les polypes, il offe, an contraire, chez les animaux supérieurs unc complication evtrème. Chez ces derniers, le tube alimentaire s'étend d'une extrémité du corps à l'autre, mais la plus grande partie de l’appar cil digestif est logée dans une vaste cavité qui occupe toute la portion postérieure ou inférieure du tronce equiest désignée sous le nom d'abdomen ou ventre (fig. 3). Chezl'homme el les antres mammiferes, cette cavite est separe du thoras (oupoitrine) far une cloison charnue, formce par le muscle diaphragme, el elle es terminée infiricurement par le bassin, espèce de large ceinture usseuse (fig. 77) dont le milien est occupe par une sorte de plancher charnu. En arriere, elle est bornce par l'épine du dos, et en avant, comme sur les coites, ses parois sont formées par de larges muscles, 'qui s'étendent du thorax au bassin dont nous venons de parler. Lat surface interne de cetle cavilé est tapissée par le péritoine, et celte membrane forme en outre divers replis entre les feuillets desquels sont renfermés les principaux visceres. Ces replis, appelés mésenleres, naissent tons de la partie postérieure de l'abdomen, et quelques-uns d'entre eus se probongent beaucoup au delà de l'oreane yüils doivent recourrir, et forment ainsi des especes de voiles ou de tabliers, nommés épiploons.

Le tube alinentaire ainsi logé prend, dans ses diverses portions, des noms différents. Sa partie antirieure élargie, et remphlissant les usages d'ume sorte de vestibule, est appelie bouche. La cavité gui y fail suite se nomme arriere-bouche ou pharyna: (voyez fig. :3); lat troisiome partie du canal digestif constitue

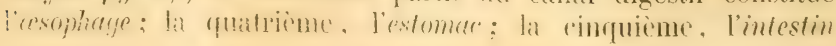


gréle; et la sixieme, le gros intestin, qui se termine it l'amus.

$\$ 46$. Actes du travail digestif. - Les phénomènes qui ont lieu daus ces diverses parties de l'appareil digestif constituent une série d'actes plus ou moins distincts, et doivent itre classés dans l'ordre suirant: 1" la préhension des aliments; 20 la mastication; $3^{\circ}$ l'insalivation; to la déglutition; 30 la chymitication on digestion stomacale; $6^{\circ}$ la chylification ou digestion intestinale; $7^{\circ}$ la defécation; 8o l'absorption du chyle.

Nous allons maintenant étudier sucessivement ces divers actes du travail digestif et les organes qui l's produisent chez l’homme et les animaux les plus rapprochés de nous.

\section{Préhension des aliments.}

$\$$ \{. Lintroduction des aliments dams le canal digestif s'eflectue: de diverses manieres, et le mécanisme en est varié stuivant que ces substances sont solides on liquides; néanmoins, chez l'homme, elle se fait toujours, soit a l'aide des mouvements de la bouche, soit au moyen des membres supérieurs.

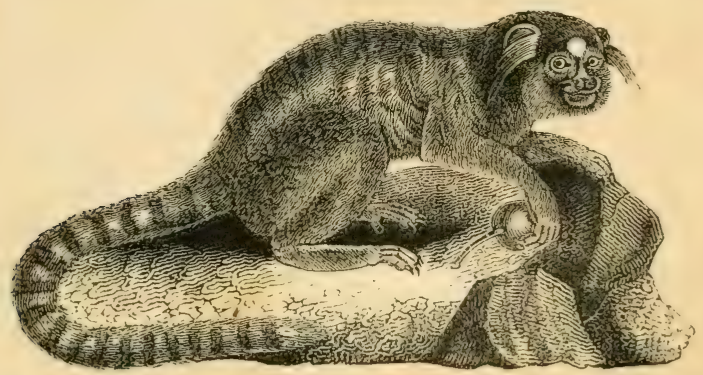

Fig - Onistili il pinceau.

Peur les anatomistes, la bonche un consiste pas seulement dans l'ouverture qui sépare les deu levers, mais dans la cavité ovalaire formese en hat par la màchoire suprepiempe et le palais, en bas pal la lansue et la michoire inforienre, lateralement par les jumes, en arriere par le voile du palais, el en avant par les liveres. Linver-

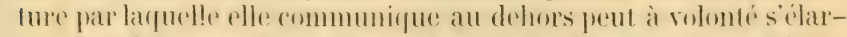
grir el se fermer, soit par le mourement des leveres, soit par l'écartement ou le rapprochement des matohoires. Il est done facile de comprendere comment alle pent servir à la préhension des aliments.

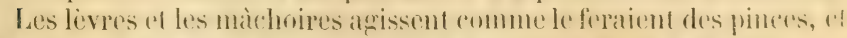

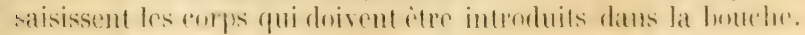


Chez la plupart des animaux, ce sont ces mèmes organes qui vont au-devant des aliments, pour s'en saisir; mais chez l'homme, les singes (fig. 4) et quelques autres animaux, la division du travail est en général portée plus loin; car ce sont les membres antérieurs qui rem-plissent ces fonctions. La main place les aliments dans la bouche, et les lèvres et les màchoires ne se rapprochent que pour les y retenir.

Certains animaux dont les mouvements sont lents ou dont l'ou-

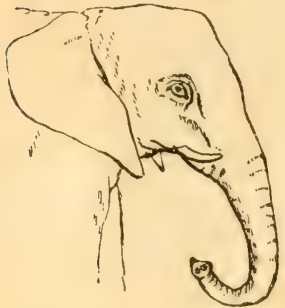

Fig. 5. Têle d'Éléphant. verture bucale est très-petite, s'emparent de leur proie à l'aide d'une langue très-longue et très-protractile. Enfin, chez d'autres, la préhension de ces matières est facilitée par l'action d'un prolongement du nez, tel que la trompe de l'éléphant ( $f g .5$ ), ou par les mouvements d'espèces de barbillons qui entourent la bouche et qui, chez les insectes, sont désignés sous le nom de palpes (fig. 6 et 7, a), tandis qu'on les appelle des tentacules chez les mollusques $(f g .8, a)$, les polypes (fig. 2), etc.

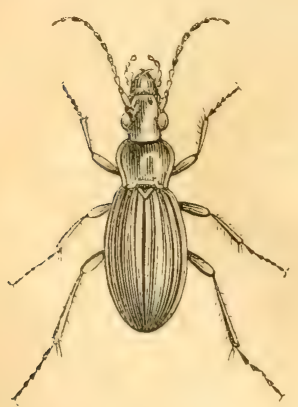

Fig. 6. Carabe.

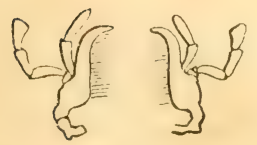

Fig. 7. Mâchoires du méme insecte.

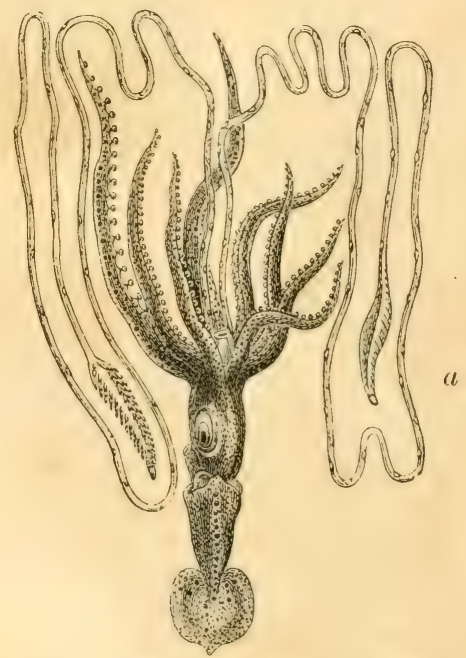

Fig. 8. Mollusque du genre Calmaret. 
$\$$ 48. La préhension des boissons se fait de deux manières : tantìt le liquide est versé dans la bouche et y tombe par l’effet de sa propre pesanteur; d'autres fois il est pompé par cette cavité, soit par la dilatation du thorax, qui l'aspire en mème temps qu'il détermine l'entrée de l'air dans les poumons, soit par les mouvements de la langue, qui, en se retirant en arrière, agit à la manière d'un piston. Ce dernier phénomène constitue l'action de sucer ou de teter.

Quelquesanimaux inférieurs sont destinésà se nourrir uniquement de liquides qu'ils trouvent dans les plantes, ou qu'ils puisent dans le corps d'autres animaux, sur lesquels ils vivent en parasites. Beancoup d'insectes sont dans ce cas, et on remarqueque leur bouche, au lieu d'offrir la structure ordinaire, constitue une espèce de tube ou de suçoir très-allongé, à l'aide duquel ils aspirent comme avec une pipette les sucs dont ils ont besoin (fig. 9). Lorsque nous traiterons de l'organisation des insectes, nous exposerons plus en détail ce mode de structure.

Les boissons ne séjournent pas dans la bouche et

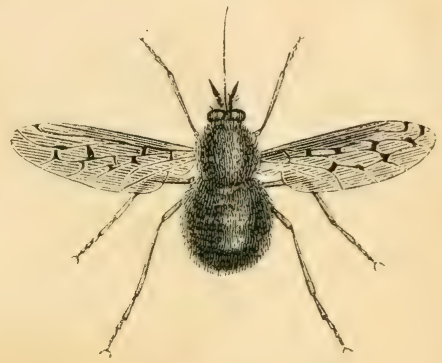

Fig. 9. Bombyle peint. descendent de suite dans l'estomac; mais les aliments solides y restent pendant un certain temps, et y sont soumis à la mastication et à l'insalivation.

\section{Mastication .}

\$ 49. La mastication ou la division mécanique des aliments est opérée, comme nous l'avons dẹjà dit, par les dents.

Dents. - Ces organes sont des corps d'une dureté extrème, qui ressemblent beaucoup à des os, et qui sont fixés solidement au bord de charque màchoire, de façon à agir les uns contre les autres. La manière dont ils se forment mérite

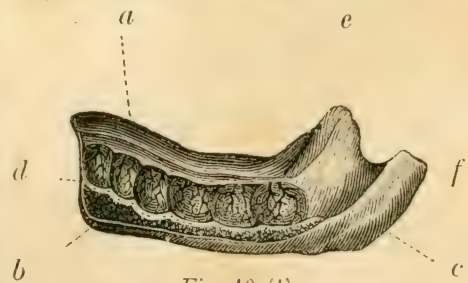

Fig. $10(1)$.

(1) Cette figure represente la machoire inferieure diun tris-jeune enfant; la majeure partie de la surface exterieure de l'os a ete enleve pour mettre a nu les capsules des 
de fiser notec attention; chez l'homme, que nous choisirons ici romme exemple, chague dent se développedans l'intérieur d'un petil sac nembraneux logé dans l'épaisseur de l'os de la màchoire $(b)$; ce sac, que l'on nomme la capsule dentaire, se compose de deux membranes rasculaires ef renferme dans son intérieur un petit

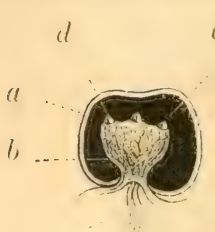

c

Fig. 11 ' d noxau pulpeux semblable it un bourgeon dans lequel vienmentse ramifier des filets nerveus et un grand nombre de vaisseaux (fig. 11). Ce noyau, appelé le bulbe ou germe de la dent, scri à former celle-ci qui grandit peu à peu, et qui, en s'allongeant, remonte vers le bord de. la màchoire, qu'elle perce bientôt pourse montrer au dehors; cette portion saillante et dinudée constitue ee que l'on nomme la couromme de la dent, el sa racine, ou portion basilaire, reste engagere dans la màchoire, comme un clou qui serait enfoncé dans du bois. Ja caviti osseuse qui loge ainsi la dent est appelée alcéole, et on drisigne soms le nom de collel de la dent le point de réunion de la remrome ave la racine. Lorsque le bulbe dentaire est five au fond de. sa capsule far non ou plosicur's pédicules, il arrive un moment oil la matiere pierreuse qui se dépose à sa surface l'entoure de toutes parls at comprime ses vaisseaux nourriciers, de farcon à en déterminer lobliteration; la dent cesse alors de croilre, le bulbe se flétrit, et mo caviti eentrale indique seule la place de cet organe; mais lorsque le bulbe ne presente pas eette disposition et que la dent ne se forme qüa sa surfare supérieure, ce bulle ne cesse pas

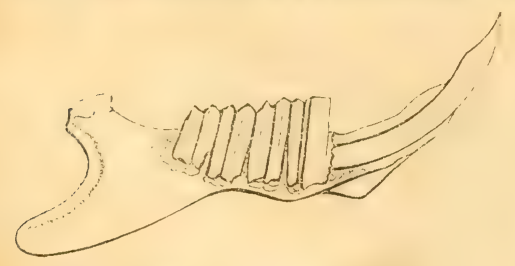

Fiy. 12. Mâchoire el dents d'un Lapin.

de fonctionner, la croissance de la dent ne s'arrète pas, et on ne trouve pas dans son intérieur de cavité centrale; les grandes dents qui occupent le devant de la bouche deslapins (fig. 12) nous offrent

dents renfermes daus sum interienr : - "gencive; - b hord inferieur de la màchoire: $-c$ angle de la machoire; - $l$ capsules dentaires: $-e$ apophyse cormoüde; - f eondyle de la màchoire.

I Coupe dime capsule dentaire grossie pour nontrer la disposition du germe ef la maniere dout la matiere pierreuse se depuse a sa surface: - n capsule; - b bube ou

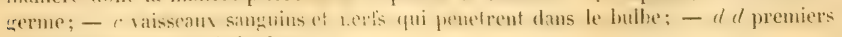
rudiments de trivoire de la dent. 
un exemple de celte disposition, et si leur longueur n'augmente pas sans cesse, c'est parce qu’elles s'usent par leur extrémití libre ì mesure qu'elles croissent par leur base.

$\$ 30$. On distingue aussi dans chaque dent des parties qui different rntre clles par leur structure. La substance qui en forme presyue toute la masse et qui en oceupe l'intérieur se nomme ivoire; celle qui d'ordinaire en revèt l'extérieur et qui constitue, à la surface de la courome, une sorte de vernis ou de couverte pierreuse, se nomme émail; enfin vers l'extrémité de la raciue de la pltipart des dentse el quelquefois mème autour de la couromne (chez les boufs, par exemple), on reneontre une troisieme substance qui recouve l'imail, et yui, à raison de la place qu'elle oecupe, a reçu le nom de substance corticale.

L'ivoire des dents se compuse d'une matiere animale analogue it la gélatine, de phosphate de chaux (dans la proportion d'environ 6.4 pour 100 chez l'homme adulte), de earbonate de chaur (à peu prés ä centiènes), et d'une quantite tres-petite de phosplate de magnésie. L'imail dont la couleur est un peu différente de celle de l'ivoire et dont la dureté est si grande qu’il fait feu au briquet i la manière d'un caillou, offre à peine quelques traces de matieresorganisées, et le phosphate de chaux entre dans sa composition pour pres des neuf dixiemes. (Juant à la sulstance corticale, elle existe à peine chez l'homme, mais chez le bœuf, ou elle est tries-développée, clle a fourui par l'analyse chimique environ 42 jour 100 de matière organique, 30 pour 100 de phosphate de chaus et 't pour 100 de carbonate de la mème base.

Examiné au microscope, l’ivoire des dents de l'homme et de la plupart des autres mammifères laisse apereevoir dans sa substance une multitude de tubes flexueux el rameux d'une ténuité extrème, qui vont déboucher dans la cavite centrale, et qui renferment dans leur intérieur des matieres granuleuses de nature caleaire; elles se dirigent vers la surface de la dent, et leurs divisions se terminent frequemment par de petites cavités ou cellules renfermant aussi m dépot caleaire, et ayant bancoup de ressemblance avec les cellules fqu'om rencontre dans le tissu ossemx. L'émail, sommis rigalement à l'investigation micosenpique, parait forme d'ume mulitude de fibres on phatet de prismes hexagonatox, d'un aspeet cristallin, serrés les mons eontre les autres et diriges à peu pres perpendiculairement à la surface de la dent. Eufin la substance corticate est caracterise par la presence d'un grand nombre de cellules osseuses el de tubes calcigères irréguliers.

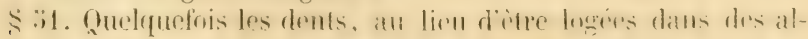




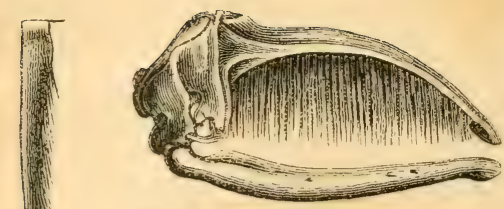

Fig. 1'. Tête osseuse de la Baleine garnie de ses fanons.

véoles, se soudent par leur base à la màchoire qui les porte et font corps avec elle; c'est le cas chez plusieurs poissons, el d'autres fois ces organes, au lieu de ressembler à des os, n'offrent que la consistance de la corne. Enfin chez la baleine ( $f \mathrm{~g} .1 \mathrm{1})$, les dents paraissent ètre remplacées par les grandes lames flexibles connues sous le nom de fanons (fig. 13), et chez d'autres animaux, mème dans la classe des mamFig. 15. mifères, elles manquent complétement : chezle fournilier, Fanon. par exemple (fig. 22).

$\$$ 52. Chez les animaux qui avalent leurs aliments sans les màcher (les crocodiles et les autres reptiles par exemple), les dents ne

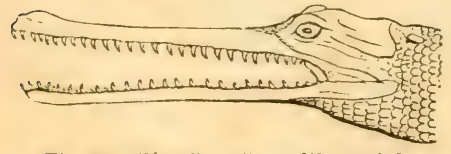

Fig. 15. Tíle d'un Crocodile gariale. servent qu'à saisir ces matieres, et alors tous ces organes sont à peu près semblables entre eux et ont, en général, la forme de crochets ou de petits cones; mais chez les animaux (qui màchent leurs aliments, la bouche est armée de dents dont les formes varient, et dont les usages different.

Ainsi, chez l'homme et la plupart des autres mammifères, il existe trois especes de dents: les unes se terminent par une lame mince et tranchante; aussi servent-clles à couper les substances introduites entre les màchoires, et ont-elles recu le nom de dents incisices (fig. 16). I)'autres sont coniques, et chez beaucoup d'animaux s'avancent bien au delà des dents voisines; elles ne peuvent pas servir à couper les aliments comme les dents incisives, mais à s'y implanter et i les dechirer. On les appelle dents canines. Enfin, d'autres se terminent par une surface large et inégale et présentent les conditions les plus favorables pour écraser et broyer les aliments: ce sont les dents molaires ou machelières.

La manière dont ces différentes dents sont implantées dans les màchoires varie aussi bien que la forme de leur couronne, et ici encore il est facile de s'apercevoir combien leur disposition est en accord avec leurs usages. Les dents incisives, dont lejeu doit tendre a lesenfoncer dans leurs alvéoles plutôt que de les en arracher, n'ont qu'une seule racine assez courte. Les dents canines se prolongent dans l'intérieur des màchoires bien plus profondément que les in- 


\section{DE LA DIGESTION.}

cisives, et les dents molaires, qui doivent supporter les plus grands efforts, présentent deux ou trois racines divergentes qui augmentent la solidité de leur insertion, et les empèchent de s'enfoncer trop loin dans leur alvéole lorsqu'elles viennent ì ètre pressées de la sorte.

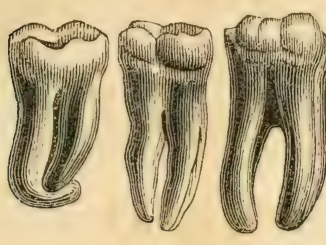

Grosses molaires.
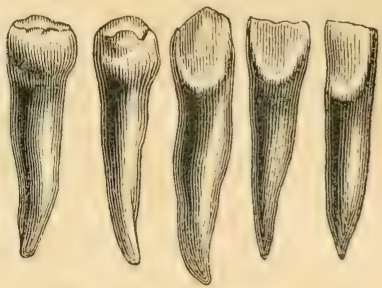

Petites molaires. Canine. Incisives.

Fig. 16. Den/s de l'Homme.

§̋3. La disposition del’appareil dentaire variechez les différents mammifères suivant le genre d'aliments dont ceur-ci sont destinésà se nourrir, et cette harmonie de la nature est toujours si évidente que, par la seule inspection de leur appareil masticateur, on peut arriver à connaitre le régime, les mœurs et mème la structure génćrale de la plupart de ces animaux. Effectivement, chez ceux qui se nourrissent de chair, les molaires (fig. 17) sont comprimées et tranchantes, de façon à agir les unes contre les autres, cotinme le font les lames d'une paire de ciscanx; chez ceux qui vivent d'insectes, ces dents (fig. 18) sont hérissées de pointes coniques qui se correspondent de manière que les unes s'emboitent daus les intervalles

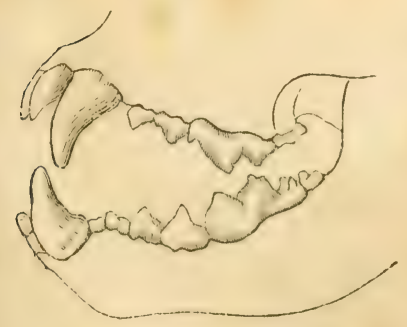

Fig 17. Dents d'un carnassier.

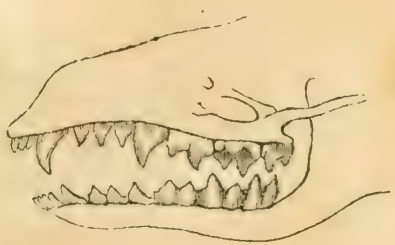

Fï. 18. Den/s t'un insectirore. 
que les autres laissent entre clles. Lorsque la nomrriture de ces animaux consiste principalement en fruits mous, ces dents (fig. 20) sont simplement garnies de tubercules arrondis; et lorsfu'elles sont destinces à broyer des substances vegritales plus ou moins dures, clles somt terminies par une latre surface aplatic et rude comme celle d'une meule (fic;. 19). be toutes les dents, les molatires sont ge-

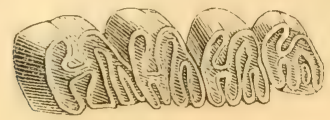

Fig. 19. Denls d'un herbivore.

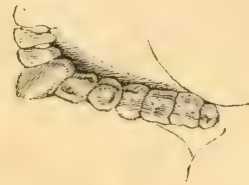

Fig. 20. Dents d'un firugivore.

néralement les plus utiles; aussi leur existence est-elle plus constante que celle des incisives ou des canines: celles-ci sont nécessaires pour saisir et dévorer une proie vivante, et ne manquent, par conséquent, chez aucun carnassier; mais elles sont moins utiles aux herbivores, et les unes ou les autres manquent chez plusicurs des mammiferes qui ont un régime végétal. (Quelquefois aussi elles neserventplus à la mastication, maisprennent un grand développement el constituent des défenses plus ou moins puissantes (fig. 21).

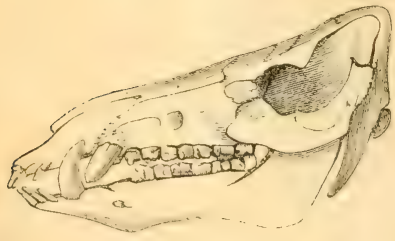

Fig. 21. Tềle de Sanglier.

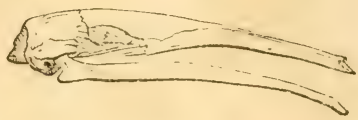

Fig. 22. Tële de Fourmilier.

§̈̌́. A l’éporque de la naissance, le développement des dents de l'homme est peu avancé; il est bien rare qu'aucun de ces corps ait encore percé la gencive, et ce n’est communément que de l'ìge de six mois à un an que leur évolution commence. Les dents qui se forment alors sont destinées ì tomber au bout d'un petit nombre d'années, el ì faire place à d'autres. On les appelle dents de lait, ou de la première dentition. et on en compte vingt, savoir : à charque màchoire, quatre incisives, qui oeeupent le devant de la bonche; deux canines, situces une de chaque cotc, immédiatement apres les 
incisives; et quatre molaires, placées ver's le fond de la bouche, deux de chaque côté.

Vurs l'àye de sept ans, ees dents commencent à tomber et à ètre remplacéés par une antre série de dents, qui se sont formées dans des capsules situées plus profondément que celles dont les premièes sont sorties; aussi leurs racines sont-elles bien plus longues, et leur insertion plus solide.

Les dents de la seconde dentition sont ígalement plus nombreuses que celles de la première; la série complete se compose de trentedeux de ces corps, savoir : pour chaque michoire, quatre incisives, deux canines et dix molaires, dont les deux premieres de chaque côté n'ont que deux racines, et sont appelées petites molaires ou fausses molaires; tandis que les trois situées plus en arrière sont pourvues de trois racines, et appelées grosses molaires (fig. 16).

Dans la vieillesse extrème, ces dents tombent comme les dents de lait tombent dans l'enfance; mais elles ne sont pas remplacées, et les alvéoles s'oblitèrent.

$\S 33$. Mécanisme de la mastication. - Les dents, dont nous venons d'étudier le développement et la structure, sont les instruments passifs de la mastication. Elles sont mises en mourement par Jes màchoires, dans lesquelles elles sont implantées. La màchoire supéricure ne peut sc mouvoir sur le reste de la tète, mais l'inférieure, dont la forme ressemble un peu à celle d'un fur à cheval, ne s'articule avec le cräne que par l'extrémité de ses deux branches, et peut s'écarter ou se rapprocher de la màchoire supérieure. Un grand nombre de muscles fixés à cet os par une de leurs extrémités, et aux parties voisines de la tète par leur extrémité opposée, déterminent ces mouvements en se contractant, et lesaliments, continuellement ramenés entre les dents par les mouvements de la langue ou desjoues, et pressés ainsi entre denx surfaces dures, ne tardent pas à ètre divisés en portions plus ou moins petites, el comme broyés.

\$36. L’importance de celte opération est tres-crrande; car plus la mastication est complete, plus la digestion est facile : ce qui, du reste, est bien aisé à comprendre, car celte division multiplie les surfaces par lesquelles les sues de l'estomac peuvent altaquer les matieres alimentaires. Nous avons déjèt vu que chez divers animatux destines à se momrir de subslances dures, il n'existe cependant pas de dents; mais alors la nature supplée souvent à ce défaut, en dommant à ces ètres d'autres instruments de trituration. C'est ainsi que chez les oiseaux granivores, par exemple, l'un des

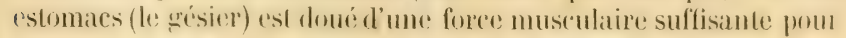
icraser tous les aliments introduits daus sa (a) vile. 


\section{Insalivation.}

$\$: 7$. Pendant que les aliments subissent dans la bouche de l'homme et de la plupart des autres manmiferes cette division mécanique, ils s’imbibent de salive, et quelquefois mème se dissolvent dans ce liquide.

$\$ 38$. La salice se forme dans des glandes situces à l'entour de la bouche, et composées de petites gramulations agglomérées entre clles. Chez l'homme il en existe trois paires placées symétriquement de chaque côté de la tète: savoir, les glandes parotides, situées audevant de l'oreille et derriere la michoire inférieure, les ylandes sous-maxillaires, logies sous l'angle de la michoire (fig. 23), et les glandes sublinguales, placées au-dessous de la langue, daus l'espace que les deux côtés de la màchoire laissent entre eur. Cés glandes communiquent chacune avec la bouche par un conduit excréteur particulier, et y versent la salive en quantités variables.

Ce liquide est composé, en grande partie, d'eau (environ 993 parlies sur 1000), mais il contient aussi un peu de matiere animale, et divers sels, tels que du sel marin (ou chlorure de sodium) et du tartrate de soude. On y trouve aussi une petite quantite de soude libre qui le rend alcalin.

Le mélange de la saliveavec lesaliments est une circonstance qui a plus d'importance (qu' on ne le croirait au premier abord. Il facilite la mastication, il aide puissamment à la déglutition, et, commenous le verrons par la suite, il parait jouer aussi un grand rôle dans la digestion de quelques-unes de ces substances.

\section{Déglutition.}

$\$ 59$. Chez les mammifères la cavité lunceale est garnie en arrière d'une espèce de rideau mobile nommé voile du palais (fig. 23), qui demeure baissé pendant toute la durée de la mastication, afin d'empècher lesaliments de passer outre; cette cloison mobile, qui n’existe pas chez les oiscaux et les antres animanx qui ne màchent pats leurs alimentsavant de lesavaler, est suspendue transver'salement an bord postérieur du palais et peut s'appliquer eontre la base de la langue ou s'élever de faron it laisser un libre passage entre la bouche et le reste du tube digestif. Lorsque la mastication est termince et que les aliments, rassemblés sur le des de la langue en ume petite masse appelée bol alimentaire, viennent it presser contre cette cloison charnue, elle s'élève en effet, et la déylutition s'opiere.

On donne ce nom au passage des aliments de la bouche jusque dans l'estomac à travers le pharynx et l'osophage. 
\$60. Le pharynx ou arvière-bouche (fig. 23) est une cavité qui fait suite i la bouche, et qui est placée à la partie supérieure du cou. Le's arrière-narines en occupent le sommet, et en haut et en avant il u'est séfraré de la bouche que par le voile du paalais. En bas eten avant il communique avec le larynx et la trachée-artere, conduits par lesquels l'air se rend aux poumons; enfin, en bas et en arrière il se continue avec l'arsophaye, tube étroit qui deseend le long du cou, traverse le thorax en passant entre les deux poumons derriere le cour, et au-devant de la colonne vertébrale, traverse le muscle diaphragme, et se termine enfin à l'estomac (fig. 3 et 2.t).

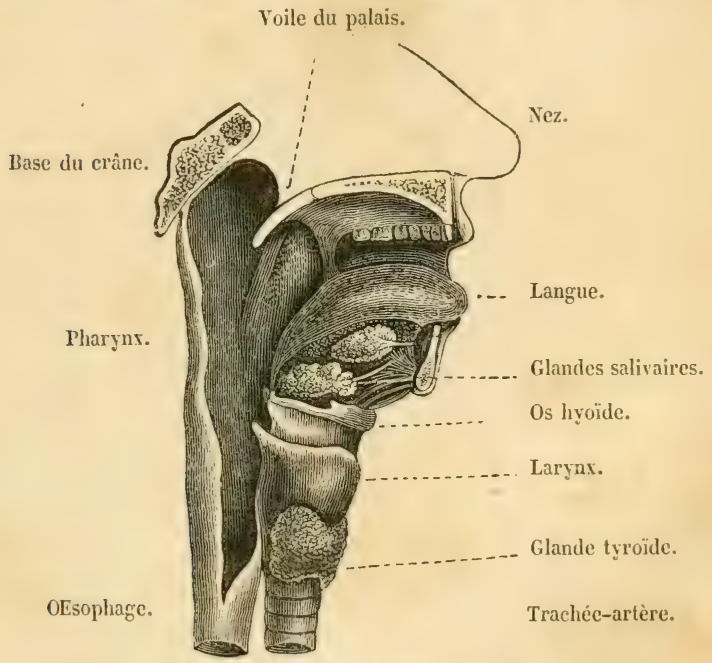

Fig. 25. Coupe verticale de la bouche el du gosier.

$\$ 61$. Le hol alimentaire, en traversant le pharynx, doit passer devant les arriere-narines et l'suverture du larynx (nommée glotte) sans y jénétrer, et doit descendre directement dans l'asophage. C'est principalement le voile du palais, qui en s'élevant de faron it devenir presque horzontal et à s'appliquer contre la paroi postirieure de l'arriere-bouche, empeche les aliments de remonter dans les fusses nasales et qui le dirige vers l'esophage. Ponr qu'ils ne: pénetrent pats dans la ghofte, cetteonverturese pesserre an moment

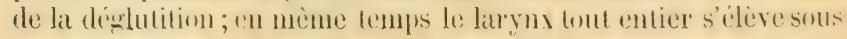


la lase de la langue comme sous un abri, et, en exéculant ce mouvement, fait abaisser une sompape nommée épiglotie qui, ainsi que son nom l'indique, est située au-dessus de la glotte, et qui la recouvre alors comme le ferait un écran. Il ne reste done de passage libre que celui conduisant vers l'estomac, et, pendant que ces mouvements ont lieu, le bol alimentaire se trouve poussé jusque dans l'osophage par la contraction des muscles nombreux dont le pharynx est revètu. Ces contractions, ainsi que les mouvements du larynx, s'effectuent indépendamment de la volonté et d'une manière trèsrapide, en sorte que les aliments franchissent presque instantanément ce passage qui peut ètre comparé à un carrefour où la route digestive croise la voie par laquelle l’air nécessaire à la respiration arrive aux poumons. Quelquefois cependant la déglutition ne se fait pas convenablement, et on avale de traver's, e'est-it-dire que les aliments, au lieu d'arriver à l'œsophage, pénètrent dans la glotte.

Enfin, le bol alimentaire, parvenu dans l'œesophage, excite la contraction successive des fibres charnues qui cntourent circulairement ce conduit et qui achèvent la déglutition.

\section{Digestion stomacale ou chymification.}

\$ 62 . C'est à l'aide du mécanisme dont l'étude vient de nous occuper que les aliments arrivent dans l'estomac, ou ils doivent ètre digérés et se changer en chyme.

L'estomac (fig. 2.t) est une poche membrancuse, qui est placée en travers à la partie supérieure de l'abdomen, et qui, chez l'homme, a la forme d'une cornemuse (1). Il se rétrécit graduellement de gauche à droite et se recourbe sur lui-mème, de facon que son bord supérieur est concave et tres-court, tandis que son bord inférieur (appelé grande courbure de l'estomac) est convexe et tris-long. L'ouverture par laquelle ce viscère commmique arec l’osophage est appelée ouverture cardiaque, parce qu'elle est située du côté du coeur, el celle qui conduil del'estomac dans les intestins se nomme pylore (2). Les parois de l'estomac sont très-extensibles: lorsque sa cavité n'est pas remplie d'aliments, elles se contractent, eton voil alors à leur

(1) C'est, en effet, avec l'eshmac d'animaux ou cet organe ressemble beauroup, à celui de l'homme, que l'on fait le réservoir à air des cornemuses.

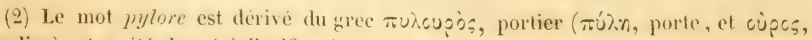
gardien), et a été donne a liorifice intestinal de l'estomac pour rappeler les fonctims quil remplit : tant que la digestion des aliments niest pas assez avaneee penr que com-ri

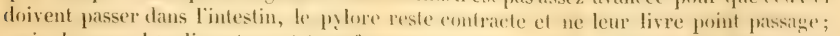
mais, lorsque les aliments sont transformes en chyme, cette ouverture se desserre et se laisse iraverser. 
\$63. Les substanecs alimentaires qui s'accumulent dans l'estomac y sont assez fortement pressies par l'action des parois musculaires de l'abdomen, et tendraient à remonter dans l'oesophage, si la jortion de ce conduit voisine du cardia n'était pas fermée frar la contraction de ses fibres musculaires. Buelquefois cette résistance est vaincue, et les aliments lemontent jusque rers la bouche, ou mème sont rejetés au dehors: phénoménes qui portent les noms de régurgitation et de vomissement.

D'un autre coite, les aliments ne peurent traverser simplement l'estomac, et pénétrer de suile dans les intestins, carr l'ouverture du pylore est complétenent fermée par la contraction énergrique des fibres musculaires dont elle est entourée.

$\$ 6.4$. Les aliments sont done retenus dans l'estomac et s'y accumulent, principalement dans la partie cardiaque ou grand-culde-sac de eet organe. (buelques-unes des substances ainsi ingérées sont alors simplement absorbees par les parois de l'estomac, et pénètrent daus le sang sans avoir subi d’altération préalable; l'eau, l'alcool faible et quelques autres liquides sont dans ce cas. D'autres substances pénètrent dans l’intestin, et sont mème expulsées au dehors avec les excréments sans avoir étéaltérées; mais en général les aliments y sont digérés, et transformés ainsi en une masse pulpeuse, semi-liquide, appelée chyme.

On remarque d'abord que les fragments placés vers la surface de la masse alimentaire, et prìs des parois de l'estomac, s'imbibent de suc gastrique, deviennent acides comme ce liquide, et se ramollissent peu à peu de la superfieic vers le centre. Tuute la masse des aliments finit par subir la mème altération et, par suite de ce ramollissement, ces sulsstances se transforment en une matiere molle, pultacée, en général grisàtre, et d'une odeur fade et particulière, qui est du chyme mìlé à des déloris d'aliments.

$\$ 6 \%$. Nature du travail digestif. - On a fait un grand nombre d'expériences, dans la vue de nous éclairer sur ce qui se passe pendant la dienestion des aliments dans l'estomac. Les plus remarquables sont celles de Spallanzani, physiologiste célèbre de Modène. A l'époque où il entreprit ses recherches, on croyait que ce phénomène n'étail autre chose qu'une espece de trituration, et que le chyme n'était que des aliments broyés de facon à les réduire en pulpe ; mais Spallanzani montra qu'il en était autrement. Il fit avaler à des oiseaux des aliments reufermés daus des tubes et dans des espèces de petites boites métalliques, dont lesparois étaient criblées de trous, de faren à préserver ces substances de tout frottement, mais à ne point les soustraire à l'action des liquides contenues dans l'estumac, et il 
Irouva rque la digestion s'en faisait comme dans les circonstances ordinaires. Il en comelutaveraison, que le sue gastrique devait ètre la causeprincipale de la chymificationdes aliments; ef, pour le mieux demontrer, il eut encore recours ì des expériences très-ingénieuses. Il fit avaler à des corbeaus et à d'autres oiseaur de petites iponges allachées à more ficelle, au moyen de laquelle il retira eeseor ps de l'estomac, apres qu’ils y eurent séjourné quelques minutes et qu’ils s'y furent imbibés des liquides contenus dans cette cavité. Il se procura ainsi une quantité considérable de sue gastrique, qu'il plaça dans de petits vases, avec des aliments convenablement divisés; il cut soin en mème temps d'élever la température, de faron à imiter, autant que possible, les circonstances dans lesquelles la chymification a lieu, et au bout de quelques heures il vit la masse alimentaire, soumise à cette digestion artificielle, se transformer en me matiore pulpeuse semblable en tout point à colle qui se serait formée dans l'estomac par suite d'ume digestion naturelle.

D'autresolservations failes sur l'homme lui-mème ont conduit à des résultats semblables. Cellesque l'on doità un médecin américain, le docteur Beaumont, offrent surtout un grand intéré; elles ont été faites sur un jeune homme tres-bien portant, mais dont l'estomac avait été ouvert par une blessure d'arme à feu, et dont la guérison, était restée imparfaite, de façon que la plaie, quoique cicatrisée, laissait béant un orifice an moyen duquel il était facile de voir tout ce qui se passait dans l’intérieur de cet organe. Ce médecin s'est assuré, de la sorte, quelesaliments, en arrivant dans l'estomac, excitent la sécrétion du suc gastrique, s'en imbibent, et sont ensuite digrérés par la seuleaction de cetagent; car, lorsqu'il les retirait de l'estomac, ainsi imbibés, il les voyait encore se transformer peu à peu en une masse chymeuse. A l'aide d'un tube, il lui était facile aussi de se procurer de ce suc gastrique, qu'il voyait suinter des farois de l'estomac, et 'n employant ce liquide comme l'avait dejai fait Spallanzani, pour des dignestions artifieielles, il a réussi à trantoformer des morceaux de beruf en une sulsstance semi-fluide, semblable au chyme que cette matiere alimentaire an'ait produit par la digestion naturelle.

Il est dunc évident que le suc gastrique est la cause principale des allérations que les alimentséproucent pendant leur séjourdans l'estomac, et la commatisianee de ee fait doit nous condure à chercher qual est le principe yui domme ì ce liquide des propriétés si remarcfuables.

$\$ 66$. Justu’en ces derniers temps, on attribuait le pouvoir dissolvant du sue gastriyue a l'acide ehlorhydrique (ou hydrochlorique) et à l'acide lactique, qui entrent toujours dans sa composition; cesacides 
possèdent en effet la propriété d'atlaquer plusieurs des substances qui servent le plus ordinairement à l'alimentation, mais leur action est trop faible pour expliquer les phénomènes de la chymification; et d'après des expériences récentes, que l'on doit à MII. Eberle, Schwan et Müller, de Berlin, il paraitrait que le suc gastrique renferme une matiere particuliere, dont l'action sur la plupart des aliments est assez analogue à celle de la diastase sur l'amidon. Ciette matière, encore imparfaitement connue, à laquelle on a donné le nom de pepsine, n’agit qu'autant qu’elle est combinćc à de l'acide chlorhydrique ou à de l’acide acétique, et posside alors la propriété de dissoudre ou de réduire en une espèce de bouillie la fibrine, l'albumine coagulée, et la plupart des autres substances alimentaires les plus solides; elle détermine aussi des changements importants dans la nature chimique de quelques-unes de ces matières, dans l'albumine par exemple.

Certaines substances alimentaires, telles que le caséum, la gélatine et le gluten, ne sont pas dissoutes par la pepsine, et il paraitrait que, pour ètre digcérées dans l'estumac, elles doivent ètre préalablement sommises à d'autres agents. La salive est un de ees dissolvants; et, chez les animaux qui se nourrissent spécialement de substances vígetales, il cxiste souvent, entre la bouche et l'estomac froprement dit, une première cavité destinée à loger les aliments pendant que ce liquide les imbibe: chez les mammifères de l'ordre des Ruminants, ce premier estomac porte le nom de panse (fig. 23); et chez les oiseaux, on l'appelle jabot.

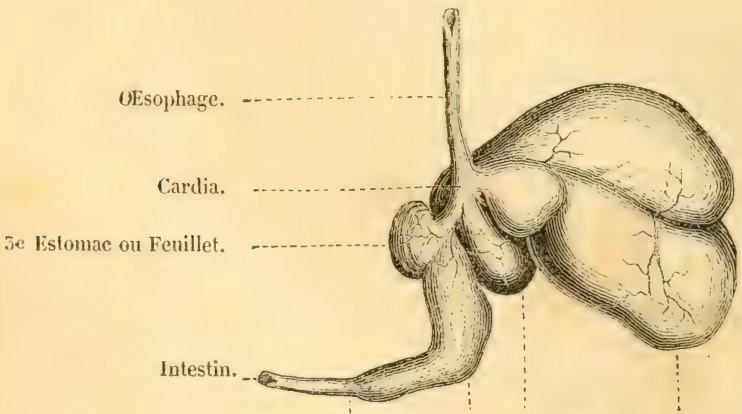

Pylore. Estom. pr. dit. 2e Est. Panse ou 1 er Estomac.

Fig. 25. Estomacs du mouton. 
Ainsi, c'est par l'action de la salive, et surtout du suc gastrique, que les aliments sont transformés en chyme; mais certaines substances peuvent résister à ces liquides et traverser l'estomac, sans avoir été dissoutes: pour la digestion de celles-là, l'influence d'un autre agent est nécessaire, et, comme nous le verrons bientòt, c'est en avancant plus loin dans le tube iutestinal qu'elles le rencontrent.

Pendant que la chymification s'opiere, les parois de l'estomac. deviennent le siége de contractions circulaires qui se succèdent d'abord de droite à gauche; mais, après un certain temps, ces mouvements vermiculaires, que l'on nomme péristaltiques, se font dans le sens opposé et portent le chyme vers le pylore, puis jusque dans l’intestin grèle.

\section{Chylification.}

$\$ 67$. Intestins. - La portion du canal alimentaire dans laquelle les aliments pénètrent après leur digestion dans l'estomac, porte le nom d'intestin (fig. 2'ł). C'est un tube membraneux et contourné sur lui-mème, dont le diamètre est peu considérable, mais dont la longueur est très-grande, étant, chez l'homme, environ sept fois celle du corps. Chez les animaux qui se nourrissent exclusivement de chair, les intestius sont, en général, plus courts que chez l’homme et les autres animaux omnivores; tandis que chez les herbivores, leur longueur est beaucoup plus considérable. Ainsi, dans le lion, elle n'est que d’environ trois fois celle du corps, et, dans le bélier, elle est souvent égale à vingt-huit fois cette longueur. La raison de ces différences est facile à saisir, ear il est évident que les substances herbacées, qui se digèrent très-lentement, el qui renferment une très-petite portion de matière réellement nutritive, doivent ètre prises en plus grande quantité et doivent séjourner pendant plus longtemps dans le canal alimentaire que la chair musculaire, dont la digestion est tries-prompte et dont presque toute la masse est composéc de matières nutritives.

Les intestins, comme nous l'avons déjà dit, sont logés dans l’abdomen, et renfermés dans les replis d’une membrane nommée péritoine qui les fixent à la colonne vertébrate (fig. 3). Ils se composent de deux parties distinctes : l'intestin gréle et le gros intestin.

L'intestin gréle fait suite à l'estomac, el c'est dans son intéricur que la digestion s'achive. Il est très-étroit et forme environ les trois quarts de la longueur totale des intestins. Sa surface extérieure est lisse, les fibres museulaires qui l'entourent sont serrées les unes contre les autres, et la membrane muqueuse qui en tapissel'intérieur présente à sa surface mo foule de petits follicules ot de pretils appendices saillants nommés villosités. On y remarque aussi num grand 
nombre de phis transversaux, nommés valuules conniventes. Les follicules sécrètent continuellement une humeur visqueuse, dont la quantité est très-considérable. Les villosités, comme nous le verrons bientit, paraissent servir specialement à l'absorption des produits de la digestion, et les valvules comnirentes à retarder la marche du chyme.

Les anatonistes distinguent dans l'intestin grèle trois portions, le duodénum, le jéjunum et l'iléon; mais cette distinction est de peu d'importance en physiologie.

S6. Foie et pancréas. - Les matières alimenlaires qui pénètrent dans eet intestin s'y mìlent avec les humeur's sérétées par ses parois, ef avee deux liquides particuliers, la bile et le suc pancréatique, qui sont formés chacun dans un organe glandulaire, situé dans le voisinage de l'estomac.

Le foie (fiy. 24), qui est l'organe producteur de la bile, est le viscere le plus volumineux du corps. Il est situća la partie supérieure de l'abdomen de l'homme, principalement du crité droit, et desecnd juspu'au niveau du bord inférieur des còtes. Sa face supérieure est convexe el sa face inférieure irrérulierement concave. La couleur de cet organe est rouge-brun et sa substance est molle et compacte, et, lorsqu'on la déchire, elle parait ètre formée par l'agglomération de petites granulations solides, dans lesquelles aboutissent les vaisseaux sanguins, et desfueiles naissent les conduits excréteurs destinés à porter la bile au dehors.

Cescanaux excreteurs se rémissent sucessivement entre eux pour former des rameaux, des branches, el enfin un trone qui sort du foie par la face inférieure de cet organe pour se porter au duodénum, et qui communique aussi avec une poche membraneuse adhérente au foie, habituellement distendue par de la bile, et nommée vésicule du fiel. La terminaison du canal se voit dams le duodénum, ì peu de distance de l'estomac.

Chez les animaux inférieurs, le foie est souvent remplace, soit par une agghomération de petits tubes terminés en cul-de-sac, et insérés sur les rameaur d'un ranal excréteur (comme chez les crabes et les écrevisses); soit par des vaisseaux simples, mais très-longs, comme chez les insectes. Enfin, chez les ètres placés encore plus bas dans la séric zoologique, il manque tout à fait ou n’est représenté que par un tissu glandulaire qui entoure une portion de l'intestin ; mais c'est un des organessícréteur's dont l'existence est la plus constante dans le Règne animal.

\$ 69. La bile est un liquide visfueur, filant, verdàtre el d'une saveur tres-amère. Elle est toujours alcaline of a heaucoup d'analogie avec 
à dissoudre certaines substances alimentaires qui ont pu résister à la digestion stomacale, les matières grasses, par exemple, enfin à stimuler par son contact irritant les parois de l'intestin, et à y réveiller les mouvements péristaltiques. Quant au suc pancréatique, il doit probablement agir à peu près de la mème manière, à raison de ses qualités alcalines, mais on ne sait rien de positif à cet égard.

$\$ 72$. Onoi qu'il en soit, c’est, comme nous le voyons, dans l'intestin grèle que la digestion s'achève ordinairement, et, pendant ce travail, il se dégage de la masse alimentaire divers gaz qui distendent plus ou moins le tube intestinal. Ces gaz sont principalement de l'acide carbonique et de l'hydrogene pur; quelquefois on y trouve aussi de l'azote.

\section{Expulsion du résidu laissé par la digestion.}

$\$$ 73. Les matières alimentaires qui n’ont pu ètre transformées en chyle doivent ètre rejetées au dehors, et pour cela elles pénètrent dans le gros intestin et s'y amassent.

Le gros intestin (fig. 24) fait suite à l'intestin grìle, et chez la plupart des mammifieres se distingue facilement par les dilatations nombreuses que l'on remarque sur ses parois entre les divers faisceanx formés par ses fibres musculaires. On le divise en cocum, en colon et en rectum. Le eoecum (1), qui est situé près de l'os de la hanche, du còté droit, se prolonge en cul-de-sac an delà du point d'insertion de l'intestin grèle, et présente, à son extrímité, un appendice vermiforme. Des replis, disposés en manière de valvules, garnissent l'ouverture de l'intestin grèle, et s'opposent à ce que les matières poussées dans le coecum puissent rentrer dans l'iléon et retourner vers l'estomac.

Le colon $(2)$ fait suite au coecum, remonte vers le foie, traverse l'abdomen immédiatement au-dessous de l'estomac, et redescend dı còté gauche pour gagner le bassin, où il se continue avec le rectımı (3), qui se termine à l'anus.

$\$ 7$. Le résidu provenant de la digestion des aliments est poussé peu à peu depuis le exéum jusquau rectum, où il s'accumule et séjourne pendant un temps plus ou moins long. En traversant ainsi le gros intestin, les matières fécales acquièrent de la consistance:

(1) Les anatomistes ont nomme creum la première portion du gros intestin, parce qu'elle se prolonge inferiemement sous la forme d'un cul-de-sac de cacus, aveugle).

(2) On fait venir ce nom de zờú(1), jarrète, parce que cet intestin retient longtentps les matières excrémentitielles dans ses replis.

(5) Cet intestin est ainsi nommé parce qu'il est à per près droil. 
changent de couleur et prennent une odeur particulière. Il se dévelopje en mème temps dans cet intestin une quantité plus oumoins considérable de gaz qui different essentiellement de ceux de l'intestin grèle par l'existence presque constante d'hydrogène carboné, et quelquefois aussi par lit présence d'un peu d'hydrogène sulfuré.

Les fibres charnues qui entourent l'anus et qui forment le muscle sphincter de cette ouverture sont continuellement contractées et s'opposent par conséquent à la sortie des matières accumulées dans le gros intestin. En général, pour que l’expulsion de celles-ci ait lieu, il ne suffit mème pas de la contraction des fibres musculaires qui entourent cet intestin, il faut aussi que le diaphragme et les autres muscles de l'abdomen concourent au mème but, en comprimant la masse des viscères renfermés dans cette cavité.

\section{Absorption du chyle.}

§ 73. Pour terminer l'étude de la digestion, il nous reste encore ì examiner comment la matièe nutritive, extraite des aliments, passe du canal intestinal dans la masse du sang qu'elle est destinée à renouveler.

Artère aorte. Canal thor. Ganglions lymphatiques.

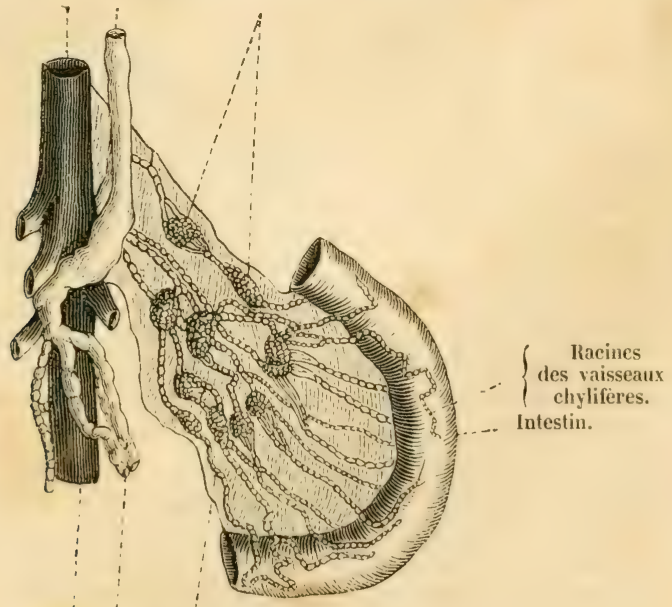

Vaiss. lymph. Mésentère.

Fig. 26. Vaisseaux chyliferes. 
Quelques-uns des liquides introduits dans l'estomac sont absorbés directement par les veines qui serpentent dans les prarois de cet organe, et dans eelles de l'intestin grèle; mais le chyle suit me autre route, et pénitre dans un système particulier dè canaux destinés à en effectuer le transport. Ces raisseaux, appelischyliferes (ou lactés, à raison de l'apparence qu'ils prement ordinairenent lorsqu’ils sont remplis de chyle), appartiennent, comme nous l'avons déjà dit, à l'appareil des vaisseaux lymphatiques (1). Ils premnent naissance par desorifices imperceptibles à la surface des villosités de la membrane muqueuse intestinale, ef se rémissent en branches plus ou moins grosses qui marchent entre les deux lames du mésentere. Pemlant ce trajet, ces vaisseaux lymphatiques traversent des ganglions appelés yanglions mésentériques (fig. 26), et vont déboucher dans le cantal thoracione, qui, à son tour, va se terminer dans la veine sons-claviore du colé gauche.

76. Lorsqu'un animal est à jeum, ees vaisseaux sont à peu près vides; mais lorsque la digestion intestinale est en pleine activité, ils ne lardent pas à se gorgerer de chycle, dont la couleur est, en géneral, blanche, et l'aspeet semblable à celui du lait.

Ce sont les villosilés dont la surface de la membrane muqueuse de l'intestin est garnie, qui paraissent ètre spécialenent charges de l’absurption du chọle. Aussitit que ee phénomène commence, on les troure ganflés et imbibées de ee liquide comme des éponges qui seraicent imbibes de lait. Le chyle passe ensuite dans les vaisseaux lymphatiques qui naissent de ces villosités, ef coule, avec assez de vitesse, dans le camal thoracique; mais on ne comnait pas bien la cause de son mourement ascensiomel.

\$ 77. Chyle. - L'aspect de ce liquide varie suivant la nature des aliments dont il provient, et suivant les animaux ou on l'observe. Dans l'homme et la plupart des mammiferes, e’est en général un suc blane laitesix, d'une odeur particuliere et d'une saveur salée et alealine. Examminc an miresosenpe, il parait compusé d'un liquide sereux, tenant an susponsion des gontteledes graisseuses et des globules circulares. Le ehyle provenant d'aliments qui ne renferment pas de matiores grasses, est beaneup moins opaque que celui formi far des substances contenant de la graisse on de l'huile; ot chez les viseaux il est presque hujours transparent.

Lorsqu'on examine le chyle dans les vaisseanx lactés pres de leur origine, on trouve que les matieres organiques qu'il contient consistent principalement en albunime; nats, fuand on l'observe plus loin dans son trajet vers la veine sous-claviere, on voit que sesqua-

(1) Voyez page 22. 


\section{DE LA DIGESTION.}

lités ne restent plus les mèmes : à mesure qu'il avance dans l’intérieur des vaisseaux lymphatiques, il se charged'une quantité deplus en plus considérable de filsine; principe qui lui donne la propriété de se coaguler spontanément à la maniere du sang. En général, ce liquide prend en mème temps une teinte rosée el devient susceptible de rougir lígerement au contact de l'air. Sa nature, par conséquent, se rapproche deplus en plus de celledu sang, avec lequel il va s'unir dans la veine sous-clavière où délonuche le canal thoracique.

C'est de la sorte que les matieres mutritives ćlabrées par la digestion sontabsorbées el mèlées au fluide nourricier. Pour continuer l'étude des phénomènes de la nutrition, nous devons, par conséquent, nous occuper maintenant de ce fluide et de la maniere dont se fail la distribution des matières organiques qu'il charrie.

\section{DU SANG.}

$\$ 78$. Dans les animaux dont la structure est la plus simple, tous les liquides de l'économie sont semblables entre eux; ils ne paraissent ètre que de l'eau plus ou moins chargée de particules de matières organisées; mais, daus les itres qui ocenpent un rang plus élevé dans la séric zoologique, les humeurs cessent d'ètre toutes de mème nature, et il en est un qui est destiné d’une manière spéciale à subvenir aux besoins de la nutrition: ce liquide nourricier est le sang.

C'est ce liquide qui entretient la vie daus les organes et leur fournit les matériaux dont ils se composent.

C'est aussi le sang qui est la source de toutes les humeurs formées dans le corps: la salive, l'urime, la bile, les larmes, par exemple.

$\$ 79$. Chez tous les animaux qui par leurstructure se rapprochent le plus de l'homme, tels que les mammiferes, les oiseaus, les reptiles etles poissons, et mème chez la plupart de's vers de la classedes amélides, le sang est d'une couleur rouge intense. Matischezpresque tous les animaux inférieurs, au lieu d'ètre rouge et épais, il ne consiste qu'en un liquide aqueux, tankit complétement incolore, tantôt ligirement teinté en jaune, en vert, en rose ou en lilas: aussi est-il assez difficile à voir, ef pendant longlemps a-t-on pensé que ces ètres en étaient (omplétement dépourvus, el les ap)pelait-on des animaux exsangues.

Les Axniex a saxg BLAxe, ofl ayant le sang à peine teinte, sont très- nombreux : tous les insectes rentrent dans cette categorie, et c'està fort gue lon regarde vulgatrement les monches enmme ayant

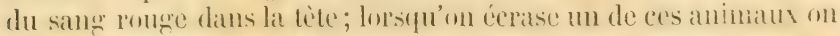
voil s'epancher, il est vrai, un liquide rougeitre, mais cette matliepe nest pas du sange el provient miquement des yeux de ces 
petits ètres. Les araignées, les crabes, les écrevisses el tous les animaux qui se rapprochent de ces derniers et qui sont désignés par les zoologistes sous le nom de crustacés, n’ont aussi que du sang presque incolore; enfin les limarons, les moules, les huitres, les vers intestinaux et les autres animaux de la classe des mollusques et de celle des zoophytes sont dans le mème cas.

ș 80. En examinant au microscope le sang d'un animal à sang rovge, tel qu'un mammifiere, un oiseau, un poisson, on voit qu'il est constamment formé de deus parties distinctes: d'un liquide jamnàtre et transparent, auquel on a donné le nom de sérum, et d'une foule de petits corpuscules solides, réguliers et d'une belle couleur rouge qui nagent daus le fluide dont nous venous de parler, et que l'on appelle les globules du sang.

$\$ 81$. Globules du sang. - Chez les animaux de la mème espèce, tous les globules du sang ont la mème forme et à jeu près la mème grosseur (1); mais lorsqu'on les compare chez des animaux d'espèces différentes, on y remarque des différencesimportantes à signaler. En général, ces corpuscules se ressemblent beaucoup plus chez les diver's animaux d'une mème classe que chez des animaux appartenant à des elasses différentes: chez les premiers leurs dimensions peuvent varier, mais ils affectent presque toujours la mème forme ; tandis que d'une classe à une autre les différences de volume deviennent souvent beaucoup plus considérables, et la forme elle-mème peut changer.

Ainsi chez l'homme (fig. 27), et chez presque tous les autres animaux de la classe des mammiferes (le chien, le

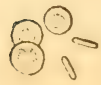
cheval, le bouf, par exemple), les globules du sang sont circulaires (2); tandis que chez les oiseaux, les reptiles et les poissons, ils ont une forme elliptique

\section{Fig. 27 (3). (voyez fig. 28).}

C'es corpuscules sont toujours microsropiques; mais c'est surtout chez les mammiferes, qu’ils sont d'une petitesse extrème. Dans l'homme, le chien, le lapin et quelques autres mammiferes, leur dianètre est igal à environ la cent vingt-cinquieme partie d'un

(1) Avant la naissance, les globules onf quelquefois des dimensions ou mème une forme differentes de celles qu'ils offrent pendant tout le reste de la vie. Ainsi le poulet, dans l'oeuf, a d'ahord des grlobules circulaires, et ce n'est qu'a une période plus avancée de l'incubation que les qrlobules ofrent tous me forme elliptique. Mais apres la naissance les globules ne varient plus.

(2) Les chancanx et les lamas font ex eption it cette règle, far clez ces mammiferes les globules du sang sont elliptiques.

(5) Fig. 97 , globules du sang de lhemme, erossis a peu pres qualde cents fois (en diametre). 
millimètre, et, chez la chèrre, ils n'ont que un deux cent cinquantième de millimetre.

Dans les oiseaux les globules du sang sont plus grands que chez les mammifires. Mais c'est dans la classe des reptiles qu'ils atteignent les dimensions les plus considérables : ainsi, dans le sang de la grenouille, elles ont environ un quarante-cinquième de millimètre en longueur sur un soixantequinzième en largeur; et dans le protée, qui est de tous les animaux connus celui chez lequel ils sont les plus grands, leur longueur est d'environ un dix-septième de millimètre.

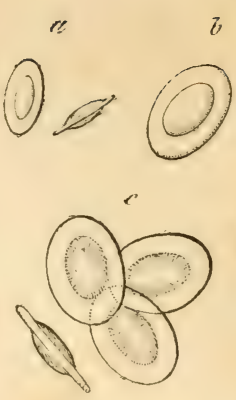

Fig. 28 (1).

Enfin chez les poissons ces corpuscules sont intermédiaires pour la grosseur entre les globules des oiseaux et des reptiles.

Du reste, les globules du sang sont toujours aplatis, et présentent une tache centrale entourée d'une espèce de bordure de couleur plus foncée. Leur structure intérieure est quelquefois très-difficile à connaitre; mais, lorsqu' on a soin de les prendre chez un animal où leur volume est le plus considérable, et qu'on les examine à l'aide d'un microseope puissant, on voit qu'ils sont composés de deux parties distinctes, d'un noyau central et d'une enveloppeayant l'apparence: d'une petite vessie. En général, cette enveloppe est déprimée, et forme autour du noyau un rebord plus on moins mince, de façon que le tout offre l'aspect d'un petit disque renflé au milieu; elle est de couleur rouge et semble ètre formée d'une espèce de gelée facile à diviser, mais très-élastique. Le noyau central a la forme d'un sphéroïde et n'est pas coloré. Chez l’homme et les autres mammiferes, lia portion centrale des globules est au contraire, moins saillante que le bord, et le noyau n'est pas bien distinct; mais, suivant toute probabilité, il doit exister comme dans les autres classes d’animaux vertébrés.

Ces globules rouges, qui donnent au sang sat couleur, ne sont pas les seuls qu'on y découvre à l’aide du microseope. Il existe aussi dans ce liquide, mais ('n beaucoup) moindre quantité, d'autres corpuscules incolores ef d'une forme sphérique qui ressemblent beaucoup aux glohules du ehyle; en général, ils sont difficiles à apereevoir ì cause de leur mólange avec les globules rouges.

$\$ 52$. Chez les animaux sans verlebres dont le sang est blane, on

(1) Fig. 22, ghlolules elliptique's du sang des viseaux, des reptiles et des prissons:-

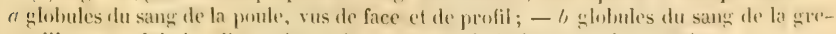
nouille; $-c$ stubules d'un poisson du genre squale 'mème grvossissement). 
à peine coloré, on trouve aussi des globules, mais ces corpuscules different beaucomp de ceux des amimaux vertébrés; leurgrosseur est tres-variable chez le meme individu, leur surface offre un aspect framboise; on u’y dislingue ni noyau central, ni enveloppe extérieure, el leur forme est en général sphírique.

5 83. Composition du sang. - La chimic nous apprend que le sang se compuse d'un grand nombre de substances différentes. Chez les animaux supérieurs, on y louve de l'cau, de l'albumine, de la fibrine, me matiere colorante rouge comtenant du fer, unc autre matierecolorante jaune, plusieurs matieres gratsses, telles que la cholestérine el la cérébrine, substance dans la composition de latquelle il entre du phosihore, un grand nombre de sels, tels que de l'hydrochlorate de soude ou sel marin, de l'hydrochlorate de potasse, de l'hydrochlorate d'anmoniague, du sulfate de potasse, du carbonate de soude, du carbonate de chanx, du carbmate de magnésie, des phosphates de somde, de chaux el de magnésie, des lactates de sonde, des sels alcalins formés par des acides gras; enfin, on y recommatitaussi la présence du fer, de l'acide carbonique libre, du gaz azoleet dugaz oxygene. Mais cette complication, toute grande qu'elle peut nous faraitre, est eneore an-dessous de la realite, ef si nos moyens d'analycse chaicut plus parfait. son découvrirait dans le sang d'autres substances encore, qui y existent hien certainement, mais ne s'y trourent qu'en quantités trop petites pour que le chimiste puisse les saisir. Pour s'en convaincere, il suffit d'arreter l'action de eertains organes chargés de séparer du sang divers liquides particuliers, tel que l'urine; car des matières qui chaient expulsées de l'éconmie frar cette voie, et qui ne se montrent jas d'ordinaire dans le sang, s'y aceumulent alor's, et deviennent de la sorte faciles à recomnaitre, ainsi que nous le verrous du reste plus en détail lorsque nous arrirerons à l'étude des séerétions.

Les substances que nous venons d'énumérer comme étant contenues dans le sang sont aussi celles qui entrent dans la composition de presque toules les prarties, soit solides, soit liquides, de l'économie; l'allumine forme la hase d’un grand nombre de tissus, la fibrine est le princige constituant des muscles, les sels contenus dans le sang se rencontrent aussi soit dans les os, soit dans les huneurs, et, d'apres l'ensemble des faits comnus, on est en droit de penser que les matiriaux destines à devenir de la chair, de la bile, de l'urine, etc., existent dijà dans le fluide nomrricier : les organes qui doivent se les approprier les puisent dans ee liquide, et ne les créent pas; aussi n'est-ce pas sans raisont que le sance a été appeté par quelques auteurs de la chair coslante. 
\$84. Les proportions dans lesquelles les diverses matières constituantes du sang s'y trouvent réunies varient beaneoup chez les différents animaux. Dansl'homme, on trouve ordinairement sur cent parties de sang environ soixante-dix-neuf parties d'eau, dix-neuf centiemes d'allumine, un centième de sels, et quelques millièmes seulement de fibrine et de matiere colorante. Dans le sang des oiseaux, la proportion d'eau est en génciral un peu moins forte; mais, dans le sang des reptiles et des poissons, on en trouve davantage. Dans celui de la grenouille, par exemple, il existe plus de quatrevingt-huit centièmes d'eau.

bes differences analogues se remarquent, lorsqu'on compare les quantités relatives de sérum et de globules dans le sang des divers animaux; et, comme nous le verrons par la suite, il existe un rapport remarquable entre la proportion de ces globules et la chaleur développée par ces ètres. Les oiseaux sont de tous les animanx ceux dont le sang est le plus riche en globules, et ceux aussi dont la température est la plus ćlevée. Le sang des mammiferes en renferme un peu moins (7 à 12 centiemes); chez les reptiles et les poissons, que l'on appelle des animaux à sang froid, à cause du peu de chaleur qu'ils développent, la quantité relative des gl bules est beancoup plus faible encore, et ne dépasse guère cinq ou sir centièmes du poids total du sang.

Du reste les proportions des éléments solides et liquides rarient aussi chez les différents individus d'une mème espète, et diverses circonstances peuvent apporter des modifications dans le sang d'un mème animal. Ainsi la quantité des globules est plus grande et celle de l'eau plus faible dins le sang de l'homme que dans celui de la femme, et dans le sang' des individus d'un tempérament sanguin que dans ceux d'un temperament lymphatique.

8.). Goagulabilité du sang. - Mauns l'état ordinaire, le sang est toujours fluide et se compose, comme nous l'avens déjai dit, d'un liquide aqueux tenant en susprension des ghobules solides; mais

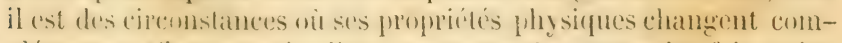
pletement. Co'st ce qui a lien, par exemple, toutes les fois qu'on extrait lo singr des vaisseaux si il est contenu, dans l'intérieur du corps d'un animal vivant; abandonne a lui-meme, il se transforme alon's, all bout de equelques instants, en me matsie de consistance gélatinetise qui se sépare peu à peu en deux parties, l'une liquide, jaunatreet transparente, formée par le sérum, l’autrephos ou moin.s solide, complitement oparque, et d'une couleur rouge, it larquelle on donne le nom de caillot ou de cruor du sang.

Ce phéremene est dè à la présence de la fibrine contenue dans 
le simg. Cetle substance, qui est dissoute dans le sérum, a la propricie de se solidifier lorsqu'elle n’est plus soumise à l'influence de la vie et, en se solidifiant ainsi, elle entraine avec elle les globules, et forme avec eux une masse gélatineuse, de la mème manière que du blanc d'eeuf, enployé pour clarifier un liquide trouble, entraine les corpuscules qui s'y trouvent mèlés, lorsque par l'effet de la chaleur il vient à se coaguler. Pour s'assurer que la coagulation du sang dépend de la fibrine, il suffit de battre ee liquide avec des verges aussitôt qu'il est tiré de la veine; la fibrine, au moment de sa solidification, s'attachant alors aux baguettes, s'extrait facilement, et le sangr perd la propriété de se coaguler. A l'aide d'une expérience tres-simple, on peut également se convaincre que cette fibrine se trouve dans le sérum, et n'est pas contenue dans les globules, comme on le croyait jusque dans ees derniers temps. Effectivement, si l'on jette sur un filtre du sang dont les globules sont très-volumineux, du sang de grenouille, par exemple, il est possible de faire passer le sérum et de retenir tous les globulesavant que la coagulation se soit effectuée, et, dans cé cas, bien que les globules soient restés intacts sur le filtre, le sérum se prend en masse conme d'ordinaire; seulement le caillot, formé alors exclusivement de fibrine, est blanc au lieu d'ètre rouge, comme lorsque les globules s'y trouvent englobés.

$\$ 86$. Usages du sang. - Le sang, avons-nous dit, est l'agent spécial de la mutrition. Mais il ne sert pas seulenent à réparer les pertes que subissent les organes et à les nourrir, il est destiné aussi à produire dans ces parties une excitation sans laquelle la vie ne saurait s'y maintenir. L'expérience suivante peut, mieux que toute autre, donner une idée de l'importance du rôle que ce liquide joue dans l'économie.

$\$$ 87. Lorsqu'on saigne abondamment un animal, on le voit s'affaiblir de plus en plus; et, si l'hémorrhagie est très-abondante, il ne tarde pas à perdre connaissance ; sa respiration s'arrète, tout mouvement musculaire cesse, et la vie ne se manifeste plus par aucun signe extérieur; enfin, si la perte de sang est poussée assez loin, et qu’on laisse l'animal dans cet état, la réalité succède bientôt à l’apparence, et la mort ne tarde pas à arriver. Mais si, au lieu d'abandonner à son sort cette espece de cadavre, on injecte dans ses veines du sang semblable à celui ru’il a jerdu, on le voit avec étomement revenir à la vie; à mesure qu'on introduit dans ses vaisseaux de nouvelles quantités de sangr, l'animal se ranime de plus en plus; bientît il respire librement, se ment avec facilité, reprend ses allures habiluelles, et il peut mème se rélablir complétement.

Celle operation, que l'on désigne sous le nom de transfusion, est, 
certes, une des plus remarquables que l'on ait jamais faites, el elle prouve mieux que tout ce que l'on pourrait dire l'importance de l'action des globules de sang sur les organes vivants; ear, si l'on emploie, de la mème manière, du sérum privé de globules, on ne produit pas d'autre effet que si on se servait d'eau pure, et la mor't n'en est pas moins une suite inévitable de l'hémorrhagie.

La fibrine du sang joue également un rôle tris-important dans l'économie. En effet, II. Magendie a constaté que, lorsqu'on injecte dans les veines d'un chien du sang dépouillé de sa fibrine, l'animal tombe bientôt dans un état de faiblesse extrème et périt au bout de quelques jours, en présentant tous les symptòmes qu'offrent les malades en proie à certaines fievres pernicieuses.

$\S$ 88. L’influence du sang sur la nutrition est également facile à démontrer. Ainsi, lorsque, par des moyensmécaniques, on diminue d'une manière notable et permanente la quantité de ce liquide recue par un organe, on voit celui-ci diminuer de grosseur el souvent mème se flétrir et se réduire jresque à rien. D’un autre còté, on observe également que plus une partie queleonque du corps fonctionne, plus elle recoit de sang, et plus aussi son volume s'accroit. En effet, chacun sait que l'exercice musculaire tend à développer davantage les parties qui en sont le siége; que chez les danseurs, par exemple, les muscles des jambes et surtout du mollet acquierent une grosseur remarquable, tandis que chez les boulangers, et les autres hommes qui exécutent, avec leurs bras, des travaux rudes, les muscles des membres supéricurs deviennent plus charnus que les autres parties. Or les muscles recoivent plus desang lorsqu'ils se contractent que lorsqu'ils sont en repos, et par cet afflux de sang le travail nutritif dont ils sont le siége est activé et leur volume s'accroìt.

$\$ 89$. Le liquide nourrieier, en agissant ainsi sur les organes avee lesquels il est en conlact, en éprouve à son tour des modifications, et à raison de cechangement il perd bientiot ses fualités vivifiantes. Le sang qui arrive dams les diverses parties du corps est d'une couleur rouge-vermeil, tandis qu'il présente, apries les avoir traversćes, me teinte sombre d’un rouge moiratre, et dans cet état il ne posside plus la faculté d'entretenir la vie dans les organes auxquels il se rend. Mais du sang ainsi vieié, ou du moins en fuelque sorte usé, reprend, par l'action de l'air, ses propriétés primitives et redevient alors propre à exciter le mouvement vital.

La fonction ì l'aide de laquelle ee changement imporlant s'opère: est celle de: la respiration, dont nous aurous bientit à nous oremper.

Le sang qui a subi l'action de l'air el qui est propere à l'entretien

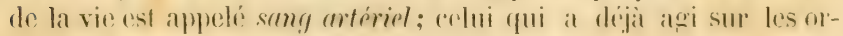


ganes, et qui ne peut continuer ì y exciter le mouvement vilal, se nomme sany veineux: il contient, en géneral, moins degolobules que le sang artériel, et se coagnle moins promptement, mais cest par sa couleur noiratre ef par' son mode d'action sur les tissus vivants qu'il s'en distingue le plus.

\section{GIRCULA TION DU SANG.}

$\$ 90$. Diaprès ce que nous venons de dire sur le roole que les liquides nomreicers remplissent dans léemomic animale, el sur l’influence que lat respiration exeres sur les proprictés physiologiques de res liquides, il est évident qu'ils doivent ère le siéged’un mouvement continuel.

En effot, puisque c'est le sang qui distribue à toutes les parties du corps les materiaux nécessaires à leurnutrition, et que ce liquide est aussi la voie par laquelle les particules éliminées de la substance destissus sont entrainés an loin, il ne pent rester en repos, et il doit nécessairement traverser siuns cesse tous les organes. Nais, chez la plupart des animaux, ces conditions d'existence ne sont pas les scules gui rendent le mouvement du sang indispensable pour l'entretien de la vie: lorsque l'air ne pénetre pas lui-mème dans l'úpaisseur de tous les tissus (comme cela a lieu chez lesinsectes), et n'agit rque par l'intermédiaire d'un orezane spécial de la respiration (tel que les pumons), il est cigalement facile de voir que le sang, qui a déjà traversé les tissus, doit aussi se rendre daus l'appareil respiratoire jour y subir l'influence vivifiante de l'air avant que de relourner de nouveau vers ces mèmes tissus.

Or, c'est ce (fui a réellement lieu; ce monvement constitue re

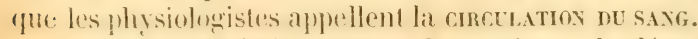

Ce phénomine itait incommu des anciens; la déenuverte en est due a Ilarver, mérlecin du roi d'Angleterre Charles fer (en 1619).

91. Appareil de la circulation. - Chezquelques animauxinferieurs lo simg no circule que dans les latumes qui existent entre les divers organes du corpos ou entre les lamelles comstituantes de ces organes. Hais thez lous les animaux supéricurs, et aussi chez la plupart de ceux appartenant aux classes moins élevées dans la série zoologique, la circulation a lieu dans l'intérieur d’un appareil trèscomplique, composi : 1" d'un systime de canaux servant à conduire le sang dans tontes les parties ou il doit passer; $2^{\circ}$ d'un organc particulier destiné ì mettre ce liquide en mouvement.

Ces canaux portent le nom de eaisecax sanguins, et cet organe moteur est le cour.

Le cour est le centre de l'appareil de la circulation; c'est une 
espèce de poche charnue en communication avec les vaisseaux sanguins, qui recoit le sang dans son intérieur, et qui, en se resserrant de temps en temps, lance ee liquide dans ces canaux et y détermine ainsi un courant continuel.

Presque tous les animanx ont un cour. Cet organe existe nonseulement chez les mammifires, les viseaur, les reptiles et les poissons, mais aussi chez les colimarons, les huitres et les autres animaux de la classe des mollusques; chez les crabes et les écrevisses; chez les araignées, ete.

Les vaisseaux sanguins sont de denx ordres, savoir :

$1^{\circ}$ Les arteres, qui servent à porter le sang du cour dans toutc les parties du corps;

$2{ }^{\circ}$ Les reines, qui rapportent ce liquide de toutes les parties du corps dans le cøeur.

Les arteres partent du cour et se divisent en branches, en rameaux et en ramuscules de plus en plus nombreux et de plus en plus déliés à mesure qu’elles s'avancent et qu'elles se distribuent à des parties plus nombreuses et plus éloignées.

Les veines présentent une dispusition semblable, mais qui est destince à produire un résultat tout contraire, parce que le sang suit dans ces vaisseaux une marche inverse. Elles sont tres-nombreuses loin du ceur, mais peu à peu elles se réunissent pour former des canaux plus gros qui, à leur tour, se réunissent aussi de facon à se terminer au cour par un ou deux trones seulement.

Les dernières ramifications des artères dans la substance des organes se continuent avec les racines des veines, de manière à former une suite non interrompue de canaux étroits dans lesquels le sang coule pour traverser ces organes (fig. 29).

On domne le nom devaissean capillaires à ces canaux déliés qui élablissent ainsi la communication entre l'extrémité des artères et des veines, et ce nom leur vient de leur finesse extrème, qui les a fait comparer à des cheveux.

Par l'extrémité opposée à celle où se trouvent les raisscaus capillaires, les artères et les veines communiquent entre

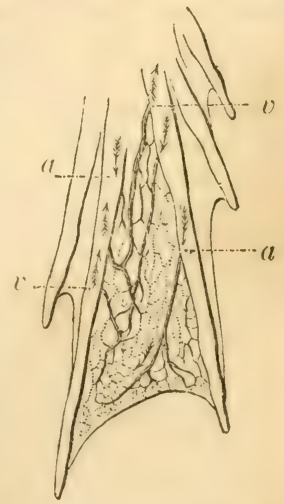

Fig. 29. Taissenux crmillaires de la patte d'une grenouille (1).

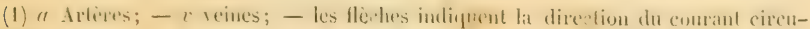
latoire. 
elles par l'intermédiaire des cavitís du cenur. 11 en resulle que l'appareil vasculaire forme un cercle complet dans lequel le sangy se meut pour revenir sans cesse a son premier proint de départ; el e'est en raison de la nature de ce mouvement qu'on l'apjelle circulation.

Le cercle circulatoire peut ètre comparé à un arbre dont le trone serait reployé sur lui-mème, de manière à faire rencontrer les dernières ramifications des branches avec les dernières divisions des racines : la portion supérieure du trone et ses branches représenteraient les artères, la portion inférieure du tronc et les racines représenteraient les veines; et c'est aupoint de réunion de ces deux portions du tronc que serait la place du cœur.

Dans tous les animaux où la respiration se fait dans un orcane spécial, tel que le poumon, les vaisseaux sanguins se ramifient, non-seulement daus les tissus qu'ils doivent nourrir, mais aussi dans l'organe où le sang doit subir l'action de l'air, et ce liquide: Iraverse, par conséquent, deux ordres de vaisseaux capillaires, l'un servant à la nutrition, l'autre à la respiration : la circulation qui se fait dans l'appareil respiratoire est appclíe la petite circulation; et celle qui se fait dans le reste du corps, la grande circulation.

Du reste, la route suivie par le sang et la structure de l'appareil circulatoire varient beaucoup dans les différentes classes d'animaux. Nous indiquerons plus loin ces différences; mais, avant que de nous en occuper, il convient d'étudier avec plus de détails la conformation et le mécanisme de cet appareil chez un animal qui pourra nous servir ensuite comme terme de comparaison.

Description de l'appareil de la circulation che: les animax supérieurs.

\$ 92. Cour. - Chez l'homme, et chez les animaux qui, par leur structure, se rapprochent le plus de nous, le carur est logé entre les poumons dans la cavité de la poitrine que les auatomistes appellent le thorax (fig. 3 et 30); son cxtrémité inférieure est dirigée un peu obliquement à gauche et en avant, et son extrémité supéricure, qui donne naissance à tous les vaisseaux en communication avec som intérieur, est fixée aux parties voisines, à peu près sur la ligne. médiane du corps. Dans le reste de son étendue le coeur est complétement libre, et il est enveloppé par une espèce de double sac membraneux, le péricarde, dont la surface interne est partout en contact avec elle-mème, parfaitement lisse ef contimuellement litt- 


\section{CIRCULATION DU SANG.}

meclée par un liquide atqueux; disposition qui sert à rendre les mouvements de cet organe plus faciles (1).

La forme générale du cour (fig. 30) est celle d’un cône ou lyramide irréguliere etrenversée; son volume est à peu pres égal à celui du poing, et sa substance est presque entierement charnue: e'est

$$
\text { vj ac } \quad t \text { ac vj }
$$

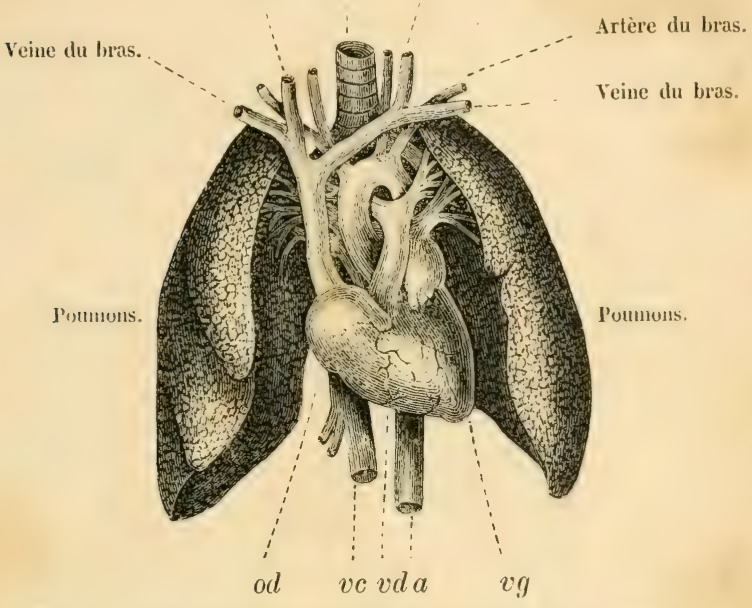

Fig. 30. Poumons, crur el principaux vaisseaux de l'homme (2).

(1) Colte tunique ainsi que te piriteine, dont it a ete deja question, est une de celles que les anatomistes designent sous le nom de sirruses, et la disposition de ses memhranes merite dètre remarquée: elles ont toujours la forme d'une espèce de sac dont la surface interne, extrêmement lisse et constamment enduite d'une courhe de liquide, est partout en contact avec elle-mème; l'une des moities de ce sac adhère par sa face evferne aux parois de la cavite qui lugre les visceres, et l'autre moitie entoure ces visceres eux-mèmes, et y adhere par sa face esterne. Pour me servir d'une comparaison triviale, mais qui peint parfaitement la chose, ces menbranes ressemblent ì un bonnet de coton qui entourerait les visceres comme ce bonnet enveloppe la tète, et dont la moitie exterieure serait five aux parois d'une cavite renfermant et le bonset et la tete. Ces membranes tendent a diminuer le frotfement de ces parlies entre elles, et, par consingunt, it laciliter leurs mourements: anssi trouve-t-on des puches analogues partout ou des oryanes frottent continuellement ou ave force les uns contre les autres, comme aux articulations des os des membres, autour des poumons, des intestins, etc.

(2) od, red oreillette et ventrieule droits; - ry ventricule gatuche; - a artere anrte; - ac arteres rarotides; $-v c$ veine cave inferienre; $-v j$ veines jugrulaires on veines du cou; $-\ell$ trachee. 
un muscle creux qui, chez les oiseaux aussi bien que chez tous les mammiferes, renferme quatre cavités ou chambres distincles. En effet une grande cloison verticale (fig. 31) le divise intérieurement en deux moitićs, ef chacume de ees moitiés, à son tour, esl subdivisée gar une cloison transtersile, de facon it former deux cavités superposées, un tentricule et une oreillette (fig. 31 et 34).

Veine cave supér. Art. pulm. Aorte. Artère pulmonaire.

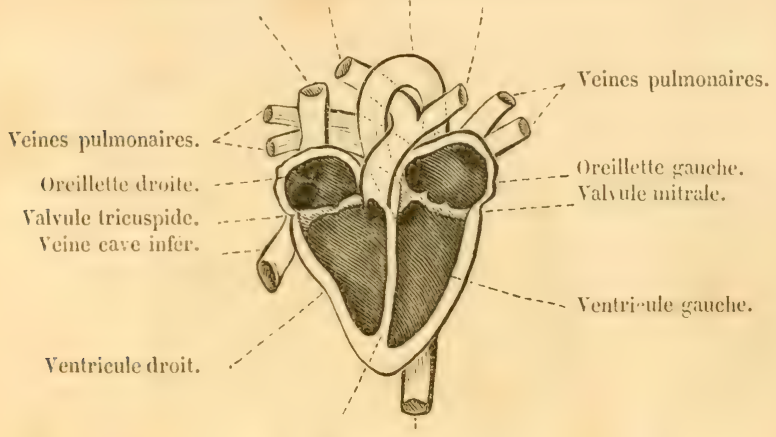

Cloison. Aorte.

Fig. 51. Coupe théorique du cour de liomme.

Les deur ventricules du ceur en oceupent la partic inféricure et ne commminuent pas entre eux, mais s'ouvent chacun dans l'oreillette situécan-dessus, au moyen d'un grand orificenommé auriculoentriculuire. Les cavités du coité gatuche contiemnent du sang artériel, celles du coité droit le sang veineux. On remarque que les parois des ventrieules sont douées d'une force bien plus grande que celles des oreilletter, et l'utilité de cette disposition est évidente; car les oreilletles ne doivent chasser te sang̨ que dans les ventricules situés au-dessous, handis queces dernieres eavités doivent l'envover à une distance bien plus considerable, soit aux poumons, soil aux autres parties ducorjs. Le? ventricule ganche est anssibien plus fort que le ventriculedroit, et l'étendue du trajel que les contractions de ces ca-

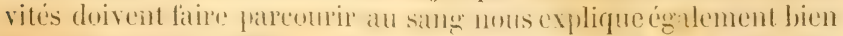

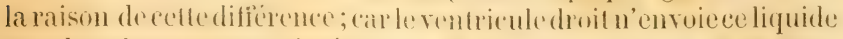
que dans les poumons situés à peu de distance du ceeur, et le ventrieule gauche le pousse justu’aux parties les plus éloignées du corps.

$\$ 93$. Vaisseaux sanguins. - Les vaisseaux daus lesquels le sang circule communiquent tous avee le coeur, par l'internédiaire d'un 
petit nombre de gros trones, et se distinguent, comme nous l'avons déjà dit, en artères et en veines, suivant qu’ils sont destinés à porter le sang du cour vers une autre partie, ou bien qu'ils rapportent ce liquide de divers organes vers le cœur.

Les artères et les veines sont formées, intérieurement, par une membrane mince et lisse qui se continue avec celle qui tapisse les cavités du coeur, et qui a de l'analogie avec celles désignées par les anatomistes sous le nom de séreuses. Dans les artères, cette tunique interne est entourée d'une tunique moyenne, gaine épaisse, jaunàtre el très-ćlastique, qui se compose de fibres d’une nature particulière disposées circulairement; et le tout est renfermé dans une troisième tunique externe ou celluleuse, formée jar du tissu cellulaire dense et serré. Dans les veines on ne trouve pas de tunique moyenne ou élastique distincte, et la membrane interne n'est entourée que par une couche mince de fibres longitudinales, làches et extensibles. Il en résulte une différence très-grande daus les propriétés physiques de ces deux ordres de vaisseaux. Les veines ont des parois minces et flasques qui s'affaissent, lorsqu'elles ne sont pas distendues par le sang, et qui se cicatrisent facilement lorsqu'elles ont été divisées. Les artères, au contraire, ont des parois beaucoup plus épaisses et conservent leur calibre, lors mème qu'elles sont vides, comme cela arrive toujours après la mort; enfin lorsque ces derniers vaisseaux sont ouverts, les bords de la plaie tendent à s'écarter, à raison de l'élasticité des filsres de leur tunique moyenne, et la cicatrisation ne s'effectue jamais d'une manière complète, à moins que l’on ne détermine l'oblitération de l'artère dans le point divisé: aussi, pour arrèter le sang qui s'échappe d'une veine, suffitil de maintenir, pendant quelque temps, les bords de la plaie en contact, tandis que, lors de l'ouverture d'une artère, il faut lier le vaisseau ou l'oblitérer au moyen de la compression.

\$ 9'. Système artériel. - Les vaisseaux qui doivent transporter le sang artériel dans tous les organes naissent du ventricule gauche du cocur par un seul tronc appelé artère aorte (fig. 32). Cette grosse artire remonte d'abord ver's la base du cou, puis se recourbe en las, passe derriere le cour et descend verticalement au-devant de l’épine du dus jusqu'ì la partie inférieure du ventre. Pendant ce trajet, il se sépatre de l'aurte un grand nombre de branches, dont les principales sont les deux arteres carotides, qui remontent sur les côtés du cou et distribuent le sanğ à la tète; les deux artères des membres supéricurs, qui prement sucessivement les noms d'artères sousclacieres, axillaires et brachiales, suivant qu'clles passent sous la rlavicule, qu'elles traversent le creus de l'atsselle, su qu'elles des- 
rendent le long du bras; l'artire coliaque, qui se rend à l'estomac, au foie et à lat rate; les artères mésentériques, qui se ramifient daus

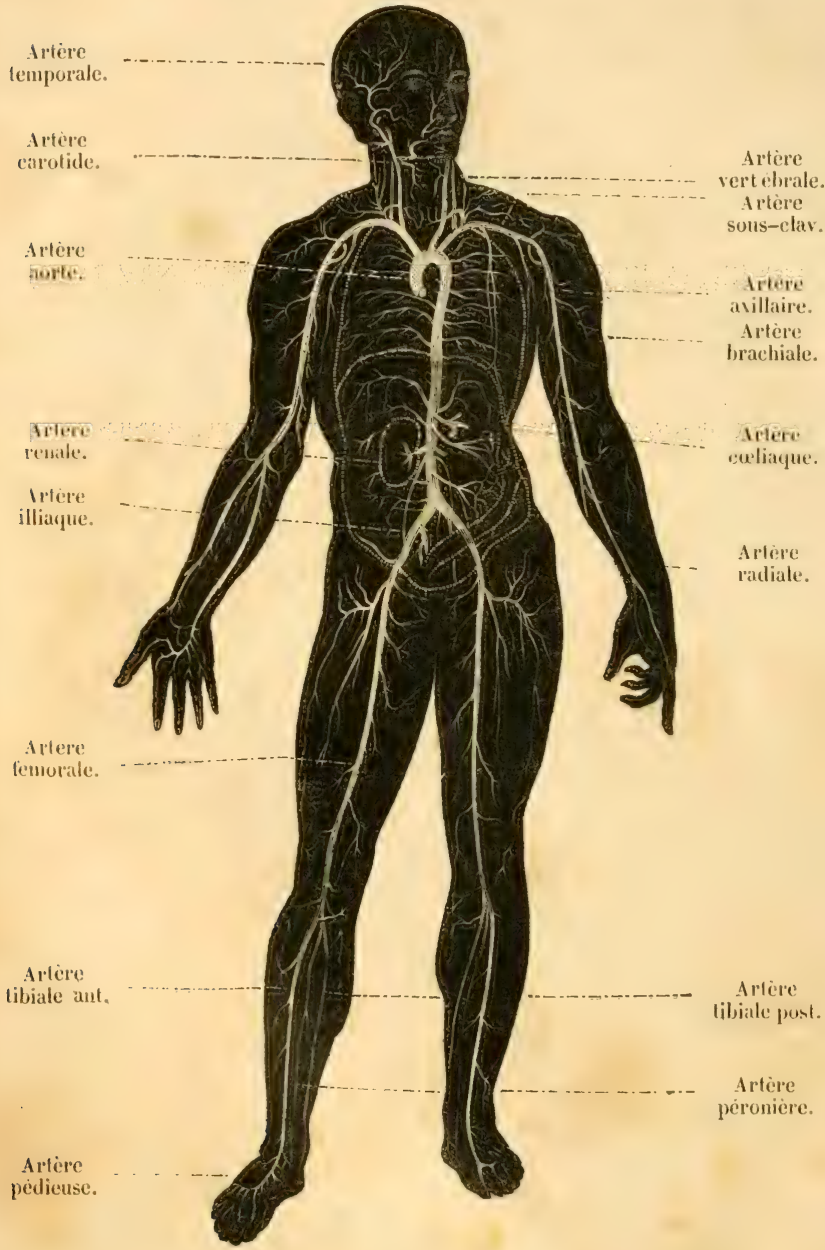

Fig. 5̇. Siystime artériel de l'homme. 
les intestins; les artères rénales, qui pénètrent dans les reins; et les artères iliaques qui terminent, en quelque sorte, l'aorte, et qui portent le sang aux membres inférieurs.

$\$ 93$. Système veineux. - Les veINES qui communiquent avec: les dernières ramifications des artères, par l'intermédiaire des vaisseaux capillaires, et qui recoivent le sang après qu'il a ainsi arrosé toutes les parties du corps, suivent à peu près le mème trajet que les artères; mais elles sont plus grosses, plus nombreuses, et, en général, situées plus superficiellement. Un grand nombre de ces vaisseaux marchent sous la peau, d'autres accompagnent les arteres, et en dernier résultat, tous se réunissent pour former deux gros trones qui s'ouvrent dans l'oreillette droite du cœur, et qui ont reeu les noms de veines caves supérieure et inférieure (fig. 30).

Les veines des intestins présentent dans leur marche une particularité remarquable, le trone commun, formé par leur réunion. pénètre dans la substance du foie et s'y ramifie, de façon que le sang de ces organes ne retourne au cour qu'après avoir circulé dans un systeme particulier de canaux capillaires contenus dans le foie, et domnant naissance à des vaisseaux qui se réunissent entre eux pour aller s'ouvrir dans la veine cave inférieure. Cette portion de l'appareil veineux est appelée le système de la veine porte.

$\$ 96$. Petite circulation. - Le sang veineux, qui arrive de toutes les parties du corps, pénètre dans l'oreillette droite du cour par les veines caves, et passe de cette cavité dans le ventricule situé audessous, pour se rendre ensuite aux poumons.

Le vaisseau destiné à conduire le sang veineux du cœur aux poumons est nommé artère pulmonaire (fiy. 30 et 31 ); il nait de la partie supérieure et gauche du ventricule droit, remonteà côtédel'aorte, ct se divise bientôt en deux branches qui s'écartent presque transversalement l'une de l'autre, et vont se ramifier dans les poumons; celle du côté droit passe derrière l'aorte el la veine cave supérieure; celle du côté gauche passe au-devant et au-dessus de la crosse de l'aorte. La premiere se subdivise en trois brauches avant que de pi:nétrer dans la substance des poumons, la deuxiène en deux; l'une et l'autre vont se ramifier sur les parois des cellules pulmonaires.

$\$ 97$. Les veines pulmonaires naissent dans la substance des ponmons, des dernieres divisions eapillaires des arteres dumème nom, et se rassemblent en rameanx of en branches qui suivent le mème trajet que ces vaisseallx; ellesforment enfin quatre trones, qui aballdomnent deuxà deus ehatgue poummon, ef se rendent dams l'oreilleter

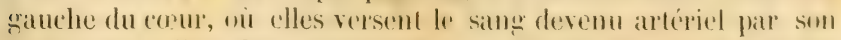

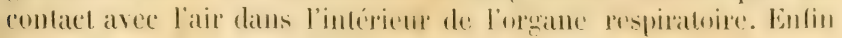


cotte oreillette communique arec le ventricule gauche, d'où nait, comme nous l'avons déjà vu, l'artère aorte.

\section{Mécanisme de la circulation.}

98. Mouvements du cœur. - Le mécanisme à l'aide duquel le sang se meut dans tous ces vaisseaux est facile à comprendre. Les cavités du cour, comme nous l’avons dijà dit, se resserrent et s'agrandissent alternativement, et poussent ainsi le sang dans les canatux avec lesquels elles sont en communication.

Les deux ventricules se contractent en mime temps; ef, pendant que leurs parois se relà hent ensuite, les oreillettes se contractent à leur tour. Ces monvements de contraction portent le nom de systole (1), et on appelle diastole (2) le monvenent contraire. Ils se renourellent tressfréfuemment; chez l'homme adulte, on en compte ordinairement de soixante à soixante-quinze par minute; chcz les

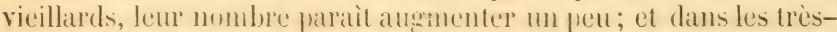
jeunes enfants, il s'elive, ('n general, à envipon cent vingt. Du reste, une fonte de ciremstances influent sur la fréfuence el la foree des battements do cour ; ils sont acceléres par l'exercice, par les émotions de l'àme, et jar un grand nombre de maladies; dans la defaillance et la syneone, jls sont considerablement diminués ou mème interrompus momentanément.

99. Passage du sang dans les cavités du ccur. - L'oreillette

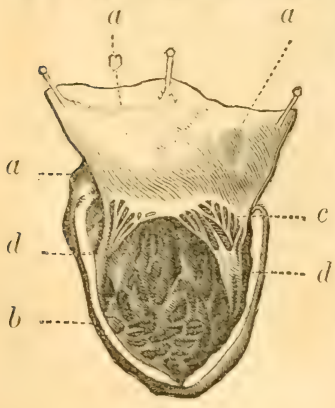

Fig. 53. Section du cour (3). gauche, qui reçoit le sang venant des poumons, communique, comme nous l'avons vu, avec les reines pulmonaires, d'une part, el avec le ventricule gauche, de l'autre; lorsqu'elle se contracte, elle expulse de sa cavité la majeure partie du sang qui s'y trouvait, et il est évidentque ce liquide doit tendre à s'échapper par ces deux voies : c'est en effet ce qui a lieu. Mais, comme le ventricule se dilate en mème temps, c'est dans son intéricur que la presque totalité du sang pénètre, et très-peu retourne dans les veines pulmonaires.

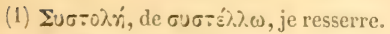

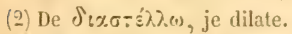

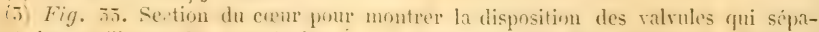
rent les oreillettes des ventricules: - "lune des areillettes ouverte et etendue; - b cavité du ventricule dont les parois sont garnies d'un grand nombre de cu- 
Bientôt après, le ventricule gauche se contracte, à son tour, et chasse te sang qu'il vient de recevoir: or, il existe autour des bords de l'onverture qui fait communiquer le ventricule avee loreillette placce au-dessus, un grand repli membraneux (fig. 33 et 34), disposé de maniere à s'atfaisser, lor'squ'il est poussé de haut en bas, et à se relever et à fermer l'ouverture, lorsqu'il est poussé en sens contraire (1) : il en résulte que, pendant la contraction du ventricule, le sang ne peut retourner dans l'oreillette, et qu'il est poussé dans l'artère aorte. Les contractions du ventricule se succédant rapidement, de nouvelles ondées de sang pénètrent à chaque instant dans ce vaisseau; le liquide contenu dans son intérieur doit, par conséquent,

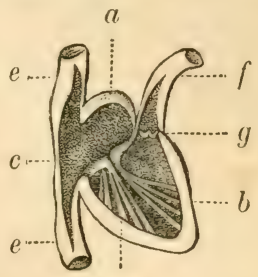

$d$ s'y mouvoir et couler du cour vers l'extré- Fig. 5千. Scction duccur (2). mité capillaire du système artériel, car il existe aussi à l'entrée de l'artère aorte des valcules (3) disposées de facon à s'opposer à son reflux dans le cœur.

\section{$\$ 100$. Cours du sang dans les artères. - D’après la nature des} mouvements dont nous venons de parler, on pourrait croire que le

lonnes charnues disposées irrégulièrement, de façon à former des espèces de cellules; - $c$ valvule dont le hord externe est fivé au pourtour de l'ouverture auriculoventriculaire, et dont le bord libre dome attache à un grand nombre de petits tendons (d) provenant de colonnes charnues fixées aux parois du ventricule par leur extrémite inférieure.

(1) Cette espèce de soupape a reçu le nom de rulvule mitrale, à cause de la division de son bord libre en deux langruettes. Le mécanisme au moyen ducquel elle ferme louverture auriculo-ventriculaire est très-simple; de petites cordes tendineuses, yui naissent de colomnes charnues fivces inferienrement aux parois du ventricule, s'insèrent à son bord liłre et l'empèchent de se renverser dans l'oreillette, taudis qu'elles n'opposent aucun olstacle à son aflaissement. (Yovez la fig. 34.)

(2) Figure thenrique de l'interieur du corur prour montrer le mécanisme du jen des valvules: - 1 oreillette recevant les veines $(e c) ;-l$ ventricule separe de l'oreillette par les valsules $(c) ;-d$ freins charnus de ces valvules; $-f$ artère naissant du ventricule; $-g$ valvules situces à l'entrée de ce vaisseau.

(5) Ces valuules (worez la fiy. $\bar{i}$, gi, au nombre de trois, sont formées par les replis de la membane interne de l'artere, et sont nommees, à cause de leur forme,

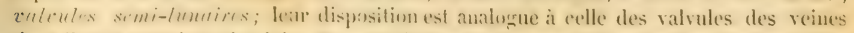

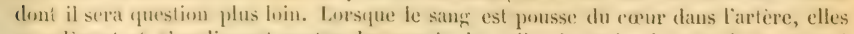
se relevent et sappliquent contre les parois de celle-ci; mais, lorsque le sang tend it rentrer daus le ventricule au monent ou celui-ci cesse de se contracter, le poids du liquide les distend of tes ablisisse' : elles ressemblent alors asse\% hien aur petits paniers dans lesquels on fait couver les pigeons; et comme elles se touchent par leur hord lihre, elles ferment l'artère. 
samg ne chemine dans les arteres que par saccades, chaque fois que le ventricule gauche se contracte, et que, pendant la dilatation de cette cavité, il doit rester en repos. II en est cependant tout autrement: si l'on ouvre un de ces vaisseaux sur un animal vivant, on voit le sang s'en échapper en formant un jet continu, qui devient plus fort au moment de la contraction du cœur, mais qui n'est pas interrompu lors du mouvement contraire. Cela dépend de l'action des parois des arteres sur le cours du sang. Ces parois sont trèsélastiques; lorsqu'une ondée de sang est projetée dans l'aorte par la contraction du ventricule, elles cèdent à la pression ainsi exercée, comme le ferait un ressort, mais elles tendent ensuite à revenir sur elles-mèmes, et à chasser le sangr qui les distendait.

Pour démontrer l’influence des parois artérielles sur le cours du sang, il suffit de meltre à 11 une grosse artire sur un animal vivant, et d'en intereepter une portion entre deux ligatures serrées avec force, puis de pratiquer une petite ouverture entre les deux points ainsi oblitérés. Le sang qui s’y trouve est complétement soustrait à l'influence des mouvements du cour, et cependant il s'échappera encore de l’artère en formant un jet très-élevé et le vaisseau ne tardera pas à se vider par le seul effet du resserrement de ses parois. La portion de l'artère situće au delà des ligalures diminue ainsi de calibre, et fait passer dans les veines la majeure partie du sang qui s'y trouvait.

C'est ainsi par l'élasticité des artères que le mouvement intermiltent imprimé au sang par les contractions du cour se trouve. Iransformé en un moucement continu. Dans les grosses artires, les siccarles vecasionnées par ses contractions se font encore sentir; mais dans les vaisseaux capillaires, et mème dans les petites branches artérielles, on ne les apereoit presque plus, et le sang n'y coule que par l'effet de la pression exercée par les parois élastiques des artères.

$\$ 101$. Onvoit done que les contractions du cour servent à remplir continuellement les grosses artères, et, pour ainsi dire, à tendre le ressort représenté par les parois de ces vaisseaux, el destinéà pousser, d'une manière continue, ce liquide jusque dans les veines.

Ainsi les cavités gauches du cour remplissent les fonctions d'une double pompe foulante (fiy. 33̈) qui serait disposíe de faron que les deux pistons alternassent dans leurs mouvements et que le lifuide chassé du premier corps de pompe (a) šintroduisit dans le second (b) sans pouvoir revenir sur ses pas, ef fiut lance par cette seconde pompe dans le conduit $(f)$ représentant le systeme artériel. 
$\$ 102$. Le phénomène connu sous le nom de pouls n'est autre: chose que le mouvement oceasionné par la pression du sang sur les parois des artères, chaque fois que le cœur se contracte. D’après la fréquence et la force de ces mouvements, on peutjuger de la manière dont cet organe bat et en tirer des inductions utiles pour la médecine. Mais le pouls ne se fait pas sentir partoul; pour le distinguer il faut comprimer légèrement une artère d'un certain volume entre le doigt et un plan résistant, un os par exemple, et choisir

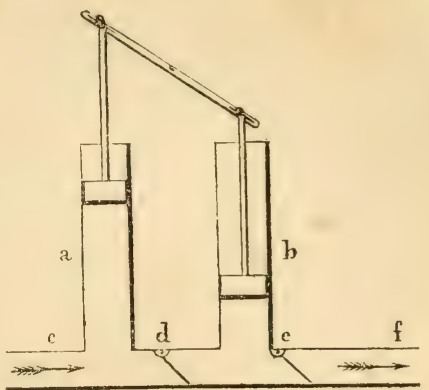

Fig. 35 (1). aussi un vaisseau situé près de la peau, comme l'artère radiale au poignel (fig. 32).

$\$ 103$. Bien que ce soil le mème agent moteur qui fait couler le sang dans toutes les parties du système artéricl, on observe cependant que ce liquide n'arrive pas à tous les organes avec la mème: vitesse. La distance qui les sépare du cocur est une des causes de. ces différences, mais elle n'est pas la seule.

Tantoit ces vaisseaux marchent ì peu pries en ligne droite, tantoit ils forment des coudes plus ou moins nombreux; or, toutes les fois que la colonne de sang, mise en mouvement par les contractions du cour, rencontre une de ces courbures, elle tend à reJresser le vaisseau, et perd ainsi une partie de la force qui la faisait mouvoir : ce qui ralentit d'autant la rapidité de son cours.

On sait, d'après les lois de la physique, que, toutes choses égales d’ailleurs, la rapidité avec laquelle une quantité délermincée de liquide coule dans un systeme de canaux non capillaires, diminue toujours lorsque la capacité de ces conduits devient plus considérable; c'est de la sorte qu'ume rivière ralentit son courant. quand son lit s'élargit. Or, l'observation nous apprend que la capacité tolale des divers rameaux d'une branche artérielle, ou des diverses branches d'un trone, est toujours supérieure à celle des

(1) a Corps de pompe representant l'oreillette ef recevant le liquide par le canal (c); - b corps de pompe representant le ventrieule; - d canal de communieation representant lorifice auriculo-ventriculaire et sarni d'un clapet dout te jeu permet le passige

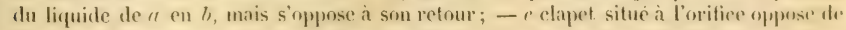
la pompe b, representant les valoules sigmoïdes de l'artire aurte, ef fonctionnant coumus: le précédent; $-f$ canal représentant l'aorte. 
vaisseaux desquels ils naissent. Il en résulte que plus une artere se subdivise avant que de pénétrer dans la substance d'un organe, plus le sang doit arriver avec lenteur dans cette partie; et, sous ce rapport, on observe dans l'économie animale des différences trèsgrandes: tantòt ces vaisseaux ne se distribuent aux organes qu'apres s'etre subdivisés un grand nombre de fois, et tantit, an contraire, e'est le trone artériel lui-mème qui s'enfonce dans l'épaisseur de la partie où il doit se ramifier.

Ces dispusitions, à l’aide desquelles l’imprétunsité du cours du sang est moderée daus certains points de l'appareil circulatoire, se remarquent principalement dans les artères chargées de porter ce liquide à des organes dont la structure est la plus délicate et les fonctions les plus importantes, au cerveau par exemple.

Du reste, la nature, dans sa prévoyance éclairée, ne se borne pas à ces précautions pour assurer l'arrivée d'une quantité convenable de sang dans chacune des parties du corps. On concoit facilement que, par la compression el par d'autres accidents, une artere peut se trouver oblitéree dans un point de sa longueur, et que, le sang ne pouvant alors arriver à l'organe ou ce vaisseau se distribue, la mort de la partie en résulterait incivitablement; mais c'est ee qui n'a pas lieu, car la plupart des arteres ont entre elles des communications fréquentes, nommées anastomoses, au moyen desquelles ces vaisseaux peurent recevoir du sang d'une artere voisine, lors mème qu'ils ne communiquent plus directement avec le cour.

$\$ 10$. . Cours du sang veineux. - Nous avons dijà vu que le saung passe des arteres dans les veines en traversant les vaisseaux capillaires; l’impulsion qui détermine la circulation de ce liquide dans les premiers de ces vaisseaur est encore la cause de son mouvement dans les veines: ainsi, dans tout le trajet de la serande circulation, ce sont les contractions du ventricule gauche du cour et le resserrement des parois artérielles qui déterminent essentiellenent le cours du sang.

En effet, si l'on interrompt le passage du satng dans une artere, et que l'on ouvre la veine correspondante, ee liquïde continuera à s'érouler de ce dernier vaisseau, lant que l’artiere, en se resserrant, n’aura pas expulsé tout le sang yui le distendait; mais, atssitui après, l'hémorrhagie cessera, hien que la veine soiteneore remplie de sang, et la sortie du liruide recommencera dies que la circulation sera rélablie dans l'artère.

Nhais il est aussi d'autres ciremstances qui tendent à favoriser ce mouvement, et qui méritent d'etre mentionnés. Ainsi, dans les veines des membres el de diverses autres parties do romps 
(fig. 36, a), la membrane qui tapisse ces vaisseaux forme $\mathrm{m}$ grand nombre de replis ou valvules $(b)$ qui laissent le passage libre lorsque le sang les pousse des extrémités vers le cour, et le ferment, au contraire, lorsque ce liquide tend à revenir du coeur vers les extrémités. Or, cette disposition empèche par conséquent le sang de refluer vers les capillaires, et contribue aussi d'une manière active à faciliter son passage vers le cour; car, chaque fois que, par les mouvements des parties voisines, la veine se trouvecomprimée, le sang est poussé en avant, et, lorsque la compression cesse, il ne peut plus retour-

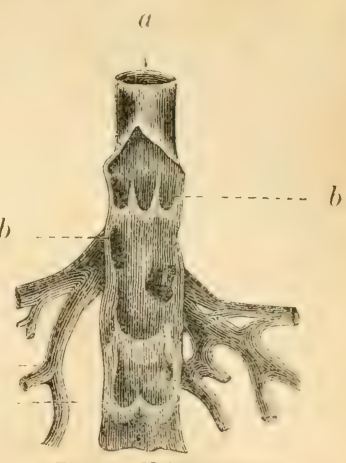

Fig. 3t5. Find nutertr. ner en arrière, mais est remplaré par une nouvelle quantilé do liquide venant de la partie inférieure de la reine. Toute compression intermiltente de ces vaisseaux contribue dons an relour du sang vers le cœur.

$\$ 105$. La dilatation de la poitrine produite par les mouvements respiratoires, en aspirant ce liquide à la manière d'une pompe. facilite aussi l’arrivée du sang veineux dans les cavités du cœur (1).

Néanmoins, le sang coule beaucoup moins vite dans los reines que dans les artères, et la nature a multiplié les moyens propres a empècher que l'obstruction d'un de ces vaisseaux n'arrètàt le retour de ce liquide vers le cœur. Effectivement, il existe en général plusieurs veines destinćes à remplir les mèmes fonctions, et ces vaisseaux communiquent entre eux par des anastomoses nombreuses.

\$ 196. LE PASAAGE UU SANG A TRATERS LFS CAVTTÉS DU CÒTÉ DROIT Du coeta se fait de la mòme maniere que de l'oreillette ganuche dans le ventricule du mème còté.

Lorsque l'oreillette droile se relàche, le sing y afflue des deux reines caves, et, lorsorue cette cavité se contracte ensule, la matjenre partie de er liquide passe dans le ventricule, car il existe

(1) Les mouvements d'expiration suspendent, au contrate, d'une manitre mo mentanee, le cours du sanch dans les grosses veines, of l'accélèrent dans les artires qui partent du cœur, et qui se trouvent alors comprimées.

Cest a cus denx phenomines que lon doit attribuer le gonflement des weines (surtout colles de lat tête au cou), qui a lieu pendant une forte expriration. Dams lintéricur du crame, ec fonflement est si marque, quà chacpue mourement respiratoire, les vaisseaux situes sous la base du correau walivent ce viscere et y pruduisent une espèce de pulsation. 
sur le bord de l'ouverture de ces vaisseaux une valvule destinée i s'opposer au reflux du sanọ dans la veine rave inférieure, et par l'effet de la pesanteur ce liquide doit nécessairement tendre à tomber dans la cavité rentriculaire plutòt que de remonter dans la veine cave supérieure.

L'ouverture par laquelle le ventricule droit communique avec l'oreillette (fig. 31) est garnie d'une soupape (1) comme celle du rentricule gauche, et par ses contractions cette cavité pousse le sang dans l'artère pulmonaire, en soulevant d'autres valvules qui entourent l'entrée de ce vaisseau $(f i g .34, g)$, et qui empèchent le liquide contenu dans son intérieur de rentrer dans le cœur.

Enfin le sang passe des artères pulmonaires dans les veines du mème nom, en traversant les raisseaux capillaires des poumons, et rentre dans l'oreillette gauche, de la mène manièe qu'il se meut dans les canaux de la grande circulation.

\section{Cours du sang che: les divers animaux.}

$\$ 107$. Mammifères et Oiseaux. - La circulation du sang se fait de la mème manière chez l'homme, chez tous les autres mammiferes, et chez les oiseaux. Dans tous ces animaux (fig. 37) le cœur se compose de deux moitiés parfaitement distinctes et divisées rhacune en deux carités : une oreillette ot un ventricule. Le sang artériel remplit les cavités gauches du cœur et passe du ventricule dans l'aorte et ses dépendances; ce système d'arteres le conduit dans toutes les parties du corps, où il traverse les vaisseaux capillaires et se transforme en sang veineux. Les veines de la grande rirculation reçoivent alors ce liquide et le conduisent dans l'oreillette droite du cœur. Cette cavité verse ensuite le sang dans le ventricule droit, et ce ventricule le pousse dans l'artère pulmonaire. Le sang veineux arrive de la sorte aux poumons, et, en traversant les vaisseaux capillaires par lesquels les artères pulmonaires se terminent, il subit le contact de l'air et redevient sangr artériel. Enfin le sang ainsi vivifié passe dans les veines pulmonaires, yui le versent dans l'oreillette gauche du cœur, et cette oreillette le pousse ensuite dans le ventricule gauche, d'oì il sort de nouveau pour recommencer le trajet que nous venons d'indiquer.

On voit lone que, chez les mammifères et les oiseaux, le sang, en parcourant le cercle circulatoire, passe deux fois dans le cœur et traverse deux systimes de vasseaux capillaires, servant l'un à

(1) On la nomme valvule tricuspide, parce qu'elle est divisée en trois portions triangulaires; sa iisposition est analogue à celle du la valvule mitrale. (Voyez. page 69.1 
CIRCULATION DU SANG.

Petite crrculation.

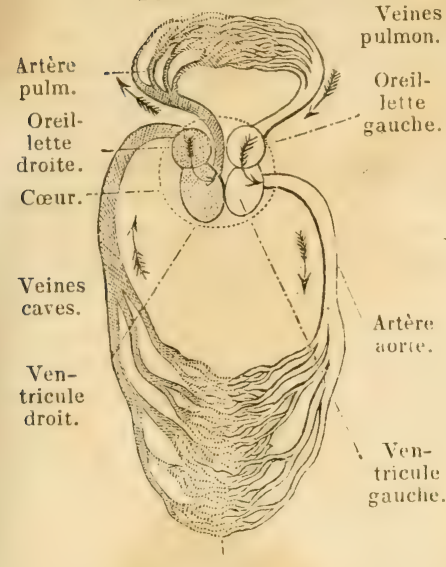

Grande circulation.

Fig. 37. Mammifères el Oiseaux.

Petite circulation.

\section{Ventricule.}

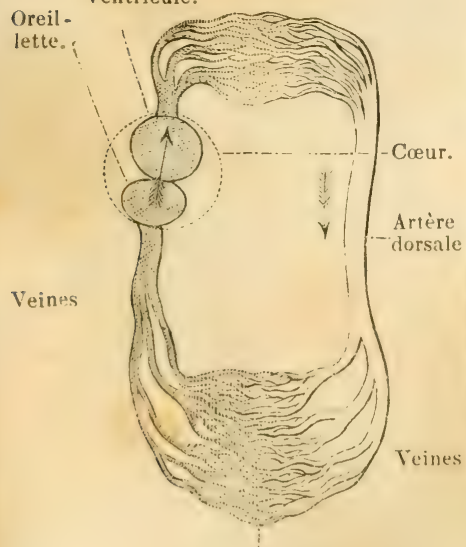

Grande circulation.

Fig. 39. Poissons.
Petite circulalion.

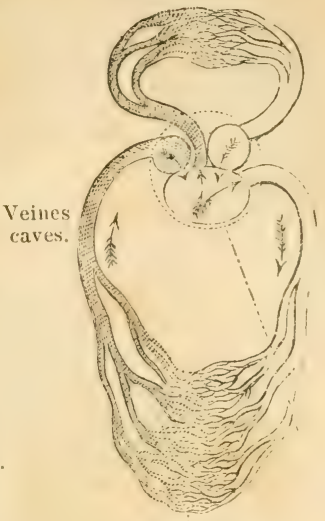

Grande circulation.

Fig. 38. Repliles.

Petite circulation.

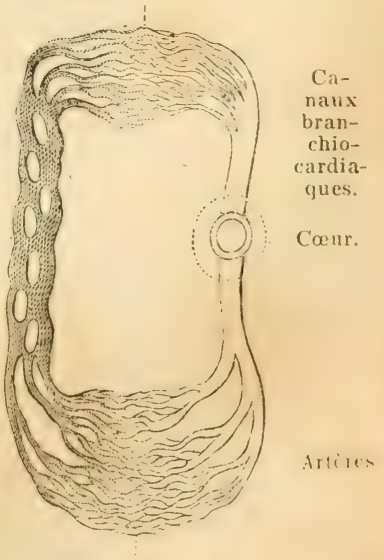

Grande circulation.

Fig. 40. Crustacés.

Cueur.

Artère aorte.
Ventricule unique

Figures theoriyues de la circulation (1).

(1) Dans tontes ces figures, les parties ombrees indiquent les catvités ou se trumb 
la nutrition din corps, l'autre à la respiration; c'est ce que l'on exprime en disant que chez ces animaux la circulation est double. Il cst aussi à remarquer que dans ces deux classes d'animaux la circulation est compléle, c'est-a-dire que la totalité du sang veineux est conduit à l'appareil respiratoire, et transformé en sang artériel, avaut que de retourner aux organes qu'il est destiné à nourrir.

Avant la naissance, lorsque l'air ne distend pas encore les poumons, la circulation ne se fait pas de la mème manière que pendant tout le reste de la vie. Il existe alors une ouverture qui fait communiquer l'oreillette droite arec l'oreillette gauche, et un ou plusieurs vaisseaux se rendent directement du ventricule droit à l'artère aorte, de façon que le sang, venant des diverses parties du corps, peut parvenir dans cette artere sans traverser le système pulmonaire. Mais, lorsque le jeune animal commence à respirer, ces communications entre le svstème veineux et artériel ne tardent pas à s'oblitérer, et la circulation se fait de la manière indiquée ci-dessus.

$\$$ 108. Reptiles. - Dans la classe des reptiles la circulation n'est pas complete conme chez les mammifèreset les oiseaux; une portion plus ou moins considérable de sang veinetix se mèle au sang artériel avant que de se rendre aux poumons, et par conséquent le liquide nourricier qui trarerse les organes n'est qu'imparfaitement revivifié. En général, ce mélange s’effectue dans le cœur, cet organe n'étant pourvu que de trois cavités, savoir : deux oreilletles et un seul rentricule (fig. 38 ) ; le sang reineux renant de diverses parties du corps est versé par l'oreillette droite dans le ventricule unique, qui reçoit aussi le sang artériel venant des poumons et contenu dans l'oreillette gauche; une portion rle ce mélange de sang artériel et de sang veineux retourne ensuite aux poumons, et le reste se rend, par les artères, aux organes qu'il est destiné à nourrir. Cette conformation de l'appareil circulatoire rappelle un peu ce qui existe chez les mammifères et les oiseaux avant la naissance, lorsque les deux moitiés du coeur communiquent entre elles.

Quant au trajet des vaisseaux sanguins, il ne diffère aussi que peu de ce que nous arons vu chez les mammifères. Il est seulement à noter qu'il part du cour deux aortes qui, après avoir fourni chacune une crosse dirigée l'une à gauche, comme chez les mammifères, et l'autre à droite, se réunissent pour constituer un trone unique (voyez fig. 41 ).

le sang veineux; et les parties dessinées au trait, celles qui contiennent le sang artériel : le cœur est représenté par un cercle ponctué. Enfin les flèches indiquent la direction du courant sanguin, qui est la même dans toutes ces figures. 
Chez quelques reptiles, les crocodiles, par exemple, la circulation se fait d'une manière un peu différente, comme nous le verrons en traitant spécialement de ces animaux.

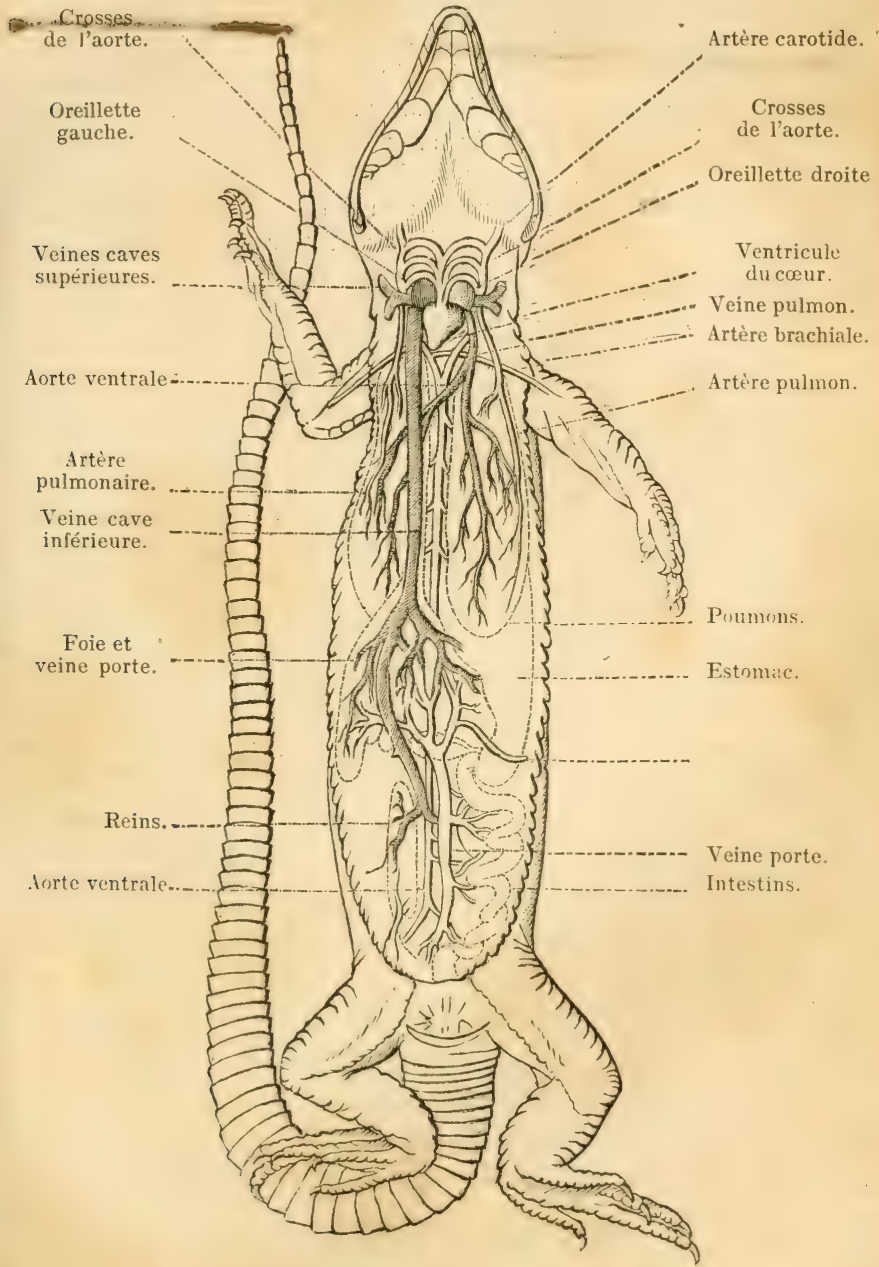

Fig. 41. Appareil circulaloire d'un Lezard. 
$\$$ 109. Poissons. - Chez les poissons l'appareil circulatoire se simplifie davantage. Le cour ne présente que deux cavités, une oreillette et un ventricule, et ne reçoit que du sang veineux (fig. 39); par ses fonctions il correspond par conséquent à la moitié droite du cour des animaux supérieurs te sang qui en part se rend à l'appareil respiratoire, et, après avoir subi l'influence vivifiante de l'air, passe directement dans les vaisseaux artériels destinés à le transporter dans toutes les parties du corps; enfin ce liquide, après avoir servi à la nutrition des organes, revient par les veines dans l'oreillette du coeur, qui le verse dans le ventricule, d'où il s'échappe pour retourner le nouveau à l'appareil respiratoire (voyez fig. 42).

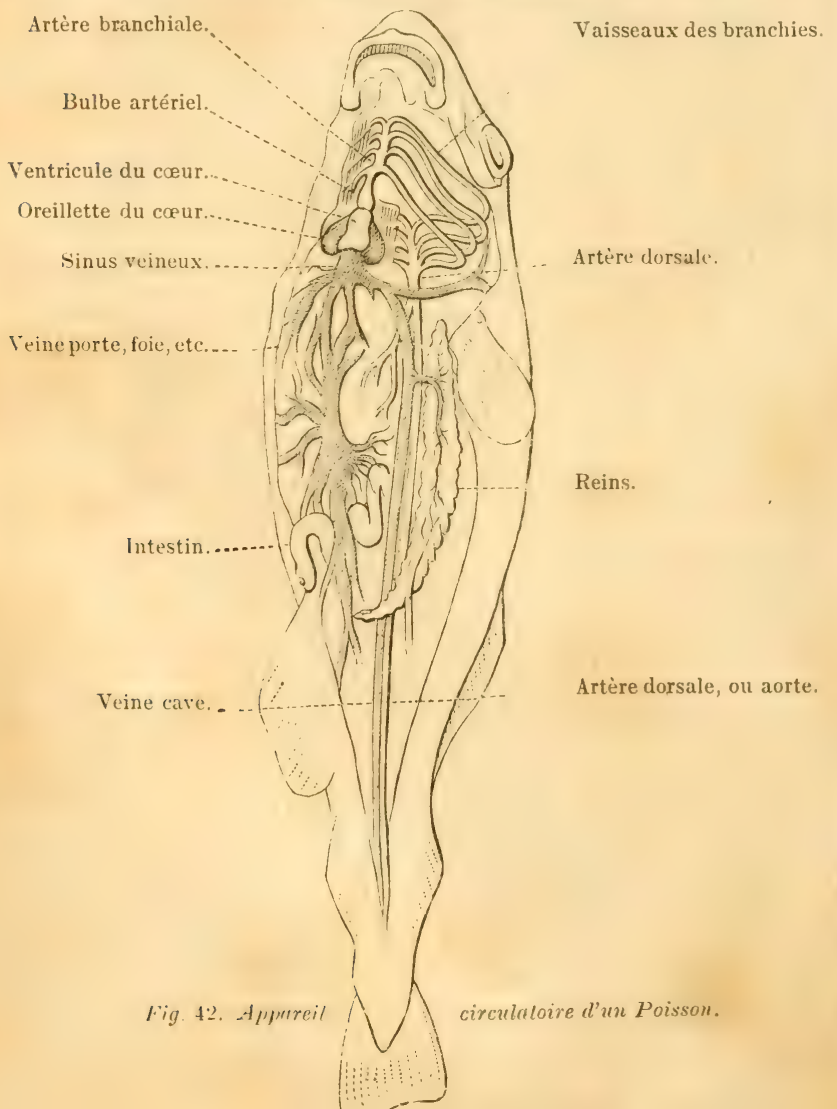


On roit donc que chez les poissons le sang, en parcourant le cercle circulatoire, ne traverse qu'une seule fois le cœur, et cela à l'état veineux. Mais la circulation est encore double et complète, car ce liquide traverse deux systèmes de vaisseaux capillaires, et toute la masse du sang veineux se transforme en sang artériel avant que de retourner aux organes (voyez fig. 39, page 75).

$\$ 110$. Mollusques. - Chez la plupart des mollusques la circulation se fait à peu près comme chez les poissons, avec cette différence cependant que le cour est aortique au lieu d'ètre pulmonaire, c'est-à-dire se trouve sur le trajet du sang qui se rend de l'appareil respiratoire aux diverses parties du corps. Le cœur de ces animaux se compose ordinairement d'un ventricule $(f i g .43, a)$, d'où naissent les artères $(b)$, et d'une ou de deux oreillettes $(c)$ en communication avec les vaisseaux $(d)$ qui y apportent le sang artériel de l'appareil respiratoire $(e)$, auquęl ce liquide arrive directement par des veines plus ou moins complètes $(f)$. C'est le cas pour les limacons, les huîtres et tous les autres mollusques de la classe des gastéropodes et de la classe des acéphales; mais quelquefois il n'existe pas d'oreillettes, et on trouve des espèces de cours veineux tout à fait distincts du ventricule aorlique et situés à la base des organes de la respiration; c'est le cas des poulpes, des seiches et des autres céphalopodies. Quoi qu'il en soit, chez tous ces animaux le sang artériel traverse le cour, puis se rend dans toutes les parties du corps, se dirige ensuite vers l'ap-

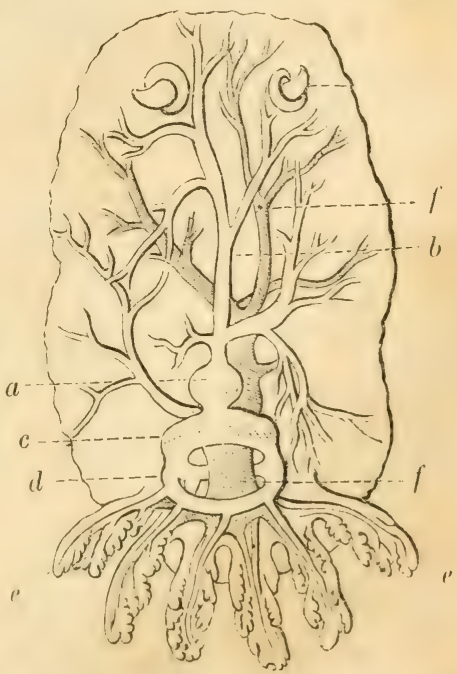

Fig. 43. Appareil circulatoire d'un .Hollusque le Dorisl. pareil de la respiration, et, apres avoir subi l'influence de l'air, retourne de nouveau au cour pour recommencer le mème trajet (1).

(1) Chez les mollusques, la circulation se fait par conséquent de la mênu manière que chez les crustacés (royez fig. 40); si ce n'est quil existe des reine sem. blables à celles des animaux supérieurs. 
$\$ 111$. Crustacés. - Dans les écrevisses, les crabes et les autres animaux de la classe des crustacés, le sang suit la mème marche que chez les mollusques; seulement le cœur, destiné à le distribuer dans toutes les parties du corps, ne se compose que d'un rentricule $(f i g .40)$, et les veines sont remplacées par une des cavités irrégulières qui n'affectent pas la forme des raisseaux, et qui constituent dans diverses parties dı corps des espèces de réservoirs nommés sinus veineux (royez fig. 14).

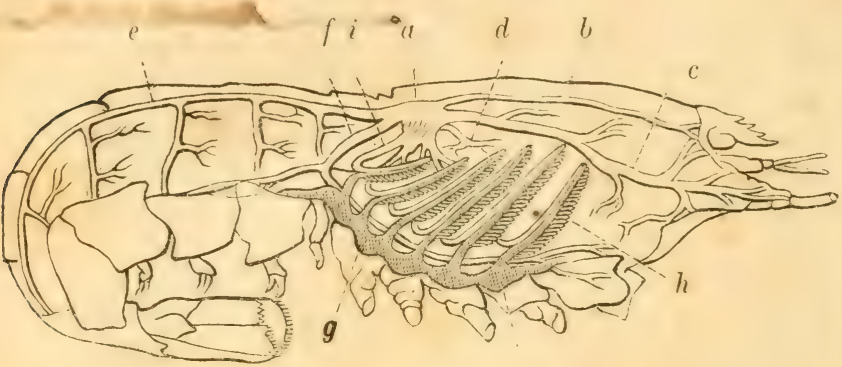

!)

Fig. 44. Appareil circulatoire du Homard (1).

$\$ 112$. Vers. - Les vers de la classe des Annélides ont aussi une circulation et un appareil vasculaire bien distincts; mais, en général, il n'existe pas de cœur proprement dit, et le liquide nourricier n'est mis en mourement que par les contractions des principaux vaisseaux. Aussi le cours du sang est-il bien moins régulier que chez les divers animaux dont nous venons de parler, et sourent la direction du courant n'est pas constante.

$\$ 113$. Insectes. - Dans les insectes, le sang n’est plus renfermé dans un système de vaisseaux particuliers; il n'existe ni artères ni reines, et le lluide nourricier est répandu dans les interstices qui existent entre les divers organes; mais cependant il est encore animé d'un mouvement circulatoire, et l'agent principal de cette circulation vague et incomplète est un vaisseau dorsal situé sur la ligne médiane du corps, au-dessus du tube digestif (fig. 4

(1) a Le cceur ; - b l'artère ophthalmique; $-c$ lartère antennaire; - $d$ l'artère hépatique; - $e$ l'artère abdominale supérieure ; $-f$ l'artère sternale; $-g g$ sinus veineux recerant le sang qui arrire des direrses parties du corps et l'enroyant à l'appareil respiratoire (les branchies, 1 ), dou il retourne au cour par les vaisseaux branchio-cardiaques (i). 
diverses fonctions; bientòt après, laction de tous les organes sinterrompt, la vie cesse de se manifester, et l'animal tombe dans un état d'asphyxie ou de mort apparente; enfin, la vie s'éteint complétement et ne peut plus ètre rappelée.

Ce phénomène est l'un des plus généraux de la nature organique; l'influence de l'air est indispensable à tous les animaux, comme elle l'est à tous les végétaux; et, lorsqu'un ètre vivant en est privé pendant un certain temps, il meurt toujours. Partout où il y a vie, l'air paraît être nécessaire.

Au premier abord, on pourrait croire que les animaux qui vivent toujours au fond de l'eau, comme les poissons, sont soustraits à l'influence de l'air, et font, par conséquent, exception à la loi dont nous venons de parler; mais il n'en est pas ainsi, car le liquide dans lequel ils sont plongés absorbe et tient en dissolution une cortaine quantité d'air qu'ils peuvent facilement séparer, et qui suffit pour l'entretien de leur vie; il leur est impossible d'exister dans de l'eau purgée d'air, et on les roit s'y asphyxier et mourir, comme périraient des mammifères ou des oiseaux que l'on soustrairait à l'action de l'air atmosphérique sous sa forme ordinaire.

Les rapports de l'air arec les ètres organiques forment une desparties les plus importantes de leur histoire physiologique, et la série des phénomènes qui en résultent constitue l'acte de la respiration.

$\$ 117$. L'air, disons-nous, est nécessaire a la vie de tous les animaux; mais ce fluide n'est pas un corps homogène; la chimie y a démontré l'existence de principes très-différents, et qui, par conséquent, peuvent ne pas jouer le mème ròle dans le phénomène de la respiration. En effet, outre la vapeur d'eau dont l'atmosphère est toujours plus ou moins chargée, l'air fournit, par l'analyse, vingt et un centièmes d'oxygène et soixante-dix-neuf centièmes d'azote, ainsi que des traces de gaz acide carbonique. La première question qui se présente à l'esprit, lorsqu'on aborde l'étude de la respiration, est rlone de savoir si ces gaz différents agissent de la mème manière sur les animaux, ou bien si c'est à l'un d'eux qu'appartient plus spécialement la propriété d'entretenir la vie.

Pour la résoudre, il suffit d'un petit nombre d'expériences. Si l'on place un animal vivant dans un vase rempli d'air, et que l'on intercepte toute communication de ce fluide avec l'atmosphère, on voit qu'au bout d'un temps plus ou moins long cet animal s'y asphyxie et périt; l'air qui l'entoure a donc perdu la faculté d'entretenir la vie, et, si on en fait alors l'analyse chimique, on s'apercoit qu'il a perdu en mème temps la majeure partie de son oxygène. Si on place ensuite un autre animal dans un vase rempli de gaz 
azote, on le voit périr promptement; tandis que si l'or enferme un troisieme animal dans de l'oxyogene, il y respire arec plus d'arlivité que dans l'air, et ne présente aucun symptòme d'asphyxie.

Il est donc évident que c'est à la présence de l'oxygène que l'air atmosphérique duit ses propriétés vivifiantes.

La découverte de ce fait important ne date que de la fin du siècle dernier (1777), et elle est due à un des chimistes français les plus célèbres, Lavoisier, qui, malgré ses titres nombreux à la reconnaissance publique, périt sur l'échafaud, victime de la tourmente révolutionnaire.

$\$ 118$. Par l'acte de la respiration, disons-nous, tous les animaux enlèvent à l'air qui les entoure une certaine quantité d'oxygène ; mais les changements qu'ils déterminent ainsi dans la composition de ce fluide ne se bornent pas là ; l'oxygène qui disparaît est remplacé par un gaz nouveau, de l'acide carbonique, qui, loin d'ètre comme le premier propre à l'entretien de la vie, fait périr les animaux qui le respirent en quantités un peu considérables. La production de cette substance est un acte non moins général parmi les animaux que l'absorption de l'oxygène; el c'est dans ces deux phénomènes que consiste essentiellement le travail respiratoire.

$\$$ 119. Quant à l'azote de l'air respiré, son volume ne change que peu; et l'usage principal de ce gaz parait ètre d'aflaiblir l'acfion de l'oxygène, qui, à l'état du pureté, excite trop fortement les animaux et produit chez eux une espèce cle fierre.

On a remarqué, cependant, que, dans quelques cas, une partie de l'azote de l'air disparait pendant la respiration, et que d'autres fois son volume ancrmente. Il parait mème que les animaux en absorbent et en exhalent continuellement, comme ils exhalent et absorbent less liquides renfermés dans la cavité du péricarde, du péritoine, etc., et que les variations que nous venons de simnaler dépendent de ce que ces deux fonclions opposées se font en généra! équilibre, de manière que leur résultat n'est pas apparent, mais que l'absorption de l'azote est quelquefois plus active que son exhalation, tandis que d'autres fois la quantité de ce saz exhalée excode celle qui est absorbée : d'où résulte tantót une diminution, tantùt une augmentation dans son volume, lorsqu'on le compare avant et après qu’il a servi à la respiration.

$\$ 120$. Enfin, il s'échappe aussi du corps, avec les produits de la respiration, une quantité plus ou moins considérable de vapeur d'eau; cette exhalation, qui a reçu le nom de transpiration pulmonaire, est mìme un des phénomènes les plus apparents de la respiration, lorsque, par l'action réfrigérante de l'air ambiant, ces 
vapeurs se condensent à la sortie du corps et forment un nuagre plus ou moins épais.

$\$ 121$. Pendant que l'air respiré éprouve les changements que nous venons d'indiquer, le sang, qui parcourt les membranes en contact avec ce fluide, éprouve également des modifications importantes; il redevient propre à entretenir la vie, et passe d'un rouge noirâtre à un rouge vif et éclatant. Pour bien observer ce fait, on n'a qu'à ouvrir une artère sur un animal vivant, et à comprimer en mème temps son cou, de façon à empècher l'air de pénétrer dans ses poumons; le sang qui s'écoulera de l'artère sera d'abord d'un rouge vif, mais ne tardera pas à devenir noirâtre et semblable à du sang veineux. Si alors on permet de nouveau l'accès de l'air dans les poumons, on voit ce liquide changrer encore de couleur et reprendre la teinte propre au sang artériel.

$\$ 122$. Théorie de la respiration. - Tels sont les principaus phénomènes de la respiration des animaux. Cherchons maintenant à nous eu rendre compte, à en trouver l'explication.

Et d'abord, que devient l'oxygène qui disparait, et quelle est l'origine de l'acide carbonique produit pendant l'exercice de cette fonction?

Lorsqu'on fait brûler du charbon dans un vase rempli d'air, on voit que l'oxygèe disparait et est remplacé par un volume égal de gaz acide carbonique; il se fait en mème temps un dégagement considérable de chaleur. Or, pendant la respiration, les mèmes phénomenes ont lieu, et on observe toujours un rapport remarquable entre la quantité d'oxyçène employée par l'animal et celle? de l'acide carbonique qu'il produit; dans les circonstances ordinaires, le volume de ce dernier n'est que de peu au-dessous de celui du premier, et les animaux, comme nous le verrons par la suite, dégagent tous plus ou moins de chaleur.

Il existe donc la plus grande analogie entre les principaux phénomènes de la respiration et ceux de la combustion du charbon, et cette parité dans les résultats a fait penser que la cause des uns et des autres devait ètre la mème. On a donc supposé que l'oxygène de l'air inspiré se combinait dans l'intérieur de l'organe de la respiration avec du carbone provenant ru sang, et que, de cette espece de combustion, naissait l'acide carbonique dont l'expulsion est en quelque sorte le complément de l'acte respiratoire.

Mais celte théorie, proposée par le célebre Laroisier, et adoptée jusqu'en ces dernieres années par la plupart des physiologistes, ne s'accorde pas avec les résultats de l'espérience et, par conséquent, doit etre abandonnée, car on sait anjourd'hui que la consommation 


\section{DE LA RESPIRATION.}

de l'oxygène par la respiration n’est pas liée immédiatement à la production de l'acide carbonique; ce dernier gaz existe tout formé dans le sang veineux, et vient simplement s'exhaler à la surface de l'organe respiratoire pendant que l'oxygène de l'air absorbé par celte mème surface va se dissoudre dans le liquide nourricier et donne à celui-ci les qualités caractéristiques du sang artériel

$\$ 123$. Pour prouver que l'acide carbonique n'est pas le produit de la combinaison directe de l'oxycene inspiré avec le carbone du sang qui traverse l'organe respiratoire, il suffit d'une expérience très-simple, faite il y a quelques années par M. William Edwards. Placez dans un vase rempli d'azole, ou de quelque autre gaz qui ne contient pas d'oxygène, un animal susceptible de résister pendant assez long-temps à l'asphyxie, une grenouille, par exemple; puis faites l'analyse du gaz: vous trouverez que l'animal, ainsi privé d'oxygène, aura continué néammoins à donner de l'acide carbonique comme s'il avait respiré dans l'air. Or, dans ce cas, il est impossible d'attribuer la formation de l'acide carbonique à la combustion directe admise par Lavoisier, car cette combustion aurait nécessairement cessé aussitòt que l'air respiré ne contenait plus d'oxygène ; le dégagement de l'acide carbonique se continuant, il faut que ce gaz existe déjà tout formé dans le corps de l'animal, et soit simplement exhalé par l'organe respiratoire.

$\$ 124$. En effet, c'est le sang qui est la source de l'acide carbonique dégagé pendant l'acte de la respiration, et on a constaté récemment qu'il existe toujours, en ciissolution dans le liquide nourricier, une certaine quantité de ce raz, ainsi qu'un peu d'oxygène et d'azote. Les recherches d'un chimiste cie Berlin, M. Nagnus, ont fait roir aussi que le sang possècle la propriété de dissoudre une certaine quantité de tous les gaz avec lesquels il se trouve en contact; mais que toutes les fois que ce liquide, étant déja chargé d'un gaz, vient à en absorber un autre, il ne le fait qu'en abandonnant une certaine quantité du premier, lequel semble céder la place au second. Aiusi, lorsqu'on agite du sang veincus aree de l'hydrogène, une portion de ce gaz est dissoute, et uns quantité correspondante de l'acide carbonique déjà existant dans le liquide est dégag̣ée. Lorsque, au lieu de se servir d’hydrogène commo dans l'expérience précédente, on emploie de loxycrene, on obtient un résultat analogrue; le sangr veincux dissout une cerlaine quantité de ce gaz, abandomne une quantité à peu près épuivalente de son acide carbonique, ot par l'effet de cette substitution chance de leinte, fasse du lougresombre au rouge-rormeil et devient semblable à du sang artériel. $\$ 12 \%$. On roit que, dans cette expérience, tous les principaus 
phénomines de la respiration se reproduisent indépendamment de l'influence de la vie et par le seul effet de la propriété que possède le sang de dissoudre alternativement les divers gaz avec lesquels il est en contact. Il est donc à présumer que les choses se passent de la mème manière dans l'intérieur du corps des animaux vivants, et que la respiration ne consiste que dans l'absorption de l'oxygrène el des autres matières que l'atmosphère peut nous fournir, absorption qui détermine à son tour le dégagement et l'exhalation de l'aride carbonique et des autres gaz dont le sang se trouve préalablement chargéé.

Nous savons, d'ailleurs, que l'interposition d'une membrane analogue à celle qui forme les parois des vaisseaux respiratoires dans lesquels le sang circule, n'est pas un obstacle au passage du gaz: si l'on place du sang veineux dans une vessie bien fermée, et qu'on expose celle-ci à l'action de l'oxygène, on observera les mèmes phénomènes que si l'on mettait ces deux fluides en contact immédiat; l'oxygène se dissoudra en partie dans le sang, et sera remplacé par l'acide carbonique expulsé de ce liquide, dont la couleur passera en mème temps du rouge-brun au rouge-vermeil. Nous avons déjà vu que les organes respiratoires sont conformés de la manière la plus favorable à l'absorption, et on sait, par des ('xpériences nombreuses, que toutes les substances volatiles introduites dans le torrent de la circulation sont, de mème que l'acirle carbonique, expulsées peu à peu du corps par l'exhalation dont ces organes sont le siége.

$\$ 126$. D'après cet ensemble de faits, on peut se former une idée nette de ce qui se passe dans l'acte de la respiration.

Le sang veineux qui arrive de toutes les parties du corps tient en dissolution de l'acide carbonique en quantité assez considérable, un peu d'azote et quelques traces d'oxygène. En traversant l'organe respiratoire, ce liquide arrive en contact avec l'air et en dissout une portion; de l'oxygène et une certaine quantité d'azote sont ainsi absorbés, et ces fluides, en se dissolvant dans le sang, en chassent une quantité correspondante des gaz qui s'y trouvaient déjà, et qui consistent principalement en acide carbonique mêlé à un peu d'azote; il en résulte donc un dégagement d'acide carbonique (1) et d'azote en mème temps qu'il y a absorption d'oxygène

(1) Il est essentiel de noter que la quantité d'acide carbonique contenue dans le sang veineux, quoique médiocre, suffit pour rendre compte de toute la quantité de ce gaz dégráée pendant la respiration: ainsi chez l'homme, ce liquide en contient au moins $1 / 5$ de son volume; et comme la quantité de sang qui traverse les poumons en une minute peut être évaluéc à environ 250 pouces cubes, il doit y passer pendant ce même espace de temps environ 50 pouces cubes de gaz acide 
et d'azote, et cela dans des proportions telles, que l'acide carbonique exhalé égale presifue en volume l'oxygène absorbé, et que l'azote pareillement exhalé remplace souvent exactement la quantité d'azote absorbée ou bien n'en .liffère que peu, soit en plus, soit en moins; enfin une portion de l'eau contenue dans le sang s'exhale aussi sous la forme de vapeur, et constitue la transpiration pulmonaire. Ainsi, le sang perd de l'acide carbonique, de l'azote et de l'eau, tandis qu'il se charge d'oxygene et d'azote; aussi s'eston assuré (fue le sang artériel tient en dissolution une proportion beaucoup plus considérable d'oxygène que le sang veineux, et c'est. à la présence de cet oxygène que ce liquide doit ses propriétés vivifiantes et sa couleur vermeille. La respiration consiste donc essentiellement dans un phénomène d'absorption et d'exhalation, par suite duquel le sang, venant en contact avec l'air atmosphérique, se débarrasse de son acide carbonique et se charge d'oxygène.

Quant à la source de l'acide carbonique contenu dans le sang, on ne sait rien de positif; mais il y a quelque lieu de croire que ce gaz est un des produits du travail nutritif, et se forme dans toutes les parties du corps là où le liquide nourricier agit sur les tissus vivants, pour y entretenir la vie et se transformer de sangr artériel en sang veineux.

$\$ 127$. Activité de la respiration. - Nous avons vu que la respiration est indispensable à l'entretien de la vie de tous les ètres, mais le degré d'activité de cette fonction varie beaucoup dans les différents animaux.

Les oiseaux sont, de tous les ètres animés, ceux dont la respiration est la plus active; dans un temps donné, ils consomment plus d'air que tous les autres animaux, et ils succombent aussi a l'asphyxie avec plus de rapidité.

Les mammiferes ont également une respiration très-active, et on a fait un grand nombre d'expériences pour apprécier la quantité d'oxygàne que l'un d'eux, l'homme, emploie de la sorte dans un temps domé. Cette quantité varie suivant les individus, les âgres et diverses autres circonstances; mais elle parait ètre, terme moyen, d'environ sept cent cinquante litres ou décimèires cubes par jour. Or, l'oxygene ne forme que les vingt et un centiemes (en volume) de l'air atmosphérique; il s'ensuit done que l'homme consomme, pendant cet espace de temps, au moins trois mille cinq cents litres ou décimètres cubes rle ce dernier fluide.

carbonique; or, la quantité de ce gaz, dégagée par la respiration pendant ce même lapss de temps, ne dépasserait pas, même d’après l'évaluation la plus élevée, 27 pouces cubes. 
Les animaux des classes inf rieures ont, en général, une respiration bien plus bornée, surtout ceux qui vivent dans l'eau.

Mais néanmoins, si on réfléchit à la consommation énorme d'oxygène que tous ces ètres doivent faire chaque jour, on roit que l'atmosphère en serait dépouillée à la longue et que tous les animaux périraient asphyxiés, si la nature n'employait des moyens puissants pour renouveler sans cesse la quantité de ce gaz répandu autour de la surface du globe.

C'est en effet ce qui a lieu; et une chose digne de remarque, c'est que ce moyen est précisément un phénomène du mème ordre que celui dont il est destiné à contrebalancer les effets : c'est la respiration des plantes.

Les végétaux absorbent l'acide carbonique répandu dans l'atmosphère, et sous l'influence de la lumière solaire ils en extraient le carbone et mettent l'oxygène à nu. Ainsi, c'est le règne végétal qui donne aux animaux l'oxygène qui leur est nécessaire, et c'est la respiration des animaux qui fournil sans cesse aux régétaux l'acide carbonique indispensable à leur accroissement.

On voit donc que c'est en grande partie du rapport qui existe entre les animaux et les végétaux que dépend la nature de l'atmosphère, et qu'à son tour c'est la composition de l'air qui doit régler en quelque sorte le nombre relatif de ces ètres (1).

$\$ 128$. Il existe toujours un rapport remarquable entre la quantité d'air consommé par chaque animal, dans un temps déterminé, et la vivacité de ses mouvements. Les animaux dont les mouvements sont lents et rares ont, toutes choses égales d'ailleurs, une respiration bien moins étendue que ceux qui se meuvent avec rapidité et ne restent que peu de temps en repos. Les grenouilles ou les crapauds, par exemple, consomment moins d'air que certains papillons, bien que leur corps soit d'un volume bien plus considérable que celui de ces insectes; mais ces reptiles ne se meuvent que peu et lentement, tandis que les papillons exécutent sans cesse les mouvements les plus vifs.

$\$ 129$. L'activité de la respiration varie aussi chez le mème animal, suivant les circonstances ou il est placé; et on peut établir, en thèse générale, que tout ce qui tend à diminuer l'énergie du mouvement vital détermine une diminution, soit dans l'absorption de

(1) D’après cela, on pourrait croire que dans les villes, où un grand nombre d'hommes vivent réunis et où il existe très peu de plantes, l'atmosphère doit être moins riche en oxygène que dans les campagnes; mais ce serait une erreur. L'analyse chimique montre que l'air a partout la même composition, et cette uniformité doit être attribuée aux courants dont l'atmosphire est continuellement agitée. 
l'oxygène, soit dans la proportion relative de l'acide carbonique exhalé, tandis que, d'un autre còté, tout ce qui augrmente la force de l'animal produit un changement corresponilant dans l'étendue de la respiration.

Ainsi, chez les jeunes animaux, ce Iravail est moins actif que chez ces mèmes c̀tres à l'àge adulte. Pendant le sommeil, l'étendue de la respiration est également diminuée. La fatigue, l'abstinence, l'abus des liqueurs spiritueuses, produisent le mème effet. Un exercice modéré et l'alimentation activent au contraire cette fonction.

Jusqu'ici nous nous sommes occupés seulement des phénomènes de la respiration, considérés en eux-mèmes, ol sans aroir égard aux organes qui en sont le siége. Voyons maintenant quels sont les instruments destinés à cette fonction importante, et royons aussi comment ils sont modifiés dans les divers animaux.

\section{Appareil de la respiration.}

$\$$ 130. Dans les animaux dont l'organisation est la plus simple, la respiration n'est l'apanage d'aucun appareil spécial, mais s'effectue dans toutes les parties qui sont cn contact avec l'élément dans lequel ces ètres vivent et puisent l'oxygène nicessaire à leur existence.

L'enveloppe générale du corps, on la peau, est aussi le siége d'une respiration plus ou moins active chez la plupart des animaux des classes les plus élevées, et notamment chez l'homme; mais, chez tous ces ètres, une partie déterminée de la membrane tégumentaire est plus spécialement destinée à agir sur l’air, et se modifie dans sa structure de manière à mieux remplir cette fonction.

La partie ainsi modifiée, pour agir sur l'air, présente une texture molle, spongiense et fine; elle reçoit une crande quantité de sang, et elle est toujours disposée de maniere à offrir, sous un volume comparativement pelit, une surface d'autant plus étendue que la respiration doit ètre plus active. On peut établir aussi, en thèse grénérale, que cet organe sera un instrument d'autant plus puissant que son organisation s'éloi nnera davantage de celle de l'enveloppe créné rale du corps, et que toutes choses érales d'ailleurs) la respiration yui a lieu par la pean sera d'autant moins actice que celle dont ces organes spéciaux sont le siége sera au contraire plus étendue.

$\$$ 131. Du reste, la structure des organes respiratoures varie suivant qu'ils sont destinés à ètre en contact avec l'air à l'état de gaz, on à agir sur de l'ean tenant en dissolution une certaine quantité de ce fluide. 
En effel, chez tous les animaux qui vivent plongés dans l'eau ot qui respirent par l'intermédiaire de ce liquide,

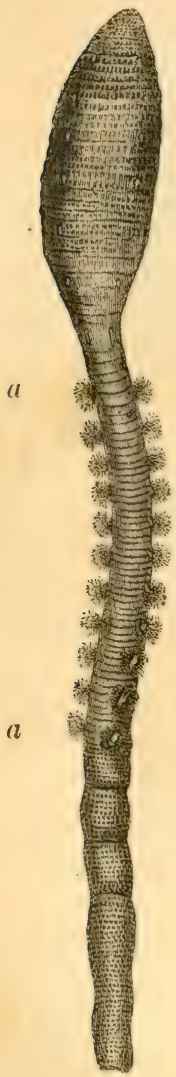

Fig. 46.

L'Arénicole. les instruments spéciaux de la respiration sont saillants, et portent le nom de branchies; tandis que, chez les animaux à respiration aérienne, il n'y a pas de branchies, mais bien des cavités intérieures qui servent aux mèmes usages, et que l'on appelle des poumors ou des trachées.

\section{$\$ 132$. Organes de la respiration aquatique. -} Les bRaxcues varient beaucoup dans leur forme; quelquefois elles ne consistent que dans des tubercules ou des prolongements foliacés, qui ont une texture un peu plus délicate que celle du reste de la peau, et qui reçoivent une quantité de sang un peu plus considérable; d'autres fois, cesorganes se composent d'une multitude de filaments rameux, et ressemblent à de petits arbuscules ou à des panaches vasculaires $(a, a, f i g .46)$; enfin, d'autres fois encore, ils sont formés par un grand nombre de petites lamelles membraneuses disposées comme les feuillets d'un livre ou comme les dents d'un peigne. Lé premier de ces modes d'organisation se rencontre chez plusieurs vers marins, tels que l'arénicole, si commun sur nos còtes; le second se voit aussi chez divers annélides, ainsi que chez plusieurs crustacés; enfin, le dernier est propre à la plupart des mollusques et des poissons.

11 est aussi à noter que, chez les animaux inférieurs, les branchies sont, en général, situées à l'extérieur, de façon a flotter librement dans l'eau ambiante, tandis que chez les animaux plus élevés dans la série zoologique, tels que la plupart des mollusques et tous les poissons, ces organes sont logrés dans une cavité qui sert à les protéger, et qui est disposée de telle sorte, que l'eau peut facilement se renouveler dans son intérieur.

$\$$ 133. Organes de respiration aérienne. - Les cavités intérieures qui servent à la respiration aérienne affectent tantòt la forme de trachées, tantòt celle de poumons.

- Les trachées sont des vaisseaux qui communiquent avec l'extérieur par des ouvertures nommées stigmates et se ramifient dans la profondeur des divers organes. Ils y portent ainsi laair, of cest. 
par conséquent, dans toutes les parties du corps que s'effectue la respiration. Cie mode de structure est particulier aux insectes et à quelques arachnides.

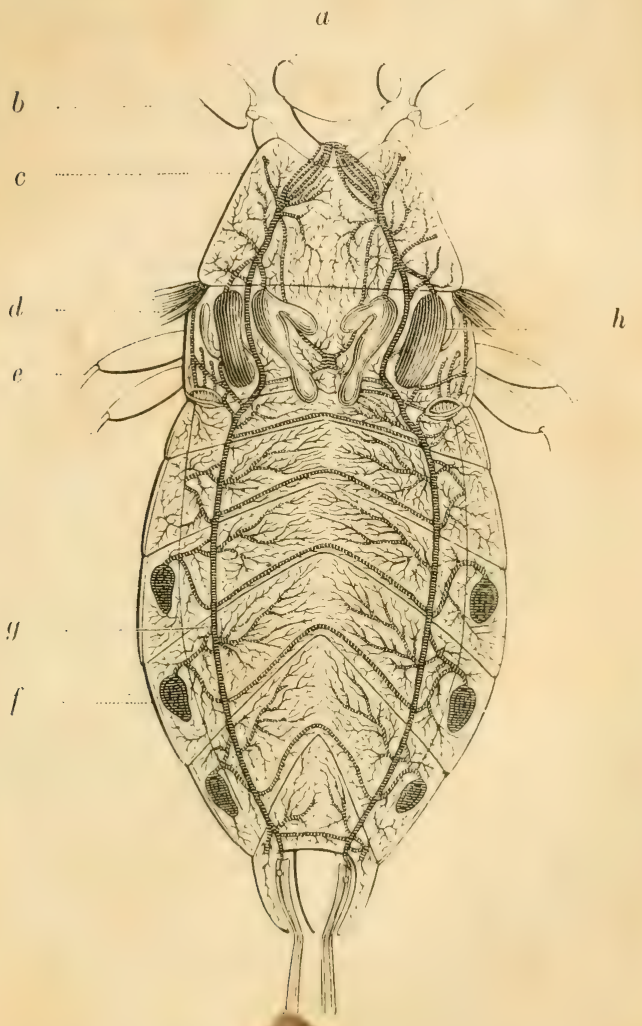

Fig. 47. Apparcil respiratsircind'un Insecte (la Nèpe) (1).

$\$ 134$. Les porvass sont des poches plus ou moins subdivisée. en cellules qui reçoivent également l'air dans leur intérieur et dont

(1) $a$ Tête; $-b$ base des pattes de la première paire; $-c$ premier anneau du thorax; $-d$ base des ailes; $-c$ base des pattes de la deuxième paire; $-f$ stigmates; - g trachées; $-h$ vésicules atériennes. 
les parois sont traversées par les vaisseaux contenant le sang qui doit ètre soumis à l'influence vivifiante de l'oxvgène.

Il existe des poumons (mais dans un élat de simplicité extrême) chez la plupart des araignées, et chez quelques mollusques, tels que les limaces. Les reptiles, les oiseaux et les mammifères en sont également pourvus.

$\$ 133$. Dans l'homme (de mème que dans tous les autres mammifères), les poumons sont logés dans une cavité nommée thorax, qui occupe la partie supérieure du

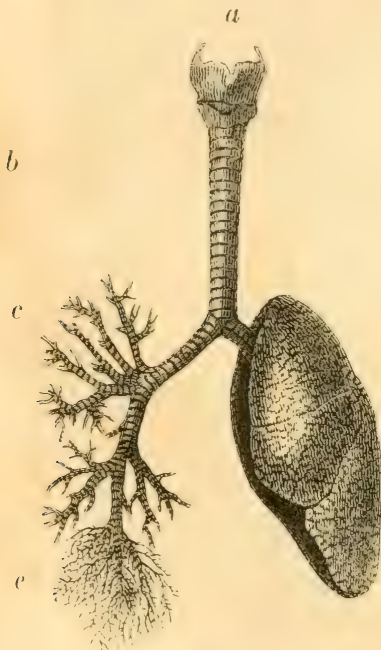

Fig. 48. Poumons et trachée de l'homme (1). tronc (fig. 3, p. 29). Ces organes sont, pour ainsi dire, suspendus dans cette cavité, et sont enveloppés par une membrane mince et très-unie qui tapisse également les parois du thorax et qui est appelée plèvre (2). Ils sont au nombre de deux, placés de chaque côté du corps, et ils communiquent au dehors, à l'aide d'un tube, la trachée-ard tère $(b, f i g .48)$, qui monte le long de la partie antérieure du cou et vient s'ouvrir dans l'arrière-bouche.

Ce conduit est formé par une série de petites bandes cartilayineuses placées en travers et affectant la forme d'anneaux incomplets post l'intérieur, il est tapissé par une membrane muqueuse qui est de

la mème nature que celle de la bouche et qui se continue avec elle (3). Enfin, à sa partie inférieure, la trachée-artere se divise

(1) L'un des poumons est resté intact (d), mais, de l'autre cité, on en a détruit la substance pour mettre à nu les ramifications des bronches $\ell$ e).

a Larynx et extrémité supéricure de la trachée-artère; $-b$ trachée; $-c$ division des bronches; $-e$ rámuscules bronchiques; $-d$ l'ufhdes poumons.

(2) La disposition de la plivre est analogue à celle des autres membranes séreuses dont il a été question (page 63).

(3) Il est à noter que la membrane muqueuse dont la trachée et les bronches sont tapissées est garnie diune sorte de duvet microscopique, et que chacgue brin de ce duvet est anime diun monvement ondulatoire tres-rapide; re mouvement ribratile 


\section{DE LA RESPIRATION.}

en deux branches qui prennent le nom de bronches et qui se ramifient dans l'intérieur de chaque poumon comme les racines d'un arbre dans l'intérieur du sol (c,e,fig. 48).

$\$ 136$. Les poumons, comme nous l'avons déjà dit, présentent dans leur intérieur une foule de cellules, dans chacune desquelles s'ouvre un petit rameau de la bronche correspondante. Les frarois de ces cavités sont formées par une membrane très-fine et très-molle et sont creusées d'une multitude de vaisseaux capillaires qui reçoivent le sang veineux de l'artère pulmonaire et l'exposent à l'action de l'air.

Sous un mème volume, la surface par laquelle la respiration s'opère sera rlonc d'autant plus grande et le sang recevra le contact de l'air par des points d'autant plus nombreus, que les poumons seront formés par des cellules plus petites. Il existe, par conséquent. un rapport direct entre l'activité de la respiration et la grandeur des cellules pulmonaires; et, en effet, chez les grenouilles, par exemple, où cette fonction ne s'exerce que d'une manière faible et lente, les poumons ont la forme de sacs divisés seulement par quelques cloisons, tandis que, chez les manmifères et les oiseaux où la respiration est le plus active, ces organes sont divisés en cellules si petiles, qu'à l'œil nu il est difficile de les apercevoir.

\$ 137. Dans l'homme et dans les autres mammifères, les bronches se terminent toutes dans les cellules pulmonaires, et celles-ci sont toujours terminées elles-mèmes en cul-de-sac; il en résulte que l'air qui entre dans les poumons de ces animaux ne pénètre pas au delà. Mais chez les oiseithx, où la respiration est encore plus active, quelques-uns de ces canaux traversent les poumons de part en part, et vont s'ouvrir dans le tissu cellulaire qui les entoure, et qui, dans tout le reste du corps, remplit les espaces que les divers organes laissent entre cux; or, les cavités contemues dans ce tissu communiquent toutes entre elles, et l'air qui y arrive pénètre ainsi dans toutes les parties du corps, mème dans la substance des os.

$\$$ 138. Mécanisme de la respiration chez l'homme. - D'après ce que nous avons dit des altérations que l'air subit par la respiration, il est évident que ce fluide doit ìtre sans cesse renouvelé

détermine dans te liquide en contact avee rette surface des courants souvent tris . rapides, et persiste pendant un certain temps aprés que la membrane qui en est le siegre a the sefarée du eorps de l'animal : de sorte qu’à l'aide d'un microscope puissant on preut lacilement létudier. La direction du courant ainsi prodnit parat être de lextérieur vers lintérieur de l'appareil respiratoire, et un monvement semblable soberve a la surface de la membrane qui tapisse la premiere portion des voies aériemnes, cest-à-clire les fosses nasales; mais, en général, on 1 "aperģoit rien d'analogue dans l'arrière-bouche. 
dans l'intérieur des poumons; c'est ce qui a lieu à l'aide des mouvemenls d'inspiration et d'expiration que nous exécutons alternativement, et ces mouvements, à leur tour, dépendent du jeu des parois de la cavité thoracique où sont logés les poumons.

Le mécanisme par lequel l'air est appelé dans les poumons, ou en est expulsé, est très-simple et ressemble en tous points au jeu d'un soufflet, si ce n'est que, dans les poumons, le fluide pénètre dans l'organe et s'en échappe par le mème concluit. En effet, les parois du thorax sont mobiles, sa cavité peut alternativement s'agrandir et se resserrer, et les poumons en suivent tous les mouvements; aussi, dans le premier cas, l'air pressé par tout le poids de l'atmosphère se précipite dans la poitrine à travers la bouche ou

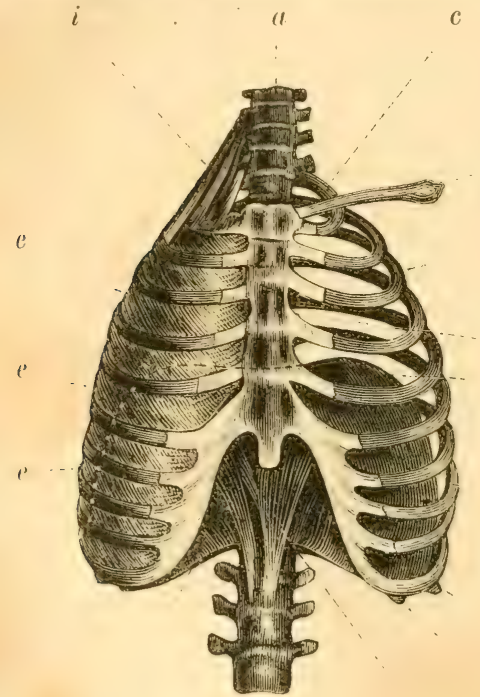

c

(l)

Fig. 49. Thorax de l'homme, 1). les fosses nasales et la trachée-artère, et vient remplir les cellules pulmonaires de la mème manière que l'eau mon-

$d$ te dans un corps de pompe dont on élève le

c piston. Dans le second cas, lors du mouvement d'expiration, l'air con-

$b$ tenu dans les poumons y) est, au contraire, comc primé et s'échappe en $c$ partie au dehors par la c' voie qui a déjà servi a l'entrée de ce fluide.

Pour comprendre comment le thorax de c' l'homme se dilate et se resserre, il est indisc' pensable d'en examiner la structure.

Cette cavité (fig. 49) a la forme d'un conoïde dont le sommet est en

(1) Du côté gauche les muscies ont été enlevés, tandis que du chité opposé ils sont en place. La voute formée daus l'intérieur du thorax par le diaphragme $|g|$ se voit à gauche, et du côté droit la continuation de cette voûte est indiquée par une ligne ponctuée. - $h$ piliers du diaphragme sinsérant aux vertèbres lombaire's; $i$ muscles élévateurs des côtes; $-d$ clavicule. 
haut et la base en bas, et ses parois sont formées en majeure partie par une espèce de cage osseuse résultant de l'union des côtes $(c)$ avec une portion de la colomne vertélurale (ou épine du dos) en arrière $(a)$, et avec l'os stermum en avant $(b)$.

Les espaces que les còtes laissent entre elles sont remplis par des muscles qui s'étendent de l'un de ces os à l'autre $(e)$; des muscles se portent aussi de la première còte à la portion cervicale de la colonne vertébrale $(i)$; enfin, la paroi inférieure de la poitrine est formée par le muscle diaphragme $(g)$, espèce de cloison charnue qui s'attache au bord inférieur de la charpente osseuse dont nous venons de parler.

$\$$ 139. La dilatation du thorax peut se faire de deux manières, par la contraction du diaphragme ou par l'élévation des côtes.

En effet, le diaphragme, dans l'état de repos, forme une voùte élevée qui remonte dans l'intérieur de la poitrine $(g)$, et il est facile de comprendre que la contraction de ce muscle doit diminuer la courbure de cette voute, et en l'abaissant doit agrandir d'autant la cavité du thorax.

Le jeu des còtes est un peu plus compliqué; ces os ( $c$ et c'), au nombre de douze de l'un et de l'autre còté, décrivent chacun une courbure dont la convexité est tournée en dehors et un peu en bas; leur extrémité antérieure, qui est unie au sternum $(b)$ à l'aide de cartilages intermédiaires, est beaucoup moins élevée que leur extrémité postérieure, et l'articulation de celle-ci avec la colonne vertébrale leur permet de s'élever et de s'abaisser. Le premier de ces mouvements est déterminć par la contraction des muscles de la base du cou (i). Or, lorsque les còtes s'élèvent ainsi, elles tendent à se placer sur une ligne horizontale; car, en mème temps que leur extrémité antérieure remonte en entrainant avec elle le sternum, elles tournent un peu sur elles-mèmes, de façon que leur courbure ne se dirige plus en bas, mais en dehors : il en résulte que les parois latérales et antérieure du thorax s'éloiơnent alors de la colonne vertébrale, et que la cavité de la poitrine s'aģrandit.

$\$ 140$. Dans le mourement d'expiration, les poumons, à raison de l'élasticité de leur tisin, se resserrent, le diaphragme se relàche, et cette cloison musculaire remonte en forme de voùte. Lorsque les muscles, qui ont produit l'élévation des còtes el du sternum, cessent de so contracter, leur poids et la traction exercée par l'élasticité des poumons déterminent aussi l'abaissement de ces os: mais il est écralement d'autres forces qui peurent contribuer à déterminer le resserrement du thorax et l'expulsion de l'air hors des poumons : telle est la contraction des muscles qui formenl 
les parois du ventre et qui se fixent à la partie inférieure de la poitrine.

$\$$ 14. On remarque plusieurs degrés dans l'étendue de ces mourements et dans la respiration ordinaire, la quantité d'air aspirée par le thorax ou chassée des poumons n'excede gruère la septiène partie de celle que ces oranes peuvent contenir. On éralue à environ 4,380 centimètres cubes la quantité d'air contenue ordinaire-

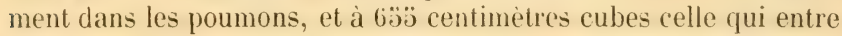
dans la poitrine ou en sort à chaque inspiration ou expiration.

Le nombre de mouvements respiratoires rarie suivant les indivirlus et suivant les àges; dans l'enfance ils sont plus fréruents que chez l'homme adulte, et chez ce dernier on compte en général vingt inspirations par minute.

On voit donc que, dans l'état ordinaire, il doit entrer dans les poumons d'un homme environ 13,100 centimitres rubes d'air par minute, ce qui fait, pour une heure, environ 786 litres, et par jour à peu près 19,000 litres de ce fluide.

$\$ 142$. Le soupir, le baillement, le rire et le sanglot ne sont que des modifications des monvements ordinaires de la respiration. Le soupir est une large et profonde inspiration dans laquelle une grande quantité d'air entre peu à peu dans les poumons; aussi ce phénomène ne dépend-il pas seulement des affections morales, qui en sont la cause la plus fréfuente, et le besoin de soupirer se fait-il sentir toutes les fois (juc le travail respiratoire ne seffectue pas avec assez de rapidité.

Le baillement est une inspiration encore plus profonde, qui est accompagnée d'une contraction presque involontaire et spasmodique des muscles de la màchoire et du voile du palais.

Le rire consiste en une suite de petits mourements d'expiration saccadés et plus ou moins fréquents, qui dépendent en majeure partie de contractions presque convulsives du diaphragme. Enfin, le mécanisme du sanglot diffère peu de celui du rire, bien que ce phénomène exprime des affections de l'àme toutes différentes.

\$ 143. Mécanisme de la respiration chez les autres animaux.Le mécanisme de la respiration est essentiellement le mèmechez lous les mammiferes, les oiseaux et la plupart des reptiles; seulement, dans ces deux dernières classes, le muscle diaphragme manque plus ou moins complétement, et par conséquent c'est principalement par le jeu des còtes que l'air est appelé dans les poumons; mais chez les tortues et les reptiles de l'ordre des batraciens (c'est-à-dire les grcnouilles, les salamandres, ete.), le thorax n'est pas conformé de manière à pouvoir se dilater activement et à agir comme une pompe 
aspirante: aussi, chez ces animaux, la respiration se fail d'une manière différente, et c'est par des mouvements de déglutition que l’air est poussé dans les poumons.

\section{DE L'EXHALATION ET DES SÉCRÉTIONS.}

1.14. Nous venons de passer en revue les moyens par lesquels les matières étrangères nécessaires à l'entretien de la rie s'introduisent dans le corps des animaux et ront se mèler au sangr, qui les distribue à toules les parties de l'économie. Nous arons maintenant ¿ nous occuper d'une série de phénomènes d'un ordre inverse, et a examiner comment les substances contenues dans la masse générale des humeurs et renfermées avec elles dans les vaisscaux sanquins peuvent en sortir, soit pour pénétrer dans des cavités intéricures du corps, soit pour s'échapper au dehors.

$\S 14:$. Nous avons vu que lintroduction des matières étrangères, nécessaires à la nutrition, s'effectue de deux manières: tantòt par l'absorption simplement et sans que ces matières aient subi de inorlification préalable, tantòt par l'effet du travail dig̣estif qui sépare ces matières des autres substances avec lesquelles elles se trouvent mèlées, les prépare en quelque sorte et leur donne la forme la plus convenable avant que de les faire pénétrer dans l'intérieur de l'économie. Le premier de ces actes, qui s'exerce par la surface pulmonaire, par la peau ou par toute autre voie, est un phénomène en quelque sorte mécanique; tandis que le second, bien plus compliqué, est, le résultat d'un travail chimique.

Pour se débarrasser des matières inutiles contenues dans un corps vivant et pour les expulser au dehors, la nature emploie aussi deux procédés analogues, savoir: l'exhalation et la sécrétion. L'exhalation est une conséquence de la perméabilité des tissus, tet peut s'effectuer dans tous les points; elle ne change pas la nature des fluides ciont elle amène l'expulsion, et peut ètre considérée, ainsi que l'absorption, comme un phénomène presque entièrement physique. La sécrétion, au contraire, ne consiste pas seulement dans la sortic des liquides dont les tissus sont imbibés; elle choisit dans le sanor certains principes de préférence à d'autres, les sépare, les modifie quelquefois dans leur nature intime, et donne ainsi naissance à des humeurs particulières; enfin, elle ne peut d'ordinaire s'effectuer que par l'intermédiaire de certains organes déterminés, et, sous tous ces rapports, elle est à la simple exhalation re que la dirgestion est relativement a l'absurption. 


\section{EXHALAT I ON.}

$\$ 446$. Nous avons déjà vu que les parois des vaisseaux sanguins sont perméables aux liquides. Il en résulte que l'eau et les autres matières fluides contenues dans ces canaux ne peuvent pas y ètre emprisonnées d'une manière complète, et doivent pouvoir s'en échapper avec plus ou moins de facilité pour se répandre à l'entour; cette espèce de filtration de l'intérieur des vaisseaux sanguins vers le dehors a effectivement lieu, et c'est à ce phénomène qu'on donne le nom d'exhalation.

Dans quelques circonstances, une portion du sang lui-mème s'échappe des vaisscaux avec toutes ses parties constituantes, et il peut arriver que cet épanchement sanguin s'effectue sans que les parois des raisseaux offrent des ouvertures qui établissent une communication directe du dedans au dehors. Le sang suinte alors à traver's le tissu dont ces parois sont composées, mais ce phénomene est rare; et, en général, les vaisseaux ne laissent point sortir de leur intérieur les globules solides que le sang charrie, tandis que les parois de ces canaux n'opposent qu'une barrière plus ou moins incomplete au passage des parties les plus fluides du liquide nourricier. L'eau, contenue en si grande abondance dans le sang, peut, de la sorte, se répandre au dehors, en n’entrainant arec elle qu'une petite quantité des sels et des autres matières solubles du sérum. Les gaz dissous dans le sang peuvent s'en dégager de la mème manière, et cela, à raison sıulement des propriétés physiques des parois vasculaires.

Pour rendre ce phénomène pour ainsi dire palpable, il suffit d'injecter dans les veines d'un animal rirant certaines substances qui ne se trouvent pas naturellement dans le sang, mais s'y dissolvent très-bien, et qui sont faciles à reconnaittre: car, au bout de quelque temps, on décourrira des traces de ces matières étrangères dans tous les liquides qui se trouvent répandus dans les différentes cavités du corps, et qui s'y sont produits par exhalation. Ainsi, lorsqu'on injecte du prussiate de potasse dans les veines d'un chien, on ne tarde pas à retrower ce sel dans le liquide aqueux qui s'accumule dans le thorax et dans l'abdomen, et chacun sait que lorsque des matières odorantes, telles que des liqueurs spiritueuses, ont été absorbées et sont introduites de la sorte dans le torrent de la circulation, elles viennent s'exhaler des vaisseaux à la surface pulmonaire, et s'échappent au dehors avec l'air expiré.

$\$$ 147. Mécanisme de l'exhalation. - L'exhalation (pui a lieı 
chez tous les ètres vivants n'est pas, comme la plupart des autres fonclions physiologiques, un effet des forces vitales: c'est un phénomène essentiellement physique, qui n'est pas dépendant de la vie, bien que sa marche puisse ètre modifiée par l'influence de ces forces. Effectivement, tout ce qui constitue une véritable exbalation s'observe sur le cadavre aussi bien que chez l'animal vivant; et c'est nè̀me après la mort que quelques uns de ses effets sont le plus faciles à constater, car alors rien ne vient en empècher la manifestation.

Ainsi, lorsqu'on pousse dans l'appareil circulatoire d'un animal récemment mort une dissolution de gélatine colorée par du vermillon réduit en pou lre très-fine, l'injection rouge pénètre dans les vaisseaux capillaires, et on voit alors une portion de l'eau chargée de gélatine et dépouillée de matière colorante suinter à travers les parois de ces canaux, pour se répandre au dehors, tandis que le vermillon est retenu dans leur intérieur. Or, ce qui arrive ici pour l'injection a lieu aussi pour le sang qui, pendant la vie, traverse sans cesse ces vaisseaux; les globules et les parties les moins fluides du sang se trouvent arrèlés, comme le vermillon, par les parois de ces canaux, tandis qu'une portion de l'eau du sérum, tenant en dissolution les sels propres au sang et une petite quantité d'albumine, filtre à travers ces parois, comme a suinté la dissolution crélatineuse de l'injection, et se répand dans toutes les parties voisines, ou s'échappe au dehors.

$\$ 1 \$$. On voit donc que l'exhalation, de mème que l'absorption, est un phénomène d'imbibition, et c'est à tort que beaucoup de physiologistes ont cru devoir en attribuer les effets à de prétendues bouches, qui d'après ces hypotheses seraient spécialement destinées à livrer passage aux fluides exhalés, mais qui dans la réalité n'existent pas. Le mécanisme de l'exhalation est le mème que celui de l'absorption, seulement le mouvement s'effectue en sens contraire; toutes les parties qui sont le siége de l'une de ces fonctions peurent ètre le siécre de l'autre, et en général elles ont lieu simultanément dans les mèmes parties; enfin tout ce qui tend a morlifier la marche de l'une influe aussi sur l'autre.

Ainsi, la texture plus ou moins spongieuse d'un organe, et prar conséquent plus ou moins favorable a l'imbibition, est une condition yui agit de la mime manière sur la marche de l'absorption et de l'exhalation. L'une ef l'autre de ces fonctions sont aussi, loutes choses érales d'ailleurs, d'autant plus actives, que la partie qui en est le siége est traversée par un plus grand nombre de vaisseaux sanguins. 
Les variations dans la masse des liquides contenus dans le corps agissent, au contraire, d'une manière inverse sur ces deux fonctions. Plus la quantité de ces liquides est considérable, plus l'exhalation est abondante.

La pression que le sang supporte dans les raisseaux influe aussi l'une maniere puissante sur l'exhalation: et lorsque la circulation dans les veines est entravée de façon à déterminer l'accumulation de ce liquide, la portion la plus fluide du sang s’exhale en abondance dans les parties roisines et en détermine le gonflement: c'est ce qui produit l'enflure des parties qui ont été fortement serrées par les ligatures.

$\$$ 149. Siége de l'exhalation. - L'exhalation peut aroir lieu à la surface du corps en contact avec l'atmosphere, ou bien dans lintérieur de cavités plus ou moins grandes, qui ne communiquent pas librement au dehors; et de là une distinction importante à établir : celle des exhalations externes et des exhalations internes.

$\$ 1: 30$. L'exhulation exterme, qu'il ne faut pas confondre arec la production de la sueur, et qui a lieu par la surface interne des poumons aussi bien que par la peau, donne lieu au phénomine désigné sous le nom de transpiration insensible, parce que l'eau qui s'échappe ainsi se dissipe par évaporation, et, en grénéral, n'est pas apercue par nos sens. Les pertes que l'homme et les autres animaux éprouvent par celte voie sont tres-considérables. Dans l'état de santé, le poids du corps d'un homme adulte ne varieg guere, et les pertes quil éproure par les diverses excrétions contre-balancent le poids des aliments dont il fait chaque jour usage. Or, d'apres les expériences de Sanctorius, il parait que souvent la transpiration insensible entre pour les cinc huitiemes dans les pertes totales dont nous venons de parler.

Du reste, l'éraporation qui se fait à la surface du corps n'a pas lieu toujours avec la mème intensité, et ici encore l'influence des agents physiques se fait senlir à peu près de la mème manière sur l'animal vivant et sur le cadare. Dans l'un comme dans l'autre, les pertes par évaporation sont auggmentées par l'élévation de la température, par l'agitation de l'air, par sa sécheresse, par la diminution de la pression atmosphérique, etc.

C'est aussi à un phénomene d'exhalation qu'il faut rapporter le dégagement d'acide carbonique qui s'effectue comme nous l'avons déja vu dans l'acte de la respiration (roy. $\$ \$ 124$, etc.).

$\$$ L̈I. Les exhalations internes ont lieu à la surface des parois des cavités plus ou moins vastes creuscies dans l'intérieur du corps; elles consistent aussi en de l'eau mèlée à une petite quantité de 


\section{EXIIALATION.}

maticres animales et des sels contenus dans le samy d'ou ces liquides s'échappent. Telle est la source des humeurs qui humeclent continuellement les membranes séreuses dont les grands visceres de la tète, de la poitrine et de l'abdomen sont enveloppés, de la sérosité qui baigne les lamelles du tissu cellulaire si abondamment répandu dans toutes les parties du corps, et d'une partie des humeurs qui remplissent l'intérieur de l'wil.

Comme ces exhalations internes ont lieu à la surface de cavilés yui n'ont pas d'issue au dohors, il est évident que la quantité des liquides contenus dans ces espèces de réservoirs irait toujours en augmentant si les parties qui exhalent ainsi n'étaient pas en mème temps le siége d'une absorption non moins rapide. Dans l'état de santé, ces deux fonctions s'exercent simultanément et se contrebalancent de manière à maintenir toujours la mème quantité de liquide dans l'intérieur rle la cavité; mais il arrive quelquefois que cet équilibre est rompu et que l'exhalation devient plus active que l'absorption. Les liquides s'accumulent alors dans les parties, et il en résulte des maladies conmues sous le nom d'hydropisies (1).

\section{SÉ CRÉTION S.}

$\$ 132$. Ainsi que nous l'arons déjà dit, on donne le nom de sírrétion à la formation des humeurs spéciales qui, dans l'économie animale, se produisent aux dépens du sangr et différent essentiellement de la partie séreuse de ce fluide.

$\$ 1: 3$. Organes sécréteurs. - Les principaux instruments à l'aide desquels la nature opère ce travail de chimie vitale, se composent de cavités, en rénéral, d'une petilesse extrème, qui ont la forme de poches, de bourses ou de canaux d'une grande ténuité, et qui reggoirent un nombre consilérable de vaisseaux sanguins, ainsi que des nerfs. On désigne ordinairement ces orames sous le nom commun de dis.upes; mais ils présentent dans leur structure des différences essontiolles, ot on les distingue en glandes parfuites ou

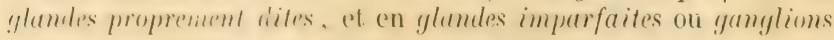

1. (ies amban dean premuent diverses dénominations suivant les patrties qui en

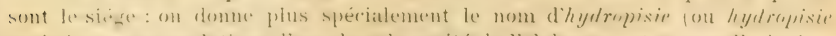
uscile) aux arcumulations deatu dans lat anvite de labulomen; et on appelle hegelro fisie d: fuilrine colles qui se forment dans la plevre, membrame qui envelopple les poumons; hydropisie du caur, celles qui ont lieu dans le péricarde, membrane

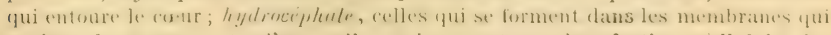
revêtent le cerveau, et roleme, celles qui se montrent dans lo tissu cellulaire des diverses parties du corps. 
vasculaires, suivant qu'ils ont un orifice servant à verser au dehors le prodnit de leur sécrétion, ou bien qu’ils ont la forme de cavités sans ouverture, de l'intérieur desquelles les liquides sécrétés ne peuvent sortir que par voie d'absorption ou par rupture.

$\$ 1: 4$. La disposition des GLANDES PRopREnext DITES varie beaucoup; mais, lorsqu'on les étudie avec soin, on voit que ces oroanes peuvent tous se rapporter à deux types principaux, et qu'ils se composent toujours, soit de petits sacs à orifices plus ou moins rétrécis, soit de tubes d'une ténuité extrème, et que les différences que l'on y rencontre dépendent du mode de groupement de ces parties, en quelque sorte élémentaires.

$\$ 1503$. Les petits sacs sécréteurs dont nous venons de parler penvent ètre désignés sous le nom commun de follicules. Dans leur élat de plus grande simplicité, ces oryanes ne consistent que dans de petites dépressions creusées à la surface de certaines membranes, et ressemblent à des fossettes plutòt qu'à des poches: on les nommo alors cryptes, et on en voit beaucoup à la surface des membranes muqueuses. Lorsque ces cavités se creusent davantage et que les bords de leur ouverture se resserrent en manière de goulot, on les appelle follicules proprement dits. Tantòt ces follicules sont rlisséminés à la surface des membranes, y débouchent chacun sćparément par un orifice distinct, et sont désignés sous le nom de follicules simples la membrane muqueuse du tube digestif nous en a déjà olfert des exemples; tantòt ils sont serrés les uns contre les autres, de facon à former une masse plus ou moins considérable, tout en conservant chacun son ouverture particulière, et se nomment alors follicules agrégés (telles sont les glandes de Meibomius qui bordent les paupières, les glandes gastriques de quelques mammifères, etc.), et d'autres fois encore ils se groupent de la mème manière, mais se réunissent encore plus intimement, de facon que leurs orifices particuliers ne débouchent au dehors que par l'intermédiaire d'un petit nombre d'ouvertures, ou mème d'unc seule; disposition qui caractérise les organes appelés par les anatomistes des follicules ayglomérés, et qui se rencontre dans les amygoglales placées de chaque côté de l'isthme du gosier. Enfin, d'autres fois encore ces sacs sécréteurs, au lieu de s'ourrir presque immédiatement au dehors, ne communiquent avec l'extérieur que par un col très-allongé, de façon à ressembler à un tube terminé par une ampoule, et alors ils peuvent encore rester isolés ou bien s'agrylomérer en grappes, a l'aide de canaux excréteurs communs qui, à leur tour, se réunissent successivement, de façon a se terminer par un seul conduit et à ressembler à des racines at- 
Lachées à un seul tronc, et portant à l'extrémité de chacune de leurs dernières divisions chevelues un petit renflement vésiculaire ( $f g . \quad \ddot{50})$. Ces organes sécréteurs, que l'on pour. rait appeler des follicuies ampullaires, se rencontrent à l'état de simplicité et d'isolement sous la peau de certains poissons, et paraissent constituer aussi sous cette forme les

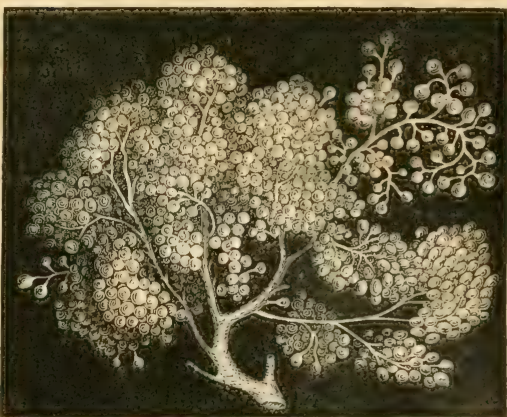

Fig. 50. Struclure untıme d'une glande composie (la parotide). glandes sudorifères logées dans la peau de l'homme; groupés sur un canal excréteur commun rameux ( fig. 50), ils constituent la plupart des glandes composées, désignées par les anatomistes sous le nom de glandes conglomérées, telles que les glandes salivaires et le foie des mammifères.

$\S 1506$. Les organes sécréteurs, qui affectent la forme de tubes, présentent aussi dans leur disposition des différences analogues à celles dont il vient d'ètre question. Ces tubes, dont la longueur varie et dont l'une des extrémités est ordinairement fermée, tandis que l'autre reste béante et sert pour la sortie du liquide sécrété, sont tantòt simples et parfaitement isolés, chacun allant s'ouvrir directement au dehors, comme cela se voit dans les glandes chargées de lubrifier la peau de certains poissons, et dans les vaisseaux biliaires de divers animaux inférieurs; tantòt a grglutinés entre eux, de façon a former une masse, sans cesser néanmoins de rester complétement indépendants les uns des autres, disposition qui s'observe dans les appendices qui, chez divers poissons, paraissent remplacer le pancréas; d'autres fois, ces tubes, également agrégés et simples, mais peu allongés et serrés parallelement les uns à còté des autres, vont déboucher dans une cavité commune, en forme de cellule ou de canal, comme cela se roit dans les glandes grastriques de plusicurs oiseaux; enfin, d'autres fois encore, ces mèmes tubes (fig. 51) arquièrent une longueur extreme sans changer de calibre, se pelotonnent sur eux-mèmes, et vont se terminer par un conduit excréteur peu ou point ramifić à son origrine, de fatcon it donner naissance à une glande congloméré, telle gue les reins 
et quelyues autres or aranes dont l'importance est tres-grande dans

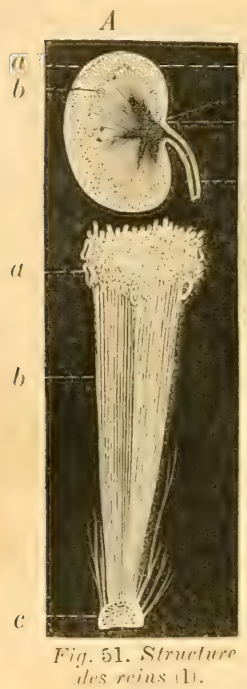
l'économie. Il est aussi à noter que plua sieurs glandes composees sont, ell outre, $a$ pourvues d'une espèce de réservoir placé $c$ sur le trajet de leur conduit excréteur, et destiné à permettre l'accumulation du d liquide sécrété. La vésicule du fiel, que nous avons déjà rul'occasionde mentionner ( $f g .24)$, et la vessie urinaire $(f g .52)$, sont des poches de cette nature.

$\$ 157$. Les glandes imparfaites varient encore davantage dans leur mode de con$B$ formation. Les unes consistent en de petites cellules fermées de toutes parts, et tantòt isolées, tantôt agglomérées en masse ; les autres, que l'on appelle quelquefois des ganglions vasculaires, sont composées essentiellement de vaisseaux sanguins ou lymphatiques, lesquels, après s'ètre divisés en ramuscules très-déliés, se réunissent de nouveau. Comme exemple des premières, nous citerons les vésicules ovariennes et les cellules adipeuses où se forme la graisse; nous citerons, comme exemple des secondes, la glande thyroüde $(2)$, le thymus $(3)$, la rate (fig. 29), et les ganglions mésentériques (fig. 26), (lont il a

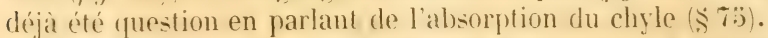

Les ganglions rasculaires paraissent ètre destinés à medifier les liquides qui circulent dans leur intérieur; mais on ne sait presque

(1) A Coupe verticale d'un rein : $-a$ substance corticale ; $-b$ substance tubuleuse; $-c$ calice et bassinet; $-d$ canal de l'uretère.

$B$ Structure intime de cette glande : - $a$ jortion terminale des tubes urinaires ; - $b$ portion médullaire de ces tubes ; $-c$ leur terminaison dans le calice.

(2) Le corps lhyrröde est une masse ovoïde, molle, spongieuse et dapparence glandulaire, qui se trouve à la partie antérieure et inférienre du cou, au-derant de la trachée-artère ifig. 23, page 41 ). Il f'st, en général, plus gros dans l'enfant que dans ladulte, et il existe chez tous les mammifères, mais manque chez les oiseaux, la plupart des reptiles, les poissons et les autres animaux des classes inférieures. C"est un gonflement maladif de ce corps qui occasionne les tuneurs rommues sous le nom de goîlres.

(3) Le thymus est une masse glandiforme renfermée dans la poitrine entre les deux lames du médiastin antérieur f cloison qqui est formée par ladossement des plivres, et qui loge le cour). 11 est extérieurement développé chez le firtus; mais, pen après la naissance, son volume diminu, beancenp, et chez l'adulte il est com plétement atrophié. 
rien de positif sur leur histoire, et par conséquent nous ne nous y arreterons pas ici, et nous ne nous occuperons que des organes sécréteurs proprement dits.

$\$ 138$. Nature du travail sécréteur. - Ces organes, dont nous venons d'indiquer les principales formes, sont toujours disposés de facon à constituer une lame membraneuse très-étendue, dont la surface externe est baignée par le fluide nourricier (1), tandis que la surface opposée est libre, et circonscrit d'ordinaire une cavité; le liquide sécrété suinte de cette dernière surface, et les matériaux dont cette humeur se compose sont puisés dans le sang : aussi une grlande peut-elle ètre comparće à une sorte de filtre, qui, interposé entre le sang et une cavité, ne laisse passer dans celle-ci que certaines matieres déterminées, et possìde mème quelquefois la propriété de modifier la nature chimique des substances qu'il sépare de lix sorte.

$\$ 139$. Les liquides qui résultent du travail sécrétoire dont les glandes sont le siége, varient beaucoup entre eux et different aussi beaucoup, soit du sang liui-mème, soit du sérum qui serait dépouillé de fibrine et de globules sanguins. Ces humeurs contiennent ordinairement en assez grande abondance des matières qui n'existent qu'en proportions extrèmement faibles dans le liquide nourricier; et quelquefois on y troure des substances que la chimie n'est pas encore parveuue à découvrir dans le sang, ou qui ne s'y rencontrent qu’à l'état de combinaison avec des principes dont elles sont séparées lorsqu'elles passent dans la sécrétion. Tantòt ces liquides rontiennent des acides libres, tandis que le sang dont ils proviennent est alcalin; d'autres fois, ils sont alcalins comme le sang, mais bien plus fortement, et d'autres fois encore ils sont caractérisés surtout par la présence de certaines matieres qu'on ne voit guère ailleirs, telles que l'urée, le caséum, le beurre, etc.

$\$ 160$. Jadis, on crovait que les glandes araient le pouroir de créer, aux dépens de l'albumine ou de quelque autre matière contenue dans le liquide nourricier, loutes les substances qui, telles que liurée, se rencontrent (n abondance dans certaines humeurs, et cependant ne se trourent pas d'ordinaire dans le sang luimème. Ifais des expériences que nous arons déjà eu l'occasion de signaler montrent que, dams la plupart des cas (et probablement

11. Les vaiseraux sanguius qui se distribuent dans une glande se ramifient autour des vesicules on des tubes sécréteurs dont cet organe est composé, mais ne communipuent jamais directement avee la cavite creusée dans leur interienr, ef cest a tort yue plusieurs anatomistes ont eru que les rateines des canaux excre teurs se continuatent sams interruption aver les dermeres divisions des vatisseaux sanguins. 
toujours), les matériaux constitutifs des liquides sécrétés existent tout formés dans le sang, seulement en quantités trop petites pour que leur présence soit décelée par les moyens d'analyse dont la chimie dispose.

Ainsi l'urine sécrétée par les reins contient chez l'homme, le chien et la plupart des autres mammifères, une quantité considé rable d'urée ; et cependant, dans les circonstances ordinaires, on ne découvre pas de traces de cette substance dans le sang; si les reins, oì l'urine se forme, étaient le siége de la production de cette urée, il est évident qu'après la destruction de ces organes, cette matière ne se montrerait plus dans l'économie; mais il en est tout autrement : bientòt après celte opération on en découvre dans le sang, et au bout de quelque temps elle s'y Irouve en proportion assez forte. Il est donc évident que les reins ne produisaient pas cette urée, mais ne faisaient que la séparer du fluide nourricier au fur et a mesure qu'elle y apparaissait; et que si on peut facilement en constater l'existence dans le sang après avoir interrompu la sécrétion rénale, c’est parce que, n'étant plus enlevée par les reins, elle s'accumule dans ce liquide.

$\$ 161$. Mature des liquides sécrètés. - Les humeurs produites par les divers appareils sécréteurs diffèrent beaucoup entre elles, mais on n'a pu découvrir aucun rapport entre ces différences et la structure des grandes qui les súcrètent. Il arrive mème quelquefois que la nature d'une sécrétion change sans que l'on apercoive aucune modification bien notable dans l'organe qui en est le siége. Enlin, il s'elablit quelquefois, d'une manière anormale, de vérilables sécrétions dans des parties qui d'ordinaire n'en présentent aucune trace; la formation du pus qui accompagne si fréquemment les inllammations est un phénoméne de ce genre.

Quant à la nature mème du travail sécrétoire, on ne sait rien de positif; seulement il paraitrait que l'action du système nerveux a une grande influence sur ce phénomène.

Les liquides sícrétés dans le corps de l'homme et de la plupart des animaux sont extrèmement nombreux et très-variés; les uns sont destinés à y rester et à y remplir des usagges plus ou moins imporlants: tels sont les humeurs de l'œil, le suc gastrique, la bile, etc.; d'autressont rejetés immediatement au dehors, et, parmi ces derniers, il en est qui ne paraissent servir qu’a débarrasser l'économie des matières inutiles ou nuisibles; on les désigne sous le nom d'excrétions, et la plus importante d'entre elles est la sécrétion urinaire, dont l'étude doit maintenant nous occuper. 


\section{Sécrétion urinaire.}

$\$ 162$. Celte fonction a son siége dans les reins, organes qui, chez les animaux de boucherie, sont connus sous le nom vulgaire de rognons. Ce sont deux glandes volumineuses, placées dans l'abdomen, de chaque còté de la colonne vertébrale, et entourées le plus ordinairement de beaucoup de graisse; leur couleur est d'un rouge brun, et leur forme semblable à celle d'une graine de haricot $(f i g .52)$.

Leur substance (fig. 51) se compose essentiellement de tubes sécréteurs d'une ténuité très-grande et d'une longueur extrème qui, chez les mammifères, sont contournés sur eux-mèmes dans tous les sens vers leur extremité libre $(a)$, et qui ensuite se dirigent en ligne droite vers le milieu du bord interne

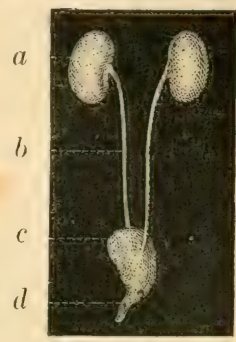

liig. 52. Apurareil urinare (1). de la glande, de façon à former un certain nombre de faisceaux pyramidaux $(b)$ dont le sommet s'engage dans une cavité membraneuse nommée calice $(c)$, et dont la base, dirigée en dehors, est arrondie et pour ainsi dire coiffée par la portion pelotonnée deces canaux, portion qui constitue ce que les anatomistes appellent la substance corticale des reins, tandis qu'ils nomment substance tubuleuse ou médullaire. celle formée par ces faisceaux eux-mèmes. Dans le jeune âge et mème durant toute la vie chez quelques animaux, tels que l'ours et la loutre, ces pyramides restent distinctes, et chaque rein se compose alors de plusieurs lobes séparés; mais en général ils se soudent bientòt d'une manière intime, et les calices, qui ne sont autre chose que des canaux excréleurs communs, se réunissent aussi de facon à former une petile puche membrancuse appelée hassinet (fig. $\ddot{31}$ A). Une multitude de vaisseanx capillaires sancouins serpentent entre ces tubes sécréteurs, et constituent, dans la portion corticale de la rylande, un lacis très-serré, au milieu duquel on remarque un grand nombre de petits corps sphériques formés aussi par des canaux sanguins pelotonnés sur eux-mèmes.

C'est dans la portion corticale des reins que l'urine se forme. Ce liquide descend par les canaux dont se compose la substance médullaire, et par les calices, jusque dans le bassinet, et passe de la dans la vessie en traversant un long tube membraneux de la grosseur d'une plume à écrire, qui se porte obliquement du bas-

(1) $a$ Reins; $-b$ uretères; $-c$ ressie; $-d$ canal de l'urètre. 
sinet à la vessie, et se nomme uretere (fig. $\ddot{2} 2,6$ ). La vessie est une poche conoïde qui remplit les fonctions de réservoir pour l'urine, et qui est située à la partie inférieure de l'abdomen, derrière la portion antérieure ciu bassin, nommée arcade du pubis (fig. 3). Elle est formée par une membrane muqueuse entourée de fibres charnues, et se continue inférieurement avec un canal étroit qui débouche au dehors et s'appelle canal de l'urètre.

$\$$ 163. L'urine est un liquide jaunàtre et acide qui, chez l'homme, se compose, dans l'état normal, d'environ yuatre-vingt-treize centiemes d'eau, de trois centièmes d'une matière particulière nommée urée, d'un milième d'acide urique et d'une petite quantité d'acide lactique et de divers sels, tels que du chlorure de sodium, ou sel marin, du phosphate de chaux, etc.

Dans les mammiferes carnivores, sa composition chimique esl à peu prés la mème que chez l'homme, si ce n'est qu'on n'y rencontre pas d'acide urique; mais dans les animaux herbivores on y trouve une substance particuliere, l'acide hippurique, et chez les oiseaux ainsi que chez la plupart des reptiles (les lézards, les serpents, etc.), elle ne renferme guère que de l'acide urique; enfin, chez les grenouilles et les tortues, on y trouve de l'urée et de l'albumine. Sa composition parait ètre à peu près la mème chez les poissons; mais, chez les insectes, on y trouve de l'acide urique. Pendant certaines maladies, sa composition chance aussi chez l'homme.

\$ 164. La rapidité avec laquelle les boissons, introduites dans l'estomac, passent dans la ressie et sont expulsées au dehors par les roies urinaires, est extrème. Chacun a pu en faire la remarque, et les expériences sur les animaux vivants le prouvent égaltment. Mais cependant, il n'existe aucune communication directe entre ces deux organes, et les liquides ne peuvent parvenir de l'estomac à la ressie qu’après avoir été absorbés, mèlés a la masse du sang, portés aiusi dans la substance des reins, et séparés par le travail sécrétoire dont ces glandes sont le siége. Lorsqu'on introduit dans le torrent de la circulation (soit par injection, soit par absorption) certaines substances faciles à reconnaitre (telles que cie la rhubarbe, de l’indigo, de la garance, de la gomme gutte ou du cyanure jaune de potassium et de fer), on ne tarde pas à les roir expulsées avec les urines, et, comme nous l'avons déjà dit', c'est aussi dans le sang que les reius puisent les diverses parties constituantes de ce liquide.

$\$$ 163. Du reste, direrses circonstances influent sur l'activité de cette fonction, et peuvent modifier, soit la masse des liquides expulsés par les voies urinaires, soit la quantité de matières solides 
séparées du sang par les reins, et tenues en dissolution dans la partie aqueuse de l'urine.

La quantité d'eau expulsée par la sécrétion urinaire dépend en grande partie de celle des boissons ingérées dans l'estomac.

L'eau introduite dans la masse du sang par suite de l'absorption s'en sépare plus ou moins rapidement, de façon qu'après un cerlain temps, l'équilibre se rétablit dans l'économie, quelle que soit la quantité de boissons ingrérées daus l'estomac; et c'est par deux voies distinctes que ce liquide s'échappe ainsi de notre corps, par l'exhalation soit pulmonaire, soit cutanée, et par la sécrétion urinaire. Or, ces deux fonctions se suppléent en quelque sorte, et, la masse des liquides en circulation reslant la mème, on observe que tout ce qui tend à diminuer l'une tend à augmenter l'autre.

Ainsi, l'action de la chaleur sur le corps tend à augmenter la transpiration, et diminue par conséquent la sécrétion urinaire : aussi cette dernière fonction est-elle plus active en hiver qu'en été, et lorsqu'on prend une quantité considérable de boissons, on peut presqu'à volonté en déterminer l'expulsion par l'une ou l'autre de ces voies, suivant qu'on se place dans les circonstances favorables, soit à la transpiration, soit a la sécrétion urinaire.

La quantité de substances solides expulsées par les reins et tenues en dissolution daus la partie aqueuse de l'urine dépend en grande partie de l'abondance et de la nature des aliments employés.

En effet, M. Chossat a constaté que, lorsqu'on se nourrit des mèmes aliments, et qu'on en varie seulement la quantité, la sécrétion de l'urée et des divers principes, autres que l'eau, expulsés par les reins, varie dans la mème proportion. Elle diminue à mesure que l'on s'assujettit à une abstinence plus rigoureuse, et elle aug̣mente à mesure que l'on fait usage d'une quantité plus crrande d'aliments, pourvu toutefois que celle quantití ne devieune pas trop considérable pour ètre digérée.

()n a constaté aussi que la sécrétion de ces matières augmente a mesure que l'on se nourrit de substances plus animalisées, c'esta-clire qui renferment une portion plus considérable d'azote.

Du reste, l'élat de l'économie animale exerce aussi beancoup d'influence sur les résuliats de la sécrétion urinaire; tout ce qui tend a affaiblir le corps parait tendre aussi à ralentir cette sécrétion, mais on a constaté qu'elle se continue sans interruption lors mème que l'animal est astreint pendant très-long-temps à une diete complète.

$\$$ 166. L'urine laisse quelquefois déposer dans l'intérieur des voies urinaires diverses substanees yui s'y trourent en dissolution. 
et ces dépôts solides constituent ce qu'on nomme graviers et calculs urinaires.

Les graviers sont presque toujoürs formés par de l'acide urique, et dépendent de la sécrétion trop abondante de ce principe. En général, ce dépòt se forme dans les reins, et est entrainé au dehors par les urines. Les calculs urinaires sont des concrétions plus volumineuses qui se forment aussi quelquefois dans les reins, mais qui, en général, se développent dans la vessie, où ils séjournent et grossissent peu à peu par l'addition d'une nouvelle quantité de matière déposée par l'urine.

\section{DE L'ASSIMLATION ET DE LA DÉCOMPOSITION NUTRITIVE.}

$\$ 167$. Assimilation. - En étudiant les diverses fonctions dont I'histoire vient de nous occuper, nois arons vu que les animaux attirent continuellement dans l'intérieur de leurs corps des matières variées, puisées dans le monde extérieur et destinées à servir à la composition de leurs organes. Ce passage du dehors en dedans est effectué par l'absorption, dont les différents points de la surface de ce corps sont le siége; et cette surface citant formée presque exclusivement dans la peau, par les parois des cavités respiratoires et par celles du tube digestif, il en résulte que c'est par celte triple voie que les matières étrangères doivent pénétrer dans l'économie.

C'est effectivement ce que nous avons vu, mais nous avons vu aussi que la peau étant recouverte par l'épiderme n'absorbe que difficilement les fluides qui la baignent, tandis que, par les poumons et par le canal alimentaire, l'absorption est des plus rapides: aussi la surface extérieure du corps ne prend-elle qu'une part trèsfaible dans ce travail, et c'est presque exclusivement par les cavités ('igestives et respiratoires que s'introduisent ces molécules nouvell rs destinées à subvenir aux besoins de l'animal.

L'absorption, avons-nous dit aussi, ne peut guère s'exercer que sur des substances à l'état fluide; par conséquent, lorsque l'animal ne trouve pas sous cette forme toutes les matières nécessaires à son existence, il doit pouvoir les y amener, et pour arriver à ce résultat la nature l'a pourru de la faculté de digérer les aliments solides dont il se nourrit en partie.

Les matieres que les animaux puisent ainsi au dehors étant destinées a derenir des parties constituantes de ces organes, il est évident qu'elles doivent renfermer tous les principes élémentaires dont ces organes sont eux-mèmes composés. Or, nous avons vu que les substances qui constituent en quelque sorte les matériaux 
de l'organisation sont formées essentiellement de carbone, d'azote, d'hydrogène et d'oxygène; il en résulte que c'est aussi du carbone, de l'azote, de l'hydrogène et de l'oxygène dont ces ètres doivent s'emparer de la sorte.

C'est dans l'atmosphère que les animaux puisent une partie de cet oxygène dont l'absorption constitue un dés principaux phénomènes du travail respiratoire. De l'hydrogène combiné à une nouvelle quantité d'oxygrene est en mème temps introduit dans l'économie sous la forme d'eau, et pénètre tant par la surface respiratoire ou culanée que par les roies digestives.

Ces principes pour ètre absorbés ne nécessitent aucune préparation, et par conséquent vont se mèler immédiatement aux liquides nourriciers; mais il n'en est pas de mème pour le carbone et l'azote absorbés; ces éléments ne deviennent propres à servir aux besoins de la nutrition des animaux que lorsqu'ils ont été déjà combinés sous l'influence de la vie et qu'ils constituent des composés organiques ou organisés. De là la nécessité d'aliments provenant du corps de quelque plante ou de quelque autre animal, et aussi la nécessité de facultés digestives; car ces aliments, en général solides, ont besoin d'une sorte de préparation avant que de pouvoir ètre absorbés, et c'est par la digestion que cette élaboration s'effectue.

Ainsi, le carbone et l'azote nécessaires à l'animal sont introduits dans son corps, combinés arec l'hydrogène et de l'oxygène, sous la forme d'aliments, et y entrent par les voies digestives; une autre quantité d'oxygène et d'hydrogène est également absorbée par l'appareil digestif, sous la forme d'eau; enfin, de l'oxycrène libre, et un peu d'eau (c'est-à-dire de l'oxygène et de l'hydrogène) pénètrent dans l'économie par l'intermédiaire des organes respiratoires.

$\$$ 168. Ces éléments nutritifs se mèlent, comme nous l'avons déjà vu, arec le sang, et en deviennent des parties constituantes. Ce liquide, élaboré par des procédés qui nous sont inconnus, devient riche de tous les principaux composés, dont les tissus sont à leur tour formés: et, poussé rlans les diverses parties du corps par l'effet du mouvement circulatoire (lont il est animé, il distribue à chacune de ces parties les matières nécessaires à son entretien et à son accroissement. Ces matériaux nouveaux, destinés à entrer dans la constitution des tissus vivants, existent tout formés dans le fluide nutritif qui les traverse, ou bien s'y produisent par suite des altérations que ces parties elles-mèmes déterminent dans quelques-unes des substances contenues dans le sang; enfin, le tissu virant choisil, 
en quelque sorte dans ce liquide les molécules qui sont semblables a ceus dont il est déja forme, les arrète au passage, se les appropric, et leur communique la force vitale dont il est lui-mème doué.

C'est ce dépôt de molécules nouvelles dans la profondeur de la substance des parties vicantes, leur arrangement en un tissu oraanisé, el leur admission an partage des propriétes vitales, qui constiluent le phénomène de l'assmulation.

Quant a la manière dont cette assimilation s'opère, on ne sait rien de positif, on ne sait mime pas comment les matieres nutritives s'échappent de l'intérieur des vaisseaux sanquins, pour aller se fixer dans la substance des tissus voisins. Probablement c'est le sérum chargé de fibrme qui, seul, passe par imbibition des raisseaux capillaires dans la profondeur des parties solides situées à l'entour, et le liquide ainsi épanché, après aroir déposé une portion de ses éléments constituants, est repris par les vaisseaux lymphatiques et porté par ces canaux, sous la forme de lymphe, jusque vers le centre de l'appareil circulatoire, oi il est rendu au sang dont il provient.

Mais pourquoi tel tissu, formé essentiellement de fibrine, ne prend-il guere dans ce liquide nourricier que de la fibrine, tandis que tel autre tissu, composé principalement d'albumine, y puise surtout de l'albumine; ou que tel autre encore, contenant comme partic constituante des sels calcaires, en extrait de nouvelles quantités de ces mèmes sels? Pourquoi les molécules ainsi déposées sunt-elles toujours arrangées de facon a constituer, dans chaque partie de l'économie, un tissu d’une texture délermince, et à revètir dans leur ensemble des formes constantes? Pourquoi, enfin, participent-ils à la vie doat les molécules auxquelles ils se réunissent sont déjà animées: Ce sont autant de questions auxquelles il est impossible de répondre, et dont la solution n'est guère à espérer ; car tous ces phénomènes paraissent toucher de trop près à l'essence du principe vilal, pour ètre accessibles à notre investigation. II est seulement à noter que, chez les animaux pourvus d'un système nerveux bien développé, cet appareil parait exercer une influence considérable sur tous les phénomènes de la nutrition.

$\$ 169$. Quoi qu'il en soit, c'est dans les premiers temps de la vie que ce travail d'assimilation est le plus puissant; aussi, est-ce dans celte période de l'existence surtont que le volume total du corps augmente rapidement. En effet, la croissance est un caractère commun à tous les ètres vivants; et, loujours aussi, après avoir duré pendant un certain temps, re mourement se ralentit ous sarrite. II 
paraitrait que cette période de croissance se prolonge beaucoup plus chez les animaux inférieurs, que chez ceux qui sont plus élevés dans la série zoologique. Chez quelques-uns des premiers, le volume du corps augrmente pendant toute la durée de la vie, tandis que les derniers prennent d'ordinaire tout leur développement avant yue d'avoir atteint le tiers ou mène le quart de leur carrière.

$\$ 170$. La force assimilatrice ne détermine pas seulement le dépòt de nouvelles molécules, or ģanisées au milieu de celles dont une partie vivante se compose déjà; elle peut mème devenir plus active et amener la formation de parties nouvelles. En effet, la plupart des amimaux possèdent la faculté de réparer, jusqu'à un certain point, les mutilations qu'ils éprouvent, et c'est par un travail analogue à celui de la mutrition ordinaire que ce résultat s'oblient. C'est de la sorte que, dans le corps de l'homme, une portion nouvelle de peau vient recouvrir une plaie qui se cicatrise, et qu'a la suite d'une fracture un tissu osseux nouveau se développe pour remplir le vide laissé entre les fragments de l'os brisé et les réunir. Mais c'est chez les animaux inférieurs que cette faculté régénératrice est portée à son plus haut degré : chacun sait que, lorsque la queue d'un lézard vient à ìtre cassée, cet organe, d'une structure compliquée, ne tarde pas à repousser; et on a conslaté que, chez les arairnées et les crabes, une patte nouvelle se développe à l'extrémité du moignon laissé par une patte brisée. Des expériences faites sur les salamandres ou lézards d'eau ont conduil à des résultats plus surprenants encore, tels que la reproduction d'un œil tout entier, et d'une grande partie de la tète; enfin, les vers de terre et beaucoup d'autres aunélides peuvent reproduire de la sorte la plus grande partie de leur corps; et, chez les hydres ou polypes deau donce (fig. 2), un fragment quelconque du corps peut se coimpléter et devenir a son tour un animal parfait dans son espèce.

$\$ 171$. Du reste, diverses circonstances, que nous n'arons pas le loisir d'examiner ici, peurent modifier la marche du travail d'assimilation, l'activer, la ralentir, ou en changer la direction. C'est de la sorte que, dans certaines maladies, on voit la nutrition s'arrèter presque entierement, et que dans d'autres certains tissus changent de nature. Il est aussi a noter que ce travail ne se fait pas avec la mème rapidité dans toutes les parties du corps ; pour s'en assurer, il suffit d'observer les changements de forme qu'amenent souvent les progres de l'àge ; car ces changements dépendent principalement. de ce que certaines parties croissent plus rapidement que d'autres. Ainsi, depuis le moment de la naissance jusqu'a l'àge adulte' les membres du corps de l'homme grandisient plus vite que le tronc. 
d'où il résulte qu'en général celui-ci est une portion d'autant moins considérable du tout, que la croissance s'est prolongée davantage.

$\$ 172$. Excrètion. - Pendant que les parties vivantes s'approprient de la sorte des molécules nouvelles et les incorporent a leur substance, il se fait aussi dims ces meimes parties un mourement de décomposition qui amène un résultat inverse, c'est-à-dire la síparation d'une portion des molécules constituantes des tissus oryanisés et leur expulsion au dehors. Une foule d'expériences et d'observations démontrent l'existence de ce mourement in testin, qui lui-mème échappe à nos sens. Quant à son mécanisme, il nous est tout à fait inconnu, et nous ajouterons seulement que quelques faits nous portent à croire que c'est sous l'influence du contact de l'oxycène absorbé par la respiration, que les matières organisées dont se composent les tissus vivants sont peu à peu détruites et transformées en acide carbonique, en eau et en quelque produit très-azoté, tel que l'urée ou l'acide urique.

C'est en effet sous ces trois formes que les animaux expulsent au dehors la presque totalité des matières dont ils ont a débarrasser leur corps. L'acide carbonique s'échappe presque en enticr par les organes de la respiration; une portion de l'eau est exbalée par la surface pulmonaire et la peau sous la forme de transpiration insensible; enfin, l'urée ou les substances qui la remplacent sortent ar ec une nouvelle quantité d'eau par les voies urinaires. Quant aux déjections alıines, elles se composent presque en entier du résidu des aliments laissés par la digestion, mèlé à une portion de la sécrétion biliaire, et par conséçuent elles ne doivent pas ètre confondues arec les produits excrémentitiels du travail nutritif.

Ainsi, il parail rait probable que c'est pendant laction du sang artériel sur les tissus que ceux-ci éprourent la décomposition moléculaire, ayant pour résultat l'élimination d'une portion de leur substance, et que l'un des produits de cette réaction est l'acide carbonique, qui, dissous dans le sang, translorme ce liquide en sangr reineux, et va ensuite s'exhaler par la surface respiratoire. Le sang est ausi le réhicule a l'aide duquel les autres produits du travail éliminatorre sont entrainés au loin et transportés jusque dans les organes chargés de les expulser; organes parmi lesquels il faut ranger en premiere ligne les poumons et les reins, puis la peau, le foie et les membranes muqueuses en général, qui laissent continuellement suinter de leur surface de l'eau chargée de quelques sels et d'un peu de matière animale.

Dans le jeune âgre, ce mouvement de décomposition est bien moins 
actif que le mouvement d'assimilation, mais à l'âge adulte ces deux phénomènes deviennent égaux et se contre-balancent, de sorte que, malgré l'absorption active des matieres étrangères par les voies respiratoires et digestives, le poids du corps demeure ordinairement. stationnaire. Et cela doit ètre; car, si l'on tient un compte exact de tout ce qui entre sous la forme de l'air que nous respirons, et des boissons ou des aliments que nous avalons, on verra que la quantité totale d'oxygène, d'hydrogène, de carbone et d'azote, ainsi ingérée dans notre corps, est représentée exactement par celle de ces mimes éléments expulsés sous la forme d'acide carbonique, d'eau, d'urée, etc.

$\$ 173$. Il ne faut pas croire que toutes les substances nutritives absorbées soient réellement employées à l'assimilation, et que toutes les matières excrétées proviennent de la décomposition nuIritive des organes; une certaine quantité des premières ne font pour ainsi dire que traverser le corps et s'échappent au dehors sans avoir servi, ou bien paraissent concourir à l'entretien de l'espèce de combustion déterıninée dans la profondeur des tissus par l'oxygène inspiré ; combustion qui tend en mème temps à détruire ces mèmes tissus et qui a pour résultat la production de l'acide carbonique exhalé. Une autre portion des matières ingérées, tout en restant dans le corps, est employée, non pas à la nutrition des tissus vivants, mais à la production des humeurs sécrétées dans les différentes parties de l'économie. Enfin, lorsque ces matières nutritives dépassent de beaucoup les besoins du moment, la nature en met une portion en réserve pour ètre employée plus tard; car c'est là l'un des usages de la graisse(1), qui, dans beaucoup de circon-

(1) La graisse se dépose dans de petites vésicules membraneuses logées à leur tour dans le tissu cellulaire, et elle se compose essentiellement de deux matières particulières, l'olíine et la stiarive, dont l'ume est liquide et l'autre solide a la température ordinaire; les proportions relatives de ces deux substances varient beaucoup chez les différents animaux, et il en résulte des différences rorrespondantes dans la consistance de leur graisse. En général, les principaux usages de cette matiere sont tout mécaniques, et elle sert, comme le ferait un coussin élastique, pour urotéger les organes quelle entoure; c'est ce qui se voit dans lorrbite, où l'œil repose sur une couche épaisse de graisse, a la plante des pieds oi il s'en trouve aussi une quantité considérable, et dans d'autres parties du corps exposées à une pression considérable ou à des frottements fréquents. La graisse peut également, a raison de la lenteur avec lauuelle elle laisse passer le calorique, contribuer a conserver la chaleur qui se degage dans l'intérieur de notre corps; enfin elle peut aussi étre considárée comme une espèce de réserve de matières nutritives déposées dans certaines parties du corps, afin de servir au travail de la combus. tion respiratoire lorsque lanimal ne pourra plus puiser au dehors les substances nécessatres à l'entretien de la vie; en effet, lorsque les personnes grasses restent long-temuls sans manger, leur graisse est absorbée peu à peu; on remarque aussi 
stances, se dépose en quantité si considérable dans certaines parlies du corps, et qui disparait ensuite pour peu que l'alimentation cesse d'être assez abondante.

Tels sont les principaux points de l'histoire des fonctions de nutrition, et nous derrions maintenant passer à l'examen des fonctions de la vie animale, s'il ne nous restait encore à dire quelques mols d'un phénomène très-important, qui parait se lier d'une manière intime à la nutrition, savoir : la production de la chaleur.

\section{DE I.A CHA L.EUR ANIMA LE.}

$\$ 17$. La faculté de produire de la chaleur parait ètre commune à tous les animaux; mais la plupart de ces ètres développent si peu de calorique qu'il ne peut ètre apprécié par nos thermonètres ordinaires, tandis que chez d'autres la production de chaleur est si grrande qu'on n'a mème pas besoin d'instruments de physique pour en constater l'existence. Pour mieux juger de cette différence, on n’a qu'à placer un lapin et un poisson ayant à peu près le mème volume dans deux calorimetres, et à les y entourer de glace à la température de $0^{\circ}$; la quantité de ce corps fondu dans un temps donné sera proportionnelle à la quantité de chaleur déreloppée par ces deux animaux. Or, dans l'instrument renfermant le poisson, la quantité de crlace fondue dans l'espace de trois heures, par exemple, ne sera pas appréciable, tandis que, dans celui contenant le lapin, on trouvera, apres le mème laps de temps, plus d'une livre d'eau liquide, et pour fondre cette quantité de oglace il faut autant de chaleur que pour échauffer, depuis la température de la ylace fondante jusqu'à l'ébullition, environ trois quarts de ce poids d'eau; or, cette chaleur n'a pu ètre fournie que par l'animal soumis à l'expérience.

Cette différence énorme dans la faculté de produire de la chaleur occasionne des différences correspondantes dans la température

que les aninaux hibernants, qui passent une grande partic de la saison fruide sans prendre daliments et plongés dans un état de léthargie, sont surchargés de graisse lorsqüils s'engourdissent, et sont au contraire très-maigres lorsquils se réveillent de ce sommeil de plusieurs mois.

La graisse ne se dépose pas arec la même facilité dans toutes les parties du rorps; clle abonde surtout entre les feuillets du mesentère (portion du péritoine 'qui enveloppe les intestins', autour des reins et sous la peau. Le repos rxerce une grancie influence sur son accumulation; les très-jeunes enfants sont ordinairement rès-yras, mais, lorsquils commencent à faire beaucoup d'exercice, leur graisse se issipe peu à peu, et, tant que laccroissement du corps est rapide, il est rare qu'il sen dépose des quantités considérables. 
des divers animaux. Un thermomètre placé dans le corps d'un chien ou d'un oiseau, par exemple, s'élèvera toujours à $360 u 40$ degrés (centigrades), tandis que, dans le corps d'une grenouille ou d'un poisson, il indiquera une température à peu près égale à celle de l'atmosphère au moment de l'expérience.

On donne le nom d'animaux à sang froid à ceux qui ne produisent pas assez de chaleur pour avoir une température propre et indépendante des variations atmosphériques; et on appelle animaux à sang chaud ceux qui conservent une température à peu près constante au milieu des variations ordinaires de chaleur et de froid auxquelles ils sont exposés. Les oiseaux et les mammifères sont les seuls ètres qui appartiennent à cette dernière catégorie; tous les autres animaux sont des'animaux à sang froid.

$\$ 173$. La température de l'homme et de la plupart des autres mammifères ne varie guère que de 36 à 40 degrés : celle des oiseaux s'élère à environ 42 degrés centigrades.

Du reste, la faculté de produire de la chaleur varie dans les divers animaux de ces deux classes, et varie aussi dans le mème individu, suivant l'àge et les circonstances où il est placé. Ainsi la plupart des mammifères et des oiseaux produisent assez c'e chaleur pour conserver la mème température en élé et en hiver et pour résister aux causes ordinaires de refoidissement, mème à un froid tres-rif. Mais il en est d'autres qui produisent seulement assez de chaleur pour élever leur température le 12 ou l:3 degrés au-dessus de celle de l'atmosphère; il en résulte que, pendant l'été, leur température est à peu près la nìme que celle des autres animaux à sang chaud, mais que, pendant la saison froide, elle s'abaisse beaucoup; or, toutes les fois quie ce refroidissement atteint une certaine limite, le mouvement vital se rálentit, et l'animal qui l'éprouve tombe dans un état de torpeur ou de sommeil léthargique qui dure jusqu à ce que la température se relève de nouveau. On appelle animaux hibernants les ètres qui présentent ce singulier phenomiene, et, sous ce rapport, ils sont en quelque sorte intermédiaires entre les animaux à sangr chaud non hibernants et les animaux à sang froid.

$\$ 176$. Dans les premiers temps de la vie, tous les animaux à sang chaud se rapprochent aussi plus ou moins des animaux à sang froid; de mime que ces derniers, ils ne produisent, en crinéral, pas asse de chaleur pour conserver leur température, lorsyu ils sont exposés à des causes de refroidissement mème très-légeres. Mais l'abaisicment de température, qui est sans inconvénient pour les animaux à sang froid, agit sur ceux-ci d'une maniere bien différente; car 
toutes les fois qu'il est porté au delà d'un certain degré, ou qu'il dure pendant un temps déterminé, la mort en est la suite. Sous le rapport de la faculté rle produire de la chaleur, les jeunes animaux à sang chaud qui naissent les yeux ouverts, et qui, aussitòt après la naissance, peuvent courir et chercher leur nourriture, diffèrent bien moins des adultes que les mammiferes qui naissent les yeux fermés, ou des oiseaux (qui, au sortir de l'œuf, ne sont pas encore couverts de plumes. Si on tient des chats ou des chiens nouvean-nés, par exemple, éloignés pendant un certain temps de leur nere et exposés à l'air, mème en été, ils se refroidissent au point d'en mourir.

Les enfants produisent aussi bien moins de chaleur dans les premiers jours qui suivent leur naissance qu'à une époque plus avancée de leur vie; leur température s'abaisse alors très-facilement, et l'intluence du froid leur est trés-nuisible; aussi, pendant l'hiver, en meurt-il un bien plus grand nombre que pendant le reste de l'année.

$\$$ 177. La cause de la production de la chaleur dans le corps des animaux parait ètre l'action que le saný artériel exerce sur les tissus, sous l'influence d'un systeme nerveux. En effet, il existe un rapport évident entre la faculté de produire de la chaleur, lintensité de l'action nerveuse, la richesse du sang et la transformation plus ou moins rapide du sang veineux en sang artéricl.

On a constaté par l'expérience que tout ce qui tend à affaiblir considérablement l'action du systeme nerveux tend aussi à diminuer la production de la chaleur. Ainsi, lorsqu'on détruit le cerveau ou la moelle éjuiniere d'un chien, et qu'en imitant, par des moyens artificiels, le mécanisme à l'aide dluquel l'air se renouvelle dans ses poumons, on entretient la vie de l'animal, la production de la chaleur cesse néanmoins, et le corpss se refroidit aussi rapidement que le ferait un cadavre placé dans les mèmes circonstances. En paralysant l'action du cerveau au moyen de certains poisons énergqiques, tels que l'opium, on produit encore le mème effet, et ces expériences, varićes de diverses manières, ont mis hors de doute que l'une des conditions nécessaires au développement de la chaleur animale est l'influence que le système nerveux exerce sur te reste du corps.

D’un autre còté, l'action du sang sur les organes paraît ètre également indispensable à la manifestation de ce phénomène : car, la suspension de la circulation de ce liquide, dans une partie quelconque du corps, est suivie du refroidissement de cette partie, et il existe un rapport remarquable entre la faculté de produire de la chaleur chez les divers animaux et la richesse de leur sang. Les oiseaux, qui sont de tous les animaux ceux dont la température 
est la plus élevée, sont aussi ceux dont le sang est le plus chargé de particules solides (en grénéral de 14 ou 13 parties sur 100); les mammifères, dont la température est un peu moins élevée, ont aussi le sang plus aqueux; en général, le poids des globules et de la fibrine ne constilue que les 9 ou 12 centièmes du poids total de ce liquide; enfin chez les animaux à sang froid, tels que les grenouilles et les poissons, on ne trouve guère au delà de 6 centièmes de globules et de fibrine pour 94 parties de sérum.

Mais l'açtion du svsteme nerveux et d'un sang plus ou moins riche ne sont pas les seules circonstances qui influent sur la production de la chaleur animale; pour que le liquide nourricier exerce șur l'économic l'action nécessaire à l'exercice de cette faculté, il faut qu'il ait toutess les propriétés qui caractérisent le sang artériel; et, comme il ne les acquiert que par la respiration, on voit que le développemen I du calorique doit ètre dépendant aussi de cette derniere fonction. En effet, toutes les causes qui rendent la transformation du sang veineux en sang artériel moins complète ou moins rapide tendent aussi à diminuer la faculté productrice de la chaleur, et il existe toajours un rapport intime entre elle et l'activité de la respiration.

La formation de l'acide carbonique, dont l'exhalation est l'un des phénomènes les plus remarquables de la respiration des animaux, peut mème nous expliquer la cause de la production de la majeure partie de la chaleur développée par ces ètres. Si l'oxygène absorbé pendant la respiration est employé à former ce gaz par son unicn avec du carbone provenant du sang ou des tissus vivants, comme nous avons tout lieu de le croire, cette combinaison doit ètre accompagnée d'un dégagement de chaleur, de mème qu'il s'en dégrage lors de la combustion du charbon à l'air. Or, la production de l'acide carbonique parait s'effectuer dans la profondeur de toutes les parties animées du mouvement uutritif, et par conséquent, si ce phénomene est réellement la principale cause de la chaleur animale, cette chaleur doit se développer à la fois dans tous les points de l'économie: et effectivement, elle n'émane pas d'un foyer unique, tel que les poumons, comme quelques physiologristes le croient, mais se dérage en quantité plus ou moins considérable de tous les tissus vivants.

Des experiences nombreuses, et faites avec une précision extreme, montrent que la chaleur que prodhirait la combustion du carbone contenu dans le saz acide carbonique exhalé par les animaux a sangr chaud, est égale à plus de la moitié dle la quantité totale de calorique décragce par ces itres. Et, si l'on admet que 
l'oxyg̣ène absorbé, sans ìtre remplacé par de l'acide carbonique. se combine dans l'intérieur du corps avec de l'hydrogène pour former de l'eau, on voit que la chaleur produite par cette combustion et celle du carbone, dont il a déjà été question, équiraut à la totalité de celle développée par l'animal.

En dernière analyse, nous royons donc que la respiration est probablement la cause primitive de la production de la chaleur animale, puisqu'elle fournit au sang l'oxygène qui parait servir à brùler pour ainsi dire une portion du carbone contenu dans la substance des organes; mais nous royons aussi que cette espece de combustion est, suivant toute probabilité, l'une des suites du travail nutritif, travail qui résulte de l'action du sang artériel sur les lissus virants, et qui ne semble s'effectuer que sous l'influence du système nerveux.

Du reste, cette fonction importante ne s'exerce pas arec la mème énergie dans toutes les parties du corps; celles où le sang circule avec le plus d'abondance et de rapidité (et où, par conséquent, la vie est le plus actire) sont aussi celles où il se dégage le plus de chaleur : il en résulte que les organes les plus éloignés du cœur doivent ètre, toutes choses égales d'ailleurs, ceux qui produisent le moins de chaleur, et qui, par conséquent, se refroidissent le plus facilement. C'est ce qu'on observe en effet; la température de nos membres est moins élevée que celle du tronc, et, lorsque nous sommes exposés à l'action d'un froid intense, ce sont ces parlies qui se gèlent les premières.

$\$ 178$. La faculté de produire de la chaleur nous explique pourquoi les animaux à sang chaud ont une température qui peut se soutenir au-dessus de celle de l'atmosphère dont ils sont environnés. Mais comment se fait-il que ces ctres puissent conserver encore la mème température lorsqu'ils sont placés dans de l'air plus chaud que leur corps? Un homme, par exemple, peut rester pendant un certain temps dans ume éture sèche oì lair est échauffé mème à un degré voisin de celui de l'eau bouillante, sans que la chaleur de son corjs aurrmente notablement, et s'élève au delà de 2 ou 3 deưrés.

La faculté de résister ainsi à la chaleur dépend de l'évaporation d'eau qui a lieu continuellement à la surface de la peau ou dans l'appareil de la respiration, et qui constitne la transpiration cutanée et pulmoncire: car l'eau, pour se transformer en vapeur, enlève du calorique à tout ce qui l'environne, et par conséquent refroidit le corps à mesure que la chaleur extérieure l'échauffe. C'est par la mème rause que l'eau placée dans les vases poreux 
nommés alcarazas (1) se refroidit si promptement, mème au milien de l'été. Or, la quantité d'eau qui s'évapore ainsi augmente avec la temprérature de l'air, et il en résulte une cause de refroidissement d'aulant plus puissante que la chaleur de l'atmosphère est elle-mème plus grande.

\section{DES FONCTIONS DE RELATION.}

$\$$ 179. En faisant l'énumération des diverses facultés dont les animaux sont doués, nous avons vu que les unes étaient exclusivement destinées à assurer l'existence de ces ètres, tandis que d'autres servaient à leur faire connaìtre ce qui les entoure. Les premières constituent les fonctions de nutrition, dont nous renons de faire l'étude; les secondes, les fonctions de relation, dont nous allons maintenant nous occuper.

$\$ 180$. Lorsqu'on examine ce qui se passe chez un animal dont la structure est des plus simples, et dont les facultés sont les plus bornées, on remarque d'abord qu'il se meut, et que les mouvements qu'il exécute sont déterminés et dirigés par une cause intérieure. Parmi ces mouvements, il en est qui se répètent de la mème manière, quelles que soient les circonstances où l'animal se trouve, et qui ne peuvent ètre modifiés par lui. Mais il en est aussi d'autres qui varient suivant les besoins de l'animal et sont soumis à l'empire d'une puissance intérieure, que l'on désigne sous le nom de volonté.

Ces deux ordres de phénomènes constituent deux des fonctions les plus importantes de la vie de relation, savoir : la contractilité, ou la faculté d'exécuter des mourements spontanés, et la volonté. dont dépend la faculté d'exciter cette contractilité et d'en varier les eflets, dans la vue d'arriver à un résultat prévu par l'animal.

Il est une autre propriété inhérente à tous les ètres animés et qui est encore plus remarquable : c'est la sensibilité, ou la faculté de recevoir des impressions des objets exterieurs et d'en avoir la conscience.

Ces trois facultis paraissent itre communes à tous les animaux, mais ce ne sont pas les seules quion observe chez les ètres animés.

(1) C'es rases laissent suinter leaul gu'ils renferment et ont ainsi une surface constamment humecter, où se fait une évaporatton rapide qui refroidit le liquide contenu dans leur interieur. C"est par la mêne cuusc que l'on éprotwe une sensation de froid si vil lorsqu'on verse de l'éther sur la peau et que l'on souffle sur la partic ainsi mouillée. 
On remarque qu'il existe chez tous une force intérieure qui les porte à faire cortaines actions utiles à leur conservation, mais dont ils ne peurent certainement pas préroir le résultat, et dont la cause ne dépenil d'aucun besoin apparent. Ainsi, une foule d'animaux construisent, avec l'art le plus admirable, des demeures destinées à loger leur progéniture, et calculées de manièe à répondre à tous les besoins des jeunes, et ils le font toujours de la mème manière et avec la mème habileté, mème lorsque, éloirnés de leurs semblables depuis le moment de leur naissance, ils n'ont jamais vu exécuter des travaux analogrues. D'autres, a une époque déterminée de l'année, émigrent vers des pays lointains dont le climat leur sera plus farorable, et s'y dirigent arec assurance, comme si le but de leur voyage était devant leurs yeux.

On donne le nom d'instinct a la cause qui porte ainsi les animaux à exécuter certains actes déterminés, qui ne sont pas l'effet de l'imitation, et qui ne sont pas le résultat du raisonnement. Ces espèces de penchants varient, pour ainsi dire, dans chaque animal, et les phénomènes qui en résultent sont tantòt d'une simplicité extrime, ef tantòt d'une complication qui étonne.

D'autres ètres plus privilégriés jouissent encore de facultés intellectuelles, ou du pouvoir le rappeler à l'esprit les idces produites précédemment par les sensations, de les comparer, d'en tirer des idées générales, et d'en déduire des motifs de conduile.

Enfin, il est aussi quelques animaux qui jouissent de la faculté de communiquer à leurs semblables les ilées qui les occupent, soit à l'aide de certains mouvements, soit en produisant des sons divers.

Les phénomènes variés, à l'aide desquels les animaux se mettent en relation avec les objets qui les environnent, peuvent, comme on le voit, se rapporter à six facultés principales : la sensibilité, la contructilité, la rolonté, l'instinct, l'intelligence, l'expression. Les quatre premieres existent chez tous les animaux, les deux dernières chez un petit nombre seulement, et la manière dont les uns et les autres s'exécutent varie presque à l'infini.

Chez qualques animaux d'une structure tres-simple, les polypes par exemple, les direrses facultés de la vie de relation ne sont l'apanage d'aucun organe particulier, toutes les parties peuvent sentir et se mouvoir sans le concours d'un autre organe; mais, chez l'homme et chez l'immense majorité des animaux, l'exercice de toutes ces fonctions est dépendant de l'action d'une partie déterminée du corps qui porte le nom de systeme nerveux. 


\section{DU SYSTEME NERVEUX.}

$\$ 181$. Ce sysleme est formé par une substance particulière, molle et pulpeuse, qui est presuge lluide dans les premiers temps de la vie, et qui acquiert plus de consistance a mesure que l'homme s'avance vers l'àge mur. L'aspect de celte substance, que l'on nomme tissu nerveux, varie beaucoup : tantot elle est blanche, d'autres fois grise ou cendrée; tantòt aussi elle forme des masses plus ou moins considérables, el d'autres fuis elle constitue des cordons allongrés et ramifiés. Ces derniers organes portent le nom de nerfs, et les premiers celui de ganglions ou de centres nerveux, car ils servent de point de réunion pour tous les filaments dont il vient d'ètre question.

$\$$ 182. Dans l'homme et dans tous les animaux qui s'en rapprochent le plus, l'appareil nerveux se compose de deux parties appelées système nerveux de la vie animale ou cérébro-spinal, el système revreux de la vie oryanique ou ganglionaire, et chacun de ces systèmes se compose, à son tour, de deux parties, l'une centrale, formée de masses nerveuses plus ou moins considérables; l'autre périphérique, formée de nerfs (qui se rendent, de ces centres, aux diverses parties du corps (fig. 5\%).

$\S$ 183. Système cérébro-spinal de l'homme. - La portion centrale du système cérébro-spinal est souvent désignnée sous le nom d'axe cérébro-spinal, ou d'encéphale. Elle se compose essentiellement du cerveau, du cervelet et de la moelle épiniere, et elle est logée dans une gaine osseuse formée par le cràne et la colomme vertébrale, ou épine du dos.

$\$ 184$. Enveloppes de l'encéphale. - I)iverses membraness entourent aussi l'encéphale, et serrent à fixer ou à protégrer cet organe, dont la structure est tres-délicate, et dont l'importance sit extrème.

La premiere de ces tunirques porte le nom de dure-mire : c'est une membrane fibreuse, ferme, épaisise, blanchitre, et comme moirée, qui adhere, par plusieurs points de sal surface extérieure, aux parois du crane et au canal vertébral, ef qui forme autour du syteme nerveus une gaine tres-résistante. A sa face intérieure, on remarque plusieurs replis qui s'enfoneent dans des sillous plus on moins profonds de la masse nerveuse encéphalique, et forment des especes de cloisons qui emperchent ces parties de so déplatcer at les soutiennent de facon qu'elles ne peicent point les unes sur les autres, quelle que soit la position du corps. Enfin, il existe dansi 
son épaisseur des canaux veineux très-vastes, qui portent le nom de sinu de la dure-mère, et qui servent de réservoir pour le sang provenant des diverses parties de l'encéphale.

En dedans de la dure-mère se trouve une seconde tunique, nommée arachnö̈le, à cause de sa ténuité et de sa transparence, qui l'ont fait comparer à une toile d'araignée. Elle appartient à la classe des membranes séreuses, et représente une sorte de sac sans ouverture, replié sur lni-mème, qui enveloppe l'encéphale et tapisse les parois de la cavité de la dure-mère, de la mème maniere que la plère enveloppe les poumons, et le péritoine les intestins. Son principal usage est de fournir un liquide qui baigne cet organe et en facilite les mouvements.

Enfin, on trouve encore au-dessous de l'arachnoïde une troisieme tunique cellulaire, qui manque dans certaines parties et qui est appelée la pie-mère. Ce n'est pas une membrane proprement dite, mais une trame cellulaire et a peine consistante, dans laquelle se ramifient et s'entrelacent, dans mille directions différentes, une multitude de vaisseaux sanguins plus ou moins fins et tortueux qui proviennent de l'encéphale, ou qui ront se répandre dans sa substance. En effet, la circulation du sang dans l'encéphale se fait d'une manière toute particulière. Les artères, avant que de pénétrer dans cet oryane, dont la texture est extrèmenent délicate, se réduisent en vaisseaux capillaires, et celte division a pour but de modérer la force avec laquelle le sang y arrive.

$\$ 18.3$. Encéphale. - L axe cérébro-spinal, qui est protégé par ces diverses enveloppes, se compose, comme nous l'avons déjà dit, Je plusieurs organes distincts; mais toutes ces parties sont intimement unies entre elles et peuvent ètre considérées comme une continuation les unes des autres. Sa portion antérieure ou supérieure 'st très-volumineuse et occupe l'intérieur du cràne : c'est à elle surtout que convient le nom d'encéphale. On y distingue deux parlies principales, le cerveau et le cervelet : l'un et l'autre se continuent inférieurement avec un gros cordon nerveux, logé dans la colonne épinière et appelé la moelle épinière.

(1) a Corveau; $-b$ cervelet; $-c$ moelle épinière; $-d$ nerf facial; $-e$ plexus brachial formé par la réunion de plusieurs nerfs qui proviennent de la moelle épinière ; - $f$ nerf médian du bras; $-g$ nerf cubital ; $-h$ nerf cutané interne du bras; $i$ nerf radial et nerf musculo-cutané du bras; - j nerfs intercostaux; $-k$ plexus fémoral formé par plusieurs nerl's lombaires et domnant naissance au nerf crural; - $l$ plexus sciatique donnant naissance au nerf principal des membres inférieurs, lequel se divise ensuite pour former le nerf tibial $(m)$, le nerf péronier externe $(n)$, le nerf saphène externe $(0)$, etc. 
DU SYSTEME NERVEUX.

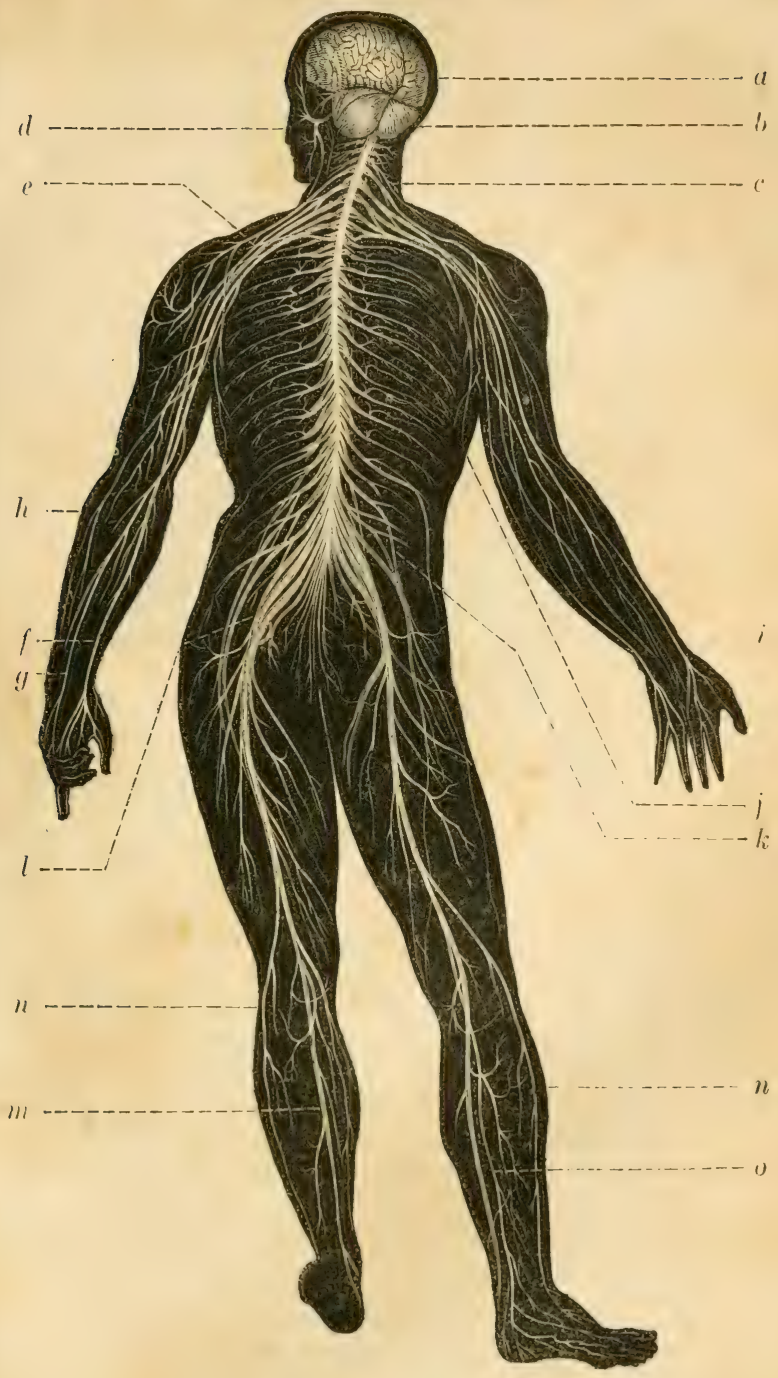

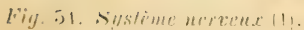


$\S 186$. Cerveau - Le cerveau ( fig. $54 a ; f i g .55$ et $56, a, b, c)$ est la portion la plus volumineuse de l'encéphale de l'homme : il occupe toute la partie supérieure du cràne depuis le front jusqu'à l'occiput. Sa forme est celle d'un ovoïde, dont la grosse extrémité
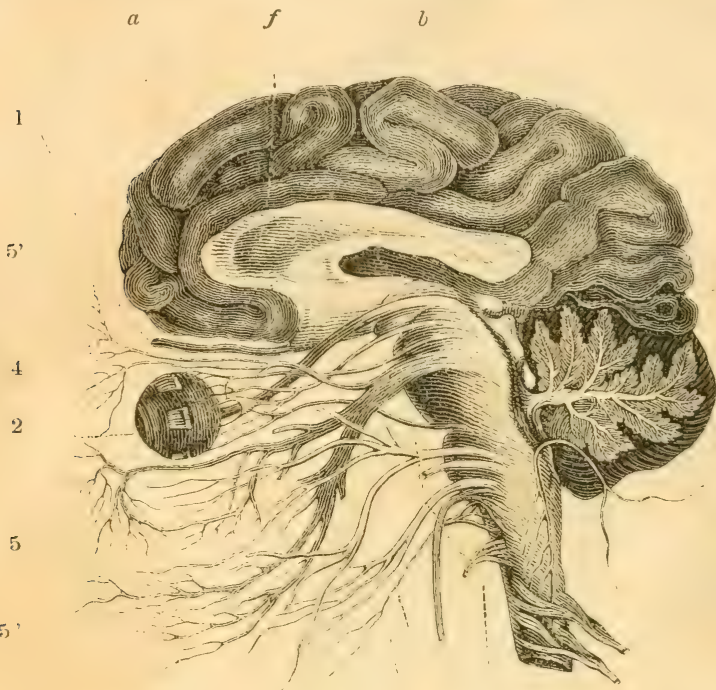

Fig. 55. Coupe du cerveau, elc. (1).

(1) Coupe verticale du cerveau, du cervelet et de la moelle allongée : $-a$ lobe antérieur du cerveau; $-b$ lobe moyen; $-c$ lobe postérieur du cerveau; $d$ cervelet; $-e$ moelle épinière; $-f$ coupe du corps calleux situé au fond de la scissure qui sépare les deux hémisphères du cerveau; au-dessous de cette bande transversale de matiere blanche, se trouvent les ventricules lateraux du cerveau; - globes optiques cachés sous la face infírieure du cerveau; - 1 nerfs olfactifs; - 2 œil dans lequel vient se termmer le nerf optique dont on peut suivre la racine sur les cótés de la protubérance anuulaire jusqu'aux lobes optiques. Derrière l'oxil on voit le nerf de la troisième paire; -4 nerf de la quatrième paire, qui se distribue, comme le précédent, aux muscles de l'œil; - 5 branche maxillaire supérieure du nerf de la cinquième paire; - 5' branche ophthalmique du même. nerf; 5" branche maxillaire inféricure du même nerf; -6 nerf de la sixième paire se rendant aux muscles de l'œil; - 7 nerf facial; au-dessous de l'origine de ce nerf on voit un tronçon du nerf acoustiquue; - 9 nerf de la neuvième paire ou nerf glosso-pharyngien; - 10 nerf pneumo-gastrique; - 11 nerf de la onzième paire, ou nerf hypoglosse; - 12 nerf de la douzitme paire ou nerf spinal ; - 14 et 15 nerfs cervicaux. 
est tournée en arrière; sa face supérieure est assez régulièrement bombée; sur les còtés il est un peu comprimé, et en dessous il eat aplati. On y distingrue dabord deux moitiés latérales, nommées hémisphères du cerreau, et séparées par une scissure profonde, dans laquelle s'enfonce une cloison verticale, formée par un repli de la dure-mere et appelée, à cause de sal forme, la faux cérébrale. En avant et en arriere, cetle scissure livise le cerveau dans toute sa hauteur; mais, au milieu, elle n'en occupe que la partie supérieure, et est bornée inférieurement par une lame médullaire, qui s'étend d'un hémisphere à l'autre, et qui se nomme corps calleux

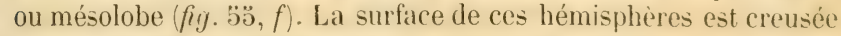
par un grand nombre de sillons tortueux et irréguliers et plus ou moins profonds, qui séparent des éminences, arrondies sur les bords, contournées sur elles-mèmes et ayant quelque ressemblance avec les replis de l'intestin grèle dans l'abdomen. Ces éminences portent le nom de circonvolutions du cerrenu, et les sillons qui les séparent et qui logent des replis de la lame intérieure de l'arachnoïle sont appelés anfractuosités. Ils sont plus ou moins profonds, et il est à remarquer que, dans l'enfant naissant et dans la plupart des animaux, mème les plus voisins de l'homme, les circonvolutions sont peu prononcées. A la face inférieure du cerveau, on distingrue encore dans chaque hémisphère trois lobes, séparés entre eux par des sillons transversaux, et désignés sous le nom de lobes antérieur, moyen et postérieur $(b, c, d, f i g . \ddot{b} 6)$; on remarque anssi dans cette partie du cerveau deux éminences arrondies, placées pros de la ligne médiane (éminences mamillaires), et deux pédoncules lrisgros, qui sembient sortir de la substance de cet or rane. pour se continuer avec la moelle épiniere (cuisses du cerreau ou pédoncules cérébraux). C'est également de cette partie du cerveau que sortent les nerfs auxquels ce viscere donne naissance.

La surface du cerveau est presque entierement formée de sul)stance nerveluse grise; mais, dans son intérieur, on ne frouxe guère que de la substance blanclie. Lorspuon incise cet or wane, on roit aussi qu il existe dans son inlérieur direrses cavités qui communiquent toutses an dehors, et qui sont appeleres les rentricules du cerveau $(f i g . \breve{3}, f)$.

$\$$ 187. Cervelet. - Le repreled esl plare all-ilrsious de la partio

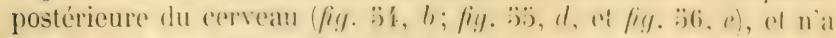
pas le tiers du volume de cet oreane. mème cher l'homme adulte, où il est proportionnellement plus gros que che\% l'enfiant. On y distingue, comme an cerroan, denx hémispheres ou lohes latciand séparés par une rainure ef un lobe moyen siture en arriere of an 
bas, dans l'enfoncement dont nous venons de parler. La surface des hémisphères et du lobe moven est formce par de la matiere grise et ne présente point de circonvolutiuns, mais un crand nombre de sillons à peu près droits et placés parallelement les uns à coté des autres, de facon à divis:r cet orane en une multitude de lames disposées comme les feuilles diun livre. Inférieurement le cervelet se continue avec la moelle ápiniere au moven de deux pédoncules courts et gros, et dans le mème point il entoure ce dernier organe par une bande de substance blanche qui se porte Iransversalement d'un hémisphere à l'autre, en passant au-devant de la moelle épiniere, avec laquelle elle est intimement unie, et qui porte le nom de protuliérance anmulaire on de pont de larole (1).

$\$ 188$. Lobes optiques. - Lorsqu'on soulive les lobes postérieurs du cerveau, on voit, entre cet organe et le cervelet, quatre petites éminences arrondies, placées par paires de charjue còté de la lig̣ne médiane (fig. : :3. y). Elles s'élevent sur la face supérieure des prolongements médullaires. qui se portent du cerveau à la moelle épiniere, et constituent ce que les anatomistes appellent les lubes optiques ou tubercules quadrijumeaux, dont nous aurons souvent a parler dans la suite de ces leçons.

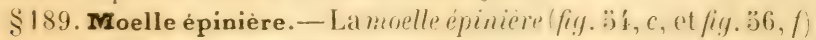
est en quelque sorte un prolongement du cerveau et du cervelet. Elle a la forme d'une grosic corle et présente, en avant comme en arrière, un sillon médian et longitulinal qui la divise en deux moiliés laterales et symétriques. A son extrémité supérieure à laquelle les anatomistes donnent le nom de moelle allongéej, on remarque divers renflements appolés corpss olivaires, pyjramidaux et restiformes, el de chaque cuté on en roit sortir successivement un wrand nombre de nerfs dont les premiers se dirigent directement en dehors. mais dont les derniers descendent de plus en plus obliquement, de façon que la moelle épiniere parait so terminer en se divisant en un grand nombre de filaments Iongitudinaux, disposés à peu prés comme les crins d une queue de cheval figf. : $; 6, j$, ressemblance grossiere qui a valu a cette partie le nom de l'objet auquel on l'a comprarée. Au niveau de l'origine des nerfs qui se distribuent aux menbres thoraciques, la moelle épinière présente un renflement biensensible; elle se rétrécit ensuite, et son volume augmente de nouveau vers la partie dou naissent les nerfs des membres abdominaux : enfin son extrémité inférieure est très-grèle et se trouve vers la partie supérieure de la régrion lombaire de la colonne vertébrale.

(1) Ainsi nommé en lhonneur d'un anatomiste célébre du xir siècle, Taroli. 
La moelle épinière se compose, comme le cerveau et le cervelel, de deux substances médullaires de couleurs différentes ; mais ici la matière grise, au lieu d'ètre située à la surface de l'organe, en occupe la profondeur, et c'est la matière blanche qui la recouvre. La gaine, formée par la dure-mère, n'est pas 11 occupée en entier par la moelle épinière, mais est distendue par une quantité considérable de liquide au milieu duquel celle-ci est suspendue, disposition admirablement bien calculée pour la préserver des pressions ou des commotions qui pourraient résulter des mouvements trop violents de la colonne vertébrale ou de toute autre cause, et qui produiraient sur cette partie du système nerveux des accidents encore plis graves que sur le cerveau.

\section{$\$ 190$. Structure de l'encéphale -} Nous avons dit que la substance qui forme l'axe cérébro-spinal était molle et pulpeuse; dans la matiere blanche on peut cependant distinguer des fibres, et l'étude de la marche yu'elles suivent conduit à l'explication de certains phénomènes des plus remarquables.

La moelle épinière présente, comme nous l'avons déjà dit, deux moitiés qui sont unies entre elles par des bandelettes formées principalement de fibres médullaires transversales; de chaque còté on troure aussi, lans lar substance

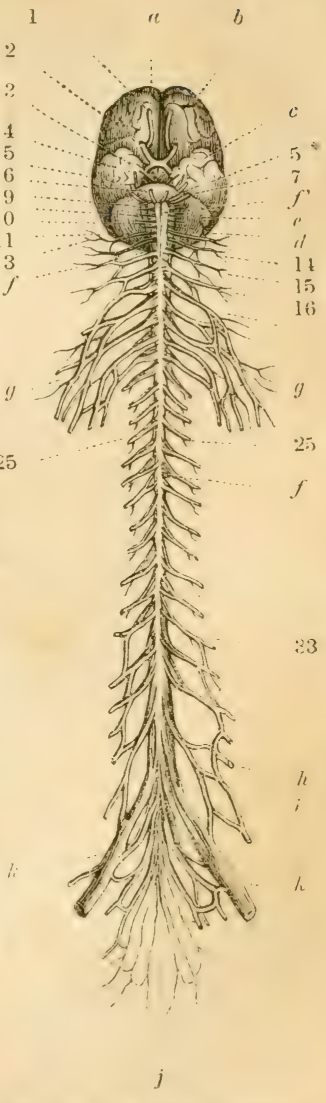

Fig. Jfi. Ase cereibro-spiutul, l).

(1) Système nerveux cérebro-spinal vu par sa face antérieure (les nerfs etant coupés à peu de distance de leur origine) : $-a$ cerveau; $-b$ lobe antérieur de l'hemisphere gauche du corvan; $-c$ lobe mosen; $-d$ le lobe postérieur, prespue entièrement caché par le cervelet ; - e cervelet; $-f$ moclle allongée; $-j$ moclle épiniere; -1 merts de la premiere paire ou merfs olfactifs; - 2 nerfs optiques ou nerfs de la seconde prate; -3 nerls de lat troisieme paire yui naissent derriere l'entrecroisement des nerfis optiques, au-derant du pont de Varole et au-dessus des pédoncules du cerveau; - 4 nerls de la quatrieme paire; - 5 nerls trilacianx ou de la cinquieme paire; - 6 neris de la sixieme patire, couche's sur le pont de Varole; -7 nerfs de lis septieme faire ou nerfs taciaux, et nerfis de la huitiente 
blanche de cel organe, un grand nombre de fibres longitudinales, qui à la partie supérieure se réunissent en six faisceaux principaux. Quatre de ces faisceaux occupent la face antérieure de la moelle allongée; ils constituent les renflements désignés sous le nom de pramides antérieures et corps olivaires, et ils pénètrent dans le cerveau. Lne partie des fibres des pyramides présentent une particularité très-remarquable : celles du còté droit se portent à sauche et celles du cùté gauche à droite. Ce n'est qu'apres cet entrecroisement qu'elles s'enfoncent dans la protubérance annulaire, et en continuant leur marche en avant constituent les pédoncules du cerveau. Ces fibres diveruent ensuite et se répandent dans les circonvolutions inférieures, antérieures et supérieures des lobes antérieurs et morens du cerveau. Les fibres longitudinales qui sortent des éminences olivaires montent, comme celles des pyramides, a travers la protubérance annulaire, et ront former la partie postérieure et interne des pédoncules cérébraux; elles traversent, comme celles des pyramides, diverses masses de substance grise, augmentent de volume et de nombre, et en suivant des directions différentes forment diverses parlies du cerveau, telles que les couches des nerfs optiques et les corps striés; enfin elles s'épanonissent dans les circonvolutions dont la masse entière constitue les hémisphères cérébraux; par l'intermédiaire d'autres fibres transversales, les deux moiliés du cerveau communiquent entre elles, et ces fibres forment le corps calleux dont nous avons déjà parlé, ainsi que plusieurs autres bandes transversales désignées par les anatomistes sous le nom général de commissures.

Les fibres longitudinales des pyramides postéricures de la moelle épinière se réunissent à quelques fibres renant des parties voisines de la moelle allongée, et constituent ainsi les pédoncules du cervelet, qui plongent jusqu'au centre de l'hémisphère correspondant de cel organe, et envoient vers sa circonférence une multitude de feuillets qui se subdivisent et forment, par leur assemblage, des espèces de rameaux enveloppés de matière grise et appelés par quelques anatomistes l'arlbre de vie (fig. $.3 \ddot{3}, \mathrm{~d})$. On distingue aussi,

paire ou nerfs acoustiques; -9 nerfs de la neuvieme paire ou glosso-pharyngiens; - 10 nerfs de la dixieme paire ou pneumo-gastriques; - 11 nerfs des onzième et douzième paires; - 13 nerfs de la treizième ou nerfs sous-occipitaux; - 14, 15,16 trois premières paires de nerfs cervicaux, - g nerfs cervicaux formant le plexus brachial; - 25 l'une des paires de nerfs de la partie dorsale de la moelle épinière; - 33 l'une de's paires de nerfs lombaires; - $h$ nerfs lombaires et sacrés formant les plexus d'vù naissent les nerfs des membres inférieurs; $i$ et $j$ terminaison de la moelle épinière appelée queue de cheval; $-k$ grand nerf sciatique se rendant aux membres inférieurs. 
dans le cervelet, des fibres transversales, qui font communiquer entre eux les deux hémisphères. Une parlie de celles-ci entourent la moelle allongée en avant et forment la protubérance annulaire, dont il a déjà été question.

$\$$ 191. INerfs. - Les nerfs, qui naissent de l'encéphale el qui établissent la communication entre ce système et les diverses parties du corps, sont au nombre de yuarante-trois paires (voy. fig. 54 , page 123 , et fig. 56 , page 129$)$. Ils proviennent tous de la moelle épiniere ou de la base du cerveau, et on les distingue, d'apries leur position, par des numéros d'ordre, en procédant d'avant en arrière. Les douze premières paires naissent de l'encéphale (fig. 5:3) et sortent de la boite osseuse du crâne par les dirers trous situés à sa base. Les trente et une paires suivantes proviennent de la portion de la moclle épinière, qui est renfermée dans le canal vertébral, et sortent de cette gaine osseuse par des trous situés de chaque côté entre les vertèbres.

Chacun de ces nerfs se compose d'un grand nombre de faisceaux formés par des fibres médullaires, et entourés d'une membrane nommée névrilème. Ces fibres élémentaires sont en général d'une ténuité extrème, et se portent parallèlement entre elles d'une extrémité du cordon nerveux à l'autre, sans jamais se réunir ni se diviser ; par leur extrémité supérieure, elles se continuent aussi sans interruption avec les fibres de la moelle épinière ou de la base du cerveau; et, par leur extrémité opposée, elles vont se terminer dans les organes auxquels elles sont destinées. En général, les différents faisceaux de filıres médullaires appartenant au mème nerf ne sont pas tous réunis au moment où ils quittent l'encéphale, et il en résulte que le nerf présente à son origine plusieurs racines; à mesure qu iils s’éloignnent de ce point, ces faisceaux se séparent pour se rendre à des parties différentes, de façon que le nerf lui-mème semble se diviser successivement en branches, en rameaux et en ramuscules; quelquefois aussi, cellains de ces faisceaux ou de leurs fibres constitutives, apres s'ètre siparés de la sorte, vont s'accoler à quelques nerf: voisins pour en suive le trajet, et il en résulte ce que les anatomistes appellent des anastomoses (1) ou des

(1) I.'s nerfs ayant été regardés par quelyues anatomistes comme étant des canaux destines à conduire le fluide nerveux, on a donné le nom d'ancsiomoses à lat remion de leurs branches on de leurs rameatux; mais ce not, comme nous l'avons dejat dit, signifie réllement un abouchement ou une communication entre deux vatisseaux, et, par conséquent, ne devrait pas être employé ici, car, lorsquiune fibre nervense se sépare d'un nerf peur s'aceoler à un autre, elle ne se confond aree ancune des fibres de celle-ci et continue son trajet sans interruption jusque dans la partie à laquelle elle est destinée. 
plexus (1). Enfin, lorsqu'une branche nerveuse est parvenue dans l'organe où elle doit se rendre, ses fibres primitives s'y répandent et s'y terminent presque toujours en formant des anses.

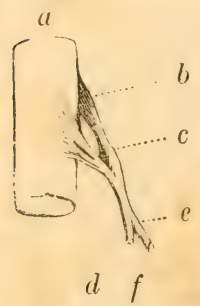

Fig. 57 (2).

Les nerfs qui sortent de la moelle épiniere en naissent par deux racines composées chacune de plusieurs faisceaux (fig. 57 ) ; liune de ces racines provient de la partie antérieure de cet organe, lautre de sa partie postéricure; et cette dernièr: racine, avant que de se réunir à la première, présente un renflement ou ganglion, composé en partie de substance médullaire grise. Quelquesuns des nerfs cérébraux présentent une disposition semblable, mais il en est d'autres qui n'en offrent aucune trace; rt, comme nous le verrons bientôt, cette différence est indicative d'autres particularités dans les propriétés physiologiques de ces cordons médullaires.

\$192. Système ganglionaire. - Le système nerveux ganglionaire, appelé aussi nerf grand sympathique, ou système nerveux de la vie organique, se compose d'un certain nombre de petites masses nerveuses bıen distinctes, mais liées entre elles par des cordons médullaires, et de divers nerfs qui vont s'anastomoser avec ceux du systeme cérébro-spinal, ou se distribuer dans les organes voisins. Ces centres nerveux portent le nom de ganglions: on en trouve à la tète, au cou, dans le thorax et dans l'abdomen. La plupart d'entre eux sont placés symétriquement de chaque còté de la ligne médiane au-devant de la colonne vertébrale, et forment ainsi une double chaîne depuis la tète jusqu'au bassin ; mais on en trouve aussi dans d'autres parties : près du cœur, et dans le voisinage de l'estomac, par exemple.

Les nerfs du système cérébro-spinal se rendent aux organes des sens, à la peau, aux muscles, etc. ; ceux qui font partie du système ganglionaire se distribuent aux poumons, au cœur, à l'estomac, aux inteslins, aux parois des vaisseaux sanguins. En un mot, les

(1) Plexus (de plecto, jentremêlei est le nom que l'on donne à une espéce de lacis formé par la réunion de plusieurs nerfs ou vaisseaux. Les principaux plexus: nerveux sont ceux formés par les nerfs des membres, peu après leur sortie de lia colonne vertébrale. (Voyez fig. $52, e, l$, et fig. 54 , g et $h$.)

(2) Tronçon de la moelle épinière, montrant la disposition des nerfs qui en naissent : - a moelle épinière; $-b$ racine postérieure de l'un des nerfs spinaux ; - $c$ ganglion situé sur le trajet de cette racine; $-d$ racine antéricure du même nerf, allant se réunir à la racine postérieure, au delà du ganglion : - e tronc commun formé par la réunion de ces deux racines; - $f$ petite branche qui ra s'anastomoser avec le nerf grand sympathique. 
premiers appartiennent spécialement aux organes de relation, les derniers aux organes de nutrition.

$\$$ 193. Système nerveux des autres animaux. - Le système nerveux de tous les mammifères, des oiseaux, des reptiles et des poissons, est conformé d'après le mème plan général que celui de l'homme. Chez tous ces animaux, il existe un cerveau, un cervelet et une moelle épinière; des nerfs naissent de cet axe cérébro-spinal et se distribuent aux divers organes de la vie de relation : enfin, il existe aussi un système ganglionaire pourvu également de nerfs et destiné aux principaux organes de la vie de nutrition.

Mais, chez les mollusques, les insectes, les crustacés et les autres animaux sans vertèbres, il n'en est pas de mème ; chez ceux-ci, l'axe cérébro-spinal paraît manquer, et tous les nerfs du corps vont se réunir dans un certain nombre de ganglions plus ou moins éloignés entre eux (fig. 58). Enfin, dans la grande division des zoophytes, on ne trouve tout au plus que des vestiges d'un système nerveux rudimentaire, et, en général, cet appareil paraît manquer complétement. En faisant l'histoire de ces divers groupes d'animaux, nous aurons l'occasion d'indiquer les particularités qu'ils présentent à cet égard.

Telles sont les diverses parties dont

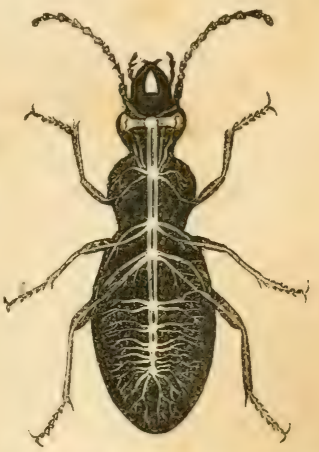

Fin. 55. Système nerreux d'un insecte (Carabe des jardins). se compose l'appareil nerveux de l'homme et des autres animaux supérieurs; voyons maintenant quels en sont les usages, et occupons-nous en premier lieu de l'étude de la sensibilité.

\section{DE LA SENSIBILIT É.}

$\$ 19 \%$. La sensibilité, avons-nous dit, est la faculté de receroir des impressions et d'en avoir la conscience. Elle appartient à tous les animaux; mais le degré auquel elle se développe varie presque pour chacun d'entre eux. A mesure que l'on s'élève dans la série zoologique, et que l'on se rapproche de l'homme, on voit les sensations devenir de plus en plus variées; l'animal acquiert le pouvoir de prendre connaissance d'un plus grand nombre des propricités que possiedent les objets dont il est environné, et d'en mieux apprécier les nuances différentes; les impressions produites devien- 
nent plus vives, ct à mesure que la faculté de sentir se perfectionne ainsi, on voit la structure des organes de la vie de relation se compliquer de plus en plus; car ici, de mème que pour toutes les autres fonctions, c'est par la division du travail que la nature arrive à des résultats de plus en plus parfaits.

$\$ 19: 3$. Partout ou les sensations productes par des objets extérieurs sont un peu variées, il existe un srsteme Nenvecx distinct, et c'est de som action que dépend la fuculté de sentir. La structure en est d'abord très-simple, et alors toutes les parties qui le composent paraissen! remplir à peu près les mèmes fonctions. Dans le rer de terre, par exemple, c’est un cordon noueux, étendu dans toute la longueur du corps, et dont toutes les parties possèdent les mèmes propriétés: car, si on coupe l'animal transversalement en plusieurs troneons. on roit chacun cles fragments continuer à sentir et à se mouroir comme aupararant: mais dans les ètres dont l'organisation est plus compliquée et dont les facultés sont plus parfaites, cet appareil se compose, comme nous l'avons déjà vu, de plusieurs parlies dissemblables, et alors chacune de celles-ci agit aussi d'une manière diflérente des autres, et remplit des fonctions spéciales. Ce sera donc chez l'honme et chez les autres animaux supérieurs, que l'étude de ces fonctions nous offrira le plus d'intérèt.

$\$$ 196. Fonctions des nerfs. - Toules les parties de notre corps ne sont pas ézalement douées de sensibilité: quelques organes possèdent cette propriété à un haut degré, tandis que d'autres peuvent ètre excités de toutes les manières, froiscés par des corps étrangers, coupés et mème déchirés, sans que l'animal en éprouve la moindre sensation. Or, les parties les plus sensibles sont toujours celles jui régoisent le plus grand nombre de nerfs; et, là où il n'y a point de nerfs, il ny a pas de sensibilité. Si l'on fait une incision à la patte d'un animal virant, et que l'on mette à décourert le nerf qui se rend à colte partic, on remarque aussi que ce cordon est doué d'une sensibilité extreme; pour peu quion le pince ou quion le pique, l'animal montre tous les signes d'une doulrur des plus rives, et les muscles ausquels le nerf ainsi blessé se distribue sont agites par des contractions comvulsives.

D'après cela, on pourrait déjà deviner que c'est aux nerfs que nos organes doivent leur sensibilité, et, pour mettre ce fait hors de doute, il suffit de détruire l'un de ces cordons; car, si l'on pratique l'expérience sur un des membres d'un animal vivant, toutes les parties auxquelles le nerf se rendait sont aussitòt frappées u. jaralysie, c'est-à-dire privées de la faculté de sentir et dle se mouroir.

Mais ce nerf, dont l'action est indispensable à l'exercice de ces 
fonctions, est-il en relation directe avec l'âme, et est-il chargé de déterminer les mouvements et de percevoir les sensations, ou bien remplit-il seulement le ròle d'un conducteur, et est-il destiné uniquement à transmettre aux muscles l'excitation développée dans un autre orq̣ane par l'influence de la volonté, et à porter à cette partie, qui serait en mème temps le siége de la perception des sensations, les impressions résultant du contact d'un objet extérieur avec la surface du corps ou de l'action de tout autre stimulant?

Pour résoudre cette question, les physiologristes ont eu encore recours à des expériences sur les animaux vivants.

Si l'on coupe, dans un point quelconque de sa longueur, le nerf qui se rend à la patte postérieure d'une grenouille, par exemple. et que l'on pique ou que l'on pince l'extrémité ainsi séparée du reste du systeme nerveux, on voit qu'elle est complétement insensible, tandis que la partie situće au-dessus de la section conserve toute sa sensibilité; les parties du menbre qui reçoirent des branches nerveuses du fragment inférieur du nerf sont également paralysées.

Un nerf séparé du système dont il faisait partie cesse donc de remplir ses fonctions; il ne peut, par conséquent, ètre le siége de la perception des sensatious, et on doit nécessairement conclure qu'il sert à transmettre à l'oryane où s'exerce cette fonction les impressions reçues par les parties douées de sensibilité.

C'est, en effet, ce qui est démontré clairement par toutes les recherches faites à ce sujet sur les animaux, et en observant les phénomènes déterminés par certaines opérations chirurgicales, il a été facile de s'assurer qu'il en est de mème chez l'homme. L'impression produite par le contact d'un corps avec le nerf lui-mème, ou avec la partie dans laquelle ce nerf se ramifie, ne peut ètre perçue, et ne peut, par conséquent, produire une sensation, si elle n'est transmise par le nerf à d'autres oryanes.

$\$ 197$. Ce fait une fois bien établi, on est naturellement conduit a se demander ou les sensations doivent arriver pour que l'animal en ait la conscience? quel 'sit l'organe chargé de les perceroir? ou, en d'autres moli, quel est le siéye du moi, quelle est la partie matérielle de l'économie qui est unie directement au principe citul des animaux privés de raison ou à l'ame de l'homme?

5 198. Influence de l'encéphal... - Les nerfs dont nous venons d'étudier les fonclions aboutissent tous au cerveau ou a la moelle épiniere, qui elle-mème se termine dans le cerveau; il est done 
évident que c'est dans une partie quelconque de l'encéphale que doit résider cette faculté de perception. Cherchons par l'expérience si c'est dans la moelle épinière, dans le cervelet ou dans le cerveau.

Lorsqu'on pratique sur la moelle épinière les mèmes expériences que celles déjà faites sur les nerfs qui cn partent, on remarque d'abord (que cet organe est extrèmement sensible : la moindre piqùre produit une douleur vive et des mouvements convulsifs; et, si on le coupe en travers, on voit anssitòt une paralysie complete de toutes les parties dont les nerfs naissent au-dessous de la section, tandis que celles dont le: nerfs proviennent de la portion de la moelle épinière encore en communication avec le cerveau continuent à jouir de la faculté de sentir et de se mouvoir.

En ayant soin d'entretenir artificiellement la respiration de manière à empècher l'animal ainsi expérimenté de périr asphyxié à la suite de la paralysie des muscles inspirateurs, on peut constater que toutes les parties de la moelle épinière perdent la faculté de déterminer des mouvements volontaires et celle de donner naissance à des sensations aussitòt qu'elles sont séparées du cerreau, et on en doit conclure que ce n'est pas en eux que réside la faculté de percevoir les sensations ou de déterminer les mouvements volontaires.

Mais il en est tont autrement pour le cerveau. Si l'on met a nu les deux hémisphères de cet orạane chez un animal vivant (chez un pigeon, par exemple), et qu'on irrite lerir surface avee la pointe d'un instrument tranchant, on est d'abord frappé de leur insensibilité; on peut couper et déchirer la substance du cerreau sans que l'animal donne le moindre siogne de douleur, et sans qu'il paraisse s'apercevoir de la mutilation qu'on lui fait subir; mais si, comme l'a fait $\mathbf{H}$. Flourens, on enleve cet organe, l'animal tombe dans un état de stupeur dont rien ne pent le faire sortir. Tout son corps devient insensible, ses sens n'agissent plus, et s'il se remue, ce n'est que pousié par quelque cause étrangère et sans que la volonté paraisse entrer pour rien dans la détermination de ses mouvements.

On voit par cette expérience que l'action du cerveau est indispensable a la perception des sensations et a la manifestation de la volonté, et yue c'est à cet organe que les impressions recues par les nerfs doivent arriver pour que l'animal en ait la conscience.

$\$$ 199. Dans la fonction de la sensibilité, il y a done une division du travail bien remarquable: les parties qui, far leur contact avec les corps étrangers, sont susceptibles de domner naissance a 
des sensations, ne peuvent pas percevoir elles-mèmes ces impressions, é, d'un autre còté, l'oryane qui est le siége exclusif de la perception de ces impressions ne pent lui-mème en recevoir direclement; il est insensible et ne peut ètre excité que par les inpressions qui lui sont transmises par l’intermédiaire des nerfs.

Ainsi, on peut distinguer dans l'appareil de la sensibilité trois propriétés, savoir : $1^{\circ}$ la faculté de recevoir au contact d'un corjs étranger ou de quelque autre agent une impression de nature a donner naissance à une sensation; $2^{\circ}$ la faculté de transmettre ces impressions, du point ou elles ont été produites, à l'organe charré de les percevoir; $3^{0}$ celle de donner à l'animal la conscience de leur existence ou de les percevoir.

Il résulte des expériences de M. Flourens el de quelques autre's physiologistes, que chez les animaux qui avoisinent l'homme, tels que les mammiferes el les oiseaux, cette dernière faculté réside principalement dans les hémisphères du cerveau; et, comme nous l'avons vu il y a un instant, la faculté de recevoir des impressions et de les conduire au cerveau, où elles doivent ètre perçues, est l'apanage des nerfs.

$\$ 200$. Il est aussi a noter que, dans la transmission des impressions vers le cerveau, chacune des fibres élémentaires d'un nerf agit d'une maniere complétement indépendante des fibres r oisines; et comme ces fibres, seulement accolées en faisceaux, ne se rénnissent jamais entre elles, mais continuent chacune son trajet jusque dans l'encéphale, et il en résulte que les sensations renant des différents points du corps arrivent chacume par une route particuliere et ne se confondent pas entre elles. Nons jugeons du siége de la sersisation par la voie a l'ande de lanpelle elle parvient a notre cerveau, et éest toujours a la partic du corps ou se termine la fibre nervense élémentaire ansi mise en action que nous rapportons la sensation produite (1).

(1) La sensation dépendante de lexcitation d'un nerf cst encore rapportée frar l'intelligence à l'organe où ce nerf se distribue, lors mêmo que cette excitation a son sienge plus près du cerreau sur un point queleonque du trajet do ce neri. Ainsi, lorsquion emprime le nerf radial au coude, c'est dans la main que la donleur semble exisier, paree que cist cans cette derniere partie que le nerf en question val se termincr. ("'st également pour eette ratison quaprès la section d'un nerf on éproure souvent de la douleur dans la partie ou ce nerf se distribuait, et oì la sensibilité est crementant completement detruite. Enfin, la connaissance de ce fait nous explyque aussi comment, après l'amputation d'un membre, le malade peut éprouver des senvations dont le siegge semble être dans la partie qu'il a perdue; cest qu'il rafuprte instinctiement aux organes où allaient se terminer Jes diverses branches du nerf coupé, lexcitation dont le tronçon de ce nerf est maintenant le siege. 
$\S 201$. INerfs de la sensibilité. - Du reste, tous les nerfs du corps ne possedent pas la propriété de transmettre les sensations; il en esi qui sont consacrés exclusivement aux mouvements, et parmi les nerfs de la sensibilité tous ne jouissent pas de la faculté de conduire an cerveau les mèmes impressions. La sensibilité de certains nerfs ne peut pas toujours ètre mise en jeu par des agents qui sont susceptibles d'exciter des sensations dans d'autres nerfs: ainsi la lumiere, par exemple, produit une sensation vive lorsqu'elle frappe sur la partie terminale des nerfs optiques, mais n'est. susceptible d'émouvoir aucun des autres nerfs de l'économie; êt ces nerfs optiques, si sensibles à l'influence de cet agent subtil, peuvent ètre comprimés, piqués ou déchirés sans qu'il en résulte aucune sensation de douleur, tandis que les nerfs spinaux, qui restent indifférents à l'action de la lumiere, conduisent avec la plus granile perfection les sensations produites par le contact matéried d'un corps étranger, el ne peuvent ètre excités de la sorte un peu fortement sans qu'il en résulte une douleur plus ou moins intense.

$\$ 202$. Modifications de la sensibilité - II existe done lifférentes espeeces de sensibilité aples a itre mises en jeli par des excitants différents; c'est de la sorte que nous pouvons apprécier les diverses propriétés physiques des objets dont nous sommes entourés, et ce sont ces modıfications de la sensibilité qui constituen les cinq sens dont l'homme et la plupart des animaux sont dowés.

La sensibilité tactile ou le toucher, la sensibilité gustative ou le goût, la sensibilité olfaclive ou l'odlorat, la sensibilité auditive ou l'ouie, et la sensibilité optique ou la vue, sont par conséquent autant de facultés distinctes, ayant chacune leurs instrmments particuliers, dont l'action est excitée par des causes distinctes et dont le jeu nous procure des connaissances différentes. Le contact d'un corps qui résiste à la pression, ou qui est notablement plus chaud ou plus froid que nos or zanes, détermine, dans les parties qui jouissent de la sensibilité tactile, des sensations particulières, d'après lesquelles nous jugeons de la consistance, du joli, de la température et jusqu'à un certain point du volume et de la forme de cet objet; le conlact de ce mème corps sur une autre partie. dont les nerfs sont doués de la sensibilité gustative, peut nous donner la sensation des saveurs, et lorsque, après avoir été réduit en particules extrèmement ténues, il vient à toucher les parties douées de la sensibilité olfactive, il peut encore donner maissance a une sensation d'un autre ordire, celle des odeurs; le mouvement vibratoire dont re corps peut itre animé échappera inaperegu aux organes du gout et de l'odorat, mais produira la sensation du son 
Lorsqu'il parviendra aux parties douées de la sensibilité auditive ; enfin la lumière que ce corps nous envoie n'excitera aucun des sens dont il vient d'ètre question, mais déterminera sur les parties donées de la sensibilité optique des sensations différentes de toutes celles que nous venons d'énumérer, et propres à nous faire connaitre la forme, la couleur et la position des objets dont nous sommes environnés.

La sensibilité olfactive est l'apanage des nerfs cérébraux de la première paire; la sensibilité optique appartient aux nerf's cérébraux de la seconde paire, appelés pour cette raison nerfs optiques; la sensibilité gustative est propre à certaines fibres des nerfs cérébraux de la cinquième paire; la sensibilité acoustique réside dans les nerfs auditifs ou nerfs cérébraux de la huitième paire; enfin la sensibilité tactile est exercée presque exclusivement par les nerfs spinaux et les nerfs cérébraux des cinquième, neuvième, dixième et douzième paires.

\section{$\$ 203$. Fonctions différentes des deux racines des nerfs spi-} naux, etc. - Les nerf's qui sont doués de la sensibilité tactile servent aussi aux mouvements; mais il est bien évident que la faculté d'exciter les contractions musculaires et celle de conduire les sensations ne résident pas dans les mèmes fibres élémentaires, et si ces nerfs possèdent en mème temps ces deux facultés, cela dépend seulement de ce qu'ils sont formés par la réunion de fibres sensibles et de fibres motrices. Dans le trajet du nerf il n'est pas possible de distinguer ces deux ordres de fibres, mais a son origine cette distinction est facile, car la nature les a séparées. En effet, tous ces nerfs naissent, soit de la moelle épinière, soit de la base du cerveau, par deux racines, et, d'après les observations intéressantes de MiM. Bell et Magendie, on sait aujourd'hui à ne pas en ciouter que les fibres dont se compose l'une de ces racines servent à la transmission des sensations, tandis que celles qui constituent l'autre rarine conduisent aux muscles l'influence dont dépendent les mouvements volontaires.

En effet, si l'on coupe les racines postérieures de l'un des nerfs spinaux, on prive aussitòt ce cordon de la faculté de transmettre les impressions: la partie du corps a laquelle il se rend devient insensible, mais le's mouvements restent sounis a l'influence de la volonté; tandis que la section des racines antérieures, les racines postérieures restant intactes, détermine la paralysie des mourements sans détruire la sensibilité.

En coupant les racines postérieures de tous les nerfs spinaux, on n'empéche pars l'animal d'exécuter des mouvements volontaires, 
mais on rend tout son corps à l'exception de la tète, dont les nerfs naissent dans l'intérieur du cràne) complétement insensible. Les racines postérieures sont done des nerfs de la sensibilité, rt les racines antérieures des nerfis du mourement, et c'est par leur réunion que le cordon résultant de leur jonction jouit en mème temps de ces deux facultés.

Les différentes parties ree la moelle épinière ne possedent pas toutes, au mème degrré, la faculté de transmettre les sensations ou d'exciter les mouvements; la sensibilité est exquise à la face postérieure de cet organe, el beaucoup plus faible a sa face antérieure.

$\$ 204$. Système ganglionaire. - ()uant au systime nerveux ganglionaire, il n'est que peu ou point sensible : on peut pincer ou couper les ganglions, ainsi que les nerfs qui en partent, sans produire de douleur et sans occasionner de contractions musculaires. Il est à remarquer aussi que, dans l'état de santé, les oryanes intérieurs qui recoivent ces nerfs ne nous transmettent que de: sensations faibles et tres-confuses, et c'est seulement dans certains états maladifs que leur sensibilité se développe. Dans ce cas, il est à présumer que les sensations arrivent au cerveau par l'intermédiaire des branches qui unissent les nerfs du systime ganglionaire a chacun des nerfs spinaux. Mais ce point de physiologic réclame de nouvelles investigations.

$\$ 20 \%$. Organes spéciaux des sens. - L'appareil de la sensibilité ne se compose pas seulement des diversés parties du système nerveux dont nous venons dindiquer les usages; les nerfs doués de la faculté de transmettre au cerveau les sensations yui nous viennent du dehors ne se terminent pas librement à l'extérieur, de façon à recevoir directement le contact des agents qui déterminent ces sensitions, mais ront aboutir dans des instruments particuliers destinés à recucillir, pour ainsi dire, l'excitation el a la préparer de facon a assurer son action. Ces instruments sont les organes des sens, et c'est essentiellement par leur intermédiaire que les sensations nous arrivent; mais ils ne sont pas indispensables pour l'exercice de loutes ces facultés; la sensibilité tactile peut ètre mise en jeu partout où il existe des nerfs propres à conduire les sensations ordinaires, et c'est seulement pour les sens spćciaux, r'est-a-dire pour le gout, l'odorat, l'ouie et la vue, fue cetle espece d'intermédiaire entre le nerf et lo monde extérieme cst une condition nécessaire.

Ayant étudié d'une maniere géncirale le phénomino de la sen-

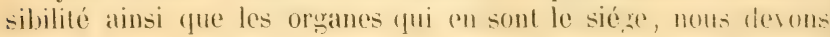


maintenant examiner plus en détail chacune des formes sous lesquelles cette propriété se manifeste, ou, en d'autres mots, nous occuper de, l'histoire particulière de chacun des sens dont la nature a doué les animaux.

\section{DU SENS DU TOUCHER.}

$\$ 206$. Tous les animaux jouissent d'une sensibilité tactile plus ou moins délicate, et c'est surtout par l'intermédiaire de la membrane dont la surface de leur corps est recouverte, que cette faculté s'exerce. Pour l'étudier, il faut donc avant tout examiner quelle est la structure de la peau.

Dans l'homme, la surface extérieure du corps et celle des cavités creusées dans son intérieur, mais communiquant avec le lehors, tel que le canal digestif, ctc., sont revètues d'une membrane tégumentaire plus ou moins ipaisse et bien distincte des parties qu'elle recouvre. Cette membrane est partout en continuité avec elle-mème, et ne formè récllement qu'un seul tout; mais ses propriétés ne sont point partout les mèmes, et on la désigne par des noms différents, lorsqu'elle se reploie en dedans pour tapisser des cavités intérieures, ou lorsqu'elle s'étend sur la surface extérieure du corps. La portion intérieure de la membrane tégumentaire gónérale est appelée membrane muqueuse, et la portion externe peau.

$\$ 207$. Structure de la peau. - La peau se compose de deux couches principales: le derme ou chorion, et l'épiderme.

Le derme forme la couche la plus profonde et la plus épaisse de lat peau. C'est une membrane blanchàtre, souple, mais assez élastique et tres-résistante. On y distingne un srand nombre de fibres et de lamelles entrecroisées d'une manière très-serrée. Sa face interne est unie aux parties voisines par une couche plus ou moins épaisse de tissu cellulaire, et domne, rans quelques points, attache à des fibres musculaires servant a la mouvoir. Enfin, sa surface est hérisse d'un grand nombre de petites saillies rougeâtres, ypii sont tres-sensibles, et qui, disposeres par paires, forment, dans certaines parties du corps, felles yue la paume des mains et l'extrénité des doints, des séries rémulieres. Ce sont ces corps que l'on désigne sous le nom de papilles de la peau, et c'est le derme de la preau de certains animaus qui, préparé par le tamnage, constitue le cuir.

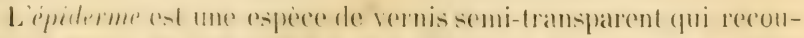

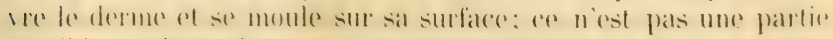
sensible, mais un tissu composi d'ulricules plus ou moins applaties. 
qui parait ètre sécrété par le derme, et qui ne prend une certaine solidité que par le desséchement : aussi dans les parties du corps qui sont soustraites à l'action de l'air, l'épiderme est-il toujours mou et peu distinct. Il se compose d'un nombre plus ou moins considérable de couches superposées, et sa couche la plus interne, qui conserve de la mollesse et qui renferme la matièe pigmentaire a laquelle la peau (loit sa couleur, a été considérée par beancoup d'anatomistes, comme constituant une membrane particuliere, et a été désignće sous le nom de réseau muqueux de la peau. Chez l'homme et les autres mammiferes, les couches les plus superficielles de l'épiderme se séparent peu à peu de la peau et tombent sous la forme d'une poussiure blanchàtre composéc de petites écailles; quelquefois aussi il se détachr dans toute son épaisseur et laisse le chorion à nu; c'est ce yui arrive lorsyu'à la suile d'une brùlure, par exemple, il se forme une cloche sur la peau; mais il se reproduit avee beaucoup de rapidité. Enfin, il est des animaux qui, à des époques déterminées, se revètent d'un épiderme nouveau et se dépouillent de l'ancien comme d'une qaaine, sans le rompre ni le déformer; les serpents nous offrent un exemple remarquable de ce phénomène.

On observe à la surface de l'épiderme une multilude de petites ouvertures appelées pores de la meau. Elles correspondent au sommet des papilles dont nous avons déjà parlé, et lirrent passage à la sueur. liquide acide qui est formé par voie de ścerétion, et qu'il ne faut pas confondre avec l'eau qui s'exhale continuellement par la surface de la peau ef uni constitue la transpiration insensible. Ces pores, d'une petilesse extrème, ne traversent pas le derme, et ne sont autre chose que les orifices des conduits sécréteurs, d'autant de petites ampoules qui sont logées dans la substance de la peau et qui sécrètent la sueur.

On trouve ausia a la surface de cette membrane d'autres onvertures plus grandes, dont les unes livrent passage à des poils, sur le mode de formation desyuels nous reviendrons par la suite, et dont les antres laissent suinter une matière gorasse, sécrétée par des follicules locrées dans l'épaisseur du derme; enfin, dans quelques points de la surface du corps, on roit sortir de la substance de la peau des lames cornées, appelées ongles, dont la nature est semblable à celle des poils.

$\$ 208$. Le principal usage de l'épiderme est d'opposer des obstacles a l'évaporation des liquides contenus dans le corps, et de protéger la peau proprement dite du contact immédiat des corps étrangers, de façon à modérer les impressions produites par ce 
contact. Nous avons déjà vu que cet enciuit solide est par lui-mème insensible: et, comme il s'interpose toujours entre le derme et les b) jets extérieurs dont le contact sur cette membrane détermine les sensations, il est facile de comprendre que plus la conche épidermique est épaisse. plus aussi le lerme doit ètre soustrait à l'action des corps étrangers, et plus les impressions quil éprouve doivent ètre obtuses. Or, dans quelques parties du corps, au talon par exemple, l'épiderme présente une épaisseur considérable, tandis que dans d'autres, à l'extrémité des doiģts, sur les levres, etc., if est extrèmement mince. On remarque aussi (que, partout où la peau est exposée à des frottements, son épiderme s'épaissit. Chacun sait combien la couche qui se forme dans la main des forgrerons et autres ouvriers employés à des travaux analogues derient épaisse, dure et rugueuse. Enfin, chez quelques animaux, l'épiderme s'encroùte de matières calcaires et devient tout à fait inflesible; dans ce cas, il rend la surface du corps complétement insensible.

$\$$ 209. La sensibilité dont la peau est qouée réside dans le derme et dépend des nerfs qui se distribuent dans sa subslance, et qui appartiennent à la classe des nerfs du tact, lesquels naissent, comme nous l'avons déjà ru, de la moelle épinière on cie la base du cerveau par deux racines, et doivent aux fibres dont se rompose leur racine postérieure la propriété de transmottre les sensations. Ces nerfs ront presque ious se terminer sous la forme de houppes dans les papilles du derme, et ce sont ces papilles qui possedent, par conséquent, au plus haut degré la sensibilité tactile; aussi là ou elles sont le plus nombreuses, cette sensibilité est-elle le plus exquise.

210. Organes spéciaux du toucher. - Lil sensibilité tactile, telle qu'elle exisle dans toutes les parties de la surface de notre corps, suffit pour nous faire jugerer le la consistance, de la température et de quelques autres propriétés des corps qui arrivent en contact aver elle. Ce sens ne s'exerce alors que d'une manière en quelque sorte passive, qui peut ètre désignée sous le nom de tact; mais, d'autres fois, la partie donée de celte sensibilité joue un ròle actif; des contractions musculaires, dirigées par la volonté, multiplient of varient les points de conlact avec l'objet extérieur, et on donne alors à ce sens le nom de toucher.

Le toucher n'est dunc que le tact perfectionné el devenu actif; mais il ne peut itre exercé par loutes les parties qui sont donées de la somsibilité laclile, et il ne peut appartenir qu'à des or wanes disposés de maniere a leur permettre de se mouler en quelque sorte sur les objets soumis à leur examen.

Dans l'homme, la main est l'organe spécial du toucher, et sa 
tructure est très-favorable à l'exercice de ce sens : l'épiderme y est mince, poli et très-souple ; le chorion y est abondamment pourvu de papilles et de nerfs, et repose sur une couche épaisse de tissu cellulaire graisseux très-élastique: enfin, la mobilité et la flexibilité des doigts sont extrèmes, et la longueur de ces organes est considérable. Or, ces circonstances sont des plus avantageuses, car elles tendent à augmenter la sensibilité de celte partie, et lui permettent de s'appliquer sur les objets, quelle que soit l'irrégularité de leur figure. Mais une autre disposition organique qui contribue non moins à la perfection de notre toucher, est la faculté qu'a l'homme d'opposer le pouce aux autres doigts, de manière a pouvoir serrer les petits objets entre les parties de la main qui sont précisément celles dont la sensibilité est la plus exquise.

Chez la plupart des animaux, les organes du toucher sont disposés d'une manière beaucoup moins farorable. Chez les mammifères, par exemple, on voit ce sens devenir de plus en plus obtus, à mesure que les doigts deviennent moins flexibles et s'enveloppent davantage dans les ongles dont ils sont armés; quelquefois cependant les mains sont remplacées par d'autres organes ci'une structure presque aussi parfaite, tels que la trompe de l'éléphant $(f i g . \ddot{3})$; enfin, il est des animaux qui emploient principalement leur langue comme instrument du toicher, et d'autres sont pourvus d'appendices particuliers, qui servent aux mèmes usages, el qui sont appelés tentacules, palpes, etc. ( fig. 6, 8$)$.

$\$ 211$. Le toucher nous fait apprécier plus ou moins exactement la plupart des propriétés physiques des corps sur lesquels il s'exerce: leurs rlimensions, leur forme, leur température, leur consistance, le degré de poli de leur surface, leur poids, leurs mouvements, etc. Ce sens est tellement parfait, que plusieurs philosophes de l'antiquité et des temps modernes l'ont regardé comme nous étant plus utile que la vue ou que l'ouie, et comme étant mème la source de notre intelligence; mais ces opinions sont évidemment exagérées, car le toucher n'a réellement aucune prérogative sur les autres sens; et cliez quelques singes, dont l'intelligence est incomparablement moins développée que celle de l'homme, les organes du toucher sont presque aussi parfaits que dans le corps humain.

\section{DU SENS DU GOUT.}

$\$ 212$. Le sens du goùt, comme celui du toucher, est mis en jeu par le contact des objets extérieurs sur certaines surfaces de notre corps; mais il nous fail conmaitre des propriétés qui échappent au toucher, les saveurs des corps. 
$\$ 213$. Saveurs. - Toutes les substances n'agissent pas sur l'organe du goùt. Les unes sont très-sapides, d'autres ne le sont que peu, et il en est un grand nombre qui sont complétement insipides. On iggnore la cause de ces différences, mais on remarque qu'en général les corps qui ne peuvent pas se dissoudre dans l'eau n'ont pas de saveur, tandis que la plupart de ceux qui sont solubles sont plus ou moins sapides. Leur dissolution parait mème être une des conditions nécessaires pour qu'ils agissent sur l'organe du goùt; car, lorsque cet organe est complétement sec, il ne nous donne plus la sensation des saveurs; et on connait des substances qui, étant insolubles dans l'eau, sont insipides dans leur état ordinaire, mais qui acquièrent une saveur forte si on parvient à les dissoudre dans quelque autre liquide, dans de l'esprit de vin, par exemple.

$\$$ 214. Organe du goût. - La connaissance de la saveur des corps sert principalement à diriger les animaux dans le choix de leur nourriture: aussi, l'orgame du goùt est-il toujours placé à l'entrée du tube digestif. C'est la langue qui en est le siége principal, mais les autres parties de la bouche peuvent aussi éprouver la sensation de certaines saveurs

La membrane muqueuse qui recouvre la langue de l'homme est abondamment fournie de vaisseaux sanguins, et présente, sur le dos de cet organe, un grand nombre d'éminences de formes variées qui rendent sa surface rugueuse. Ces éminences, nommées papilles, sont de diverses natures : les unes, lenticulaires et en petit nombre, consistent en autant d'amas de follicules muqueux; d'autres, fungiformes ou coniques et très-nombreuses, sont vasculaires ou nerveuses; ces dernières recouvrent les filets terminaux du nerf lingual et paraissent servir principalement au sens du goùt.

La langue, dont la masse pst formée par un grand nombre de muscles entre-croisés, reçoit les branches de plusieurs nerfs; les uns servent à y exciter les mouvements, les autres à conduire au cerveau les impressions des saveurs. Le nerf trifacial, ou nerf de la cincuieme paire, est celui qui remplit ces dernières fonctions. Il nail de l'extrémité supérieure de la moelle épinière ( $f(g .5 \%$ ), et, après sa sortie du crâne, se divise en trois branches principales, savoir: le nerf ophthalmique, qui se rend à l'appareil de la vue, etc., le nerf maxitlaire supérieur, qui se rlistribue à la màchoire supérietire et à la joue; ef le nerf maxillaire inférieur, dont l'un des principaux rameaux porto le nom de nerf lingual et se termine dans la membrane muqueuse de la langue.

21:. Si lon coupe ce nerf lingual sur un animal virant, on ne 
paralyse pas les mouvements de la langue, mais on rend cet organe insensible aux saveurs; et si on coupe le tronc du nerf trifacial dans l'intéricur du crâne, on détruit le sens du goùt non-seulement dans la langue, mais aussi dans toutes les autres parties de la bouche.

La section des nerfs hypoylosses ou nerfs de la onzième paire. qui se rendent également a la langue, ne prive pas l'animal de la faculté de sentir les saveurs, mais entraine la perte du mouvement dans la langue et les autres parties auxquelles ces nerfs se distribuent.

Il s'ensuit done que la branche linguale du nerf de la cinquième paire est le nerf spécial du sens du goùt. Mais les nerfs de la neuvième paire ou glosso-pharyngiens, qui se distribuent principalement autour de l'arrière-bouche et qui président à la sensibilité tactile de celte partie, paraissent ètre doués aussi d'une certaine sensibilité gustative.

$\$ 216$. La langue présente à peu près la mème structure chez les autres mammiferes; mais, chez les oiseaux, elle est en général cartilagineuse et dépourvue de papilles nerveuses : aussi le goùt est-il plus ou moins obtus chez ces animaux; chez les poissons, ce sens est aussi presque nul; et, chez les animaux inférieurs, il ne parait pas avoir son siéçe dans un organe particulier, mais s'exerrer par toutes les partics de louverture buccale.

\section{DU SENS DE L'ODORAT.}

$\$ 217$. Certains corps possèdent la propriété d'exciter en nous des sensations d'une nature particulière, et qui ne peuvent ètre perçues à l'aide des sens du toucher et du goùt, et qui dépendent de l'odeur qu'ils exhalent.

Les odeurs sont produites par des particules d'une ténuité extrème, qui s'échappent des corps odorants et qui se répandent dans l'atmosphère comme des vapeurs. Tous les corps volatils ou gazeux ne sont pas odorants; mais, en général, ceux qui ne peuvent se transformer facilement en vapeurs ne répandent que peu ou point d'odeur; et, dans la plupart des cas, on voit les substances odorantes le devenir d'autant plus que les circonstances où elles sont placées sont plus favorables a leur volatilisation. Du reste, la quantité de matière qui se répand ainsi dans l'air, pour produire les odeurs mème les plus furtes, est extrèmement petite Un morceau de musc, par exemple, peut parfumer liair de tout. un appartement pendant un temps considérable, sans changer notablement de poids. Une foule de corps, tels que l'eau, les vè- 
tements, etc. peuvent s'imbiber de ces vapeurs et devenir odorants à leur tour; mais d'autres substances, telles que le verre, s'oppusent complétement a leur passage. Nous pouvons sentir l'odeur de corps placés à une très-grande distance de nous; mais, pour que notre sens olfactif soit réveillé, il faut toujours que les particules odlorantes, émanées de ces corps, arrivent en contact avec l'organe destiné à les recevoir. Et, en cela, le mécanisme de l'odorat est analogue à celui du goùt et du toucher, tandis que, pour la vue et l'ouie, comme nous le verrons bientòt, il en est tout autrement.

\$218. L'air, disons-nous, est le véhicule ordinaire des odeur's; c'est ce fluide qui les transporte au loin, et qui les fait arriver jusqu'à nous. Il est donc érident que l'organe destiné à les sentir doit itre toujours placé de manière à en recevoir le contact : et en effet, c'est à l'entrée des voies respiratoires qu'il est placé, nonseulement chez l'homme, mais aussi chez tous les autres mammifères, chez les oiseaux et chez les reptiles.

Chez tous ces ètres le sens de l'odorat a son siége dans les fosses nasales, et ces cavités sont continuellement traversées par l'air, qui se renl aux poumons, pour subvenir aux besoins de la respiration.

219. Les fosses nasales, comme nous l'avons déjà dit, communiquent au dehors par les narines $(b)$ et s'ouvrent postérieurement dans l'arrière-bouche $(c)$ : elles sont séparées entre elles par une cloison verticale, qui est dirigée d'avant en arrière, et qui occupe la ligne médiane de la tète; leurs parois sont formées par divers os de la face et par les cartilages du 11ez, et leur élendue est très- $n$ considérable. Sur la paroi externe de chacune d'elles, on remarque chez l'homme trois

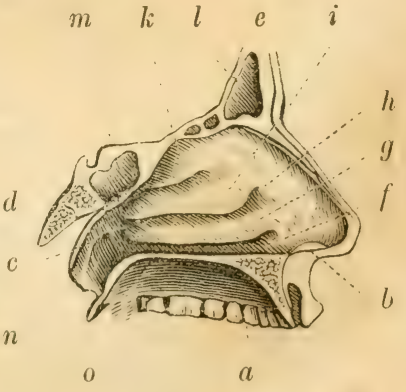

Fig. 59. Fosses nasales (1). lames saillantes, qui sont recourbées sur elles-mèmes, et qui sont appletes les cormets du nez $(y, i, k)$. Ces cornets augmentent la surface de cette faroi, et sont séparés entre eux far des gronttières

(1) Cette coupe verticale des fosses nasales représente la faroi cxterne de l'un de ces cavités : $-a$ bouche; $-d$ portion de la base du crâne; - e front; $m$ sinus sphénoidal; - $n$ ourerture de la trompe d'Eustache; - o voile du palais 
longitudinales, nommées méats $(f, h)$. Enfin ces fosses communiquent avec des cavités ou sinus plus ou moins vastes, qui sont creusés dans l'épaisseur de l'os du front (1), des os de la mâchoire supérieure, etc. La membrane muqueuse qui tapisse les fosses nasales s'appelle membrane pituitaire; elle est épaisse et se prolonge au delà des bords des cornets, de façon que l'air ne peut traverser les cavités olfactives que par des routes étroites et assez longues, et que le moindre gronflement de cette membrane rend le passage de ce fluide difficile ou mème impossible. La surface de la membrane pituitaire présente une foule de petites saillies, qui lui donnent un aspect relouté; on y remarque aussi un mouvement vibratile produit par des cils microscopiques, et analogue à celui dont nous avons déjà signalé l'existence dans d'autres parlies du corps (2); enfin, elle est continuellement lubrifiée par un liquide plus ou moins visqueux, appelé mucus nasal, qui parait se former en grande partie dans les sinus déjà mentionnés, et elle recoit un assez grand nombre de filets nerveux, dont les uns viennent des nerfs de la cinquième paire, et les autres du nerf olfactif ou de la première paire.

$\$ 220$. Le mécanisme de l'odorat est très-simple; il faut seulement que le mucus nasal s'imbibe des particules odorantes répandues dans l'air qui traverse les fosses nasales, et que ces particules soient ainsi arrèlées sur la partie de la membrane pituitaire qui recoit les filets du nerf olfactif.

D'après cela, on concoit facilement quelle est l'importance du mucus nasal pour l'exercice de l'odorat, et on comprend comment les changements dans la nature de ce liquide, qui surviennent pendant le coryza ou rhume de cerveau, peuvent faire perdre mo mentanément ce sens.

Le nerf olfactif est l'instrument destiné à porter au cerveau les impressions produites par les odeurs, et c'est à la partie supérieure des fosses nasales que les branches de ce nerf sont le plus nombreuses, que le mucus nasal est le plus abondant, et que les routes suivies par l'air sont le plus étroites; aussi, est-ce dans cette partie que les odeurs sont le plus aisément et le plus vivement senties. Il paraitrait mème que le principal usage du nez est de diriger vers la roùte des fosses nasales l'air inspiré.

(1) Le's sinus fronlunx $(l$, fi! $) .59 \mid$ n'existent pas dans l'enfance, mais se déreloppent arec l'âge et acquièrent des dimensions très-considérables : ce sont ces cavités qui contribuent le plus à faire avancer la partie inférieure du front audessus de la racine du nez.

(2) Voyez page 92. 
L'étendue de la membrane pituitaire est une des circonstances qui paraissent influer le plus sur l'activité de ce sens; à cet égard, l'homme est loin d'ètre le plus favorisé, et c'est chez les mammi-. fères carnivores, les ruminants et quelques pachydermes, que l'appareil olfactif atteint son plus haut degré de développement; chez ces derniers animaux les cornets du nez deviennent d'une complication extrème, et présentent, comme nous le verrons par la suite, une disposition très-remarquable. Chez les reptiles, au contraire, cet appareil est d'une grande simplicité.

$\$ 221$. Chez les animaux qui vivent dans l'eau, l'odorat s'exerce par l'intermédiaire de ce liquide, et l'organe qui est le siég̨e de ce sens n'offre pas la même structure que chez les animaux qui respirent dans l'air. Ainsi, chez les poissons, les fosses nasales ne communiquent pas avec l'arrière-bouche, mais sont des cavités terminées en cul-de-sac; et la membrane pituitaire, dont elles sont tapissées, présente une multitude de plis disposés comme des rayons autour d'un point central, ou rangés parallèlement comme des dents de peigne de chaque còté d'une bande médiane.

Enfin, il existe aussi beaucoup d'animaux qui possèdent un odorat mène très-fin, et chez lesquels on n'a encore découvert aucun organe spécialement affecté à cet usage : les insectes, les crustacés, les mollusques, etc., sont de ce nombre.

\section{DU SENS DE L'OUIE OU DE L'AUDITION.}

$\$ 22.2$. Structure de l appareil auditif. - L'audition est une fonction destince à nous faire connaìtre les sons produits par les corps vibrants.

L'appareil de l'ouïe est tres-compliqué; les diverses parties dont Il se compose sont, pour la plupart, d'une petitesse extrème; aussi n'occupe-t-il que peu d'espace et est-il renfermé presque en entier dans l'épaisseur d'une saillic ossense qui, de chaque còté de la tète, avance dans l'intérieur du crâne et constitue la partie de l'os temporal appelée, à cause de sa grande dureté, le rocher (fig. 60, e)

On y distingue chez l'homme trois portions, savoir : l'oreille externe, l'oreille moyenne et l'oreille interne.

L'vreille exterme se compose du pavillon de l'oreille et du conduit auriculaire.

Le pavillon de l'oreille (a) est une lame fibro-cartilagrineuse, souple ef élastique, qui est parfaitement libre dans la plus grande partie deson étendue, ef qui arlhere an bord du combluit anrien- 
laire. La pean qui le comre est mince, siche et bien tendue; sa surface se contourne de plusieurs manières et présente diverses éminences et enfoncements, dont le plus considérable est appelé conque auditive (d). Elle constitue une espice d'entonnoir très-

$(1)$

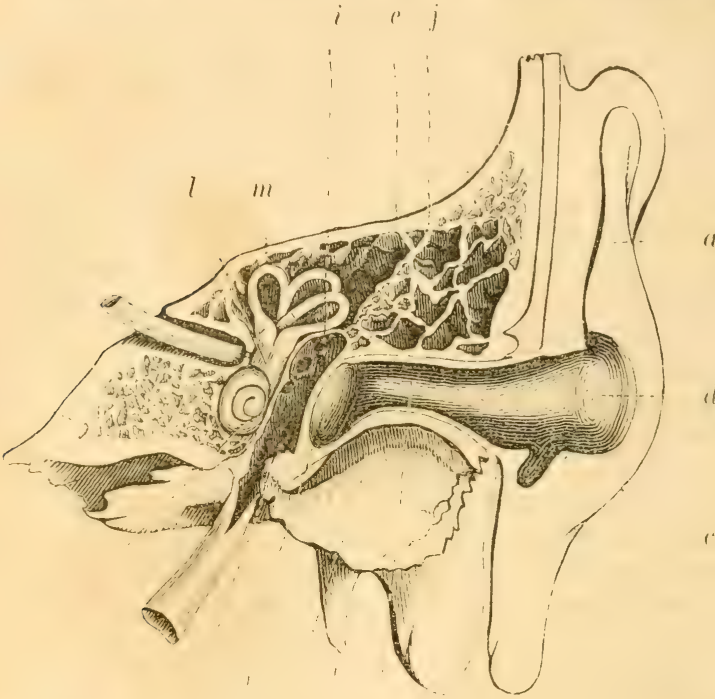

1

li ll g $\quad$ "

Fig. 60. Appareil andilif (1).

(1) Cette figure représente une coupe verticale de lappareil auditif, dont les partice intericures sont un peu grossies pour les faire mieux distinguer : - " pavillon de l'orcille; $-b$ lobule du pavillon; $-c$ petite éminence appeléc antitragus; - $d$ conque dont le fond se continue arec le conduit auriculaire $(f)$; $c e$ portion de l'os temporal, appelée rocher, dans laquelle est logé l'appareil auditif; $-e$ ' apophyse mastoïde de l'os temporal; $-e$ " portion de la fosse glénoïdale de l'os temporal dans laquelle s'articule la mâchoire inférieure; $e^{9 "}$ apophyse styloïde du temporal, servant à l'insertion des muscles et des ligaments de l'os hyoüde; - $e$ "' extrémité du canal, que traverse l'artère carotide interne pour pénétrer dans la cavité du crâne; $-f$ conduit auricnlaire; g tympan; - $\iota$ caisse dont on a retiré la chaine des osselets ; $-i$ ouvertures conduisant de la cavité de la caisse dans les cellules (j) dont le rocher est creusé : sur la paroi interne de la caisse on aperçit les deux ouvertures appelées fenêtres ovale et ronde; - $k$ trompe d'Eustache, conduisant de la caisse dans le haut du pharynx; $-l$ restibule; - $m$ canaúx semi-circulaires; $-n$ limaçon; $-o$ nerf acoustique. 
('vasé el se continue arec le conduit auriculaire (f) qui s'enfonce dans l'os temporal. (ot se recourbe en haut et en avant. La peau qui tapisse ce conduit se termine en cul-de-sac à son extrémité interne, et au-dessous d'elle on trouve un yrand nombre de petits follicules sébacés qui fournissent la matière janıne et amère connue sous le nom de cérumen.

Loreille moyenne se compose du tympan, de la caisse et des parties qui en dépendent.

La caisse $(f i g .60, h)$ est une cavité de forme irrégulière, qui est creusée dans la substance du rocher, et qui fait suite au conduit auriculaire, dont elle est séparée par une cloison membraneuse, bien tendue et très-élasti-que, nommée tympan $(g)$. Vis-à-vis l'ouverture dans laquelle le tympan est comme enchâssé (c'est-àdire à la partie interne de la caisse), se trouvent deux autres trous qui sont bouchés de la même manière par une membrane tendue; on les appelle, à raison cle leur forme, fenêtres ovale et ronde. A la paroi postérieure de la caisse, on voit une ouverture qui conduit dans des cellules creusées g d

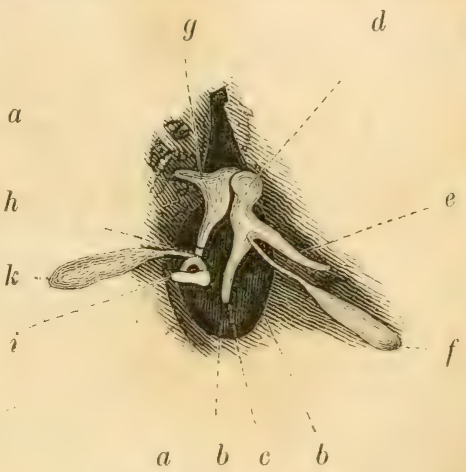

Fig. 61. Tympan et osselets $\{1\}$ dans la portion mastoüdienne de l'os temporal; et à sa paroi inférieure, on remarefne l'embouchure de la trompe d'Eustache (li, jig. 60), conduit longr et étroil qui vient aboutir à la partie postérieure des fosses nasales (fig. . $99 \mathrm{n}$ ), et qui ćtablit ainsi une communication entre l’intérieur de la caisse et l'air extérieur. Enfin ectle cavité est traverséc par une chaime de petits osselets (fig. 61),

(1) Cette fizure represente la paroi externe de lat caisse, le tympan, les osselets de l'onïc et leurs muscles, le tout grossi : - $a$ a cadre du tympan; $-l$ tympan ; - $r$ manche du marteau dont lextremité sappuir sur le milieu du tympan; d tête du martean sarticulant avee l'enclume; - e apophyse qui nait au-dessous du col du martean, et senfonee dans la scissure glénö̈dale de los temporal; son extremite domme attarke au muscle antérieur du marteau; $-f$ muscle interne du marteau; - ! conclume dont la branche horizontale s'appuie sur les parois de la caisse, ct dont la branche verticale s'articule arec l'os lenticulaire $(h)$; - i étrier. dont le sommet s'articule avec l'os lenticulaire, et dont la base s'appuie sur la membrane de la fenêtre orale; $-k$ muscle de l'étrier. 
qui s'étend depuis le tympan jusqu'à la membrane de la fenètre ovale et qui s'appuie, à l'aide d'une branche dirigée de còté (g), sur la paroi postérieure de la caisse.

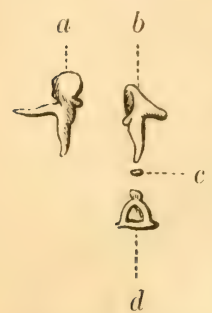

Frig. 6:2. Osselets de l'oreille.

Ces os sont au nombre de quatre et portent les noms de marteau (fig. $62 a$ ), d'enclume (b), d'os lenticulaire (c) et d'étrier (d). Lne petite tigge, qui peut ètre comparée à un manche, et qui appartient au marteau, appuie sur le tympan (c, fig. 61), et la base de l'étrier repose aussi sur la membrane de la fenètre ovale. Enfin des petits muscles $(f, k)$, fixés à ces osselets, leur impriment des mourements par suite desquels ils pressent plus ou moins fortement sur ces membranes, et augmentent ou diminuent, par conséquent, le degré de tension de chacune d'elles.

L'oreille interne, de mème que l'oreille moyenne, est renfermée tout entière dans le rocher. Elle se compose de plusieurs cavités qui communiquent toutes entre elles, et que l'on nomme le vestibule, les canaux semi-circulaires et le limaçon. Le vestibule (l, fig. 60) en occupe la partie moyenne et communique avec la caisse par la fenêtre ovale. Les canaux semi-circulaires (mi) s'élèvent de la face supérieure et postérieure du vestibule : ils sont au nombre de trois et ont la forme de tubes arrondis et renflés en forme d'ampoule à une de leurs extrémités. Enfin, le limacon $(n)$ est un organe très-singulier, qui est contourné en spirale, comme la coquille de l'animal dont il porte le nom; sa cavité est divisée en deux parties par une cloison longitudinale, moitié osseuse, moitié membranense; elle communique avec l'intérieur du vestibule, et n'est séparée de la caisse que par la membrane de la fenètre ronde. Cette dernière cavité est remplie d'air; l'oreille interne, au contraire, est remplie d'un liquide aqueux, et la membrane qui tapisse le vestibule, ainsi que les canaux semi-circulaires, n'est pas appliquée contre les parois osseuses de ces cavités, mais comme suspendue dans leur intérieur.

Le nerf de la huitième paire, qui nait de la moelle allongée, près d'une éminence appelée corps restiforme, et qui se sépare de l'encéphale entre le pédoncule du cervelet et la protubérance annulaire, pénètre dans le rocher par un canal osseux nommé conduit auditif interne, et vient se terminer dans l'intérieur des poches membraneuses du vestibule et des canaux semi-circulaires, ainsi que dans le limaçon. C'est de lui que dépend la sensibilité de l'organe auditif, et on le nomme, pour cette raison, nevf acouslique. 
§ 223. Mécanisme de l'audition. - Telles sont les parties principales de l'appareil auditif de l'homme et des animaux qui se rapprochent le plus de nous. Voyons maintenant quel est le ròle que chacune d'elles remplit dans l'exercice du sens de l'ouie.

L'audition, avons-nous dit, est destinée à nous faire sentir les sons. Le son résulte d'un mouvement vibratoire très-rapide qu'éprouvent les particules des corps sonores. Pour s'assurer de l'existence de ce mouvement, il suffit de répandre, sur une lame de verre ou sur la table d'un violon, du sable fin, et de faire produire à cetle lame ou à cet instrument un son quelconque : on verra aussitòt les grains de sable s'agiter et ètre lancés en l'air avec d'autant plus de force que le son sera plus intense. Les ondulations qu'éprouve le corps sonore se communiquent à l'air qui est en contact avec sa surface, comme elles se sont communiquées au sable dans l'expérience précédente; et c'est ainsi, de proche en proche, que les sons se propagentau loin. Or, pour que nous puissions les entendre, il faut que les mouvements vibratoires dont nous venons de parler arrivent jusqu'à l'oreille interne, et que, sous leur influence, le liquide qui baigne immédiatement le nerf acoustique entre luimème en vibration. Pour se rendre raison du mécanisme de l'audition, il faut donc suivre la marche de ces mouvements ondulatoires à travers les diverses parties de l'appareil auditif qui se trouvent interposées entre l'air extérieur et le nerf acoustique.

$\$ 224$. C'est d'abord sur le pavillon de l'oreille que viennent frapper les vibrations sonores de l'air. Dans les animaux où cette partie a la forme d'un cornet, elle sert à réfléchir les vibrations et à augmenter l'intensité du son qui arrive à son extrémité rétrécie, comme cela est facile à constater par l'expérience. Chacun sait que les personnes un peu sourdes entendent avec plus de facilité lorsqu'elles appliquent à leur oreille un cornet analogue; et si l'on élend sur le sommet ourert d'un còne en carton une membrane mince, recouverte de sable fin, on verra que les mouvements de cette poussière seront bien plus intenses lorsque le son arrivera à la membrane par le còté évasé de l'entonnoir que lorsqu'il viendra du còté opposé.

Chez lhomme, la conque de l'oreille et le conduit auriculaire remplissent les mimes fonctions; mais les autres parties du pavillon ne sont pas disposées de manière à pouvoir réfléchir ainsi les sons vers le tympan, et clles ne sont pas d'une tris-rande utilité; aussi la perte du pavillon tout entier n’affaiblit l'vuie que très-peu.

Les ribrations, excitées dans le pavillon de l'oreille ou dans les 
parties roisines de la tète par les ondes sonores qui les frappent, se communiquent anx parois du conduit auriculaire et de là aux parties plus profondes de l'apprareil de l'ouie; mais ces mouvements ne pervent ètre que tres-faibles, el c'est principalement par l'intermédiaire de l'air contenu dans ce conduit que les sons pénètrent dans l'intérieur de l'oreille : aussi, en bouchant ce tube avee du coton ou tout autre corps mou qui s'oppose à leur passage, on en rend la perception très-difficile.

$\$$ 22:). Le tympan sert principalement a faciliter la transmission des vihations sonores de l'air extérieur vers le nerf acouslique. En effet, les expériences d'un de nos physiciens les plus habiles, Savart, prouvent que les sons, en venant frapper sur line membrane mince et médiocrement tendue, y excitent tresaisément des vibrations. Si lon tend sur un cadre une feuille de papier, et que l'on en saupoudre la surface avec du sable, on voit relui-ci s'agiter virement et se rassembler de maniere à former des lignes virićes, aussitòt que l'on en approche un corps sonore en vibration. Si lon fait la mème expérience avec une planchette de bois ou une feuille de carton, on ne verra pas de mouvenent somblable, à moins d'employer un son extrèmement intense; malis, si l'on arlapte à ces derniers corps un disque membraneix semblable au tympan, on les verra ribrer facilement sous l'inlluence d'un son qui, auparavant, n'aurait produit sur eux aucun effet appréciable.

Il est donc érident que le tympan doit entrer aisément en vibration, lorsque les sons viennent le frapper, et que sa présence doit augmenter la facilité avec lacpuelle les autres parties de l'appareil auditif éprouvent des mouvements semblables.

$\$ 226$. Les vibrations se transmettent de la membrane du tympan aux osselets de l'oreille, aux parois de la caisse, et surtout ¿ l'air dont cette cavité est remplie : elles parviennent ainsi à la paroi postérieure de la caisse, et là il existe, comme nous l'avons vu, des membranes tendues sur des ouvertures conduisant dans l'oreille interne, a peu pres comme le tympan est tendu entre le conduit auriculaire ef la caisse. Or, ces membranes doivent agir de la mème maniere que celle-ci, c'est-ì-dire entrer facilement en ribration of transmettre ces mouvements aux parties voisines.

La face postéricure de ces cloisons membraneuses est en contact avec le liquide aqueux qui remplit l'oreille interne, et dans re liquide sont suspendues les poches membraneuses (1), qui, à leur

(1) On les appelle le vestibule membraneux et les tubes semi-circulatires, suirant 
tour, sont distendues par un autre liquide, dans lecpuel plongent les filets terminaux du nerf acoustique. Les ribrations que ces membranes exécutent doivent donc se transmettre à ce liquide, se communiquer ensuite au sac membraneux du vestibule, el arriver enfin au nerf sur lequel leur action produit l'impression dont résultera la sensation du son.

$\$ 227$. On voit, par ce qui précèle, que l'air contenu dans la caisse joue un ròle très-important dans le mécanisme de l'audition; or, si cette cavité ne communicquait pas avec l'extérieur, c'et air ne tarderait pas à ètre absorbé et à disparaître, et les vibrations du tympan ne se transmeltraient plus à l'oreille interne que par les parois osseuses de la caisse, et n'y arriveraient que tres-difficilement. Cela rous rend compte des usages de la trompe d'Eustache, et nous explique comment l'obstruction de ce conduit peut devenir une cause de surdité.

Le tympan est très-utile pour la transmission des sons, mais il n'est pas indispensable à l'audition; car, lorsque cette membrane est déchirée, les vibrations de l'air contenu dans le conduit auditif se communiquent sans interruption à l'air de la caisse et arrivent. ainsi aux membranes des fenètres orale et ronde.

$\$ 228$. Nous arons vu que la chaine d'osselets qui traverse la caisse et s'appuie sur le tympan et sur la membrane de la fenètre ovale, pouvait exécuter certains mouvements au moyen desquels la pression qu'elle exerce sur ces membranes augmente ou diminue. L'utilité de cette disposition est facile à comprendre : si l'on saupoudre de sable une membrane tendue sur un cadre, et qu'on en approche un corps sonore en vibration, on verra que, sans rien changer à l'intensité du son, on peut augmenter ou diminuer à volonté la force avec laquelle le sable est lancé en l'air, suivant qu'on diminue ou qu'on augrmente la tension de la membrane. Dans le premier cas, celle-ci exécutera, sous l'influence d'un son de mème intensité, des mouvemients vibratoires bien plus étendus que lorsqu'on viendra à la tendre davantage. On peut en conclure que la pression plus ou moins forte, exercée par le marteau sur le tympan, et par l'élrier sur la membrane de la fenctre ovale, a prour visagxe d'empecher ces membranes de vibrer trop fortement sous l'influence de sons tres-intenses, sans les priver pour cela de la faculte de vibrer lorspu'un son faible vient les frapper. La pression exercée sur la membrane de la fenètre ovale se communique ausis a la

qu'elles occupent le vestibule ou les eanaux semi-circulaires; dans le limaçon il n'y a rien de semblable, ot le liquide dont celui ri est rempli est le méme qui baigne le vestibule membraneux. 
membrane de la fenètre ronde, par l'intermédiaire du liquicle dont l'oreille interne est remplie; et il en résulte que, dans les circonstances ordinaires, les osselets de l'ouie, en appuyant sur les deux membranes auxquelles ils sont fixés, empèchent les vibrations sonores qui arrivent au nerf acoustique d'ètre assez intenses pour endommager cet organe délicat.

La perte du marteau, de l'enclume et de l'os lenticulaire affaiblit l'ouie, mais ne la détruit pas; celle de l'ótrier est, au contraire, suivie de la surdité, car cet os adhérant à la membrane de la fenètre ovale, sa chute détermine la déchirure de cette cloison. et alors le liquide contenu dans le vestibule se perd, et le nerf acoustique ne peut plus remplir ses fonctions.

$\$ 229$. Nous voyons donc que toutes les parties qui composent l'oreille externe et l'oreille moyenne servent à perfectionner l'audition, sans cependant ètre absolument nécessaires à l'exercice de ce sens; aussi disparaissent-clles peu à peu à mesure que l'on s'éloigne de l'homme, et que l'on étudie la structure de l'oreille chez. les animaux de moins en moins élevés dans la série des ètres. Chez les oiseaux, il n'y a plus de pavillon de l'oreille; chez les reptiles, le conduit auditif externe manque aussi ; le tympan devient externe, et la structure de la caisse se simplifie; enfin, chez la plupart des poissons, il n'y a plus de vestige, ni d'oreille externe, ni d'oreille moyenne, ot l'appareil de l'ouie ne se compose que d'un vestibule membraneux surmonté de trois canaux semi-circulaires, garni en dessous d'un petit sac qui parait représenter le limaçon, et suspendu dans la partie latérale de la grande cavité crânienne.

Chez les animaux placés encore plus bas dans la série des ètres, il en est de mème pour le limaçon, et les canaux semi-circulaires, parties dont nous ne connaissons pas bien les usages (1); mais le vestibule membraneux est un organar qui ne manque jamais : partout où existe un appareil auditif, on trouve un petit sac membraneux rempli de liquide, dans lequel vient se terminer le nerf acoustique, et ce vestibule est un instrument indispensable pour l'exercice du sens de l'ouïe. Mais, chez la plupart des mollusques et des insectes, on ne trouve plus aucun vestige d'un instrument spécial pour l'ouie, bien que ces animaux ne paraissent pas ètre insensibles aux sons. Enfin, chez les zoophyles et plusieurs autres animaux des plus inférieurs, ce sens lui-mème parait manquer complétement:

(1) D'après les expériences de M. Flourens, il paraîtrait que la destruction des canaux semi-circulaires ne détruit pas l'ouic, mais la rend confuse et douloureuse. 


\section{DU SEXS DE LA VUE.}

$\$$ 230. La vue est une faculté qui nous rend sensibles à l'action de la lumière, et qui nous fait comnaitre, par l'intermédiairc de ret agent, la forme des corps, leur couleur, leur grandeur et leur position.

L'appareil chargé de cette fonction se compose, chez l'homme et les animaux les plus voisins de nous, du nerf de la deuxième paire, de l'œil, et de diverses parties destinées à protéger cet organe ou à le mouvoir.

$\$ 231$. Structure de l'œil. - Le globe de l'oxil, dont nous nous occuperous d'abord, est une sphère creuse, un peu renflée en avant et remplie d'humeurs plus ou moins fluides. Son enveloppe extéricure se compose de deux parties bien distinctes : l'une blanche, opaque et fibreuse, nommée sclérotique $(s)$; lautre transparente, et semblable à une lame de corne, qu'on appelle, pour celte raison, la cornée (ci. Celle-ci occupe le devant de l'œil, et se trouve comme enchâssée dans une ouverture circulaire de la sclérotique. Sa surface externe est ch $s \quad s \quad c r$

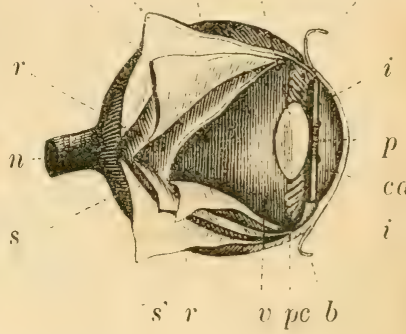

Fig 63. Globe de l'cil ouverl (1). plus bombée que celle de cette derniere membrane, et elle ressemble à un verre de montre qui serait appliqué sur une sphère creuse, et qui ferait saillie à sa surface,

A une petite distance derrière la cornce, on trouve, dans l'intérieur de l'oeil, une cloison membraneuse (i), qui est tendue transversalement et fixio au bord antérieur de la sclérotique, tout aulour de la cornée. Cette espeece de diaphrag̣me, qui est coloré diversement, suivant les individus, est appelé iris, et présente dans son milieu une onverture circulaire nommée pupille $(p)$. On distingue

(1) Intérieur de l'œil : $-c$ cornée transparente; $-s$ sclérotique; $-s$ ' portion de la sclérotique renversée en dehors pour montrer les membranes situées dessous; - ch choroïde; $-r$ rétine; $-n$ nerf optique; $-c a$ chambre antérieure de l'œil placte entre la cornée et liris, et remplie par l'humeur aquense; - i iris; $p$ pupille; - or cristallin, placé derrière la pupille; - pe procés ciliaires; $v$ humeur vitréc; $-l$, b portion de la conjonetive qui, apres avoir recourert la partic antérieure de l'ceil, s'en détache pour tapisser les paupiéres. 
daus le tissu de cet organe des fibres musculaires qui se dirigent, en rayonnant, du bord de la pupille vers la sclérotique, et d'autres fibres de mème nature qui sont circulaires et qui entourent cette ouverture comme un anneau. Lorsque les premières se contractent, la pupille se dilate; et lorsque les dernieres viennent à agir, elle se resserre.

L'espace compris entre la cornée et l'iris constitue la chambre antérieure de l'œil 'ca, fiy. 63) : elle communique par l'ouverture de la pupille avec la chambre postéricure, cavité située derriere liris, et elle est remplie, de mime que cette derniere chambre. par l'humeur aqueuse, liquide parfailement transparent et composé d'eau tenant en dissolution un peu d'alloumine et une petite quantité des sels qu'on rencontre dans toutes les sécrétions de l'é. conomie animale. On croit cette liuneur formce par une membrane qui se trouve derriere lïris, et qui présente un srand nombre de plis rayonnants, nommés procis ciliuires $p c)$.

Presque immédiatement derriere la pupille se troure une lentille transparente, nommée cristallin ( $\mathrm{cr}$ : elle est lorée dans une poche membraneuse et diaphane (la capsule du rrislallii), et parait ditre le produit diune sécrétion opérée par elle; car, lorsquion la retire de l'œil d'un animal vivant, sans détruire sa capsule. on voit bientèt un nouveau cristallin remplacer lancien. On remarque aussi que ce corps se compose diun grand nombre de couches concentiques, dont la dureté va en croissant depuis la circonférence justju au centre, ce qui s'accorde tres-bien arec ce que nons renons de dire sur son mode de formation. Enfin, chacune de ces conches se compose à son tour de fibres flont les bords paraissent s'engrener entre eux, et dont la disposition est tres-remarquable.

Il est egalement essentiel de noter que la face postérieure du cristallin est beaucoup plus convexe que l'antérieure.

Derriere le cristallin, on trouve une masse gélatinerise et diaphane tres-rolumineuse, qui ressemble à du blanc d'ouf, ot qui est enveloppée par une membrane d'une ténuité extrime. dont un qrand nombre de lamelles so portent en derlans, de facon à former des cloisons ou des cellules. Celte membrane est nommée hyalvïde, et l'humeur qui s'y trouve humeur vitrée (v).

Partout, excepté en arant, ou se trourent le cristallin e! l'iris, l'humeur ritrée est entourée par une membrane molle et blanchàtre, nommée reline $r$, qui n'est séparée de la sclérotique que par une autre membrane, également mince, quon appelle chorvö̀le (ch) Celte derniere es forncie principalement par un lacis de

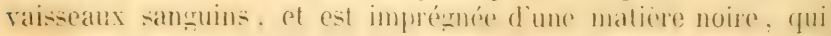


donne au fond de l'œil la couleur foncée quon voit à travers la pupille, et qui manque chez les personnes et chez les animaux appelés albinos.

Le globe de l'œil recoit plusieurs nerfs : le plus remarquable par sa grosseur et par ses fonctions est le nerf optique (o), qui traverse la partie postérieure de la sclérotique et se continue avec la rétine. Cette membrane parait mème n'ètre qu'un épanouissement du nerf optique, dont les fibres élémentaires vont former à sa surface antérieure une multitude de papilles cylindriques serrées les unes contre les autres, et offrant, sous le microscope, l'aspect d'une mosaïque. Les autres nerfs du globe de l'œil sont excessivement grrèles: on les nomme nerfs ciliaires; ils naissent d'un petit gangrlion formé par la réunion de quelques branches des nerfs des Iroisieme et cinquième paires, et ront se distribuer à l'iris et aux parties voisines de l'intérieur lu globe de l'œil (fig. 5:) :

S232. Mécanisme de la vision. - C'est par l'intermédiaire de la lumiere, avons-nous dit, que les corps placés à l'entour de nous agrissent sur notre vue. Ceux yui émettent de la lumiere, le soleil et les corps en ignition, par exemple, sont visibles par eux-mèmes; mais les autres ne le deviennent que lorsque la lumiere qui les frappe est réfléchie par eux, de façon à arriver jusqu“ à nous.

Cet agent se meut avec une vitesse extreme : il ne peut agir sur nos sens qu'autant (qu’il vient frapper sur la réline, située au fond de notre œil; les corps opaques le rélléchissent ou l'absorbent; mais les corps transparents, tels que l'air atmosphérique et l'eau, Iui livrent un passage facile (1).

On voit donc yue la première condition pour l'exercice de la vision est l'absence de tout corps opaque entre les objets extéricurs et le fond de notre ouil : aussi la cornée qui recourre la partie anféricure de cet or:ane, comme un verre de montre, est-elle complétement tiansfarente, of la lumiere qui la traverse, et qui passe par l'ouverture de la pupille, arrive-t-elle facilement sur la rétime; car clle ne rencontre sur la route que le cristallin, qui est diaphane, et des humeurs qui le sont éralement.

Mais, dans (furelyues maladies, il en est autrement, et eette perte de transparence entraine toujours la cécité; dans l'affection connue sous lo nom de calaracle, par exemple, le cristallin devient opanure, ot s'oppose ainsi au passage de la lumiere; et lorsque des taches bianches ou taies se forment sur la cornée, cette membrane devient

(1) La lumiere quai frappe $u n$ corps transparent ne le traverse pas en entior une portion plus on moins comsiderable en est reflechice, et ceest à raison de cette propriété que ces corps remplissent, plus ou moins bien, loffice de miruirs. 
une espèce d'écran qui empèche les rayons lumineux de pénétrer dans l'œil, et qui rend la vision impossible.

Les parties diaphanes du globe de l'œil ne servent pas seulement à livrer passage à la lumière. Leur principal usage est de changer la direction des rayons qui pénètrent dans cet organe, de façon à les rassembler sur un point quelconque de la rétine; en effet, l'intérieur de l'œil ressemble assez exactement à l'instrument d'optique connu sous le nom de chamlre noire, et l'image des objets que nous voyons se peint sur la rétine comme sur l'éran placé derrière cet instrument (1).

$\$$ 233. Lorsqu'un faisceau de rayons lumineux tombe sur la cornée, une partie de ceux-ci est réfléchie par elle, tandis que le reste la traverse: c'est la lumière ainsi réfléchie par la cornée qui donne aux yeux leur brillant et qui fait qu'on peut s'y mirer. Les

(I) Pour faire comprendre cette partie de l'étude de la vision, il est indispen sable de rappeler quelques principes de physique.

La lumière marche ordinairement en suivant une ligne droite, et les différents rayons qui partent d'un point quelconque sécartent entre eux de plus en plus, à mesure quils avancent dans l'espace. Lorsque ces rayons tombent perpendiculairement sur la surface d'un corps transparent, ils traversent celui-ci sans changer de direction; mais lorsqu'ils viennent le frapper obliquement, ils sont toujours plus ou moins dériés de leur direction primitive. Si le corps dans lequel ils pénètrent est plus dense que celui dont ils sortent, s'ils passent de l'air dans de l'eau ou dans du verre, par exemple, ils forment alors un coude et se rapprochent de la perpendiculaire au point d'immersion; si, au contraire, ils passent d'un milieu plus dense dans un milieu plus rare, ils s'écartent de cette perpendiculaire, et ces dériations sont dautant plus grandes que le rayon frappe la surface du corps transparent plus obliquement.

Ce phénomène, qui est connu sous le nom de réfraction de la lumière, est facile à constater; c'est à cause de ce changement dans la direction des rayons lumi-

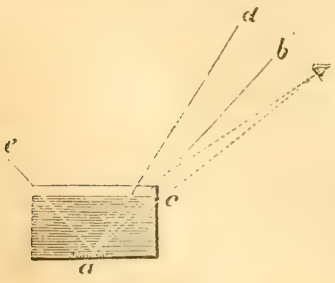

Fig. 61. neux, lors de leur passage de l'eau dans l'air, qu'un bâton droit, plongé à moitié dans ce liquide, paraît toujours comme s'il était coudé au point d'immersion; et si l'on place une piece de monnaie $(a)$ au fond d'un vase vide, de façon à ce que le bord de celui-ci s'élève juste assez haut pour empêcher l'œil de l'observateur d'apercevoir cet objet, il suffira, pour le rendre visible, de remplir le vase avec de l'eau $(c)$, car alors les rayons de lumière qui partent de la pièce, au lieu de marcher toujours en ligne droite, seront réfractés lors de leur passage de l'eau dans l'air, et s'éloigneront de la perpendiculaire : or, en changeant ainsi de direction, les rayons ( $l$ ou $U$ ), qui, auparavant, passaient au-dessus de l'œil de l'observateur, viennent le frapper.

Les rayons lumineux, avons-nous dit, se rapprochent de la perpendiculaire au point de contact, toutes les fois qu'ils pénètrent obliquement dans un corps plus dense que celui dont ils sortent. Il en résulte que la forme de ces corps influe beau- 
rayons qui pénètrent dans cette lame transparente passent dans un corps beaucoup plus dense yue l'air : ils sont, par conséquent, réfractés et rapprochés de la perpendiculaire ou de l'ase du faisceau avec d'autant plus de force que la surface de la cornée sera plus convexe; car p! us cette membrane sera bombée, plus les rayons divergents qui viennent la frapper formeront, avec sa surface, un angle aigu.

$\mathrm{Si}$, après avoir traversé la cornée, les rayons lumineux rencontraient de l'air, ils se réfracteraient avec autant de force que lors de leur entrée dans cette membrane, mais en sens contraire; ils reprendraient, par conséquent, leur direction primitive. Mais l'humeur aqueuse qui remplit la chambre antérieure de l'œil a un pouvoir réfringent beaucoup plus considérable que l'air, de façon qu'en y entrant les rayons s'écartent moins entre cux quils ne s'étaient

coup sur la nuarche de la lumière qui les traverse; suivant que leur surface est convexe ou concave, les rayons seront rapprochés ou écartés entre eux.

Quelques exemples rendront cette proposition facile à comprendre. Supposons yue trois rayons divergents, partis du point $a$, traversent l'air et viennent tomber

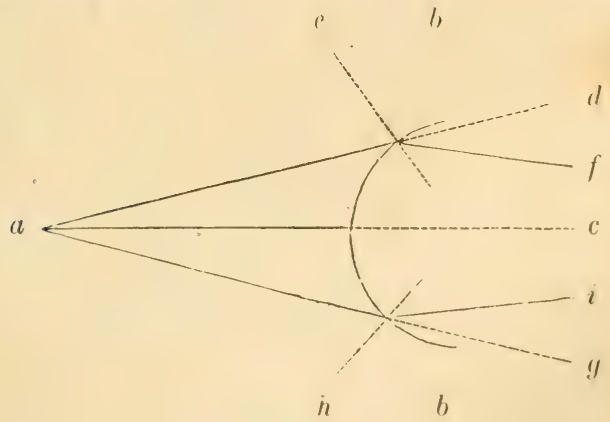

Fig. 65 .

sur une lentille, dont la surface est convexe, comme la ligne $b \quad b(f i g .65)$. Le rayon a $c$ frappera perpendiculairement cette surface, et par conséquent trarer-. sera la lentille, sans éprouver de deviation; mais le rayon $a d$, tombant obliquement sur cette surface, serat réfracté et rapproche de la perpendiculaire tirée au point dimmersion : or, ectte perpendiculate aura la direction de la ligne ponctuee $e$, et, en s'en rapprochant, le rayon lumineux, au lieu de poursuivre sa route: vers le point $d$, suiva la lisne, f. Il en sera de même pour le rayon $a$ g, qui, c'n continuaist sal marche, se rapprochera de la perpendieulaire $h$, et se dirigerat vers le point $i$, au lien de con'inuer à se porter en digne droite vers le point $g$. Le's au tres rayons qui viendraient frapper la lentille seraient réfractés d'ume maniere. analogue, et par consenuent, au lieu de continuer a s'érarter entre cux, ils se raf' 
rapprochés lors de leur passage de l'air dans la cornée; l'acion de ces parties rend, par conséquent, ces rayons moins divergents qu'arant leur entrée dans l'ceil, et fait qu'une quantité plus considérable de lumière arrive dans l'ouverture de la pupille.

Une grande partie de la lumière qui parvient au fond de la chambre antérieure de l'œil rencontre l'iris et est absorbée ou réfléchie au dehors par ce corps; celle qui tombe sur la pupille pénètre seule vers le fond de l'œil, et la quantité en est rl'autant plus considérable, que cette ouverture est plus large. Aussi, lorsque la lumière qui arrive à l'ocil est tris-faible, la pupille se dilate-t-elle, landis qu'olle se resserre sous l'influence d'une lumière vive: l Iris, comme on le voit, est le régulateur de la quantité de lumière qui

procheront et pourront même se rémir tous dans un même point, que l'on appelle le foyer de la lentille.

Si la surface du cristal, au lieu d'être convexe, est coneare, les rayons lumineux ne se rapprocheront pas de l'axe du faisceau, comme dans le, cas précédent, mais an contraire divergeront davantage. Le rayon $a d(f i g .66)$, par exemple, devra se ratpprocher de la perpendiculaire au point de contact, latulelle aura la direction de la ligne ponctuée $e$, et, en se deviant ainsi, ce rayon prendra la direction de la ligne $f$. Le rayon " $g$ sera également rapproché de la perpendicu. laire $h$, de façon à prendre la direction de la ligne $i$.

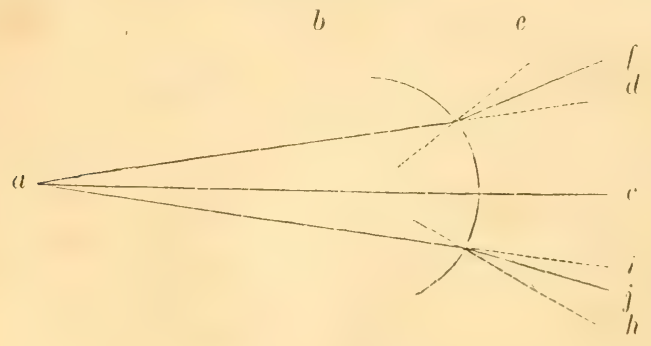

b)

Fig. c6.

La déviation que les rayous lumineux éprouvent, en traversant de la sorte des lentilles convexes ou concaves, est d'autant plus forte, que la courbure de la surface de ces corps est plus grande : et la simple inspection des figures dont nous venons de nous servir suffira pour faire comprendre qu'il doit en être ainsi ; car plus la courbure de la surface sur laquelle les rayons divergents riennent frapper sera grande, plus les perpendiculaires au point d'immersion s'éloigneront de la direction de ces mêmes rayons.

La physique nous apprend aussi que les corps transparents réfractent la lumière arec d'autant plus de force qu'ils sont plus denses fr'est-a-dire que, sous un même volume, ils ont un poids plus considérable) et quils sont formés de matières plus combustibles. 
cloit parvenir jusqu’a la rétine, et il est a noter que c'est chez les animaux destinés à poursuirre leur proie apres le coucher du soleil que la pupille est le plus dilatable.

Les rarons de lumiere qui ont traversé la pupille tombent sur le cristallin, espece de lentille diaphane, qui change de nouveau leur direction et qui les fait tous converger vors un point nommé foyer, où ils se réunissent. Or, ce foyer se trouve précisément sur la surface de la rétine; et c’est ainsi que les rayons lumineux, rmvoyés à l'ail de divers points d'un corps placé à distance, sont rassemblés sur cette membrane nerreuse, de façon à y peindre en petit l'image de l'objet dont ils proviennent.

$\$ 34$. Il est aisé de s’assurer, par l'expérience, que les images se forment ainsi au fond de l'aeil : il suffit de prendre un oeil de lapin ou de jigreon, dont la sclérotique est a peu près transparente, ou, micus encore, des yeux d'animaux albinos, et de placer devant la cornée un objet fortement éclairé, une bougie allumée, par exemple, pour voir distinctement l'image de celui-ci se peindre sur la réline..

Les images qui se forment de la sorte sont toujours renversées, ot la cause de ce phénomène est facile à trourer. En cffet, si l'on observe la marche que les rayons lumineux, partant des deux extrémités d'un objet $(a, c, f i g .67)$, doivent suivre pour parvenir à la rétine, on voit qu'ils doivent toujours se croiser

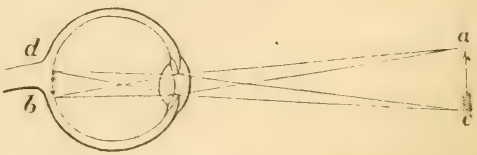

Fig. 67. avant que d'y arriver, et que, par conséquent, celui qui viendra de l'extrémité supérieure de l'objet $(a)$ se trourera à lat partie inférieure de l'espace occupé sur la réline par le faisceau entier de rayons formant l'image (b), tandis que celui venant de l'extrémité inférieure de l'objet $(c)$ occupera le haut du mème espace $(d)$ : il en sera de mème pour tous les autres rayons, et il en résulterat qu'au fond de l'œil l'objet paraittra renversé.

$\$ 23 \%$. Lat matiere noire qui est silués derriere la rétine et qui tapisse tout le fond de l aril ainsi que la face postérieure de l'iris, sert a absurber la lumiere imméliatement apres quelle a traversé la rétine; si celte lumiere élat rélléchie vers d'autres points de cette membrane, elle trotblerait considérablement la vue et empecherail la formation d’images bien netles an fond de l'(eil. Aussi, chez les hommes ef les animaux albinos ou ce przment manque, la vision estefle extrimement imparfaite. Pendant lo jour, ils voient at peime 
de manière à pouvoir se conduire, et c'est pendant le crépuscule ou mème pendant la nuit que leur vue devient distincte.

$\$ 236$. Le globe de l'œil sert, comme on le voit, à conduire la lumière et.à la concentrer sur la rétine; il remplit l'office d'une espèce de lunette; mais c'est un instrument d'optique plus parfait qu'aucun de cenx que les physiciens sont encore parrenus à construire; car, en mème temps qu'il est en général achromatique et qu'il ne présente point d'aberration de sphéricité (1), sa portée peut varier considérablement.

En effet, l'homme peut, en général, voir d'une manière tout aussi nette des objets placés à quelques pouces de l'œil ou à une distanee. mème très-considérable de cet organe. Dans nos instruments d'op.tique, au contraire, l'image qui se forme au foyer d'une lentille avance ou recule, suivant la distance à laquelle se trouve l'objet: on a donc supposé que, pour donner à notre vue des portées si différentes, le cristallin devait se rapprocher ou s'éloigner de la

(1) La lumière blanche est formée par la réunion de plusieurs rayons élémertaires diversement colorés, qui, étant séparés, donnent naissance au spectre solaire, et ces rayons ne sont pas également réfrangibles. Il en résulte que, lorsqu'on fait passer la lumière blanche à travers un corps qui la réfracte, clle est plus on moins complétement décomposée, et les objets qui la projettent paraissent avoir les couleurs du spectre sulaire; mais, si le corps qui réfracte la lumière se compose de plusieurs couches donées de forces réfringentes différentes, il est possible que les rayons élémentaires, qui ont été trop fortement écartés de leur route par l'une de ces couches, ne le soient pas assez par une antre, et que, ces différences se compensant, il n'y ait, en dernier résultat, atucune décomposition semblable dans la lumière réfractée, et, par conséquent, aucune production de couleurs.

On appelle achromatisme cette propriété de dévier la lumière de sa marche, sans y dérelopper des couleurs, et, par conséquent, les l'ntilles achromatiques sont celles qui forment en leurs foyers des images incolores vu n'ayant que les couleurs de l'objet représenté. On obtient des lunettes achromatiques en combinant différents rerres, dont les uns corrigent la dispersion de la lumière produite par les autres, de façon à réunir tous les rayons en un même foyer. Il est probable que l'achromatisme de l'œil dépend de quelque disposition analogue; mais les physiciens ne sont pas daccord sur l'explication de ce phénomène : les uns pensent qu'il dépend de la diversité des humeurs de cet organe; d’autres l'attribuent aux différences de densité qui existent dans les différentes couches du cristallin.

L'aberration de sphéricilé consiste dans la réunion des rayons qui tombent sur différentes parties d'une lentille à des foyers sensiblement différents, d'où résulte un défaut de netteté dans les images; lorsque les lentilles sont très-convexes, les rayons qui passent près des bords ne se réunissent pas au même foyer que ceux qui traversent la partie centrale de l'instrument, et, pour obtenir des images nettes, on est obligé dintercepter le passige des premiers, en plaçant au-devant de la lentille un diaphragme percé d'un trou. Or, les images qui se forment derrière le cristallin de l'wil ne sont jamais diffuses, et on attribue cette absence d'aberration de sphéricité à l'iris, qui remplit la fonction des diaphragmes placés dans lintérieur des lumettes. 
rétine, suivant les besoins, ou bien que la forme du globe de l'veil devait changer. Mais l'observation directe ne confirme pas ces hypothèses, et jusqu'ici cette particularité n'a pas pu trouver d'explication satisfaisante. Il est seulement à noter que c'est sous l'influence de la volonté que s'opère le chanı̌ement qui survient dans l'œil, lorsque cet organe se dispose pour la vision distincte à telle ou telle distance, quelle que soit, du reste, la nature de ce changement.

Mais l'œil ne posside pas toujours, au mème degré, cette faculté précieuse : quelquefois on ne peut roir distinctement qu'à la distance de plusieurs pieds; plus près toutes les images sont confuses; et d'autres fois, au contraire, la vue ne devient nette que lorsque les objets sont approchés de l'œil à une distance de quelques pouces, et tout ce qui se trouve au delà paraìl comme enveloppé d'un nuage.

La première de ces infirmités, connue sous le nom de presbytisme, dépend d'un léfaut de convergence dans les faisceaux lumineux qui traversent les humeurs de l'œil. Les rayons qui arrivent à cet organe, d'un objet très-éloigné, divergent très-peu et peuvent ètre rassemblés au point où se trouve la rótine, bien que la force réfringente de l'œil ne soit pas considérable; mais ceux qui viennent d'un objet très-rapproché divergent beaucoup, et la force réfringente de l'oeil se trouve trop faible pour les rapprocher de façon à les réunir sur un point déterminé de la rétine. Aussi les presbytes ont-ils ordinairement la pupille contractée, comme s'ils faisaient un effort continuel pour ne laisser entrer dans leur oeil que les rayons qui tombent sur le centre du cristallin, et qui n’ont pas besoin d'ètre beaucoup déviés de leur route, pour se rassembler derrière le cristallin au point occupé par la rétine.

Ce défaut de pouvoir réfringent daus l'weil parait tenir, en général, a un aplatissement de la cornée ou du cristallin, circonstances qui effectivement doivent tendre à produire le presbytisme, el qui se montrent presque tolijours chez les vieillards.

La myopic résulte d'un effet contraire : les rayons qui traversent l'oeil sont alors déviés de leur route arec tant de force, qu'à moins d'ètre très-divergnents, ils se croisent avant que d'arriver sur la rétine. Cette imperfection de l'organe visuel dépend, en général. d'une trop srande convexité de la cornée ou mème du cristallin; mais elle peut ètre une suite de l'habitude que l'oeil prend de s’adapter à la vision à courte distance, et c'est de la sorte que, par l'usage de verres grossissants, il est possible de se rendre myope à volonté, stratagreme auquel on a vu de jeunes conscrits avoir recours pour se faire exempter du service militaire. 
On remarque que les personnes qui ont la vue trop courte deviennent moins myopes par les progrès de l'àge; et cela se comprend facilement, parce que la sécrétion des humeurs de l'xil devient toujours moins abondante pendant la vieillesse : or, celto diminution, qui tend à rendre la cornée moins convexe, rend lat vue plus longue; dans la plupart des cas elle détermine le presbytisme, mais ici elle ne fait d'abord que corriger les défauts de l'œeil et donner à la vue sa portée ordinaire. Il en résulte qu'en général la rue des myopes s'améliore à l'âge oì celle de la plupart des personnes s'affaiblit; mais, comme celte diminution dans labondance des humeurs de l'œeil continue toujours, il arrive un moment où l'œil du myope devient aussi trop peu réfringent, et sa vue, par conséquent, trop longue.

Pour corriger ces défauts naturels de l'œil, on a recours à des moyens dont l'efficacite vient confirmer l'explication que nous venons de donner de la cause, soit de la myopie, soit du presbytisme. On place devant les yeux des verres dont les surfaces sont disposées de façon à augrmenter ou à diminuer la diver rence des rayons qui les traversent. Les myopes se servent de verres concaves qui tendent à disperser la lumière, et les presbytes emploient des verres convexes qui tendent, au contraire, à rapprocher les rayons divergents de l'axe du faisceau.

$\$ 237$. C'est le contact de la lumière sur la rétine, avons-nous dit. qui détermine la vision; et, effectivement, lorsque cette membrane est frappée de paralysie (état qui constitue la maladie connue sous le nom de goutte sereine), ce sens est complétement détruit. Mais la sensibilité de la rétine est tout à fait spéciale : cette membrane nervense ne jouit que peu ou point de la sensibilité tactile, et on peut la toucher ou mème la pincer et la déchirer sur un animal vivant, sans que celui-ci manifeste aucun signe de douleur.

Tous les points de la rétine sont aptes à recevoir l'impression de la lumiere; mais la partie centrale de cette membrane jouit d'une sensibilité bien plus exquise que tout le reste, et c'est seulement lorsque les images des corps extérieurs se forment dans celte partie, que nous les royons bien distinctement : aussi, lorsque nous regardons un objet quelconque, avons-nous le soin de diriger sur lui l'axe de nos yeux.

Du reste, cette sensibilité particulière de la rétine a des bornes : une lumiere trop faible est sans action sur cette membrane, et une lumière trop forte la blesse ef la met hors d'état d'agir. Mais à cet igari, l'influence de l'habitude est extrème: lorsqu'on est resté 
long-temps dans l'obscurité, une lumière, mème très-faible, éblouit les yeux, et rend, pendant quelques instants, la rétine incapable de remplir ses fonctions, tandis que les personnes accoutumées a la lumière du jour n éprouvent ces mèmes effets qu'en regardant les objets les plus éclatauts, en cherchant, par exemple, à fixer le soleil.

Lorsqu'on regarde pendant long-temps le mème objet, sans changer de position, le point de la rétine qui en recoit l'image ne tarde pas à se fatiguer, et celte fatigue, portée au delà d'une certaine limite, prive, pendant quelque temps, la partie qui l'éproure de sa sensibilité ordinaire. Ainsi, lorsque nous regardons pendant quelque temps une tache blanche située sur un fond noir, et qu'ensuite nous transportons notre vue sur un fond blanc, nous crorons y voir une tache noire, parce que le point de la rétine, précridemment fatigué par la lumière blanche, y est devenu insensible.

La fatigue qu'éproure la rétine par l'exercice de ses fonctions dépend aussi en partie des efforts que l'on fait pour regarder les objets placés sous les yeux. Si l'on cherche à voir avec attention des corps très-faiblement éclairés, on éprouve bientòt un sentiment douloureux dans l'orbite et mème dans la tète.

Il est aussi à noter que l'impression produite sur la réline par le contact de la lumiere dure pendant un certain temps après que ce contact a cessé ; aussi, lorsque des ima:-es différentes viennent se peindre successivement sur le mème point de celte membrane, avec assez de rapidité pour que l'impression de l'une ne soit pas encore éteinte avant que celle de lautre commence, ces images se confondent, ot la sensation qui en résulte ne differe pas de celle qui dépendrait d'une seule et mène imagre. C'est pour cette raison que, lorsqu'un corps décrit un cercle avec beaucoup de rapidité, on croit voir un anneau, et qu'une rone qui tourne avec ritesse ne parait plus avoir de rayons séparés par des intervalles rides, mais ressemble à un disque.

$\$ 238$. Le nerf optioue, qui, en s'épanouissant au fond de l'œil, forme la rétine, transmet au cerveau les impressions produites sur cette membrane par le contact de la lumiere : aussi sa section produit-elle immédialdment une cécité complete.

Ce sont les hémisphères du cerveau qui paraissent ètre le siege de la perception de ces sensations, comme de toutes les autres: car, lorsfuion les détruit, l'animal devient aussitot areugre. Mais. il est d'autres pa:ties de l'encéphale qui exereent aussi la plus graude influence sur ce sens : ce sont les lobes optiques ou lubercules quadrijumeaux (paye l26, fig. :3.) y). Si on les delruit sur 
un oisealu (où ces parties sont trés-développées), on détermine également la cécité, et il est à noter que les animaux qui ont la rétine la plus déreloppée et les nerfs optiques les plus gros, sont aussi ceux ou ces lobes acquièrent le plus de volume et ont la structure la plus compliquée ; on peut mème considérer ces orđ̧anes comme une dépendance des nerfs optiques, et comme étant les liens qui les unissent aux hémisphères cérébraux.

Mais ce qui frappe le plus dans ces expériences sur l'encéphale, c'est de voir que la destruction de l'hémisphère cérébral ou du lobe optique d'un còté n'entraine pas la perte de la vue du mème còté : c'est l'ail du còté opposé qui derient areugle; el l'anatomie nous donne, jusqu'à un certain point, l'explication de ce fait; car les nerfs optiques, peu après leur séparation du cerveau, se réunissent et s'entre-croisent, de facon que celui qui vient du lobe droit envoie une grande partic de ses fibres ou mème la totalité à l'œil gauche, et vice versâ ( fig. Łi6).

$\$ 239$. Organes moteurs de l'œil. - En abordant l'étude de la vision, nous arons dit que l'appareil chargé de l'exercice de ce sens se composait d'une partie essentielle, qui est le globe de l'œil et le nerf optique, et de diverses parties accessoires destinées à mouvoir ou à protéger la première.

$\$ 2$ 210. Les organes moteurs, destinés à faire varier la direction des yeux, sont des muscies qui, au nombre de six, entourent le

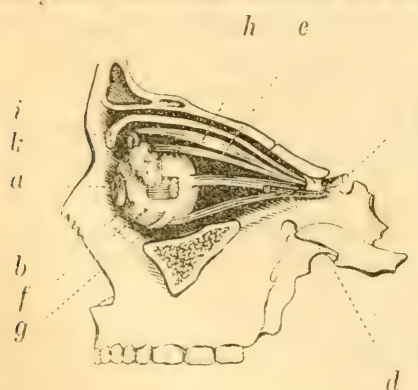

Fig. 68 (1). globe de l'œil et qui s'insèrent à la sclérotique par leur extrémité antérieure, tandis que

c parleur extrémité postérieure ils se tixent aux os situés derriere cel organe ( fig. 68). Le globe de l'œil lui-mème repose sur du lissu cellulaire graisseux sans y adhérer fortement, et il en résulte quo chacun de ces muscles en sc contractant le tire de son còté, de façon à le faire rouler sur lui-mème el à changer la direction de son axe.

(1) Coupe verticale de lorbite pour montrer la position de l'oeil et de ses muscles $a$ cornée; $-b$ sclérotique; - $-c$ nerf optique, dont l'extrémité opposée pénètre dans le globe de l'œil; - 1 muscle droit inférieur de ló il; $-e$ muscle droit supérieur de l'oeil; - f portion du muscle droit externe de l'oxil; au fond de l'orbite on voit l'autre extrémité de ce muscle, dont toute la partie moyemes a été en- 
Les nerfs qui domment le mouvement a ces muscles appartionnent exclusivement à l'appareil de la rision : ce sont ceux de la troisième, de la quatrième et de la sixième paire (fig. 53̈). Les uns sont entièrement soumis à la volonté, les autres agissent souvent inclépendamment d'elle, et c'est de la contraction de ces derniers que dépend le renversement des yeux pendant la syncope.

$\$ 2$ 2. Parties protectrices de l'oil. - Les parties protectrices de l'appareil de la vision méritent aussi de fixer notre attention. Celles que nous devons signaler d'abord sont les cavités osseuses qui loyent les yeux et qui sont appelées orbites. Ce sont des fosses profondes creusées dans la face, cloisonnées par divers os de la tète, et renfermant beaucoup de graisse qui constitue une sorte de coussin élastique autour de l'œil.

\$2 2.2. En arant, cet organe est protégé par les sourcils, par les paupières et par un liquide particulier, les larmes, dont sa surface est toujours baignée.

Les sourcils sont des saillies transversales formées par la peau, qui, dans ce point, est garnie de poils et pourvue d'un muscle spécial destiné à la mouroir. Ils servent à protéger l'œil contre les violences extérieures, à empècher que la sueur qui coule du front, n'aille irriter la surface de cet organe; enfin, à le garantir de l'impression d'unc lumière trop vive, surtout lorsyue celle-ci vient d'un lieu élevé.

$\$ 243$. Les paupières, chez l'homme et tous les autres animaux manmifères, sont au nombre de deux, situées l'une au-dessus de l'autre, et dislinguées, par cette raison, en supérieure et en inférieure. Ce sont des espèces de voiles mobiles placés au-devant de l'orbite, et dont la forme s'accommode à celle du globe de l'œil, de façon (qu'étant rapprochés, ils couvrent complétement la face antérieure de cet orwane. Extérieirement, elles sont formées par la peau, qui, dans ce point, est très-fine, demi-transparente, et soutenue par une lame fibro-cartilagineuse (cartilage tarse). Leur face interne est tapissée par une membrane muqueuse nommée conjonelive, qui se rétléchit sur le grlobe de l'œeil, recourre toute la partice antérieure de la sclérotique ot se confond avec la cornée transparente. Le bord libre des paupuieres cst garni d'une rangée de cils et présente, derrière ces poils, une série de petits trous en communication arec les glandes de Mëbomius, follicules logés dans:

lerée pour montror le nerf optique situé derriere elle; - g extrémité du muscle. petit ohlique; - h muscle graud oblique, dont le tendon passe dans une petife poulie avant de se fixer à la sclérotique; - i nuscle relévateur de la paupière supérieure; - k glande lacrymale. 
l'épaisseur des cartilages tarses, et servant à sécréler une humeur particulière, qui, lorsqu'elle est épaissie et desséchée, comme cela arrive souvent après le sommeil, est connue sous le nom de rhassie. Enfin, on trouve encore, dans l'épaisseur des paupières, des muscles destinés à les mouroir; l'un de cenx-ci entoure leur ouverture comme un anneau, et les resserre avec plus ou moins de force $(f i g .78, h)$; l'autre s'étend de la paupière supérieure jusqu'au fond de l'orbite, el sert à relever ce roile $(f i g .68, i)$.

Les paupières empèchent l'accès de la lumière à l'oil pendant le sommeil. Pendant la veille, elles se rapprochent ou s'écartent, de façon à ne laisser passer que la quantité de lumière nécessaire à la vision, mais insuffisante pour blesser la rétine; clles garantissent aussi l'œil du contact des corps étrangers qui voltigent dans l'air, le préservent des chocs par leur occlusion presque instantanée, et s'opposent aux effets du contact prolongé de l'air par des mouvements continuels, qui reviennent à des intervalles à peu prís égaux.

Lun des usages de la conjonctive est de faciliter ce mouvement, nommé clignement. Cette membrane, dont la sensibilité est exquise, sécrète une humeur qui augmente le poli de sa surface, et qui adoucit le frottement continuel de la portion palpébrale de la conjonctive sur la portion oculaire; mais ce liquide ne suffit pas à cet effet, et, pour que la conjonctive remplisse convenablement ses fonctions, il faut que sa surface soit continuellement lubriliée par les larmes.

\$2 \$4. Cette humeur, qui se compose d'eau tenant en dissolution quelques millièmes de matière animale, et des sels qu'on retroure dans tous les liquides de l'économie animale, se forme dans une glande assez volumineuse, située sous la roùte de l'orbile, derricre la partie externe du bord de cette cavité et au-dessus du globe de l'œil (page 168, fig. 68, k).

Cette glande lacrymale verse des larmes à la surface de la conjonclive par six ou sept petits canaux, qui viennent s'ouvrir sur cette membrane, vers la partie supérieure et externe de la paupiere supérieure. Les larmes se répandent ensuite sur toute la surface de la conjonctive, en empèchent la dessiccation, et forment une conche uniforme, qui donne à l'oeil son poli et son brillant. Elles doivent aussi servir à empècher l'évaporation des humeurs du globe de l'oeil et celle des lipuides dont la comée est imbibée; et en eflet, lorsque aprós la mort les larmes cessent de se répandre ainsi sur la surface de l'oeil, celui-ci ne tarde pas a devenir flasque, et la cornée perd sa transparence. 
Les larmes qui ne s'éraporent point ou qui ne sont pas absorbées jar la conjonctive ront se rendre dans les fosses nasales, en trarersant des canaux dont les ouvertures se voient au bord libre de chayue patupière, près de l'anghle interne de l'oeil, au point ou ces organes quittent le globe de l'ail pour se porter sur la caroncule. lacrymale, corps saillant et de couleur rosée, qui est formé principalement d'un amas de petits follicules. Ce's deux ouvertures, nommées points lacrymaux, sont extrèmement étroites et communiquent avec des canaux très-fins, qui sont loçés dlans l'épaisseur des paupières, et se dirigent directement en dedans, pour déboucher dans lo canal nasal. Ce dernier conduit s'étend depuis l'ang̣le interne de l'oeil jusqu'au méat inférieur des fosses nasales, el traverse, pour s'y rendre, un canal osseux pratiqué entre l'orbite ef le nez.

Dans l'état ordinaire, l'absorption des larmes par les points lacrymaux ne se fait que d'une maniere fort lente; mais, lorsque colles-ci deviennent tres-abondantes, et qu'elles roulent dans les yeux, leur passage dans les fosees nasales devient si rapide, qu'on éprouve a chaque instant le besoin de se moucher. Quelquefois, dans certaines émotions vives de l'àme, par exemple, la sécrétion des larmes devient mème si abondante, que ce liquide déborde les panpières et tombe sur les joues.

$\$ 2$ 2. La structure de l'appareil de la vision et le mécanisme de la vue sont, à peu de chose près, les mèmes chez l'homme el chez tous les mammiferes, ainsi que chez les oiseaux, les reptiles et les poissons. L'ail de quelques mollusques, tels que les poulpes, ressemble éralement beaucoup au nótre; mais, chez la plupart des animaux de cette classe, sa strueture est lrès-différente, et chez les arachnides, les crustacés et les insectes, ces oryanes ont à peine quclques points de ressemblance avec les yeux des animaux supéricurs. Dans la suite de ces lecons, nous ferons connaìtre ces particularités.

\section{DES MOUVEMENTS.}

\section{Contraclion musculaire.}

$\$ 2$ 2fo. Les direrses modifications de la faculté de sentir que nous avons étudiées lans les précédentes lecons, rendent l'homme ot les animaux aptes a connaitre ee qui les entoure; mais leurs rapports aver le monde extérieur ne consistent pas seulement dans ces phénomines, en quelpue sorte passifs. Ces ètres penvent anssi agrir sur les corps étrangers, leur imprimer des changements matériels, se mouvoir, ol souvent mème exprimer d'une maniere plus ou moins précise leurs sentiments ou leurs idées. 
Cette nouvelle série de fonctions, dont nous allons maintenant nous occuper, dépend essentiellement d'une propriété, qui n’est. pas moins crénérale parmi les animaux que la sensibilité, savoir, la contractilité.

On donne ce rom à la faculté qu'ont certaines parties de l'économie animale de se raccourcir tout à coup et de s'étendre alternativement.

Dans quelques animaux d'une structure extremement simple, tels une les Hydres (fig. 2), toutes les parties du corps paraissent susceptibles de se contracter ainsi; mais pour peu que l'on s'élève dans la série des ètres, on roil cette faculté devenir l'apanagye d'organes particuliers, que l'on nomme muscles. Ces muscles, qui sont les instruments actifs de tous nos mourements, forment la majeure partie de la masse du corps, et constituent ce que l'on nomme vulgairement la viande ou la chair des animaux. Leur couleur est en général blanchàtre; chez quelques animaux, ils sont au contraire d'un rouge plus ou moins intense; mais cette couleur ne leur appartient pas en propre et dépend seulement du sang qu'ils contiennent.

\$.77. Structure des muscles. - Chaque muscle est formé par la réunion d'un certain nombre de faisceaux musculaires, qui sont unis par du tissu cellulaire et sont composés de faisceaux plus petits; ceux-ci à leur tour sont formés de faisceaux d'un moindre volume, et de division en division on arrive ainsi à des fibres d'une ténuité extrème, qui sont droites, rangées parallèlement entre elles, et qui, rues avec un microscope puissant, paraissent en général ¿tre formées chacune par une série de petits disques. Après la mort, le tissu musculaire est mou et facile à déchirer; mais, pendant la vie, il est très-élastique et très-résistant. Enfin il se compose essentiellement d'une malière que nous avons déjà rencontrée clans le sang, et que les chimistes appellent fibrine. On y trouve aussi de l'alloumine, de l'osmazòme et quelques sels.

$\$ 24.50 u s$ l'influence de certaines causes excitantes, les fibres musculaires se raccourcissent brusquement, et on voit en mème temps les faisceaux qu'elles forment devenir plus gros et plus durs que dans l'état de relàchement. Chacun peut obserrer sur luimème ce phénomène : il suffit pour cela d'exécuter un mourement quelconque et d'observer les changements qui surviennent dans les muscles mis en action pour le produire. (Gue ron ploie avec force l'avant-bras sur le bras, par exemple, et l'on verra aussitot les muscles de la partie antérieure du bras se gonfler et se durcir.

Le mécanisme par lequel sieffectue la contraction musculaire n'est pas encore bien connu. A l'aide du microscope, on est par- 
venu à reconnaitre qu'au moment où ce phénomène se maniféste les stries transwersales; faciles à observer sur la plupart des fibres charnues, se rapprochent $(1)$ : or, ce rapprochement détermine nécessairement un raccoureissement correspondant dans la longueur totale des muscles. Les deux extrémités de celui-ci se rapprochent donc, et comme elles sont fixées aux parties destinées a ètre mises en mouvement, par leur action elles doivent nécessairement les entrainer avec elles; et en effet, c'est de la sorte qu'elles en opèrent le déplacement.

\$29. Cette insertion des muscles sur le's parties mobiles ne se fait pas directement, mais a lieu par le moyen d'une substance intermédiaire, d'une texture fibreuse, qui pénètre dans la substance de ces organes, de façon à envoyer un prolongement a chacune des fibres dont ils se composent. Tantòt ce tissu fibreux, qui est blanc et nacré, prend la forme d'une membrame, et on l'appelle alors aponérrose; d'autres fois, il ressemble a une corde plus ou moins longue, et constitue alors ce que les anatomistes nomment des tendons (2).

$\S 2: 0$. Influence du système nerveux sur la contraction musculaire. - Nous avons dit plus haut que la contractilité appartenait spécialement aux fibres musculaires: les muscles sont, en effet, les seules parties de l'économie qui, chez les animaux: supérieurs, possèdent la faculté de se contracter; mais, cette propriélé, ils la doivent au système nerveux.

$\$ 2: 31$. Influence des nerfs. - Chaque faisceau musculaire recoit un ou plusieurs nerfs. Ces nerts, qui sont entourés par une espèce de gaine, nommée névrilème, se composent, comme nous l'avons déjà dit, d'un graand nombre de filaments longiludinaux, et ces filaments se répandent dans tout le muscle, en marchant a peu pres parallelement entre eux et en pasiant transversalement sur les fibres musculaires. Après aroir continué ainsi leur trajet pendant quelque temps, on voit ces fibres nerveuses se recourber, former des anses et retourner vers le cerveau, de facon qu'elles paraissent former avee cet organe un cercle continu.

(1) Lors de la publieation de la première édition de cet ourrace, les physiologristes pensaient que la contraction musculaire dépendait diun plissement i'n zi-fzag qui sobserve souvent daus les fibres diun muscle en action; mais de nourelles recherehes ont aypris que ce plissement est un accident et nom pas la cause du phénomine, car on s'est assuré quïl se manifeste dans les fibres qui ne se contrace tent pas en mene temps que leurs voisines, et qui, se trouvant alors plus longues que celles auxquelles elles adhèrent, sont obligées de se froncer.

(2) Ce somt les tendons et les ligaments que l'on appelle ruleritement les merls bien quils n'aient avec ces organes rien de commun. 
Or, lorsqu'on coupe le nerf qui se distribue ainsi à un muscle, 't qu'on sépare de la sorte celui-ci de la masse centrale du système nerveux, on empèche ses fibres de se contracter; on les paralyse. Il suffit mème de comprimer le cerveau d'un animal vivant pour lui faire perdre aussitòt la faculté d'exécuter des mouvements.

$\$ 232$. On a fait beaucoup de recherches pour découvrir la nature de l'influence que le système nerveux exerce ainsi sur les muscles lorsqu'il détermine leur contraction. Les plus célèbres sont celles d'un physicien de Bologne, Galvani; car, en mème temps qu'elles ont jeté de nouvelles lumieres sur cette question délicate, elles ont conduit à l'une des plus grandes découvertes du siècle dernier, celle de l'électricité galvanique.

Les travaux de Galrani, de Volta, et de quelques autres savants, ont montré que toutes les fois que certains corps de nature différente, du cuivre el du fer, par exemple, se touchent, ils développent de l'electricité, et que cette électricité passe avec une grande vitesse a travers certains corps, tels que les nerfs et les métaux, que l'on nomme, pour cette raison, des corps bons conducteurs de lélectriciti, tandis qu'elle est arrètée par d'autres. tels que le verre et la résine.

Or, lorsquion a paralysé un muscle par la section du nerf qui s'y rend, on peut, pendant quelque temps, suppléer au défaut de l'action nerveuse par de l'électricité, ct déterminer, à l'aide de cet agent, des contractions semblables a celles qui, dans les circonstances ordinaires, ont lieu sous linfluence de la volonté.

La manière la plus commode de faire ces expériences est de dépouiller une grenouille de sa peau el de la couper en travers au niveau des reins, puis de saisir les nerfs lombaires et de les enrelopper dans une petite feuille d'étain repliée; on pose ensuite les membres abdominaux sur une plaque de cuivre, et chaque fois que l'étain touche à ce dernier métal, on voit les muscles se contracter; les jambes se replient et s'agitent, et cette moitié de grenouille semble reprendre vie pour sauter. Ces effets singuliers peuvent se produire encore assez long-temps après la mort de l'animal, et sobservent aussi chez l'homme; car, en faisant passer un courant électrique à tràers le corps de quelques suppliciés, on a ru ces cadarres agités de convulsions horribles.

Un phénomene analogue a lieu lorsque, apres anoir compé un nerf sur un animal vivant, on pince ou on brule la portion restée adhérente aux muscles : cenx-ci se contractent aussitòt; mais, du reste, cet effet parait dépendre de la mème cause que les convulsions produites dans les rxpériences précédentes. car 
on a constaté que, dans tous ces cas, il y a production d'électricilé.

On voit, par ce qui précèle, que les courants électriques agissent sur les muscles de la mème manière que l'influence nerveuse, el la connaissance de ce fait a conduit plusieurs physiologistes à penser que cette influence nerveuse elle-mème n'était autre chose que lo passage de quelque fluide subtil, analogue à l'électricité, qui s'échapperait de l'encéphale ponr se répandre dans les muscles, et qui y serait conduit par les nerfs. Pendant quelque temps, on a cru mème pouvoir expliquer tous les phénomènes de la contraction musculaire d'après les propriétés connues des courants électriques: mais cette théorie, toute plausible qu'elle paraissait, ne s'accorde pas avec divers faits constatés récemment, et, par conséquent, il nous semble inutile de nous y arrèter ici.

Quoi qu'il en soit, nous royons que la contraction ne peut avoir lieu que dans le tissu musculaire, et que laction du systeme nerveux en est la cause déterminante. Cherchons maintenant quels sont les róles que les diverses parties de ce svistème jouent dans la production de ce phénomène important.

2:33. Les muscles présentent entre cux des différences trèsgrandes; les uns ne se contractent que sous l'influence de la volonté; d'autres sont également soumis à l'empire de cette force, mais leur contraction a lieu aussi indépendamment d'elle; enfin, il en est d'autres encore sur los mouvements desquels la volonté n'a aucune influence. Les muscles des membres, etc., appartiennent à la première de ces trois classes; ceux de l'appareil respiratoire, à la seconde; et le cour, l'estomac, etc., à la troisième (1).

$\$ 234$. Les muscles dont les mouvements peuvent êlre déterminés par la volonté recoivent tuus des nerfs du systeme cérébro-spinal. Mais tous les nerfs de ce système ne remplissent pas ces fonctions; quelques-uns, comme nous l'arons déjà vu $(\$ 20)$, appartiennent. exclusirement à la sensibilité. Les nerfs cérébraux des troisième, quatrième, sixieme, septième, neuvième et onzieme paires (fig. $\dddot{3} \ddot{3})$ paraissent, au contraire, itre exclusivement affectés aux mouvements: enfin, les nerfs cérébraux de la cinquième et de la dixième paire, et tous les nerfs qui naissent de la moelle épinière, remplis-

(1) 11 est à noter que les muscles soumis it linfluence de la volonté different de lat plupart des muscles independiunts de la volonté, par leur structure aussi bien yue par leturs fonctions; chez les animaux superieurs, les faisceaux de fibres dont les premiers sont compesés offrent toujours les stries transversales, tandis que la plupart des derniers n'en préentent pas; mais ectte difference n'est pas constante, car les fibres du cour ressmblent, sous re ripport, à cenx des muscles dont les mourements dépendent de la volonté. 
sent ces fonctions en mème temps qu ils servent à la sensibilité : leur racine postérieure, comme nous l'arons déjà vu, leur donne la faculté de transporter les impressions au cerieau $(\$ 203 j$; et c’est par leur racine antérieure que l'influence nerveuse, nécessaire pour déterminer les mouvements volontaires, se propage du cerveau aux muscles.

En effet, lorsqu'on coupe, sur un animal rivant, les racines antérieures des nerfs spinaux, on prive les parties auxquelles ces nerfs se distribuent de la faculté de se contracter, tout comme si l'on coupait leurs deux racines.

$\$$ əö.̈. Influence de l'encéphale. - Lorsqu'on divise la moelle épinière, on détruit égralement les mourements de toutes les parties dont les nerfs naissent au-dessous de la section, tandis que celles dont les nerfs sont encore en communication arec le cerveau continuent à se mouvoir. Mais si, au lieu d'expérimentel ainsi sur la moelle épinière, on agit sur le cerveau, qu'on l'enlève ou quion le comprime de maniere à l'empècher de remplir ses fonctions. on paralyse en mème temps tous les muscles des mouvements volontaires.

Il paraitrait aussi que certaines parties du syslime nerveux exercent sur les mourements une influence d'une autre nature. Ainsi, II. Magendie a constaté que, lorsqu'on coupe la portion du cerreau désignée par les anatomistes sous le nom de corps striés. l’animal ainsi mutilé ne reste plus maitre de ses mouvements, mais semble poussé en avant par une puissance intérieure a laquelle il ne peut résister : il sélance en arant, court arec rapidité, el s'arrète enfin. mais ne parait pas pouroir reculer. Si, au contraire, on blesse les deux còtés du cervelet chez un mammifere ou un oiseau ( I) on le voit aussilòt marcher, nager, ou mème voler en arrière, sans jamais pouvoir se porter en asant.

Lorsquion ne pratique ces lésions que d'un seul còté, on observe d'autres phénomènes qui, au premier abord, paraissent ètre des plus singuliers, mais qui sont des conséquences des effets dont nous renons de parler. Ainsi, lorsquion coupe verticalement l'un des còtés du cervelet, ou de la protubérance annulaire, l'animal se met aussitòt à rouler latéralement sur lıi-mème, en tournant du còté blessé, et quelquefois arec une telle rapidité, qu'il fait plus de soixante révolutions par minute.

D aprés ces expériences curieuses, et d'après les recherches sur le mème sujet, faites par M. Flourens et par quelques autres phy-

(1) D'après les expériences de M. Magendie, il paraitrait que lés mêmes eflets ne s'observent pas chez les reptiles et les poissons. 
sulogistes, on voit que le cervelet et les parties voisines de l'encéphale ont, entre autres usages, celui de régler les mouvements de la locomotion.

Les mouvemenls qui, toul étant soumis à lempire de la rolonté, se font aussi indépendamment de son influence, paraissent dépendre alors de l'action de la moelle allongée. Lin effet, lorsque le cerveau ne remplit plus ses fonctions, et que, par conséquent, il n'y a plus de volonté, les muscles de l'appareil respiratoire continuent à ag̣ir comme lorsfue leurs mouvements pouvaicnt itre réglés par cette force; mais, lorsqu'on clétruit cette portion de la moelle, lout en laissant le cerveau intact, on les arrète aussitòt.

$\$ 236$. Influence du système ganglionaire. - ()uant aux muscles dont les contractions sont entièrement independantes de la tolonté, ils recoivent leurs nerfs du système ganglionaire, et c'est dans ce système que réside leur principe d'action; car, si l'on maintient la respiration par des moyens artificiels, on peut détruire tout l'encéphale, ainsi que la moelle épinière, sans arrèter les baltements du cœur ou les contractions péristaltiques des intestins.

\$2:7. Ainsi, en résumant les faits précédents, on voit (que, dans la production d'un mourement, de mème que dans le phénonène de la sensibilité, il existe une division de travail très-remarquable: lorsque c'est la volonté qui détermine un mourement, l'impulsion part du cerveau; les nerfs le conduisent aux muscles, et ceux-ci, en se contractant, exécutent, pour ainsi dire, les ordres ainsi transmis; mais, pour coordonner leur action, ces ordres ont besoin d'ètre, pour ainsi dire, régularisés, et c'est le cervelet ou les parties roisines de l'encéphale qui sont préposés à cet cffet. Enfin, pour les mourements dont l'animal ne doit pas ètre le maitre d'interrompre le cours, la cause déterminante ne dépend pas de l'action du cerveau, instrument spécial de la volonté, mais réside dans d'autres organes, tels que la moelle allongére, ef probabloment aussi les centres nerveux du systeme cranglionaire.

\section{$\$ 238$. Durée et force des contractions musculaires. - Lal} contraction de la filore musculaire est un phénomène essentiellement intermittent. Les muscles ne peurent rester dans un élat de contraction permanente, et, an bout d'un temps plus ou moins long, ils se relàchent néces-airement. Ainsi, le coeur, dont l'action ne' s'arrète quarec la vie, se contracte et se repose alternativement: mais, pour les muscles des mouvements volontaires, ces mèmes contractions, interrompues par des repos plus ou moins rapprochés, ne peurent ètre continuées au delà d'un certain tempsos, car elles produisent un sentiment de lassitude yui augrmente jusigu à ce 
quienfin ces mouvements deviennent impossibles, et cette sensation ne se dissipe que par l'inaction.

La promptitude avec laquelle la fatigue musculaire se manifeste varie beaucoup, suivant les individus; mais, toutes choses égales d'ailleurs, elle est en raison de l'intensité des contractions, de la durie de chacune d'elles, et de la rapidité avec laquelle elles se succèdent.

La force déployée par la contraction d un muscle dépend de la texture de cet organe et de l'énergie nerveuse de l'individu. Les muscles les plus gros, les plus fermes et les plus ronges sont susceptibles de se contracter avec plus de force que les muscles grèles, flasques et pâles; mais c'esl seulement lorsque ces conditions sont réunies à une puissance nerveuse très-forte que ces organes peuvent produire les plus grands effets, et presuge toujours elles sont en sens inverse. Par la seule influence de laction du cerveau, l'énergie des contractions musculaires peut itre portée à un deg̣ré extraordinaire: on connait la force diun homme en colire el celle des maniagues; et lorsque, dans l'état ordinaire de l'économie, une énergie nerveuse analogue se réunit à un grand déreloppement matériel du svileme musculaire, il en résulte des effets étonnants, dont les anciens nous ont transmis des recits en parlant de leurs athletes, et dont les bateleurs de nos jours nous rendent aussi quelquefois témoins.

\section{De l'appareil du mouvement en général.}

$\$ 239$. Lat contraction musculaire a jouc un grand ròle dans plusieurs des fouctions dont nous avons dejj fait l'histoire; mais le sujet dont nous allons maintenant nous occuper s'y rattache d'une maniere encore plus directe, car nous allons aborder l'étude des mourements généraux et partiels de notre corps, dont dépendent les attitudes, la locomotion, et une foule d'autres phénomènes entièrement mécaniques.

Chez les animanx les pius inférieurs, les muscles s'insèrent tous a la membrane tégumentaire. qui est molle et flexible; ct c'est en agrissant sur elle qu'ils modifient la forme du corps, de façon à le faire mouvoir en totalité ou en partie; mais chez les animaux diune structure plus parfaite, lappareil moteur se complique davantage et se compose non-seulement de muscles, mais aussi d'un système de pieces solides servant à augrmenter la précision. la force et l'élendue des mourements, en mème temps qu'il détormine la forme générale du corps, et protège les viscères contre les violences extérieures. 
$\$ 260$. Cette espece de charpente solide, a larpuelle les muscles s'attachent, porte le nom de squelette. Dans certains animaux, tels que les insectes et les écrevisses, elle est située à l'extérieur et ne consiste que dans une modification de la peau; mais chez l'homme et tous les animaux qui s'en rapprochent (savoir, les autres mammifères, les oiseaux, les reptiles et les poissons), le squelette est situé à l'intérieur du corps, et se compose de parties qui lui appartiennent d'une manière spéciale.

Chez quelques poissons (tels que les raies), le squelette est formé d'une substance blanche, opaline, compacte, en apparence homogène, très-résistante et très-élastique, que l'on nomme cartilage. Il en est de mème pour le squelette de l'homme et des autres animaux dans les premiers temps de la vie; mais cet état, qui est. permanent chez les poissons dont nous venons de parler, n'est ici que transitoire, et les cartilages du squelette ne tardent pas à se charger de matières pierreuses de nature calcaire qui les rendent. roides, cassants et très-durs, et qui les font passer à l'état d'os.

$\$ 261$. Des os. - Pour s'assurer que les os ne sont que des cartilages durcis par le dépòt de sels calcaires dans leur épaisseur, il suffit de les faire macérer pendant quelque temps dan; un liquide particulier appelé acide muriatique ou chlorhydrique; ce liquide a la faculté de dissoudre les matières pierreuses contenues dans les os, mais n'attaque pas le cartilage, de façon qu'on sépare ainsi ce dernier des sels qui en masquaient les propriétús (I).

L'ossification du squelette commence par une multitude de points qui s'étendent de plus en plus; il en résulte que le nombre des pièces osseuses est d'abord très-considérable; mais par les progrès de l'ossification, plusieurs d'entre elles se réunissent, de sorle que, chez l'animal adulte, on trouve beaucoup moins d'os distincts que chez le jeune, et que, dans la vieillesse extrème, on voit souvent plusieurs de ceux-ci se sonder entre eux, et des parties, qui jusqu'alors élaient restées cartilagineuses, s'encroùter de matieres calcaires. L'utilité de ce mode de déreloppement est facile à comprendre : pour que la charpente solide du corps ne s'oppose pas a ses mouvements, il

11) D'après lanalyse fate far M. Berzélius, les os du squelettr humain, farlai . tement dejoullés de graisse, sont composés, sur 1010,00 : de cartilage, $3: 2,17$; vais seatux, 1,1:3; sous pliosphitte de chatux, aree un peu de fluorure de calceim, 5)3, (1) carbonate de chatux, 11,30, phosphate de magnesie, 1,16; et sonde, avee un prent de chlorure de sendium, 1,20. Datns un os de bouf, ce chimiste a trouve la mime proportion de matieres animales, mais beancoup moins de carbomate de chatux.

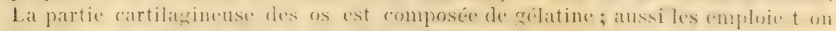

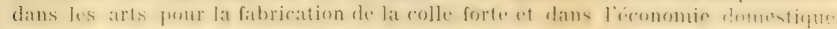
pour la préparation de bouillons économiques. 
faut toujours qu'elle se compose d'un gुrand nombre de pièces mobiles, mais c'est surtout lorsque toutes ses parties doivent se prèter a l'accroissement des oraranes situés dans son intérieur que cette division est le plus nécessaire.

La surface des os est toujours recouverte d'une couche memIraneuse à laquelle on donne le nom de périoste, et leur substance se compose de fibres ou de lamelles faciles à distinguer. Lorsque res organes doivent occuper peu de volume et doivent présenter beaucoup de solidité, comme cela a lieu pour les os plats qui recourrent la plupart des visceres les plus importants et les plus délicats, le tissu ossenx est extremement rompacte; mais lorsque les us doivent occuper un long espace, et qu'ils nuiraient aux mou. rements si leur poids était considérable, leur tissu n'est dense et serré que vers la surface, et dans leur intérieur il existe de grandes cellules ou mème des canaux appelés médullaires, parce qu’ils sont remplis de moelle. Enfin ce tissu lui-mème, examiné au unicroscope, parait formé principalement par des tubes très-déliés, ou par des cellules entourées de lamelles concentriques entre les(quelles on distingue des corpuscules opaques et ovoidles.

$\$ 262$. La forme des os varie beaucoup: on les distingue en os longs, os courts et $0 s$ plats. Les premier's seulement présentent une cavité médullaire; îs sont toujours à peu près cylindriques, et les tubes dont leur tissu est composé sont disposés longiludinalement. Dans les os plats ces tubes sont paralleles à la surface de l'os, et dans les os courts ils sont remplacés par des cellules. On remarque souvent aux uns et aux autres des éminences qui donnent attache aux muscles ou a d'autres parties, et qui, toutes les fois qu'elles font une saillie considérable, sont désignées par les anatomistes sous le nom d'apophyses. Les os présentent aussi à leur surface des dépressions plus ou moins profondes qui servent à loger des parties molles ou a recevoir d'autres os qui doivent se mouvoir dans ces cavités, et dans beaucoup d'endroits on leur voit des trous destinés à livrer passage à des vaisseaux sanguins ou à des nerfs.

$\$ 263$. Articulation des os. - On donne le nom d'articulation à l'union des divers os entre eux. Les moyens de jonction que la nature a employés à cet usage varient beaucoup, suivant que les os doivent conserver toujours entre eux les mèmes rapports, et rester fixes, ou bien exécuter des mouvements plus ou moins étendus.

Lorsque l'articulation des os n'est pas destinée à permettre des mouvements, elle peut avoir lieu de trois manières : par juxtaposition, par engrenage ou par implantation. Les articulations par simple juxtaposition des surfaces artieulaires ne se roient que 
dans certaines parties du squelette, où la position des os est telle, qu'ils ne peuvent se déplacer. Dans les articulations par engrenage (ou par suture), les surfaces articulaires offrent une série d'aspérités et d'enfoncements anguleux qui se recoivent réciproquement: aussi ces articulations peuvent-elles avoir beaucoup de solidité sans que leurs surfaces soient très-étendues. Enfin les articulations par implantation sont celles où un os est enchìssé dans une cavité creusée dans la substance de l'os qui lui sert de base: ce sont les articulations les plus solides, mais elles sont rares (1).

$\$ 264$. Dans les articulations mobiles, les os ne sont pas unis directement entre eux, mais sont maintenus en contact par des liens qui s'étendent de l'un des os à l'autre.

Tantôt ces surfaces articulaires sont unies par une substance cartilagineuse ou fibro-cartilagineuse intermédiaire, qui adhère fortement à l'une et à l'autre, et ne leur permet de se mouvoir qu'à raison de son élasticité (c'est ce qu'on nomme articulation par contimuité); d'autres fois les surfaces articulaires glissent l'une sur l'autre, et ne sont maintenues en rapport que par des ligaments (2), qui les entourent, et qui sont disposés de manière à poser des bornes à leurs mouvements. Ce mode de jonction constitue ce que les anatomistes appellent articulation par contiguité, et se voit toujours là où les mouvements doivent ètre très-étendus. Les surfaces qui s'articulent ainsi sont toujours extrèmement lisses, et encroùtées d'une lame cartilagineuse qui en augmente encore le poli ; mais ce ne sont point la les seuls moyens employés par la nature pour diminuer le frottement dans ces jointures; car elle y a placé une espèce de poche membraneuse, appelée bourse synoriale, qui a de l'analogie avec les membranes séreuses, et qui est remplie d'un liquide visqueux, lequel permet à ces surfaces de glisser facilement l'une sur l'autre. Cette poche, qui entoure l'articulation de toutes parts, contribue aussi, d'une manicre efficace, à maintenir les os en contact, ear elle exclut les fluides ambiants de la eavité que ces corps laissent entre eux, et par conséquent ceux-ci ne peuvent s'écarter sans y déterminer un vide; il en résulte que tout le poids de l'atmosphere tend à maintenir ces surfaces articulaires dans leurs rapports naturels : et pour se: convaincre de l'influence de cette cireonstance, il sulfit de s'atsurer de la difficulté que l’on

(1) Les dents sont les seules perties qui s'articulent ainsi.

2) On dome le um de ligaments a des faisceaux de fibres analognes à ceux des tendons, tres-resistants, arrondis ou aplatis, et d'un hlane nace, yui lient entre eus les os. 
éprouve pour déboiter sur le cadavre un os dont l'articulation est intacte, et de voir combien cette opération devient, au contraire, facile, dis qu'une ouverture faite à la membranc synoviale permet l'entrée de l'air dans la cavité articulaire.

$\$$ 26\%. Action des muscles sur les os. - Tous les muscles destinés à produire les grands mouvements du corps sont fixés au squelette par leurs deux extrémités. Il en résulte que, lors de leur conIraction, ils doivent déplacer l’os qui leur présente le moins de résistance, et l'entrainer vers celui qui reste immobile et qui leur sert de point d'appui, pour mouvoir le premier. Or, dans la plupart des cas, les os sont d'autant plus mobiles, qu’ils sont placés plus loin de la partie centrale du corps: aussi les muscles qui se fixent à deux d'entre eux agissent-ils, en général, sur celui qui est le plus éloigné, et voit-on toujours les muscles destinés à mouvoir un os s'étendre de cet organe vers le trone: ainsi, les muscles servant à remuer les doigts se trouvent à la paume de la main et à l'avant-bras; ceux qui fléchissent l'avant-bras sur le bras oceupent le bras, et ceux qui meuvent le bras sur l'épaule sont placés dans l’épaule.

Dans certaines cireonstances, cependant, ces muscles déplacent les os qui, dans les cas ordinaires, leur servent de point d'appui. Ainsi, lorsque le corps est suspendu par les mains et que l'on cherche à s'élever, les muscles fléchisseurs de l'avant-luras, ne pouvant déplacer celui-ci, en rapprochent le bras et entrainent tout le corps.

En général le genre de mouvement déterminé par la contraction d'un muscle dépend, d'une part, de la nature de l'articulation de l'os qu'il déplace, et de l'autre, de sa position par rapport à cet os: il l'entraine toujours de son côté et le rapproche du point auquel son extrémité opposée se trouve fixée. Ainsi, les muscles qui font fléchir les doigts occupent la face palmaire de la main et de l'avant-bras, tandis que ceux destinés à les étendre sont situés du côté opposé du membre.

Souvent plusieurs muscles sont disposés de facon at pouvoir concourir à la production d'un mème mouvement: on les appelle alors congénères, et on appelle l'antagoniste d'un muscle celtii qui détermine un mouvement contraire.

On désigne aussi les muscles, d’après leurs usagres, sous les noms de fléchisseurs et d'extenseurs, d'adducteurs et d'abducteurs, de rotateurs, etc.

$\$ 266$. La force avee laquelle un muscle se contracte déperd de soni volume, de la puissance de la volonté el de quelques autres rireonstances dont il a dijat cle fait mention: mais leffet prociuit 
par cette contraction dépend aussi en grande partie de la maniere dont il se fixe à l'os qu'il doit mouvoir.

Ainsi, toutes choses égales d'ailleurs, le mouvement délerminé par la contraction d'un muscle sera d'autant plus grand, que ce muscle s'insérera moins obliquement sur l'os mobile: lorsqu il s'y insire à angle droit, toute sa force est employée à déplacer celui-ci; mais, dans le cas contraire, une partic plus ou moins consiclérable de cette force est perdue.

En effet, si le muscle $m$ (fig. 68 ), dont nous supposons la force égale à 10 , est fixé perpendiculairement à l'os $l$, dont l'extrémité $a$ est mobile sur le point d'appui $r$, il n'aura à vaincre que le poids de cet os, et le portera de la position $a b$ dans la direction de la ligne $a, c$, en faisant parcourir au point auquel il s'insère un espace que nous représentons encore par 10 ; mais, si

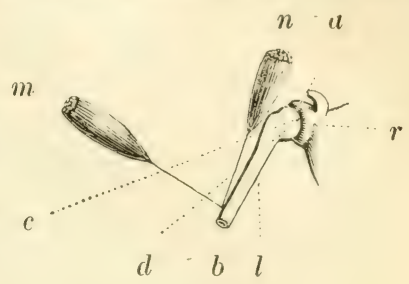

Fig. 68. ce muscle agit obliquement sur l'os, dans la direction de la ligne $n b$, par exemple, il en sera tout autrement; car alors il tenlra à le porter dans la direction $b n$, et, par conséquent, à le rapprocher de la surface articulaire $r$, sur laquelle l'extrémité de l'os repose; mais, celui-ci étant une tige inflexible, ce déplacement ne peut avoir lieu; l'os ne peut que tourner sur le point $r$, comme sur un pivot, et la contraction du muscle $n$, sans rien perdre de l'únergie que nous lui avons supposée, ne pourra porter cet os que dans la direction $a d$; les trois quarts de la force quil a déployée seront perdus, et il ne produira. par conséquent, qu'un déplacement pour lequel ie quart de sa force suffirait s'il chait appliqué, comme le muscle $m$, perpendiculairement à l'os.

Or, dans l'économie animale, les muscles ne s'inserent, pour la plupart, que d'une maniere tres-oblicque, et, par conséquent, dume maniere tres-per farorable a löntensite du résultat de leur contraction Sourent il existe cependant une disposition qui tend a diminuer l'obiliquité de ces insertions : c'est ie renflement qui se trouve à l'extrémité de la plupart des os longs, et qui sert principalement à donner à leurs ariculations plus de solidité. Les tendons $(i)$ des muscles $(m)$, situés audessus de l'articulation, s'insirent. en

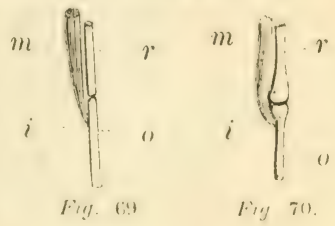


général, immédiatement all-dessons de ce renllement, of arricent ainsi sur l'os mobile $(0)$, en suivant une direction qui se rapproche davantage de la perpendiculaire, comme on peut s'en ronvaincre en comparant la disposition du muscle $m$, dams la fig. 70, ou ces renflements existent, et dans la fig. 69, où on a représenté les extrémités articulaires sans renflement stmblable.

\$267. La distance qui sépare le point d'attache du muscle du point d'appui sur lequel l'os se meut, et de l'extrémité opposée du levier que cet organe représente, influe aussi de la maniere la plus puissante sur les effets produits par sa contraction. Pour expliquer ce fait, il est nécessaire d'avoir recours à la mécanique.

Les os, disons-nous, représentent des leviers, nom que l'on donne en physique à toute verge inflexible qui se meut sur un point fixe, que l'on appelle le point d'uppui. La force qui met le levier en mouvement se nomme la puissunce, et celle qui s'oppose à son déplacement se nomme la résislance. Enfin, on appelle bras de levier de la puissance, et bras de levier de la résistance. la distance qui sépare le point d'appui de celui où sont appliquées l'une ou l'autre de ces forces.

Or, la longrueur de ces bras de levier influe extremement sur la

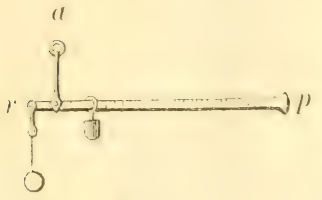

Fig. 71 . force nécessaire pour faire équilibre à une résistance donnée. Pour s'en convaincre, il suffit d'observer le mécanisme de la balance commue sous te nom de romaine (fig. i i). Le fléau est partagé en deux parties, de longueur inégale, par le point d'appui $a$. A l'extrémité de l'une des branches $(r)$, qui est tress-courte, se trouve lat résistance oir liobjet que l'on reut peser), et sur l'autre $(p)$ glisse un poids quelconyue, qui fait équilibre à une résistance d'autant plus considérable, quion l'éloigne davantage du point d'appui et quion allonge. par consépuent, le bras de levier de la puissance celui de la résistance restant toujours le mème.

Chacun sait aussi combien est grande la différence dans la foree qu'un homme peut déployer, lorsqu'il cherche à soulever un fardeau avec le bras fléchi ou tendu. Or, dans ces mouvements, ee sont les mèmes muscles qui agissent. et le bras de levier de la puissance reste le mème; cest seulement le bras de levier de la résislance, représenté par la distance qui sépare lópaule de la main. qui s'allonge.

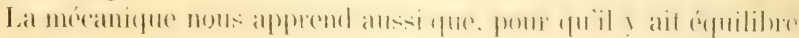


dans un levier quelconque, il faut que la résistance et la puissance soient réciproquement proportionnelles aux longueurs de leurs bras de levier, c'est-it-dire que, multipliées par leurs bras de levier respectifs, elles doment toutes deux le mème produit.

Ainsi, pour faire équilibre à une résistance $(r)$ égale à 10, qui serait appliquée à l'extrémité d’un levier $(a b)$ d'une longueur de 20 , il faudrait que la puissance $(p)$, si elle était appliquée au mème point $(b)$, et, par conséquent, également éloi-

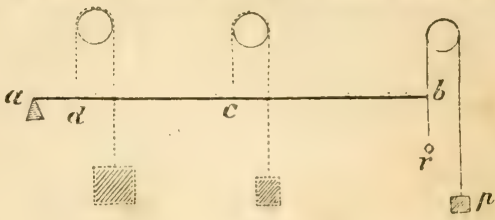

Fig. 72. gnée du point d’appui $(a)$, fùt aussi égale à 10 ; mais, si elle était appliquée au point $c$, elle devrait ètre, pour produire le mème effet, égale à 20 , car la résistance, que nous avons supposée égale à 10 , étant multipliće par la longueur de son bras de levier, 20 , donnera pour produit 200 ; et, d'un autre colé, le bras de levier de la puissance $(c$ a) n'étant égal qu’à 10, celui-ci devra ètre multiplié par une force égale à 20, pour domner ce mème produit de 200. Enfin, en placant la puissance encore plus près du point d'appui, au point $d$, il faudra lui domner une force égale à 100 , car son bras de levier ne sera plus que de 2 , et $2 \times 100=200$.

La disposition des levirrs infue autant sur la rapidité des mouvements produits que sur leur force; et si, en employant une puissance comparativement faible, on peut vaincre ainsi une résistance beaucoup plus forte, on peut aussi, en employant une force motrice d'une vitesse queleonque, obtenir, à l'aide de ces instruments, un mouvement plus lent ou plus rapide.

Ainsi, supposons que la puissance p) agrisse sur le levier a $r$, de façon à faire parcourir au point d'insertion $c$ un espace de š dans une seconde, il déplacera en mème temps l'extrémité $r$ du levier, et le fera arriver en $b$ avee une vitesse

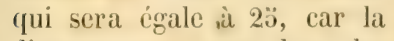
distance parcourue dans des temps égaux par ce point sera cinq fois plus considérable que celle parcourue par le point $b$.

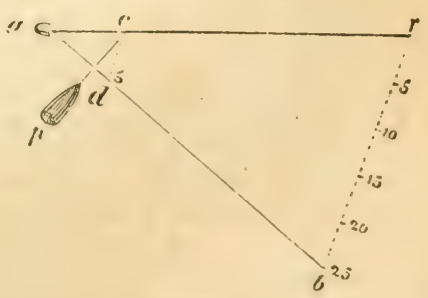

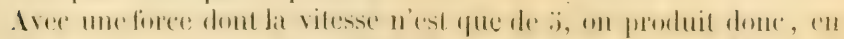
16. 
l'appliquant au point $c$, le mème résultat que si un appliquait directement au point $r$ une force dont la vitesse serait égale à 23 .

Nais, d'après ce que nous avons dit plus haut, on voit que tout ce que l'on gagne ainsi en vitesse se perd en force; car, c'est surtout en rendant le bras de levier de la résistance plus long proportiomnellement à celui de la puissance, qu'on arrive à ce résultat.

Or, dans l'économie animale, presque tous les leviers représentés par les os sont disposés de facon à favoriser de la sorte la rapidité des mouvements aux dépens de la forece nécessaire pour les produire. Ainsi, lorsque l’on abaisse le bras tendu, si la vilesse avec laquelle ses muscles se contractent est telle que leur point d'insertion soit déplacé de trois pouces dans unc seconde, l’extrénité du membre s'éloignera de sa position primitive avec une vitesse de près de trois pieds dans le mème laps de temps.

Ces notions préliminaires sur la mécanique animale étant acquises, nous pouvons maintenant nous livrer à l'étude des diverses parties de l'appareil du mouvement, que nous examinerons de préférence chez l’homme.

\section{Description de l'appareil moteur de l'homme.}

\$268. L'appareil moteur de l'homme et des autres animaux supéricurs se compose, ainsi que nous l'avons dijì dit, du squelette et des muscles.

Le squelette, formé par la réunion d'un grand nombre d'os, se divise, comme le corps, en trois parties: la tète, le trone et les membres.

Sุ 269. Tète. - La tète se compose de deux portions principales, le cràne el la face.

Le cràne est une espece de boile osseuse de forme ovalaire qui

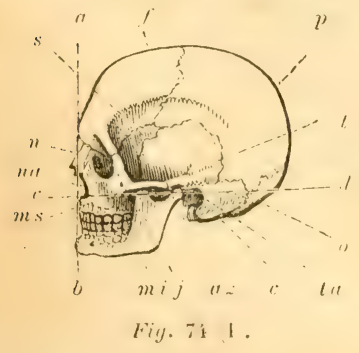
occupe toute la partie postérieure et supérieure de la tète, et qui loge, comme nous l’avons déjà vu (\$184), le cerveau et le cervelet. Huit os se réunissent pour en former les parois, savoir : le frontal ou coronal $(f)$ en avant, les deux pariétaux $(p)$ en haut, les deux temporaux $(t)$ sur les còtés, l’occipital (o) en arrière, et le sphénoïde $(s)$ et l'ethmoïde en bas; tous cesos, à l'exception du dernier,

1) fos frontal ou coronal; - $p$ parietal; $-\ell$ temporal; - o uccipital; - 
ont la forme de grandes lames minces, d'une texture tres-compacte; et tous s'articulent entre eux de manière à itre complétement immobiles, et à domner au cràne une grande solidité. Ces articulations sont mème très-remarquables, en ce qu'elles varient de forme dans les différentes parties du cràne, afin de mieux résister aux violences extérieures qui pourraient tendre à désunir ces us, et qui doivent produire des effets différents, suivant le point sur lequel elles agissent. Ainsi, lorsqu’un coup porte sur le sommet de la tète, le mouvement se propage dans tous les sens et tend à écarter les os parićtaux et à chasser en avant ou en arrière les os frontal ou occipital : aussi, tous ces os sont-ils liés entres eux par des sutures engrences des plus solides. Mais, quand le cràne recoil un choc sur le côté, l'effort agissant sur le temporal tend à enfoncer cet os, et, pour empècher cet accident, la nature a uni le temporal aux os voisins, non pas à l'aide d'engrenures propres seulement à empècher leur disjonction, mais à l'aide d'un bord articulaire taillé très-obliquement, de façon à rendre cet os extérieurement beaucoup plus grand que l'espace dans lequel il se trouve comme enchàssé.

La voùte du cràne ne présente d'ailleurs rien de remarquable; mais, à sa hase, on voit une multitude de trous qui servent au patssage des vaisseaux sanguins du cerveau et des nerfs qui naissent de: l'encéphale; un de ces trous, creusé dans l'os occipital et beaucoup plus grand que tous les autres, est traversé par la moclle épiniere, et il existe pres de son bord et de charfue cote une apophyse large et convexe appelée condyle, qui sert à l'articulation de la lète sur la colonne vertébrale. La tète est presque en équilibre sur celle espece de pivot; mais, cependant, la portion situce au devant de l'articulation est plus volumineuse que celle qui est siluée en arriere, et qui tend à faire contre-poids à la premiere : aussi les muscles qui se portent de la colomne vertebrale à lat partie pesterieure de lia tète, et qui servent à redresser celle-ci, somt-ils bien plus mombreus et plus puissants que les museles flechissimes placés de la mime maniere au-devant de la colonne; ed, lorsque les premiors se relichent, comme cela arrive dans le sommeil, la tète lend-elle ordinairement à retomber en avant el à s'appuyer sur la poitrine.

Sur les côtés de la base du cràne, on remarque encore deus apm-

$s$ sphénoïde; $-n$ os nasal; $-m s$ maxillaire superieur; $-j$ os jugral ou os de la

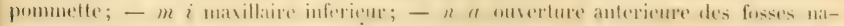
sales; $-\ell$ a trou auditif; $-\| \approx$ arcade zygomatique formace par une portion des

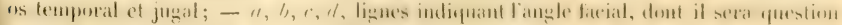
plus loin. 
physes très-grosses, appelées mastö̈les (fig. 76), auxquelles s'insèrent des muscles qui descendent obliquenent vers la poitrine à la partie antérieure du cou, et qui servent à faire tourner la tète sur la colonne vertébrale. Enfin, immédiatement en avant de ces apophyses, se trouve l'ouverture du conduit auditif externe, qui, de mème que les diverses parties de l'oreille moyenne et de l'oreille interne, est creusée dans une portion de l'os temporal appelée rocher, à cause de sa grande dureté (voyez $\$ 222$ ).

$\$ 270$. La face est formée par la réunion de quatorze os de formes trìs-diverses, et présente cinq grandes cavités destinées à loger les organes de la vue, de l'odorat et du goùt. Tous ces os, excepte celui de la màchoire inférieure, sont complétement immobiles et s'articulent entre eux ou avec les os du cràne. Les deux principaux sont les os maxillaires supérieurs ( $m s$, fig. 7.4), qui constituent la presque totalité de la màchoire supéricure, et qui s'articulent avec le frontal, de facon à concourir aussi à la formation des orbites et des fosses nasales; en dehors, ils s'articulent avec les os jugaux ou os des pommettes $(j)$, et en arriere avec les os palatins, qui, à leur tour, se joignent au sphénoïde.

Lesorbites, comme nous l'avons déjà vu ailleurs (\$2.1), sont deux fosses eoniques, dont la base est dirigée en avant; la voùte de ces cavités est formée par une portion de l'os frontal, et leur plancher par les maxillaires supérieurs; en dedans, c'est l'ethmoïde et un petit us appelé lacrymal, qui complètent leurs parois; et en dehors, elles sont formées par l’os jugal et le sphénoïde, qui en oecupe aussi le fond ou se trouvent les ouvertures servaut au jassage du nerf optique et des autres branches nerveuses appartenant à l'appareil de la vision. A la voùte de l'orbite, on remarque une dépression qui loge la glande lacrymale, ed à sa paroi externe se trouve un canal qui deseend verticalement dans les fosses nasales, et live passage aux larmes.

Le nez est formé, en majeure partie, de eartilages: aussi, dans le squelette, l'ouverture antérieure des fosses nasales (na, fig. 74) est-elle tris-grande, et la portion osseuse du nez, formée par les deux petits os appelés nasaux $(n)$, est-elle peu saillante. Les fosses nasales sont très-étendues; supérieurement, elles sont creusées dans l'os ethmö̈le dont tout l'intérieur est rempli de cellules; inférieurement, elles sont séparées de la bouche par la voùte du palais, qui est formée par les os maxillaires superieurs et par les deux os palatins; enfin, elles sont séparées entre elles sur la ligne medianc par une cloison verticale, formée supérieurement par unc lame de l'olnmö̈le, ef infériemrement par un os particulicer, 
nommé romer. On trouve encore, dans l'intérieur de ces fusses, deus os distincts qui forment les cornets inféripurs, et on y remarque louverture des sinus frontaux, sphénoïfaux ot maxillaires, cavilés plus ou moins rastes creusées daus l'épaisseur des os dont elles portent les noms ( $\mathrm{ig} .59, \mathrm{p} .147$ ).

C'est dans l'os maxillaire supérieur que sont implantées toutes les dents de la mâchoire supérieure : dans le jeune âge, il est formé de plusieurs pièces; et, chez la plupart des animaux, on

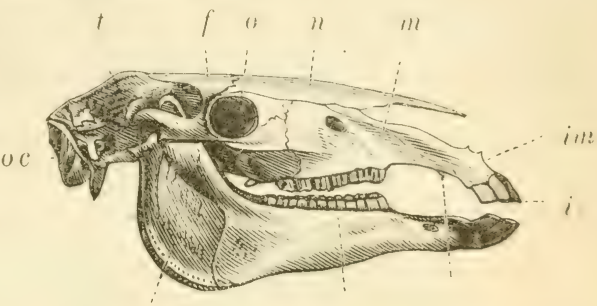

$m i$

mo

C

Fig. 75. Têle de chevul (1).

en distingue toujours une portion antérieure, quion appelle lis intermaxillaire (im, fig. 75 ).

La màchoire inférieure de l homme ne so compese (fue d'un seul 0 , car les deux moitiés dont elle est forméc chez un crand nombre d'animaux se soudent entre elles de tres-bonne henre of se confondent completement. Cet os, appelé maxillaire inférieur, a une ressemblance grossiere arec un fer à cheral dont les extrémités coudées sóleveraient beaucoup). Il sarticule avee les os temporaux par un condyle saillant situé a dhacune de ses extremites, of reful dans une cavité nommée glénoüdale: entin, all-derant de ces condyles s'élève, de chaque còté, une apophyse åppelée coronoïle, qui sert à l'insertion de l'un des muscles releveurs de la mâchoire (le muscle temporal); ces muscles (fiy. 76 : - $^{2}$ fivent toms ress lamprle de la mâchoire et à peu de distance du point d'appuis-mr leyucl ce levier se ment. Dans la plupart des cas, c'est, au contraire, vers la partic antérieure des màchoires qu'est

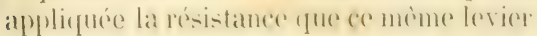

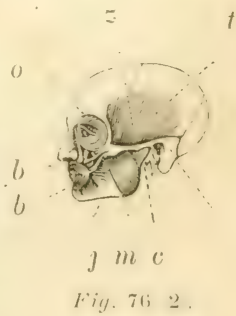

(l

Fig. $\pi 6 ; 2$

(1) oc, $t, f$, os occipital, temporaux et frontal; $-n$ os nasal; $-m$ maxillaire supérieur; - im inter-maxillaire; - mi maxillaire inférieur; - o orbite; $i$ dents incisives; $-c$ canines; - mo molaires.

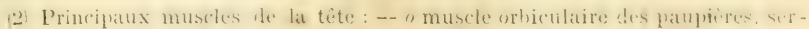
vant à fermer les yeux; $-b$ muscle orbiculaire des levres, servant à rapprocher 
doit vaincre pendant la mastication; aussi ces muscles, quoique très-puissants, ne peuvent-ils alors produire que des effets trèsfaibles; et, pour écraser entre les dents les corps les plus durs, est-on obligé de porter ceux-ci aussi loin que possible vers le fond de la bouche, de manière à raccourcir le bras de levier de la résistance, et à le rendre égal ou mème plus court que celui de la puissance. Ces muscles se fixent à la face interne aussi bien qu'à la face externe de la màchoire, et vont prendre leur point d'appui sur les còtés de la tète jusqu'au haut des tempes, en passant entre les parois latérales du cràne el une arcade osseuse, nommée zyyomatique (z), qui sútend de la jommette jusquà l'oreille, et qui sert aussi à l'insertion de ces organes.

La tète, comme on a pu le voir, se compose essentiellement de vingt-deux os; mais leur nombre est réellement plus considérable; car, dans lintérieur de chaque os temporal, il existe, ainsi

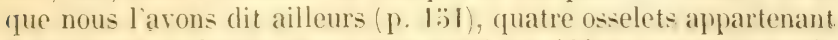
a l'appareil de l'oüe; et on peut aussi considérer comme une dépendance de la tète los hyö̈de (fig. 20), (qui est suspendu aux os temporaux par des ligaments, et qui est placé en travers de la partie supérieure du cou, où il sert à porter la langue et à soutenir le larynx.

$\$ 271$. Tronc. - La partie la plus importante du trone et mème de tout le squelette, celle qui sert de soutien a toutes les autres et rui varie le moins chez les divers animaux, est la coloxve vertébrale ou colonne épinière.

On donne ce nom a une espèce de tige osseuse qui regne dans toute la longueur du corps et qui se compose d'un grand nombre de petits os appelés rertebres, placés bout a bout et solidement unis entre eux.

res organes; $-j$ muscle des joues; $-m$ muscle masséter, servant à élever la mâchoire inférieure; $-t$ muscle temporal, servant au nême usage; $-z$ arcáde zygomatique ; $-c$ articulation de la mâchoire inférieure ; - $\bullet$ trou auditif et apophyse mastoïde. 
(Is frontal.

Orbite.

Maichoire infér.

Vertèbres cervicales.

Omoplate.

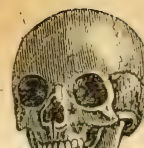

Os pariétal.

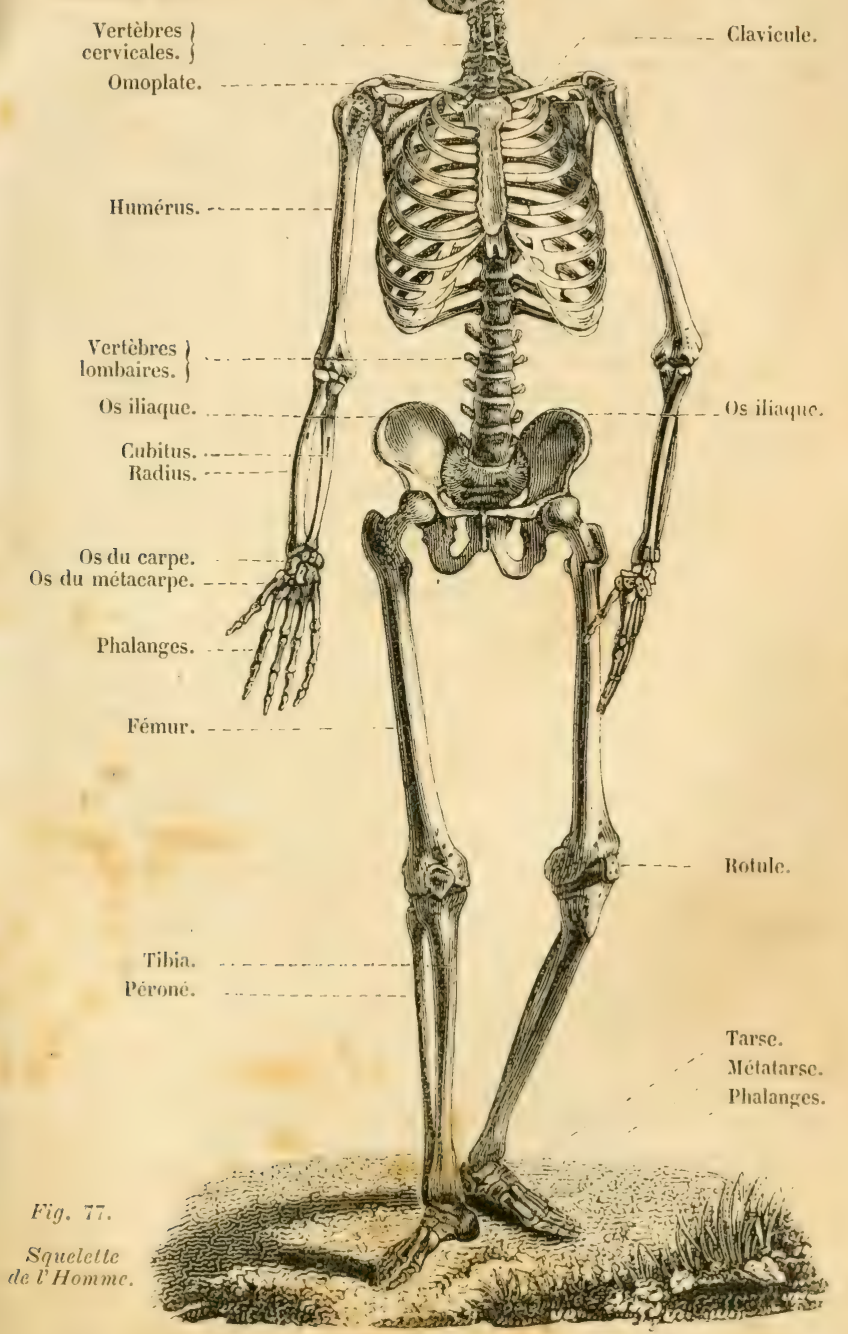


Cette colomme (fig. 78), qu'on appelle aussi l'épine du dos, occupe la ligne médiane et postérieure du corps (fig. 77), et

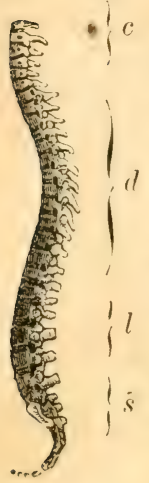
supporte à son extrémité supéricure la tète, qu’on peut eonsidérer comme en étant la continuation. Dans l'homme, on y compte trente-trois vertebres, et on y distingue cind portions, savoir : une portion cervicale, composée de sept vertibres (c); une portion dorsale, composée de douze de ces os $(d)$; une portion lombaire, formée de cing vertebres $(l)$; une portion sacrie, qui en offre également cing $(s)$; et une portion coceygienne, où l'on en voit quatre $(c x)$. Elle présente plusieurs courbures et augmente de grosseur depuis son extrémité antérieure ou supérieure jusqu'au commencement de la portion sacrée. Vers le moment de la naissance, toutes les vertibres sont parfaitement distinctes et sont simplement articulées entre elles; mais bientot apres, les cind vertebres c $x$

Fig. 78. sacrées se soudent entre elles et ne forment plus qu'un seul os nommé sacrum $(s)$.

Le caractère essentiel des vertebres est d'etre traversées par un trou (fig. 79) qui, en se réunissant ì ceux des autres vertehres, forme

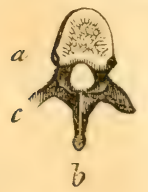

Fig. 79. un canal s'étendant depuis le cràne jusque vers l'extrémité du corpss et logeant, comme nous l'avons déjà dit, la moelle épiniere; dans l’homme, les vertelores coceygiemnes ne présentent eependant joint de canal semblable, car elles sont réduites à un état rudimentaire, et ne consistent qu'en autant de petits noyaux solides. Sur les coilés, ce canal vertébral communique au dehors par une série de trous appelés trous de conjugaison, parce qu'ils résultent de la réunion de deux échancrures, pratiquées sur les bords superieur et inférieur de chaque vertibre, de façon à se correspondre lorsque ces os sont unis entre eux. Ces trous, comme nous l'avons déja vu, livrent le passage aux divers nerfs qui naissent de la moelle épiniere et qui vont se distribuer aux différentes parties du corps.

On distingue dans chaque vertebre un corps et diverses apophyses. Le corps de la vertebre (fig. 79, a) est un disque épais situé au-devant du canal vertébral (ou au-dessous, si la colomne est dans une position horizontale, comme chez la plupart des animaux), el servant à dommer de la solidité à l'articulation de ces os entre eux. Les deux faces de ce disque sont à peu pres parallèles, ef charume d'elles est mie a la surface rorrespondaute de la ver- 
tebre voisine par une couche épaisse de fibro-cartilage qui adhère à l'me et à l'autre dans toute l'étendue de ces surfaces articulaires, et ne leur permet de s'éloigner entre elles qu’à raison de l'élasticité dont son tissu est doué. L’articulation des vertèbres est encore fortifiée par l'existence de quatre petites apophyses qui sont situées sur les còtés du canal vertébral et qui s'engrènent avec celles des vertèbres voisines. Enfin, en arrière de ce canal, il existe une apophyse appelée épineuse (b), qui concourt au mème but, en limitant la flexion de la colonne en arrière, et des faisceaux de fibres ligamenteuses s'étendant encore d'un os à l'autre de facon à les lier entre eux.

L'articulation des vertèbres entre elles est, conme on le voit, extrèmement solide: aussi les mouvements que chacun de ces os peut exécuter, sont-ils, en général, très-bornés; mais ces petits mouvements, s'ajoutant les uns aux autres, donnent à l'ensemble de la colonne assez de flexibilité sans nuire à sa force. Du reste, cette mobilité varie beaucoup dans les différentes jarties du trone: au dos, elle est presque nulle; aux lombes, elle est, au contraire, assez marquée; mais c'est dans la portion cervicale de la colonne qu'elle est le plus prononcée: aussi, dans ces parties, la couche fibrocartilagineuse qui doit se prèter à ces déplacements est-elle plus épaisse qu'au dos, et les apophyses épineuses sont-elles plus écartées l'une de l'autre, de façon à permettre une courbure plus considérable de la colonne avant qu'elles ne viemnent à se rencontrer.

Le poids du corps tend contimuellement à courber la colonne vertébrale en avant; aussi y a-t-il, pour résister à cette flexion et pour redresser l'épine dorsale, des museles puissants qui s'insirent le long de sa face postérieure; et, afin de rendre leur action plus puissante, la nature a disposé leur point d'attache de façon à les faire tirer perpendiculairement sur un bras de levier assez long. En effet, la plupart d'entre eux se fixent à l'extrémité des apophyses dites ipineuses, qui forment une crite saillante dans toute lat Iongruenr du dos; et d'autres prennent leur point d'attache sur deux autres apophyses (c, fig. 79), qui sont écralement très-saillantes et rue l'on nomme, i cause de leur direction, apophyses transverses.

It est à remarfuer aussi que, daus les portions de la colonne où ces muscles doivent diployer le plus de foree, comme aux lombes, ces apophyses sont bien plus longues, et, par consiyuent, forment un levier bien plus puissant fue dans les parties ou toute cette force n'est pas néessaire, au con, par exemple. Par la suile nous an-

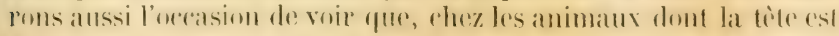


pesante et se trouve à l'extrémité d'un cou long et horizontal, ces apophyses prennent un accroissement extrème au dos, où elles servent à l'altache des ligaments et des muscles destinés à soutenir ces parties et à relever le cou (voyez fig. 80 ).

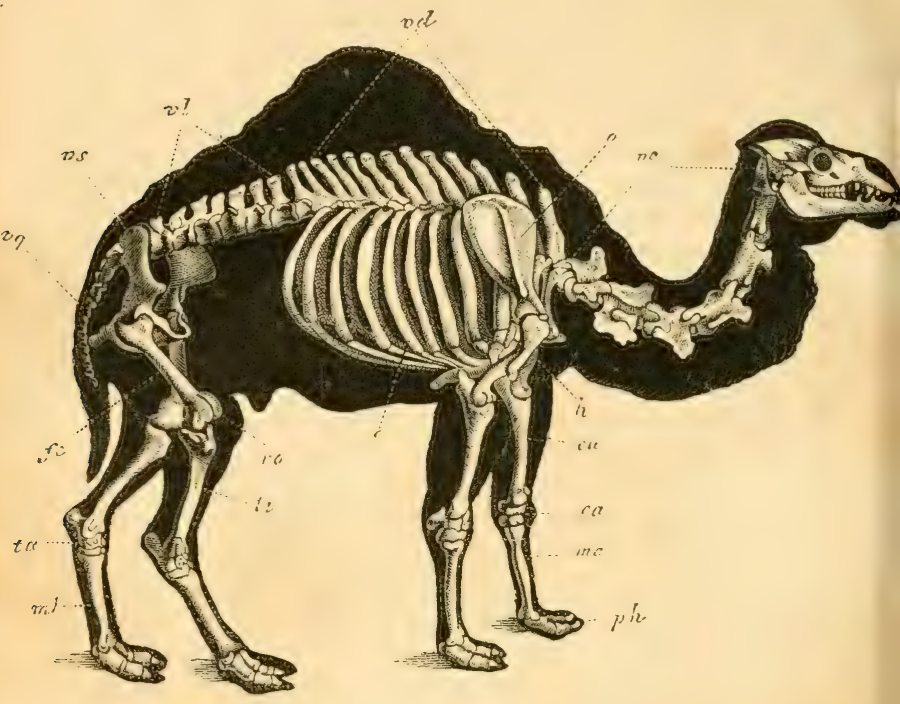

Fig. 80. Squelelte du Chameau (1).

Les mouvements de flexion de la colonne en avant ne nécessitent presque aucun déploiement de force, et les muscles employés à les produire, et situés au-devant du corps des vertibres, sont, par conséquent, grèles et en petit nombre.

La preniere vertìbre du cou nomméc atlas, est beaucoup plus mobile que toutes les autres : clle a la forme d'un simple anneau et tourne autour d'une espèce de pivot formé par une apophyse qui s'élève du eorps de la vertèhre suivante (ou axis). C'est mème dans celte articulation que s'effectuent presque entièrement les

(1) Le squelette du chameau sur un fond noir représentant la silhouette de l'animal. $-v c$ vertebres cervicales; $-v d$ vertebres dorsales; $-v l$ vertèbes lombaires: - vs sacrum; - $v q$ vertèbre de la queue; $-c$ côtes; - o omoplate; $-h$ humérus; - cu cubitus; - ca carpe; - mc métacarpe; - ph phalanges; - fé fémur; - ro rotule; - li tibia ; - la tarse; $-m$ l métatarse. 
mouvements de rotation exécutés par la tète. Les liens qui unissent ces deux vertebres sont incomparablement moins forts que ceux des autres vertebres; el en effet, dans la position ordinaire du corps, le poids de la tète pressant sur l'atlas, tend plutôt à les maintenir en contact qu'à les séparer; mais lorsque c'est la tète qui supporte tout le poids du corps, comme cela a lieu chez les persomnes pendues, il en est tout autrement : ces deux vertibres se séparent alors facilement et leur luxation produit une mort presque instantanéc par suite de la compression de la moelle épinière, précisément dans le point où naissent les principaux nerfs de l'appareil respiratoire. C'était dans la vue de déterminer cette dislocation du cou, et, par conséquent, d'abréger les souffrances des criminels condamnés à périr sur la potence, que les bourreaux avaient autrefois l'habitude d'appuyer, avec les pieds, sur l'épaule des suppliciés, au moment ou ils les lançaient de leur échelle la corde au cou; et cést par la mème cause qu'on a vu quelquefois ume mort subite arriver

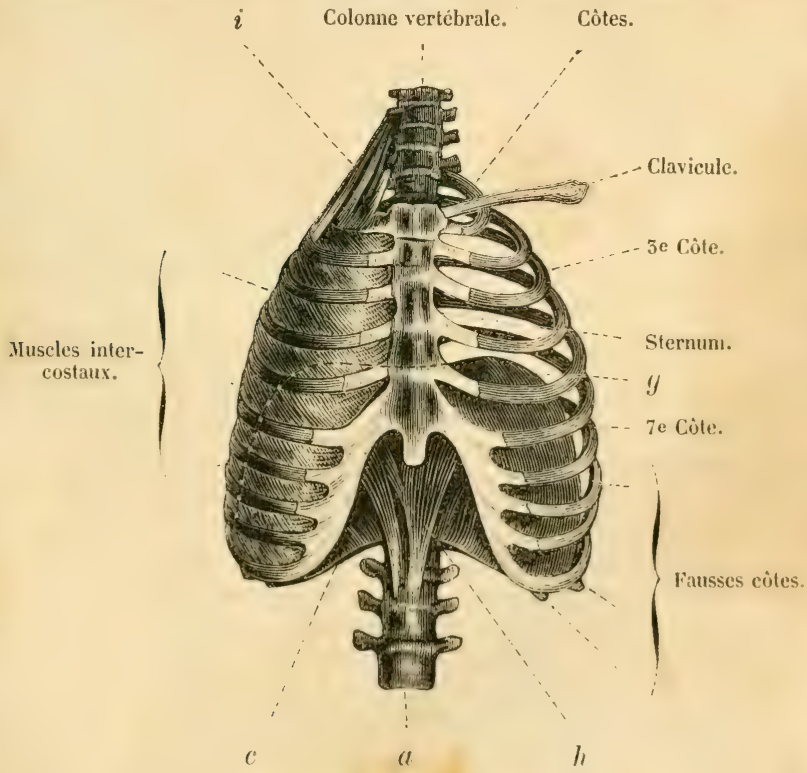

Fig. S1. Thorax de l'Ilomme (1).

(1) Voyez l'explieation de cette figure, page 94. 
$\zeta$ au milieu des jeux imprudents dans lesquels on souleve les enfants en les tenant, entre les deux mains, suspendus par la tète.

$\$ 272$. Les vertèbres cervicales ne s'articulent qu'entre elles ou avec la tète et la première vertèbre du dos; mais chacune des douze vertebres dorsales porte une paire d'arceaux tres-longs et aplatis, qui se recourbent autour du tronc, de facon a former une sorte de cage osseuse destincé à loger le cœur et les poumons. Ces arceaux sont les côtes (fig. 77 et 81), dont le nombre est, par conséquent, de donze de chaque côté du corps; leur extrémité postérieure est articulée avec le corps de la vertèbre correspondante et avec l'une des apophyses transverses; l'autre extrémité se continue avec une tigecartilagineuse, qui, chez certains animaux (les oiseaux par exemple), est toujours ossifiéc et porte alors le nom de cóte sternale. Les cartilages des sept premières paires de côtes, que l'on appelle les vraies côtes, viennent se joindre au sternum (fig. 81), os impair qui oceupe en avant la ligne médiane du corps et sert à compléter les parois de la cavité thoracique; les cinq dernières paires de cotes n'arrivent pas au sternum, mais se joignent aux cartilages des còtes précédentes : on les distingue sous le nom de fausses côtes.

\$273. Membres. - C'est sur la cage osseuse dont nous venons de parler que se fixent les menbres supériecrs. On distingue, dans chacun de ces appendices, une portion basilaire, qui peut ètre comparéc à un socle, sur lequel s'insère la portion essentiellement mobile du membre, celle qui représente un levier, auquel la première sert de point d'appui.

Cette portion basilaire se compose de deux os, l'omoplate et la clavicule.

L'omoplate est un grand os plat, qui oceupe la partic supéricure et externe du dos : sa forme est à peu près triangulaire, et il présente en haut et en dehors une cavité articulaire assez large, mais peu profonde, destinée à recevoir l'extrémité de l’os du bras (fosse glénöidale de l'omoplate). A son bord supérieur, on remarque une apophyse saillante appelée coracoüde; et sur sa face externe se trouve une crète horizontale très-saillante, qui vient se terminer au-dessus de l'articulation de l'épaule, en formant une apophyse, nommée acromion, à l'extrémité de laquelle s'articule la clavicule (fig. 77 et 81). Ce dernier os est grèle el cylindrique : il est placé en travers à la partie supérieure de la poitrine, et s’étend, comme un arc-boutant, du sternum à l'omoplate. Son principal usage est de maintenir les épaules cicartíes : aussi se brise-t-il tres-souvent. lorsque, dans les chutes sur le côté, cette partie est poussée aver: 
violence vers le sternum, et, chez les animaux qui doivent porter avec force le bras vers la poitrine (comme les oiseaux le font pendant le vol), cet os est-il très-développé, tandis qu’il manque complétement chez ceux qui n’exécutent jamais de mouvements semblables et rui ne meuvent leurs membres que longitudinalement, comme les chevaux, etc.

Des muscles nombreux fixent l'omoplate contre les còtes. L'un des principaux d'entre eux est le grand dentelé, qui se porte de la partie antéricure du thorax au bord postéricur de cetos, en passant entre lui et les còtes. Chez l'homme, il est peu développé; mais, chez les animaux qui marchent à quatre pattes, il est extrèmement fort, et constitue avec celui du còté opposé une espèce de sangle qui supporte tout le poids du trone, et qui empèche les omoplates de remonter vers la colonne vertébrale. Dans l'homme, le muscle trapèze, qui s'étend de la partie cervicale de la colonne vertébrale à l'omoplate, a également des fonctions très-importantes; car il sert à relever l'épaule et à soutenir le poids de tout le membre thoracique : aussi est-il très-développé.

$\$ 274$. La portion du membre thoracique qui constitue le levier auquel l'oplomate sert de point d'appui, se compose du bras, de l'avant-bras et de la main.

Le bras est formé par un seul os, long et cylindrique, nommé humérus (fig. 77). Son extrémité supéricure (ou tête) est grosse, arrondie et articulée avec la cavité glénoïde de l'omoplate, dans laquelle elle peut rouler dans tous les sens. Les museles destinés à mouvoir l'humérus s'insèrent au tiers supéricur de cet os et s'attachent, par leur extrémité opposée, à l'omoplate ou au thorax. Les trois principaux sont le grand pectoral, qui porte le bras en dedans, en mème temps qu'il l'abaisse; le grand dorsal, qui te porte en arrière et en bas; et le deltö̈de, qui le relève.

L’extrémité inféricure de l'humérus est élargie et a la forme d'une poulie, sur laquelle l'avant-bras se meut comme sur une charnière.

\$27.3. Deux os longs, placés parallelement, forment eette portion du membre thoracique : c'est le cubitus en dedans, et le radius en dehors. Ils sont unis entre eux par des liganents, et par me? cloison aponévrotique qui s'étend de l'un à l'autre dans toute leur longueur; mais, cependant, ils sont mobiles, et le radius, qui porte a son evtremite la main, peut tourner sur le cubitus, qui lui sert de serutien. I'apres les usages differents de ees deux os, on peut proivoir quelles doivent etre les principales différenees de leur forme

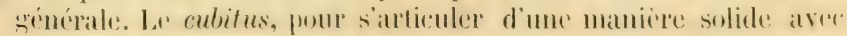


l'humérus, doit présenter à son extrémité supéricure une certaine grosseur et une surface articulaire étendue, tandis qu’ì son extrémité inférieure, où il doit servir de pivot an radius, il doit ètre grèle et arrondi. Le radius au contraire doit ètre, pour la mème raison, grèle à son extrémité supérieure el trèslarge à son extrémité inférieure, à laquelle est suspendue la main: e'est effectivement ce qui a lieu, el on remarque aussi que ces deux os ne se touchent que par leurs deux extrémités, ce qui rend plus faciles les mouvements de rotation du radius sur le cubitus.

Le cubitus, qui entraine avec lui le radius, ne peut se mouvoir sur l'humérus que dans un sens : il n'exécute que des mouvements de flexion et d'extension, et, dans ces derniers, il ne peut former avec l'humérus qu'une ligne droite, ear il présente au delà de sa surface articulaire une apophyse, nommée olécrane, qui s'appuie alors sur l'humérus, et oppose ainsi un obstacle invincible à toute extension ultérieure. Les muscles extenseurs et fléchisseurs de l'avant-bras s’étendent de l'épaule ou de la partie supérieure de l'humérus à la partie supéricure du cubitus : il en résulte qu’ils sont disposés d'une manière favorable à la rapidité des mouvements de l'avant-bras, mais très-défavorable au déploiement d’une grande force, car le loras de levier de la puissance, représenté par l'espace compris entre l'articulation du coude et leur insertion, est trèscourt, tandis que le bras de levier de la résistance, qui est égal à toute la longueur du membre à partir de la mème articulation, est au contraire très-considérable.

Les mouvements de rotation du radius et de la main sur le cubilus sont effectués par des muscles qui sont situés à l'avant-bras, et qui se portent obliquement de l'extrémité de l'humerus ou du cubitus à l'une et à l'autre de ces parties.

$\$ 276$. La main se divise en trois portions : le carpe, le métacarpe et les doigts.

Le carpe ou poignet est formé par deux rangées de petits os courts, unis tres-intimement entre eux, de facon que l'ensemble de cette partie jouit de quelque mobilité, quoique chacum des os dont elle se compose ne se déplace qu’à jeine, disposition qui est de nature àdommer ì leurs articulations une solidité tris-grande. On en compte huit. (Wuatre de ces us, savoir : le scaphoüde, le semilunaire, le pyramidal, et le pisiforme, composent la première ranzée; les quatre autres, que l'on nomme trapèze, trapésoüde, yrand os et os erochu, en forment la seconcle. Il est at remarquer que ces

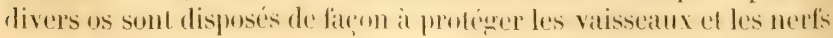


parties principales, la cuissè, la jambe et le pied, lesquelles répondent au bras, à l'avant-bras et à la main.

$\$ 279$. La hanche, ou portion basilaire du membre abdominal, est formée par un grand os plat, nommé os iliaque (du mot latin ilia, flane) ou os coxal (du mot coxa, qui en gree signifie hanche). Cet os résulte de la soudure de trois pièces principales, toujours distinctes dans le jeune àge, que l'on peut comparer au corps de l'omoplate, à l'apophyse coracoüde de cet os, et à la clavicule. Les os iliaques ne trouvent point, comme les os de l'épaule, des còtes et un sternum, pour s'y appuyer; ćtant destinés à soutenir tout le poids du corps, ils doivent cependant ètre fixés de la manière la plus solide au trone: aussi les voit-on s'articuler en arrière avec la portion de la colonne vertébrale appelée sacrum, et en avant se réunir entre eux, en formant une arcade nommée pubis. Ils sont complétement immobiles, et il résulte de l'union de ces deux os entre eux et avec le sacrum une large ceinture osseuse, qui termine inférieurement l'abdomen, et qui, à cause de sa forme évasée, est appelée bassin (fig. 77, page 191). Cette espèce d'anneau est bouché inférieurement par des muscles. Sur le còté et en dehors, on remarıue sur chaque os iliaque nne cavité articulaire, à peu près hémisphérique, qui sert à loger la tète de l'os de la cuisse, Enfin la plupart des muscles destines à mouvoir la cuisse et la jambe prennent insertion sur le bassin, et les muscles, qui cloisonnent, comme nous l'avons vu ailleurs, la cavité abdominale, s'y fixent pour s'étendre de là au thorax.

$\$ 280$. La cuisse, comme le bras, ne se compose que d'un seul os, que l’on nomme fémur (voyez fig. 77, page 191). Son extrémité supérieure est coudée en dedans, et sa tète, qui est arrondie, est séparée du corps de l'os par un rétrécissement, appelé col du fémur. Au bas de ce col et dans le point où il se joint an corps de l'os, en formant un angle ouvert, on remarque plusieurs grosses tubérosités, qui peuvent ètre senties à travers la peau, et qui servent à l’insertion des principaux muscles moteurs de la cuisse; enfin son extrémité inférieure est renflée et présente deux condyles comprimés latéralement et arrondis d'avant en arriere, qui glissent sur la surface articulaire du principal os de la jambe et ne permettent à celui-ei que de se ployer en arrière ou de s'étendre, landis que le fémur lui-mème jeut se mouvoir sur le bassin dans tous les sens.

$\$ 281$. La jambe differe davantage de l'avant-bras. Outre le péroné et le tibia, qui sont les deux os principaux dont cette partie du memhre inférieur se compose, comme l'avant-loras se compose dn cubitus et do radius, on trouve au devant du genou un troisieme os 
appelé rotule, qui peut ètre considéré comme l'analogue de l'apophyse olécrane du cubitus, et qui sert principalement à éloigner du genou le tendon des muscles extenseurs de la jambe et à rendre son insertion au tibia plus oblique, disposition qui, ainsi que nous l'avons déjà vu $(\mathbb{S} 266)$, doit tendre à augmenter la puissance de son action. Le pied ne devant pas exécuter des mouvements de rotation comme la main, et devant, pour soutenir tout le poids du corps, présenter dans son articulation beaucoup de solidité, les deux os de la jambe ne sont pas mobiles l'un sur l'autre, et celui d'entre eux qui s'articule avec le fémur ( le tibia ) est aussi celui qui porte le pied à son extrémité opposće. Le péroné, qui est grèle et situé du côté externe du tibia, ne sert, pour ainsi dire, qu’à maintenir le pied dans sa position naturelle et à l'empècher de tourner en dedans. Son extrémité supérieure est appliquée contre la tète du tibia, et son extrémité inférieure constitue la cheville malléole ou externe.

$\$ 282$. Le pied se compose, ainsi que la main, de trois parties principales, savoir : le tarse, le métatarse et les doigts.

Il y a sept os au tarse, et son articulation avec la jambe ne se fait que par l'un d'entre eux, l'astragale, qui s'élève au-dessus des autres et présente une tète en forme de poulie, destinée à s'emboìter dans la cavité formée par la surface articulaire du tibia et les deux malléoles (1). L'astragale repose sur le calcanéum, qui se prolonge beaucoup plus loin en arriere, et constitue le talon; enfin un troisième os, appelé scaphoüde, termine la première rangée des os du tarse, et la seconde rangée se compose, comme à la main, de quatre petits os, dont trois ont reçu le nom d'os cunéiformes, et le quatrième, placé en dedans, est appelé os cuboïle.

Les os du métatarse, au nombre de cinq, ressemblent exactement a ceux du métacarpe : seulement ils sont plus forts et moins mobiles, surtout l'interne, qui est disposé comme lesautres. Il en est de mème pour les orteils; on y compte le mème nombre de phalanges quaux doigts de la main, mais ces os sont plus courts et beaucoup) moins mobiles. Le gros orteil n’est pas détaché des autres, et ne peut leur ètro opposé, comme le pouce s'oppose aux autres doigts.

Du coté interne du pied, les os du tarse et du métatarse forment une espece de voùte, destince à loger et à protéger les nerfs e les vaisseaux qui descendent de la jambe vers les orteils. Lorsque cette disposition n'existe pas, et que la plante du pied est plate, comme cela arrive quelruefois, ees nerfs somt comprime's

(1) La mallende inferne est me apophỵse du tibia; lexterne, comme nous lavons dèjà dit, est formée par le péroné. 
par le poids du corps, et la marche ne peut ètre continuće longtemps sans douleur. Du reste, le pied pose sur le sol dans toute son étendue, et forme une base de sustentation large et sulide; il ne peut se mouvoir sur la jambe que dans le sens de sa longueur, et les muscles servant à cet usage entourent le tibia et le péroné. Les extenseurs du pied, qui forment la saillie du mollet, se fixent au calcanéum par un gros tendon, appelé tendon d'Achille, et sont disposés d'une maniere favorable à leur action; car leur insertion a lieu presque à angle droit, et se trouve plus áloignée du point d'appui que ne l'est la résistance qu'ils doivent vaincre lorsque le poids du corps, pressant sur l'astragale, est soulevé par le pied.

\section{Des attitudes et de la locomotion.}

$\$ 283$. Tous les mammifères, les oiseaux, les reptiles et les poissons ont un squelette intérieur plus ou moins semblable à celui de l’homme, composé à peu près des mèmes os (fig. 80), et mu également par des muscles placés entre cette charpente solide et la peau ou membrane tégumentaire. C'est ce squelette qui donne ì leur corps sa forme générale, et c'est de sa disposition et de l'action des muscles fixés à ses diverses parties que dépendent les attitudes aussi bien que les mouvements de ces animaux.

$\$ 28$. Station. - Un petit nombre de ees ètres (les serpents, par exemple) posent habituellement sur le sol par toute la longueur de leur corps, et ne se déplacent que par les ondulations de leur trone; mais les autres sont ordinairement soutenus sur leurs membres, et on donne le nom de station à cet état dans lequel un animal se tient de la sorte sur le sol, dressé sur ses jambes.

Pour que les membres puissent rester fermes et soutenir ainsi le corps, il faut que leurs muscles extenseurs se maintiennent contractés, ear, sans cela, ces organes fléchiraient sous le poids qu’ils supportent et en détermineraient la chute. Nous avons déjà vu que les muscles se fatiguent d'autant plus vite que chacune de leurs contractions dure plus longtemps; aussi, chez la plupart des animaux, la station est-clle à la longue plus fatigante que la marehe, car pendant celle-ci les muscles extenseurs et fléchisseurs se relaient mutuellement.

$\$ 28 \%$. Celte condition n'est pas la seule qui soit indispensable a la station; pour que le corps reste debout sur ses membres ainsi roidis, il faut qu’il soit en équilibre.

L'équilibre s'établit non-seulement lor'squ'un corps pesant appuic sur un objet résistant par toute l'étenduc de sa surface la plus 
large, mais aussi lorsqu'il est placé de telle facon que, si une partic de sa masse s'abaissait ver's la terre, une partie opposée, également pesante, s'élèverail d'autant; le poids d'une partie sert alors i contre-balancer celle de l'autre, et on appelle centre de gravité le point autour duquel toutes ces parties se font réciproquement équilibre, et qu'il suffit de soutenir pour maintenir en place la masse entière. Or, pour sontenir le centre de gravité, il suffit que la base de sustentation (c'est-ì-dire l'espace occupé par les points par lesquels la masse s'appuie sur un objet résistant ou cclui compris entre ces points) soit située verticalement au-dessous de ce centre.

Pour que le corps d'un animal reste en équilibre sur ses pattes, il faut par conséquent que la verticale passant par son centre de gravité tombe dans les limites de l'espace que les pieds laissent entre eux ou recouvrent eux-mèmes; et plus cette base de sustentation sera large par rapport à la hauteur à laquelle se trouve le: centre de gravité, plus son équilibre sera stable; car plus aussi il pourra ètre déplacé sans que la ligne de gravité, dont nous venons de parler, cesse de tomber dans les limites de cette base. II en est de mème pour tout corps pesant: ainsi la table a représentée

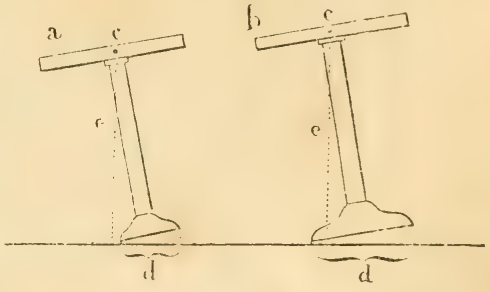

Fig. 82.

dans la figure $\$ 2$ devra tomber, paree que la verticale $(\rho)$, abaissie de son centre de gravité $(c)$, dépassera les limiles de sa base de sustentation $(d)$, c'est-ì-dire l'espace oceupé par son pied; landis que la table $b$ étant également inclinée ne sera pas renversée, paree que sal base de sustentation est assez latrefe pour que la ligne de gravile n’en dépasse pas les limiles. Il est anssi à noter que plus l'épuilibresera difficile à conserver, plus la contraction musculaire nécessaire pour le maintenir derra ètre intense, et plus la position de l'animal sera fatigante.

b'apres cela, on peut voir que, lorsqu'un animal pose ì la fois sur se's quatre membres, lat station deva etre en general plus ferme, plus solicle al moins fatigante que lorsqu’il ne pose que sur drux, et que, dans oe dernier eas, il sera eneore dans un ctat

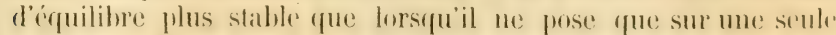
jambe; rat l'efendue de la hase de sustentation deviendra ainsi de 
plus en plus étroite. Quand un animal se tient sur ses quatre pieds, l'espace compris entre eux est très-considérable et ne peut ètre que peu modifié par l'étendue plus ou moins grande de la surface de ces organes. Les rendre très-larges aurait donc augmenté leur poids, sans ajouter notablement à la solidité de la base de sustentation: aussi, chez la plupart des quadrupedes, les membres ne touchent-ils le sol que par une extrémité à peine dilatée, et voit-on le nombre des doigts diminuer de plus en plus, sans nuire ì ces organes comme instruments de locomotion : le pied du cerf et celui du cheval nous en offrent la preuve (fig. 83 et 8.t); mais, lorsque l'animal ne pose que sur deux de ses pieds, quel que soit

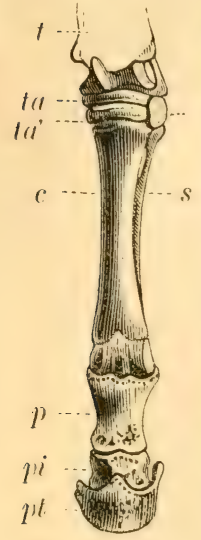

Fig. $85(1)$.

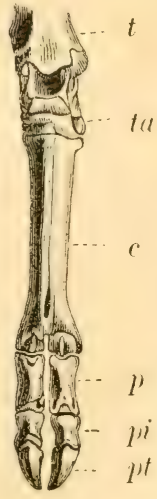

Fig. 84.

leur écartement, la base de sustentation ne peut avoir de solidité d'avant en arrière qu'autant que ces organes touchent le sol dans une étendue considérable, comme cela a lieu pour le pied de l'homme (fig. 77); et, lorsqu'un animal se tient facilement sur une seule patte, ainsi que le font les oiseaux, il faut que la nature ait donné à ces pieds encore plus de largeur aussi bien que de longueur (fig. 90).

Pour qu'un animal puisse se mettre en équilibre sur une seule de ses jambes, il faut aussi que le pied sur lequel il pose se place verticalement au-dessous du centre de gravité de son corps el que ses muscles soient disposés de façon à lui permettre de maintenir alors ce membre inflexible et immobile. L'homme y parvient; car le centre de gravité de son corps se. trouve vers le milieu de son bassin, et, en se plaçant dans la posilion verticale, il lui suffit de se courber un peu du côté qui ne pose pas, pour que la ligne de gravité tombe sur la plante du pied du côté opposé; mais pour la plupart des quadrupèdes, la chose est impraticable.

La plupart de ces derniers animaux ne peuvent mème se tenir

(1) Fig. 8.5, jambe posterieure du cheval; et fig. S.4, jambe de cerf; - t tibia; la premiere rangee des os du tarse; - lu' deusieme rangee de ces os; $-c$ metatarse

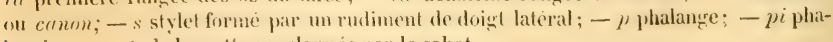
langine; - pl phalangette enveloppée par le sabot. 
dressés sur leurs pattes postéricures, à cause de la direction de ces membres, relativenent au tronc; et, s'ils y parviemment pour un instant, il leur est impossible de maintenir l'équilibre, parce que leur base de sustentation est très-étroite, le centre de gravité de leur corps est placé très-haut (vers la poitrine), et les muscles qui servent à leur faire prendre cette attitude sont obligés de se contracter avec une violence qui nécessite un prompt repos. Pour l'homme et un petit nombre d'autres mammifëres, la station verticale sur les deux membres abdominaux est au contraire plus ou moins facile; car ces membres peuvent aisément se placer dans la direction de l'axe du corps, le centre de gravité est situé trèsbas, et la base de sustentation, formée par les pieds, est assez large. Chez l'homme surtout, cette attitude est rendue solide par la largeur du bassin, la forme des pieds, et quelques autres particularités d'organisation.

$\$ 286$. Dans la station verticale, les muscles de la partie postérieure du cou se contractent pour maintenir la tète en équilibre sur la colomne vertébrale, et les muscles extenseurs de cette colonne entrent aussi en action pour l'empècher de céder sous le poids des membres thoraciques et des viscères du tronc, qui tendent à les courber en avant. Tout le poids de notre corps se transmet ainsi par la colonne vertébrale au bassin et du bassin au fémur. Abandonnés à eux-mèmes, ces derniers os se ploieraient sur le bassin, et le trone tomberait en avant; mais la contraction de leurs muscles cxtenseurs les maintient etendus. Les muscles extenseurs de la jambe enpèchent en mème temps les genoux de fléchir, et les muscles extenseurs du pied maintiennent la jambe dans la position verticale, de facon que le poids du corpss se transmet de la cuisse à la jambe, de la jambe au pied et du pied au sol.

$\$ 287$. La position assise est moins fatigante que la station, parce que le poids du corps se transmettant alors directement du bassin à la hase de sustentation, il n'est pas nécessaire que les muscles extenseurs des membres abdominaux se contractent pour maintenir l'équilibre. Enfin, lorsque l’homme est couché sur le dos ou le ventre, le poids de chaque portion mobile de son corps se transmet direcfement all sol, et prar conséquent, pour se maintenir de la sorte, il n'a besoin de contracter aucun de ses muscles.

\$288. Marche. - Les mouvements progressifs par lesquels l'homme et les animaux se transportent d'un lien à un autre exigent qu’ume vitesse déterminée soit imprimée, dans me certaine directom, an centre de eravite de leur eorps. Cette impulsion lui

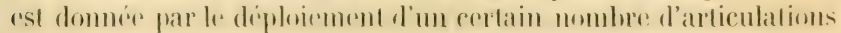


plus ou moins fléchies, et dont la position est telle, que, du cóté du centre de gravité, leur déploiement est libre, landis que, du côté opposé, il est gèné ou mème impossible, de facon que la totalité ou la plus grande partie du mouvement produit a lieu dans la première de ees directions. Il se passe alors la mème chose que dans un ressort à deux branches, dont l'une des extrémités est appuyée contre un obstacle résistant, et dont les deux branches, apres avoir été rapprochées par une force extérieure, sont rendues à leur liberté primitive: à raison de leur élasticité, elles tendront à s'écarter égralement jusqu’à ce qu'elles soient revenues dans la position qu'elles avaient avant que d'ètre comprimées; mais, celle appuyée contre l'obstacle ne pouvant le foreer, le mouvement se fera en entier dans le sens opposé, et le centre de gravité du ressort s'écartera de cet obstacle avec une vitesse plus ou moins grande. Dans le corps des animaux, les muscles fléchisseurs de la partie employée dans chaque sorte de mouvements représentent la force qui comprime le ressort, les museles extenseurs représentent l'élasticité qui tend à le redresser, et la résistance du sol, ou celle du fluide daus lequel ces ètres se meuvent, représente l'obstacle qui s'oppose au déplacement de l’ume de ses extrémités.

Ainsi, lorsque nous marchons, l'un de nos pieds est porté en avant, tandis que l'autre s'étend sur la jambe; 't, comme ce dernier membre appuie sur un sol resistant, son allongement déplace le bassin et projette en avant tout le corps ; le hassin tourne en mème temps un peu sur le fómur du coité opposé sur lequel il appuie, et la jambe, qui était d'abord restée en arrière, se fléchit, se porte en avant de l'autre, puis se redresse et sert à son four à soutenir le corps, pendant que l'autre membre, en s'ítendant, dome une nouvelle impulsion au centre de gravité. A l'aide de ses mouvements altermatifs d'extension et de flexion, chaque jambe porte à son tour le poids du corps, comme elle le ferait dans la slation sur un seul pied, et à chaque pas le centre de gravité est poussé en avant; mais on voit qu'il doit se porter en mème temps alternativement un peu à droite et à gauche pour se trouver directement au-dessus de chacune de ses bases de sustentation; et ce déplacement devient d’autant plus considérable que le bassin est plus large, ear les membres destinés à soutenir alteruativement le trone sont alors plus écartés entre eux.

$\$$ 289. Chez tous les animaux supérieurs de mème que chez l'homme, ce sont les membres qui servent à la locomotion; mais la nature de res mouvements varie heauenuy chez ees èles, et par conséquent la conformation de ces instruments doit presemler des 
différences correspondantes, car, ainsi yue nous l'avons dejà dit, les fonctions d'un apjareil sont toujours en rapport avec sa structure.

La maniere dont la nature approprie les mèmes organes à des usages différents en rapport avec les mœeurs des animaux est un sujet intéressant d’étude; car on la voit arriver ainsi aux résultats les plus variés sans se départir un seul instant du plan général qu'elle a adopté pour la conformation de tontes les especes d'une mème famille, et par le seul fait de changements légers dans la forme ou dans les proportions de quelques-uns des instruments dont l'ensemble constitue le corps de ces ètres. Les organes de la locomotion des mammiferes nous en fournissent des exemples. Effectivement, dans cette classe, il existe des ètres destinés à se mouvoir dans l'eau seulement ou bien à nager et à marcher tour à tour, d'autres qui sont organisés pour la course, d'autres qui possedent des ailes pour voltiger dans l'air à la manière des oiseaux, et d'autres encore qui n'emploient leurs membres antérieurs que pour saisir ou palper les oljets; et cependant chez tous ces animaux ces organes sont composés de la mème manière. Dans les nargeoires d'un phoque (fig. 86), l'aile d'une chauve-souris (fig. 89), et la patte d'un écureuil ou d'une taupe, on trouve les mèmes os que dans le bras de l'homme (fig. 77).

$\$ 290$. Lorsque les membres d'un quadrupède servent à la locomotion seulement, ces organes représentent des espèces de colomnes dont l'extrémité n'est que peu ćlargie. En effel, l'existence de doigts longs et flexibles nuirait à leur solidité, ajouterait à leur poids et ne serait d'aucune utilité à l'animal; aussi, chez les mammiferes les mieux organisés pour la course, tels que le cheval, le cerf ou le chameau (fig. 80), les membres sont-ils greles et peu ou point fendusà leur extrémité; le nombre des doigrts est réduit au minimum ; quelquefois il n'y en a qu'un seul (fig. 83); d'autres fois on en distingue deux (fig. 84), soit seuls, soit unis aux vestiges d'un troisieme ou meme d'un quatrieme appendice rudimentaire, et toujours les divisions terminales sont tres-courtes et peu mobiles.

I'apres ce que nous avons dit plus haut relativement à l'influence des leviers sur la vilesse du mouvement (\$ 267), on peut prévoir aussi que, chez les animaux les plus rapides à la course, les membres doivent nexssairement ère tres-lomgs; car la vitesse avec laquelle les muscles extenseurs des pattes se contratedent reslint la mème, le déplacement de l'extrémite libre de ces organes acpuerra d'autant plus de rapidite que cette extrémite serat plus bloignée du point d'insertion de ses museles moteurs ef du point d'articulation du levier aver le corps. Ainsi, pour donner à un ani- 
mal des habitudes lentes ou une grande agilité, il suffit à la nalure de le pourvoir de membres tris-courts ou de pattes très-longues, et de donner à ses muscles une puissance correspondante à l'effort qu'ils doivent exercer.

$\S 291$. Saut. - Dans la marche, le poids du corps est soutenu par une portion de l'appareil locomoteur pendant que son centre de gravité est poussé en avant par l'autre partie de cet appareil; de facon que l'animal ne cesse jamais de toucher au sol. Dans le saut, il n'en est pas de mème : le corps quitte alors momentanément le sol et s'élance dans l'air pour retomber à une distance plus ou moins considérable. Ce mouvement résulte du déploiement subit des diverses articulations des membres qui auparavant avaient été fortement fléchis; et, pour que le corps puisse c̀tre ainsi lancé avec force, il faut que l'espece de ressort, représenté par les membres, ait une longueur considérable, afin que, venant à se détendre, il imprime plus facilement une grande vitesse au corps qu'il est chargé de lancer comme un projectile. Or, chez les quadrupèdes, ce sont principalement les pattes de derrière qui servent à pousser le corjs en avant, tandis que les pattes de devant en soutiennent le poids et en assurent la stabilité. Il s'ensuit que dans le saut ce sont les membres postérieurs qui agissent principalement, et, chez les animaux les mieux conformés jour bondir avec agilité, ce sont ces membres qui doivent ètre en mème temps forts, longs et flexibles; les membres antérieurs n'ont pas besoin d'offrir un développement pareil, et, s'ils acquéraient une longueur égale à celle du train de derriere, ils embarrasseraient l'animal et ajouteraient inutilement à son poids. Aussi, chez les animaux doués de la faculté de franchir par le saut des espaces considérables, existe-

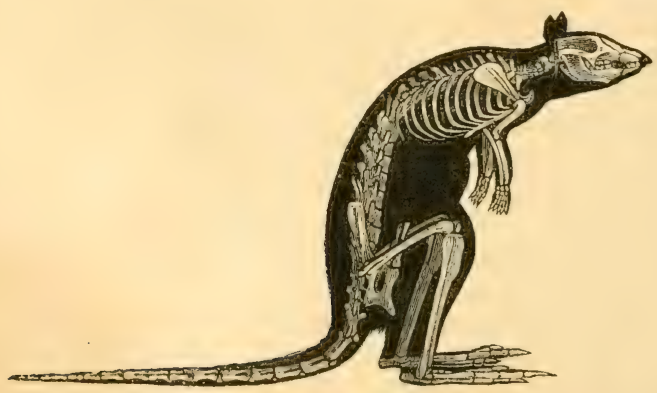

Fig. Sä. Squelelle du L̈muguron. 
l-il toujours une grande inegalité entre les membres : ceux de devant sont petits et lígers, tandis que ceux du train de derrière offrent une longueur considérable et sont disposés de facon à pouvoir se fléchir beaucoup et se redresser avec force. Ce mode d'organisation se remarque dejà chez les chats et les lapins, mais est porté bien plus loin chez les gerboises et les kangurous (fig. 83̈) parmi les mammiferes, et chez les grenouilles parmi les reptiles.

$\$ 292$. Natation et Vol. - La natation at le col sont des mouvements analogues à ceux du saut, mais qui ont lieu dans des fluides dont la résistance remplace, jusqu’a un certain point, celle du sol dans les phénomènes dont nous venons d’exposer le mécanisme.

Les membres qui, en s'étendant et en se reployant en arrière, doivent pousser le corps en avant, s'appuient dans ce cas sur l'eau ou sur l'air, et tendent à refouler ces fluides avee une vitesse plus ou moins grande; mais, si la résistance que l'air ou que l'eau présente dans ce sens est supérieure à celle qui s'oppose au mouvement de l'animal lui-mème en sens contraire, ces fluides fourniront au membre un point d'appui, et le mouvement produit sera le mème que si ce ressort touchait, jar son extrémité postérieure, un obstacle invincible, mais ne se débandait qu'avec une force égale à la différence existante entre la vitesse qu’il déploie et celle qu'il imprime au fluide ambiant en le refoulant en arriere. Or , moins le fluide dans lequel l'animal se meut est dense, moins le point d'appui qu’il lui fournira ainsi sera résistant, et plus la foree nécessaire pour dépasser de vitesse le déplacement de ce point d'appui et pour pousser le corps en avant sera considerable; aussi, le vol néessite-t-il me puissance motrice bien plos grande que la natation, ef l'un et l'autre de ces mouvements ne pourraicnl ètre effectues avec la foree qui, foutes choses cyales d'ailleurs, suffit pour déterminer le saut sur ume surface solide. Mais ce grand díploiement de foree motrice n'est pas la senle condition nécessaire à la locomotion áriemme on aquatique; comme l'animal, qui est plongé dans un fluide, frouvede tontes patrts me résistance eigale,

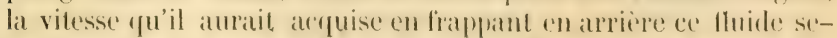

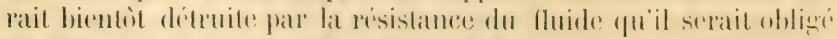
de déplacer en avant, s’il ne pouvait dimimuer consisléahlement la surface des orgaturs locomoteurs, immedialement apressen itre

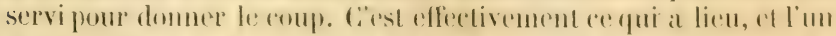

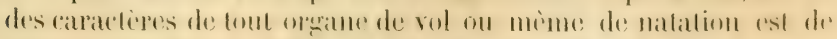

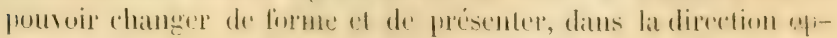


doigts cux-mèmes semblent ètre remplacés par une multitude de petites baguettes osseuses réunies sous une peau commune, mode d'organisation qui se rencontre dans les nageoires des poissons.

$\$ 294$. La structure des organes de locomotion aérienne offre beaucoup d'analogie avec celle des nageoires; aussi est-il des poissons qui se servent tour à tour des mèmes membres pour nager et pour voler, et la seule particularité qui se remarque chez ces animaux consiste dans un développement très-considérable des nigeoires pectorales (fig. 87).

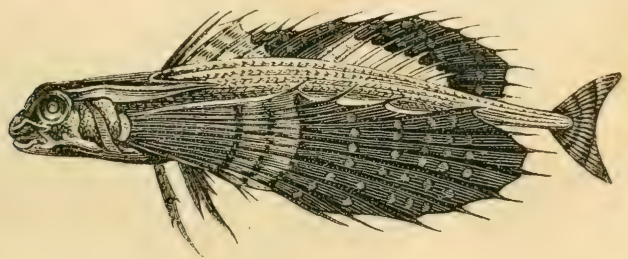

Fig. S7. Un Poisson volant (le Dactyloptère).

Quelques animaux peuvent aussi se soutenir dans l'air fendant un certain temps à l'aide d'espèces de voiles formées par un repli de la peau étendu de chaque côté du corps et soutenu par les pattes, sans que celles-ci cessent pour cela d'ètre spécialement destinces à la marche; mais cet appareil de vol dont quelques écureuils et les galéopithèques $(f i g .88)$ nous offrent des exemples, est toujours très-imparfait, et chez les animaux destinés essentiellement à la locomotion aérienne, il existe toujours des ailes.

Chez les animaux vertébrés, c’est-ìdire chez tous ceux qui ont un squelette interne, les ailes sont formées par les membres thoraciques, dont la disposition est telle qu'ils représentent une sorte de nageoire légère et très-ćtendue.

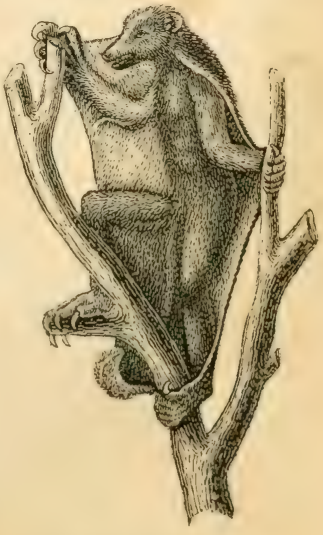

Fig. 88. Galéspilhèque. Ces conditions penvent ietre pemplies sans que la struelure de l'or-

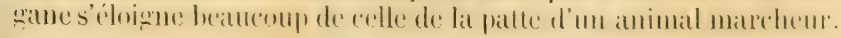


C'est ainsi que chez les chauves-souris ( fig. 89), pour constituer des organes de vol assez puissants, la nature s'est bornée à envelopper les membres thoraciques tout entiers dans un vaste repli de la peau et à donner aux doigts une extrème longueur, de facon qu'en s'écartant ils puissent tendre cette espece de voile mobile comme les baleines d'un parapluie en tendent le taffetas.

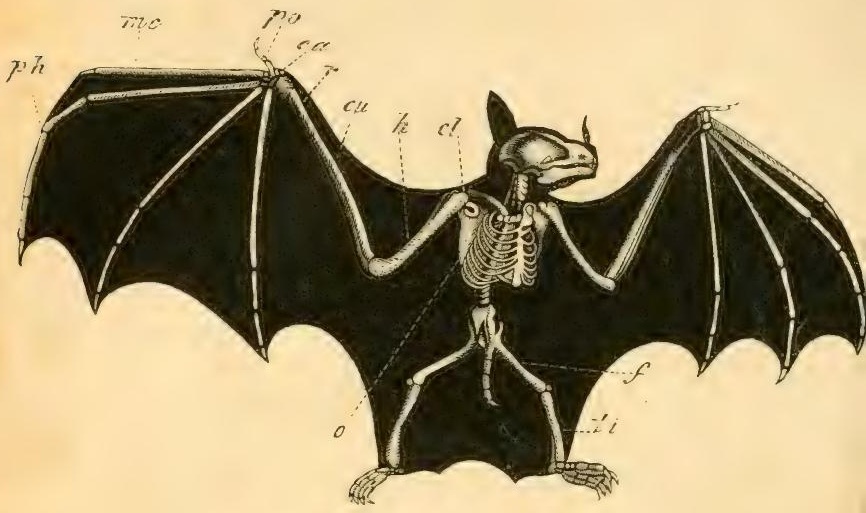

Fig. 89. Squclelle de Chaure-Souris (1).

Au premier abord les ailes des oiseaux semblent différer beancoup de celles des chauves-souris ou des bras de l'homme, et, en effel, ce qui en constitue presque toute la surface, ce sont les plumes roides dont elles sont garnies; mais la charpente solide de ces organes est au fond à peu près la mème que celle de la patte d'un quadrupede; de mène que chez ceux-ei, le membre: est somtemu sur une portion basilaire analogue a l'épaule, et se compose d'un humérus, d'un cubitus, d'un radius et d'une main (fig. 90). Cette dernière partie, destinée senlement à fournir des points d'attache aux plumes, est pen dévelnppée et ne présente des vestignes que d'un petit nombre de doigts.

Les ailes des insectes sont, en génciral, construites à peu près sur le mème plan, si ce n’est que le repli culame qui les comstitue est sontenu par des nervores cornées, au lieu de penfermer des patrties analogues aux os des membres.

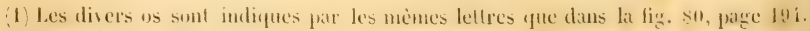
- $c$ l clavicule; - po ponce. 


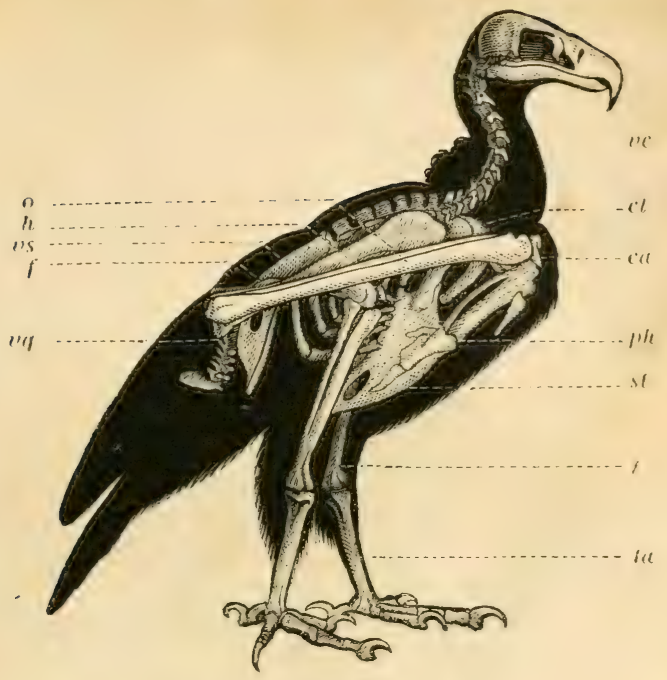

Fig. 90. Squeletic de Vautour (1).

$\$ 29: 3$. Organes de préhension. - Enfin, c'est aussi jar de légeres modifications dans la forme des os et dans la disposition de leurs articulations que les membres, au lieu d'ètre propres à la locomotion seulement, deviennent desinstrumentsplus ou moins parfaits de préhension; pour s'en convainere il suffit de comparer entre eus les membres thoraciques et abdominaux de l'homme (fiy. 77). En effet, notre main, si admirablement organisce pour saisir et palper les objets, ne diffère guère de notre pied que par les mourements de rotation qu'elle pent exécuter, et qui dépendent du mode d'articulation des os de l'avant-bras, par la longrueur des doigts, leur plus grande flexibilite ef la dispesition du pence qui peut se renverser sous les autres doigts de fiun i représenter, avee eux, une sorte de pince.

Chez les mammifieres qui vivent de fruits et qui sont les mieus organisés pour errimper sur les arbres, les quatre membles soml ferminés de la sorte par des mains, de somvent la nature les pum-

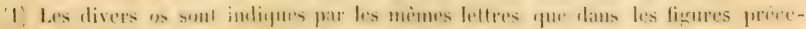
tenles. 
voit eneore d'un cinfuieme instrunent de préhension, en rendant leur queue assez longrue el assez flexible jour s'enrouler autour des liranches auxquelles ces ètres s'accrochent (fig. 91). Un grand

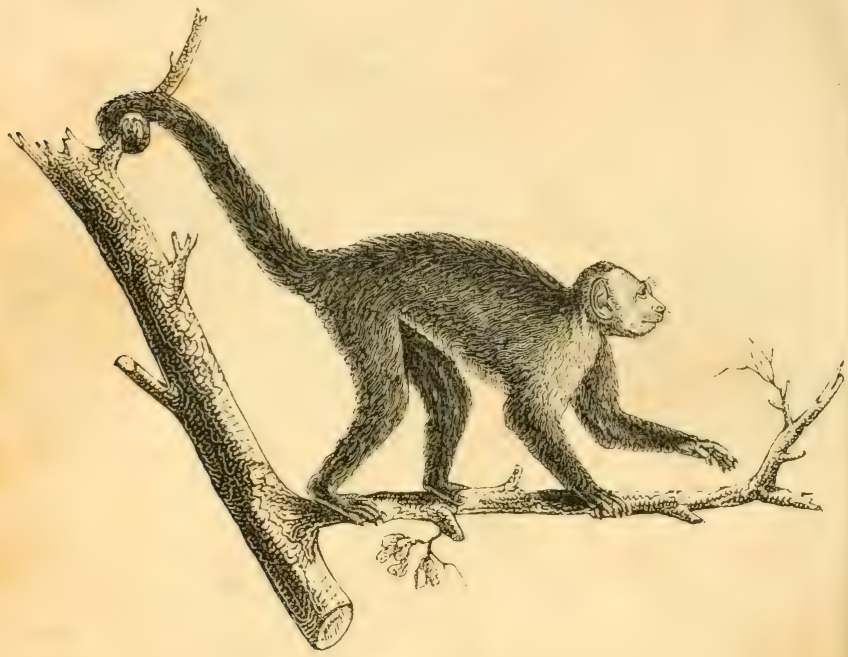

Fig. 91. Sajou it yorge blanche.

nombre des singes du nouveau continent, parmi les mammiferes, et les camélions parmi les reptiles, nous offrent des exemples de cette queue préhensile.

\section{DE LA Y 0 IX.}

$\$ 296$. Les rapports qui doivent exister entre un animal et ceux dont il est environné ne s'établissent pas seulement à l'aide des sens et des mouvements que nous venons d'étudier. Plusieurs de ces ètres sont doués de la faculté de produire des sons et peuvent mème s'en servir comme moyen d'expression et de communication.

Chez les animaux les plus inférieurs il n'existe aucune trace de rette faculté, et chez les insectes, le bruit monotone que l'on momme le chant de ces petits ètres, ne risulte que du froltement de: leurs ailes ou de quelques autres parties de leur enveloppe tigu- 
mentaire les unes contre les autres, de sorte que le son produit est une conséquence nécessaire de certains mouvements, de ceux du vol par exemple, et ne peuvent guère ètre considérés comme un phénomène d'expression; suivant toute probabilité il ne sert qu’à révéler la présence de celui qui le produit à ses semblables ou ì d'autres animaux destinés par la nature à en faire la chasse. Chez les animaux supérieurs, au contraire, la voix acquiert plus d'importance, elle est complétement sous la direction de la volonté, elle offre plus de varicté et elle dépend d'une cause différente; car chez tous ces ètres la production des sons s'effectue par le passage de l'air dans une partie déterminée du conduit respiratoire, disposée de facon à faire vibrer ce fluide.

$\$$ 297. Chez l'homme et les autres mammifëres, la voix se forme dans la portion du conduit aérifère qui est appelée larynx el qui est situce au haut du cou entre l'arriere-bouche et la trachio (voy. fig. 23, page 41). En effet, une ouverture faite à la trachéo au-dessous de eet organe, en permettant à l'air expiré des'íchapper au dehors sans le traverser, empèche complétement la production des soms, landis qu'une blessure semblable, mais située au-dessus du larynx, ne détruit pas la voix; on s'en est assuré par des expériences sur les animaux vivants, et des cas pathologriques observés chez l'homme lui-mème ont confirmé celte rérité. Ainsi, on connait des exemples de persomnes qui, à la suite d'unc blessure ou d'une maladie, portaient, au-devant du cou, une ouverture domnant dans la trachíe el livrant passage à l'air chassé des poumons par les monvements d'expiration; or, res malarles élairnt tous privés de la voix, mais il a été souvent farile de leur rendre la faculté de produire des sons e'n appliquant autour de leur eou une espèce de cravate de facon à boucher la plaie of à foreer l'air expire à suivre sa route ordinaire, cest-à-dire à traverser lt: larvnx.

\$ 298. Larynx. - Le larynx est un tube large et court qui esl suspendu it l'oshyoüle ( $h$, fig. 92) et qui se continue inferieurementaver la trachee $(t r)$. Sos parois sont formeses par diverses lames eartilagrineuses dresignees far les amatomistes sous le $10 m$ de cartilage thyproüde (1). de cartilage cricoüde (c) el de cartilayps arythénoüles. En avant on y remarque la saillie commos sous le: nom vulgatire de pomme d'alam (a), el, à l'intérieur, la membram mupueuse qui le lapisse forme vers som milieu deux grands replis latéraux dirigés d'avant en arriere, el disposés à peu pres comme

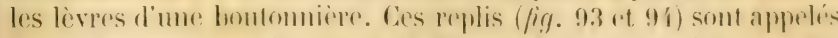

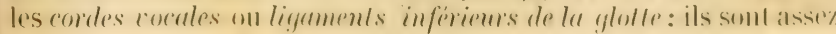


inais; leur longueur est d'autant plus considérable que la partic

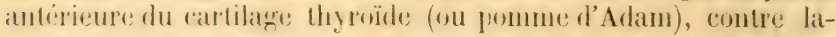
quelle ils se fixent, est plus saillante, et, à l'aide des contractions d'un petit muscle loge dans leur épaisseur et des mouvements des (artilages arythénoïles auxquels ils sont fixés en arriere (ar, fig. 93), ils peuvent se tendre plus ou moins, et se rapprocher ou s'écarter de

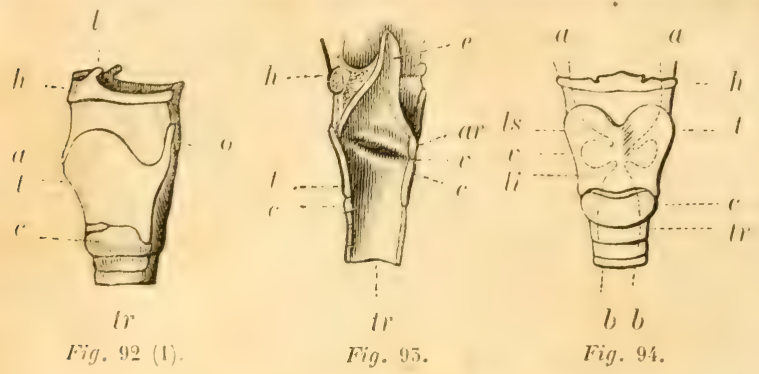

facon à agrandir on à dimimuer l’espere de fente qui les sépare. Lii feu au-dessus des cordes vocales se trouvent deux autres replis analogues de la membrane murpeuse du larynx; on les nonme ligaments supérieurs de la glotte, et on appelle esentricules du larynx les deux cofoncements lateraux qui les séparent des ligaments inferieurs ( $e$, fig. 9.3 et 94). L'espace compris entre res quatre replis constitue ce que l'on nomme la glotte; enfin, on remargue encore an-dessus de l'ouverture supérieure du larynx une rsprere de latnguette fibro-cartilagrineuse nommine épiglotte (p, fig. 9.3) yui est fixée, jar sa base, au-dessous de la racine de la langrue et fui s'rleve obliquement dans l'arriere--bouche, mais qui peut re-

1. Fïg. 9-2. Laryux de l'homme un de profil: - lo os hỵide; - l corps de l'os

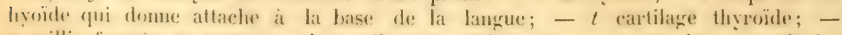
" satillie forme en asant par le cartilage thyroude, et comnue sous le noin vulgatire de promme d'Alem: le cartilage thyroide est uni à l'os hyoide par une membrane; r cartilage cricoulde; - Ir trache-artere; - " jaroi posterieure du larynx en rapport avec l'œsophage.

F̈ig. 95. Compe verticale du larynx : -1 os hỵoide; $-\ell$ cartilage thyroüle; c cartilage cricoide; - ar rartilage arģthenoide; $-r$ ventricule de la glolte, formo par liesparer que laissent entre eus les cordes vocales et les ligaments suprieurs de la glotte; - e épiglotte ; - Ir trachée.

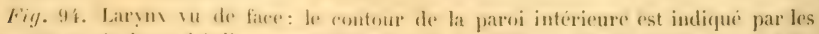

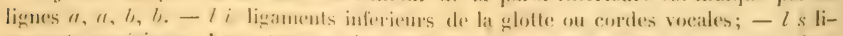

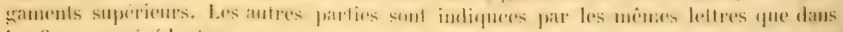
les figures précédentes 
pendant s'abaisser et couvrir la glotte, comme nous l'avons déjà dit en parlant de la déglutition ( $\$ 61)$.

\$ 299. Mécanisme de la voix. - Dans l'état ordinaire, l'air, expulsé des poumons, traverse librement le larynx et n'y produit aucun son; mais, lorsque les muscles de cet organe se contractent et que le passage de l'air dans son intérieur devient plus rapide, la roix se fait entendre. Une expérience faite par un médecin célèbre de l'antiquite, Galien, montre la nécessité de ces contractions pour la formation des sons. Il coupa, sur des animaux vivants, les nerfs qui se rendent aux muscles du larynx, et cette opération, qui détermina la paralysie de ces organes, entraina en mème temps. la perte de la voix. Enfin, d'autres expériences prouvent que c'est spécialement de l'action des ligaments de la glotte que dépend la production des sons; car, lorsqu'on coupe les ligaments supérieurs, on affaiblit considérablement la voix, et lorsqu'on coupe les replis inférieurs ou cordes vocales on la détruit.

$\$ 300$. La plupart des physiologistes pensent que dans la formation de la voix le larynx ayit de la mème manière que le ferait un instrument à anche ordinaire, un hautbois, par exemple ; c'està-dire que le courant d'air venant des poumons écarte les cordes vocales jusqu'à ce que ces lèvres élastiques, revenant sur ellesmèmes, interrompent momentanément le passage de ce fluide, qui hientòt les écarte de nouveau et produit ainsi des mouvements de va-et-vient (ou vibrations) assez rapides pour donner naissance à des sons.

On peut aussi, d'après la théorie physique des instruments de musique ordinaire, s'expliquer les principales différences que nous offre la voix humaine considérée chez des individus différents, ou chez le mème individu lorsqu'il en varie les intonalions.

Ainsi la physique nous apprend que toutes les fois qu'une corde élastique sera tendue avec plus de force, elle exécutera des vibrations plus rapides que lorsqu'elle était plus làche, et qu'elle produira, par conséquent, un son plus aigu, car la gravité et l'acuité des sons dépendent du nombre plus ou moins considérable d'oscillations qui se succedent lans un temps donné. Or, les ligaments inférieurs de la grlotte, comme nous l'arons déjà dit, sont conformés de manière à pouvoir se tendre ou se relàcher à des degrés variés, et on a constalé, par l'observation, que ces parties se tendent toujours avec d'autant plus de force qu'on cherche à rendre la voix plus aiquë. La longueur d'une corde ou d'une lame élastique, telles que celles dont on se sert pour la construction d'une anche, influe équalement sur lélévation de son produit par sa vibration, ef on 
sait, par exemple, qu'en raccourcissant de moitié la corde d'un violon, on obtient un son d'une octave plus haut que celui rendu par la mine corde lorsqu'elle avait toute sa longueur; si la voix se forme d'après des lois analogues, il faurlra donc qu'il existe un rapport entre la longueur des cordes vocales et la gravité des sons produits; et, en effet, nous avons déjà vu que, par les contractions des divers muscles du larynx, ces replis, au lien de rester libres dans toute leur longueur, peuvent ètre rapprochés au point de se toucher dans une étendue plus ou moins considérable, et, lorsqu'ils se rencontrent ainsi, la portion de leur bord susceptible de vibrer à la manière d'une anche doit éprouver nécessairement un raccourcissement correspondant, et doit donner un son plus aigu. Enfin, la longueur de ces cordes vocales est beaucoup plus considérable dans le larynx de l'homme que dans celui des femmes ou des eniants, et il existe, comme chacun le sait, une différence cunsidérable dans le diapason de leurs voix.

$\$ 30$ l. L'intensité ou le volume de la voix dépend en partie de la force avec laquelle l'air est expulsé des poumons, en partie de la facilité avec laquelle les différentes parties du larynx entrent en vibration, et de l'étendue des cavités de cet organe. Chez quelques mammiferes remarquables par leurs cris assourdissants, il existe de grandes cellules en communication avec la glotte, et c'est à la résonnance de l'air contenu dans ces carités que l'on attribue la force de leur voix : cette conformation se rencontre chez l'âne, par exemple, et est portée encore plus haut chez certains singes d'Amérique connus sous le nom de Hurleurs.

$\$ 302$. Le timbre de la voix parait tenir en partie aux propriétés physiques des ligaments de la glotte et des parois du larynx, et en partie à celles de la portion suivante du tuyau rocal. On saii que le timbre des instruments de musique varie beaucoup suivant qu'ils sont construits en bois, en métal ou en toute autre substance, et on a remarqué une coïncidence entre certaines modifications de la voix humaine et l'endurcissement plus ou moins grand des cartilages du larynx. Chez les femmes et les enfants, dont la voix a un timbre particulier, ces cartilages sont flexibles et n'ont que peu de dureté; landis que chez les hommes et chez quelques femmes dont la voix est masculine, le cartilage thyroide est très-fort et quelquefoi: mème plus: au moins complétement ossifié.

La formo de l'ouv rture extérieure de l'appareil vocal influe égalemont sur le timbre des sons produits. Lorsque ceux-ci traversent les fosses nasales seulement, ils deviennent désagréables et liasillards; quand la bouche est largement ouverte, la voix ac- 
quiert au contraire de la force et de l'éclat, et il paraiirait que le degré de tension du voile du palais et des autres parties de l'arrière-bouche modifie aussi les qualités du son.

$\$ 303$. Chez les oiseaux la voix se forme principalement dans un organe particulier qui ressemble un peu au larynx ordinaire, mais qui est placé au bas de la trachée-arlère, là où ce canal se divise pour constituer les bronches; ce second larynx, ou lur?!nx inférieur, offre une structure très-compliquée chez les oint: .x chanteurs, et nous aurons l'occasion d'en faire connaìtre la conformation dans la suite de ce cours.

$\$ 304$. Modifications de la voix. - Les sons produits par liappareil vocal ne sont pas toujours de mèmo nature, et se distinguent en cri, chant et voix ordinaire ou voix acquise.

Le cri est un son généralement aigu et désagréable, qui n'est que peu ou point modulé, et qui diffère principalement des autres sons. vocaux par son timbre; c'est le seul que puissent former la plupart des animaux, et, sous ce rapport, l'homme ne diflèe de ces derniers que par l'effet d: l'éducation. L'enfant qui vient de naitre ne sait pousser que des cris, et, quand il est privé du sens de l'ouire, sa roix ne change pas; mais, lorsqu'il entend ce qui se passe autour de lui, il apprend de ses semblables et s'accoutume par sa propre expérience à la moduler et à produire des sons d’une nature particulitre. Cette voix acquise difière du cri par zon intensité et par son timbre, mais elle n’est formée de mème que par des sons dont l'oreille ne distingue pas nettrmon les intervalles et les rapports harmoniques. Le chant, au contraire, se compose de sons appréciables ou musicaux dont les oscillations sont régulières, et pervent ètre, en quelque sorte, comptées par l'oreille.

$\$ 30 \%$. L'homme possède aussi la faculté de modifier d'une manière particuliere les divers sons de sa voix, il peut articuler ces sons, et on donne à cet acte le nom de prononciation.

Les organes de la prononciation sont le pharynx, les fosses nasales et les différentes parties de la bouche, et suivant qu'ils agissent de telle ou telle maniere, le son produit par le larynx prend tel ou tel caractere et constitue un son articulé particulier.

L'homme n'est pas le seul ètre ayant la faculté d'articuler les sons el de prononcer ainsi des mots, mais il est le seul qui sache attacher un sens aux mols (fu'il prononce et à l'arrangement qu'il leur donne; lui seul est doué de la parole. 


\section{DE L'INTELIAGENCE ET DE L'INSTINGT.}

$\$ 306$. Ayant itudié les organes à l'aide desquels l'homme el les autres animaux acquièrent la connaissance des objets extérieurs et réagissent sur ce qui les entoure, il ne nous reste plus, pour achever l'histoire des fonctions de relation, qu'à nous occuper du pouvoir qui détermine leurs actions et des phénomènes de l'entendement. Cette branche de la physiologie a été plus cultivée par les philosophes que par les naturalistes, et nous ne pourrions nous y arrèter long-temps sans sortir du cadre tracé par l'Université pour l'enseignement de la zoologie, mais il nous parait indispensable d'en dire ici quelques mots.

C'est chez l'homme que tous les phénomènes de l'entendement offrent le plus de perfection, et c'est seulement en étudiant ce qui se passe en nous-mèmes que nous pourons nous former quelque notion sur la plupart des opérations de l'esprit. C'est également chez l'homme que les facultés intellectuclles ont été le plus observées et. qu'on les a analysées avec le plus de soin; aussi est-ce l'homme qu'il nous faudra prendre comme premier exemple dans linvestigation du sujet qui nous occupe ici, et est-ce à nous-mèmes qu'il nous faudra ensuite comparer les animaux, si nous voulons juger des facultés dont la nature les a doués, et chercher les causes de leurs actions.

$\$ 307$. Facultés de l'entendement humain. - Nous arons vu yue le contact immédiat des objets extérieurs, ou l'influence d'agents intermédiaires entre ces objets et nos organes, produit dans les parties sensibles de l'économie un certain changement d'état ou impression dont la nature nous est inconnue et dont l'effet est une excitation qui, transmise par les nerfs jusqu'au cerveau, y est aperçue par notre esprit et donne ainsi naissance à une sensation. La sensation est donc une chose distincte de l'impression et de l'excitation dont elle résulte, et consiste réellement dans la conscience que nous arons de cette impression; c'est un phénomène qui n'en est pas toujours la suite nécessaire, et dans bien des cas nous ne sentons pas les impressions recues par les parties sensibles (le notre corps) (quoique l'excitation, ainsi produite, ait été conduite par les nerf́s juscqu’a l'encéphale de la manière ordinaire, car l'effet de cette exritation sur le cerveau peut passer inaperçu par la puissance intérieure (que les philosophes appellent souvent le moi, et que l'on désigne plus fréquemment dans le langage ordinaire sous 
le nom d'esprit ou d'âme. La faculté d'éprouver des sensations est, par conséquent, une propriété de l'esprit ou de quelque agen analogue, et elle constitue, pour ainsi dire, la base de tout travail intellectuel.

$\$ 308$. Pendant le sommeil rien n'est changé dans l'état de la plupart des organes des sens, et par conséquent ceux-ci doivent, comme durant la veille, recevoir des impressions sous l'influence des objets extérieurs; mais ces impressions ne donnent ordinairement lieu à aucune sensation, soit parce que le cerveau cesse momentanément d'ètre apte à transmettre à l'esprit les excitations ainsi recues, soit parce que l'esprit lui-mème perd alors de son activité. L'influence de l'âme sur les sensations est éralement évidente pendant la veille, car par l'effet de la volonté on peut concentrer, en quelque sorte, l'esprit sur telle ou telle excitation, de façon à en recevoir des sensations bien plus intenses et plus distinctes qu'on ne le ferait dans les circonstances ordinaires. Ainsi chacun sait qu'au milieu de plusieurs conversations qui se croisent avec une égale force, on peut souvent suivre le discours de la personne dont les paroles vous intéressent, et laisser passer inapercues toutes les impressions produites sur notre oreille par les autres voix; et, lorsque l'esprit est fortement préoccupé, il arrive souvent que l'on ne voit pas ce que l'on a devant les yeux, et que l'on ne sent pas la douleur que devrait produire une blessure on une maladie.

La faculté de diriger ainsi volontairement notre esprit vers les excitations reçues du dehors, ou vers les opérations de l'entendement lui-mème, constitue ce que l'on nomme l'attention.

$\$ 309$. Les sensations qui nous arrivent du dehors, ou qui résullent d'un état quelconque de nos organes eux-mèmes, varient dans leurs qualités; elles sont lantòt agréables, tantòt plus ou moins douloureuses, et varient entre elles suivant (qu'elles nous sont données par l'un ou par l'autre de nos sens, ou qu'elles sont déterminées par des causes lifférentes. Lorsque l'enfant commence à en éprourer il ne sait encore à (fuoi les attribuer; mais il existe dans notre esprit une tendance à l'induction par suite de laquelle nous sommes naturellement portés à raltacher tout effet à une cause, et a chercher cette cause dans les circonstanes dont le phénomene est accompanné ou précedé. Nous sommes conduits de la sorte it rapporter ere gue nous éprouvons aux objets dont nous sommes entourés, ePlevpérience ne tare pas a confirmer ce jugement. 1'ar la rliversité de nos sens et les manieres différentes dont chacun

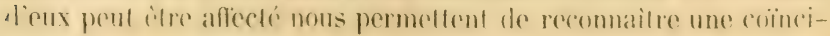


dence constante entre certaines sensations et la présence de certains objets. Nous acquérons ainsi la conscience de l'existence des corps extérieurs; nous y distinguons des qualités ou manières d'agir diverses, et nous nous formons une notion ou idée des objets, ou, en d'autres mots, nous les percevons.

Ainsi, cuand un enfant sent l'odeur d'une fleur, il cherche naturellement la cause de cette sensation, et si, en mème temps, il voit près de lui celte fleur ou s'il peut la saisir avec la main, il est porté à la considérer comme la cause de l’impression qu il a recue. Si, ensuite, son odorat cesse d'ètre ainsi excité quand il s'éloigne de cette mème fleur, et si la mème sensation revient dès qu'il touche ou qu'il voit de nouveau un objet ayant la propriélé d'agir sur le sens de la rue ou sur le sens du toucher de la mème manière que la fleur dont il vient d'ètre question, il ne tardera pas à se confirmer dans ce jugement et à associer dans son esprit la sensation venue par les sens de l'odorat, de la vue et du toucher, comme étant due à autant de qualités d'un mème corps. Puis il lui suffira de reconnaitre une de ces qualités ou caractères pour en inférer l'existence des autres jusqu'à ce qu'il rencontre (les objets ou elles ne se trouvent pas toutes réunies; et alors, s'il a quelque intérèt a le faire, il cherchera d'autres différences propres a lui faire distinguer ces corps qu il était au premier abord porté à confondre. Les sensations qui nous arrivent par les autres sens déterminent dans notre esprit un travail analogue, et c'est surtout par le concours des manières différentes de sentir que l'homme acquiert des idées sur l'existence de ce qui l'environne. Le sens qui, pour nous aider à acquérir des perceptions de cette nature, pourrait le mieux se passer de tous secours étrangers, est celui du toucher, parce qu'il peut s'exercer simultanément par des parties différentes de notre corps, et qu'il suffit à lui seul pour nous donner ainsi en mème temps deux ou plusieurs sensations, de la comparaison desquelles ressort un jugement, soit sur l'existence du corps étranger qui les détermine, soit sur la qualité de ce corps.

Lorsque l'expérience nous a appris la signification des sensations que nous éprouvons, notre esprit ne s'arrète plus entre ses sensations et les conclusions qui en découlent; il juge sans retard, sans effort, et mème sans le savoir, ce qu'il avait d'abord besoin de peser et de considérer longruement; ses jůgements sur la cause des sensations deviennent en mème temps plus sûrs, et. on apprend réellement à se servir des sens dont la nature nous a pourvus. Mais c'est à tort que, pour exprimer ce fait, les physiologistes disent souvent que nos sens se perfectionnent par l'exercice, et ont 
besoin d'une sorle d'éducation ; ce u'est pas la faculté de recevoir des impressions qui se modifie ainsi, mais la faculté d'apprécier les sensations, de les comparer, de les distinguer, en un mot de les juger. L'est en effet le jugement rui nous rend aptes à profiter de nos sensations et à nous former des notions des objets qui les déterminent. Mais ce travail de l'entendement ne suffirait pas pour amener ce résultat s'il ne s'exerçait que sur les sensations du moment, et si celles-ci ne pouvaient ètre comparées aux sensations recues antéricurement et aux idées yu'elles ont déjà fait naìtre.

$\$ 310$. Il existe effectivement une autre faculté de l'esprit qui joue un grand rôle dans tous les phénomènes intellectuels et qui nous est indispensable pour acquérir la connaissance des objets dont nous sommes environnés : c'est la mémoire ou la faculté d'avoir de nouveau la conscience d'une sensation déjà passée, ou d'une idée déduite précédemment de nos impressions. Comme chacun le sait, les sensations que nous recevons et les idées que nous ácquérons passent plus ou moins rapidement et semblent se présenter seulement à notre conscience pour s'évanouir aussitòt; mais dans la réalité elles ne s'effacent pas complétement, et peuvent fréquemment, sous l'influence de la volonté ou pour toute autre cause, se reproduire à notre esprit sans cependani revètir jamais le caractère d'une sensation actuelle. Ce pouvoir conservateur, si précieux pour l'intelligence, s'exerce, en général, d'autant plus fácilement que la sensation ou l'idée s'est présentée d'abord avec plus de force, ou s'est répétée plus frequemment; c'est comme si chaque acte de l'entendement était accompagné d'un certain changement permanent dans un point déterminé du cerveau, que ce changement fùt d'autant plus marqué qu'il résulterait d'une action plus forte ou d'une somme plus considérable d'actions faibles, et que la trace, ainsi produite, fùt appréciable à l'esprit, du moment (fu'elle offrirait un certain degré d'intensité. D'autres circonstances influent également sur ce phénomène intellectuel ; l'âge, par exemple. Ainsi, dans les premiers temps de la vie, la mémoire est trèsdéveloppée, et chez les vieillards elle est rarement assez forte pour retenir les idées produites par les sensations émoussées que l'homme éprouve dans cette période avancée de son existence, ef elle ne conserve suiere (que ce qui s'y était gravé pendant la jeunesse; quelquefois mème elle se perd complétement par les̀ progrès de l'àge, et mème, chez l'adulte, elle est déjà plus faible que chez l'adolescent et l'enfant; aussi est-ce pendant la jeunesse que l'on acquiert plus facilement toutes les conmaissances qui ne demandent pas une réflexion tresogrande, telles que les langues, 
lhistoire, les sciences descriptives, etc. Il est également à noter yue l'exercice tend à rendre la mémoire plus forte, et que dans certaines maladies mentales elle peut se perdre presque complétement sans que le malade cesse de posséder la faculté de recevoir des sensations du dehors et d'en déduire des notions sur les objets qui l'environnent.

L'intelligence humaine n'est que rarement susceptible d'ètre également impressionnée par des sensations de nature différente, et les différents hommes sont frappés d'une manière très-inégale par les idées du mìme ordre. Or, les sensations les plus vives sont toujours, comme nous venons de le dire, celles que la mémoire conserve le mieux, et par conséquent il est aisé de prévoir que la faculté de garder ainsi dans l'esprit les idées de divers ordres doit varier d'une manière analogue. Effectivement, chez le même homme, il y a pour ainsi dire autant de mémoires distinctes qu'il y a d'ordres de sensations différentes; il y a la mémoire des mots, la mémoire des formes, celle des lieux, celle de la musique, etc., et il est bien rare qu'un mème homme les possède toutes au mème degré : en général l'une de ces qualités prédomine, et dans certaines maladies mentales on a vu une espèce de mémoire se perdre complétement sans que les autres aient été notablement affectées; mais il ne faudrait pas conclure de ces faits que ce soient réellement autant de facultés distinctes; les inégalités qui se remarquent dans la mémoire, suivant qu'elle se dirige sur tel ou tel sujet, dépendent, suivant toute apparence, d'une inégalité dans la disposition de l'esprit à recevoir divers genres d'idées, et correspond avec une aptitude plus prononcée pour tel ou tel genre de travail intellectuel.

\$ 311. La faculté de jugement, dont il a déjà été question, ne s'exerce pas seulement de la manière simple dont nous l'avons vue intervenir dans la perception 0!ı la formation de nos idées relatives à l'existence ou à l'absence des qualités des objets, considérées comme causes de nos sensations. Les notions ainsi acquises ne restent pas isolées dans notre esprit; nous possédons encore le ponvoir de les comparer, de saisir les rapports qu'elles ont entre elles, d'en tirer des conclusions, en un mot de porter des jugements sur les idées aussi bien que sur les choses; nous pouvons mème lier entre eux ces jugrements pour en déduire de nouvelles conclusions et former ainsi un ruisonnement. Ces opérations de l'esprit, lorsqu'elles sont portées à un haut degré de perfection, nécessitent la réflexion ou la considération de ce qui se passe dans notre intelligenre elle-mime. et refle farultí est si développée en nous qu'ellr 
nous donne jusqu'à la conscience de nos propres facultés et nous permet d'observer les phénomènes de notre entendement aussi bien que ceux du monde extérieur.

$\$ 312$. L'imagination, ou le pouvoir de faire surgir dans notre esprit des idées qui ne naissent pas directement des sensations actuelles ou des notions déjà existantes dans notre mémoire, est aussi une faculté qui joue un grand ròle dans les phénomènes de l'intelligence humaine; mais ce qui contribue surtout à donner à celleci son immense développement, c'est la tendance que nous avons à créer des signes pour représenter nos idées, à penser au moyen de ces signes et à généraliser nos pensées.

$\$ 313$. Enfin la volonté, qui nous donne le pouvoir de concentrer en quelque sorte notre conscience sur certaines sensations actuelles, sur les traces laissées dans notre mémoire par des sensations passées ou mème sur les opérations de notre esprit, c'est-àdire de faire acte d'attention ou de réflexion, nous permet aussi d'imprimer à nos pensées une direction déterminée, d'en interrompre le cours et d'en choisir jusqu'à un certain point l'objet. Mais il existe aussi en nous des tendances naturelles qui, indépendamment de notre volonté, nous portent à exécuter certaines opérations de l'esprit avec plus de facilité que d'autres, et qui nons font préférer les idées d'un certain ordre. La tendance à l'induction, dont nous avons déjà eu l'occasion de parler, est une de ces dispositions innées de l'intelligence humaine; la confiance, le sentiment rle la justice, du beau, de la pitié, et en un mot toutes les qualités morales qui se montrent déjà avec plus ou moins de force dans la première enfance et qui se retrouvent chez tous les hommes indépendamment des effets de l'éducation, sont aussi de ce nombre, et on peut ranger encore dans la mème classe la disposition que nous avons à rechercher les causes des phénomènes dont nous sommes témoins, ou à nous occuper de calculs. de musique, etc., tendances qui, de mème que les premières, varient d'intensité suivant les indivilus, et domnent aux hommes, à raison mème de relte inégalité, des aptitudes si différentes pour les travaux divers de l'intelligence.

$\$ 31 \%$. Ces attributs de l'esprit humain ont une grande analogie avec une autre classe de facultés que l'on peut appeler affectives, telles que la disposition naturelle que nous avons à aimer et à protéger nos enfants, à rechercher la société de nos semblables, etc., Enfin ces dernieres facultés ont à leur tour une analorie non moins grande arec les instincts dont la nature nous a dowés. On domne ce nom à une tendance ou impulsion qui uous porte à exécuter 
certains actes dont ni la volonté ni l'intelligence ne déterminent les combinaisons, et dont l'esprit ne prévoit pas le résultat. Chez l'homme ces facultés instinctives ne sont que peu développées et ne sont que rarement la cause déterminante de ses actions; mais chez les animaux nous les verrons jouer un grand ròle et tenir lieu d'intelligence; c'est mème chez ces ètres seulement que nous pouvons nous en former une idée bien nette.

$\$ 315$. Brincipes d'action. - Les diverses facultés de l'esprit que nous venons d'énumérer sont la cause déterminante de la plupart de nos actions.

Nous avons déjà vu que, dans l'économie animale, certaines actions ont lieu sans le concours de la volonté et d'une manière tout automatique; tels sont les mouvements du cœur et les contractions péristaltiques des intestins.

D'autres mouvements peuvent éralement se produire indépenlamment de la volonté, mais ne sont pas complétement soustraits à l'influence de cette force; ils continuent lorsque l'animal a perdu connaissance; mais dans l'état normal celui-ci peut à volonté les accélérer, les ralentir ou les interrompre. Les mouvements respiratoires nous offrent un exemple de ces actes, que l'on pourrait appeler semi-automatiques, et nous avons vu que chr'z les animaux supérieurs la force (qui les détermine parait résider dans la moelle allongée ou portion supérieure de la moelle épinière (52:3).

Enfin, nous avons vu aussi qu'une troisième classe de mouvements est complétement dépendante de la volonté et cesse entièrement dès que les fonctions cérébrales sont interrompues. Ces actes, que les physiologistes désignent sous le nom de mouveinents volonfaires, sont les seuls dont nous ayons à nous occuper ici, car ce sont les seuls qui interviennent directement dans les fonctions de relation; et, si nous analysons les motifs qui nous portent à les exécuter, nous verrons que ces causes ou principes d'action sont de deux ordres : les uns sont rationnels, les autres instinctifs.

Effectivement, c'est quelquefois par suite d'un jugement et dans la prévision d'un résultat déterminé que notre volonté d'agir se prononce, mais d'autres fois ce qui nous porte à agir n'est pas une opération do l'intelligrence, mais une impulsion non calculée et en quelque sorte aveugle que l'on peut appeler instinctive (en donnant toutefois à ce mot son acception la plus large); par exemple, le désir de satisfaire à un besoin physique, comme la faim, ou d'obéir à quelque affection naturelle ou à quelque instinct proprement dit, tels que la tendresse maternelle, et linstinct qui, sans le secours 
de l'expérience ou de l'éducation, apprend à l'enfant nouveau-né à teter la mamelle de sa mère.

$\$ 316$. Enfin, il est aussi à noter que, par la répétition fréquente d'actions rationnelles, nous acquérons la faculté de les exécuter sans que la volonté intervienne pour les déterminer ou pour les régler, et quelquefois mème sans que nous ayons aucune conscience de ce que nous faisons; c'est là un effet bien connu de l'habitude, et les mouvements produits de la sorte offrent une grande ressemblance avec ceux qui dépendent de l'instinct proprement dit; seulement, pour ces derniers, la nature nous domme d'arance tout ce qui est nécessaire pour les faire naitre, tandis que, pour les premiers, la disposition particulière dont le phénomène dépend ne s'acquiert que par l'exercice et l'éducation.

L'étude de l'influence que la répétition d'un acte quelconque exerce sur la disposition à agir, et des rapports qui peuvent s'établir entre certaines pensées et certaines opérations de l'intelligence ou déterminations de la volonté, c'est-à-dire des effets de l'habiturle et des associations d'idées, constitue une des branches les plus curieuses de la psychologie; mais l'espace nous manque pour nous y arrèter ici, et, pour l'objet que nous avons en vue, il nous suffit d'avoir signalé l'analogie qui existe entre les résultats de l'habitude et les impulsions de l'instinct.

$\$ 317$. Facultés des animaux. - Ayant passé rapidement en revue les principales facultés de l'homme, nous pourons, à l'aicle des connaissances ainsi acquises, chercher à nous former quelques notions sur la nature de l'intelligence des animaux et sur les causes de leurs actions. Mais cette étude offre encore plus de difficultés que celle de l'entendement humain, car nous ne pouvons pas, comme chez nous-mèmes, observer directement les opérations de l'esprit, et c'est seulement en analysant les actions de ces ètres que nous pourons juger de ce qui se passe en eux.

$\$ 318$. Nous avons déjà dit que tous les animaux montrent des signes de sensibilité; mais, chez ceux dont la structure est la plus simple, les sensations ne paraissent donner lieu à aucun travail de l'entendement, analogue à celui (qui se passe dans notre esprit lorsque nous acquérons la perception de la cause de nos impressions et que nous nous formons des idées relatives à ce qui nous entoure. Nous n'apercevons chez ces ètres aucun indice d'intelligence, et la volonté ne se manifeste chez eux que par des actes d'une simplicité extrème, tels qu'un changement de direction dans leurs mouvements lorsyu'un obstacle se trouve accidentellement sur leur passagre. C'est en effet à des phénomenes de ret ordre yue 
paraissent ètre bornées les facultés de relation chez les animalcules infusoires et chez quelques autres zoophytes. Mais, lorsqu'on s'élève davantage dans la série zoologique, on voit les actes se compliquer et se diversifier de plus en plus, et souvent on ne peut se les expliquer qu'en admettant chez les ètres qui les exécutent l'existence d'instincts d'une admirable perfection, ou mème de facultés analog̣ues à celles qui, chez l'homme, sont nécessaires à la production d'actions sembiables, la mémoire et le jugement, par exemple, et mème le raisonnement. Lorsqu'on observe d'une manière superficielle les mœurs de certains animaux, tels que le castor, l'abeille et la fourmi, on est mème tenté de leur attribuer une intelligence des plus développées; mais c'est seulement chez ceux dont l'organisation se rapproche le plus de celle de l'homme, les singes et le chien par exemple, qu'il existe réellement quelque chose de semblable aux facultés que nous venons de mentionner, et chez les ètres moins élevés c'est de l'instinct que dépendent presque toutes les actions, mème celles qui semblent demander le plus de calculs et de prévisions.

$\$ 319$. Instincts des animaux. - Le caractere qui distingue surtout les actions instinctives de celles qu'on peut appeler intelligentes ou rationnelles, c'est de n'ètre pas le résultat de l'imitation ou de l'expérience, d'ètre exécutées toujours de la mème manière, et, suivant toute probabilité aussi, sans ètre précédées de la prévision ni de leur résultat ni de leur utilité. La raison suppose un jugement et un choix ; l'instinct, au contraire, est une impulsion aveugle qui porte naturellement l'animal à agir d'une manière déterminèe; ses effets peuvent quelquefois ètre modifiés par l'expérience et le raisonnement, mais n'en dépendent jamais, et ces dernières facultés influent toujours d'autant moins sur les actions d'un animal que ses instincts sont plus parfaits; chez l'homme l'intelligence remplace presque entierement l'instinct, et chez les animaux c'est l'instinct qui-supplée plus ou moins complétement au manque d'intelligence.

Comme exemple d'une action très-simple, mais cependant trèsremarquable et qui est évidemment dépendante de l'iustinct donné aux animaux pour les guider dans le cours de la vie, nous citerons un fait observé bien des fois chez de jeunes canards qui, couvés par une poule et élerés par elle, n'avaient jamais vu d'animaux de leur espèce, et qui cependant, à la première occasion, malinré les efforts de leur mere d'adoption el l'exemple des poussins dout ils étaient entourés, se sont jetés à l'eau pour y nagger et y vivre à la manière des autres animaux de leur race. Comme exemple des actes 
d'une complication extrème qui, à défaut de l'instinct dont ils dépendent, ne pourraient s'exécuter que sous l'influence d'une intelligence des plus préroyantes, et nécessiteraient de savants calculs, nous citerons aussi des faits faciles a constater par tout observateur : les travaux des abeilles, dont les constructions offrent une si grande régularité et une si admirable perfection, et sont si bien appropriés aux usages auxquels elles doirent servir. Or, ces ouvrières habiles n'ont besoin ni de modèles ni de guides; dès leur début dans leur carrière architecturale, ellesexécutent sans tàtonnements ni méprises une multitude d'opérations délicates dont l'utilité n'est pas immédiate; elles ne profitent jamais de l'expérience pour perfectionner leurs procédés, et de génération en quénération elles travaillent de la mème manière sans que les jeunes individus aient besoin des lecons de celles déjà exercées à bâtir; entin, on les voit continuer leurs travaux lorsque les circonstances dans lesquelles elles sont placées les rendent inutiles. On ne peut donc attribuer ces actes à l'influence de facultés analogues à celles de notre intelligence, car cclles-ci ne suffiraient pas pour déterminer de semblables résultats, et on ne peut les expliquer qu'en leur assignant pour cause une impulsion naturelle semblable à celle qui porte l'enfant nouveau-né à teter sans qu'il ait appris à le faire.

Les instincts des animaux varient suivant les espèces et offrent un sujet d'étude plein d'intérèt pour le philosophe aussi bien que pour le naturaliste. C'est seulement en traçant l'histoire particulière de chaque animal qu'on peut espérer de les faire bien connaitre tous, et l'espace nous manquerait ici pour en traiter de la sorte; mais, afin de fixer les idées de nos lecteurs sur la nature des phénomènes qui résultent de ce genre d’impulsion innée. nous croyons devoir décrire ici quelques-uns des plus remarquables.

$\$ 320$. On peut ranger les principales actions instinctives en trois classes, suivant qu'elles se rapportent à la conservation de l'espèce, à la conservation de l’individu, ou bien aux relations de celui-ci avec les autres animaux.

$\$ 321$. Parmi les instincts donnés aux animaux pour assurer leur bien-ètre et pour les préserver des causes innombrables de destruction dont ils sont environnés, on peut citer en première ligne la disposition a se nourrir exclusivement de certaines substances déterminées. ()uelques animaux des plus simples n'en sont pas pourvus, et avalent indistinctement tout ce qu'ils rencontrent: divers zoophytes sont dans ce cas; mais la plupart des animaus en donnent des signes plus ou moins évidents, of puelyuefois mime cet instinct est si puissant, qu'on voit ces itres refuser toute esprece 
de nourriture, à l'exception d'une seule à l'usage de laquelle ils sont en quelque sorte prédestinés. En effet, non-seulement certaines espèces ne mangent que des matières animales, et d'autres uniquement des substances régétales; mais parmi ces dernières on en connait un grand nombre qui ne s'attaquent qu'aux feuilles ou bien aux fruits d'une seule plante et restent indifférents à tout autre aliment; l'odorat et le goùt sont les instruments qui les dirigent dans leur choix, mais on ne peut attribuer qu'à un instinct particulier la cause qui les détermine à ne manger que des substances qui agissent sur leurs sens de telle ou telle manière; et chose remarquable, il arrive quelquefois que cet instinct change tout à coup de direction lorsque lanimal arrive à une certaine période de son dévelopjement, et le détermine à abandonner son: régime primitif pour rechercher exclusivement des substances dont il ne faisait aupararant aucun usage. C'est ainsi que certains insectes, qui sont carnasiers à l'état de larve, deviennent toujours phytivores à l'état parfait, et que les grenouilles, qui se nourrissent de matières végétales lorsqu'elles sont à l'état de tètard, deviennent au contraire carnassières lorsqu'elles ont achevé leurs métamorphoses.

$\$ 322$. Cette faculté instinctive ne détermine que des actes d'une grande simplicité; mais il n'en est pas de mème de celle que la nature a donnée à divers animaux carnassiers pour les diriger dans les moyens qu'ils emploient pour capturer leur proie.

Ainsi la larve du fourmilion $(f i g .96)$, petit insecte du genre des éphémères, est destinée à se nourrir de fourmis et d'autres insectes

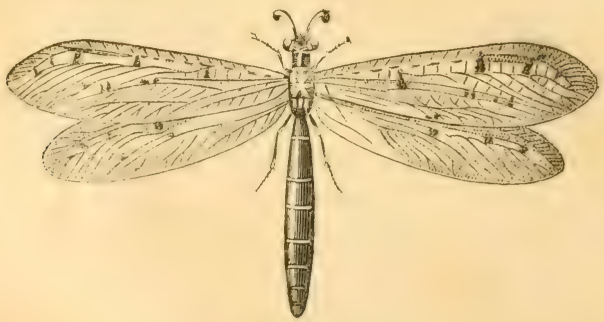

Fig. 95. Fourmilion.

dont elle suce les humeurs, mais elle ne se meut que lentement et avec peine; de sorte qu'clle ne pourvoirait que difficilement à ses besoins, si la nature ne lui avait appris à tendre des piéges pour s'emparer de la proie qu'elle ne peut pas poursuivre. Mais son ins- 
tinct la porte à creuser dans du sable fin une petite fosse en forme d'entonnoir (fig. 97), puis à se cacher au fond de ce piçre et à attendre patiemment qu'un insecte tombe dans le petit précipice qu'elle a ainsi formé; et si sa victime cherche à s'échapper, ou si elle s'arrète dans sa chute, elle l'élourdit et la fait ıouler jusqu'au fond du trou, en lui jetant, à l'aide de sa tète et de ses mandibules, une multitude de grains de sable. La manière dont le fourmilion creuse sa fosse est également curieuse : après avoir examiné le sol où il va s'établir, il commence par tracer un cercle qui doit correspondre à l'embouchure de son entonnoir; puis se plaçant en dedans de cette ligne et se servant d'une de ses pattes comme d'une bèche, il se met à creuser, entasse ainsi une certaine quantité de sable sur sa tète, et, à l'aide d'une secousse, rejelte sa charge à quelques pouces en dehors de son cercle; il continue de la sorte en lournant tout autour de son trou projeté, en marchant à reculons et en se servant de la mème patte pour remuer le sable; mais, lorsqu'il est revenu à son point de départ, il change de còté, et ainsi
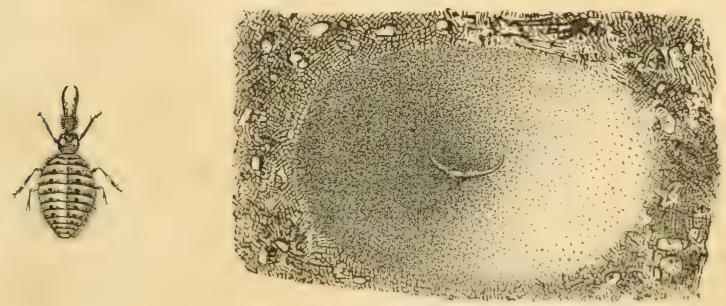

Fig. 96. Larve.

Fig. 97. Piége du Fourmilion.

de suite jusqu’à ce que son lravail soit achevé; si dans le cours de son opération il rencontre quelque pierre dont la présence nuirait à la perfection de son piége, il la négligre d'abord, mais y revient après avoir acheré son excavation; fait tous ses efforts pour la charger sur son dos et la rejeter au dehors; s'il y parvient il la pousse encore assez loin, comme pour l'empercher de retomber, et s'il ne peut s'en débarrasser il abandonne son ourre et recommence ailleurs sur nouveaux frais. Lorsque la fosse est achevée, elle a ordinairement environ huit centimetres de diametre sur cing de profondeur; et, lorsque la pente de ses parois a été altérée par quelque éboulement, comme cela arrive presque toujours lorsqu'un insecte s'y laisse choir, le fourmilion se hâte de réparer les déçàts.

Certaines araignées dressent des piéges encore plus singuliers, 
car les toiles que ces animaux tendent de diverses manières sont surtout destinées à arrêter les monches et les autres insectes dont ils doivent faire leur proie. I a disposition des fils varie suivant les espèces et n'offre quelquefois aucune régularité; mais d'autres fois elle est d'une élégance extrème, rt on s'étonne en voyant des animaux si petits construire avec lant de perfection une trame si étendue que l'est, par exemple, la toile de l'Épeire-Diadème qui habite dans nos jardins. Il est mème des araignées qui ne se bornent pas à dresser de pareils pićzres, mais qui se serrent également de leurs fils pour emmaillotter leur victime el l'empècher ainsi de se rléfendre jusqu'a ce fu'elles l'aient percée avec leurs crochets venimeux.

On peut citer mime des poissons qui, pour s'emparer de leur proie, exercent une industric instinctive non moins remarquable : tel est l'Archer qui habite le Gange, et qui, destiné à se nourrir d'insectes, mais ne pouvant les poursuive, a l'art de lancer des gouttes d'eau sur ceux qu'il voit sur les herbes aquatiques, afin de les faire tomber et de s'en repaitre; il parait qu'il est mème asse\% habile dans ce grenre de chasse pour manquer rarement son but a une distance de plusieurs pieds.

Enfin, les especes de ruse's employées par beaucoup de quadrupèdes dans leurs chasses doivent itre aussi rapportées à l'instinct: car elles se reprorluisent de la mème maniere chez lous les individus de l'espèce, et souvent se montrent lorsque ceux-ci n'ont encore eu l'occasion de s'instruire ni par l'imitation ni par l'expérience.

$\$ 323$. C'est encore daus cette classe d'instincts qu'il faut ranger la disposition innée qui détermine beaucoup d'animaux à amasser des provisions pour leur usige futur et à les enfouir dans des caches. En général, cet instinct n’est développé que dans des espèces plus ou moins sédentaires qui, pendant une partie de l'année, ne trouvent pas dans le pays qu'elles labitent les substances don! elles se nourrissent. Cette apparente prévision les empèche de souffrir du défaut d'aliments lorsque le sol ne leur ('n fournit plus. mais ne peul dépendre d'aucun calcul de l'intellicrence; car elle se montre arant que l'expérience ait pu apprendre à l'animal l'utilité de semblables maxasins, of on la retrouve encore chez des individus vivant, ainsi que leurs parents, flans des climats où une saison de disette n'est plus à craindre.

L'écureuil de nos huis (fig. 98) nous donne un exemple de cette disposition innée à pourvoir aux besoins de l'avenir. Pendant l'été ces petits animaux, à allures si vives et si gracieuses, amassent res provisions de noisetle's, do rlands, d'amandes, etc., et se servent 
ordinairement d'un arbre creux pour y établir leur magasin; ils ont l'habitude de faire ainsi plusieurs dépòts dans des cachettes

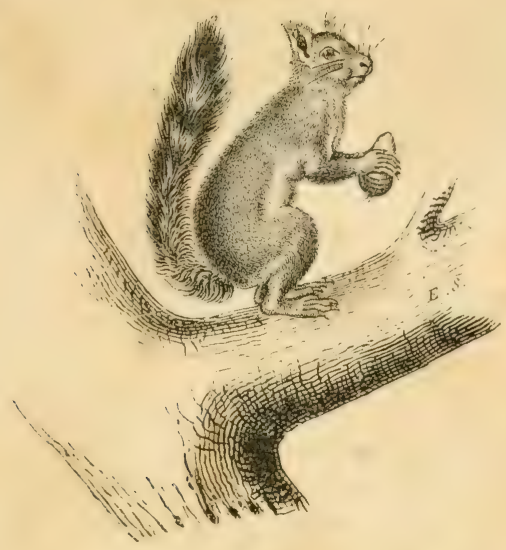

Fig. 93. Écurcuil commun.

différentes, et en hiver, quand la disette se fait sentir, ils savent fres-bien les retronver, mime lorsque la neige les reconve. Mais cette impulsion, yui doit leur ètre si utile quand le froid vient interrompre leurs récoltes journalières, les porte encore à cacher les aliments qui leur restent, lors mème quils n'ont jamais connu un temps de disette et qu'ils n'en auront pas à redouter. Un autre mammifère rongrur, qui ressemble beancoup a nos lapins ef qui habite la Sibérie, lo Lagmm!gs pica. ast douó d'un instinet encore plus remar(quable, car non-soulement il cueille, en autorne, l'herbe dont il aura besoin pour se nourrir durant le long hiver de ce pays inhospitalier, mais il fait du foin, exactement comme le font nos fermiers. Ayant coupe les herbes les plus vigoureuses et les plus succulentes de la prairice, il les étale pour les faire sécher au soleil; ef, colte opération termince, il les rassemble en meules et a le soin de placer celles-ei à labri de la pluie et de la neige, et de ereuser, au-dessous de chacun de ses magrasins, une gralerie souteraine aboutissant a sa demeure ef disposée de facen a lui permetlre de visiter en tout temps son dépot de provisions. L'abeille, sur l'histoire de latpuelle nous aurons bientòt l'oceasion de revenir, est

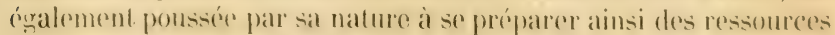


pour l'avenir, et exécute, a cet effet, des travaux encore plus compliqués.

$\S 32$.'. Un autre genre d'instinct qui se rapporte, comme les précédents, à la conservation de l'individu, est celui qui détermine certains animaux à se construire une demeure, qui leur enseigne toutes les opérations compliquées nécessaires à cet but, et qui leur fait suivre invariablement dans leurs travaux la mème rontine, quoiqu'en général l'ouvrier n'ait jamais vu faire rien de semblable et n'ait pas de modèle.

C'est ainsi que le ver à soie se construit, avec les fils (fu'il sécrète, un cocon dans lequel il se renferme, pour subir en sùreté ses métamorphoses et derenir papillon; que le lapin se creuse un terrier, et que le castor construit les huttes qui l'ont rendu célère. Nous aurons l'occasion de revenir sur cet instinct architectural lorsque nous parlerons des travaux communs exéculés par des troupes d'animaux vivant en société, et que nous nous occuperons des soins qu'un grand nombre de ces ètres donnent à leur progéniture; mais nous ne pourons quitter ici ce sujet curieux sans donner quelques exemples à l'appui de ce qui vient d'ètre dit.

Le hamster (fig. 99), petit rongeur assez voisin du rat, qui se rencontre dans les champs, depuis l'Alsace jusqu'en Sibérie, et qui nuit beaucoup à l'agriculture, se construit une demeure souterraine offrant toujours deux issues : l'une, oblique, sert à l'animal pour rejeter au dehors les déblais de la terre; l'autre, perpendiculaire, est la voic par laquelle il entre et sort lui-mème. Ces galeries conduisent à un certain nombre d'excavations circulaires qui communiquent entre elles par des conduits horizonlaux : l'une de ces cellules, garnie d'un lit d'herbes sèches, est la demeure du hamster; les autres sont destinées à lui servir de magasins pour les provisions qu'il amasse en quantités très-considérables.

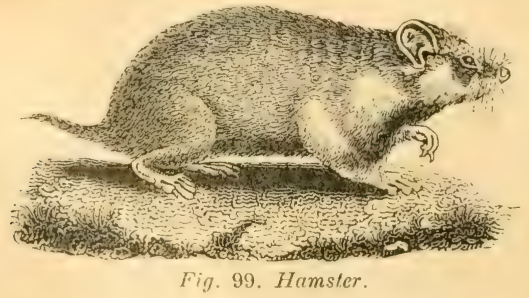

Quelques araignces, connues des zoologistes sous le nom de mygales, exécutent des travaux analogues à ceux du hamster, mais 
plus compliraués, car non-seulement elles se construisent une habitation vaste et commode, mais elles savent en fermer l'ouverture à l'aide d'une véritable porte garnie de sa charnière $(f i g .100)$. A cet effet, la mygale creuse, dans une terre argileuse, une sorte de puits cylindrique d'environ huit ou dix centimètres de long, et en tapisse les parois avec une espèce de mortier très-consistant, puis fabrique, avec des couches alternatives de terre gâchée et de fils réunis en tissu, un couvercle qui s'adapte exactement sur l'orifice de son trou et qui ne peut s'ouvrir qu'en de-

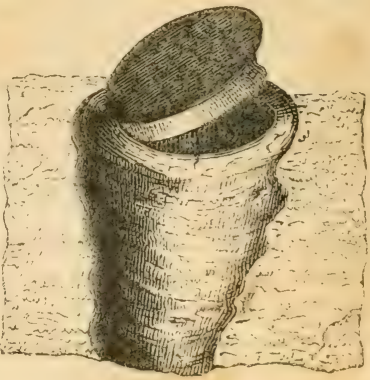

Fig. 100. Nid de Nygale. hors; la charnière qui retient cette espèce de porte est fermée par une continuation des couches filamenteuses qui se portent d'un point de son contour sur les parois du tube situé au-dessous et y constituent un bourrelet remplissant les fonctions de chambranle; la surface externe de ce couvercle est rugueuse, et, par son aspect, diffère à peine de la terre environnante, mais sa surface interne est lisse; et, lans la demeure d'une de ces araignées maçonnes, on aperçoit, du còté opposé à la charnière, une rangée de petits trous dans lesquels l'animal introduit ses griffes pour la tenir baissée lorsque quelque ennemi cherche à l'ourrir de force.

Chez les insectes, on voit aussi un grand nombre de procédés curieux employés instinctivement pour la construction d'une habiIation. Beaucoup de chenilles savent se former un abri en roulant des feuilles et en les attachant a l'aide de fils. Dans nos jardins, nous rencontrons, à chaque instant, sur les lilas, les groseilliers, etc., des nids de cette espèce, et c'est aussi de la sorte qu'est formé celui qui se trouve sur le chène ( $f \mathrm{~g} g .101)$ el qui appartient à la chenille d'un petit papillon nocturne, le Tortrix veridissima. D'autres insectes se construisent des fourreaux avec des fragments de fouilles, des brins d'étoffes ou quelqu'autre

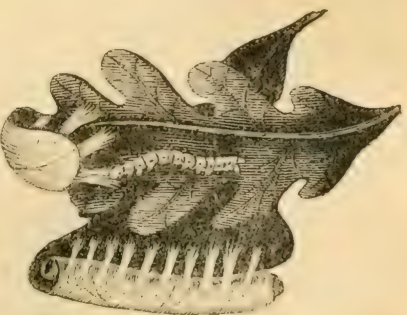

Fiil. 101. Niil du Torlitix. 
substance qu'ils savent ajuster artistement : telle est la Teigne des draps, p: tit papillon gris-argenté, qui, à l'état de chenille, s's creuse des galeries dans l'épaisseur des étoffes de laine en les rongeant rapidement. Avec les brins ainsi détachés, la chenille se construit ensuite un tuyau qu'elle allonge continuellement par sa base; et, chose singulière, lorsqu'elle devient trop grosse pour ìtre à l'aise dans sa demeure, elle fend cette espèce de gaîne et l'élargit en y mettant une pièce.

Enfin il est aussi à noter que certains animaux destinés à passer toute la saison froide dans un état de léthargie ont non-seulement l'instinct de se préparer une retraite et un lit moelleux, nais bouchent l'entrée de leur demeure lorsque l'époque de leur sommeil hivernal approche; comme s'ils pouvaient prévoir que de longtemps ils n'auraient pas besoin de sortir, et que leur porte restant ouverte livrerait accès au froid et à des ennemis dangereux. Telles sont les marmottes que l'on trouve dans les Alpes et que les petits Savoyards promènent dans nos rues.

$\$ 323$. Un troisième genre de facultés instinctives qui tantò ont pour objet, comme les précédentes, la conservation de l'indit vidu, mais qui, d'autres fois, sont destinées à assurer aux jeunes des conditions favorables à leur existence, et qui, dans l'un et l'autre cas, se lient presque toujours d'une manière étroite à l'instinct de la sociabilité, détermine certains animaux à entreprendre de longs voyages, et souvent mème à changer périodiquement de climat. Quelquefois, les animaux voyageurs ne quittent un canton que lorsqu'ils en ont épuisé toutes les ressources, et ils vont alors chercher à se nourrir dans un canton voisin. Quelquefois aussi, c'est le froid des hivers qui les chasse vers le midi, ou la chaleur trop forte de l'été qui les pousse peu à peu vers le nord; mais, dans bien des cas, leurs émigrations précèdent tout changement atmosphérique propre à nous en donner l'explication ; et leur instinct les porte, non pas à céder pas à pas le terrain qu'ils abaridonnent, mais à se dirizer de suite et sans hésitation vers la région où ils doivent se rendre. Presque toujours aussi, au moment d'entreprendre ces voyages, on voit un grand nombre d'individus se réunir en troupe pour marcher de concert.

Les singes, qui vivent en si grand nombre dans les forèts du Nouvean-.lionde, nous offrent un exemple de cette disposition à changer de quartiers d'une maniere irrégulière. Lorsqu’ils ont dévasté un canton, on les rencontre par bandes nombreuses, s'élancant de branche en branche et allant à la recherche de quelqu'antre localité abondante (nn fruits; puis, lorsque la disette les 
a suivis dans leur nouvel établissement, ils vont chercher fortune ailleurs, les mères porlant leurs petits sur leur dos ou dans les bras, et la troupe entière paraissant. se livrer à une joie bruyante.

Des royages encore plus remarquables, et qui n'offrent également rien de périorlique, sont entrepris par les lemmings sans que l'on ait encore découvert les causes de letrs émigrations. Ces animaux, qui ont beaucoup d'analogie avec les rats, habitent les bords de la mer Glaciale et descendent quelquefois des montagnes par troupes innombrables. Ils s'avancent alors par colonnes serrées et suivent toujours une ligne droite sans se laisser détourner par les obstacles les plus grands, traversant à la nage les rivières qu'ils rencontrent, et tournant les habitations ou les rochers sur lesquels ils ne peuvent grimper. C'est surtout la nuit qu'ils voyagent de la sorte, el beaucoup périssent en route; mais leur nombre est si considérable qu'ils n'en causent pas moins des dégàts immenses partout où ils se montrent, car ils détruisent toute végétation sur leur passagre, et ne se bornent pas à dévorer l'herbe jusqu'à sa racine, mais creusent aussi la terre pour en retirer les grains qui s'y trour snt. Ces émigrations de lemmings sont un fléan pour la Norwége et la Laponie : mais heureusement elles ont rarement lieu dans la mème contrée plus d'une fois en dix ans.

En général, les voyages des animaux se font périodiquement et. correspondent aux changements des saisons. Ainsi, chaque printemps, des légions d'un petit rongeur très-roisin du lemming, le campagnol des prés, qu'on appelle aussi quelquefois le rat économe, quittent le Kamtschatka, et se dirigent versle couchant; ils marchent de la mème manière que les précédents, parcourent des centaines de lieues, et sont si nombreux, que vers le milieu de juillet, lorsqu'ils arrivent sur les bords de l'Octrolsk et du Joudoma, après avoir fait une route de plus de 2̈j degrés de longitude, une seule colonne met souvent plus de deux heures à dífiler. Au mois d'octobre, ils reviennent au Kamtschatlia; et leur retour est une fite pour le pays, car l'escorte de carnassiers qui les suit fournit aux chasseurs de ces contrées arides des fourrures en abondance. Dans le voisinage du cap de Bonne-Espérance, of dans les parties septentrionales de l'Amériyue, on rencontre aussi, au printemps et en automne, des troupeaux innombrables d'antilopes ef de cerfs qui émigrent à de urandes distances. Mais c'est surtout dans la classe des oiseaux que les exemples de cot instinct des voyazes sont fréupuents et remarquables. Un srand nombre de ces animaux pasient périodiquement d'Europe en Afrique, et viennent ensuite d'Afrique en Europe, et cela avee une régularite si grande, que cest pour ainsi 
dire à jour nommé qu'ils arıivent et qu'ils partent. Ainsi, les hirondelles, qui se montrent chez nous vers le commencement d'avril, nous quittent en automne. On voit alors ces oiseaux se réunir en troupes nombreuses et se diriger vers le midi. Parvenus sur les bords de la Méditerranée, ils se rassemblent sur quelque point élevé, et, après avoir attendu quelque temps un moment favorable, partent de concert et traversent la mer par bandes innombrables. On les rencontre quelquefois loin de terre, et, lorsque les vents contraires s'opposent à leur voyage, on les voit alors s'abattre sur les corrlages des navires; il paraitrait mème qu'ils vont jusqu'au Sénégal pour y passer l'hiver. Les cailles sont également renommées pour leur instinct voyageur, et vont aussi en Afrique et en Asie-Mineure pour éviter les hivers rigoureux de nos climats; comme divers oiseaux du nord descendent sur nos rivages quand le froid les chasse des régions polaires, où ils retournent au printemps suivant.

Enfin, l'instinct des migrations se retrouve encore parmi les poissons et les insectes: le hareng, le thon, le saumon, etc., nous en offrent des exemples frappants parmi les premiers, et les locustes parmi les seconds.

$\$ 326$. Les instincts que la nature a domés aux animaux pour les mettre en état d'assurer la conservation de leur progéniture ne sont ni moins variés ni moins curieux que ceux à l'aide desquels ces ètres pourvoient à leurs propres besoins. L'impulsion intéricure qui détermine les oiseaux à se tenir pendant des semaines presque immobiles sur leurs œufs, qui leur fait construire d'avance, et avec lant d'art, une demeure pour y abriter leurs petils, et qui les pousse à veiller au bien-ètre de leur jeune famille; celle qui apprend aux insectes à choisir la place où ils doivent déposer leurs œeufs afin que les larves qui en naissent puissent trouver à leur portée les aliments dont elles ont besoin, ou qui détermine quelques-uns de ces animaux à prodignuer leurs soins à des jeunes provenant d'une mère étrangère; l'instinct qui guide quelques oiseaux et certains quadrupèdes dans l'espèce d'éducation qu'ils donnent à leurs petits; ces facultés et les phénomènes qui en résultent exciteront toujours dans notre esprit autant d'étonnement que d'acimiration, et nous enseignent, plus éloquemment que des paroles ne sauraient le faire, combien la puissance créatrice de tant de merreilles doit ètre au-dessus de tout ce que l'homme peut imaginer ou concevoir. Nais l'admiration que produisent en nous ces forces inconnues qui déterminent chez les animaux tant d'actions surprenantes est peut-ètre dépassée encore par celle que nous inspire celte affection également innée 
qui, dans l'espèce humaine, porte une mère à se dévouer lout entière au bien-ètre de ses enfants, et qui se retrouve, quoiqu'à un moindre degré, chez un assez grand nombre d'animaux.

$\$ 327$. Un des phénomènes les plus propres à donner une idée nette de ce que l'on doit entendre par instinct est celui qui nous est offert par divers insectes lorsqu'ils déposent leurs œufs. Ces animaux ne verront jamais leur progéniture et ne peuvent avoir aucune notion acquise de ce que deviendront leurs œufs; et cependant ils ont souvent la singulière habitude de placer, à còté de chacun de ces corps, un dépòt de matières alimentaires propres à la nourriture de la larve qui en naitra, et cela lors mème que le régime de celle-ci diffère totalement du leur et que les aliments qu'ils déposent ainsi ne leur seraient bons à rien pour eux-mèmes. Aucune espèce de raisonnement ne peut les guider dans cette action, car, s'ils avaient la faculté de raisonner, les faits leur manqueraient pour arriver à de pareilles conclusions, et c'est en aveugles qu'ils doivent nécessairement agrir; mais leur instinct supplée au défaut d'expérience et de raison, et leur apprend à faire précisément ce qui convient pour atteindre le but qu’ils devraient se proposer.

Les nécrophores $(f i g$. 102) qu'on rencontre assez sourent dans nos campagnes nous offrent un exemple de ce genre d'instinct; car, lorsque la femelle va pondre, elle a toujours soin d'enterrer le cadavre d'une taupe ou de quelqu'autre petit quadrupede, et d'y déposer ses œufs, de sorte que les jeunes se trouvent, dès leur naissance, au milieu des matières les plus propres à leur servir de nourriture, car, de mème que leur mère, ils vivent de charogne. Mais ce qui est plus remarquable encore, c'est de voir un insecte, dont le régime est exclusivement végétal, préparer ainsi une nourriture animale pour sa progéniture, lorsque. durant l'état de larve, ses jeunes seront carnassiers. Les pompiles, insectes voisins des guèpes, sont dours de cet instiuct singulier. A l'âge adulte, ils vivent sur les

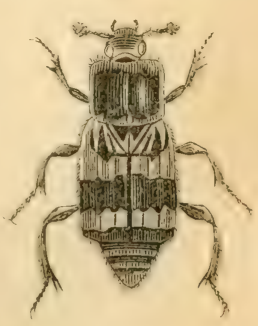

Fig. 102. Nicrnplene. fleurs; mais leurs larves sont carnassieres, ot la mere pourvoit toujours a la nourriture de celles-ci en plaçant a coté de ses oufs, dans un nid préparé à cet usage, le corps de quelque araignée ou de quelque chenille qu'elle a préalablement percée de son aigrnillon. Les xylocopes (fig. 10:3) ont des moxurs analognes, of (remsent 
dans le bois une série de loges servant en mème temps comme nids et comme magasins ( $\mathrm{fg}$. 104).

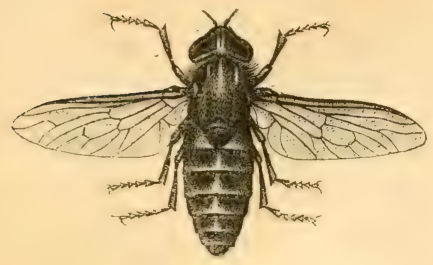

Fig. 103. Tylocope.

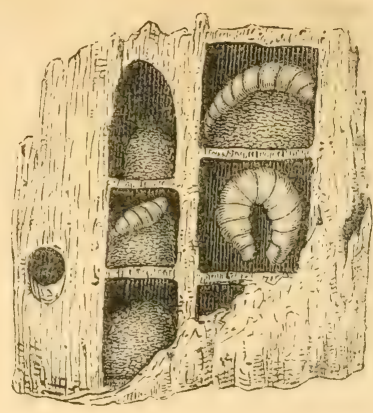

Fig. 104. Nid de Xylocope.

$\$ 328$. C'est surtout dans les premiers temps de la vie que les animaux sont faibles et ont besoin d'un abri contre les intempéries de l'air et les attaques de leurs ennemis; aussi est-ce surtout

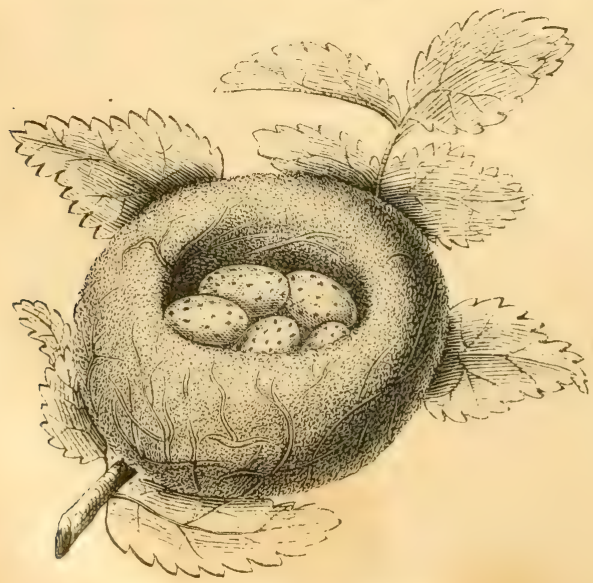

Fig. 105. Nid du Chardonneret.

dans le but de leur en procurer que la nature a donné à leurs parents l'instinct de la construction; et le nombre des espèces qui, à l'âge adulte, se bâtissent une demeure pour leur propre usage, 
est très-faible en comparaison de celui des animaux qui façonnent pour leurs petits un berceau moelleux et sùr. Parmi les oiseaux, rien n'est plus commun; et on ne peut voir sans intérèt la persévérance avec laquelle ces animaux apportent brin à brin les matériaux destinés à la confection de leurs nids, et l'art avec lequel il les arrangent; la forme et la structure de ces habitations sont toujours les mèmes pour les oiseaux d'une mème espèce, mais varient beaucoup d'une espèce à une autre, et sont toujours parfaitement bien appropriées aux circonslances dans lesquelles la jeune famille est destinée à vivre; tantòt ces berceaux sont construits à terre et d'une manière grossière, et tantòt ils sont accolés contre le flanc d'un rocher ou d'un mur, mais, en général, ils sont placés entre les branches des arbres ; la plupart ont une forme hémisphérique et ressemblent à un petit panier arrondi et évasé, dont les parois seraient formées de brins d'herbe ou de tigelles flexibles, et l'intérieur garni de mousse ou de duvet (fig. 105); quelquefois cependant leur disposition est plus compliquée. Un des nids les plus remarquables est celui du Baya, petit oiseau de l'Inde assez voisin de nos bourreuils; sa formeest à peu près celled'une bouteille (fig. 106), et il est

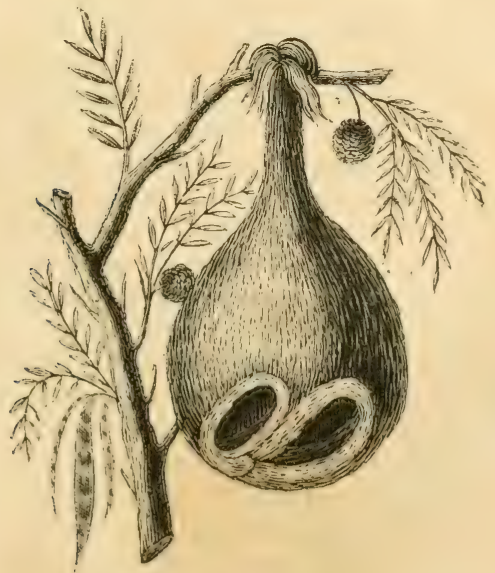

Fig. 106. Nid du Baya.

suspendu à quelque branche tellement flexible que les singes, les serpents et mème les écureuils ne peuvent y parrenir; mais, pour 
le rendre encore plus inaccessible à ses nombreux ennemis, l'oiseau en place l'entrée en dessous, de façon qu'il ne peut y pénétrer

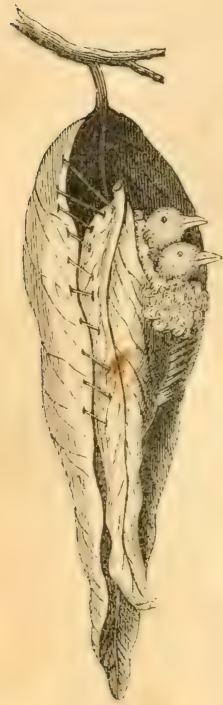

Fig. 107. Nid du Sylvia sutoria.

lui-mème qu'en volant. C'esi avec de longue's herbes que cette habitation est construite, et on y trouve intérieurement plusieurs chambres dont l'une sert à la femelle pour y couver ses œufs, et une autre est occupée par le màle, qui pendant que sa compagne remplit ses devoirs maternels l'égaie par ses chants. Un autre nid également singulier est celui d'un petit oiseau de l'Orient, voisin de nos fauvettes, le Sylvia sutoria, qui, à l'aide du coton qu'il cueille sur le cotonnier et qu'il file arec son bec et ses pattes, coud ensemble les feuilles dont sa demeure est entourée, et la cache ainsi à la vue de ses ennemis (fig. 107).

On connait mème des poissons qui construisent un nid grossier pour y déposer leurs œufs; mais de tous les animaux inférieurs, ce sont les insectes qui montrent le plus d'industrie et d'instinct dans la fabrication d'un logement pour leur progéniture. En parlant des travaux que quelques-uns de ces animaux exécutent en commun, nous aurons loccasion de décrire les nids dés abeilles et des guuèpes; aussi nous bornerons-nous à mentionner ici un seul exemple de bâtisse que certains insectes solitaires élèvent pour y loger leurs œufs.

Parmi ces derniers, un des plus remarquables est le xylocope violacé ou abeille perce-bois, gros insecte à corps noir el à ailes violacces, qui appartient à la mème famille que les abeilles proprement dites et qui n'est pas rare en France. Cet animal (fig. 103) creuse, dans le bois des espaliers et des échalas, des trous ovalaires qui s'avancent d'abord obliquement, puis se recourbent en bas, et descendent verticalement dans une longueur de 30 à 49 centimètres; en taraudant ainsi le bois, le xylocope a la précaution de rassembler en un tas les ràpures qu'il en détache, et, lorsque sa galerie est creusée, il se sert de cette matiere pour y construire des cloisons transversales et pour diviser le tout en un certain nombre de cellules closes (fig. 10 f). Ces cellules sont semblables entre elles, ot, avant que de les fermer, linsecte dépose dans chacune d'elles un deses oufs, ansis qu'un pelit tas de pollen recueilli sur les fleurs 
du voisinage, et destiné à la nourrilure de la larve qui naîtra bientôt.

$\$ 329$. Les relations qui doivent exister entre les animaux d'une mòme espèce ou entre ceux d'espèces différentes sont réglées par des instincts naturels, tout aussi bien que les actions qui se rapportent à la conservation des individus ou à la conservation de leur race. Tantòt ces ètres vivent solitaires, et quelquefois même ne souffrent dans leur voisinage aucun animal de leur espèce; d'autres fois, au contraire, on les voit se réunir en troupes nombreuses et former mène des sociélés dans lesquelles tous les membres concourent à la défense générale et mettent en conmun le fruit de leur travail. Or, ces différences ne sont pas accidentelles; tous les individus d'une mème espèce ont des mœurs semblables, ot c'est évidemment un instinct qui les pousse, les uns à se fuir mutuellement, et les autres a vivre en société.

Les associations formées par les animaux sont, les unes temporaires, les autres permanentes, et varient encore dans leur caractère.

Celles qui indiquent moins que toute autre un véritable instinct de sociabilité sont ces réunions, en quelque sorte accidentelles, que certains aninaux chasseurs, tels que les loups et les hyènes, forment pour accomplir quelque acte de rapine on de vengeance. Ces animaux, qui restent solitaires tant que leurs forces individuelles leur permettent de pourvoir à leur subsistance, se réunissent par bandes et chassent de concert lorsque la disette se fait sentir ou que quelque troupeau nombreux se montre dans le voisinage; mais, des qu'ils ont atteint le but qu'ils se proposaient, ils se dispersent ou se querellent entre eux.

Beaucoup d'animaux voyageurs se rassemblent aussi de la sorte pour faire route ensemble, et se dispersent quand ils sont arrivés a leur destination; mais ces réunions se font d'une manière plus constante et plus régulière que celles dont il vient d'ètre question. En parlant des hirondelles, nous en avons déjà vu des exemples; mais, sous ce rapport, les pigeons de passage qui habitent l'Amérique septentrionale sont encore plus remanquables. Ces oiseaux parcourent d'une manière irréguliere ce vaste continent et se montrent quelquefois en troupes si immenses que leur nombre dépasse tout ce que l'on pourrait imariner; on les voit quelquefois volant en une colonne serrée, dont la largeur est de plus d'un kilometre eet dont la longueur dépasse 10 on 12 kilometres, et un naturaliste célebre des Etats-Unis, Wilson, évalue à plus de ?,000,000,000 le nombre d'individus dont se composait une bande qu'il a rue passer 
dans te voisinage d'Indiana. Un autre auteur, digne de toute notre confiance, Audubon, nous apprend qu'un jour d'automne il quitta sa maison à Henderson sur les bords de l'Ohio. et qu'en traversant les terrains incultes près de Hardensburorh, il vit de ces pigeons en nombre plus considérable que d'ordinaire, se dirigeant du nord-est au sud-est; à mesure qu'il continua sa route vers Louisville, la bande voyageuse qui passait au-dessus de sa tèle devint de plus en plus nombreuse. "L'air, dit-il, était tellement rempli de ces oiseaux que la lumière du soleil de midi en était obscurcie comme par une éclipse, et que la fiente tombait dru comme des flocons de neige; avant le coucher dı soleil, j'arrivai à Louisville, situé à une distance de 53 milles, et les pigeons passaient toujours en rangs aussi serrés; le défilé de cette immense colonne dura trois jours encore, et pendant ce temps toute la population du pays était en armes, occupée à en faire la chasse. " C'est dans les bois que ces oiseaux établissent leur demeure; une seule troupe occupe alors toute une forèt, et, lorsqu'ils y sont restés pendant quelque temps, leur fiente y forme sur le sol une couche de plusieurs centimètres d'épaisseur; dans l'étendue de plusieurs milliers d'hectares, les arbres sont dépouillés et mème complétement tués, et les traces de leur séjour ne s'effacent qu'après plusieurs années.

Les poissons et les insectes nows offrent des exemples non moins remarquabies de ces immenses agrégations d'individus. Les locustes, insectes roisins des sauterelles, sont depuis long-temps célèbres par les ravages qu'ils occasionnent lorsque, réunis en légions innombrables, ils traversent certaines contrées de l'Afrique ou de l'Asie, dévorant tout sur leur passage; et les harengs se montrent dans les mers du nord en troupes si nombreuses, qu'ils deviennent l'objet d'une pèche des plus imprortante's; on les y rencontre serrés les uns contre les autres ef formant ainsi des bancs qui ont souvent plusieurs centaines de pieds l'épaisseur et qui couvrent la surface de la mer lans une étendue de plusieurs lieues.

$\$ 330$. Dans d'autres rassemblements temporaires formés par les animaux, le lien qui unit les membres de ces sortes de sociétés parait c̀tre seulement le plaisir qu'ils trouvent à prendre en commun leurs ébals joyeus. Ainsi, dans le voisinage du cap de BonneEspérance, le voyareur Levaillant a vu chaque soir, à la mème hemre, des nuées d'une espèce particulière de perroquets, le I'sittacus infuscatus) se réunir aver un grand bruit et se diriger ensuite vers fuelque source d'au bien limpide pour s'y baigner; la res singuliers animaux folatraicnt entre eux, se poussant daus l'eau el se roulant sur le rivage, puis retournaient sur les arbres 
où ils s'étaient d'abord donné rendez-vous, y rajustaient leurs plumes, et, leur toilette étant achevée, se dispersaient pour gagner leurs retraites respectives tt y passer la nuit.

Le besoin de la société de leurs semblables parait déterminer aussi la formation de ces colonies permanentes que nous offrent nos lapins de garenne, dont les terriers communiquent entre eux ; le chien des prairies de l'Amérique septentrionale (1), dont les habitations réunies par groupes sont connues des chasseurs sous le nom de villages et occupent quelquefois une étendue de plusieurs kilomètres; les éphémères et beaucoup d'autres insectes. Mais c'est dans les associations ayant pour objet l'exécution de travaux communs que l'instinct de la sociabilité se montre dans tout son développement; dans les colonies de castor's de gruèjes, d'abeilles et de fourmis, par exemple.

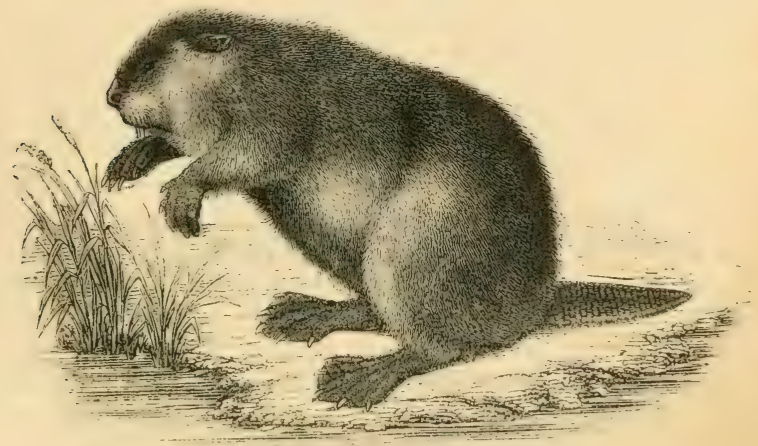

Fin 108. Cirstur

$\$ 331$. Le castor du Camada est de tous les mammiferes le plus remar(fuab) pe par sa sociabilite et son industrie instinclive; pendant l'été, il vit solitaire dans des terriers qu'il se ereuse sur le bord des lares ef des fleures; mais, lorsque la saison des neigres approche, il quitte celte retraite ol se rémnit à ses semblables, pour ronstruire en rommun ave enx sa demeure d'hiver. C'est dans les liens les plus solitaires de l'Amérique septentrionale que les

(1) Lanimal désigne ainsi par les Imérirans n'est pats un réritable rhien, mais une espéce de marmotte du genre arctomys. 
castors, souvent au nombre de deux ou trois cents par troupe, déploient tout leur instinct architectural. Pour construire leurs nouvelles demeures, ils choisissent un lac ou une rivière assez profonde pour ne jamais geler jusqu'au fond, et préfèrent en général des eaux courantes, afin de s'en servir pour le transport des matériaux nécessaires à leurs constructions. Pour soutenir l'eau à une égale hauteur, ils commencent alors par former une digue en talus : ils lui donnent toujours une forme courbe, en dirigent la convexité contre le courant, la construisent de branches entrelacées les unes dans les autres, dont les intervalles sont remplis de pierres et de limon, et la crépissent extérieurement d'un enduit épais et solide. Cette digue, qui a pour l'ordinaire onze à douze pieds de large à sa base, et qui est renforcée tous les ans par de nouveaux travaux, se couvre souvent d'une végétation vigoureuse, et finit par se transformer en une sorte de haie. Lorsque la digue est achevée, et lorsque, l'eau étant stagnante, cette barrière n'est pas nécessaire, les castors se séparent en un certain nombre de familles, et s'occupent à construire les huttes qu'ils doivent habiter ou à réparer celles qui leur ont déjà servi l'année précédente. Ces cabanes sont élevées contre la digue ou sur le bord de l'eau, et sont de forme à peu près ovalaire; leur diamètre interne est de six à sept pieds, et leurs parois, construiles, comme la digue, avec des branches d'arbres, sont recouvertes des deux còtés d'un enduit limoneux. On y trouve deux étages : le supérieur, à sec, est destiné à l'habitation des castors; l'inférieur, sous l'eau, sert de magasins pour les provisions d'écorce; enfin elles ne communiquent au dehors que par une ouverture placée sous l'eau. On a pensé que la queue ovalaire des castors leur servait comme une truelle pour bâtir ces demeures; mais il parait qu'ils n'emp)'oient à cet usage que leurs dents et leurs patles de devant. Avec leurs fortes incisives ils coupent les branches et mème les troncs d'arbres dont ils ont besoin, et c'est avec leur bouche ou avec leurs pattes antérieures qu'ils trainent ces matériaux. Lorsqu'ils s'établissent sur les bords d'une eau courante ils coupent le bois au-dessus du point où ils veulent construire leur demeure, le mettent à flot, et, profitant du courant, le dirigent là où il faut qu'il aborde : c'est également avec leurs pattes gu'ils creusent sur le rivage ou au fond de l'eau la terre qu'ils emploient. Du reste, ces travaux, qui s'exécutent arec une extrème rapidité, ne se font que pendant la nuit. Lorsque le roisinage de l'homme empèche les castors de se multiplier assez pour former de semblables associations, et d'avoir la tranquillité dont ils auraient besoin pour exécuter les travaux dont 
nous renons de parler, ils ne bàtissent plus de huttes; mais l'instinct de la construction ne s'en conserve pas moins, et on a vu un de ces animaux, qui était élevé en captivité, s'emparer de tous les morceaux de bois qu'il trouvait pour les planter en terre et commencer des bâtisses, quoique les circonstances dans lesquelles il se trouvait lui rendissent inutiles de semblables travaux.

Les sociétés parfaites sont plus rares parmi les oiseaux que parmi les mammifères; on connait cependant une espèce de moineau, le Républicain (Loxia socia), qui vit en troupes nombreuses aux environs du cap de Bonne-Espérance, et construit son nid sous une sorte de toiture commune à toute la colonie (fig. 109). Mais c'est

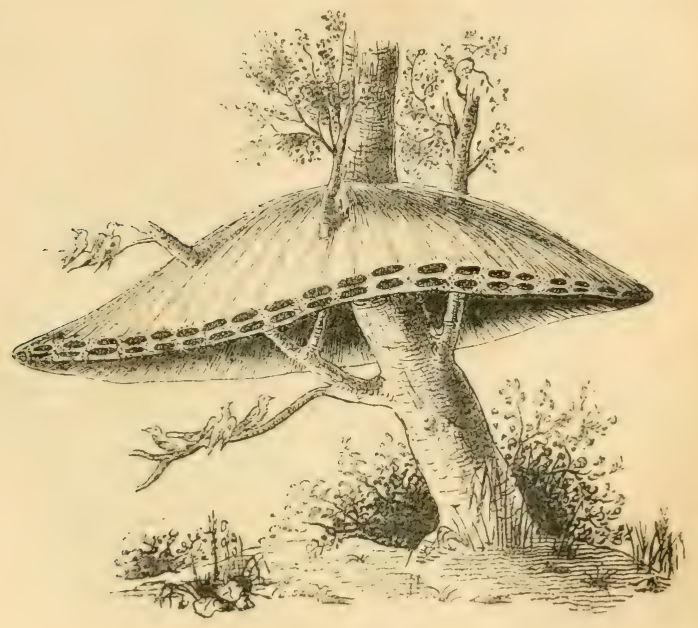

Fin. 109. Nid du Ripublicain.

dans la classe des insectes qu'on voit les exemples les plus remarquables de ce genre d'instinct, ('t que les constructions communes qui en résultent offrent le plus d'intérit. Les nids des guèpes sont construits de la sorte, et nous surprennent par leur régularité et leur perfection; pour les bàtir; ces insectes détachent arec leurs mandibules des parcelles de vieux bois qu'ils convertissent en une espere de pate semblable à du carton, puis ils se servent de cette matiere pour former des rangées de celtules hexagnonales; ces catleaux ou rayoms sont placés parallelement entre eux à une 
distance déterminée, et sont réunis, d'espace en espace, par de petites colonnes qui servent aussi à les suspendre; enfin, le tout est placé, tantòt à l'air, tantòt dans le creux d'un arbre, ou mème: en terre, et se trouve, suivant les espèces, à nu ou renfermé daus une enveloppe commune (fig. 110).

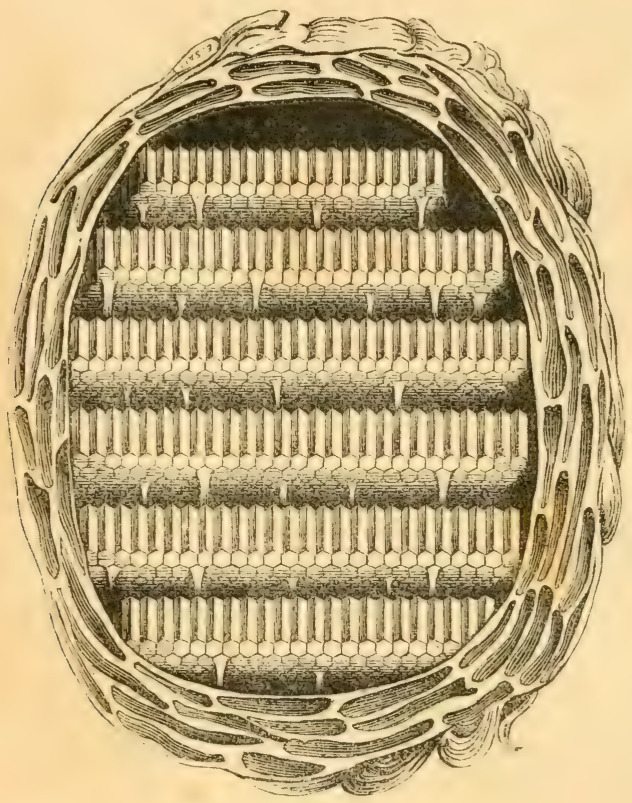

Fig. 110. Nid de Guêpe.

$\$ 332$. La communauté dans les travaux est un des trails les plus remarquables dans les mœurs des abeilles; mais ces insectes nous offrent aussi l'exemple d'un autre genre d'instinct qui détermine des aclions non moins curieux a observer et qui appartient aussi à la classe des phénomènes dont nous nous occupons en ce moment: savoir, l'instinct qui reggle les relations entre les ouvrières et leur reine.

Nos abeilles lomestiqurs, ou mouches à miel, qui paraissent ètre originaires de la Grèce, el qui ont ététransportées par l'homme dans 
toute l'Europe ainsi que dans le nord de l'Afrique et dans l'A mérique septentrionale, vivent en colonies, composées chacune de dix à trente mille ouvrières ou mulets, de six à huit cents mâles ou faux-bourdons (appelés à tort bourdons par les cultivateurs), et communément d'une seule femelle qui semble y régner en souveraine, et qui a reçu le nom de reine; ils établissent leur demeure dans quelque cavité, telle que le trou d'un vieux arbre ou l'espèce de huttes que les agriculteurs leur préparent et que l'on nomme des ruches, et ce sont les abeilles ouvrières qui exécutent tous les travaux nécessaires à l'existence et à la prospérité de la société. Les unes, nommées cirieres,

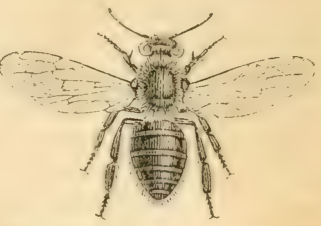

Fig. III. Abei.le ouvrière. sont chargées de la récolte des vivres et des matériaux de construction, ainsi que des bâtisses à élever; les autres, appelées, a raison de leurs fonctions, les nourrices, s'occupent presque exclusivement du soin intérieur du ménage et de l'éducation des petits.

Pour faire sa récolte, l'abeille cirière entre dans une fleur bien épanouie, dont les étamines sont chargées de la poussière appelíe pollen par les botanistes. Cette roussiere s'attache aux poils branchus dont son corps est couvert, et, en se frottant avec les brosses qui garnissent ses tarses ( $f y .106)$, l'insecte la rassemble en pelotes, qu'il empile dans les corbeilles ou palettes creusées à la face interne de ses jambes postérieures. A l'aide de leurs mandibules, les ouvrières détachent aussi de la surface des plantes une matière résineuse, appelée propolis, et en remplissent leurs corbeilles. Ainsi chargées, ces abeilles retournent à leur demeure commune, et, aussitot arrivées, se débarmasent de leur fardeau, pour re-

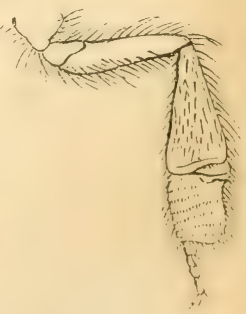

Fig. 112. P'ulle posteripure d'abeille. tourner à la recherehe de nouvelles provisions ou pour emplover celles déjà recueillics. Les travaus de l'intérieur sont plus compliqués : les aloeilles commencent par boucher avec du propolis loutes les fentes de leur habitation et n'y laissent qu'une semle ouverture, dont les dimensions sont peu considérables; elles s'orcupent ensuite de la construction des raygons on gateaux, destinés a sers ir de nids pour les petits et de magasins pour les pro- 
visions de la communauté. Ces gâteaux sont faits avec le la cire, matière qui se trouve sur diverses plantes, et qui est sécrétée aussi par les abeilles dans des organes particuliers, situés sous les anneaux de leur abdomen. Ils sont composés de deux couches de cellules (ou alvéoles) hexag̣ones, à base pyramidale, adossés l'un a l'autre, et sont suspendus, perpendiculairement, par une de leurs tranches. En général, c'est à la voùte de la ruche qu'ils sont fixés, el ils sont toujours rangés parallèlement, de manière à laisser entre eux des espaces vides, dans lesquels les abeilles peuvent circuler. Les cellules, comme on le voit, sont par conséquent disposées horizontalement et ouvertes par un de leurs bouts. C'est avec leurs mandibules que les ouvrières les façonnent : elles en taillent les pans pièce à pièce, et elles portent dans leur construction une précision étonnante. La plupart de ces loges ont exactement les mèmes dimensions et servent à loger les larves ordinaires, ou deviennent des magasins ; mais quelques-unes, destinées à contenir des larves femelles et appelées pour cette raison des cellules royales, sont beaucoup plus grandes et de forme presque cylindrique. (uand les abeilles ont fait une récolte abondante de pollen ou de miel, elles déposent le superflu dans quelques-unes des cellules ordinaires, pour subvenir soit à leur consommation journalière, soit a leurs besoins futurs. Elles ont aussi la précaution de boucher, avec un courercle en cire, les cellules contenant leur réserve de miel, et, si quelque accident vient menacer de miner leurs constructions, elles savent aussi élever des colonnes et des ares-boutants, pour empècher la chute de leurs gailcaux. Les mâles, comme nous l'avons déjà dit, ne participent pas à ces travaux, et, lorsqu'ils ne sont plus d'aucune utilité à la communauté, les ouvrières les mettent à mort, en les perçant de leurs aiguillons. C'est du mois de juin à celui d'aoùt que ce carnage a lieu, et il s'étend mème sur les larves et les nymphes de faux-bourdons. La femelle reste également étrangère à la vie active menée par les ouvrières; mais, comme c'est de sa fécondité que dépend la prospérité de l'essaim, elle est toujours choyée par celle-ci. Dès qu'elle commence à pondre des œufs, elle devient pour toute la colonie un objet de respect, et elle ne souffre dans sa demeure aucune rivale; si elle en rencontre, un combat à mort s'engage aussitòt, et une seule reine se voit toujours dans chaque essaim, quelle que soit la multitude d'individus dont celui-ci se compose. Tant qu'elle est restée renfermée dans l'intérieur de son habitation, la jeune reine ne pond pas d'œufs; mais, si le temps est beau, elle en sort peu de jours après sa naissance, et s'élève avec les 
falix-bourdons à perte de vue dans l'air ; cependant elle ne tarde pas à rentrer, et, quarante-six heures après, elle commence à pondre des œufs, qu'elle dépose un à un dans les cellules préparées à cet usage. Pendant le premier été, cette ponte n'est pas très-nombreuse et ne se compose que des œufs d'ourrières; pendant l'hiver, clle s'arrète; mais, dès que le retour du printemps se fait sentir, la fécondité de la mère-abeille devient extrème : dans l'espace d'environ trois semaines elle pond en général plus de douze mille œufs. C'est seulement vers le onzième mois de son existence qu'elle commence à donner des œufs de mâles en mème temps que des œufs d'ouvrières, et ceux d'où naitront des femelles ne viennent qu'un peu plus tard. Trois ou quatre jours après la ponte, les œufs éclosent, et il en sort une petite larve de couleur blanchàtre, qui, étant privée de pattes, ne peut sortir de son nid et chercher sa nourriture; mais les ouvrières pourvoient abondamment à ses besoins, en lui présentant une sorte de bouillie, dont les qualités varient suivant l'âge et le sexe de l'individu à qui elle est destinée, et, lorsque le moment de sa transformation en nymphe approche, elles la renferment dans sa loge, en adaptant à celle-ci un couvercle en cire. Cinq jours après la naissance d'une larve d'ouvrière, ses nourrices ferment ainsi sa cellule. Elle file alors autour de son corps une coque de soie, et, au bout de trois jours, se change en nymphe; enfin, après ètre restée sous cette forme pendant sept jours et demi, elle subit sa dernière métamorphose. Les mâles n'arrivent à l'état parfait que le vingt et unième jour de la naissance de la larve, tandis que les femelles subissent leur dernière transformation le treizième jour. L'influence qu'exerce sur le développement des abeilles la qualité des aliments dont les ouvrieres nourrissent les larves est des plus remarquables : car, en variant la bouillie qu'elles donnent à leurs éleves, ces singulières nourrices produisent à volonté des ouvrieres ou des reines. Cela se voit d'une manière évidente lorsqu'un essaim a perdu sa reine, et qu'il n'existe pas dans les rayons de la ruche de cellule royale contenant une larve de femelle; alors les abeilles se hatent de démolir plusienrs collules d'ouvrieres, pour y domner la forme d'une cellule royale, et fournissent en abondance à la larve qu'elles y laissent la paiture dont elles alimentent les femelles; or, par ce seul fait, la larve, au lieu de devenir une abeille ouvrière, comme cela serait arrivé si elle avait continué à ètre élevée de la maniòre ordinaire, devient une abeille-reine. Quand une jeune reine a acheré ses mótamorphoses et rongé les bords du couverele de sa cellule, pour sortir de son nid, on voit so manifester dans foute 
la colonie une grande agritation. D'un còté, les ouvrières bouchent avec de nouvelles quantités de cire les ouvertures qu'elle pratique, et la retiennent prisonnière dans sa loge; d'un autre còté, la vieille reine cherche à s'en approcher, pour la percer de son aiguillon et se défaire ainsi d'une rivale dangereuse; mais des phalanges d'ouvrières s'interposent pour l'en empècher. Au milieu du tumulte qui résulte de tout ce manége, la vieille reine sort de la ruche avec toute l'apparence de la colère, et suirie d'une grande partie de la société d'ouvrières et de màies, dont elle était le chef unique. Les jeunes abeilles, trop faibles pour émigrer de la sorte. restent dans la ruche, et hientòt leur nombre augmente par la sortie de celles qui étaient encore à l'état de larve ou de nymphe; les jeunes reines se dégagent aussi de leurs cellules pendant ce tumulte. S'il y en a plusieurs, elles se battent entre elles, et celle qui, après le combat, so trouve seule, devient la souveraine de la nouvelle société. L'essaim qui a abandonné de la sorte sa demeure avec la vieille reine ne se disperse pas, mais va à quelque distance se suspendre en groupe et fonder une nouvelle colonie qui recommence tous les travaux dont nous venons de parler, et qui, à son tour, fournit au bout d'um certain temps un second essaim, dont la sortie est déterminée par les mèmes causes que nous avons rues occasionner l'émigration du prenier. Une ruche donne quelquefois trois ou quatre essaims par saison; mais les derniers sont toujours faibles. La mort de l'abeille-reine, la faiblesse d'une colonie et les attaques de ses ennemis déterminent quelquefois les abeilles à se disperser; les fugitives vont alors chercher asile dans une ruche plus fortunée, mais elles en sont impitoyablement repoussées à coups d’aiguillon par les propriétaires de la demeure qu'elles voudraient partager; car aucune abeille étrangère, mème isolée, n'est reçue dans une ruche où elle n'est pas née. Quelquefois aussi toute une colonie en attaque une autre pour en piller les magasins, et, si les agresseurs ont le dessus, ils détruisent complétement la population vaincue et enlèvent tout le miel de leurs victimes, pour le déposer dans leur ruche.

$\$ 333$. L'instinct qui pousse les abeilles à piller ainsi leurs voisins offre quelque ressemblance avec celui qui porte d'autres insectes à des actions plus singulieres encore, telles que la capture d'animaux d'espèce différente dont ils font des esclaves; habitude dont l'histoire des fourmis va nous fournir un exemple.

Ces petits insectes vivent comme les abeilles en sociétés nombreuses composées de mâles, de femelles, et surtout d'individus imparfaits et stériles, que l'on désigne sous le nom d'ouvrières, ou 
de neutres, et que l'on reconnait à l'absence de leurs ailes, à la yrosseur de leur tète et à la force de leurs mandibules; ce sont aussi les ouvrières qui sont chargées de tous les travaux nécessaires à la prospérité générale, et elles y procèdent de manieres différentes suivant les espèces. Lesınes bâtissent leur demeure commune en terre, les autres en bois. Les premicres creusent dans le sol une multitude de galeries et de chambres disposées par étages, et, rejetant les déblais au dehors, élèvent souvent au-dessus de leur nid un monticule, dans l'intérieur duquel ces travailleuses infatigables creusent de nouveaux étages, semblables à l'étage silué au-dessous; quelquefois on les voit aussi construire avec celte terre des galeries qui montent le longr des tiges des arbustes où ces insectes vont chercher leur nourriture, et qui les abritent dans leurs courses journalieres. Les fourmis qui construisent leurs fourmilières en bois s'établissent dans des arbres déjà attaqués par des larves d'autres insectes, et ramollis par la pourriture. Avec leurs mandibules elles détachent des particules de bois et creusent dans l'intérieur de l'arbre plusieurs étages séparés par des planchers et. soutenus par des piliers formés de bois non rongé ou de sciure détachée des parties voisines et pétrie avec de la salive. Si quelque accident vient détruire une partie de leur édifice, on voit aussitòt. toutes les ouvrières qui ont échappé à ce désastre déployer une activité extrème, retirer des décombres celles qui y ont été ensevelies, transporter en lieu de sùreté leurs compagnes blessées, et ajouter de nourelles bâtisses à celles encore debout. Les màles et les femelles ne participent pas à ces travaux. Les premiers ne restent dans la fourmiliere que fort peu de temps et périssent presque aussitòt qu'ils en sont sortis; les femelles quittent aussi la demeure commune avec less mâles; mais, après s'ètre séparées de ceux-ci, et s'ètre dépouillées de leurs ailes, elles sont ramenées dans la fourmiliere par les ouvrieres et placées dans les chambres les plus retirées, ou olles restent prisonnieres, et sont nourries par leurs sardiemnes. Des qu'olles prondent un œuf, une fourmi ouvrière sen empare et lo tramsporte avec soin dans une chambre particuliere. Les aufs destiné a produire des femelles ne sont pats logés dans les mèmes cellules que ceux d'ou naitront les ouvrieres. Les larves recoivent aussi de la part des ouvrieres des soins assidus; chacune d'elles est appatre par celles-ci avec des sues qui lui convirinnent, et, lorsque le temps est beau, on roit ces nourrices actives transporter leurs éleves hors de la fourmiliere pour les exposer aux rayons du soleil, les défendre contre leurs ennemis. les rapporter dans leur nicl a l'approche du soir, et les con- 
Iretenir dans un état de propreté extrème. Les fourmis ne font de provisions ni pour elles-mèmes ni pour leurs nourrissons, mais vont chaque jour chercher les aliments dont elles ont besoin. Pendant que certaines ourriores s'occupent de l'entretien des bâtisses et des nouvelles constructions nécessaires à leurs colonies croissantes, d'autres vont chercher sur les fleurs des liquides sucrés et surtout y récolter un suc particulier, qui suinte du corps des pucerons et de quelques autres petits insectes hémipteres. Certaines fourmis ne se contentent pas de prendre la goulteletle sucrée que le puceron leur abandonne lorsqu'il se sent caressé par leurs antennes. Souvent elles portent ces insectes dans leurs demeures et les y élèvent comme des formiers le font pour leurs vaches laitières. On a vu les habitants de deux fourmilières voisines se disputer leurs pucerons, et les vainqueurs emporter leurs prisonniers avec le mème soin qu'elles le font pour leurs larves. Mais ce singulier instinct de prévoyance n'est pas encore le trait le plus extraordinaire de leurs moeurs. Il est des fourmis qui, après avoir vaqué pendant une partic de leur vie à leurs travaux ordinaires, semblent comprendre les plaisirs de l'oisiveté el vont faire la guerre à des espèces plus faibles, pour en enlever les larves et les nymphes, transporter celles-ci daus leur propre demeure, et charger les esclaves qu'elles se sont ainsi procurés de tous les travaux de la communauté.

$\$ 334$. Enfin, il est aussi des animaux chez lesquels l'inslinct de la société se trouve réuni à une autre tendance naturelle qui, au premier abord, semble moins remarquable que les précédentes, mais qui a pour nous une importance bien plus grande, car c'est probablement à elle que nous devons en majeure partie la possibilité de réduire quelques-uns de res ètres à l'état de domesticitc ; nous voulons parler de la disposition à l'obéissance qui place tout un troupeau sous la direction d'un chef et qui a des liaisons intimes avec l'instinct de l'imitation. Lorsqu'on étudie l'histoire du cheval, on voit un exemple frappant de l'influence qu'exerce sur tous les individus de la bande l'exemple de ceux qui sont les plus vaillants et les plus forts, el, lorsqu'on observe les mours des singes, on voit aussi combien l'instinct de l'imitation est développé chez ces animaux.

$\$ 33 \%$. Facultés de l'entendement chez les animaux. - Les instincts, dont l'élude vient de nous occuper si longuement, sont les principales causes délerminantes des actions des animaux, et chez la plupart de ces ètres on ne roit, comme nous lavons déjả dit, aucun indice de l'existence de facultés d'un ordre plus élevé; mais, lorsguion observe ce yui se passe chez certains animaux, il devient. 
impossible de refuser à ceux-ci la possession d'une espèce d'intelligence, et de reconnaitre qu'ils peuvent ètre doués, comme l'homme lui-mème, de la mémoire, du jugement, et mème de la faculté d'établir quelques raisonnements peu compliqués.

Ainsi, il est évident que beaucoup d'animaux ne sont pas privés de mémoire, et que, chez plusieurs d'entre eux, cette faculté est mème trés-développée. Le cheval, par exemple, reconnait souvent un chemin qu'il n'avait parcouru qu'une fois et qu'il n'a pas vu depuis des années. La mémoire n'est pas moins fidele chez le chien, l'éléphant et plusieurs autres mammifères, car on voit fréquemment ces animaux reconnaitre, après une longue absence, les personnes qui en avaient pris soin ou qui les avaient maltraités. Les poissons mème ne paraissent pas en ètre complétement dépourvus, car on a pu apprendre à des anguilles à accourir à la voix de leur gardien.

$\$ 336$. Parmi les actions des animaux, il en est aussi (que nous ne pouvons nous expliquer qu'en les supposant le résultat d'un raisonnement. Ainsi le chien, qui s'agite et qui déchire les barreaux de sa cage s'ils sont de bois et qui se résigne à sa captivité si ces barreaux sont de fer, doit agir de la sorte, parce que, dans le premier cas, il voit que par ses morsures il entame le bois, et qu'il croit, par corséquent, pouvoir briser ainsi l'obstacle qui s'oppose à sa fuite, tandis que, dans le second cas, trouvant le fer trop dur pour ses dents, il juge bientòt que ses efforts seront inutiles, et alors il les discontinue. Lorsque le chien, royant son maitre prendre son chapeau, juge qu'il va sortir et l'accable de caresses pour se faire emmener à la promenarle, il aygit aussi par suite d'un raisonnement, et cette opération de l'intelligence est encore plus évidente dans une multitude de stratarremes que l'on cite comme avant été employés par le mème animal pour atteindre l'objet de ses désirs; par exemple, dans la conduite d'un chien de garde qui chaque nuit parrenait a dégager son cou du collier qui le tenait à lattache et courait alors égrorger des moutons dans la campagne voisine, puis allait à la rivièe laver sa gueule ensanglantée et revenait avant le jour au logis remettre son cou dans le collier qu'il avait quitté furtivement, et so coucher sur sa litiere de façon à ne donner aucun éveil sur ses méfaits.

Les observations recueillies il y a quelques années sur un jeune chimpanzé (fig. 11.3) et un orangor-outang vivants dans la ménagerie du Jardiri du Roi, à Paris, montrent que ces singes sont doués d'une intelligence encore plus développée. L'orang-outang s’attatchait aus personnes qui le soignaient, boudait lorsqu'on ne lui cedait pati, 
et, de mème que les enfants, exprimait sa colère en criant et en se frappant la tète contre terre, comme si, n'osant s'en prendre aux personnes qui lui résistaient, il s'en prenait à lui-mème afin d'émouvoir ceux qui l'entouraient. Lorsqu'il était enfermé seul dans la chambre où on le tenait, il cherchait toujours à sortir, et montait sur une chaise placée auprès pour atteindre à la serrure et ouvrir la porte. Afin d'empècher cette manœurre, son gardien rmporta un jour cette chaise; mais l'orang fut en chercher une autre qu'il mit a la place de la première, et sur laquelle il monta de mrime pour ouvrir sa porte; or, comment ne pas reconnaitre

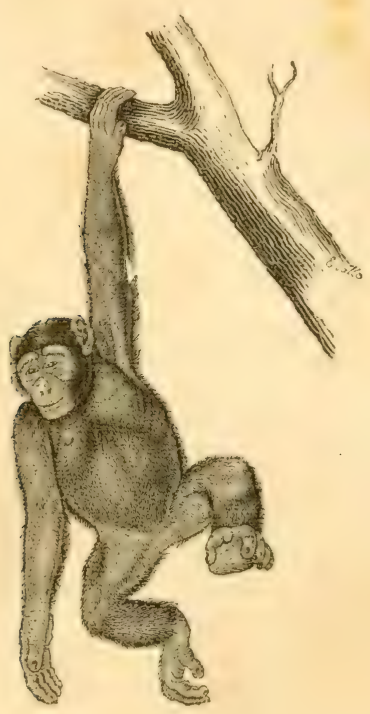

Fig. 113. Chimpanzé.

dans celte action, non-seulement la faculté de profiter des leçons de l’expérience, mais aussi celle de généraliser? Jamais on n’avait enseigné à cet animal à s'aider d'une chaise pour ouvrir les portes, et il n'avait mème vu faire cela à personne; ce devait ètre par sa propre expérimro qu'il avait appris qu'en grimpant ainsi it 
s'élevait au niveau de la clef qu'il voulait tourner, et ce ne pouvait ètre qu'en obserrant les actions de ses gardiens qu'il s'était aperçu que les chaises élaient transportables d'un lieu à un autre ; enfin, ce ne pouvait ètre qu'en généralisant les notions ainsi obtenues ot en combinant les jugements.auxquels ces idées avaient donné lien, qu'il a été conduit à ağir d'une manière si bien calculée; car, clans les circonstances anormales où il se trouvait, ses instincls naturels ne pouvaient suffire pour le guider.

$\$ 337$. Ce n'est guère que chcz les mammifères les plus voisins de l'homme que l'on trouve des indices d'une intelligence un peu développée, et à mesure que l'on descend dans la série des ètres on voit les actions électives devenir de plus en plus rares et l'instinct remplacer l'intelligence. Les singes et les carnassiers se placent en première liğne sous le rapport de l'intelligence; les pachydermes, tels que l'éléphant et le cheval, viennent ensuite; puis les ruminants; et, de tous les mammifères, les rongeurs, c'est-à-dire l'écureuil, la marmotte, le castor, le lièvre, etc., sont à cet égard les plus imparfaits. Ainsi le rongeur ne parvient pas à distinguer indisiduellement l'homme qui le soigne de tout autre homme; le ruminant distingue son maître, mais ses facultés sont si bornées qu'un simple changement d'habit suffit quelquefois pour qu'il le méconnaisse (1); le cheval et l'éléphant non-seulement gardent le souvenir des personnes, mais apprennent facilement à obéir à des signes déterminés; le chien est reronnaissant des bienfaits qu'on lui confère, comprend la tristesse de son maitre aussi bien que sa colere, et lui porte secours au besoin; enfin le singe agit avec encore plus de discernement et de calcul; mais c'est dans la jeunesse seulement qu'il est si heureusement doué, et ses facultés, au lieu de se perfectionner avec le progrès de l'àge, comme celles de l'homme, se détériorent promptement.

Chez la plupart des animaux inférieurs, on n'apercoit rien qui ressemble a de la raison, et c'est l'instinct qui parait dirigger toutes les actions; quelques insectes seulement semblent, dans certains cas, se déterminer par des jugements plutòt que par un instinct proprement dit, mais ces cas sont rares et mème incertains.

$\$ 338$. Enfin nous derons ajouter encore que certains animaux

(1) Tin bison du Jardin du Roi arait pour son gardien la soumission la plus complète; ce grarlien vint à changer d'habit, et le bison ne le reconnaissant plus se jeta sur lui; le gardien rejprit son habit ordinaire et le bison le recomut. J)eux beliers accoutumés di vivre ensemble sont -ils toudus, on les voit aussitut se préri piter l'un sur l'autre avee fureur, comme s'ils étaient étrangers entre eux. 
paraissent aroir comme thomme, quoique diune maniere bien moins parfaite, des moyens de communication à l'aide desquels ils expriment ce qu ils sentent et en informent leurs semblables.

C'est ainsi que chez les mammifères et les oiseaus rivant en troupes on roit souvent des individus placés en sentinelle, qui, par des cris particuliers, arertissent leurs compagnons de l'approche du danger: les marmottes et les flamants nous en offrent des exemples. On śest éralement assuré de l'existence d'une faculté analowue chez les hirondelles. car on a vu bien des fois que le cri de détresse poussé par ces oiseaux, lorscrue leurs petits sont menacés par quelque ennemi, attire aussitot toutes les hirondelles du roisinage, qui volent au secours des parents eflrayés et harcellent de concert lanimal dont ceux-ci redoutent l'attaque. Enfin, les insectes, aussi, paraissent quelquefois se communiquer des nouvelles: les observations faites sur les foumis par lluber, par Latreille ef par plusieurs autres naturalistes, ne peurent laisser à cel égard que peu dincertitude. Ainsi. lorsque la surface diune fourmilière rient à ètre décradée. toute la colonie est informée du désastre avec une rapidité étonnante: ancun son appréciable à nos oreilles n'est produit. mais on roit les insectes qui étaient témoins du déxàt courir çà et là, se rapprocher de leurs compasnons, les frapper arec la tite et rapprncher leurs antennes des leurs: les individus qui ont été arertis de la sorte chang̣ent la direction de leur course pour se conduire comme les premiers, el au bout de quelutes instants on roit ces petits animaux accourir par milliers sur le point ou leur demeure menace ruine. Dans les cruerres acharnees que se font souvent les habitants de deux fourmilieres roisines, on a ru aussi des éclaireurs donner au crros de larmée des informations qui l'ont fait changer de route. et des observateurs dignes de foi assurent mème que, dans des circonstances critiques. des fourmis quittent quelquefois le champ de bataille pour retourner à la fourmiliere, et que leur arrivée est suirie presyue aussitòt par le départ de renforts nombreux.

$\$ 339$. La plupart des actions des animaux śexpliquent facilement par lexistence des facultés que nous venons de cutudier, et que nous arons trowries plus ou moins analogues at celles que nous possidons nous-mèmes: mais il est diautres phénomènes dont nous ne pourons en aucune facon nous rendre compte, et qui nous portent a sompeonner que plusieurs de ces ètres pourraient hien

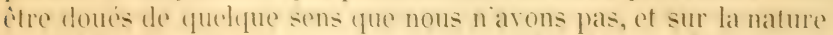

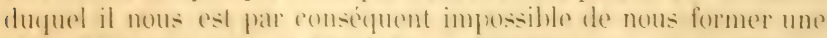

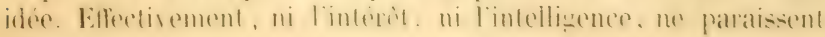


devoir suffire pour guider certains oiseaux, tels que les pigeons et les hirondelles, qui, mis en liberté après avoir été transportés dans des paniers bien fermés à des centaines de lieues de leur nid, prennent leur vol sans hésitation et se dirigent en ligne droite vers le lieu où est restée leur jeune famille, comme si celle-ci était sous leurs yeux. Lorsque le chien et les autres mammiferes retrourent leur chemin à de grandes distances ou suivent de loin la trace de quelqu'autre animal, ils se dirigent ordinairement en prenant pour ģuide les sensations reçues par le sens de l'odorat, dont la délicatesse est extrème chez ces animaux; mais pour les pigeons-messagers, qu'on voit voler d'un trait de Bordeaux à Bruxelles, par exemple, on ne peut supposer rien de semblable, et on ne peut mème faire de conjecture sur la nature de la faculté qui les guide.

\section{$\$ 340$. Rapports entre $\mathbf{I}$ intelligence et le cerveau. - Nous ne} savons également rien sur la cause de l'existence ou de l'absence de telle ou telle faculté intellectuelle ou instinctive chez un animal quelconque, ni sur le mécanisme à l'aide duquel ces facultés s'exercent; nous savons seulement que c'est par l'intermédiaire du système nerveux que se manifestent tous les phénomienes dépendants de ces facultés. Ia science est dans une ignorance complète relativement à la nature des rapports qui existent entre l'action de notre cerveau et la production de nos pensées ou la perception de nos sensations; mais il est facile de s'assurer que cet organe est linstrument spécial à l'aide duquel les opérations de l'esprit se manifestent; de mème que le cerveau ne peut receroir des impressions du dehors que par l'intermédiaire des sens, de mème les sensations ne peuvent parvenir à l'esprit que par l'intermédiaire de notre cerveau, et de mème aussi notre volonté et toutes nos autres facultés intellectuelles ne peuvent se manifester qu'a l'aide de cet agent; et toutes les fois que, par une circonstance quelconque', ses fonctions sont interrompues, nous perdous aussitit l'entendement, la volonté, la sensibilité, mème la conscience de notre ètre, et nous sommes réduits a une condition analogrue à celle d'un régrétal, car alors nous ne vivons plus que de la vie organique. En effet, pour s'en convaincre, il suffit d'observer ce qui a lieu lorsque, par suite d'une bl'ssure ou d'une apoplexie, le cerveau cesse de remplir ses fonctions: l'homme est plongé alors dans un état qui ressemble au sommeil le plus profond, el dans les expériences physiologigues on produit à volonté cet état che\% les animaux supérieurs; car chez cux allssi le cerveau est l'instrument nécessaire a foute operation de l'ontendement, ol sa destruclion entraine la perte de l'intelligence et de l'instinct. 
Mais de ce qur le concours du cerveau est indispensable à l'exercice des facultés intellectuelles, on ne peut pas en conclure que c'est cet organe lui-mème qui sent, qui juğe et qui veut; il nous est mème impossible de concevoir comment, un organe matériel pourrait engendrer la pensée, et toutes les hypothèses des matérialistes ne nous éclairent en rien sur la nature intime de ce travail. Pour s'en rendre compte, on est forcé de remonter plus haut et de l'attribuer à un principe immatériel qui, chez l'homme, est désigné tantòt sous le nom de principe vital, tantòt sous celui d'àme. On est porté à supposer que cette force est aussi la cause première de tous les phénomènes essentiellement vitaux de notre existence; phénomènes dont la nature ne varierait que parce que les organes ou instruments par l'intermédiaire desquels celte puissance unique se manifeste sont eux-mèmes différents dans les diverses parties de notre économie. Du reste, les faits nous manquent pour la discussion diune pareille question, et les physiologistes ignorent éralement quel est le degré d'analogie qui existe entre l'àme de l'homme et le principe vital qui, dans chaque animal, parait en tenir lieu et s'y montre avec des attributs variables suivant les espèces.

$\$ 3 \nmid 1$. Quoi qu'il en soit, le cerveau, comme nous l'avons déjà dit, est l'instrument à l'aide duquel la puissance intellectuelle s'exerce, et la structure de tout organe ou instrument physiologique 'st toujours en harmonie avec ses usages. Il s'ensuit donc qu'on pourrait conclure à priori que la conformation di cerveau doit varier suivant qu'il est destiné à servir d’intermédiaire pour la manifestation de tel ou tel genre de faculté, et qu'il doit présenter chez les divers animaux des différences de structure correspondantes aux différences qui s'observent dans leur intelligence. Et, en effet, l'anatomic nous apprend que, dans bien des cas, de semblables coincidences sont faciles à constater.

$\$ 3.2$. Ainsi, on remarque qu'ordinairement un oryane agit avec d'autant plus de puissance qu'il est plus volumineux, et lorsqu'on compare le développement de l'intelligence avec le développement matéricl de l’encéphale, on peut saisir également quelques rapports analogues. L'homme, qui, par ses facultés intellectuelles, est si supérieur à tous les animaux, a aussi un cerveau plus développé; chez les singes et mime chez les carnassiers, cet organe est moins grand, mais offre encore une perfection considérable; il est plus petit et plus simple chez les rongeurs, et il se trouve réduit a son minimum chez les poisoons, qui de tous les animaux vertébrés sont les plus stupides. 
Ces faits ont conduit à penser qu'on pouvait juger du degré d'intelligence des animaux et mème des hommes entre eux par le, développement plus ou moins considérable de leur cerveau, et, pour apprécier ces différences, on a recours à différentes méthodes, dont la plus célebre est celle de la mesure de l'angle facial, proposée par Camper, habile naturaliste hollandais.

Ces mesures sont destinées à faire connaître le rapport qui existe entre le volume du crâne (qui est rempli par le cerveau et le cervelet) et celui de la face, et se prennent de la manière suivante. On tire une ligne horizontale $(c d, f i g$. 14 et 115$)$, que l'on fait passer par le trou auditif et par le plancher des fosses nasales, de façon à suivre à peu près la direction de la base du cràne; puis on abaisse sur cette

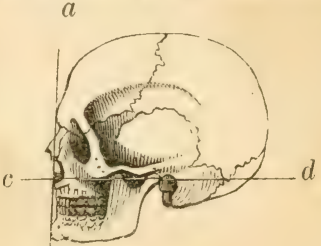

b) ligne une seconde ligne $(a b)$, que l'on fait passer sur le point le plus saillant du front et sur l'extrémité de la màchoire supérieure. Or, il est évident que cette dernière sera d'autant plus inclinée sur la première et formera avec elle un angle d'autant plus aigu, que la face sera plus développée et le front plus reculé, et que, par conséquent, la mesure de l'angle facial (car c'est ainsi qu'on nomme l'angle dont nous venous de parler) pourra indiquer avec assez d'exactitude le rapport cherché.

L'homme est de tous les animaux celui dont l'angle facial est le plus ouvert, et à cet égard il existe parmi les diverses races humaines de grandes différences; les tètes européennes l'ont ordinairement de $80^{\circ}$ (fig. 114), et les nègres d'environ $70^{\circ}(f g .115)$; dans les différentes espèces de singes, elle varie de $6 \ddot{3}^{0}$ à $30(f i g .116)$, et, à mesure qu'on s'éloigne davantage de l'homme, et que l'on descend dans la

a

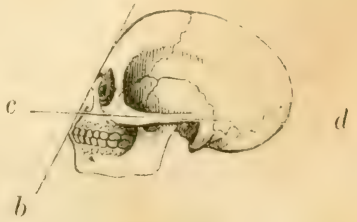

Fig. 115. série des mammiferes, il devient encore plus aigur dans le cheval et le sanglier, par exemple, le front est si fuyant, qu'il devient impossible de mener une ligne droite de l'exírémité de la màchoire supérieure au cràne, à cause de la saillie du nez, comme on peut s'en convainere en jetant les yeux sur la figure ci-jointe (fig. 117); enfin. che\% les oiseam, les reptiles of les poissons. 
l'angle facial, lorsuu'il peut ètre mesuré, devient encore plus aigu que chez la plupart des mammifères.

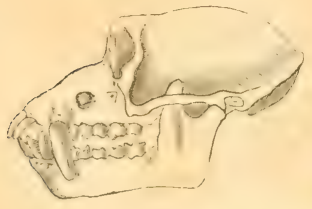

Fig. 116. Tête de Macaque.

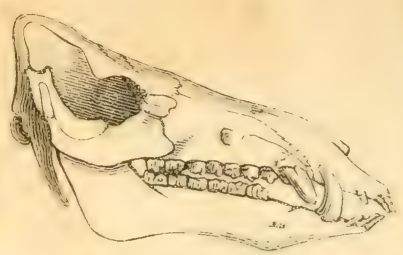

Fig. 117. Têle de Sanglier.

La coïncidence plus ou moins grande qui existe en général entre linclinaison de la lị̆ne faciale el l'étendue des facultés intellectuelles ne parait pas avoir échappé aux anciens; non-seulement ils ont très-bien remarqué que la ligne faciale relevée était un signe d'une nature plus généreuse et un des caracteres de la beauté ; mais, dans les tigures de leurs héros et de leurs dieux, ils l'ont arancée plus qu'clle ne l'est chez aucun homme, et dans quelques statues (telles (que Jupiter Olympien) ils l'ont fait incliner un peu en avant.

Le vulgaire mème est habitué a attribuer de la stupidité aus hommes et aux animaux dont le front est très-fuyant ou le museau très-allongé; et, lorsque quelque circonstance vient à relever la lig̣ne faciale, mème sans augmenter la capacité du cràne, nous trousons aux animaus qui présentent cette disposition un air particulier d'intelligence, et nous sommes portés à leur attribuer des qualités qu'ils n'ont réellement pas. L'éléphant et la chouette sont dans ce cas. La grande étendue des sinus frontaus donne à leur front une saillie considérable : or, la çhouette, comme chacun le sait, était chez les anciens l'emblème de la sayesse, et l'éléphant porte aux Indes un nom qui indique qu'il a la raison en partage, et cependant ni l'un ni l'autre de ces animaux ne sont réellement remarquables par le développement de leurs facultés intellectuelles.

Quoi qu'il en soit, il faut bien se garder d'attacher à ces mesures une grande importance; clles ne peuvent donner tout au plus qu'une idée approximative du développement du cerveau, et jusqu'ici rien ne prouve que l'étendue des facultés intellectuelles soit proportionnelle à ce déreloppement matériel de l'encéphale.

$\$ 343$. Nous venons de voir que le cerveau est le siége de plusieurs fonctions bien distinctes, ef lorsqu'on examine la manière 
dont les facultés intellectuelles et affectives s'exercent chez les différents hommes, on ne tardera pas à observer que le plus ou moins grand déreloppement de l'une d'elles n'est pas loujours accompagné d'un déreloppement égal dans toutes les autres. Tel homme, qui sera remarquable par l'amour instinctif qu'il portera à sa progéniture, pourra n'avoir que des facultés intellectuelles très-faibles, et tel autre, doué des dispositions les plus heureuses pour les sciences de calcul, pourra manquer complétement d'imagination ou de talent d'observation.

Ces considérations et une foule de faits analogues ont porté quelques philosophes à penser que le cerveau n'était pas un organe unique dont toutes les parties concourent de la mème manière à la manifestation des phénomènes de l'instinct et de l'intelligence, mais que la nature arait établi dans les fonctions de l'encéphale la mème division de travail qu'on remarque dans les autres appareils de l'économic animale, toutes les fois que les facultés de ceux-ci se perfectionnent : ils ont pensé que les facultés affectives avaicnt leur siége dans une partie déterminée du cerveau, les facultés intellectuelles dans d'autres, et en un mot que chaque genre de travail exécuté par le cerveau était lié à l'action d'un instrument ou organe particulier, et que ces organes spéciaux étaient des portions différentes de la masse nerreuse de l'encéphale.

C'est sur cette hypothèse de la localisation des diverses fonctions de l'encéphale que repose le système phrénologique du docteur Gall.

Ce physiologiste pensait que chacune de ces fonctions est l'apanage d'une partie déterminée du cerveau ou du cervelet, et que l'activité plus ou moins grande de chacune d'elles dépend en majeure partie du développement plus ou moins considérable de la partie qui en est le siégre. Or, chez l'homme et la plupart des animaux supérieurs, l'encéphale remplit toute la cavité du cràne, et les parois de cette hoite osseuse se moulent en quelque sorte sur cette masse nerveuse, de façon qu'on peut juger de la grosseur proportionnelle des différentes parties du cerveau par la saillie plus ou moins grande des parties correspondantes de la tòle. Et, en admeltant que les suppositions énoncées plus haut soient exactes, on pourratit par consépuent, d'apres l'inspection du cràne, juger des penchants of facultés de changue individu.

Ce qui vient le plus a l'appui de ces hypotheseses ce sont les particulariles qu'on a cru observer dans la configuration de la lite des hommes les plus remarquables par certaines qualités de 
l'esprit ou par la force de quelques penchants, et les différences qu'on rencontre dans la forme du crâne des animaux dont les penchants sont le plus opposés. Ce que nous avons déjà dit de la ligne faciale s'applique surtout au développement plus ou moins considérable de la partie antérieure du cerveau, et l'existence d'un front déprimé et fuyant suffit pour donner à toute tète l'aspect de la stupidité. On remarque aussi que chez les animaux carnassiers, qui vivent de chasse et qui montrent le plus de courage et de férocité, la largeur du crâne vers les oreilles est beaucoup plus considérable que chez les herbivores, dont les mours sont douces et timides. Il est aussi vrai de dire que, chez presque tous les animaux, la partic postérieure de la tète, où les phrénologistes placent l'amour de la procéniture, parait ̀̀re plus développée chez les femelles que chez les mâles, et chacun sait qu'en effet la tendresse d'une mère pour ses petits est une passion bien plus forte que celle du père.

Mais si quelques-unes des suppositions dont l'ensemble forme la base de la plirénologie paraissent réellement assez plausibles, d'autres ne sont étayées sur rien de convaincant, et doivent mème paraitre absurdes pour toutes les personnes habituées à analyser les phénomènes de l'intelligence. Ainsi, il est des phrénologistes qui admettent une faculté particulière destinée a nous faire apprécier la pesantenr des corps, une autre qui rendrait apte à juger de l'étendue des objets, et ainsi de suite.

Du reste, nous le répélons, on ne connait encore aucun fail propre à prouver que cette division du travail existe réellement dans le cerveau, et quelques expériences de M. Flourens tendraient mème à faire penser qu'il en est tout autrement.

Quant aux facultés instinctives, qui sont si remarquables chez certains animaux, les rongeurs, les oiseaux et les insectes surtout, on ne saurait indiquer, dans l'état actuel de la science, aucune relation entre leur existence et un mode de conformation quelconque du système nerveux; et il est impossible d'admettre que chez les animaus vertébrés, tels que le castor ou l'hirondelle, elles dépendent de la conformation particulière du cerveau, puisque chez l'abeille et la fourmi, où elles ne sont pas moins développées, le système nerveux diffère totalement de celui des animaux supérieurs et ne consiste plus qu'en une chaine de ganglions (voyez. page 133, fig. 58).

FIN DE LA PREMIELE PARTIE. 


\section{COURS ÉLEMENTAIRE}

I'IIISTOIRE NATURELL. 
e.

MPUIUE PAR BETHUNE ET PLON.

"दुधुक" 


\section{COURS ÉLÉMENTAIRE}

\section{D'HIS'TOIRE NATURELLE}

A l'usage des Colléges et des Maisons d'Education.

I. ÉDIf

conformémenl au Programme de l'Université du 14 septembre 1840

PAK

MM. MILNE-EDIVARDS, F.-S. BEUDANT, et A. DE JUSSIEU.

Adopté parle conseil royal d’Insiraction publique pour l’enseignement dans les colléges.

\section{ZOOLOGIE.}

PAR M. MILNE-EDWARDS,

Yembre de l'Institut, Professeur au Muséum d’Histoire naturelle, Agrégé de la Faculti: des Sciences de Paris, etc.

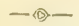

2 C PARTIE.

Classification et distribution géographique des Animaux.

\section{PARIS.}

FORITA, MASSON HT (:"1,

Place de I'École-de-Mérlecine, I.

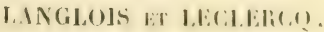

Ruo de Lit Harper, sit 



\title{
NOTIONS
}

\author{
SUR LA CONFORMITION, LI CILISSIFICITIOI
}

ET LA DISTRIBUTION GÉOGRAPHIQUE

DES ANIMUX.

CONGIDERATIONS SIR LE PLIN GENERAL SEISI PAR IAI NATIRE DANS I'ORGANISATION DES ANIIAUX.

\$34. Dans la premiere partie de ce cours nous avons éludié, un à un, les divers phénomènes qui nous sont offerts par un animal vivant et nous nous sommes appliqué à connaitre les or quines destinés à les produire; nous avons analysé en quelque sorte la vie, considérée dans ses manifestations ainsi que dans ses instruments, et nous sommes arrivé de la sorte a la connaissinnce des facultés variées dont les ètres animés sont donés par la nature. Mais nous n'aurions que des notions bien incompletes sur le règne animal si nous bornious là nos études et si nous ne cherchions à savoir comment ces instruments physioloricues, si variés, sont groupés pour constituer chacun de ces corps. Nous derons, en effet, nous occuper maintenant de l'ensemble de l'organisation, examiner le plan d'apres lequel chatue animal est formé, el voir comment la vie se modlifie dans ces divers ètres.

$\$ 3$ 亿:3. Rien neet plus varié que la conformation des animaux innombrables qui peuplent la surface de la terre, et il existe une diversité non moins grande dans les actes par lesquels la vie se manifeste dans ces machines animées. Chez les uns les fonctions sont peu nombreuses ef la sphere dans laquelle s'exeree leur activite physiologique est fort restreinte; chez d'autres, au contraire, les facultes sont extremement rariées ef les actions se? multiplient all plus haut degré; el, pour exprimer cette difleirence dams la nature des animaux, l'on dit sourent que parmi 
ces ètres les uns sont plus élevés, plus parfaits que les autres. Un poisson, par exemple, est un animal plus parfait, plus elevé qu'une huitre, car il possede un plus grand nombre des attributs de l'animalité et ses actions sont moins uniformes; mais il est lui-mème moins parfait que le chien, puisque chez celui-ci la vie se manifeste par des phénumienes plus compliqués; et le chien, à son tour, est un ètre moins parfait que l'homme, car l'homme possède des facultés qui manquent à ce quadrupède et exerce des actes plus variés.

\section{3 . Tendance à la localisation des fonctions et à la division} du travail physiologique. - Le principe qui semble avoir été adopté par la nature dans le perfectionnement des animaux est aussi l'un de ceux qui ont exercé l'influence la plus heureuse sur les progres de l'industrie humaine : la dicision du tracail.

En effet, lorsqu'on compare entre eux des animaux qui different par le nombre et l'étendue de leurs facultés, on voit toujours que le perfectionnement de ces ètres cö̈ncide avec une localisation plus considérable dans leurs fonctions; quand le mème instrument sert à la production de plusieurs phénomènes, le résultat physıologique est pour ainsi dire grossier et imparfait, et un organe remplit toujours d'autant mieux son ròle que ce ròle est plus spécial. Or, le mode d'action d'un organe ou instrument dépend toujours de sa nature intime, de sa structure et de ses autres qualités, et, par conséquent, plus il y aura d'organes doués de genres d'activité différents, plus aussi il y aura dans léconomie de parties dissemblables, et la complication plus ou moins grande dans les actes et dans les facultés des animaux devra marcher de pair avec la complication raturelle de leur organisation.

Pour démontrer cette tendance de la nature à diviser le travail physiologique, pour en perfectionner les résultats, il nous sıffira d'un petit nombre d'exemples.

$\$ 347$. Ainsi, dans les animaux dont les facultés sont les plus hornées et dont la vie est la plus simple, le corps présente partout la mème structure. Les parties qui le composent sont toutes semblables entre elles; et, l'identité d'organisation entrainant un mode d'action analogue, l'intérieur de ces ètres peut se comparer à un atelier où tous les ouvriers seraient employés à l'exécution de travaux semblables, et où, par conséquent, leur nombre influerait sur la quantité, mais non sur la nature des produits. Chacune des parties du corps remplit les mèmes fonctions que les parties voisines, et la vie générale de l'individu ne se compose 
que des phénomènes qui caractérisent la vie de l'une ou l'autre de ces parties. Cela est si vrai qu'il existe de ces animaux dont on peut diviser le corps en une multitude de morceaux sans y arrèter le mouvement vital; au contraire, chaque fragment continue à vivre, et souvent mème prend par cette excitation un développement insolite de façon à constituer bientòt un nouvel animal semblable par sa forme à celui dont il faisait partie, tout aussi complet dans son espèce, exercant les mèmes fonctions et vivant de la mème manière.

Les ètres singuliers que les naturalistes désignent sous les noms de Polypes d'eau douce ou d'Hydres, et que l'on trouve souvent sous les lentilles d'eau, offrent ce phénomène bizarre; en les mutilant de la sorte, loin de les tuer, on les multiplie. Tremblay, naturaliste genevois du siècle dernier, à qui l'on doit la connaissance de ces faits curieux , a ouvert un de ces petits animaux; puis il l'a étendu et coupé en tous sens; il l'a, pour ainsi dire, haché, et, malgré cet élat de division extrème, chacun des fragments, loin de mourir, est devenu bientòt un animal complet.

Pour comprendre ce phéno-

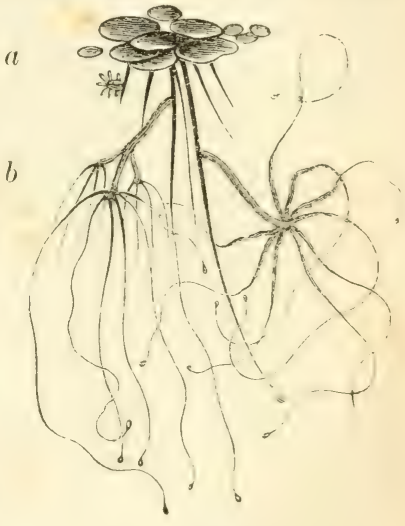

Fig. 118. Hydres (1). mène, en apparence si contradictoire à tout ce que nous montrent. les animaux supérieurs, il faut, avant tout, examiner le mode d'organisation des polypes dont nous venons de parler. Ces animaux sont trop petits pour ètre bien étudiés à l’œil nu; mais, lorsqu'on les observe an microscope, on voit que la substance de leur corps est partout identique : c'est une masse gélatineuse, renfermant des crlobules d'une petitesse extrème, et dans laquelle

(1) Dans la figure 118 on a représenté plusieurs hydres fixées à d's lentilles d'eau $a$ : ces animaux, comme nous le verrons par la suite, ne consistent qu'en un petit tube gélatineux ouvert par l'une de ses extrémités et garni d’un cercle de filaments appe és tentacules, à laide desquels ils introduisent les aliments dans leur cavité digestive. L'un de ces polypes $b$ porte sur les cîtés de son corps deux petits qui en naissent et qui ne tarderont pas à s'en détacher. - Dans la figure 2, page 28 , on voit un de ces animaux grossi davantage pour montrer sa conformat:on intérieure. 
on napercoit aucun or game distinct. Or, comme nous lavons déja fait remarquer, l'identité dans l'organisation suppose nécessairement l'identité dans le mode d'action, dans les facultés. Il s'ensuit que toutes les parties du corps de ces polypes, ayant la mème structure, doivent remplir les memes fonctions : chacune d'elles doit concourir de la mème maniere que toutes les autres à la production des phénomenes dont l'ensemble constitue la vie, et la perte de l'une ou de plusieurs de ces parties ne doit entrainer la ressation d'aucun de ces actes. Mais, si cela est rrai, si chaque portion du corps de ces animaus peut sentir. se mouvoir, se nourrir et reproduire un nouvel ètre, on ne voit pas de raison pour que chacune dielles, aprés avvir été séparée du reste, ne puisse, si elle est plarée dans des circonstances favorables, continuer d'ayir comme aupararant, et pour que chacun de ces fragments de l'animal ne puisse non-seulement continuer à remplir les fonetions nécessaires à l'entretien de sa vie, mais aussi reproduire un nouvel individu et perpétuer sa race, phénomènes dont l'expérience de Tremblay nous rend témoins.

\$ 348. Cette uniformité de structure ne se rencontre que chez un petit nombre d'animaux, et, à mesure que lon s'éleve dans la série des ètres, que l'on s'approche de l'homme, on voit l'organisation se compliquer darantage; chaque fonction, puis chaque acte dont cette fonction se compose deviennent l'apanage d'un instrument particulier, et le corps de lanimal offre des parties de plus en plus dissemblables entre elles. C'est d'abord le mème instrument qui sent, qui se meut, qui absorbe du dehors les matieres nutritives, qui respire et qui assure la conservation de l'espece; mais, à mesure que la machine animale se perfectionne, la division du travail physiologique fait des progrès, et la vie de l'individu résulte du concours d'un nombre de plus en plus considérable d'organes variés, fonctionnant chacun d'une manière spéciale.

Un premier degré dans cette localisation des phénomenes physiologiques nous est offert par dirers animaux dont l'oranisation est déja assez compliquée, mais dont le corps offre dans toute sa longueur une structure analogue, et se compose ainsi de plusieurs séries de parties identiques. Le lombric terrestre ou ver de terre nous en offre un exemple.

Chez cet animal cylindrique et effilé, la nutrition se compose d'une série d'actes exécutés par des instruments différents; la digestion s'effectue dans une cavité dont les parois ont des propriétés particulieres; il existe aussi un système de canaux servant a conduire les matiores nutritives dans toutes les parties du corps. 
et un appareil qui est devenu le siéze principal de la faculté de percevoir les impressions et de déterminer les mouvements; enfin on trouve des instruments destinés uniquement à la locomotion. Aussi ne peut-on conceroir la possibilité de diviser en tous sens le corps de ces vers comme on l'a fait pour les polypes, sans que la mort s'ensuive. Mais, lorsqu'on examine la disposition de ces divers appareils qui concourent chacun d'une maniere différente à l'entretien de la vie, on voit qu'ils s'étendent tous uniformément d'une extrémité du corps à l'autre, et que chaque segment transversal de l'animal ne diffère que peu ou point de tous les autres; il en est la répétition et représente, jusqu'à un certain point, lanimal entier, car il renferme tous les organes dont le jeu est nécessaire au mourement vital. On comprend donc sans peine la possibilité de détacher un certain nombre de ces segments du reste du corps sans faire perdre ainsi à l'un ou à l'autre troncon aucune des propriétés vitales dont jouissait l'indivịdu entier, et c'est effectivement ce qui a lieu. Si l'on coupe transversalement un ver de terre en deux, trois, dix, vingt morceaux, chacun des fragments peut continuer de virre à la manière du tout, et constituer un nouvel individu.

Mais, lorsqu'on examine des ètres dont la vie est moins simple, on ne trouve mème plus cette uniformité dans la distribution des princifaux organes, et il derient impossible de mutiler fortement le corps sans détruire quelque partie devenue le siége spécial de certains phénomene's, et par conséquent sans priver en mème temps lanimal d'une ou de plusieurs de ses facultés. Jamais on ne peut le diviser de façon à conserver dans chaque fragment tous les instruments nécessaires à l'entretien de la vie: l'ure ou l'autre portion meurt toujours, et sourent ces mutilations amènent nécessairement la destruction complete de l'individu. Toutes choses érales d'ailleurs, elles seront graves en raison de la localisation plus ou moins complete des fonctions, et auront des suites d'autant plus fàcheuses que lns parties non détruites seront moins aptes à agrir comme le faisiaiont les parlies enlevés.

$\$ 3.9$. Ce que nous venons de dire touchant la localisation des grandes fonctions se remarque également pour les divers actes qui concourent à la production de chacun de ces phénomènes. Ainsi, chez les poly pes dont il a été puestion ci-rlessus, il ne parait exister aucun organe particulier pour produire les mouremesits, ni ancun instrument spécial pour l'exereice de la sensibilite; mais, chez toms les animaux plus élerés, le mourement est développé exchusivement par le systeme musculaire, of lat sensibilite est lapanatre 
du systeme nerveux. Chez la plupart des vers, le jeu des muscles est uniforme dans toutes les parties du corps, et le systeme nerveux se compose d'une série de ganglions qui jouissent des mêmes facultés et possèdent tous le pouvoir de sentir et d'exciter des mouvements volontaires. Mais chez la plupart des insectes on distingue déjà une division de travail plus considérable dans les fonctions de cet appareil, et la faculté de déterminer les mouvements volontaires et de recevoir des sensations se concentre dans certains ganglions logés dans la tête; les modes de sensibilité se multiplient aussi, et des organes spéciaux se montrent pour recevoir les divers genres d'exécution dont dépendent la vue, l’oüie, etc.; enfin, chez les animaux qui se rapprochent encore plus de l'homme, nous avons vu le systeme nerveux se compliquer bien davantage et chacune de ses parties constituantes avoir des usages particuliers (\$198-204 et $\$ 2006)$. Si l'espace ne nous manquait. nous pourrions montrer aussi une pareille coïncidence entre la division du travail physiologique et la perfection des fonctions, dans tous les autres appareils de l'économie : dans les organes du mouvement, dans ceux de la digestion et dans l'appareil de la circulation, par exemple; mais les détails que nous venons de présenter nous semblent devoir suffire pour montrer la généralité de cette tendance de la nature.

\section{$\$ 3 \ddot{30}$. Transformations organiques et tendance à l'uniformité} de composition. - Nous venons de voir qu'il existe des différences très-grandes entre les animaux sous le rapport de la simplicité ou de la complication de leur structure; les uns possèdent une foule d'instruments que les autres n'ont pas, et l'ensemble de l'organisation est, toules choses égales d'ailleurs, d'autant plus parfait qu'il offre plus de varićté dans ses parties constituantes. Tantòt cette complication de structure est déterminée par la création d'organes complétement nouveaux qui viennent en quelque sorte se surajouter aux parties déjà existantes chez les animaux moins favorisés par la nature; mais d'autres fois ce résultat est amené par des moyens plus simples, et, s'il était permis de s'exprimer ainsi, plus économiques. Ainsi dans un grand nombre de cas la localisation des fonctions est déterminée par une simple modification dans la disposition des parties déjà existantes chez d'autres animaux moins parfaits, modification qui rend ces instruments essentiellement propres à tel ou tel travail particulier, tandis que chez les premiers ils étaient conformés dle manière à pouvoir servir en mème temps a d'autres usages. Nous citerons comme exemple de re mode de spécialisation des oreanes les différences que la na- 
ture a introduites dans la conformation des membres chez divers animaux voisins des écrevisses et appartenant comme celles-ci à la classe des Crustacés. Chez les limules ou crabes des Moluques (fig. 119), les membres de la portion céphalique et thoracique du corps entourent immédiatement la bouche et sont conformés de facon à constituer tous des pattes pour la locomotion, et à servir en même temps comme instruments de préhension par leur extrémité libre, et de mâchoires par leur base; mais, comme on le pense bien, ils rie peuvent cumuler ces fonctions sans ètre nécessairement moins propres à l'un ou à l'autre de

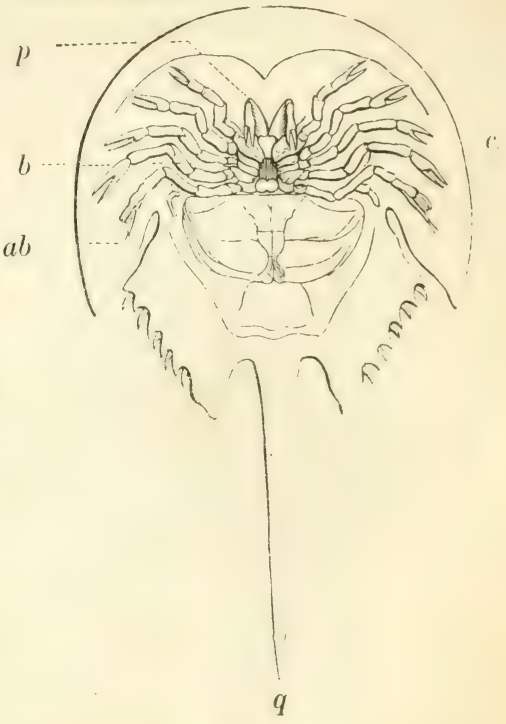

Fig. 119. Limule (1).

ces usages qu'ils ne le seraient si dans leur structure tout était calculé dans la vue d'un résultat unique; ce sont des pattes médiocres et des màchoires peu commodes. Mais, chez les animaux de la mème classe dont les facultés sont plus parfaites, ces différentes fonctions ne sont plus exécutées par un seul instrument; elles sont chatcune l'apanage d'un organe particulier, et ces organes ne sont cependant que ces memes membres dont les uns sont destinés exclusivement à la masticalion, d'autres à la préhension et d'autres encore à la locomotion; dans l'écrevisee, parr exemple (fiy. 1:0i, les memhres qui entourent immédiatement la bouche sont distraits do tont autre service pour devenir des organes spéciaux de mastication; une autre parre de membres nest. apte ni a opérer la division des aliments, ni a la locomotion, ef

(1) L'animal est vu en dessous. $-b$ la bouche; $-p$ pattes dont la base fait offlce de mâchoires; - $₫ b$ appendices abdominaux portant les branchies; $q$ stylet caudal. 
n'agrit que dans lacte de la préhension, et une troisieme série de membres est affectée exclusivement a la locomotion, et parmi ceux-ci les uns ne sont propres qu'a la marche, tandis que d'autres constituent des rames natatoires inutiles à l'animal quand il se meut sur le sol.

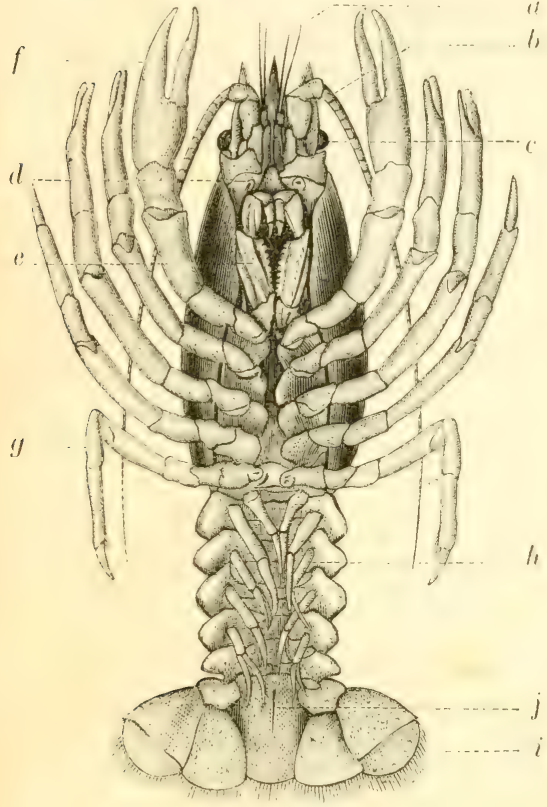

Fig. 120. Écrevisse.

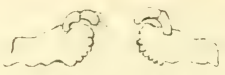

$a$
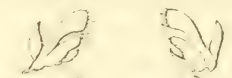

b
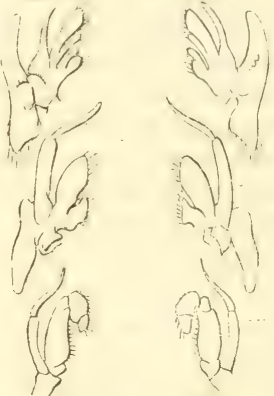

c
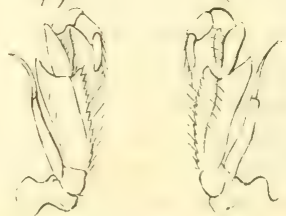

(1

$\ell$

f

Fig. 121. Appareil masticateur 11.

Celte tendance de la nature à approprier une mème partie de l'économie à des usages différents suivant les besoins de l'animal, plutòt que de créer pour chacun d'eux des parties entièrement nouvelles. se décile aussi lorsuton compare entre eux des espèces

(1) Fig. 120. L'écrevisse vue en dessous: $-a$ antennes de la première paire; $b$ antennes de la deuxième paire; $-c$ yeux; $-d$ tubercule anditif; $-c$ pattesmâchoires externes, - f pattes thoraciques de lat première paire; - g pattes thoraciques de la cinquieme paire; $-h$ fausses pattes abdominales; $-i$ nageoire caudale; - $\jmath$ anus

Fig. 121. Les six paires de membres qui co.nposent l'appareil masticateur de l'écrevisse, isolées : - it mandibules; - $b, c$ première et deuxième paires de màchoires; - $d, e, f$ les trois paires de mâchoires auxiliaires ou pattes-mâchoires 
destinées a vivre différemment. Nous en avons déja rencontré des exemples remarquables dans la conformation des membres chez les animaux rertébrés, car nous avons vu que chez ces ètres ce sont les mèmes parties qui, modifićes plus ou moins profondément dans leur structure, constituent tantòt une patte ambulatoire, lantòt une main, et sont transformées ailleurs en une nageoire ou une aile (voyez $\$ 290$, etc.). Dans la suite de ces lecons, lorsque nous étudierons les insectes, nous aurons a signaler d'autres faits de ce genre non moins curieus, mais le temps nous manque pour nous y arrèter ainsi, et nous nous bornerons à ajouter que les anatomistes désignent sous le nom de parties analogues les organes qui, tout en offrant des formes et des usages différents, paraissent ètre de simples transformations de ce que l'on pourrait appeler un seul et mème élément anatomique.

$\$ 3 \ddot{3}$. C'est en guénéral à l'aide de ces transformations que la nature varie la structure des animaux. Elle semble avoir voulu obtenir la plus grande variété possible dans ses productions toul en y employant le moins de matériaux essentiellement différents, et n'aroir eu recours à la création de parties entièrement nouvelles qu'après avoir épuisé les combinaisons auxquelles pouvaient se prèter les parties déjà existantes dans d'autres oroanismes. Cette disposition se lie intimement à une autre tendance qui se décèle a nous lorsque nous étudions comparativement la structure des divers animaux, savoir, la tendance à l'uniformité de composition organique. Il serait absurde de prétendre que tous ces ètres sont formés sur un mème plan et construits avec les mèmes matériaux; mais, lorsqu'on prend comme point de comparaison les animaux les plus compliqués, on voit que les autres en reproduisent ordinairement les principaux traits, seulement ceux-ci semblent ètre plus ou moins simplifiés et diversifiés par l'effet des transformations de parties analorues aussi bien que par le manque d'un certain nombre de ees parties ou par l'existence d'organes dont les premiers sont à leur tour privés. Une srrenouille, par exemple, differe considérablement de l'homme, et cependant on peut recunnaitre, dans la disposition sénérale de son organisation, les indices du plan d'apres lequel le corps humain est construit. Lorsfu'on sconsidere l'ensemble du rène animal, il est difificile de reconnaitre partout cette analogie de plan grénéral; mais, lorsquion circonserit davantage le champ des observations, on roit charement eque, malgrré leur nombre inmense et leur dirersité étonnante, les animaux sont tous conformés d'après un petit nombre de principaux types. Ciest ce que nous montrerons bientòt lorsque nous aurons à traiter 
des classitications zoologiques, car c'est d'après la considération de ces types généraux que l'on établit les premières divisions du règne animal.

$\$ 352$. Si l'on poursuit l'examen comparatif des différences qui séparent entre eux les animaux, on voit aussi que les grandes modifications introduites par la nature dans le mode de conformation de ces ètres semblent avoir été préparées peu à peu. Le passage d'un plan d'organisation à un autre ne se fait pas brusquement, mais s'opère à l'aide de nombreuses nuances intermédiaires qui lient entre eux les types distincts, et c'est pour indiquer cette tendance que l'on dit souvent : Natura non facit saltum.

Rien ne serait plus facile que de citer une foule des exemples de cette loi de la création zoologique, mais il nous suffira d'un lseul pour fixer les idées de nos jeunes lecteurs sur les espèces de iaisons naturelles qui s'établissent de la sorte entre les ètres. Deux

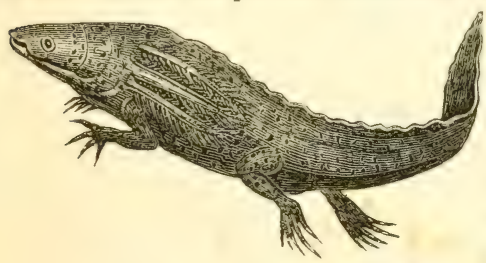

plans d'organisation bien distincts nous sont offerts par le lézard et la carpe ; la conformation générale du corps, le genre de vie, le mode de respiration, la structure et l'appareil circulatoire diffèrent considéFig. 122. Axololl. rablement dans ces deux espèces; mais les salamandres, les axolotls (fig. 122), les lépidosirens $(f g .123)$ et quelques autres animaux nous offrent des modes

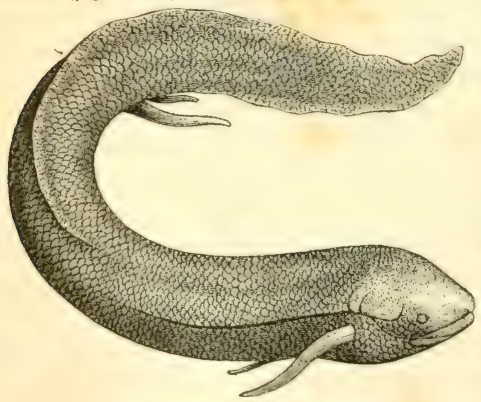

Fig. 123. Lépidosiren. d'organisations intermédiaires à ces deux types et établissent des transitions si graduclles de l'un à l'autre, qu'il est quelquefois difficile de décider si tel animal doit ètre considéré comme un reptile ou comme un poisson. Ces passages d'une forme à une autre ne se rencontrent pas seulement lorsqu'on compare entre eux les animaux dillérents; elles s'observent souvent aussi chez le mème animal aux divers degrés de son développement; les grenouilles, par exemple, offrent en naissant tous les caracteres essentiels des poissons et 
n'acquièrent que peu à peu le mode de conformation propre aux reptiles (fig. 12' à 128). Or, ces états transitoires du mème individu

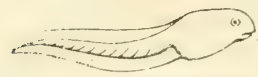

Fig. 124

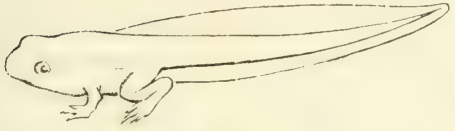

Fig. 126.

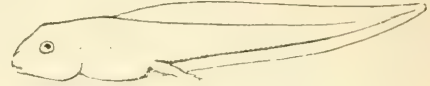

Fig. 125 .

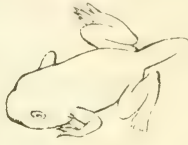

Fig. 127.

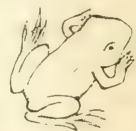

Fig. 128.

Fig. 124-128. Métamorphoses de la grenouille.

présentent souvent une grande ressemblance avec l'état qui est permanent pour d'autres espèces, et il en résulte que l'étude de ces transitions zoologiques ne conduit pas seulement à la connaissance d'une sorte de parenté entre des animaux de formes souvent très-dissemblables, mais offre un intérèt philosophique d'un ordre plus élevé, car elle semble pouvoir nous donner quelques indices de la marche suivie par l'auteur de toutes choses dans la création des produits si variés du règne animal.

$\$ 3: 3$. Cette tendance de la nature à ne changer que graduellement le plan des ètres qu'elle forme se montre quelquefois d'une manière si évidente chez les animaux qu'on n'a pu la méconnaitre; souvent, en effet, un grand nombre de ceux-ci constituent une sorte de série ou de chaine non interrompue dans laquelle le mode de structure des diverses espèces se simplifie ou se complique et se modifie de diverses manières pour s'approprier à des besoins particuliers, mais dans laquelle des liens de ressemblance semblent unir chacune de ces espèces aux espèces voisines. Quelquefois, cependant, on rencontre une sorte de lacune dans cette série, et les connexions entre deux types sont interrompues. Cela se remarque, par exemple, lor'squ'on compare les oiseaux aux autres vertébrés, c'est-i-dire aux mammiferes, aux reptiles et aux poissons; ils se trouvent en quelque sorte isolés et ne tiement par des passages graduels à aucune autre classe du règne animal; mais, dans tous les cas, on retroure quelques traces de formes intermédiaires, et, souvent, si l'hiatus est considérable, cela tient à la destruction de quelques-uns des chainons intermédiaires plutòt qu’à leur absence dans le plan crénéral de la création; pour sen convatunere il suflit 
de jeter les yeux sur plusieurs de ces fossiles, débris d'animaux qui ont depuis long-temps disparu de la surface du globe, mais (qui demeurent comme pour servir de témoins de la constance des lois zoologiques.

Quelques naturalistes ont pensé que ces modifications graduelles de l'organisation s'étaient toujours opérées dans une mème ligne et que, par conséquent, le règne animal tout entier ne formait qu'une seule série depuis la monade la plus simple jusqu'à l'homme. Ils ont mème cherché à construire une sorte de chaine ou d'échelle zoologique dans laquelle chaque ètre serait placé à raison de ses affinités organiques et du degré de perfection apporté dans sa structure; mais cette tentative a été vaine, car la série des animaux n'est pas unique; ces ètres semblent constituer un grand nombre de séries qui tantòt marchent parallèlement, tantòt rivergrent et s'élevent a des hauteurs différentes. Il est mème impossible de les ranger sur une seule ligne d'apres les degrés relatifs de complication et de perfection introduits par la nature dans leur structure, car ces perfectionnements portent fantòt sur un organe, tantòt sur un autre, et telle espece qui serait au-dessus de telle autre sous le rapport des fonctions de nutrition, par exemple, pourrait lui ètre tres-inférieure par ses instruments de locomotion. Lorsquion s'éleve dans le règne animal, depuis l'éponge ou la monade jusqu'i l'homme, on remarque, il est vrai, une complication progressive, et il est facile de sapercevoir que les mollusques sont supérieurs aux zoophytes dont il vent d'ètre question, que les poissons sont à leur tour plus élevés en organisation que les mollusques, que les reptiles l'emportent sur les poissons, les oiseaux sur les reptiles, et que tous ces ètres sont moins richement dotés que les mammifères; cependant cette gradation n'existe réellement qu'entre les animaux que l'on peut considérer comme étant. les types de chacun de ces groupes, et il arrive souvent que certaines espèces d'un groupe inférieur possèdent seulement une structure et des facultés plus parfaites que les espèces les plus dégradées d'un groupe dont les principaux représentants possèdent une organisation bien plus riche que celle de tous les premiers. Ainsi il est des poissons, certaines lamproies, par exemple, qui sont, à bien des égards, inférieurs à des mollusques tels que les poulpes, mais ce sont en quelque sorte des exceptions, et, lorsqu'on trace à grands traits l'esquisse du vaste tableau de la nature, il est permis de les négliger de mème quon néglige les petites inégalités du sol lorsqu'on cherche à apereroir d'un seul coup d'oil la configuration générale d’une chaine de montagnes. Des obstacles plus 
sérieux qui s’opposent à ce rangement linéaire des animanx naissent. de la diversité des routes suivies par la nature dans sa marche ascendante et de sa tendance à perfectionner graduellement chacun des types qu'elle a produits; ainsi les insectes ne peurent ètre placés ni avant ni apres les mollusques sans viuler quelques-unes des affinités zoologiques les plus évidentes, et si l'on voulait représenter par une figure l'enchainement naturel des animaux et les divers degrés de perfections que l'on aperçoit dans leur structure, ce n'est pas à une échelle qu'il faudrait comparer le règne animal, mais plutòt à un fleuve qui, faible à sa source, grossit peu à peu en s'avançant vers la mer, mais ne roule pas toutes ses caux dans un mème lit, se divise souvent en branches plus ou moins nombreuses qui tantòt se réunissent après un trajet plus ou moins long, tantòt restent désormais séparées, et qui, d'autres fois, se perdent mème dans les sables et disparaissent pour toujours ou surgissent de nouveau à quelque distance pour continuer leur route vers le but commun.

$\S 3 \%$. Affinités naturelles et analogies de structure. - C'est aussi par suite de la tendance de la nature à la conservation d'un mème plan général au milieu de modifications nombreuses introduites dans la structure des animaux que s'établit l'espèce de parenté qui rapproche souvent plusieurs de ces ètres, et qui constitue ce que les zoologistes désignent sous le nom d'affinités naturelles. Ces affinités seront d'autant plus intimes que les particularités de structure propres à chaque animal portent sur des parties d'une moindre importance physiologique, et entrainent moins de changements dans le plan général de l'organisation. Le lion, le tigre et le chat, par exemple, sont des animaux ayant entre eux la plus grande affinite, parce que, sauf quelques détails secondaires, ils sont conformés de la mème manière; Jesaffinités qui existent entre le lion et le chien sont encore assez grandes, parec que de l'un à l'autre le plan grénéral de l'économie n’a subi que des changements légers; mais les aflinitís naturelles qui existent entre le lion et le requin sont extremement faibles; la structure de ces deux animanx étant différente dans tous les points, excepté dans la disposition générale des partiés qui caractérise le type des vertébrés; enfin, l'affinité est, pour ainsi dire, nulle entre un poisson et une huitre. parce que ces deux ères sont conformés d'après des plans essentiellement distincts.

\$ 3:3:). Mais ces ressemblances fondamentales plus ou moins intimes ne sont pas les seules qui se remarepuent parmi les animaus. et il arrive souvent de rencontrer chez des itres applarterant a 
des types distincts des modifications du mème ordre. Ce genre de ressemblance qui ne porte pas sur le fond des choses, mais qui tient seulement à la maniere dont certains organes sont appropriés aux besoins de l'animal, est ordinairement désigné sous le nom d'analogie, et ne doit pas ètre confondu avec l'affinité naturelle; les affinités tiennent à l'identité plus ou moins complète du type, les analogies à la ressemblance dans les détails. Ainsi, la chauve-souris (fig. 89), le ptérodactyle et le dactyloptère (fig. 87), sont des animaux qui n'ont presque aucune affinité zoologique, puisque l'un appartient au type propre aux mammifères, le second au type des reptiles et le troisieme à celui des poissons; mais ils ont entre eux des analogies remarquables, car ils ont tous été conformés pour le vol et pourrus, à cet effet, d'ailes membraneuses soutenues par des especes de doigts. Des analogies frappantes peuvent se rencontrer chez des animaux appartenant à des types tout à fait dissemblables, et en comparant entre eux les divers groupes zoologiques, on croit mème apercevoir une tendance de la nature a faire passer chaque type par une série de modifications analogues. C'est ainsi que, parmi les insectes, les arachnides et les crustacés, on voit le plan général d'organisation propre à chacune de ces classes se modifier de la mème manière, suivant que l'animal doit se nourrir d'aliments solides ou vivre comme parasite en suçant les humeurs d'un autre être.

$\S 3 \ddot{6} 6$. Harmonies organiques. - Au milieu des variations sans nombre de forme et de structure que nous offrent les animaux, on découvre done une certaine harmonie générale qui semble régir toutes les parties de cette vaste création, et si l'on restreint davantage le champ de l'observation pour s'occuper, non de l'ensemble du règne animal, mais de l'ensemble des parties dont chaque ètre est à son tour composé, on aperçoit d'une manière encore plus évidente les indices d'un principe de coordination. En effet, le corps d'un animal n'est jamais un assemblage d'organes disparates réunis comme au hasard; toutes ses parties sont dans une dépendance mutuclle plus ou moins intime, et il règne un accord constant entre la conformation particulière de chacun de ces instruments et l'ensemble de l'organisation. Ces harmonies de structure sont quelquefois si faciles à découvrir que les zoologistes peuvent, dans certains cas, par la conuaissance d'un seul organe deviner la struclure du reste du corps, et déduire comme des conséquences nécessaires, de telle ou telle particularité de structure, l'histoire presque entière de l'animal. Ainsi, par la seule inspection de la dent représentée dans la fịnue ci-jointe, nous pouvons dire que 
l'animal à qui elle a appartenu devait avoir une charpente osseuse destinée à porter cet organe et à soutenir aussi toutes les parties du corps; il avait donc un squelette, or cette charpente interne n'existe jamais sans (qu'elle ait à protéger un axe cérébro-spinal; l'animal, par cela seul qu'il avait cette dent, avait done nécessairement un cerveau, un cervelet, une moclle épinière et des nerfs nombreux; et ce cerveau et ces nerfs supposent à leur tour l'existence d'organes du sens servant à établir des rapports entre l'animal et le monde extérieur; par le mode

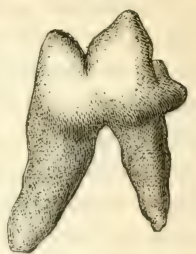

Fig. 129. Denlcarnassière du lion. de structure de cette dent, on peut affirmer qu'elle appartenait à un animal pourvu d'un appareil circulatoire tres-complet et dont les os se développent de façon à constitner autour des germes dentaires une loge profonde, caractère qui ne se voit que chez certains quadrupèdes; on peut mème affirmer que ce quadrupède était un mammifère; par la forme de cette mème dent, on voit encore qu'elle est destinée à couper de la chair; elle appartenait donc à un quadrupède carnassier; mais, pour digérer la chair dont il se nourrissait, ce carnassier devait avoir un estomac et des intestins conformés d'une certaine manière, et, pour s'emparer de sa proie, il lui fallait des or zanes de locomotion et de préhension; en poursuivant ce raisonnement on arrive, de déduction en déduction, à déterminer tous les caractères les plus saillants de l'animal, et les relations qui existent entre les diverses parties de l'économie animale sont si fixes que, mème dans les cas où la raison de ces rapports nous est inconnue, nous pouvons souvent ètre certains qu'ils ne manqueront jamais, et nous en servir d'une manière en quelque sorte empirique pour compléter l'histoire de l'ètre qu'on étudie. C'est de la sorte que l'on voit souvent se traduire pour ainsi dire au moyen de signes externes le mode de structure des organes les plus cachés, et c'est de la sorte aussi que, par l'étude des débris d'ossements enfouis dans les diverses couches du grlobe, on est arrivé à connaitre le mode de conformation d'une foule d'animaux dont la destruction complète a précédé de long-temps l'existence de lhomme sur la terre. Cuvier est le premier qui soit parvenu ainsi à reconstituer les animaux perdus, et c'est là un des plus beaux titres de gloire de ce naturaliste éminent.

\$3:37. Lorsqu'on étudie cette harmonie organique qui règne dans la structure de chaque animal, on ne tarde pas à se convaincre de l'existence d'une autre loi non moins importante à connaitre : celle de la suburdination des caracteres. En effet, on voit que l'impor- 
tance des diverses parties de l'économie n'est pas la mème; que certains organes peuvent présenter des différences nombreuses sans que ces modilications soient accompagnées d'aucun changement dans le reste du corps, tandis qu' il est au contraire quelques organes dont les modifications sont toujours suivies de changements correspondants dans le plan général de l'animal et semblent entrainer ou commander ces changements. Ces organes dominateurs sont toujours ceux dont le ròle physiologique est le plus important, et plus leur influence est considérable sur l'ensemble et l'organisation, plus aussi ils offrent de constance dans leur structure; lanatomiste peut done mesurer en quelque sorte l'importance d'un organe dans telle ou telle classe d'animaux par la fixité ou la mobilité de ses caracteres, et c'est par le degré d'importance physiologique des or zanes que le zoologriste, à son tour, deva ètre guidé dans le choix des parties dont les variations pourront l'éclairer sur les modifications apportées par la nature dans le plan général des ìtres.

$\$ 338$. Si les limites étroites de cet ourrage ne nous imposaient lobligation d'ètre bref, nous aurions amé à entrer dans plus de délails sur la nature des différences et des ressemblances que les animax ont cutre eux, car nous aurions eu a signaler encore d'autres principes qui semblent concourir a régler cette portion du grand ouvre de la création; nows aurions p) montrer, par exemple, comment la tendance à la répétition influe sur la constitution des animaux et amène la formation d'un nombre plus ou moins considérable de parties similaires ou homologues dans le corps de chacun de ces ètres; comment le principe des connexions règle d'ordinaire la place occupée par chaque or gane dans l'ensemble de la machine animale et permet souvent de prévoir comment celle-ci pourra se simplifier ou saccroitre; comment la tendance au balancement organique parait entrainer d'ordinaire un état d'imperfection plus ou moins grande dans certaines parties de l'économie lorsque d'autres parties acquierent un grand développement, comme si la force vitale de l'animal ne pouvait suffire à un travail extraordinaire dans un point de l'orquasation, sans se retirer en quelque sorte des autres parties du corps afin de concentrer ses efforts sur un seul objet. Ces considérations, pour lesquelles nous aurions à puiser largement dans les écris d’un célebre naturaliste, M. Geoffroy Saint-Ililaire, ne seraient dépourvues ni d'utilité ni d'intérèt, mais l'espace nous manque pour nous en occuper ici, et ce que nous arons déjà dit à ce sujet nous parait devoir suffire pour montrer que la nature prorède toujours dans ses créations avec règle et mesure; que le règne animal, loin d'ètre un assemblage confus d'ètres disparates, comme 
on pourrait le croire an premier aborl, se déroule aux yeux de l'observateur attentif comme un vaste tableau ou tout s'enchaine et s'harmonise; enfin que les lois zoologiques dont il nous a été donné d'entrevoir l'existence sont aussi simples que grénérales.

\section{C.LASIFICATIONS ZOOLOGIQUES.}

§ $3 \ddot{3} 9$. Objet et nature des classifications zoologiques. - Toutes les fois que l'homme fixe son attention sur des objets variés, il est naturellement porté à les grouper dans son esprit et à représenter les divers groupes ainsi formés par un nom ou un siqne particulier. Cetle tendance à la classification est une des qualités les plus remarquables de notre intelligence et concourt puissamment à en faciliter les opérations; elle nous permet de nous élerer de l'observation des eas particuliers aux considérations cénérales, de saisir avec promptitude les rapports des choses entre elles et de nous en former des idées abstraites. Aussi se révele-t-elle dès que nos facultés commencent à s'exercer et son influence se fait sentir dans tous les travaux de notre esprit. L'enfant, qui apprend à la fois à penser et à parler, obéit à cette tondance, on quelque sorte instructive, lorsqu il bégaye le mème nom pour désigner son père et tous les autres hommes qu'il apercoit et qu'il ne confond cependant pas avec le premier; le langage le plus vulgaire consacre la moitié de ses expressions pour représenter des groupes d'irlées ou de (hoses résultant de leur classification dans notre esprit, et cette disposition à classer est non moins évidente dans les opérations les plus élerées de notre intelligence, car c'est sur le classement des faits aussi bien que sur leur observation que reposent les sciences morales et physiques.

Ce besoin de remir dans notre esprit les choses semblables a certains érards et de domner à chacun des grompes ainsi formés un représentant idéal, est en cquelque sorte lorigine de toute espece de clasification of se manifeste dans toutes nos études, mais nest. jamais plus impréreas que lorsquion cherehe a commaitre le monde materiel dont thomme lui-meme fait partie. Efferetivement la necessite de ces rapprochements of de ces abstractions est dautant plus grande que les objets a considerer sont plus multipliés; of le nombre des eorps dont nous sommes environnés est si considerable que lomagination meme sem effraie, of qu il faudrait des siereles

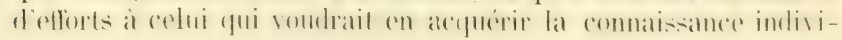


duelle. Pour se former une idée de ces corps, le naturaliste est donc obligé de les grouper et de se représenter chacun de ces groupes par un type abstrait. C'est du reste ce que nous faisons tous lorsque nous parlons de l'homme en général, du cheval ou du chène; nous réunissons par la pensée un nombre immense d'ètres qui ne sont pas identiques, mais qui se ressemblent plus ou moins, et, faisant abstraction des différences individuelles, nous donnons à chacun de ces groupes un représentant et à ce représentant un nom particulier, tel que le mot chêne ou le mot cheval. Mais ce premier pas vers la classification des ètres ne suffit pas mème aux esprits les plus vulgaires, et, dès que l'homme observe ce qui l'entoure, il rassemble aussi sous un tỵpe commun des ètres qui diffèrent davantage entro eux, mais qui offrent en commun des caractères dont il est frappé : ainsi, chez tous les peuples, on se représente par le mot oiseau ou par un terme équiralent, une classo nombreuse d'ètres divers. et on désigne par un nom particulier, tel que les mots animal o? plante, des assemblagges encore plus nombreux et plus hétérogènes.

Ainsi, a raison de la tendance de notre esprit à généralises nos idées, nous arons été conduits à établir parmi les corps naturels des groupes plus ou moins vastes, et à désigner chacun de ces groupes par un nom spécial. C'est de la sorte que dés la plus haute antiquité on a divisé ces corps en trois regnes, sous les noms de minéraux, de végétaux et d'animaux, qu'on a parlé d'une maniere générale le poissons, de reptiles, etc., et qu'on a désigné chaque espèce connue par un nom propre.

$\$ 360$. Pendant long-temps les naturalistes ne poussèrent pas plus loin l'art des classifications; mais, lorsque le domaine des sciences s'est étendu, on a senti la nécessité de donner à chacun des noms employés de la sorte une définition précise. En effet, pouvoir distinguer les objets que l'on éturlic et pouvoir les faire reconnaitre avec certitude aux autres est une condition sans laquelle les connaissances acquises ne sauraient se transmettre, et sans laquelle il n'y aurait point de science. Or, pour y arriver il ne suffit pas de donner à chaque objet que l'on considère un nom particulier, il faut aussi donner à chacun de ces noms une définition telle qu'on puisse toujours en connaitre la valeur et en faire la juste application. Aussi, pour écrire l'histoire des animaux, il est nécessaire non-seulement d'en dresser un grand catalogue dans lequel tous ces ètres portent des noms convenus, mais aussi d'indiquer pour chacun d'eux les caraclieres propres à les faire reconnaitre.

Ces caracteres doivent ètre choisis de facon à itre toujours ap)plicables : il faut dome que les animaux los portent aree enx. Des 
propriétés ou des habitudes dont l'exercice ne serait que momentané ne sauraient remplir cette condition, et il est évident que c'est dans la conformation mème de ces ètres qu'il faut chercher les traits les plus propres à les faire reconnaitre partout où on les rencontre.

Mais il n'est aucun animal qui puisse ètre reconnu par un seul des traits de sa conformation ; les caractères qui le distinguent des uns lui sont communs avec d'autres, et c'est seulement par la réunion de plusieurs de ces caractères, dont l'ensemble n'existe pas de mème ailleurs, qu'il differe de tous les autres animaux. Plus les objets qu'il importe de reconnaitre sont nombreux, plus il faut accumuler de caractères; et, comme le nombre des animaux est immense, il en résulte que, pour distinguer un de ces ètres pris isolément, il faut presque se rappeler sa description complete.

Or, il n'est point de mémoire assez forte pour suffire à de pareils efforts; et si l’on ne possédait les movens d’arriver au mème but par une route plus facile, l'étude de l'histoire naturelle resterait éternellement dans l'enfance. Mais en établissant parmi les animaux des divisions et des subdivisions successives, qui elles-mèmes sont nommées et caractérisées, une grande partie de ces difficultés disparaissent; car, à l'aide d'un petit nombre de traits et de noms, on arrive à circonserire à un tel degré le champ de la comparaison que, pour reconnaitre l'objet dont on s'occupe, on n'a enfin qui à le distinguer de ceux dont il diffère à peine.

Telle est effectivement la marche adoptée par les naturalistes. On divise d'abord le règne animal en un certain nombre de groupes de premier degré, caractérisés chacun par certaines particularités de structure; puis on subdivise chacun de ces groupes, et on caractérise de la mème manière les groupes secondaires ainsi formés; ces derniers sont à leur tour divisés de nouveau, et on multiplie ces sections successivement suivant les besoins, jusqu'à ce qu'on arrive enfin à ne laisser dans le mème groupe que les divers individus d'une mème espèce.

C'est cet échafaudaço de divisions, dont les supérieures contiennent les inférieures, qui constitue ce que les naturalistes appellent une classification. C'est une reprèce de catalogue raisonné, dans lequel tous ces ètres sont rangés dlapres un certain ordre, et réunis en rroripes reconnaissables à des caracteres detrrminés, ot rassemblés a leur tour en d’autres groupes d’un rangr plus élevé.

$\$ 361$. Lutilite pratique de ces classifications ret facile a saisir. Si le porteur doune lettre navait pour se diriger dans la recherehe de la personne à qui elle rat destinée que le sionalement de eelle:i, sil tache serait prohablement presque interminahle: mais si 
l'adresse de cette lettre lui indique d'abord le pays, puis successivement la province, la ville, le quartier, la rue, la maison, et enfin l'étage que cette personne habite, il saura facilement s'acquitter de sa mission. Or, il en est de mème pour le naturaliste; s'il voulait reconnaitre un animal en y comparant successivement la description de tous les animaux déjà connus, il aurait à exécuter un travail long et pénible, tandis qu'en s'aidant des classifications zoologiques, il arrivera promptement au but, car il lui suffira de déterminer d'abord à quelle grande division du rène animal appartient l'espèce dont il veut déterminer le nom, puis à quel groupe secondaire, à quelle subdivision de ce groupe, et ainsi de suite, en restreignant de plus en plus à chaque épreuve le champ de la comparaison. Si, par exemple, il voulait, sans se servir de moyens semblables, définir le mot lievre, il lui faudrait faire une longue énumération de caractères, et pour appliquer cette définition il aurait à comparer la description ainsi tracée à celle de plus de cent mille animaux différents; mais si l'on dit que le lièrre est un animal vertébré, de la classe des mammiferes, de l'ordre des rongeurs, du genre lepus, on saura, par le premier de ces mots, dont la définition est connue, que ce ne peut itre ni un insecte, ni un mollusque, ni aucun autre animal sans squelette intérieur; par le second, on exclura de la comparaison tous les poissons, tous les reptiles et tous les oiseaux; par le troisieme, on distinguera de suite le lièvre des neuf dixièmes des mammifères, et lorsqu'on aura déterminé de la mème manière le genre auquel il appartient, on n'aura plus qu'à le comparer à un tres-petit nombre d'animaux dont il ne differe que par quelques traits plus ou moins saillants; pour le faire distinguer avec certitude, il suffira done de quelques lignes. Il existe ici la mème différence que celle qu'il y aurait à chercher tel ou tel soldat dans une armée, dont tous les ranģs seraient mêlés, ou dans une armée bien ordonnée dont chaque division, chaque briggade, chaque régiment, chaque bataillon et chaque compannie aurait une place détermincée, et porterait avec lui des signes distinctifs.

\$ 362 . Classifications artificielles et naturelles. - Les classifications zoologrifues (et nous pourrions mème dire les classifications en général) sont de deux espèces: les unes arbitraires, les autres fondées sur la nature des objets classés et les degrés de ressemblance que ceux-ci offrent entre eux. Les premières sont nommées classifications artificielles; les secondes, classifications naturelles.

Pour donner une idée nette de ces deux gemres de classifications, il nous suffia d'un exemple familier à tous nos lecteurs. Les mots d"une langue sont classés artificiellement lorspue, dans un diction- 
naire, on les range alphabétiquement, d'après les premières lettres dont chacun d'eux se compose; ces memes mots sont au contraire distribués d'après une méthode naturelle, lorsque dans une grammaire on les divise en substantifs, verbes, adjectifs, etc.

Dans les classifications artificielles des animaux, on fonde les divisions sur les modifications que présentent cerlaines parties du corps choisies arbitrairement; dans les classifications naturelles, au contraire, on prend en considération l'ensemble de l'organisation de chacun de ces ètres, et on les rapproche ou on les éloigne suivant les de rrés de ressemblance qu'ils ont cutre eux.

$\$ 363$. Les premieres de ces classifications, que l'on nomme aussi des systèmes artificiels, sont, en général, dans la pratique, d'une application facile; mais souvent elles ne font rien connaitre d'important, si ce n'est le nom des objets. Supposons, par exemple, que l'on prenne pour base de la classification des animaux le nombre des membres dont leur corps est pourvu, on placera dans la division des (quadrupèdes les bœufs, les grenouilles, les lézards, elc., tandis qu'on séparera ces derniers des serpents et de quelques autres reptiles ayant avec eux la plus grande analogie, mais auxquels l'une des paires de membres manque; certes, on parviendra ainsi a distinguer ces animaux; mais les différents pas que l'on aura faits sucessivement pour y parvenir n'auront presque rien appris sur leur nature; jusquau dernier moment on aura à comparer les choses les plus disparates, et on ne pourra s'élever à des considérations générales dignes de quelque intérèt.

$\$ 36$. Les secondes de ces classifications, ou les méthodes naturelles, sont destinées à ètre, en quelque sorte, le tableau synoptique de toutes les modifications que la nature a introrluites dans l'organisation des animaux. Dans ces méthodes, les diverses divisions et subdivisions sont fondées sur lensemble des caracteres fournis par chaque animal, rangés dlapres leur degré d’importance respective; et les itres dont un groupe se compose se ressemblent par des points dautant plus multipliés, que ce groupe lui-mème est d'un rang moins élevé dans la hiérarchie des classifications: ausi, en comnasisant la place qu'un animal quelconque y oceupe. connait-on les trails les plus remarquables de son or wanisation el la maniere dont ses principales fonctions s'exécutent.

\$ 36:3. Les rèrles a suirre pour arriver à une classilication naturelle du rigne animal sont d'une simplicité tres-rrande, mais présentent souvent dans lapplication des difficultés extremes.

En effet, ces rigrles peurent se réduire a deus: car le but que le zoologiste se propose en établissant une pareille classification est : 
10 De ranger les animaux en séries naturelles d'après le degré de Jeurs affinités respectives, c'est-à-dire de les distribuer de telle sorte que les espèces les plus semblables entre elles occupent les places les plus voisines et que leur éloignement soit en quelque sorte la mesure de leurs dissemblances.

2 . De diviser et de subdiviser cette série d'apres le principe de la subordination des caractires, c'est-à-dire en raison de l'importance des différences que les animaux offrent entre eux.

$\$ 366$. Pour reconnaitre les affinités naturelles ou l'espèce de parenté qui existe entre des animaux différents, il suffit quelquefois d'observer les formes extérieures de ces ètres, car ces formes sont souvent une sorte de traduction du mode d'orranisation intérieure; ainsi, pour se convaincre de l'affinité qui existe entre le chat et le tirre, il n'est pas nécessaire d'étudier l'anatomie de ces animaux; mais, dans ce grand nombre de cas, on ne peut se prononcer sur des questions pareilles quapres avoir constaté directement les caractères de cette structure, et quelquefois mème on serait exposé a méconnaitre les liens de cette espéce de parenté si l'on se contentait de l'examen des animaux arrivés au terme le leur croissance : car, dans certains cas. les ressemblances s'effacent par les progrès de l’àge. Ainsi, pendant long-temps, on avait ignoré les rapports qui existent entre les Lernees, animaux parasites, à formes bizarres (fiy. 130), vivant sur les poissons, et lespetits crustacés des eaux douces, connus des zooloyistes sous le nom de Cyclopes (fig. 132), parce qu'à l'état adulte ils ne se ressemblent pas: mais depuis

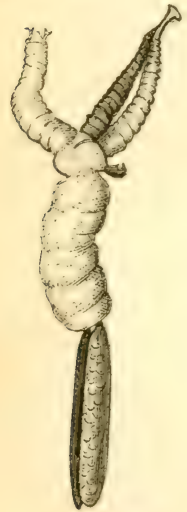

Fig. 130. Lernép.
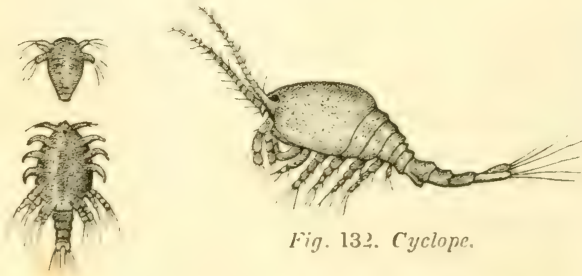

Fig. 13?. Cyclope.

Fig. 131.

Lare?

de Lernec.

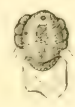

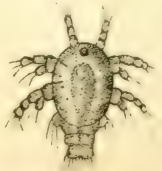

Fin. 133. Larves de Cyclope. 
qu'on a étudié leur développement, on s'est assuré de leur parenté. car dans le jeune âge ils different si peu entre eux qu'il serait souvent difficile de les distinguer (fig. 131 et 133). Enfin, pour remplir la première des deux conditions signalées plus haut, il faut vaincre encore d'autres difficultés dépendant de la multiplicité des rapports de chaque animal avec les animaux qui l'environnent et de la diversité des transitions par lesquelles la nature passe d'un type à un autre; à raison de ces circonstances, il est mème impossible de ranger les animaux en une seule série linéaire sans violer à chaque instant leurs affinités respectives, et on est obligé de les disposer sur plusieurs lignes marchant parallèlement ou s'embranchant les unes sur les autres.

$\$ 367$. La seconde condition dans l'établissement d'une classification naturelle est un rapport exact entre les divisions successives du règne animal et l'importance des modifications de structure qui servent de base à ces coupes.

Les caractères qui distinguent les animaux entre eux sont loin d'avoir tous la mème valcur: les uns, comme nous l'avons déjà dit (\$3 3.7), ne semblent avoir que peu ou point d'importance physiologique, car on les voit varier sans que ces variations paraissent entraìner des différences dans le reste de l'économie; d'autres, au contraire, ne varient jamais sans que ces changements ne coïncident avec des modifications profondes dans l'ensemble de l'organisation; elles paraissent en quelque sorte commander ces modifications, et en général il est aisé de s'expliquer sur ce genre d'influence en considérant la fonction des organes dont ces caracteres, dits dominateurs, sont tirés. Il en résulte que les divisions d'un rang trèsinférieur dans le système des classifications pourront seules ètre établies sur des caractères subordonnés, et que les coupes supérieures devront ètre fondées sur la considération de caractères qui mériteront d'autant mieux le titre de caractères dominateurs, qu'ils servent de base à des groupes d'un rang plus élevé.

Pour arriver à une clasification naturelle des animaux, il faut donc avant tout comnaitre la structure, les fonetions et le mode de développement de ces ètres; mais il faut aussi chercher à reconnaitre les caractères dominateurs dans l'organisation de chacun d'eux et en apprécier la valeur relative. On y parvient quelquefois assez facilement, soit par des corrsidérations physiologiques, soit par le secours de l'anatomie seulement. Ainsi, on a remarqué que les parties les moins sujettes à varier dans les divers animaux sont presque toujours colles qui ont le plus d'importance et qui en se modifiant entrainent le plus do changement dans les restes de loor- 
ganisation, tandis que les parties dont la structure esi la plus variable ne remplissent que des ròles secondaires dans l'économie et n'influent que peu sur la conformation générale de l'ètre. Il en résulte que la fixité est un indice de domination organique, et que les caractires propres à faire distinguer entre eux les groupes trèsnombreus sont en général aussi des traits d'une haute importance pour l'histoire rles animaux, tandis que ceux qui varient d'un petit groupe à un autre sont ordinairement d'un médiocre intérèt. Dans la plupart des eas, on peut aussi juger jusqu'à un certain point de la valeur zoologique d'une modification de structure par la nature et le degré de développement des facultés dont lorgane ainsi modifié est l'instrument. Hais, dans d'autres cas, la détermination des caractères dominateurs offre des difficultés considérables, et l'analogie n'est pas toujours un guide sur pour nous y fare arriver ; car l'importance d'un organe peut varier considérablement d'un animai à un autre, et telle partie qui maitrise en quelque sorte toute l'économie chez certaines espèces se trouve ailleurs déchue de son rang et réduite à un rôle secondaire

$\S 368$. Les zoologistes sont loin de connaitre l'anatomie et la pliysiologie de tous les animaux; ils sont loin aussi d'ètre fixés sur l'importance relative d'un grand nombre de modifications de structures offertes par ces ètres. Il est donc évident que, dans létat actuel de la science, ils ne peuvent possésler une classification parfaitement naturelle, et il ne faut pas sétonner de voir les auteurs différer entre eux dans le choix des méthodes proposées pour la distribution de certaines parties du règne animal, ni de voir ces méthodes subir chaque jour des modifications. A mesure que nous arrivons à mieux connaitre des objets que nous cherchons à classer d'après leur nature intime, nous arricons aussi à mieux saisir leurs rapports mutuels, et a mieux apprécier les coupes qu’il convient d'établir pour représenter dans nos classifications les différences et les ressemblances que les animaux offrent entre eux. Cette classification devra nécessairement se perfectionner en mème temps que nos connaissances sur l'organisation se compléteront, et son instabilité, loin d'ètre un défaut, est une conséquence nécessaire de sa perfectibilité.

$\$ 369$. L'introduction des méthodes naturelles pour la classification des ètres virants est l'un des services les plus grands que l'on ait rendus à l'histoire naturelle : elle a changé la face de celte science, et a donné un puissant intérèt à la partie de la botanique et de la zoologie qui jusqualors avait été la plus aride : aussi ne pouvons-nous omettre de citer les savants à qui l'on doit cette innovation heureuse. 
Ce furent les plantes que l'on rangea d'abord en fanilles naturelles. Jusque-là on ne les classait que d'après le nombre de leurs étamines et de leurs pistils, on d'après tout autre caractère, choisi arbitrairement et sans avoir égard à leurs analogies; mais, vers le milieu du siècle dernier, un botaniste franeais, Bernard de Jussieu, eut l'heureuse idée de les distribuer d'après l'ensemble de leur organisation et de les répartir en groupes, d’après la considération de leurs caractères dominateurs; et son neveu, Antoine-Laurent de Jussieu, appliquant cette idée à l'ensemble du règne végétal, créa la méthode naturelle, qui aujourd'hui est adoptée par tous les naturalistes.

Ce fut à une époque encore plus récente que les principes des méthodes naturelles ont été pris pour base de la classification des animaux, et c'est en majeure partie à Cuvier qu'appartient la gloire de cette application.

$\$ 370$. Mode de division du règne abimal. - Le règne animal ne se compose que d'individus, mais parmi ces individus il en est un certain nombre qui ont entre eux une ressemblance extrème et qui se reproduisent avec les mêmes caractères essentiels; ces réunions d'individus conformés d'après le mème type constituent ce que les naturalistes appellent des espéces. Ainsi les hommes, les chiens, les chevaux forment, pour le zoologiste, autant d'espèces distinctes.

Quelquefois une espèce diffère considérablement de toutes le. autres; mais, en général, il en existe un nombre plus ou moins considérable qui se ressemblent beaucoup et qui ne se distinguent que par des différences peu importantes : le cheval et làne, le chien et le loup sont dans ce cas. Dans les classifications naturelles, on réunit ces especes voisines dans des groupes appelés genres, et on joint a leur nom spécificue un nom générique qui leur est commun : ainsi on dit rézano yris, tézano piqueté, Lézand ocellé, ete., pour désigner les différentes especes du grenre LÉzArD ; et ouns brun, ouns jongleur, ouns blanc, pour les divers animaux du genre ours.

En général on remarque aussi que plusieurs genres ne different entre eux que par des caracteres d'une médiocre valeur et offrent en commun des particularités de structure d'une importance plus grande, propres à les distinguer des genres roisins. Dans les clatssifications naturelles on réunit alors ces senres semblables en un mème groupe que l'on appelle une tribu ou une famille naturelle.

Si l'on envisage ensuite la structure de ces ètres d'une maniere plus générale, on ne farde pas a remarguer dans plusieurs familles 
les mèmes caractères dominateurs qui, malqué les différences plus ou moins considérables que ces groupes offient entre eux, leur impriment un cachet commun. On arrive ainsi à former des divisions d'un rang plus élevé que l’on appelle des ordres, et à réunir à leur tour les ordres en groupes plus nombreux encore, nommés classes. Enfin les classes elles-mèmes se laissent répartir d'après les mènes principes ef constituent ainsi les embranchements ou divisions primaires du Règne animal.

$\$ 371$. Ainsi le Regne animal se divise en embranchements, les embranchements en classes, les classes en ordres, les ordres en familles, les familles en genres et les genres en especes; quelquefois mème on est obligé de multiplier encore davantage ces coupes; mais les principes sont toujours les mèmes, et toujours les divers membres d'un groupe quelconque, soit d'un genre ou d'une famille, soit d'un ordre ou d'une classe, se ressemblent plus entre eux qu'ils ne ressemblent aux espèces d'un autre groupe du mème rang, et les différences qui existent entre deux classes doivent ètre plus importantes que celles qui existent entre deux familles, comme les caractères des familles doivent ètre d'une valeur plus grande que les caractères des divers genres dont ces familles se composent. Ainsi ce sont les différences les plus grandes qui servent à l'établissement des embranchements, celles d'une importance un peu moins considérable qui constituent la base de la division de ces embranchements en classes, et ainsi de suite; les différences allant toujours en s'amoindrissant à mesure qu'on descend dans cet échafandage de divisions et de subdivisions pour arriver à l'espèce, groupe formé, comme nous l'avons déjà dit, par l'assemblag̣e de tons les individus conformés de la mème manière et pouvant se mèler pour perpétuer leur race.

On voit donc (que pour classer un animal il faut déterminer successivement l'embranchement, la classe, l'ordre, la famille, le genre et l'espece auxquels il appartient, et que, par cette seule détermination, on obtiendra en mème temps des notions précises sur tout ce que son organisation offre de plus important, puisque ce sont précisément ces particularités qui servent à caractériser les divisions successives. Or, nous le répétons, les fonctions et les mœurs d'un animal sont toujours dépendantes du mode de conformation de ses organes ou, du moins, en harmonie avec cette structure, et, par conséquent, on peut déduire aussi de cette connaissance celle de tous les points les plus importants de l'histoire de l'espèce soumise à nos investigations.

Telles sont les bases sur lesquelles reposent les elassifications 
zoologiques dites naturelles. Voyons maintenant quels ont été les résultats de l'application de ces principes à la distribution méthodique des animaux, et étudions les principaux groupes formés par ces ètres.

\section{B.ASES DE LA DIVISION DU REGNE ANIMAL EN EMBRANCHEMENTS ET EN CLASSES.}

$\$ 372$. Embranchements. - Lorsqu'on examine l'ensemble du Règne animal on ne tarde pas à reconnaitre quatre plans généraux de structure qui, modifiés de mille et mille manières, semblent avoir servi de guide pour la création des ètres animés. Ces quatre formes principales, qui dominent en quelque sorte les variations sans nombre introduites dans l'organisation des animaux, sont facile's à distinguer, et, pour fixer les idées à cet égard, nous indiquerons, comme pouvant les représenter, quatre animaux bien connus du vulgaire : le chien, l'écrevisse, le colimaçon et l'astérie ou étoile de mer (fig. 134).

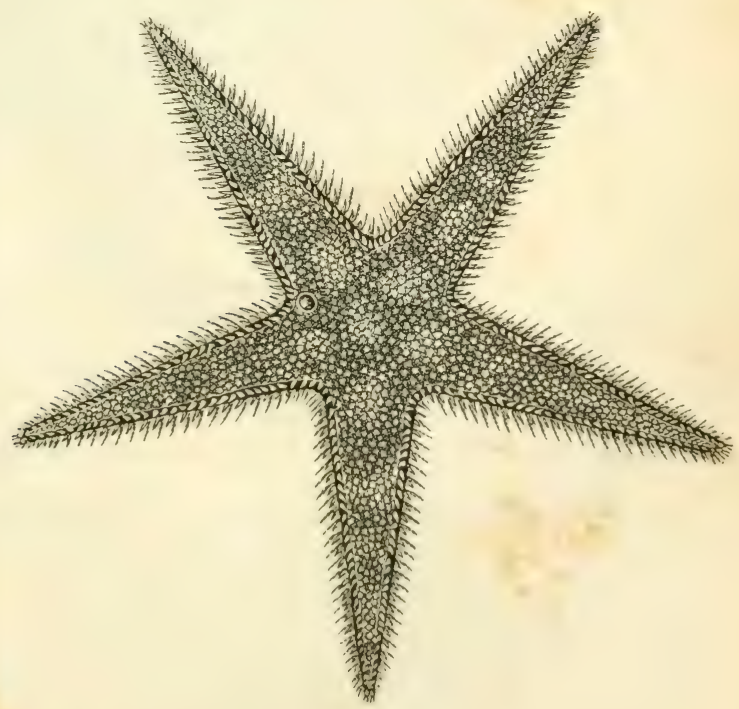

Fig. 134. Astérie. 
Pour que la classification zoologique soit une représentation fidèle des modifications plus ou moins importantes introduites dans la structure des animaux, il faut donc distribuer ces ètres en quatre groupes principaux ou embranchements, et c'est effectivement ce qui a été fait par Cuvier.

Le Reogne animal se divise ainsi en animaux vertébrés, en animaux annelés ou articulés, en mollusques et en zoophytes.

$\$$ 373. Les différences fondamentales qui distinguent entre eux ces quatre embranchements dépendent principalement du mode d'arrangement des diverses parties constituantes des corps et de la conformation du systeme nerveux. Ce sont là les deux caractères dominatenrs de toute l'organisation des animaux, et leur importance est facile à comprendre.

En effet, ce qui caractérise essentiellement l'animalité c'est la faculté de sentir et la faculté de se mouroir spontanément, et, comme nous l'avons déjà vu, c’est le sistème nerveux qui préside a ces fonctions. Nous avons iu aussi que les fonctions d'un organe sont toujours en relation arec sa structure; il est, par conséquent, évident que toute grande modilication dans l'etat du srsteme nerveux doit nécessairement entrainer des différences correspondantes dans les facultés qui remplissent le premier ròle dans l'organisme des ètres animés. On pourrait done prévoir que le mode de conformation de ce systeme influerait de la maniere la plus puissante sur la nature de ces ètres et fournirait des caracteres de premiere importance pour la division du Rirne animal en sroupes naturels ; or, la justesse de ce raisonnement est confirmée par l'ubservation des faits.

La disposition rénérale ou le mode de rémion des direrses parties constituantes du corps se lie à des circonstances également importantes; car elle exerce une inlluence extrème sur la manièe dont peut s'effectuer la localisation des fonctions et la division du travail phy̧siologique; et nous avons déjà vu combien la perfection de l'or ranisation est subordonnée à ces deux causes modificatrices (\$ 346 , etc.).

Les quatre types principaux que nous renons de signaler sont tellement distincts, qu'aucun zoologiste ne peut les méconnaitre, et il est en grénéral facile de rapporter à l'un ou à l'autre d'entre eux les animaux que l'on examine; mais chez quelques-uns de ces ètres ce cachet est moins apparent, et chez d'autres l'organisation parait en mème temps tenir, a certains égards, de deux types diflérents. Il en résulte que les limites extrèmes des embranchements sont quelquefois assez difficiles à prériser, et que, dans 
certains points de contact, ces groupes se lient entre eux comme des états voisins entre lesquels se trouvent quelques parcelles de terrain dont le droit de propriété est incertain et la possession disputée.

Il en résulte aussi qu'il est quelquefois également difficile de définir d'une manière rigourense ces groupes primaires; mais, pour en donner une notion exacte, il suffira d'indiquer les caractères les plus saillants propres au type de chacun d'eux, et de noter que la réunion de ces caractères ne se rencontre pas toujours, que tantòt l'un tantòt l'autre s'effacent à mesure que l'on descend vers les limites de ces divisions.

En procédant de la sorte il nous suffira de quelques mots pour exposer les particularités d'organisation qui distinguent entre eux les animaux vertébrés, les animaux annelés, les mollusques et les zoophytes.

$\$ 37$. Les Aximatx vertéBrés ressemblent à l'homme par les points les plus importants de leur structure : presque toutes les parties de leur corps sont paires et disposées symétriquement des deux còtés d'un plan médian longitudinal; leur système nerveux est très-développé et se compose, outre les nerfs et les ganglions, d'un axe central occupant le còte dorsal du corps (fig. 135) et composé essenticllement d'un cerveau, d'un cervelet, d'un cordon rachidien ou moelle épinière $(f i g . \breve{k})$. A ces caractères on peut ajouter que les

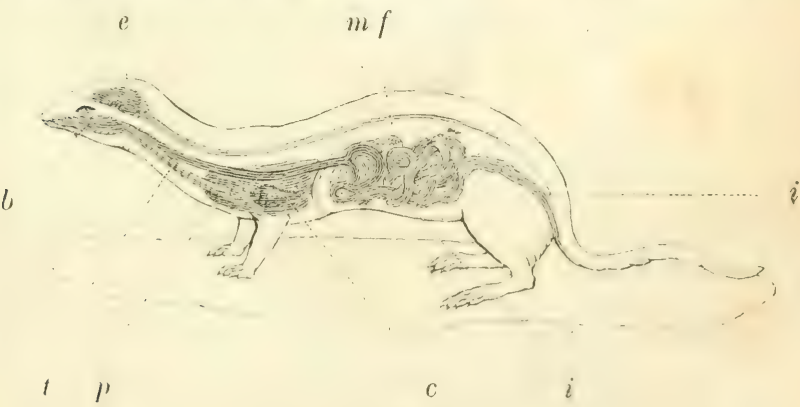

Fing. 135 (1).

(1) Cette figure theorique est destinie a indiquer la position relative de's gramds appareils orginiques daus f'emliranchement des animaux vertébrés et plus particulierement dans la rlasse des mammiferes : - b cavité buceale formant l'entré. du tube alimentaire, dont louverture opposée se trouve à l'sémitré posterieure du corps; $-i$ intestin ; $-f$ foie ; $-t$ trachéc-artère; $-p$ poumons $;-c$ coeur; - e encéphale (cerveau, etc.) $-m$ moelle épinière. 
muscles principaux ont leur's points d'attache sur une charpente solide ou syuelette intérieur ( $f g$. 236), composée de pièces atta-

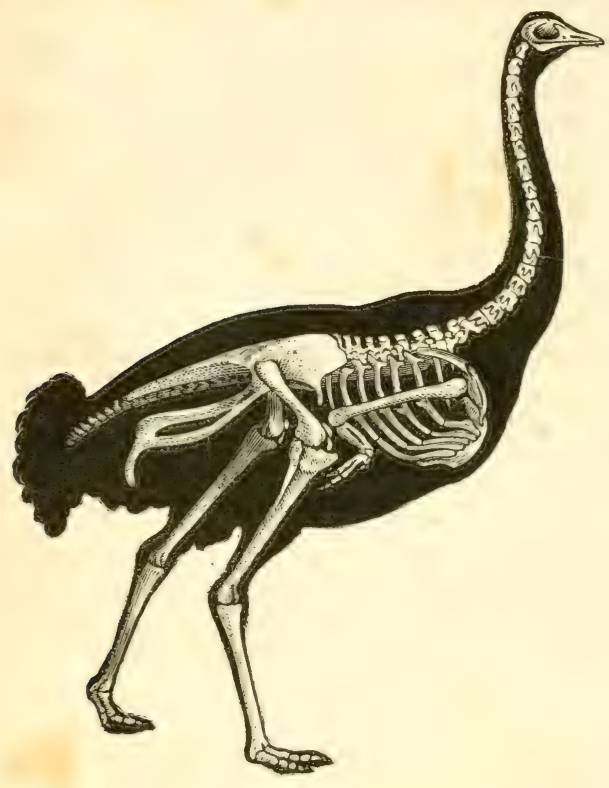

Fig. 136. Squeletle de l'Aulruche.

chées entre elles et disposée de façon à protéger les organes essentiels en mème temps qu'elle fournit des bases et des leviers pour l'appareil de la locomotion; que la partie la plus importante de ce squelette constitue une gaine pour l'axe cérébro-spinal et résulte de la réunion des pièces annulaires appelées vertèbres; que l'appareil de la circulation est très-complet et que le cour offre au moins deux réservoirs distincts; que le sang est rouge; que les membres sont presque toujours au nombre de quatre, et que jamais il n'y en a davantage; enfin, (u'il existe pour la vue, l'oüe, l'odorat et le goùt, des organes distincts logés dans la tète. Nous avons réja cité comme exemples de ce type organique l'homme et le chicu: nous aurions pu rigalement hien choisir un oiseau (fiq. 136). un lézart ou un poisson. 
$\$ 37$. Animaux annelés. - Dans le second embranchement du Règne animal, on trouve un mode général de conformation lout autre. Le corps est encore symétrique et binaire comme chez les animaux vertébrés, mais il se compose d'une série de parties qui se répètent, de façon qu'on peut le diviser en un nombre considérable de troncons homologues et plus ou moins semblables entre eux (fig. 139). Le système nerveux est médiocrement développé et se compose d'une double série de petits centres médullaires, nommés ganglions. et réunisen chaine lon zitudinale de facon à occuper la majeure partie de la longueur du corps; la petite masse formée par les premiers ganglions de cette espèce (le chapelet est logée dans la tète, et a été, pour cette raison, comparée au cerveau des vertébrés; mais on ne trouve

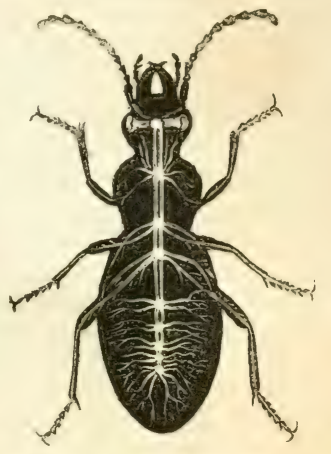
rien qui ressemble à une moelle épi- Fig. 137. Syslìme nerreux d'un nière, car le reste de la chaine ganglioinsecte (Carabe des jardins). naire est situé à la face ventrale du corps, au-dessous du tube digestif ( fig.138), et lescordons nerveux qui l'unissentaux ganglions céphaliques embrassent l'œsophage à la maniere d'un collier. Il est aussi à noter qu'ici le corps n'est plus soutenu que par un squelette intérieur, et les muscles s'attachent tous aux téguments extérieurs: mais ces téguments sont euxmèmes modifiés de façon à tenir lieu d'une charpente intéricure, car ils acquièrent une dureté souvent très-considérable, ot constituent une sorte d'étui e $f s \quad i$ ou de squelette extérieur, formé essentiellement d’anneaux placés en file, et plus ou moins mobiles les uns sur les autres. Il en résulte que, mème extérieurement, ces animaux paraissent divisés en troncons ou anneaux articulés a la suite les uns des autres, et

1) Coupe idéale du corps d'une écrevisse : - e estomac, au-dessous duquel se voient l'usophage et la bouche; $-i$ intestin $;-f$ foie $:-s$ cour $;-c$ ginglions nerveux céphaliques situés au-devant et au-lessus de l'nesophage; - g ganzlions nerveux thoraciques et athlu inaux situes au-dessous du ranal alimentater 
c'est pour rappeler celte disposition qu'on donne à ces ètres le nom d'animaux amnelés on d'animaux articulés. Il est aussi à noter que, dans cef embranchement, les membres sont en général très-nombreux; les organes des sens sont moins nombreux et moins perfectionnés que chez les animaux vertébrés; le sang est presque toujours blane, et l'appareil de la circulation est trés-incomplet; enfin, il existe dans la structure de ces animaux une foule d'autres particularités dont nous aurons à nous occuper par la suite, et, nous ajouterons seulement ici que ce mode de conformation nous cst offert par les scolopendres (fig. 139), les écrerisses, les crabes, les insectes, ctc.

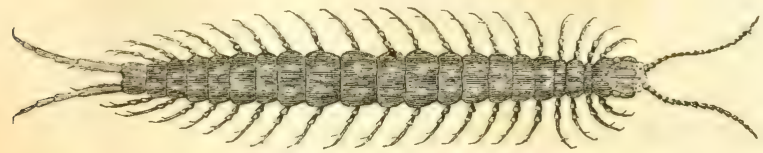

Fig. 139. Scolnpendre.

$\$ 376$. Animaux moliusques. - Les mollusques ont, comme

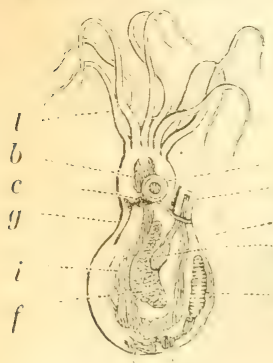
les précédents, les principaux organes pairs et symétriques; mais le corps, au lieu de se développer en longueur suivant une ligne droite, tend à affecter une disposition courbe ou spirale, de facon que la bouche et l'anus, par exemple, au ? lieu d'en occuper les deux extrémilés, $v$ sont plus ou moins rapprochés. Le syslème nerveux se compose essentiellel) ment de ganglions comme chez les animaux annelés, et ici encore une portion de ce système occupe le côté dorsal, en général, et l'autre portion est située sur $\begin{array}{cc}0 & s \\ \text { Fig. } 110 & \text { (1). }\end{array}$ le côté ventral du tube digestif, mais celle-ci ne constitue pas une longue chaine médiane comme dans l'embranchement précédent.

Les mollusques different aussi des animanx vertébrés et annelés par l'ahsence de toule espece de squelette articulé, soit intérieur, suit retérieur; lur corps est mou et leur peau constitue une

(1) Coupe idéale du corps d'un mollusque céphalopode: $-\ell$ bras ou tentacules qui entourent la tête ; $-b$ bouche $;-i$ canal alimentaire ; $-a$ anus ; $-f$ foic ; $c$ et $g$ ganglions nerveux; $-p$ branchies; $-s$ cour ; $-o$ appareil reproducteur ; - v vésicule de l'encre; - y yeux. 
enveloppe flexible et contractile; elle se recouvre souvent de plaques cornées ou calcaires nommées coquilles (fig. 14.1), et en développe quelquefois dans son épaisseur; mais elle ne constitue jamais une

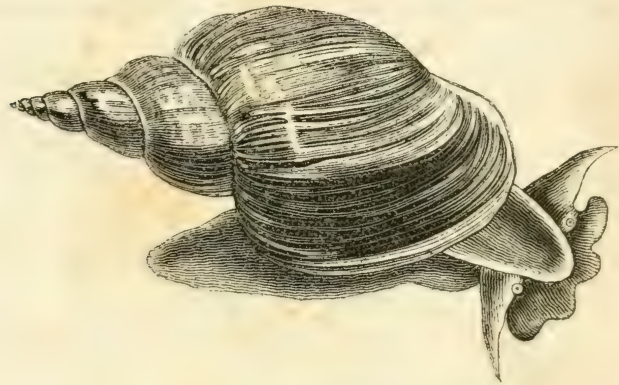

Fig. 141. Lymnée des élangs.

suite d'anneaux mobiles analognes à ceux des animaux annelés. djoutons que dans cet embranchement lis organes des sens sont presgue toujours très-incomplets; il n’exịte jamais d'organe spé-

$$
\text { c } v \text { al } p \quad r
$$

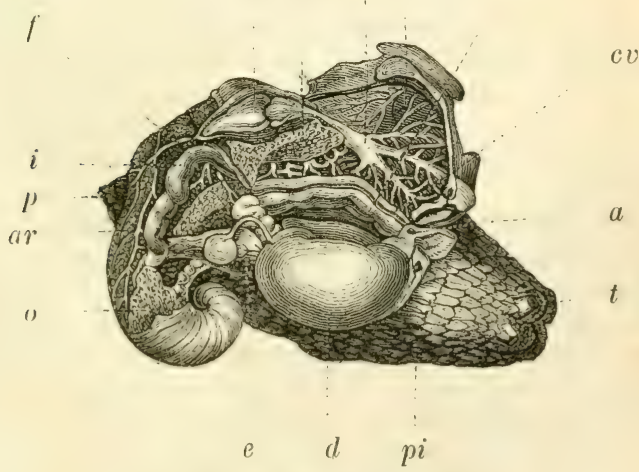

Fig. 112. Anatomie du colimaçon (1).

1) pi pièd; - $t$ tentacules à moitié contractés; $-d$ espèce de diaphragine qui sépare la eavité respiratoire des autres viscères; $-e$ portion de l'estomac; $f$ foie; $-o$ ovaire ; $-i$ intestins; $-r$ rectum; $-a$ anus $;-c$ cour (le péricarde étant ouxert); - ap artére pulmonaire se ramifiant sur les parois de la cavité pulmonaire $(p) ;-v$ glande sécréteur de la viscosité; $-c e$ son canal excréteur allant s'ouvrir près de l'anus. 
cial pour lodorat; on ne découvre que rarement un appareil d'vuie, et dans un grand nombre de ces animaux il n'y a point d'yeux ; il n'y a presque jamais de membres pour la locomotion; enfin, le sang est blanc comme chez la plupart des annelés, mais l’apparen de la circulation est beaucoup plus complet.

$\$ 377$. Zoophytes. - Enfin dans le quatrième et dernier embranchement, celui des zoophytes, les diverses parties du corps, au lieu de se grouper symétriquement

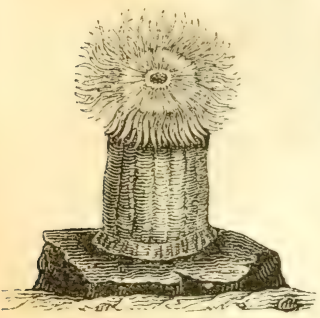

Fig. 143. Actinie. par rapport à un plan médian, tendent à se ranger autour d'un point central ou d'une ligne verticale, de facon à affecter une disposition radiaire plus ou moins complète. Quant au système nerveux, on n'en apercoit le plus souvent aucune trace; et lorsqu'il existe il est réduit à un état rudimentaire; les organes des sens manquent aussi presque complétement; enfin toutes les parties de l'économie deviennent d'une simplicité extrème, et par leurs formes aussi bien que par leur manière de vibrer. La plupart de ces animaux offrent au premier abord une ressemblance si grande avec les plantes, que pendant long-temps on en a méconnu la véritable nature, et on les a considérés comme appartenant au règne vérétal; c'est à raison de cette ressemblance yu'on les appelle des zoophyytes ou animaux-plantes; et c'est a cause de la disposition radiaire souvent si manifeste dans leurs organes qu'on les désigne aussi quelquefois sous le nom d'animaux rayonnés.

Les polypes, dont nous avons déjà eu l'oceasion de parler (\$3 177), les actinies ou anémones de mer $(f g .143)$ et les astéries ou étoiles de mer (fig. 13 í peuvent donner une idéc de l'ensemble de cette division (1).

$\$ 378$. Division des embranchements en classes. - Les divers animaux réunis dans chacun des embranchements ou groupes primaires dont nous venons de parler, se ressemblent donc entre eux par lo plan général de leur organisation, et offrent en commun

(1) Quelques zoologistes ont cru devoir admettre une cinquième dirision primaire du règne animal comprenant les éponges, et caractérisée par l'absence de toute forme régulièro; mais cette classification ne nous parait pas devoir être adoptée. car les êtres bizarres rangés dans cet embranchement des amorplıozoaires offrent dans le jeune âge les mêmes caractères que la plupart des polypes, seulement leur développement organique s'arrête à un degré qui n'est que transitoire pour ces zoophytes, et ils se déforment en grandissant. En tenant compte de leur mode de développement, on peut donc les rapporter au type des zoophytes. 
un grand nombre de caraclères saillants; mais ils sont loin d'ètre semblables sous une multitude d'autres rapports, et ils diffèrent sonvent les uns des autres par la maniere dont s'exécutent plusieurs des fonctions les plus importantes de l'organisme. Il faut, par conséquent, les diviser de nouveau en groupes secondaires et ctablir ces subdivisions d'après les grandes modifications qui s'observent dans leur structure.

$\$ 379$. Ainsi, parmi les animaux vertébrés, les uns naissent vivants et sont pourvus de mamelles pour allaiter leurs petits, les autres sortent d'un œuf où ils trouvaient des matières nutritives et sont privés d'organes de lactation; les uns respirent dans l'air, les autres dans l'ean; les uns ont une circulation complète, les autres n'envoient dans l'appareil respiratoire qu'une portion du sang rendu impropre à l'entretien de la vie par son action sur les tissus et mèlent le reste de ce liquide au sang artériel destinć à nourrir leurs organes; les uns ont le sang chaud, les autres produisent a peine de la chaleur; enfin, les uns sont conformés pour s'élerer dans l'air, d'autres pour vivre sur la terre, et d'autres encore pour nager au sein des eaux. Ces différences sont d'une haute importance physiologique et coïncident entre elles de façon à caractériser dans cet embranchement quatre types secondaires. Il en résulte que, pour classer les animaux vertébrés suivant les principes des méthodes naturelles, il faut les diviser en quatre classes : savoir, les mammiféres, les oiseaux, les reptiles, les poissons.

$\S 380$. Dans l'embranchement des animaux annelés on observe des modifications de structure non moins remarquables. Tantòt, comme dans le talitre (fig. 144), il existe des membres articulés servant comme leviers dans l'apprareil de la locomotion, et la portion céphalique du système ganglionaire acquiert une importance considérable; tantòt, au contraire, dans la sangsue, par exemple, il n'y a point de mem-

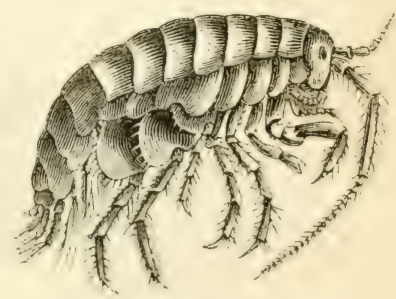

Fig. 144. Talilre bres articulés, les ganglions nerveux sont peu développés, et il existe entre tous ces petits centres médullaires une uniformité très-grande de structure et de fonctions. On peut done subdiviser cet embranchement en deux rroupes secondaires, formés liun par les animaux arliculés proprement dits, laube par les vers: mais eette classification ne suffil pas pour représentere 
toutes les grandes différences faciles à constater dans la nature de ces êtres.

En effet, parmi lesinimaux articulés proprement dits, se trouvent. lesinsectes, qui reçoivent l'air dans toutes les parties de l'économie au moyen de trachées; qui ont le córps divisé en troisparties dissemblables, la tête, le thorax et.

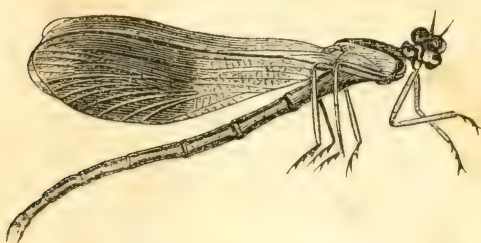

Fig. 145. Agrion.

l'abdomen; qui ont toujours trois pairesde pattes et qui sont presque toujours pourvus d'ailes; les myriapodes (fig.139), qui ressemblent aux insectes par leur mode de respiration et qui ont aussi une tête distincte, mais qui n'ont pas le trone divisé en thorax et abdomen; qui ont de 24 à 60 pairesde pattes, ou mème davantage, et qui ne portent jamais d'ailes; les arachnides (fig. 146), qui n'ont plus de tète distincte du thorax,

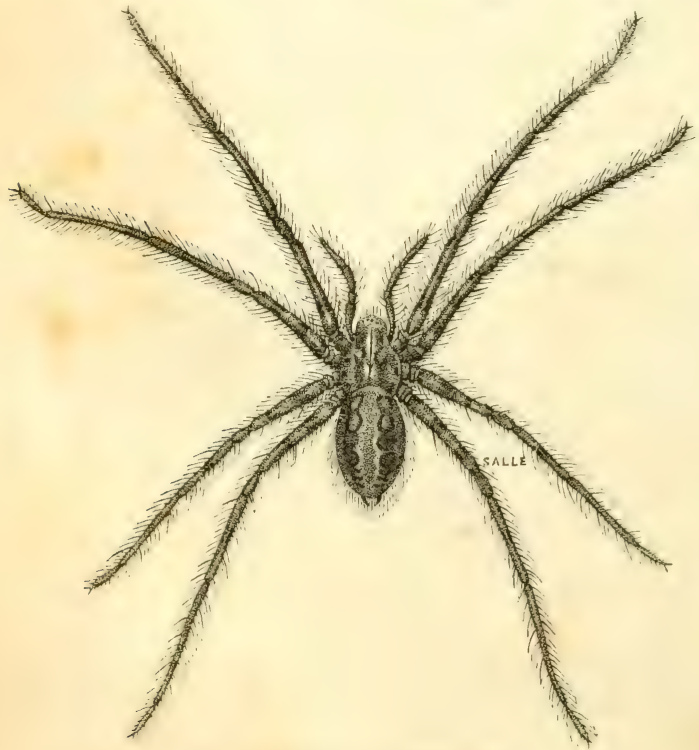

Fig. 146. Araignéc domestique. 
qui ont toujours quatre paires de pattes seulement, et (qui respirent l'air comme tous les précédents, mais qui ne possèdent plas toujour's destrachées etrecoivent alors ce fluide dans des poches pulmonaires; les crustacés (fig. 147), qui ont au contraire la respirationaquatique et branchiale, etqui ont presque toujours de cinq à sept paires de pattes propres à la locomotion; enfin, les cirrhipèdes (fig. 148, 149), qui respirent aussi par des

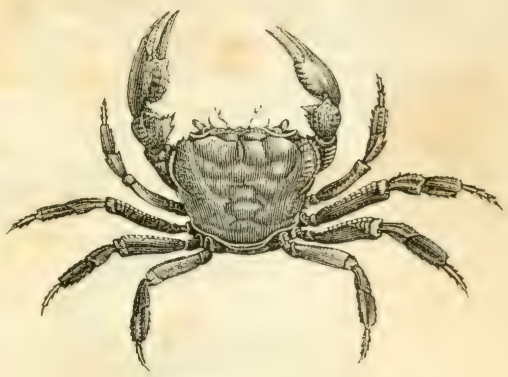

Fiv. 147. Thelphuse.

branchies, mais qui deviennent immobiles par les progres de l'àge, et alors ne possèdent pas d'organes de locomotion, bien que leurs appendices soient très-développés.

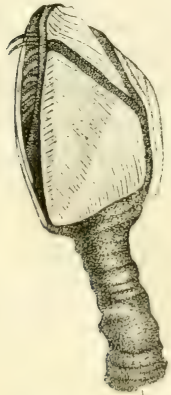

Fig. 148. Anvlife.

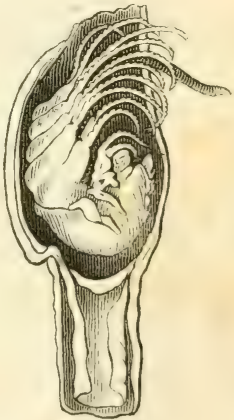

Fig. 149. Anatomie de l'analife.

Ladivision desver's doit comprendre altsi plusieurstypes bien distincts. On y remarque d'abord les amnélides $(f i y .150)$, dont lesystimo 
yanglionaire est bien visible dans toute la longueur du corps; dont le sang, ordinairement rouge, circule dans un systeme vasculaire trè-complexe, dont la respiration a presque toujours lieu dans un appareil branchial bien développé, et dont les mouvements s'exécutent en général à l'aide de soies mobiles (fig. 151). Nous y ran-

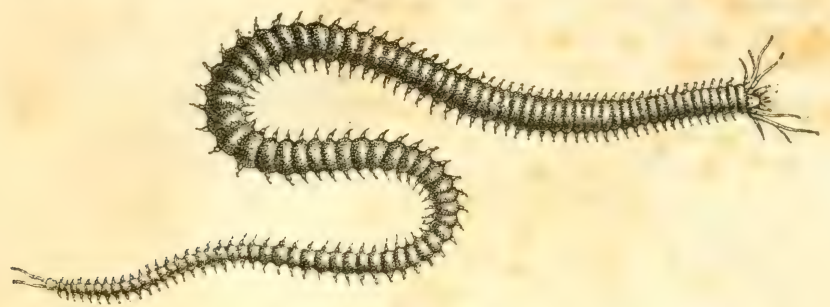

Fig. 151. Néréide.

geons aussi les systolides, animaux microscopiques, qui paraissent ètre dépourvus dorganes spéciaus pour la circulation, et qui n’ont

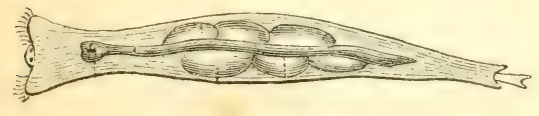

Fig. 152. Rotifer.

pas de branchies, mais qui possèdent en général des organes vibratiles dont la disposition est très-singulière (fig. 152): Enfin, e'est encore à ce sous-embranchement que paraissent devoir itre rapportés les helminthes ou vers intestinaux (fig. 1:33), qui n'offrent tout au plus que des vestiges d'un système nerveux, et qui sont en général d'une simplicité de structure très-ğrande, mais qui se lient aux annélides d'une manière intime, et qui souvent semblent ìtre en quelque sorte des représentants dégradés du mème type zoologique (1).

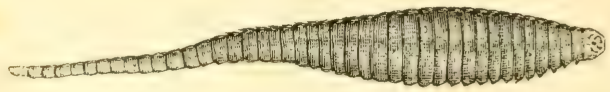

Fig. 153. Lingalule.

(1) Nous devons dire cependant que tous les naturalistes ne s'accordent pas à classer de la sorte les helminthes, et que Cuvier les range parmi les animaux rayonnés ou zoophytes; mais ils n'ont rien de radiaire dans leur organisation et offrent ordinairement, par la conformation générale de leur corps, une grande analogie avec les animaux annelés, et notamment avec les annélides : il nous semble, par conséquent, plus naturel de les rapporter ace dernier type primaire, marche qui a déjà été suivie par un de nos zoolonstés les plus célébres, M. de Blainville. 
Pour mettre la classification des animaux annelés en harmonic avec les différences que nous avorıs à signaler dans la nature de ces ètres, il faut donc les diviser en sept classes distinctes; et ce sont ces classes dont nous avons indiqué les noms en présentant les considérations qui précèdent.

$\S 381$. L'embranchement des animaux mollusques nous offre également des modifications organiques de nature à nécessiter une division analogue. Chez les uns, que l'on peut appeler les mollusques proprement dits, il existe un système nerveux composé de deux ou plusieurs paires de ganglions réunis par des cordons médullaires,

Manteau. Tentacules. Bouche. Nerfs. Muscles.

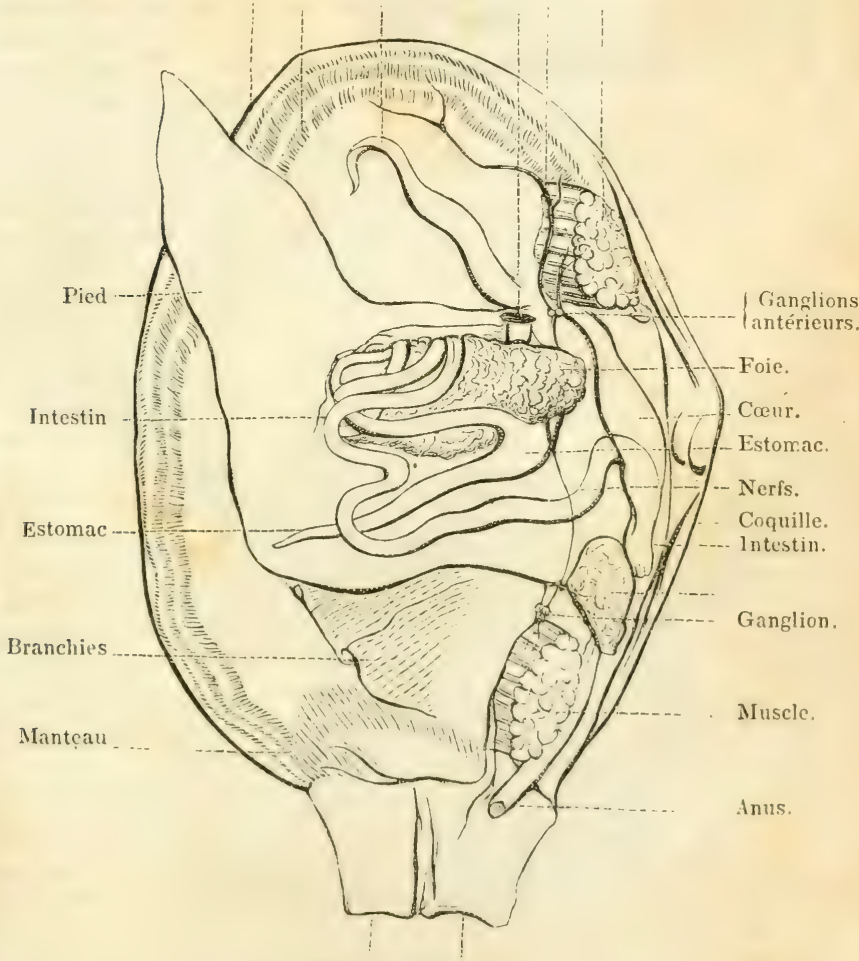

Tubes respiratoires.

Fig. 154. Anatome d'un mollusque acéphale (la Mactre) 
et la reproduction ne s'effectue qu'au moyen d'œufs. Chez les autres, (fu'on a désignés sous le nom de molluscö̈des ou de tuniciens, le système nerveux, réduit à un état rudimentaire, ne parait con-

$$
\text { b a }
$$

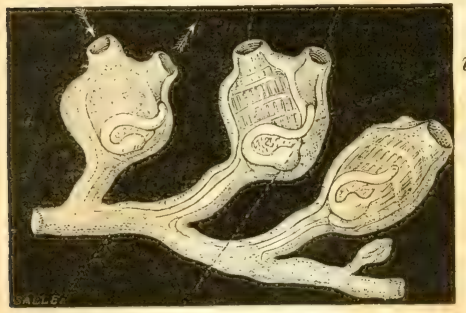

$t$

Fig. 155. Ascidies sociales (1) sister qu'en un ganglion unique, et dans la plupart des cas la multiplication des individus s'opère par le développement de bourgeons aussi bien que par une génération ovipare; et il en résulte que souvent les individus, naissant les uns des autres, demeurent unis entre eux, et constituent des masses animées d'un aspect phytoïde (fig. 155).

Les mollusques proprement dits different entre eux par des caractères dont l'importance est encore très-considérable. Ainsi chez les uns les ganglions céphaliques sont très-éloignés des ganglions abdominaux (fig. 154), il n'existe point de tète distincte, on n'apercoit aucune trace

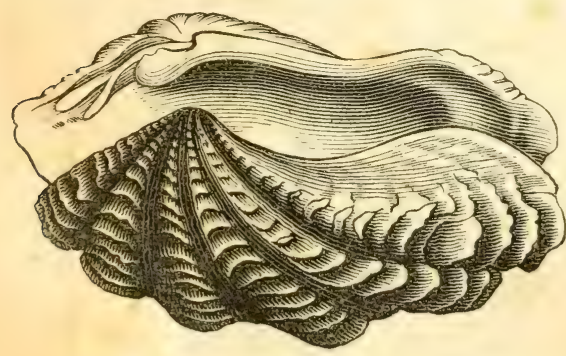

Fig. 156. Coquille de mollusque (Tridacne). d'organes spéciaux pour les sens; les organes du mouvement sont des plus imparfaits, et le corps est enveloppé par deux replis cutanés semblables à des voiles, et protégé extérieurement par une coquille bivalve (fig. 156). Les moules, les mactres (fig. 1ä1), les tridacnes ou bénitiers, etc., nous offrent ce mode d'organisation.

D’autres mollusques, tels que les lymnés (fig. 141) et les porcelaines $(f i g .1: 7)$, ont une tète distincte; leurs ganglions nerveux sont en général fort rapprochés entre eux et groupés autour de l'œesophage; il existe des yeux; la face inférieure du corps esl

(1) Ascidies du genre porophora: $-b$ bouche; $-e$ estomac; $-i$ intestins ; $a$ anus; $-t$ tige commune; - les fleches indiytient la direcion du courant deau servant à la respiration. 
occupéc par un organe charnu servant a la locomotion : enfin le dos est ordinairement protégé par une coquille; et relle-ci n'est jamais bivalve, mais représente prescyue toujours un còne plus ou moins contourné en spirale (fig. 158).

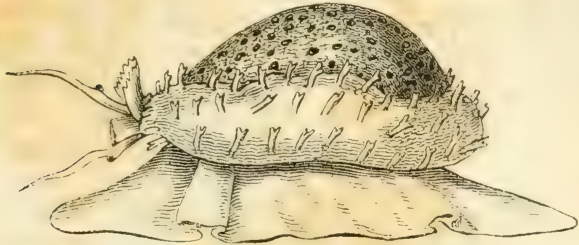

Fig. 157. Porcelaine.

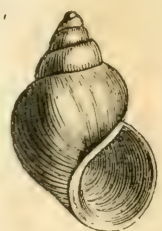

Fig. 158. Coquille de paludine.

D'autres encore, pourvus d'une tète distincte comme les précédents, portent de chaque còté du cou des espèces d'ailes membraneuses servant de rames pour la natation (fig. 160)

Enfin il en est aussi qui ont la tète garnic de longs appendices contractiles et préhensiles, remplissant à la fois les fonctions de pieds et de bras (fig. 159); qui ont le système nerveux plus développé que chez tous les autres animaux du mème embranchement, et qui ont d'ordinaire le corps soutenu par une sorte de coquille intérieure.

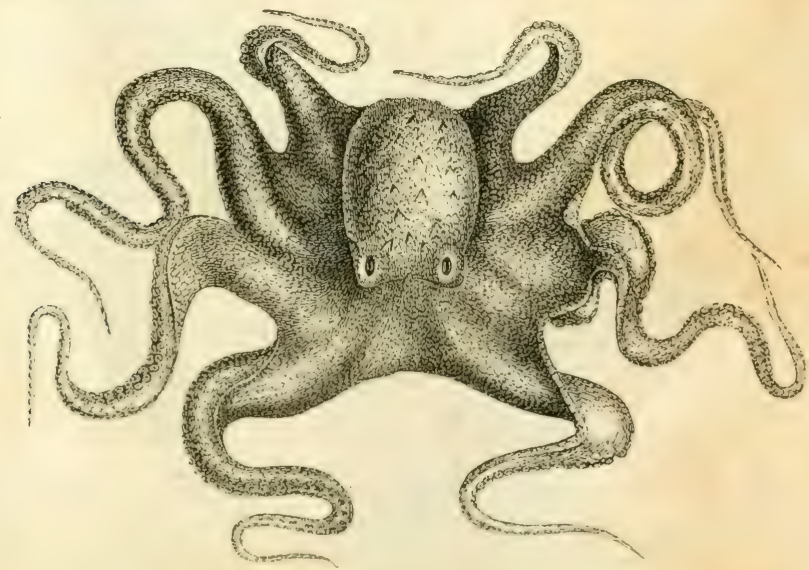

Fig. 159. Le poulpe commun. 
Ce sont ces divers modes de conformation qui servent de base a la division des mollusques proprement dits en cinq classes, dési-

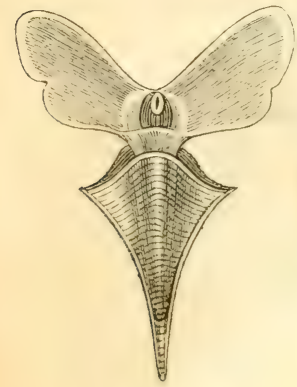

Fig. 160. Hyale.

gnées sous les noms d'acéphales, de gastéropodes, de ptéropodes et de céphalopodes. L'huître peut nous servir d'exemple du premier de ces types, c'est-à-dire de la classe des acéphales; le colimaçon appartient à la classe des gastéropodes, l'hyale $(f g .160)$ à celle des ptéropodes, et le poulpe (fig. 159) au groupe des cé- . phalopodes.

\$ 382. Enfin, le quatrième et dernier embranchement du Règne animal, celui des zoophytes, comprend aussi des êtres très-variés et se divise d'une manière correspondante en plusieurs classes. Dans lun de ces groupes, appelé la classe des échinodermes, le corps est conformé pour ramper sur le sable ou sur les rochers du fond de la mer, et, à cet effet, sa surface est garnie d'une multitude de petits appendices préhensiles; l'enveloppe tégumentaire offre aussi une consistance considérable et devient sourent d'une dureté pierreuse. Les étoiles de mer (fig. 134), dont il a déjà été question, et les holothuries (fig. 161) nous offrent ce mode de conformation, qui se retrouve aussi chez les oursins, ete.

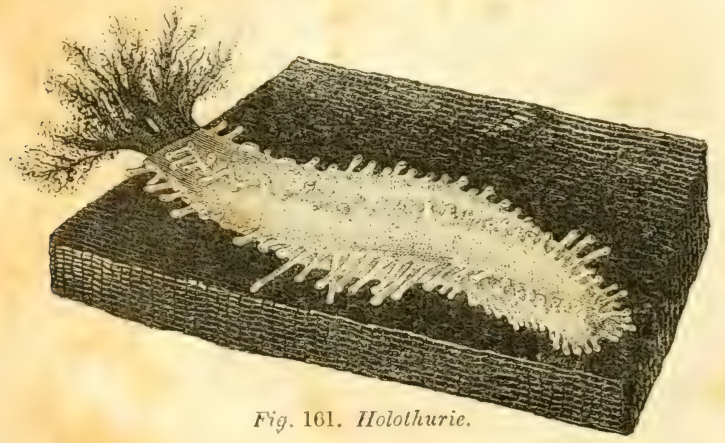

Dans un second groupe, formé par les acalèphes, le corps est au contraire entièrement gélatineux et conformé pour la nage seulement. Les méduses (fig. 162), qui flottent dans la mer et qui sont fréquemment jetées par la vague sur les plages sablonneuses do 
GRANDES DIVISIONS DU RÈGNE ANIMAL.

notre littoral, nous serviront d'exemple pour cette classe de zoophytes.

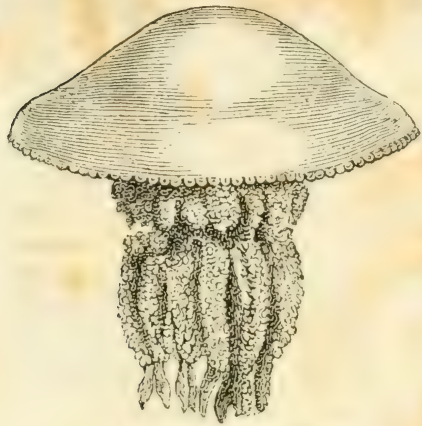

Fig. 162. Rhizoslome.

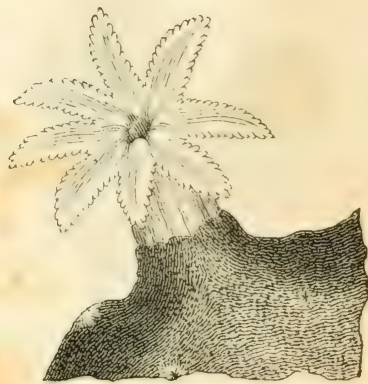

Fig. 163. Polype du corril.

Dans une troisième classe, celle des polypes, il n'existe plus aucun organe de locomotion; l'animal est destiné à vivre fixé au sol,

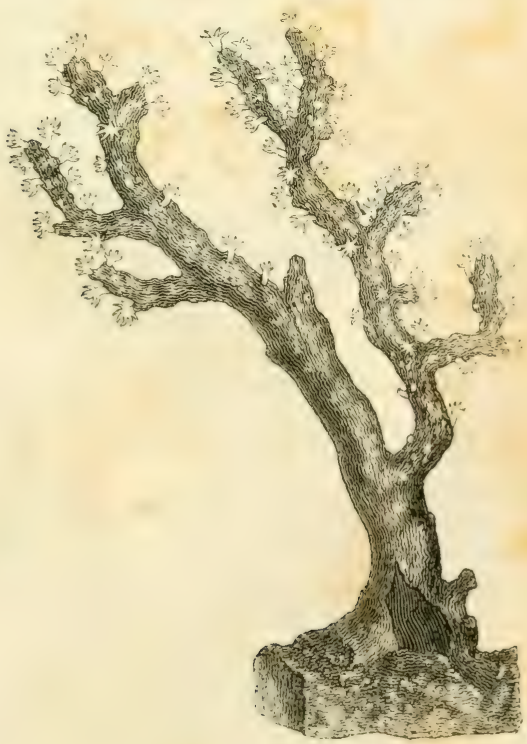

Fig. lfi1. Tige de conrril. 
ot sa bouche est entourée de tubercules mobiles (fig. 163) à l'aide desquels il puise dans l'eau ambiante les corpuscules nécessaires a

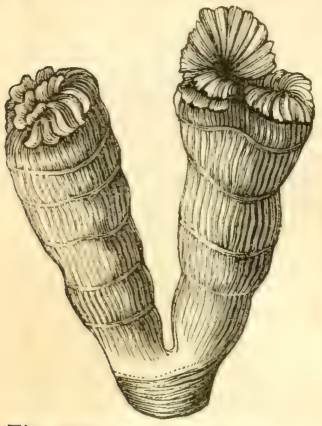

Fig. 165. Polypier du genre caryophyllie.

sa nutrition; en gériéral une portion de ses téguments s'ossifie en quelque sorte de facon à lui constituer une espèce de loge calcaire ou ccrnée (fig. 165), et, dans la plupart des cas aussi, les individus naissent par bourgeons sur la surface du corps de leurs parents, et, ne s'en détachant pas, constituent entre eux des masses animées de formes variées, dont l'apparence est, le plus ordinairement, celle d'une plante rameuse chargée de fleurs.

Les actinies ou anémones de mer (fig. 143) appartiennent àcetteclasse; il en est de mème des animaux du corail (fig. 163 et 164), dés hydres (fig. 2), des caryophyllies (fig. 16:), etc.

Un quatrième type nous est offert par les spongiaires, animaux singuliers qui, dans leur jeune àge, ont une forme ovoïde, nagent ibrenent à l'aide de cils vibratiles dont la surface de leur corps

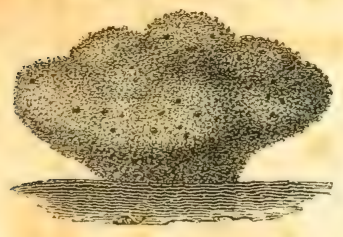

Fig. 166. Éponge. est garnic, et ressemblent aux larves des acalèphes et des polypes; mais qui ne tardent pas à se fixer, et qui non-seulement perdent alors la sensibilité et le mouvement, mais se déforment au point de ne ressembler à rien de ce yui existe dans le reste du Règne animal.

Enfin la plupart des naturalistes rangent aussi dans l'embranchement des zoophytes un cinquième groupe composé d'une multitude d'ètres d'une petitesse extrème (fig. 167) qui se montrent dans les eaux croupissantes, et qui ont recu le nom d'animalcules infusoires. Ils se meuvent à l'aide de cils vibratiles et ressemblent, en général, beaucoup aux larves des spongiaires, des polypes et des acalèphes; mais ils ne chanærent pas de forme en grandissant, et ils se font remarquer par leur reproduction sicipare et par le nombre considérable d'estomaes creusés dans l'intérieur de leur rorps pour la réception des matieres nutritives. Jusqu'en ces dernières années on confondait ces petits ètres avec les systolides.

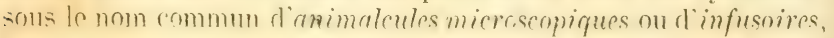


et, pour les distinguer, on les appelle sourent des infusoires polygastriques. Du reste, la place qu ils doivent occuper dans nos classifications zoologiques n'est pas encore bien déterminée.

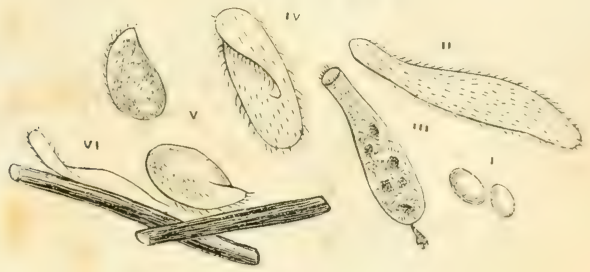

Fig. 167. Infusoires (1).

Tels sont les caractres les plus saillants des principaux types organiques que nous offre le Regne animal; l'esquisse que nous renons d'en présenter suffit pour donner une idée générale des modifications introduites par la nature dlans la structure des ètres animés : mais, si nous en bornions là l'étude, nous n'en aurions que des notions très-incomplètes, et il nous faut maintenant examiner avec plus d'attention chacune des grandes divisions correspondant à ces différences fondamentales. Avant que de passer à ces considérations nous croyons, cependant, devoir nous arrèter encore quelques instants sur la distinction des embranchements et des classes, afin de résumer, sous la forme d'un tableau synoptique, les bases de la classification zoologique telles que nous renons de les exposer.

1) Divers infusoires polygastriques vus au microscope : - T Monades; II Trachélie anas; - III Enchélide représenté dans le moment où il rejette des matiéresfécales; - W Paramécie; - V Kulpode; - v Trachélie fasciolaire marchant sur des végétaux microscopiques. 


\title{
NOTIONS
}

\section{SUR L'ORGANSITION DES AMIMAUY APPARTENANT}

AUY DIVERSES CLASSES DU RÈGNE AMIMI.

\author{
PREMIER EMBRANCHEMENT.
}

\section{A NIMAUX VERTÉBRÉ}

\$383. Les animaux vertébrés, ainsi nommés à cause de leur squelette intérieur, dont les vertèbres forment la partie la plus essentielle, sont de tous les ètres animés ceux dont les facultés sont les plus variées et les plus parfaites; et, comme on pouvait le prévoir, d'après le principe que nous avons déjà ćtabli relativement à la division du travail dans l'économie animale (\$346), ce sont aussi ceux dont les organes sont les plus nombreux et les plus compliqués.

L'existence d'une charpente solide dans l'intérieur du corps leur permet d'atteindre à une taille que les animaux articulés, les mollusques et les zoophytes n'ont jamais; et la nature de ce squelette, dont toutes les pièces sont liées les unes aux autres, donne à leurs mouvements une précision et une vigueur qu'on ne voit que rarement chez les autres animaux.

Ce squelette intérieur, dont l'analogue ne se retrouve dans aucun autre embranchement du Règne animal, est en général composé d'os et disposé à peu près de la mème manière que chez l'homme; quelquefois cependant, chez les raies par exemple, il n'est formé que par des cartilages, et on connaît mème des poissons chez lesquels il se trouve réduit à un état presque membraneux. L'étude que nous en avons déjà faite ( $\$ 259$ à 28 2 $)$ nous dispense d'en traiter plus longuement ici ; et nous ajouterons seulement que la portion de cette charpente qui ne manque jamais et qui varie le moins d'un animal à un autre est l'espèce de tige osseuse renfermant l'axe cérébro-spinal, et formée par la colonne vertébrale et le crane : les cotes manquent chez quelques reptiles, la grenouille 
par exemple; le sternum chez d'autres. Mais c'est surtout dans les membres que le squelette présente des modifications nombreuses : tantòt tous les os qui d'ordinaire entrent dans la composition de ces organes manquent complétement (comme cela se voit chez la couleuvre, etc.), tantòt leur nombre seulement est diminué, et, à cet égard, il est à noter que chez les animaux aquatiques les membres thoraciques offrent un développement plus considérable et existent d'une manière plus générale que les membres abdominaux; tandis que chez les animaux destinés à vivre sur la terre les membres postérieurs perdent moins sourent de leur importance, et ce sont les membres thoraciques qui offrent le plus d'exemples d'un développement incomplet. Quant aux modifications que ces organes subissent pour derenir aptes à remplir les diverses fonctions que la nature leur répartit, nous en avons déjà parlé ; et il est, par consé(fuent, inutile d’y revenir ici (voyez $\$ 289$ à $29: 3)$. Il est encore à noter que la portion caudale du corps, étant surtout utile dans la natation, est plus développée chez les poissons que dans les autres classeș de vertébrés; elle remplit aussi des fonctions importantes dans le vol, et, jar conséquent, présente chez les oiseaux une structure assez constante : tandis que chez les animaux essentiellement terrestres, de la classe des mammiferes ou de celle des reptiles, elle perd en général toute son utilité et manque souvent presque complétement. Enfin, il est à remarquer aussi que chez les animaux les moins élevés dans la série des rertíbrés le squelette est ordinairement formé d'un nombre de pièces beaucoup plus considérable que chez les mammiferes et les oiseaux; ce qui parait dépendre en majeure partie d'une espece d'arrét de développement par suite duquel les pièces élémentaires de cette charpente ne se soudent pas ensemble pour constituer des os plus considérables, ainsi que cela a lieu par les progrès de l'àge chez les vertébrés à sang chaud. Cette multiplicité de pièees osseuses distinctes se fait surtout remarquer dans la tète; elle est déjà trèsvisible chez les reptiles : mais c'est chez les poissons qu'elle est portée au plus haut degré, et e'est la une des circonstanes qui contribuent quelquefois à rendre tres-obseures les analogies de composition d'ordinaire si manifestes dans le squelette des divers animaux rertébrés comparé à celui de l'homme.

$\$ 381$. Le système nerveux est bien plus développé chez les animanx vertébrés que dans les autres divisions du Regne animal, ef c'est sa partie centrale qui est surtout remarquable par son volume. La sensibilite de ces amimaux est en rappert avee ce mode doucranisation. et lour intellizenee déplatse colle de tous bes autres. 
L'axe cérébro-spinal offre chez tous ces animaux les mèmes rapports de position et la mème composition fondamentale que chez l'homme; il est situé en entier du côté dorsal du corps, au-dessus du tube digestif (fig. 128), et on y distingue toujours un cerveau, composé de deux hémisphères; des lobes optiques, un cervelet et une moelle épinière : seulement l'encéphale devient de plus en plus petit et d'une structure de plus en plus simple, à mesure que l'on descend de l'homme vers les poissons. Les nerfs de tous les animaux vertébrés ressemblent aussi plus ou moins exactement à ceux de l'homme; ceux qui appartiennent aux fonctions de relation proviennent tous de l'axe cérébro-spinal, et pour la plupart en naissent constamment par deux racines dont l'une porte un ganglion près de sa base. Les nerfs des visceres appartiennent pour la plupart au système ganglionaire, et ce système se lie toujuurs au système cérébro-spinal par une multitude de petites branches qui s'anastomosent avec les nerfs rachidiens. Enfin les sens extérieurs sont toujours au nombre de cinq, et les organes qui en sont le siége offrent, à peu de chose pres, la mème disposition que chez l'homme.

\$38̈. L'appareil de la digestion ne présente aussi dans cette grande division du Règne animal que des différences assez légères: les deux orifices du canal alimentaire sont toujeurs très-éloignés l'un de l'autre; les mâchoires s'écartent en suivant la direction de la liģne médiane du corps, et ne se dirigent jamais latéralement comme chez les animaux annelés; l'intestin est fixé dans l'abdomen par un mésentère $(\$ \varangle \ddot{4})$, et le chyle est toujours transporté de l'intestin dans les veines par des canaux particuliers appartenant au système des vaisseaux lymphatiques.

$\$ 386$. Le sang, qui est toujours rouge, et qui est bien plus riche en globules que dans les animaux inférieurs, arrive au cœur par les veines; il pénètre d'abord dans une oreillette, et passe ensuite dans un ventricule, d'où il se rend en totalité ou en partie à l'appareil de la respiration : en général ce liquide nourricier revient ensuite au cour avant que de se rendre aux diverses parties du corps; mais quelquefois il se porte directement à celles-ci, et son mouvement circulatoire est déterminé tantòt par une oreillette et un ventricule seulement, tantòt par deux oreillettes réunies à un seul ventricule, et d'autres fois par un cœur composé de deux ventricules et de deux oreillettes (voyez $\$ 107,108,109$ ). La respiration a toujours lieu dans un appareil particulier, situé dans une cavité intérieure du corps; mais clle n'est pas toujours aérienne romme chez l'homme, et a son siége tantòt dans des poumons, tantòt dans des branchies. 
Parmi les organes sécréteurs dont nous avons signalé l'existence chezl'homme, il en est deux quine manquent jamais : ce sont le foie et les reins. Le pancréas existe également chez la plupart des animaux vertébrés, et on leur trouve aussi une rate plus ou moins développée.

\$387. La nature semble donc a voir suivi le mème plan général dans la création de tous ces ètres : cependant ils diffèrent tous entre eux, et quelques-unes des différences qu'ils offrent sont mème d'une grande importance dans l'économie; aussi conduisent-elles, comme nous l'avons déjà vu, à la division de cel embranchement du Règne animal en 4 classes, les mammifères, les oiseaux, les reptiles et les poissons.

\section{DE LA CLASSE DES MAMMIERES.}

$\$ 388$. La classe des mammifères se compose de l'homme et de tous les animaux qui lui ressemblent par les points les plus importants de leur organisation. Elle se place naturellement en tète du Règne animal, comme renfermant les ètres dont les mouvements sont les plus variés, les sensations les plus délicates, les facultés les plus multipliées et l'intelligence la plus développée; et elle nous intéresse aussi plus que toute autre, car elle nous fournit les animaux les plus utiles soit pour netre nourriture, soit pour nos travaux et pour les besoins de notre industrie.

Il est en général facile de distinguer, au premier coup d'œil, un mammifère d'un oiseau, d'un reptile, d'un poisson, ou de tout autre animal, par la seule considération de sa forme extérieure et de la nature de ses téguments; car les mammifères sont les seuls animaux vertébrés dont le corps est couvert de poils, et ordinarement leur forme générale ne s'éloigne que peu de celle des espèces que nous avons continuellement sous les yeux, et que nous prenons nafurellement comme types de ce groupe; mais quelquefois ils ne se reconnaissent jas à un examen aussi superficiel, car il en est dont la peau est complétement nue et dont le corps, au lieu de ressembler a celui du chien, du cheval ou d'un autre mammifere ordinaire, présente les formes propres aux poissons: le marsouin (fig. 168) et

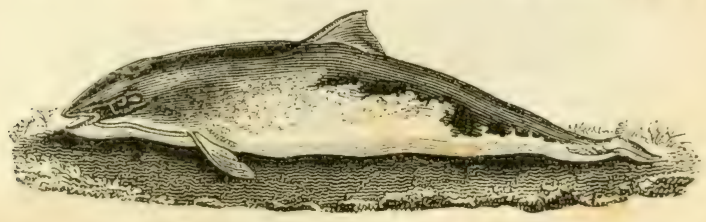

Fig. 168. Mursouin commun. 
la baleine, par exemple, sont dans ce cas : aussi le vulgaire les prend-il pour des poissons, dont ils diffèrent cependant par leurs mamelles, par leur mode de respiration, et par une foule d'autres traits des plus remarquables.

$\$ 389$. Développement et lactation. - Ce que les mammifères offrent de plus remarquable, c'est leur mode de développement et d'alimentation pendant les premiers temps de la vio. Ces animaux sont tous vivipares, et pendant la période embryonaire de leur existence ne portent pas avec eux un amas de matières nutritives, comme cela se roit chez les animaux ovipares : ils puisent ces matières directement dans le sang de leur mère; et après la naissance le jeune vit encore aux dépens de celle-cı, qui l'allaite pendant un temps plus ou moins long.

Le lait destiné à cet usage est un liquide blanc et opaque, formé par de l'eau tenant en dissolution du sucre de lait, du caséum, quelques sels et un peu d'acide lactique libre, et tenant en suspension des globules de beurre. Ses qualités varient un peu chez les différents animaux et peuvent ètre modifiées par les aliments dont ceux-ci font usage ; en général il laisse, par l'évaporation, 10 à 12 pour 100 de parties solides, mais sa richesse peut varier beaucoup suivant les circonstances.

Ce liquide alimentaire est sécrété par des glandes particulières nommées mamelles, qui existent dans les deux sexes, mais qui ne servent à l'allaitement du jeune que chez la femelle. Des organes analogues ne se rencontrent dans aucune autre classe du règne animal, et c'est à raison de leur existence chez tous les animaux du groupe dont nous faisons ici l'histoire que les zoologistes ont donné à ces ètres le nom de mammifères.

Le nombre des mamelles est en général à peu près en rapport avec celui des petits dont se compose chaque portée : souvent on n'en compte que deux (chez les singes, l'éléphant, la chèvre et le cheval, par exemple), mais quelquefois aussi leur nombre est beaucoup plus considérable : ainsi la vache, le cerf, le lion, en ont quatre, le chat huit, le cochon et le lapin dix, le rat dix ou douze, et l'agouti douze à quatorze. La position de ces glandes varie aussi . chez les singes et les chauves-souris, elles sont placées sous la poitrine comme chez l'homme; chez la plupart des carnassiers, elles sont situées à l'abdomen aussi bien qu'au thorax; et chez le cheval, le bouf, te mouton, etc., elles sont placées encore plits en arrière, prìs de l'articulation des membres postérieurs.

Tantòt les petits naissent les yeux ouverts, et peuvent de suite courir of chercher ens-memes leur nourriture; mais un grand nomber 
d'autres mammifères viennent au monde les yeux fermés, et dans un état de faiblesse telle qu'ils peuvent à peine se mouvoir : il en est mème qui naissent pour ainsi dire avant terme, car leur corps est à peine ébauché; et ils ne pourraient vivre s'ils ne se greffaient. en quelcue sorte à la tetine de leur mère, où ilš restent suspendus pendant un temps considérable. Il est aussi à noter que, chez la plupart des animaux qui naissent dans cet état d'imperfection extrème, la peau du ventre forme, au-devant des mamelles, une poche servant à loger et protéger les petits. Cette particularité de structure caractérise les sarigues $(f i g .169)$, les kanguroos et les autres mammifères de l'ordre des marsupiaux, animaux qui, pour la plupart, habitent l'()céanie. Les jeunes achèvent leur développement dans l'intérieur de cette poche, suspendus chacun à une tetine, qui pénètre fort avant dans leur bouche, et qui verse dans leur gosier lo lait dont l'expulsion est détermincé par la contraction des muscles entre lesquels se trouvent les glandes mammaires. Arrivés à un certain ìque, ils se détachent; mais ils continuent encore à teter, et, même

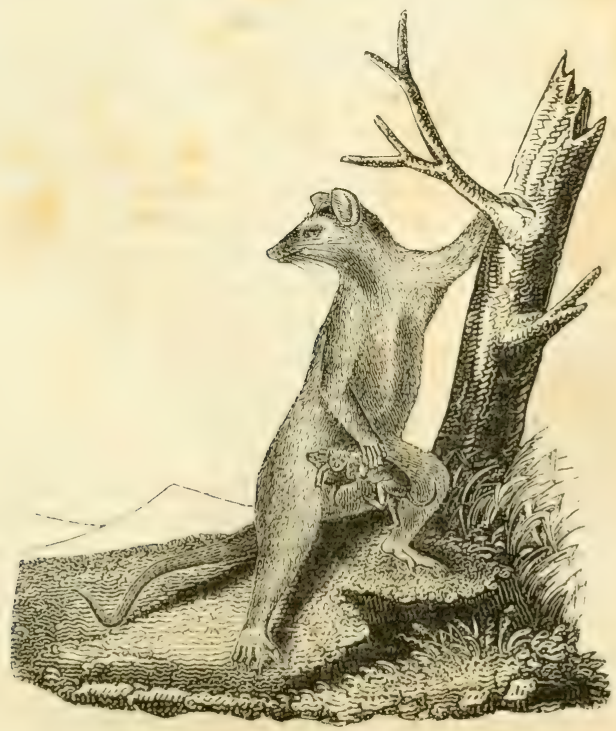

Fig. 169. Sarigue. 
lorsqu'ils sont sortis de la poche qui jusqu'alors leur avait servi de demeure, ils y cherchent encore pendant long-temps un refuge contre le froir ou les dangers dont ils sont menacés.

\$ 390. Téguments. - La peau, ainsi que nous l'avons déjà dit, présente, dans la classe des mammifères, des particularités remarquables. Chez un petit nombre de ces animaux elle est nue, mais chez la plupart elle est garnie de poils servant à la protéger et à conserver la chaleur développée dans l'intérieur du corps. L'existence de ces appendices tégumentaires est mème tellement caractéristique de cette classe, qu'un des zoologistes les plus habiles de l'époque, M. de Blainville, a proprosé de remplacer le nom de mammiferes par celui de pilifères, lequel contrasterait avec les mots de pennifères et squammifères, qu'il voudrait faire adopter pour désigner les oiseaux et les poissons.

Les poils sont produits par de petits organes sécréteurs logés dans l'épaisseur du derme ou immédiatement au-dessous de lui. Chaque poil se forme dans une petite poche ovoïde, à parois blanches et résistantes, qui communique au dehors par une ouverture étroite, et qui est appelée capsule. L'intéricur de cette cavité est revètu d'une membrane tantòt rougeâtre, tantòt diversement colorée, qui paraìt être une continuation du réseau muqueux de la peau, et à sa partie inférieure se trouve une papille conique ou bourgeon qui recoit un nerf et des vaisseaux sanguins et qui produit le poil. La substance dont ces appendices tégumentaires sont en majeure partie composés offre la plus grande analogie avec du mucus desséché. En les examinant au microscope, on voit quelquefois très-distinctement qu'ils sont formés d'une foule de petits cònes ou cornets emboités les uns dans les autres; mais, en général, ils ont l'apparence d'un simple tube corné, dont l'intérieur parait ètre rempli d'une matière pulpeuse. Chez la plupart des animaux, ils sont cylindriques et plus gros à leur base qu’à leur sommet; souvent ils sont plus ou moins aplatis, on en connaît qui sont tout à fait lamelleux et semblables à des brins d'herbe; tantòt leur surface paraìt ètre parfaitement lisse, et d'autres fois elle est cannelée ou garnie de petites aspérités, ou bien présente un aspect moniliforme; enfin, leur grosseur, leur forme et leur élasticité varient aussi beaucoup d'un animal à un autre, ainsi que dans les différentes parties du corps d'un même individu.

Les noms par lesquels on désigne les diverses variétés de poils diffèrent suivant les propriétés de ces filaments cornés et suivant les parties où ils croissert. Ainsi on les appelle piquants lorsqu'ils sont très-gros, pointus, très-roides, et qu'iis ressemblent à des 
blenàtre par du sulfure de fer (1). Tantòt les poils ont, dans toute leur longueur, la mème couleur; tantòt ils sont plus foncés à ieur extrémité qu'à leur base, et quelquefois aussi ils présentent une série d'anneaux blancs et colorés. Du reste leur couleur varie presque toujours dans les différentes parties du corps, et la disposilion générale de ces teintes constitue ce que l'on nomme le pelage des animaux. En général, les couleurs sont beaucoup plus foncées à la face supérieure qu'à la face inférieure du corps; et lorsqu'elles forment des taches, celles-ci sont presque toujours disposées symétriquement de chaque còté : à moins toutefois que les animaux ne soient réduits à l'élat de domesticité, car alors leur pelage présente souvent la plus grande irrégularité.

Le pelage est ordinairement le mème dans les deux sexes, et, en général, ne varie que peu aux différents àges. Dans quelques espèces, cependant, les jeunes ont des taches et des nuances variées qui disparaissent chez l'adulte, et souvent il arrive que la couleur des mammifères change avec les saisons.

En général, les poils tombent à une époque déterminée de l'année et sont remplacés par d'autres; cette mue a lieu le plus souvent au printemps ou en automne. Tantòt elle s'opère sans que la couleur du pelace soit modifiée; d'autres fois elle entraine des changements très-considérables, soit dans la couleur, soit dans l'abondance et la nature des poils. Ainsi, notre écureuil commun ( fig. 98), dont le pelage est d'un roux foncé en été, devient d'un beau gris-bleuatre en hiver. Dans cette dernière saison la fourrure des mammiferes est ordinairement beaucoup plus épaisse qu'en été, et on y trouve, sous les crins ou poils plus ou moins soyeux qui la composent en partie, une quantité plus ou moins considérable de duvet. L'influence de la température se fait sentir de la mème maniere sur les animaux qui habitent des climats différents : ceux des pays froids ont une fourrure épaisse et abondamment fournie de duret, tandis que ceux des pays chauds n'ont guère que des poils courts, secs, roides et peu nombreux.

Ce que l'on recherche le plus dans les fourrures, c'est la finesse, l'abondance, le moelleux et le brillant du poil ; or, d'après ce que nous venons de dire relativement à l'influence des saisons et du climat sur l'enveloppe tégumentaire des mammiferes, on peut

(1) Il existe aussi dans les différentes espèces de cheveux du soufre qui pent facilement se combiner avec le plomb et quelques autres métaux pour former des sulfures colorés; c'est de la sorte qu'on parvient à les teindre en noir par l'application de sels de plomb, de mercure, cte., le sulfure qui se forme alors dans la substance du poil étant de cette couleur. 
prévoir que ce doit ètre dans les pays les plus glacés, dans les montagnes et surtout pendant l'hiver, que se trouvent les plus belles pelleteries, et, en effet, c'est du nord que nous les tirons presque toutes. La France et les pays voisins fournissent bien quelques fourrures, connues sous le nom de sauvagines; mais c'est principalement dans la Sibérie et la frartie la plus septentrionale de l'Amérique que le commerce des pelleteries devient réellement important.

Lorsque les bulbes des poils sont extrèmement rapprochés, les filaments cornés qu'ils produisent se soudent en quelque sorte entre eux et forment des lames solides; c'est de la sorte que paraissent naître les espèces d'écailles qui recourrent tout le corps de certains mammifères très-singuliers, connus sous le nom de pangolins (fig. 171), et la cuirasse des tatous: les anatomistes s'accordent aussi à regarder les ongles et la corne comme ayant la mème origine.

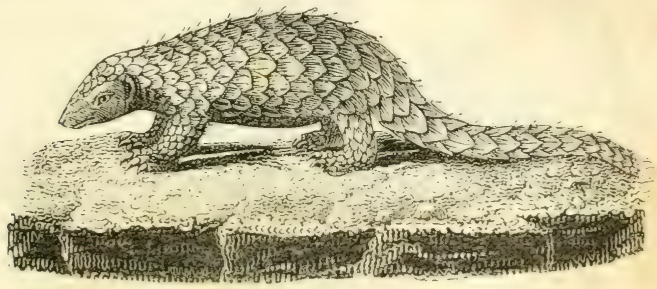

Fig. 171. Pangolin.

$\$ 391$. Squelette. - La forme générale du corps est déterminéc principalement par le squelette; quelquefois cependant elle prósente des particularités qui ne sont pas en rapport avec la disposition de cette charpente intérieure : ainsi les bosses qui surmontent. le dos des chameaux ( $(19.172)$ ne sont par soutenues pas des os ct ne consistent que dans des amas de tissu graisseux.

Le squelette offre toujours dans sa conformation la plus grande analogie avec celui de l'homme, que nous avons déja étudic (\$269, ote.). Les différences que l'on y remarque chez les divers animaux de cette classe dépendent essentiellement : $1^{\circ}$ de l'absenee des membres abdominaux dans les mammiferes pisciformes, tols que le marsouin (fig. 168) et la baleine, que les zooloristes ont compris dans l'ordre des célacris: 20 de la diminution du nombre des doigts of de labsence de la clavioule chez la plupart des esperes: 
dont les membres ne servent qu'à la marche; $3^{0}$ de quelques variations dans le nombre des vertèbres, surtout dans les régions dorsale et caudale; $4^{\circ}$ d'inégalités dans leur volume relatif offertes par les mèmes os.

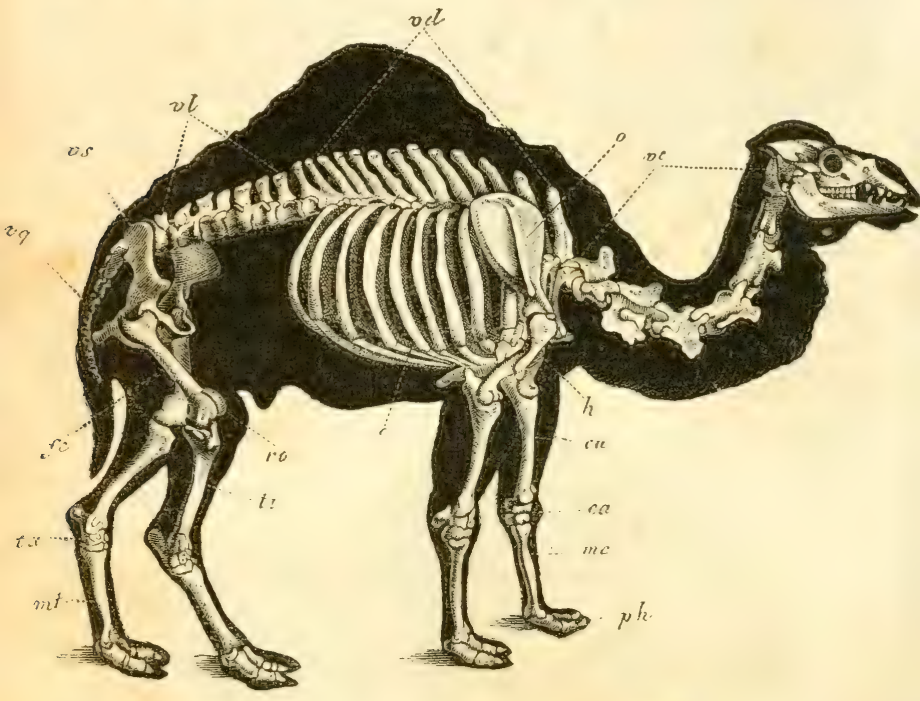

Fig. 172. Squelelle de chameau. (Voy. p. 194. )

$\$ 392$. Conformation de la tête. - La forme de la tête osseuse varie beaucoup, suivant que la face prend plus ou moins d'extension, ou bien que le crâne se développe davantag̣e, et l'étude de ces différences de proportions n'est pas sans intérêt; car, ainsi que nous l'avons déjà vu, il existe, en général, un rapport assez direct. entre le degré d'intelligence dont un animal est doué et les dimensions relatives de la portion crânienne de sa tête $(\$ 342)$. A mesure que l'on s'éloigne de l'homme, on voit le crâne diminuer, les mâchoires et les fosses nasales prendre plus d'extension, les orbites se diriger de plus en plus en dehors et devenir de moins en moins distinctes des fosses temporales; enfin le trou occipital, qui livre passage à la moelle épinière, ei les deux condyles par lesquels la tète s'articule avec la colonne vertélorale, au lieu d’ètre placés vers le milieu de la faer inférieure du erâne, se portent de plus 


\section{MAMMIEERES.}

en plus en arrière et finissent par en occuper la face postérieure, de facon que les mâchoires, au lieu de former un angle droit avec la colonne vertébrale, deviennent parallèles à l'axe du corps. Du reste, on trouve partout à peu près les mèmes 0 s; et le mode d'articulation de la mâchoire inférieure est caractéristique de la classe des mammifères : cet os se fixe immédiatement au crâne par deux condyles saillants, et la portion du temporal qui le reçoit est confondue avec le rocher et entre dans la composition des parois du crâne; tandis que, chez les oiseaux, les reptiles et les poissons, cette mâchoire est suspendue à un os intermédiaire entre lui et le rocher.

$\$ 393$. Divers mammifères offrent dans la conformation de la tète une particularité remarquable, consistant dans l'existence de cornes plus ou moins longues. Quelquefois ces prolongements ne sont que des dépendances de la peau et paraissent ètre formés de poils soudés ensemble : c'est le cas des cornes dont le nez du rhinocéros est armé ; mais en général il en est autrement, ef c'est un

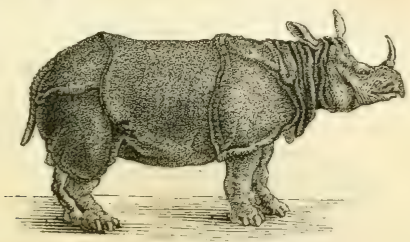

Fig. 173. Rhinocéros.

prolongement de l'os du front qui constitue l'axe de ces appendices. Les mammiferes pourvus de cornes à cheville osseuse appartiennent tous à l'ordre des ruminants, et offrent dans la structure de ces parties des différences assez considérables. Tantòt la protubérance osseuse est recouverte par la peau du front qui, dans ce point, ne differe pas de celle du reste de la tète, et qui ne se détruit pas : c'est le cas de la girafe (fig. 200). Tantòt la portion osseuse des cornes, d'abord revètue d'une peau velue, s'en dépouille, et, après ètre restée à nu pendant un certain temps, tombe elle-mème pour faire place à une nouvelle corne destinée à éprouver à son tour les memes changements : ces cornes caduques se nomment bois et ne se rencontrent que chez les animaux du genre rerf (fig. $17: j)$. Enfin, d'autres fois, laxe osseux croit pendant toute la vie, ne tombe jamais, et est revètu d'une espece de gaine composie 
d'une substance élastique appelée corne, qui est analogue à celle

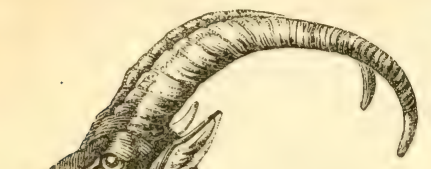
des ongles, et qui croît par couches. On donne le nom de cornes creuses à ces cornes revètues ainsi d'un étui, qui semble formé de poils agglutinés; et on les trouve chez les diverses espèces des genres bœuf, mouton, chèvre et antilope. Il est encore à noter que dans tous ces animaux, à l'exception des antilopes, la cheville osseuse de ces

Fig. 174. Têle de chèvre.

cornes est creusée de grandes cellules qui communiquent avec les sinus frontaux du nez et recoivent ainsi de l'air dans leur intérieur.

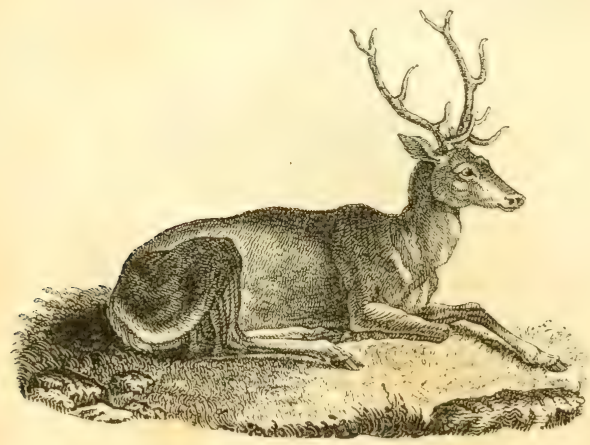

Fig. 175. Cerfo.

Le mode de formation el de renouvellement des espòces de cornes connues sous le nom de bois est très-simple et mérite d'ètre signalé. A un certain âge, il se déreloppe de chaque còté de l'os frontal un prolongement dont la formation peut étre comparée à celle des tubercules connus en médecine sous le nom d'exostoses ou à celle du cal osseux, qui se dépose autour des extrémités des os ordinaires dans les cas de fracture, et en détermine la consolidation. Ces protubérances, dont le tissu est très-compacte, croissent rapidement et soulivent la peau qui les couvre. Celle-ci, dans un état roisin de celui de l’inflammation, recoit une grande quan- 
tité de sang à l'aide de vaisseaux nombreux qui sillonnent la surface du hois; mais bientòt il se forme à la base du prolongrement osseux un cercle de tubercules, qui, en grossissant, compriment ces vaisseaux nourriciers et les oblitèrent. Or l'enveloppe cutancée de la corne, ne recevant plus de sang, meurt, puis se desseche et tombe. Le bois est alors à nu et ne tarde pas à éprouver le sort de tout os qui est dépouillé des parties molles environnantes, et reste exposé à l'air; ce qui a lieu dans bien des cals de blessure chez l'homme, a lieu ici par suite des phénomènes que nous venons de décrire : l’os est frappé de nécrose, meurt, et finit par se détacher du cràne et par tomber. L'animal reste alors sans armes; mais, peu de temps après (ordinairement vingt-quatre heures), une pellicule mince recouvre la plaie formée par la chute du bois, et bientòt un noureau prolongement osseux s'élève à la place de l'ancien. En général le nouveau bois acquiert des dimensions plus considérables que celui auquel il succède. Ordinairement le nombre des branches est aussi plus considérable; mais sa durée n’est pas plus longue, et il passe par les mèmes phases que le premier.

C'est en général au printemps que ce phénoméne curieux a lieu, et presque toujours le renouvellement du bois se fait régulièrement chaque année. Du reste il semble exister un rapport évident entre l'époque à laquelle il s'effectue et l'activité périodique des fonctions de reproduction; car chez les cerfs, ou le rut n'est pas un état de crise violent et limité, les cornes persistent plus d'une année. Enfin, c’est en général le màle seulement qui a la tète ornée de la sorte; une espece remarquable, le renne, fait cependant exception à cette règle, la femelle ayant des cornes aussi bien que le mâle.

$\$ 394$. Une autre anomalic curieuse qui se rencontre dans la conformation de la tète chez quelques mammiferes dépend d'un déseloppement exessif du nez, qui se prolonge de facon à constituer une trompe mobile et préhensile. Telle est, en effet, la nature de l'organe qui donne à l'éléphant un aspect si particulier et une si grande adresse. La trompe de ces animaux est un double tuyau qui se continue supérieurement aree les fosses nasales, et qui est revelu intérienrement d'une membrane fibro-teridineuse autour de lacpuelle se fixent des milliers de petits muscles diversement enIrelareés, et disposés de fagen à l'allonger, à la raceoureir et à la courber dans tous les sens; a sor extrémité supérieure il existe une valvule cartilghineuse é élastique, qui, a moins d'itre relevée par la contration volentaire de ses muscles, inferecepte lat communication entre les forses nasiales af lo dehers: enfin, a son 
extrémité libre, se trouve un appendice en forme de doigt, également mobile. Cette longue trompe sert à l'animal pour saisir tout ce qu'il veut porter à sa bouche, pour cueillir l'herbe et les feuilles dont il se nourrit, et pour pomper la boisson qu'il lance ensuite

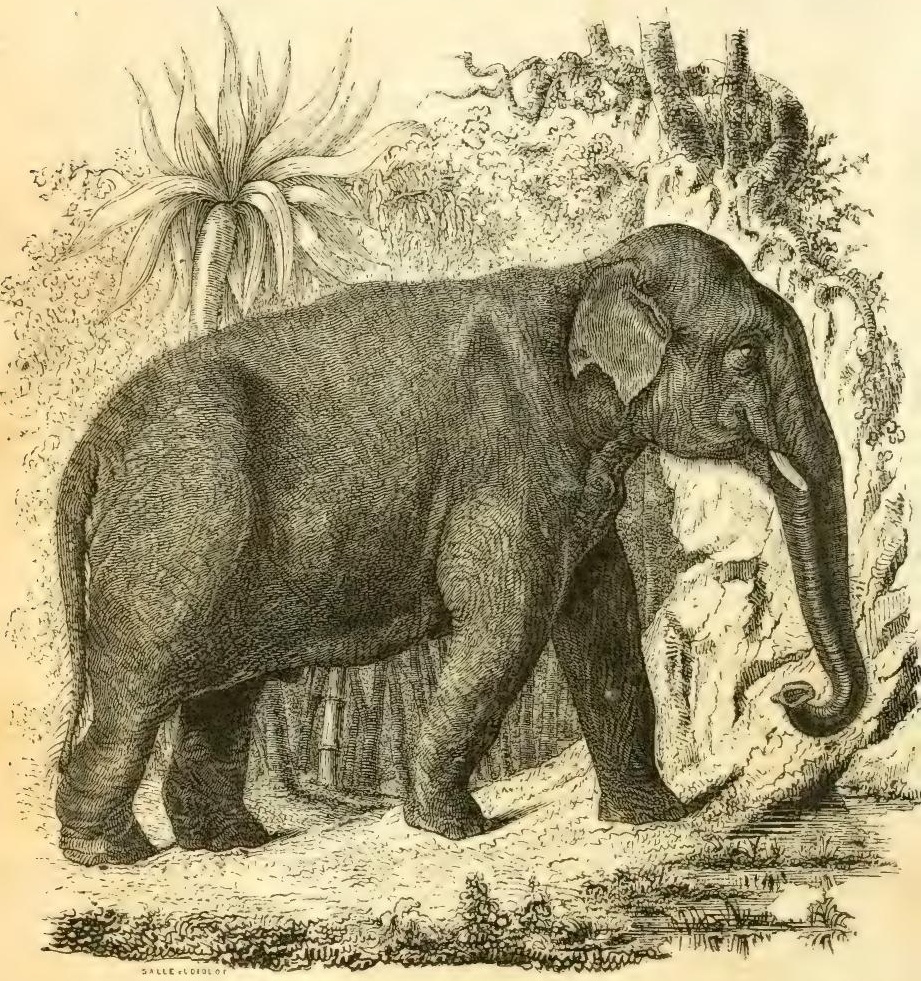

Fig. 176. Éléphant de l'Inde.

dans son gosier : sans elle, la conformation générale de son corps rendrait son existence presque impossible. En effet, pour (qu'un animal puisse chercher commodément à terre sa nourriture, il faut. lorsquil na pas dorganes speciaux de préhension, que la lon- 
gueur de son cou soil proportionnée à celle de ses jambes, de telle sorte qu'en abaissant la tète il puisse, sans les fléchir, toucher le sol avec ses lèvres. S'il est haut sur pattes, il lui faut donc un long cou; et cette disposition est à son tour incompatible avec une tète très-grosse et très-lourde, dont le poids devient d'autant plus difficile à soutenir qu'elle est placée à l'extrémité d'un cou plus long: aussi observe-t-on que chez tous les animaux dont les pattes sont allongées et dont la bouche sert à la préhension des aliments ( la girafe, par exemple $[f y .200]$ ), le cou est long et la tète petite; tandis que chez ceux dont la tète est forte et lourde, ou destinée à exécuter des mouvements très-énergiques, le cou est plus ou moins court. Or les éléphants sont de tres-grands animaux, dont la tète est fort éloignée du sol et d'un volume en rapport avec les énormes défenses dont la mâchoire supérieure est armée; son poids est par conséquent très-considérable, et le cou qui la supporte très-court : s'ils étaient dépourvus d'une trompe, il aurait donc fallu donner au reste de leur organisation un tout autre plan.

Les éléphants, dont il n'existe aujourd'hui que deux espèces, l'une propre à l'Afrique, l'autre native des Indes, sont les seuls mammifères qui soient pourvus d'un semblable or gane de préhension; mais il existe quelque chose d'analogue chez certains animaux de la mème classe, qui sont destinés à fouir la terre pour y chercher leur nourriture : ainsi, les tapırs, animaux assez voisins des cochons, ont le nez prolongé bien au-devant de la bouche et constituant une petite trompe susceptible de s'allonger et de se raccourcir (fig. 177). Les desmans (fig. 178), petits insectivores, voisins des musaraignes, mais conformés pour nager avec facilité et pour virer au fond de terriers creusés dans les berges, offrent aussi une conformation analogue.

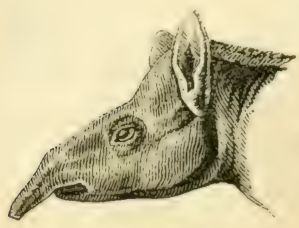

Fïg. 177. Téle de lapir.

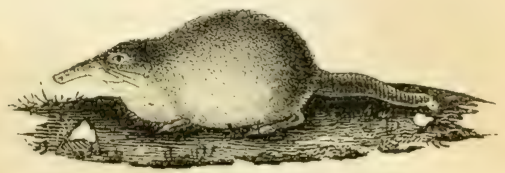

Fig. 178. Desman.

$\$ 39 \ddot{3}$. Tronc. - La colonne rertébrale ne presente, dans lit chasso des vertébrés, que des modifications léceres et offre partout 
les mèmes caracteres que chez l'homme (\$17); nous remarquerons seulement que sa longueur varie beaucoup) et que le nombre des vertèbres dont elle se compose est loin d'ètre constant. Ces différences numériques dépendent surtout de l'inécral développement de la portion caudale de la colonne; ainsi, tantòt il n'existe point de vertebres coccygiennes (chez les chauves-souris du genre roussette, par exemple), tandis que d'autres fois on en compte 40, 50 et mème plus de 60. Il est aussi à noter que ces vertebres coccygiennes sont de deux sortes. les unes conservent un canal pour le passage de la moelle épiniere, les autres n'en ont plus; enfin leurs apophyses sont d'autant plus saillantes que la queue est plus forte et plus mobile; chez la plupart des mammiferes, cet organe ne sert que peu aux mourements; mais chez d'autres il devient un instrument puissant de locomotion. Ainsi dans les kanguroos, les gerboises, etc., la queue forme, avec les pieds de derriere, une espece de trépied sur lequel l'animal se pose et s'élance (fig. 8̈̈); chez un grand nombre de singes de l'Amérique, elle est préhensile et sert à ces animaux comme une cinquieme main pour se suspendre aux branches (fig. 91); enfin, chez les cétacés, elle prend un accroissement énorme et devient l'agent principal de la natation. Chez ces derniers animaux on remarque aussi au-dessous des premieres vertèbres caudales des os en forme de V. qui semblent représenter, en quelque sorte, les còtes, et qui servent à augrmenter la force des muscles fléchisseurs de cette partie du corps (fig. 179). La longueur du cou varie aussi beaucoup) ; chez les girafes, par exemple, elle est très-considérable, tandis que chez la balcine elle ! est presque nulle, et cependant le nombre des vertèbres y est presque toujours de sept comme chez l'homme. On ne connait que deux exceptions à cette règle, savoir : l'aï, qui en a 9 ; et le lamentin, seulement 6 .

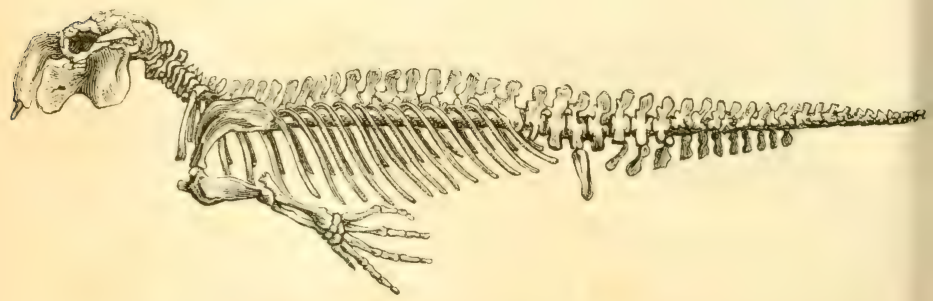


$\$ 396$. La conformation du thorax rarie peu; le nombre des còtes est en rapport avec celui des vertères dorsales, et est, en général, de 12 à l's paires: quelquefois, cependant, il s'élère davanlage. Ainsi chez le cheval on en compte 48 paires, et chez l'éléphant des Indes 20 paires. Le sternum est, en grénéral, étroit et aplati; mais chez les chauves-souris, ou les muscles abaisseurs de l'aile doivent avoir une grande puissance et trouver sur cet os une large surface pour leur insertion, il présente souvent, sur la ligne médiane, une crète élevée qui ressemble un peu au bréchet des oiseaux. Enfin, chez tous les animaux de cette classe, la cavité thoracique est séparée de l'abdomen par une cloison complète formée par le muscle diaphragme.

Membres. \$397. - Les membres sont au nombre de quatre chez tous les mammifères ordinaires; mais chez les baleines et les autres mammiferes pisciformes, désignés sous le nom commun de rétacés, il n'y en a que deux, car les abdominaux n'existent pas (fiy. 379). De mème que chez l'homme, ces organes se composent toujours d'une portion basilaire et d'un levier articulé qui se divise en trois parties principales, savoir : le bras ou la cuisse, lavantbras ou la jambe, et la main ou le pied; mais, ainsi que nous l'avons déjà vu (\$29\%, ete.), le mode de conformation de ces diverses parties rarie un peu, suivant les usages auxquels elles sont destinées.

La portion basilaire du membre thoracique, ou l'épaule, se compose essentiellement, avons-nous dit, d'un grand os plat qui est appliqué sur les còtes, qui donne attache au bras et qui se nomme lomoplate ou scapulum. Cet os est d'autant plus étendu dans le sens parallele a la colonne, que l'animal fait avec ses bras des offorts plus violents : et, en effet, cette conformation fournit aux muscles destinés à porter le membre contre le trone des points d'insertion plus étendus. Chez les mammiferes qui se servent de leurs membres thoraciques comme d'organes de préhension ou de vol, et qui les portent arec foree en dedans vers la poitrine, l'omoplate est maintenue dans sa position normale à l'aide de la clavicule qui, par l'une de ses extrémités, s'articule avee elle, et par l'autre s'appuie sur le sternum en manière d'are-boutant (fig. 77); mais chez les quadruperles qui n'exécutent que peu ou point de mourements analogues, et qui ne font quere usage de ces membres que pour la marche ou la nage, la clavicule manque complétement ou n'existe qu'à l'état de vestiqe : tous les cquatirupedes a sabols et plusieurs autres sont dans le meme cas. Chez quelques mammiferes tré-singuliers de la Nouvelle-liollande, tels gue les 
ornithorinques, les os de l'épaule prennent, au contraire, un tris-

a $\quad c 0 \quad d$

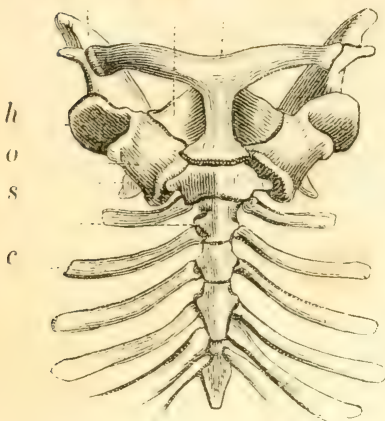

Fig. 180. grand développement, et leur disposition ressemble beaucoup plus à ce qui existe chez les lézards et les oiseaux qu'à ce que l'on voit chez les mammifères ordinaires : un os en forme d'Y $(d, f i g .180)$ s'appuie sur l'extrémité antérieure du sternum (s), et envoie ses deux branches aux deux omoplates, de la mème manière que la fourchette des oiseaux (co); deux pièces situées au-dessous de cette clavicule furculaire représentent l'os coracoïdien des oiseaux et des lézards; enfin l'omoplate elle-mème $(0)$, au lieu de se terminer par la fossette destinée à loger la tète de l'humérus, se prolonge au delà, et vient s'unir directement. au sternum $(s)$.

Les fonctions de la portion basilaire des membres abdominaux varient moins que celles de l'épaule : aussi le mode de conformation de cette partic est-il plus constant. Excepté chez les cétacés,

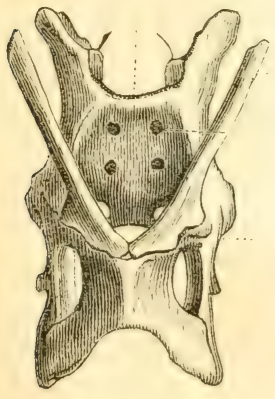

Fig. 181. où le bassin n'existe qu'à l'état de vestige, les os des hanches s'articulent tou$m$ jours d'une manière immobile au sacrum, et se réunissent entre eux par leurs extrémités inférieures, de façon à constituer un anneau complet et plus ou moins évasé, nommé bassin. La forme et les dimensions de cette ceinture osseuse varient beaucoup; et on remarque que, toutes choses égales d'ailleurs, la position verticale sur les membres abdominaux est d'autant plus facile que le bassin est plus large. Il est encore à noter que chez les sarigues et les autres marsupiaux les muscles de l'abdomen, formant la poche de ces animaux, sont soutenus par deux os particuliers qui naissent de la partie antérieure du bassin, et qui sont désignés par les anatomistes sous le nom d'os marsupiaux (fig. 181, $\mathrm{m}$ ).

Le bras et la cuisse ne présentent, chez tous les mammifères, 
qu'un seul os, l'humérus ou le fémur. Les os de l'avant-bras et de la jambe sont généralement les mèmes que chez l'homme; mais,

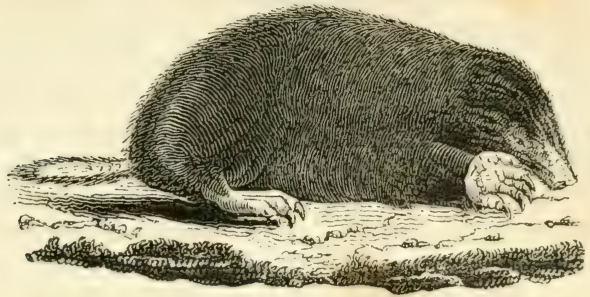

Fig. 182. Taupe

chez les chaures-souris, il existe, aux membres antérieurs aussi bien qu'aux membres postérieurs, une rotule distincte. En général,
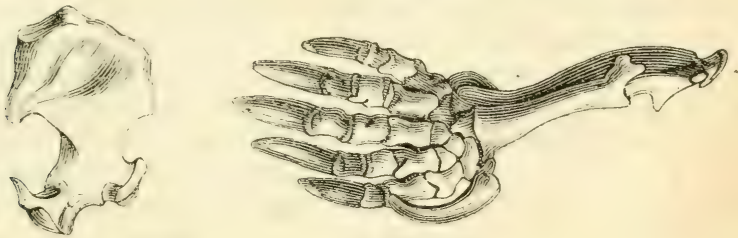

Fig. 183. Humérus de taupe.

Patte antéricure.

tous ces os sont d'autant plus courts et plus larges que l'animal a besoin de mouvoir les membres avec plus de force; et, au contraire, deviennent longs et grêles lorsque la rapidité est le caractère essentiel du mouvement que celui-ci aura à exécuter. La taupe (fig. 182), qui se sert de ses membres antérieurs pour fouir la terre, et le chamois ou le chevrotain, qui étonnent par la légèreté et l'étendue de leurs bonds, peuvent servir d'exemples de ces deux genres de modifications.

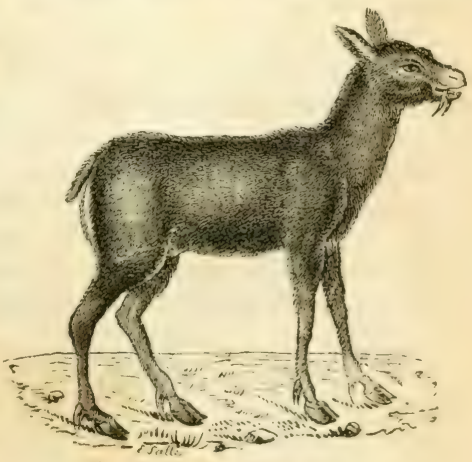

Fig. 184. Chentalain musc. 
Lorsque la main devient un organe de locomotion el non de préhension, le radius ne peut plus tourner sur le cubitus et finit par s'y souder si intimement qu'on ne peut plus l'en distinguer; il en est de mème pour le péroné, qui se confond avec le tibia chez les quadrupèdes à sabots.

La conformation de la main et du pied varie beaucoup dans celte classe d'animaux, suivant que les membres doivent servir à la marche, à la préhension, à la natation ou au vol : nous avons déjà fait comaitre ces modifications curieuses, et, par conséquent, il n'est pas nécessaire de nous y arrèter ici; nous ajouterons seulement que le nombre des doigrts ne dépasse jamais cinq et diminue d'autant plus que les quatre membres sont consacrés d'une manière plus exclusive à la marche.

$\$ 398$. Organes des sens. - Le degré de flexibilité des doigts et la nature de leurs mourements influent sur leurs usages, non-seulement comme organes de locomotion et de préhension, mais aussi comme instruments du sens du toucher. Lorsqu'ils ne peuvent embrasser les objets pour les palper, et que la main ne peut se mouler en quelque sorte sur leur forme, le tact doit ètre nécessairement très-imparfait; et ce qui tend à lémousser encore davantage, c'est lorsque l'ongle, au lieu de laisser à décourert la plus grande portion de l'extrémité du doignt, l'enveloppe en entier et prend la forme d'un sabot (fig. 83). Or la perfection plus ou moins grande de ce sens influe a son tour sur le dévoloppement de l'intelligence, et on peut dire avec vérité que, dans l’immense majorité des cas, sinon toujours, les facultés des mammiferes sont d'autant plus élevées que leurs membres sont mieux conformés pour saisir el pour palper.

$\$ 399$. Les organes des autres sens offrent, dans tous les animaux de cette classe, à peu pres le mème mode d'organisation que chez l'homme. Dans ceux qui sont remarquables par la finesse de leur odorat (et ce sont les carnassiers plus que tous les autres, le chien, par exemple) les fosses nasales et les sinus frontaux prennent un accroissement très-considérable, et les cornets qui font saillie dans l'intérieur de la cavité olfactive se développent beaucoup; dispositions dont l'utilité est facile à comprendre, car elles tendent toutes à donner à la membrane pituitaire, siége de ce sens, une surface plus étendue.

\$ 400. Le's yeux sont, en général, plus gros proportionnellement chez les mammiferes nocturnes que chez ceux qui cherchent leur nourriture en plein jour; ct chez les premiers la pupille, en se rétrécissant sous l'influence de la lumiere, au lien de conserver sa forme 
circulaire, prend ordinairement l'apparence d'une fente. Chez ceux qui sont condamnés, par leur vie souterraine, à une obscurité complete (les taupes, par exemple) les yeux deviennent extrèmement petits, et n'existent quelquefois qu'a l'état de vestiges; enfin, chez. les mammiferes qui vivent dans l'eau, le cristallin est plis sphérique que chez ceux qui vivent dans l'air : et cette disposition était nécessaire pour augmenter le pouroir réfringent de l'œil, qui, toutes choses égales d'ailleurs, a besoin de pouvoir rassembler les rayons de lumiere avec d'autant plus de force qu'il est place dans un milieu plus dense. On remarque aussi que, chez beaucoup de ces animaux, il existe au fond de l'œil, sur la choroüde, une tache colorée d'une manière très-viıe que l'on nomme tapis, mais on en ignore les usages. Plusieurs ont aussi une troisieme paupière trèsdéveloppée et placée rerticalement à l'angle interne des deux autres. Enfin la direction des yeus varie beaucoup : chez l'homme, ils sont dirigés presque directement en avant; mais à mesure que l'on descend dans la série des mammifères, vers ceux dont les facultés sont moins déreloppées, on vort ces organes devenir de plus en plus latéraux, au point que, chez plusieurs, la sphère de la vision est extrèmement différente pour chaque oil, et que l'animal ne peut voir directement devant lui.

\$ 401. L'appareil auditif présente aussi, chez les mammifères, quelques modifications qui paraissent ètre en rapport avec les mours de ces animaux. Chez ceux qui vivent dans l'eau ou sous la terre la conque auditive est, en général, très-petite on mème tout à fait rudimentaire, et, à mesure que l'on descend depuis l'homme jusqu'aux herbivores, on voit celte partie de l'oreille prendre de plus en plus la forme d'un cornet acoustique, se détacher de plus en plus de la tète, et devenir de plus en plus mobile. On remarque aussi que, dans les quadrupedes nocturnes, la membrane du tympan occupe en général plus d'espace et se trouve plus à fleur de tête que chez les diurnes.

$\$ 402$. Système nerveux. - Quant au systime nerveux, il ne differe chez les divers mammiferes que par le développement plus ou moins considérable de certaines de ses parties. Chez tous ces animaux, la masse nerveuse encéphalique est tres-considérable, soit proportionmellement au volume du corps, soit relativement is la grosseur des nerfs; mais tous les organes qui la composent ne concoment pas coralement a ce déreloppement : ainsi les hémisplocres creribraux sont tres-rolumineux, landis que les tuberenles op)ligues sont fort petits ou meme presque rudimentaires; el par la

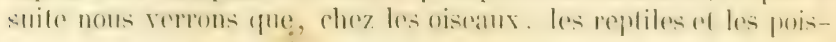


sons, il en est tout autrement. Le cervelet est de même assez. volumineux chez la plupart des mammifères; il se compose toujours d'un lobe médian (processus vermiculaire supérieur), de deux hémisphères qui ont la forme de feuillets séparés par des sillons transversaux, et d'une commissure qui entoure la moelle épinière en dessous et qu'on nomme la protubérance annulaire. Du reste, le développement de ces parties varie beaucoup chez les mammifères, non-seulement sous le rapport de leur volume, mais encore sous celui des sillons et des circonvolutions de leur surface. A mesure que l'on passe de l'homme aux singes, de ceux-ci aux carnassiers, et des carnassiers aux rongeurs et aux animaux herbivores, on voit en général le cerveau devenir de plus en plus petit et de plus en plus lisse. En général, la face se développe en sens contraire de l'encéphale et du crâne; de façon qu'on peut, jusqu'à un certain point, juger de la conformation de l'une par celle de l'autre, et apprécier d'une manière approximative, par la comparaison de ces deux parties de la tète, l'étendue des facultés intellectuelles et morales (voyez $\$ 342$ ).

Il est aussi à noter que, chez les mammifères de l'ordre des marsupiaux, le cerveau présente un autre genre d'imperfection résultant de l'absence ou de l'état rudimentaire du mésolobe ou corps calleux, qui, chez tous les autres animaux de la mème classe, unit entre eux les deux hémisphères centraux.

$\$$ 403. Fonctions de nutrition. - Les fonctions de nutrition s'exécutent chez tous les mammifères à peu près comme chez l'homme; aussi la structure des organes qui sont destinés à leur exercice ne varie-t-elle que fort peu dans cette grande classe d'animaux. C'est l'appareil digestif qui présente les différences les plus importantes.

Presque tous les mammifères sont pourvus de dents destinćes à diviser leurs alimẹts; mais, comme nous l'avons déjà vu ( $§ 53)$, le nombre et la forme de ces organes varient suivant le régime do l'animal. Quelquefois ces organes sont remplacés par des lames cornées qui, chez les baleines, constituent les fanons (fig. 13 et 14), et d'autres fois encore le museau se prolonge en une espèce de bec corné très-large, aplati et garni latéralement de lamelles transversales qui offrent la plus grande ressemblance avec le bec d'un canard, et gui a valu aux animaux chez lesquels il existe le nom d'ornithorinques.

$\$$ 404. La conformation de l'estomac varie beaucoup dans la classe des mammifères, et il résulte quelquefois de ces différences des particularités physiologiques d'une grande importanee. En gé- 
néral, cet organe est simple comme chez l'homme (fig. 24) et le singe (fig. 3); mais quelquefois il se compose d'une série nombreuse de poches distinctes, et dans ce cas il arrive ordinairement que les aliments, après avoir séjourné un certain temps dans une première cavité stomacale, remontent dans la bouche pour y subir une mastication plus complète avant que de passer dans les portions suivantes du tube digestif : phénomène que l'on désigne sous le nom de rumination.

Les estomacs des animaux qui ruminent (le mouton et le bœuf, par exemple) sont au nombre de quatre. Le premier, qui est le plus vaste de tous, se nomme panse, ou herbier (fig. 183). Sa sur-

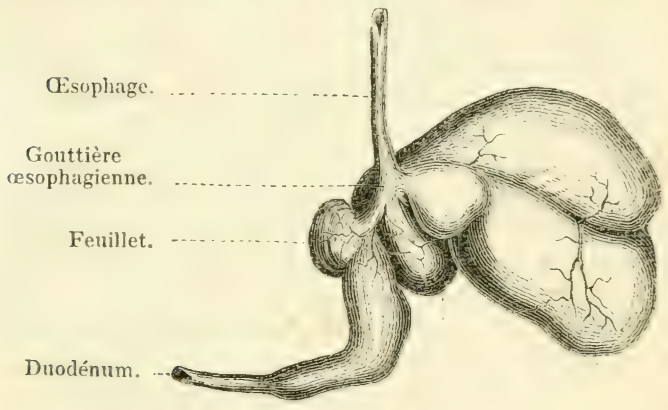

Pylore. Caillette. Bonnet. Panse.

Fig. 185. Estomac de mouton.

face interne est garnie de papilles, et revètue d'une couche épidermique (fig. 186); il occupe une grande partic de l'abdomen,

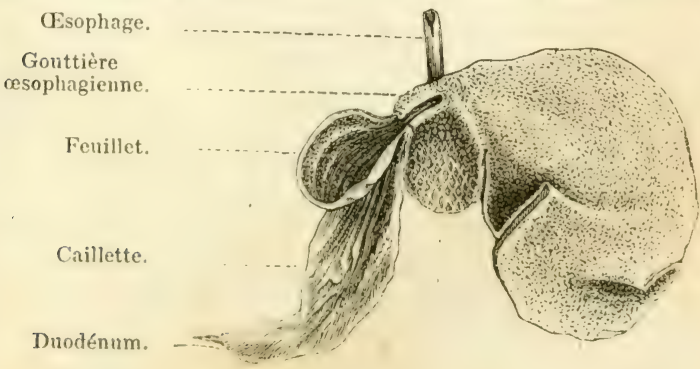

Pylore. Bonnet. Panse.

Fig. 186. Intérieur des estomacs du monen. 
particulierement du còté gauche. Le deuxième estomac, appelé le bonnet, est petit, et se trouve à droite de l'oesophage, et en avant de la panse, dont il ne semble, au premier coup) d'œil, ètre qu'un appendice. A l'intérieur la membrane muqueuse quil le tapisse forme une multitude de replis disposés de façon à constituer des mailles ou cellules polygones, semblables à des rayons d'abeilles. Le troisième estomac, qui est moins pelit que le bonnet, est placé à droite de la panse et a reçu le nom de feuillet, à cause des larges replis longitudinaux qui en garnissent l'intérieur, et qui ressemb) lent aux feuillets d'un livre. Enfin le quatrième estomac, qui est intermédiaire, pour le volume, entre la panse et le feuillet, se trouve à droile de cette dernière poche. Sa surface interne, irrégulièrement plissée, est continuellement humectée par un liquide acide, qui est le suc gastrique; et c'est à cause de la propriété que possède cette humeur de faire cailler le lait, qu'on donne à l'organe qui le renferme le nom de caillette. Les trois premiers estomacs communiquent directement arec l'osophage. Ce conduit s'ouvre d'abord presque également dans la panse et le bonnet, et se continue ensuite sous la forme d'une gouttiere ou demi-canal (fig. 182) qui longe la partie supérieure du bonnet, et aboutit au feuillet, lequel, à son tour, communique avec la caillette.

C'est dans la panse que les aliments, grossièrement divisés par une première mastication, s'accumulent, et ce n'est qu'après avoir été reportés dans la bouche et mâchés une seconde fois, ou en d'autres mots ruminés, qu'ils pénètrent dans le feuillet et de là dans le quatrième estomac, siéze de la véritable digestion,

Au premier abord, on s'étonne de voir les aliments pénétrer tantòt dans la panse, tantôt dans le feuillet, suivant que la déğlulition se fait pour la première fois on que ces substances ont cété déjà ruminćes, et on est tenté d'attribuer ce phénomène à une espèce de tact presque intelligent dont les ouvertures de ces diverses poches seraient douées; mais les expériences récentes de M. Flourens montrent que ce phénomène curieux est une conséquence nécessaire de la disposition anatomique des parties, et en donnent une explication aussi simple que satisfaisante.

Lorsque l'animal avale des aliments grossiers et d'un certain volume, comme ceux dont il se nourrit habituellement, ces substances, arrivées au point où l'œesophage se continue sous la forme d'une goutlière (voy. fig. 181), écartent mécaniquement les bords de ce demi-canal, transformé ordinairement en un tube par la contraction de ces paroi.;, et tombent dans les deux premiers estomacs placés au-dessous; mais lorsque l'animal avale des boissons 
cu des aliments atténués et demi-fluides, leur présence dans ce demi-canal ne détermine pas l'écartement de ses bords. Cette portion terminale de l'ossophage conserve par conséquent la forme d'un tube, et conduit les aliments en totalité ou en majeure partie dans le feuillet, où elle se termine. C'est par conséquent l'état d'ouverture ou d'occlusion de cette portion de l'ossophage, qui détermine l'entrée des aliments dans les deux premiers estomacs ou leur passage dans la troisième cavité digestive; et c'est l'aliment luimème qui décide de cet état, selon qu'il est assez volumineux ou non pour dilater l'cosophage, naturellement affaissé, ou pour couler dans la rigrole toujours ouverte par laquelle ce conduit mène vers le feuillet. Or, les aliments, lors de leur premiere dégrlutition, ne sont qu'imparfaitement divisés et consistent en fragments grossiers et assez volumineux; tandis qu'après avoir été ruminés, ils sont transformés en une pâte molle et demi-fluide : cette circonstance suffit par conséquent pour déterminer leur chute dans la panse ou leur passage dans le feuillet. Quant à l'espèce de régurgitation régulière par laquelle les aliments contenus dans la panse et le bonnet remontent dans la bouche pour ètre ruminés, elle est généralement attribuée à l'action du bonnet lui-mème, qui, dit-on, saisit une portion de la masse alimentaire, la comprime de manière à en former une sorte de pelote arrondie et la pousse dans l'œsophage, dont les contractions vermiculaires de bas en haut achèvent le phénomène; mais, d'après les nouvelles expériences du physiologiste que nous venons de citer, il paraitrait que la panse et le bonnet, en se contractant, poussent la masse alimentaire qu'ils contiennent entre les bords du demi-canal osophagien, lequel, en se contractant à son tour, en saisit une portion, la détache et en fait une pelote destinée à remonter le long de l'osophage.

La panse, avons-nous dit, est extrèmement grande; mais elle ne présente pas toujours les mèmes dimensions, et les changements qu'on y observe muntrent combien les organes des animaux peuvent être modifiés par les circonstanees où ils sont placés. En effet, pendant que les ruminants tettent et ne vivent que de lait, la panse est moins grande que la caillette, et elle ne prend son énorme volume quà mesure qu'elle recoit dans son intérieur de l'herbe, substance peu nourrissante et dont l'animal est par conséquent obligé de manger des masses considérables.

\$ 40:3. L'intestin, comme nous l'avons dejà dit, présente des différences très-considérables dans sa longrueur et dans son ampleur, suivant que les aliments qui doivent y pénétrer sont fournis par: le Regrno animal ou par le Regrne vécétal : ainsi, daus beatucoup de 
carnassiers, sa longueur n'est que d'environ trois ou quatre fois celle du corps, tandis que chez les herbivores elle est ordinairement de dix à douze fois et quelquefois de près de vingt-huit fois cette longueur (dans le mouton, par exemple). En général il se termine directement au dehors; mais quelquefois cependant il se rend dans une cavité nommée cloaque, où débouchent aussi les canaux urinaires : cette disposition se rencontre chez les ornithorinques, par exemple, et se retrouve encore dans la classe des oiseaux. Enfin les glandes salivaires, le foie, le pancréas, le péritoine et les autres annexes du canal digestif ressemblent presque toujours à ce que nous avons vu chez l'homme.

$\$ 406$. Il en est de mème de l'appareil de la circulation et de celui de la respiration. Le cœur présente partout quatre cavités bien distinctes, savoir: deux oreillettes et deux ventricules (voy. \$107, fig. 30, 31); toujours les poumons renferment aussi un nombre immense de tres-petites cellules et ne laissent point passer l'air de leur intérieur dans les différentes parties du corps, ainsi que cela se voit chez les oiseaux.

Il est aussi à noter que dans cette classe d'animaux le sang est toujours très-riche en matières organisées et que ses globules sont presque toujours de forme circulaire (voy. \$ 81 , fig. 27).

$\S 407$. Les mammiferes sont de tous les animaux ceux qui se rapprochent le plus de l'homme sous le rapport intellectuel. Mais, à cet égard, ils présentent entre eux les différences les plus grandes; nous avons déjà eu l'occasion de le montrer ( $\$ 337$ ), et, si l'espace ne nous manquait ici, il nous serait facile de multiplier la preuve de cette inégalité. L'étude des mœurs des mammifères nous fournirait aussi des exemples curieux des divers genres d'instincts donnés à ces ètres par la nature pour suppléer au défaut de facultés plus élevées; mais l'étude de ces instincts nous a déjà occupés, et par conséquent nous pouvons nous dispenser d'y revenir en ce moment.

La classe des mammifères est aussi de toutes les divisions du Règne animal celle qui nous intéresse le plus par les services qu'elle rend à l'homme lui-mème. En effet, c'est à elle qu'appartiennent presque tous nos animaux domestiques : le chien, le cheval, le mouton et le bouf, par exemple, et chacun sait combien leur conquête nous a été utile. Notre domination sur ces ètres est devenue si complete que l'espèce primitive, vivant à l'état sauvage, a presque toujours disparu de la surface du globe, et par la domesticité nous sommes parvenus à exercer une influence considérable jusque sur les formes physiques et sur les qualités morales des individus 
yui naissent des races ainsi subjuguées. Les différences qui caractérisent les diverses variélés de nos chiens domestiques, par exemple, sont immenses, et cependant tout porte à penser que c'est notre influence qui les a déterminés, et que ces variétés proviennent d'une souche commune, qui ne serail ni le loup ni le chatcal, mais un chien peu différent de notre chien-loup ou de notre chien de berger.

Mais par quelle puissance pouvons-nous subjuguer ainsi des animaux, et comment, par la domesticité, pourons-nous en modifier les formes et les qualités?

L'instinct de ces ètres les porte à fuir tout ce qui leur inspire de la défiance : ce n'est donc point par la violence que nous pourrions disposer un animal sauvage a l'obéissance. Il ne serait pas naturellement porté à se rapprocher de nous qui ne sommes pas de son espèce, et, au premier sentiment de crainte que nous lui ferions éprouver, il nous fuirait s’il était libre, ou nous prendrait en aversion s'il était captif. Ce n'est qu'en lui inspirant de la confiance que nous pouvons l'attirer et le rendre familier. et ce n'est que par les bienfaits que nous pourons faire naitre cette confiance.

Satisfaire les besoins naturels des animaus est l'un des premiers moyens à employer pour amener leur soumission. L'habitude de receroir leur nourriture de notre main, en les familiarisant avec nous, nous les attache; et, comme l'étendue d'un bienfait est toujours en proportion des besoins qu'on en éprouve, leur reconnaissance est d'autant plus vive et plus profonde, que la nourriture que nous leur donnons leur est derenue plus nécessaire : anssi la faim est-elle entre nos mains un levier puissant pour ployer a la captivité tous les animaux; car, en mème temps qu'clle fait naitre des sentiments affectueux, elle produit un affaiblissement physique, qui, en réagissant sur la volonté, l'affaiblit à son tour. Si l'on ajoute à l'influence de la faim celle d'une nourribure choisie, et surtout, si, par des aliments que la nature ne leur fournissait pas, on parrient a flatter beancoup le gout des animaux, on excite en eux une recomaissance bien plus grande encore, et on développe d'une maniere artificielle des besoins nonveaux que l'homme seul perut sultisaire (1); entin, à ces moyens de captation on peut joindre ansi les caresses, dont lönfluence sur certains animaus est extrème.

1. ("est principalement au moyen de suere et d'autres friandieses que lon parvient a ilresser les cheraux, les corls, ete., aux exercices estrandunates dent 11. cirques nous rendent quelquefois les témoins. 


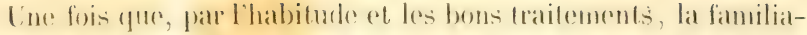
rife est établie et la contiance oblenue, l'homme peut faire sentir son allorite of appliquer des chatiments, aldin de transformer les sentiments dont il veut réprimer la manifestation en relui de la

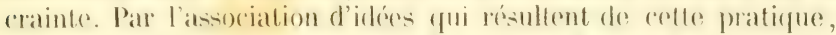

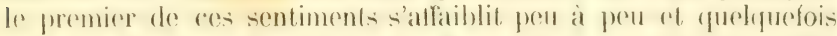
mene finit par se détruire juscpue dams son greme; mas l'omploi de la foree ne doit jamais cotre satms limites: an les chatiments

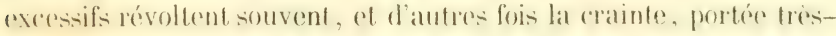
loin, trouble toutes les facultés. Ia veille foreée est aussi un puissant moven d'affaiblir la volonté d'un animal et de le disposese a lobésisanere; car il ne sait pas rapporter la fatigne ot le malaise quil en éprouve a colui qui en est rexllement la cause, at, dans cot élat, les sentiments affereluenx oceasionnes par les bienfail-

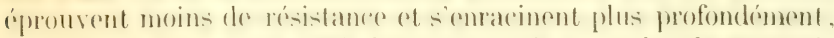
tamdis que, d'un andre cote, la crainte arit avee plus de promptitude et de force.

Cost, romme on le voit, far les besoins sur lespuels nous pouvons exereer yuelygue influence, ol en réprimant la manifestation de cortanins sentiments par le développement de quelpues autres, yur nous parrenons a apprivoiser les amimanx; mais tous les mam-

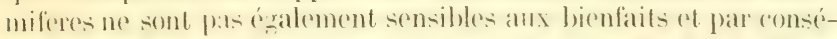
quent ne se latisent subjugner ni aver la mène facilité ni d'une maniere ansi complefe; sourent leurs passions sont trop riolentes jour you lamimal parvienme jamais a les matriser ot a devenir docile pour son maitre. Souvent aussi leur détianee naturelle est

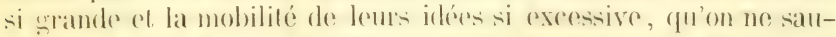
latit leur imposer aucune regle de conduite, et d'autres fois encore

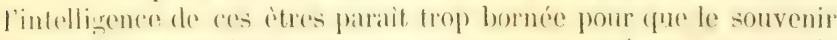
du bien-elre persiste apres yue sa callse a cessó, of pour yu'ils atsogenent dans leur mémoire le bienfait et le bienfaiteur.

Par ces moyersis on parvient a dompter plus ou moins complétr-

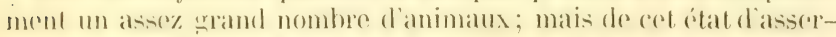
visioment individued a la dorilité complote et héréditaire, que la

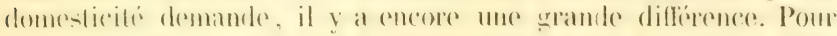

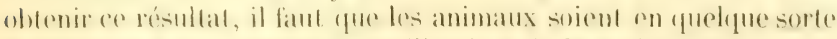

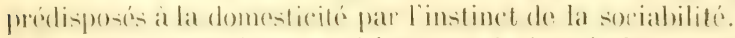

lin effet, lo sentiment qui les porte a vive isolés et mome as se

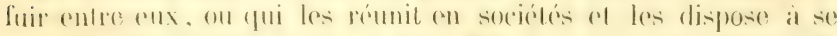

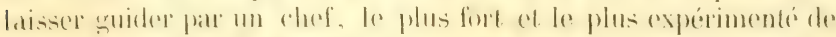

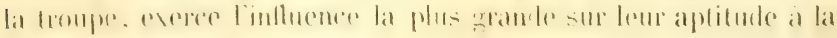
rlomesticité 
Aueun mammifere solitaire. equelque facile yu il soit a apprivoiser, nest devenu romplétement domestique (1): landis yure prespue tous les animamx dont lat race est sommise a lempire de lhomme vivent naturellement en troupes flus ou moins nomhreuses. La sociabilite est une condition de la domestieite. ef cest en développant a notre profit, on dirigeant vers nous par nos bienfaits le penchant qui prortait ers animbux at se rémir entrre eux ques l'homme est parvenu a lier lene esistence a la sienne ol a prendre sur eux l'autorité qu'aurait eue le chef de la troupe dont ils auraient fait partie s'ils avaient véen dans leblat de nature.

Comme l’a tres-bien démontré un habile zoolouriste. Frédérie Cuvier, la disposition a la domesticite peut dere considérécemme le développement extreme de l’mstinet de la sociabilite. el la domesticiti elle-mème comme un ritat dans leguel les animanx sociables reconnaisedent thomme comme membre of comme chef de lowe troupe.

S io8. Nous eomprenons maintenart romment lhomme peut soutmette a som empire des races entieres d'animaux. Voyons comment il peut ensuite influer sur les formes ef les qualités yu ils apportent arec eux en naissant, ot créer, pour ansi dire, à son crice, des vatriétés nouvelles.

Ene loi physiologique, généralement reconmue, "st relte tendance qu ont les animaux a resisembler à leurs parents non-sentement deune maniere grencerale. mais aussi par des particularilés qui peurent distinguer eses derniers. Dans lespece humaine, par exemple, les influenees héreditaires se manifestent dams une foule de circonstances : conformation, facultes, calrateferes, inlirmiles mème, se lixpuent de grénération en géneration, et pour les animan rhez lespuels moins de circonstances chamgeres viennent agrir sur les individus et oceasionner des perturbations daus celte repelition des mèmes formos ol des mèmes qualités, la tentame des petits a ressembler aux auteurs de leurs jours est encore plus é idente. ()r. tous les individus deune mème espece ne possedent pas au meme degré les qualités physiques, morales el intellectuelles, dont chatem deux est done, el par lexereiee ou par linfluenee des conditions physiques nous pourous, en lexereant, dérelopper telle ou telle

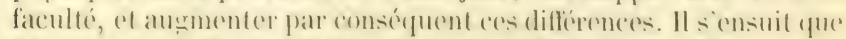
thomme peut, dans certaines limites. moditier a volonti les raters:

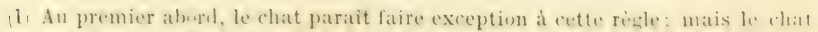
nest pas dans la realite un animal soumis a lempire de l'hemme : il vit dans mes habitations parce quil y troure mieux quailleurs a satislaire ses hesuins : mais il ne nous obéit pas et n'est guère susceptible d'éducation. 
car il est maitre de choisir ou mème de produire des différences individuelles transmissibles par hèrédité et de régler la succession des générations, de façon à en écarter tout ce qui tendrait à éloigner la race du type qu'il reut produire, et il peut aussi agir sur les qualités héréditaires des petits, comme il l'a fait sur celles de leurs parents. Il en résulte qu'à chaque génération nouvelle, il fait un pas de plus vers le but qu'il s'était proposé; car il agit sur des individus déjà modifiés par suite de modifications imprimées à leurs parents $(1)$.

En s’attachant a développer, de génération en génération, telle qualité ou telle particularité physique, nous pouvons done la porter bien plus loin quil ne nous aurait été possible de le faire dans le principe, et nous pouvons créer des racies artificielles, dont les caractères ne s'effaceront que lorsque des circonstances opposées à celles qui ont déterminé ces particularités viennent en détruire l'effet.

C'est aussi ce que nous faisons lorsqu'un intérèt puissant donne de la persévérance à nos efforts, et c'est de la sorte que de nos jours on a produit des races de moutons, de bœufs et de chevaux, caractérisées par des particularités des plus remarquables. Ainsi on avait. remarqué que les moutons qui présentent certaines particularités de onformation s'engraissent beaucoup plus facilement que d'autres, et un des hommes qui ont rendu le plus de services à l'agriculture anglaise, Bakewell, en ayant soin de croiser des moutons chez lesquels ces caractères extérieurs se voyaient a un haut degré, est. parvenu à créer une race des plus précienses sous ce rapport. Le poids des quatre quartiers de la careasse des grands moutons de la race wurtembergeoise, que l'on élère dans quelques-unes de nos provinces, comme étant particulièrement propres à fournir la viande

(1) Les limiers, qui ont été transportés en Amérique par les Espagnols, et qui n'étaient empluyés autrefois qu'à chasser le cerf ou l'homme, fournissent une preuve bien remarquable de l'influence de l'éducation individuelle sur les qualités héréditaires. Dans diverses parties de l'Amérique, sur le plateau de Santa-Fé, par exemple, ces chiens ont conservé les habitudes et les dispositions instinctives qui les rendaient jadis célebres; mais chez les pauvres habitants des bords de la Madelaine ils se sont abâtardis, en partie par le mélange, en partie par le défaut d'une nourriture suffisante, et chez cette race dégénérée un nouvel instinct semble devenir héréditaire. La chasse à laquelle on emploie depuis long-temps presque exclusivement ces animaux est celle du pécari à mâchoire blanche. L'adresse du chien consiste à modérer son ardeur, à ne s'attacher à aucun animal en particulier, mais à tenir toute la troupe en échec; or, parmi ces chiens, on en voit maintenant qui, la première fois qu'on les mène au bois, savent déjà comment attaquer, tandis q̧u'un chien d'une autre espèce se lance tout d'abord, est environné, et, quelle que soit sa force, est dévoré dans un instant. 
de boucherie, est de cinquante-deux à cinquante-cinq pour cent du poids total de l'animal; tandis que, dans les moutons anglais de la race de Dishley ou $\mathbf{N} e u$-Leicester, cette proportion s'élève à soixante-dix ou mème à soixante-quinze. Nos agriculteurs sarent aussi combien la finesse des laines s'accroit par des soins analogrues, et combien, sous ce rapport, nos troupeaux de moutons indigènes ont été améliorés par leur mélangre arec les mérinos de l'Espagne (1).

Enfin, les diverses races de chevaux, qui nous intéressent également à un si haut degré, sont aussi une preuve de l'influence de l'homme sur les animaux virant sous son empire. Les chevaux que l'on élève dans nos établissements agricoles doivent en partie leur taille, leurs formes et leurs qualités à la race dont ils descendent; mais les circonstances où ils sont placés pendant le jeune àge exercent sur eux, à la longue, une influence non moins grande. On remarque qu'en général le poulain tient de sa mère plus que de son père pour la taille et le volume; tandis que, pour la forme de la tète, les pieds, le courage, la légèreté, etc., il ressemble davantage au dernier. Du reste, les défauts, comme les qualités, se transmettent de génération en génération, et, pour maintenir une race dans sa pureté ou pour l'améliorer, il faut avoir soin d'en écarter tous les individus qui ne possèdent pas les qualités que l'on désire obtenir. Pour faire disparaitre un défaut, on croise pendant plusieurs générations des individus de crtte race défectueuse arec d'autres ayant une disposition opposée, et en appareillant avec persévérance les chevaux qui possèdent telle ou telle perfection, on crée une race où elle devient héréditaire et quénérale. C'est en qrande partie à des soins de cette nature que les cheraux arabes doivent leur célébrité si bien méritée. Les Arabes attachent une telle importance à la pureté de la race de leurs chevaux nobles, appelés kochlani, que leur filiation est toujours constatéc par des actes authentiques : ils font remonter à près de deux mille ans la généaloşie connue de plusieurs de ces beaux animaux, et il en est dont la lignée peut. ètre démontrée par des preuves écrites pendant une série de quatre siecles. D'un autre coté, linfluence des croisements de race est également bien démontrée par des chevaux de course anglais; car c'est au mélange des juments indig̣enes avec des étalons apportés de l'Orient qu'on doit la création de cette race, si remarquable par la finesse de ses formes of son étonnante rapidité. L'abondance plus

1) Cefut en 1776 que lintendant des finances Daniel Trudaine teuta l'introduction des merinos en France, et c'est a Daubenton, Ir collahorateur de Bufiom, que l'on doit principale:nent le succès de cette tentatire. 
011 moins grande et la qualité de la nourriture, la sécheresse ou l'humidité du pays, les soins journaliers et mème une foule de circonstances en apparence peu importantes, exercent aussi une influence puissante sur la taille, les formes et les qualités des chevaux. Pour en donner la preuve, nous pourrions montrer avec quelle rapidité dégénent les plus beaux chevaux anglais dans certaines localités, telles que le haras de Kopschan, sur les bords de la Morave; mais, sans aller si loin, nous trouverons des exemples encore plus frappants de la puissance modificatrice des circonstances extérieures. Si de deux poulains nés de la mème race, en Lorraine, par exemple, liun est transporté dans la Flandre et l'autre dans les herbages de la Normandie, au lieu de conserver les mèmes caracteres, ils seront, a làge de ciny ans, presquie aussi différents entre Pux que s ils provenaient de deux races distinctes : l'un deviendra un cheval de carrosse léger et élégant, l'autre un animal énorme presque incapable d'aller au trot, mais constitué pour trainer lentement lesplus lourdes charges. Là où la nourriture est abondante et où, par la préroyance de l'homme, elle ne manque en ancune saison. les cheraux sont ordinairement grands et étoffés, tandis que, dans les contrées ou elle est peu abondante. mème pendant une partie de l’année seulement, ces animaux n'acquierent qu'une taille petite ou médiocre. Les phrsiologristes ont constaté quelque chose de semblable en étudiant les ínis de la croissance de l'homme, et, pour nous convaincre de la vérité de cette observation, relativement aux chevaux, il suffit de comparer ceux yui, dans un mème pays, appartiennent a de paurres cultirateurs ou a de riches propriétaires. Le paturage dans les prairies grasses et humides, celles qui conviennent le mieux pour l'engrais des bestiaux, tend à donner aux chevaux des formes lourdes et empàtées, à rendre leur peau épaisse et leur poil srossier, et à diminuer la vivacité de leur caractère. La nourriture fournie par les prairies seches n'occasionne rien de semblable, ot. lorsfuion la rend encore plus substantielle par l'arldition d'une proportion considérable de graines céréales, elle devient. éminemment propre à conserver, et mème à produire l'élégance des formes ef l'encrup musculaire caractéristique d'une race noble. Lorsfu'une température un peu basse vient ajouter son influence a celle de l'humidité et d'une nomriture abondante et aqueuse, les chevaux acquierent la taille la plus forte, mais deviennent en mème temps le moins énergiques et le plus lymphatiques. Dans les pays tres-chauds ou tres-froids, an contraire, la crossanee s'arrète plus lot, et les grandes races ne tardent pas a perdre leur haute stature. Entin, les soms jonmaliers que lon prodigne a certains chevaus, 
et qui manquent complétement à d'autres, ont aussi leur influener sur la beauté de ces animaux : ainsi, le bouchonnement fréquent, l'usarge desconvertures, la précaution de nettoyer et de sécher les extrémités, el mème de les entourer de bandes de flanelle, sont des circonstances qui ne laissent pas que de contribuer puissamment a donner aux chevaux anglais la netteté que l'on remarque dans la partie inférieure de leurs jambes, et à rendre leur peau et leurs poils d'une si grande finesse.

Linsi, en modifiant les circonstances dans lesquelles un animal est placé, on imprime à son organisation certaines modifications; pt en nemployant à la propagation de la race que des individus ainsi modifiés, l'homme parvient à donner à toute cette race un caractère particulier el des qualités qu'elle n'avait pas dans le principe. C'est probablement de la sorte qu'il a obtenu les races variées des chiens dont les formes sont si variées quau premier abord on a peine à croire qu'ils appartiennent à une seule et mème espèce. Mais, du reste, cette puissance modificatrice a toujours des limites assez ctroites, et elle n'efface jamais le cachet distinctif de l'espece zoologique.

$\$$ 409. Classification des mammifères. - Il existe, comme nuus avons vu, des différences considérables parmi les mammiféres, et ces morlifications de structure servent de bases pour la division de cette classe en groupes d'un rang inférieur nommés ordres. La plupart de ces groupes sont si nettement séparés de tout ce qui les entoure qu'on ne peut aroir de doute sur leurs limites, et que tous les zoologistes s'aceordent à les admettre comme formant autant de divisions naturelles; mais, dans d'autres, le type principal se morlifie tellement qu'il se fait un passigne presque insensible des uns aux autres, ef que la ligne de démarcation devient très-difficile a établir. Tel mammifere, par exemple, a tout autant d'analogie aver le type qui représente l'ordre des quadrumanes qu'arec celui des identés, et on peut, avec presque autant de raison, le placer dans l'une ou l'autre de ces divisions. Les différences fuion rencontre dans ces síries d'animaus plus on moins dissemblables ont aussi paru à quelques naturalistes plus importantes qu'a d'autres. of les ont portés à répartir ces rotres dans un nombre d'ordres plus considerable : aussi les auteurs n'adoptentjls pas tous les mènes bases pour la classifieation des mammiferess ef nesont-ils pas d'aceord sur le mode le plus naturel de les distribuer.

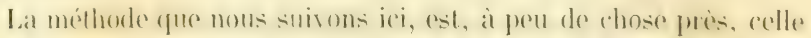
de curier. Elle repose principalenent sur les differences que les 
mammifères présentent dans leur mode de déreloppement et dans la conformation de leurs membres et de leur appareil de manducation, parties dont les modifications entrainent toujours avec elles une foule d'autres différences dans la structure de diverses parties du corps, dans les mours, et mème dans l'intelligence.

$\$$ 410. En ayant égard à l'ensemble de ces caracteres, on est conduit à diviser d'abord la classe des mammifères en deux groupes désignés sous les noms de monodelphiens et de didelphiens

Les Manufires noxodelpuexs sont les plus nombrenx et se distirguent principalement par leur mode de développement; ils ne viennent au monde que lorsqu'ils sont déjà pourvus de tous leurs organes, et avant la naissance ils tirent leur nourriture d'un lacis de vaisseaux sanguins nommés placenta. Il est aussi à noter que leur cerveau est plus parfait que chez les didelphiens, ses deux hémisphères étant liés erıtre eux par une large commissure nommée mésolobe ou corps calleux (\$ 186); enfin les parois de l'abdomen ne sont jamais soutenues par des branches osseuses fixées sur le bord du bassin, comme nous le verrons dans la seconde grande division de cette classe. Les mammifères organisés de la sorte diffèrent beaucoup entre eux par la conformation générale de leur corps et se divisent pour cette raison ('n deux groupes secondaires : les mammifères ordinaires et les mammifères pisciformes.

$\$ 411$. Les MuMmfenes ondixares sont conformés pour vivre plus ou moins complétement à terre el sont tous pourvus de quatre membres; leur peau est garnie de poils, et leur corps ne se termine jamais par une nageoire semblable à celle des poissons. Ces animaux se divisent à leur tour en dix ordres : les bimanes, les quadrumanes, les carnassiers, les amphibies, les chéiropteres, les insectivores, les rongeurs, les édentés, les pachydermes et les ruminants. Les huit premiers de ces groupes sont pourvus de doigts flexibles dont l'extrémité n'est garnie d'une lame cornée que du còté dorsal et conserve en dessous la mollesse et la sensibilité nécessaire à l'exercice du toucher; on les désigne pour cette raison sous le nom de mammifères onguiculés ou a petits on rles, tandis yue les pachydermes et les ruminants, dont l'extrémité du doigt est entouré par un sabot. sont appelés des main mifères ongulés.

$\$$ 412. L'ondne des nIuAves est principalement caractérisé par l'appropriation des membres antéricurs et postérieurs à des usages essentiellement distincts. Les membres postérieurs sont destinés, comme d'ordinaire, à soutenir et à mouvoir le corps, tandis que les membres antérieurs ne servent plus à la locomotion et agissent romme instruments de préhension ef de toucher; aussi, non-sen- 
lement les doigts qui les terminent sont longs, flexibles et soutenus à l'extrémité par un ongle aplati, mais encore l'un de ces appendices, le pouce, est disposé de façon à pouvoir s'opposer aux autres et à constituer avec eux une sorte de pince sensible, disposition qui n'existe pas aux membres postérieurs. Liexistence de mains aux membres antérieurs seulement, suffirait pour distinguer les bimanes de tous les autres mammiferes ordinaires; mais ce caractère coïncide avec plusieurs autres particularités de structure dont l'importance physiologique est également très-grande. Ainsi le corps est organisé pour se mouvoir dans une position verticale; l'appareil masticateur est composé de trois sortes de dents $(\$ 52)$ et indique par sa conformation que ces ètres sont des frugivores; enfin le cerveau est plus développé et plus parfait que chez aucun autre animal.

Ce mole d'orwanisation ne se rencontre que chez un seul mammifère, l'nonue. L'ordre des bimanes ne se compose, par conséquent, que d'une seule espèce qui, du reste, se distingue des autres animaux par ses facultés intellectuelles encore plus que par les caractères anatomiques dont il vient d'ètre question.

Les hommes, tout en se ressemblant entre eux par les caractères essentiels de leur organisation, présentent des variations assez grandes dans la couleur de leur peau, dans les traits de leur visage et dans les proportions de diverses parties de leur corps, et. c'est pour exprimer ces différences que les naturalistes divisent l'espèce humaine en plusieurs variétés, dont les plus remarquable's sont la variété caucasique ou blanche, la variété mongolique on jaune, et la variété éthiopique ou nègre.

La variété caucasique se distingue par la beauté de l'ovale que forme sa tìte, par le développement de sont front, la direction horizontale de ses yeux, le peu de saillie de ses pommettes et la teinte de sa peati: elle est remar(uable aussi par sa perfectibilité, car c'est elle qui a donné naissance à tous les peuples les plus civilisés de la terre. El'́c oceupe l'Europe, l'Asie occidentale et la partie la plus septentrionale de l'Afrique.

Dans la variété mongolique, la face est aplatie, le front bas et oblique, les pommettes saillantes, les yeux étroits et obliques, el la peau olivatre. Les Chinois, les Japonais, les habitants des iles Philippines, Mariamnes ef Carolines appartiennent a cette race.

La variété éthiopique on ne sre se fait remarquer par la couleur noire de la peau, la saillie de la bouche, linclinaison de la limne faciale, les cheveux crépus, etc. Elle peuple la plus grande partic de l'Afrique centrale et méridionale. 
Les indigenes de l'Amérique ne paraissent appartenir à aucune des rariétés dont nous venons de parler, et dowent probablement. appartenir a une quatrieme division de l'espece humaine.

4.13. L'ondre des Qcidruanes se compose des mammifères ordinaires (qui ont le pouce opposable aux membres abdominaux aussi bien qu'aux membres̉ thoraciques, et qui emploient tous ces organes aux doubles fonctions de la locomotion et du toucher. De meme que les bimanes, ces animaux sont frugivores, et leur appareil dentaire se compose dincisires, de canines ef de molaires.

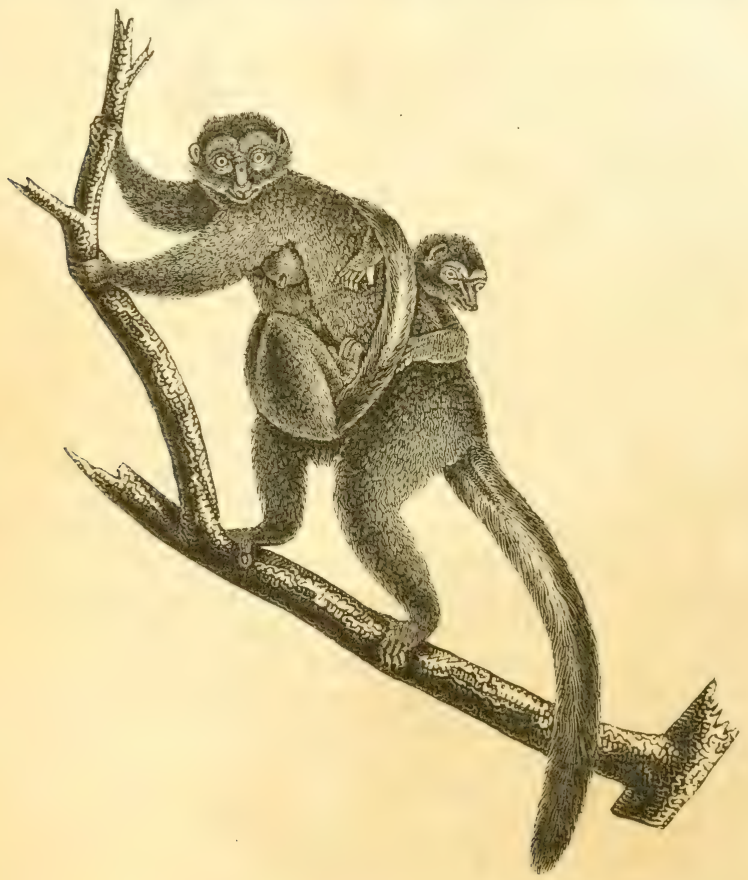

Fig. 187. Mraki ì fronl blanc arec son petil.

On range dans ce groupe les singes (fig. 91 et 113 ), les ouistitis (fig. 4), et les makis (fig. 187).

\$ 41\%. L'onda: des carissiens se compose également de mammiferes ordinaires onguiculés, qui sont pourvus d'un appareil 
dentaire complet; mais chez ces animaus, le pouce niest pas op posible anx autres doights, et par conséquent il n'y a pas de main: les quatre membres sont conformés pour la marche, et l'ap-

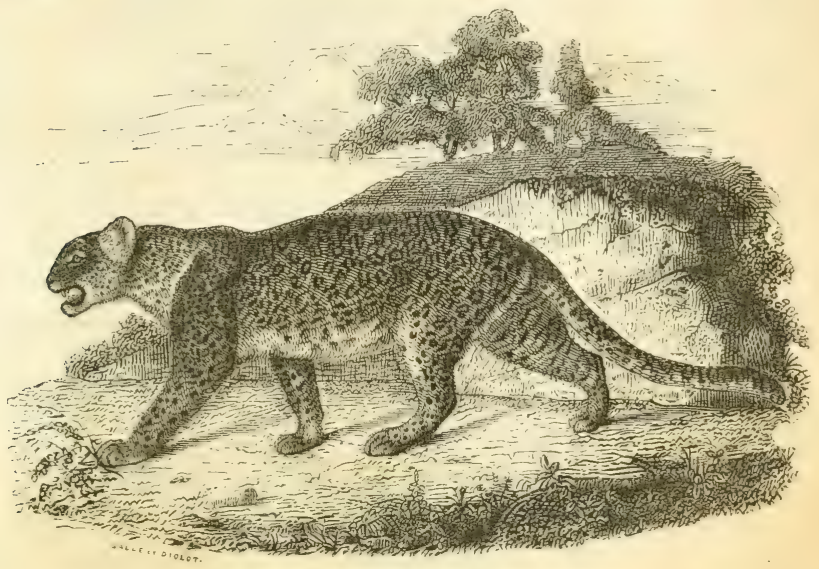

Fig. 188. Panthire.

pareil digestif est adapté a un rérime essentiellement carnassier; ainsi les dents molaires, par exemple, au lieu d'etre larges et bosselées comme dans les ordres précédents, s'élevent en forme de crète tranchante et se rencontrant comme des lames de ciseaux, sont admirablement bien disposées pour couper de la chair (fig. 17).

Nous citerons comme exemple de ce groupe le genre chat qui comprend le lion, le tigre, le léopard, etc., le genre chien dans lequel on range le loup et

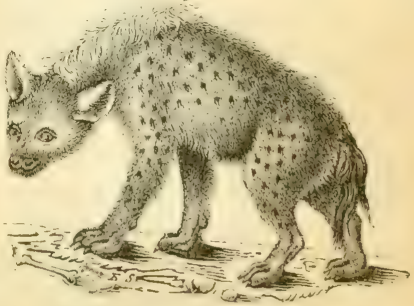

Fig. 189. Hyìne.

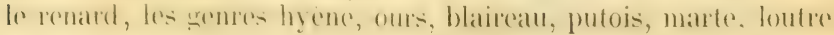
et genette.

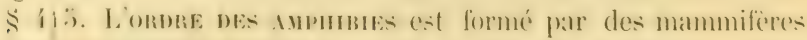

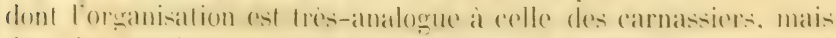
doml les memberese sont pat properes a lat marehe of remstituent

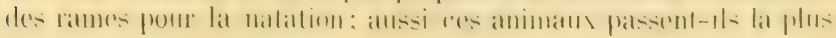


grande partie de leur vie dans l'eau. Les phoques et les morses appartiennent à cette division.

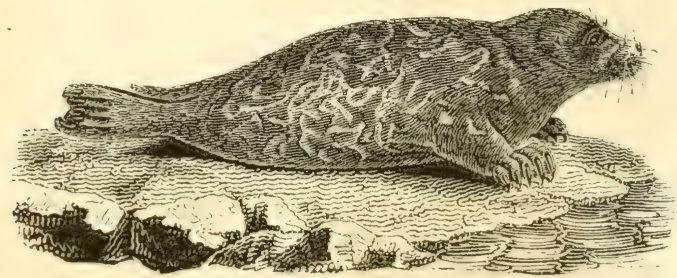

Fig 190. Phoque.

416. Londre oes chérnoptèns se lie dune manière étroite à celui des quadrumanes, mais il est caractérisé par une modification

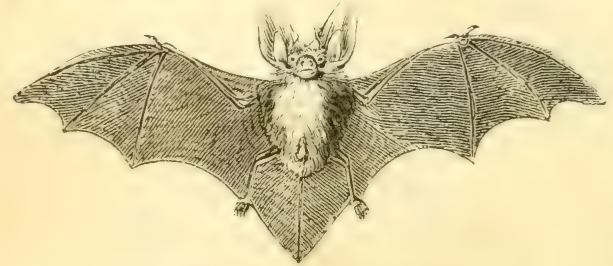

Fig. 191. Chauve-Souris Oreillard.

smoguliere des membres antérieurs, ces organes étant transformés en ailes, a l'airle d'un srand repli de la peau des flanes qui s'étend jusqu'aux doigts. Il est aussi à noter que, chez ces animaux, le cerveatu est bien moins développé que dans les groupes précédents et que le systeme dentaire se compose encore de canines et

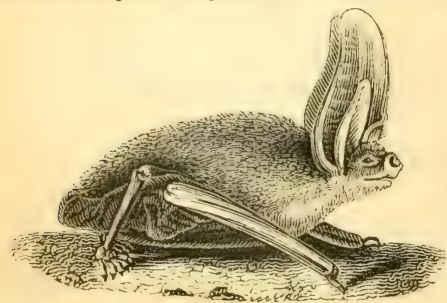

Fig. 192. Oreillard (marchint ì terrei. d'incisives aussi bien que de molaires. Les uns sont frugivores, les autres sunt insectivores, et dans le premier cas leurs molaires sont semblables à celles des quadrumanes, tandis que dans ceux qui vivent d'insectes, ces organes sont conformés de la mème manière que dans l'ordre suivant. Les chanves-sourio sont les représentants primeipans de ce groupe. 
$\$ 417$. L'ondre des INsectivones se compose encore de mammifères ordinaires de la division des onguiculés, dont les quatre membres, conformés pour la marche, ne se terminent point par une main, et dont la bouche est armée de trois sortes de dents; mais ici les molaires, au lieu d'ètre tranchantes comme chez les carnassiers, sont hérissées de pointes coniques (fig. 18), ce qui les rend propres à saisir et à écraser les insectes destinés à servir d'aliments à ces animaux. Leur cerveau ressemble beaucoup à celui des chéiroptères et n'offre pas de circonvolutions comme chez les bimanes, les quadrumanes, les carnassiers, les amphibies. La plupart des insectivores vivent plus ou moins complétement sous terre et s'engourdissent en hiver. Nous cite-

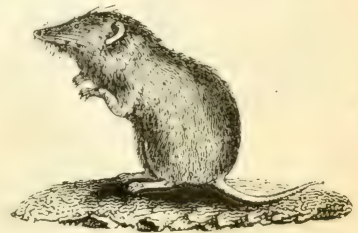

Fig. 193. Musaraigne. rons comme exemples de ce groupe la taupe (fig. 18\%), le hérisson, le desman (fig. 178) et la musaraigne (fig. 193).

$\$ 448$. L'OndRE DEs Roxgecrs comprend les mamnuferes ordinaires onguiculés, dont la bouche est armée de fortes incisives et de molaires, mais manque de canines. La disposition de ces dents les rend propres à ronger des substances végétales très-dures, telles que des écorces et des racines, et le régime de ces animaux se compose principalement de ces matières. Le cerveau des rongeurs ressemble beaucoup à relui des insectivores et leur intelligence est trèsbornée, matis plusieurs sont doués de

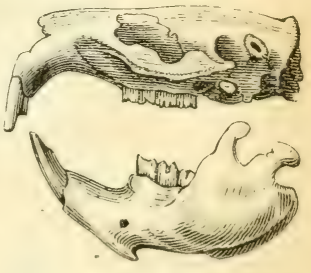

Fig. 194. Téle d'un rongeur. facultes instinctives tres-remarquables. Les écureuils (fig. 98),

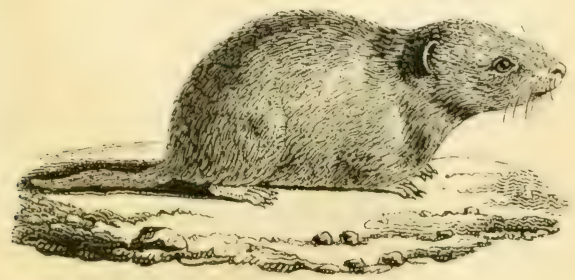

Fig. 195. Cumpugnol ordinaire. 
les marmoltes, les rats. les hamstus (fig. 99), les campagnols (fig. 193̈), les lières, les castors (fig. 108), les pores-épıcs (fig. 170), et plusieurs autres animaux conformés d'après le mème plan général, prennent place dans cette division.

\$ 19 . L'ORDRE DEs ÉnETtís semble établir le passace entre

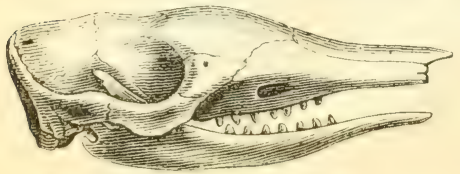

Fig. 196. Tête de Tatou.

les mammifères onguiculés et lẹs ongulés, car leurs ongles prennent un grand développement et enveloppent en grande partie l'extrémité des doigts; mais ce qui les caractérise surtout est l'absence de dents sur le devant de la bouche (fig. 196). L'appareil masticateur ne se compose que des molaires et des canines, et quel-

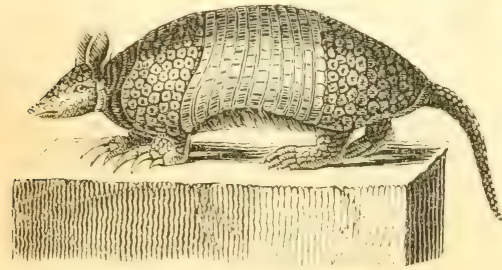

Fig, 197. Le Talou cabrissou.

quefois même manque complétement ( fig. 22); aussi les édentés se nourrissent - ils principalement d'insectes mous ou de feuilles faciles à arracher. Nous citerons comme exemples de ce groupe les tatous, les pangolins et les fourmiliers.

$\$$ 420. Londre des pAcHIDERues apparient à la division des mammiferes à sabots, et se coninpose de tous les ongulés dont l'appareil digestif est conformé de la maniere ordinaire et n'est pas disposé pour la rumination. Ces animaux sont remarquables par l'épaisseur de leur peau; leur cerveau présente des circonvolutions nombreuses a peu pres comme chez les carnassiers, et ils sont tous plus ou moins completement herhivores. Les uns ont le nez prolongé en une longue trompe préhensile, et sont nommés jour cette raison les proboscidiens; les éléphants (fig. 176) sont dans ce cas. I'autres pachydermes se distinguent par la conformation de leurs pieds qui ne sont pas divisés au bout et se terminent par un doigt mingue garni diun seul sabot; ce sont les diverses especes du grenre cheval telles que le cheval proprement dit, l'àne et le zebre qui offrent ce caractere et il leur a valu le nom commun de solipedes. Entin les pachydermes ordinaires ont les pieds terminés par des doigls dont le nomber dare de 2 a 4 : le sanglier, le tapir. 
le rhinocéros (fig. 173), l'hippopotame (fig. 199) appartiennent it ce groupe.

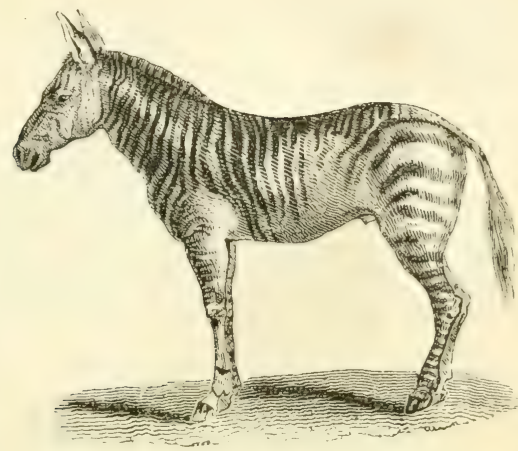

Fig. 198. Zilire.

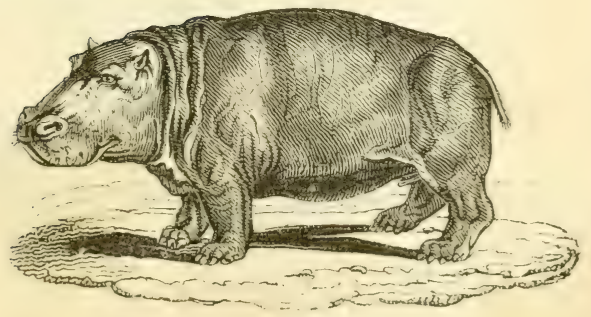

Fig. 199. Hippopotame.

\$ 121. Londue bes rimisars se distingue non-seulement des autres mammiferes ongulés parhỵlermes, mais encore de fous les groupes précédents, par l'existence de puatre estomac's disposés pour la rumination (\$ 40 i). Ces animaux sont essentiellement herbivores el manquent de dents sur le devant de la madiohe supérieure; entin ilsont tous le pied fourchu, ed cest seulement parmi eux quion remeontredes especes dont le front est armede cornessontenues par un axe osseux. Les principalux représentants de cette division sont les boufs, les montons, leschevres ef les cerfs ; mais on y range aussi les antilopes, la grirafe fig. 200) les chameaux, les lamas, ote. 


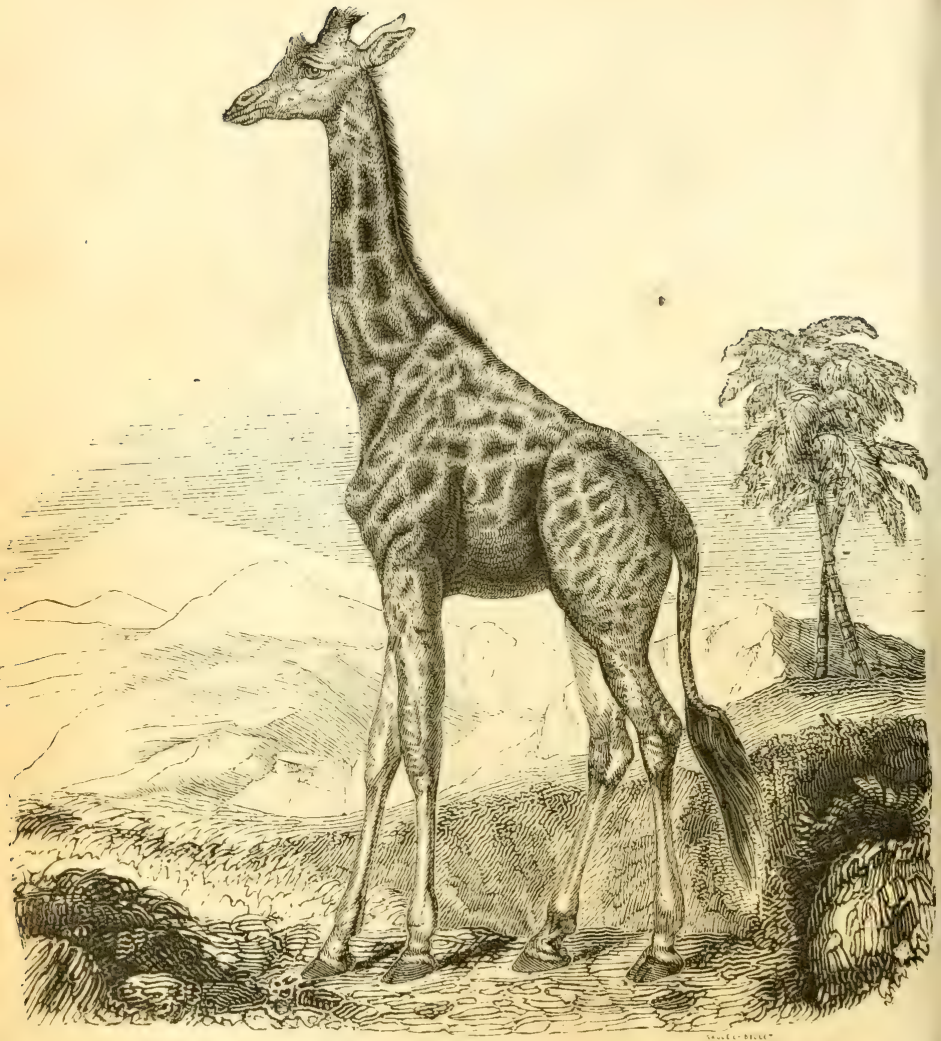

Fig. 200, Girafe.

\$ 422. La division des MunMIFènes PISciforues ne comprend qu'un seul ordre, celui des cétacés, dont la ronformation est adaptée à une vie tout aquatique, et dont la forme extérieure est celle d'un poisson plutòt que d'un mammifère ordinaire. Ici les membres postérieurs manquent, et les membres thoraciques sont transformés en nageoires; enfin la queue se termine aussi par une 
large nageoire horizontale. Les marsouins (fig. 168), les dauphins, les cachalots et les baleines (fig. 201) appartiennent à cet ordre.

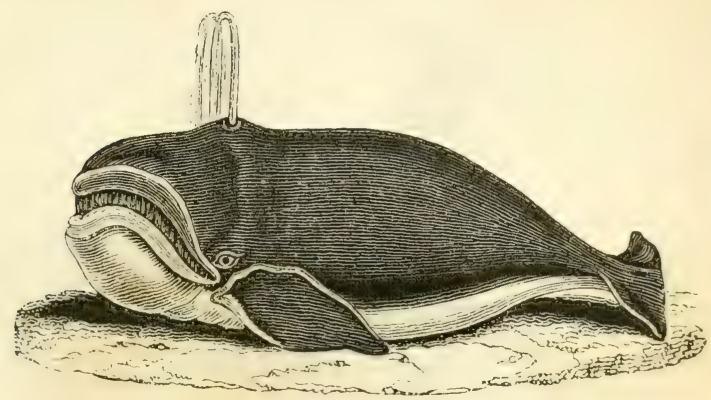

Fig. 201. Baleine.

$\$$ 423. La division des mammferes didelphiens se distingue par plusieurs caractères d'une grande importance physiologique ; en général les petits naissent dans un élat d'imperfection extrème, et il parait que durant leur vie embryonaire ils ne tirent pas leur nour:iture d'un placenta, comme cela a lieu chez les mammifères ordinaires. Le cerveau est moins parfait que dans la division précédente et manque de mésolobe ou corps caileux ; enfin il existe toujours chez ces animaux deux tiges osseuses (appelées os marsupiaux) qui, fixées par leur extrémité postérieure au-derant du bassin, s'avancent entre les muscles du bas-ventre et servent à soutenir les parois de cette cavité viscérale (fig. 181).

Ce groupe se compose de deux ordres : les marsupiaux et les monothrèmes.

\$2.2. L'OndRE nes Manstruax est principalement caractérisé par l'existence d'une sorte de poche destinée à contenir les petits pendant les premiers temps qui suivent leur naissance. Cette poche est formée par deux replis de la peau du ventre, et renferme les mamelles, auxquelles les jeunes se fixent; coux-ci y arrivent dans un état d'imperfection extrème et y achèvent leur développement (fig. 169). Le révime des marsupiaux varie beaucoup; fes uns sont carnassiers, d'autres sont insectivores, d'autres encore sont herbivores, of il en est dont la structure rappelle exactement celle des rongeurs parmi

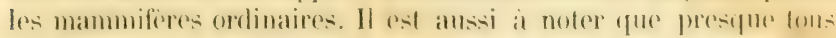


ces animaux appartiennent à la Nourelle-Ilollande. Les sarigues (fig. 169), les phalangers et les kanguroos (fig. 202) sont les principaux représentants de ee groupe singulier.

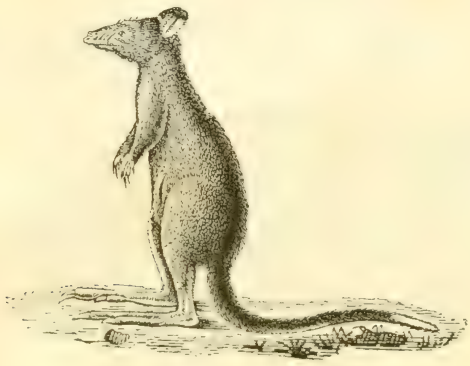

Fìg. 202. Káanguroo.

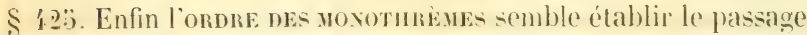
motre les mammiferes et les vertabrés ovipares. L'intestin, au lieu de sourrir directement au dehor's comme chez les mammiferes ordinaires, débouche dans un cloaque commun, de la mème manière que chez les oiscaux; lappareil de la reproduction presente aussi

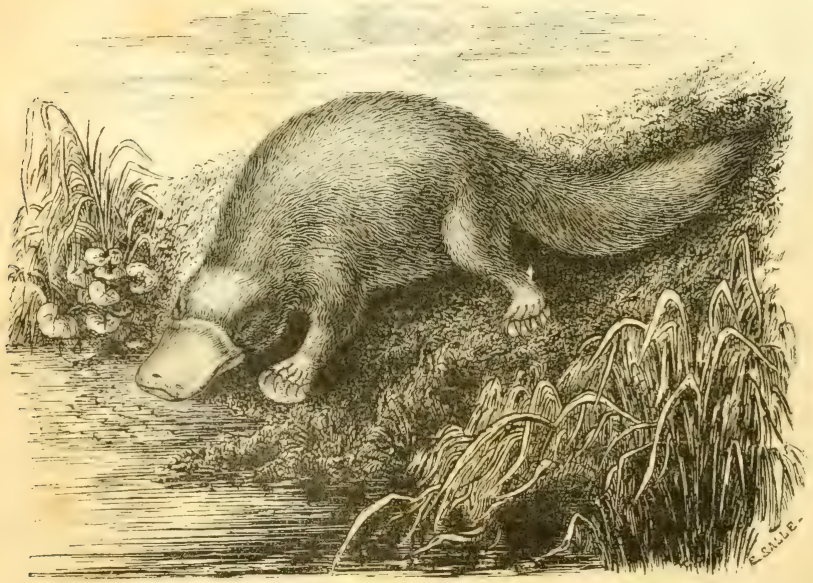

Fig. 203. Ornilhorhinque. 


\section{MAMMIFERES.}

des anomalies très-grandes et le systeme dentaire est rudimentaire; quelquefois les màchoires sont grarnies de lames cornées qui ressemblent beaucoup à un bec de canard. On ne connait que deux genres ayant ce mode d'organisation, savoir, les ornithorhinques: et (fig. 203) les échidnés.

\section{CLASSE DES OISEAUX.}

$\$$ \{26. La classe des oiseaux, fui comprend tous les animaux à squelette intérieur les mieux or ranisés pour le vol, est une des subdivisions du règne animal les plus distinctesest les plus nettement caractérisées, soit que l'on considere seulement la confịguration extérieure de ces ètres, soit que l'on sattache exclusivement aux particularités de leur structure intérieure, ou à la manière dont leurs fonctions s'exécutent. Pour définir ce sroupe, il suffirait de dire que les oiscaux sont des animaux vertébrés ovipares, dont la circulation est double et complste; mais, pour donner une idée exacte de ses principaux caractires, il faut ajouter que la respiration des oiseaux est aérienne et double. c'est-i-dire qu'au lieu de s'effectuer dans les poumons seulement. comme celle des mammiferes et des reptiles, elle s'opere en mème tempis dans ces organes et dans la profondeur de toutes les parties du corps: que leur sang est chaud comme celui des mammiferes; entin, que leurs membres anterieurs ont la forme d'ailes, et que leur peau est garnie de plumies.

La conformation de ces animaux ne varie que peu, et est en rapport aree le mode de locomotion auquel ils sont essentiellement destiné. Ils natteignent presque jamais une grande taille, et la présence d une quantité considérable d’air dans lintérieur de leur corps les rend très-légers.

5 127. Les plumes qui couvent tout le corps des oiseaux sont des proiluctions tres-analognes aux poils des mamniferes, mais d'une structure plus compliquée. On peut, en général, y distinguer un tube corné qui en oceupe la partie inférieure et qui est percé a sun extremité, une ligne qui surmonte ce tube, enfin des barbes qui naisiont de ehaque cole de la lige, et sont elles-memes

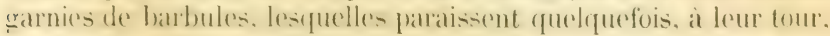
frangées sur le bord.

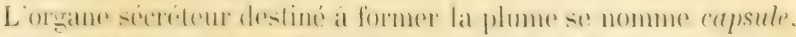
(1) alrepuiret 
vations de Frédéric Cuvier, il paraitrait que la capsule croit pendant toute la durée du dévelonpement de la plume, et qu'à mesure que sa base s'allonge son extrémité meurt et se dessèche dès qu'elle a formé la portion correspondante de cet appendice. Chacun de ces petits appareils se compose d'une gaine cylindrique, revèfue a l'intérieur de deux tuniques unies par des cloisons obliques et d'un bulbe central. La substance de la plume se dépose a la surface du bulbe, et, pour former les barbes, se moule en quelque sorte dans les espaces que les petites cloisons dont nous venons de parler laissent entre elles. Dans la portion correspondant a la tige, le bulbe est en rapport avec la surface inférieure de celle-ci, et, apris y avoir déposé une substance spongieuse, se desseche et meurt; mais, là où le trone de la plume est tubulaire, la lame de matière cornée que cet organe sécréteur dépose se contourne autour de lui et l'enveloppe complétement; cependant le bulbe, lorsqu'il a rempli ses fonctions, ne s'en desseche pas moins, et il forme, en se flétrissant, une série de cònes membraneux emboités les uns dans les autres, qui remplissent l'intérieur du tube, et sont appelés l'âme de la plume.

La plume nouvelle est d'abord renferméc dans la gaine de sa capsule, qui est sourent saillante de plusieurs pouces hors de la peau et se détruit peu à peu. La plume se montre alors à nu, et ses harbes, roulées dans le principe, s'étalent latéralement; l'extrémité de son tuyau reste implantće dans le derme, mais en général s'en détache facilement, et, à une certaine époque, tombe pour faire place à une plume nouvelle. Ce renouvellement des plumes, qui est appelé mue, s'effectue en général chaque année après la saison de la ponte, et a quelquefois lieu deux fois dans la mème année, en automne et au printemps; il arrive plus tòt pour les vieux individus que pour les jeunes, et c'est pour l'oiseau une époque de malaise pendant laquelle il perd la voix.

La forme de ces appendices tégumentaires varie beaucoup : on en connait qui manquent de barbes et qui ressemblent à des piquants de porc-épic; l'aile du casoar ( fig. 204) en offre quatre ou cinq; d'autres dont les barbes sont roides et garnies de barbules qui s'accrochent entre elles, de facon à former une grande lame que l'air ne traverse pas (celles qui garnissent les ailes de l'aigle et du corbeau, par exemple); d'autres encore dont les barbes et les barbules sont longues, flexibles et ne s'accrochent pas, ce qui leur donne une légereté et une mollesse extrèmes (romme celle de la queue et des ailes de l'autruche); enfin, il en est qui ressemblent a un simple duvet (celles appartenant à cerlaines cigognes. et con- 
nues sous le nom de marabouts, sont dans ce cas). Enfin, leurs couleurs sont variées à l'infini, et sourent surpasient en beauté et en éclat celles des plus belles fleurs ou des pierres les plus

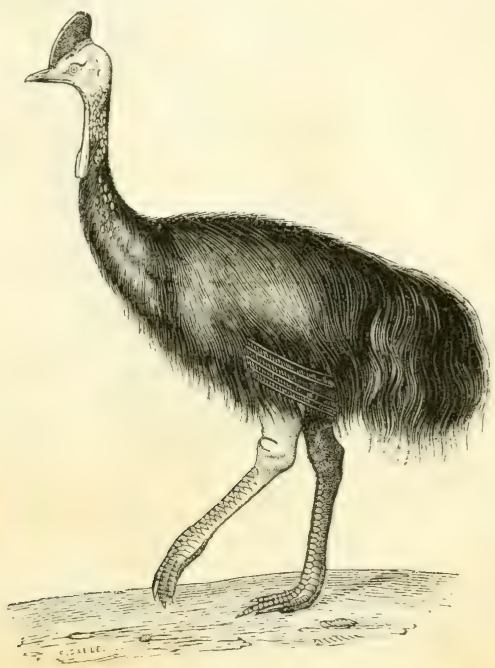

Fig. 201. Casoar ù casque.

brillantes. En général, les femelles ont un plumage moins riche que le mâle, et il est rare que le jeune oiseau présente les couleurs qu’il conservera toule sa vie; souvent elles changent deux ou trois ans de suite, et quelquefois ladulte a un plumage d'été tout à fait différent de celui de l'hirer. Enfin, il e-t aussi à noter que chez. les oiseaux aquatiques ces appendices tégumentaires sont enduits d'une matiere crrasse qui les rend imperméables à l'eau, ce qui leur permet de préserver la peau de l'animal du contact du liquide dans lequel il est en partie plongé.

$\$$ 428. Le squelette qui détermine la forme générale des oiseaux, et qui est en mème temps l'une des parties les plus importantes de l'appareil du mourement, se compose à peu pres des memes ciléments que chez le: mammiferes; mais la forme et la disposition de plusieurs de ses os sont différentes, et à volume éral ils sont 
aussi plus légers, car la plupart d'entre eux sont creusés par de nombreuses cellules remplies d'air.

Sacrum. Omoplate. Humérus.
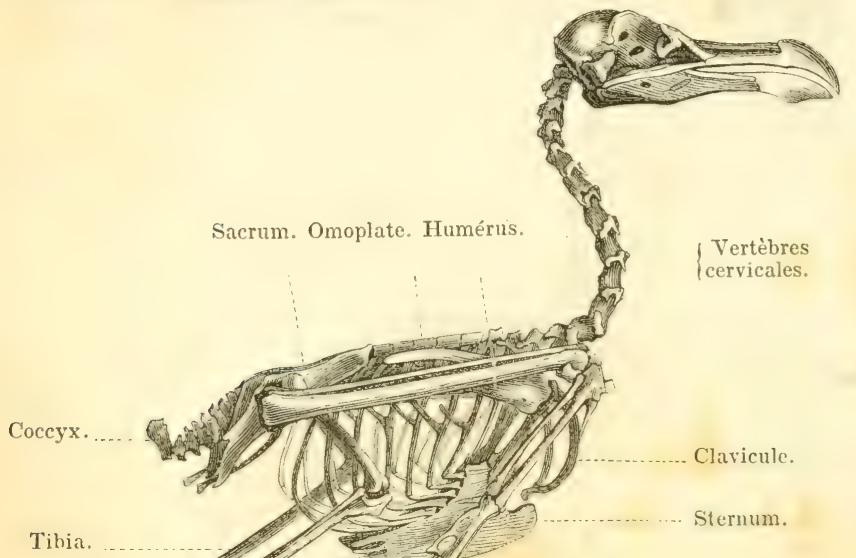

Tibia.

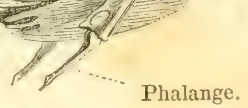

Tarse.

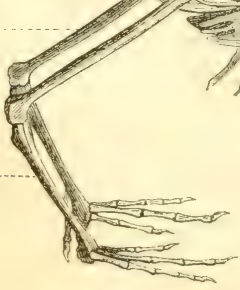

Fig. 205. Squelette du Goülanu.

La tète de ces animaux (fig. 206) est, en général, petite; dans le très-jeune âge, le crâne se compose des mèmes os que chez les

Orbite. Cloison interorbitaire.

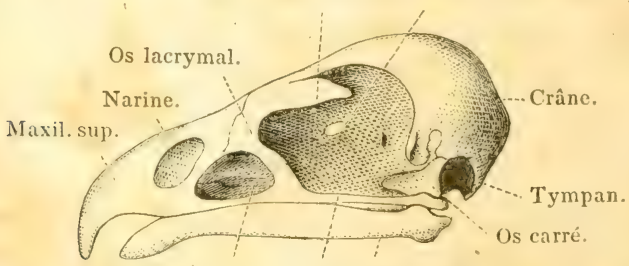

Fosses nasales. Os jugal. Mâch. infér.

Fig. 206. Têle d'Aigle. 
mammifères (savoir: deux os frontaux, deux pariétaux, un occipital, deux temporaux, un sphénoïde et un ethmoïde); mais toutes ces parties se soudent de fort bonne heure, et cessent alors d'ètre reconnaissables. La face est formée, en majeure partie, par les màchoires, qui sont très-allongées et qui, étant destinces à constituer le principal organe de préhension, varient beaucoup sous le rapport de leur grandeur et de leur forme, suivant la nature des objets dont l'oiseau lui-nème aura besoin de s'emparer. La mandibule supérieure est unie au front de facon à conserver quelque mobilité; et l'inférieure, au lieu de s'articuler directement au crâne par un condyle saillant comme chez les mammiferes, est suspendue à un os mobile, nommé os tympanique ou os carré, quii est l'analogue d'une portion du temporal détachée en quelque sorte du rocher, auquel elle est soudée dans la classe précédente. Il est aussi a noter que chacune des branches de celte màchoire est composée de deux pièces au lieu d'ètre formée d'un seul 0 s, et que c'est par une fossette qu'elle s'articule avec l'os tympanique.

L'articulation de la tète avec la colonne vertébrale permet des mouvements plus étendus que chez les mammiferes, car elle se fait par un seul condyle, espèce de pivot demi-sphérique, situé sur la ligne médiane du corps, au bas du grand trou orcipital, et reçu dans une fossette correspondante de l'atlas.

$\$$ 429. Le cou des oiseaux est, en général, beaucoup plus lonğ et plus mobile que celui de la plupart des mammiferes; comme le bec est presque toujours l'unique organe de préhension a l'aide duquel ils ramassent à terre leurs aliments, la portion cervicale de la colonne vertébrale (fig. $20: 3$ ) derient d'autant plus longue que ces animaux sont plus ćlevés sur leur: pattes, et, lorspu'ils sont. essentiellement nageurs (comme le crone) et doirent plonger la tète dans lean! pour s'emparer de leur proie, dans bien des cas la longueur de leur con dépasse notablement la hauteur de leur trone. Le nombre des rertebres quion y (ompte varie beaucoup), suivant. les esperes: ordinairement, il y en a de douze à quinze, mais quelequefois on n'en trouve pas aulant, et d'autres fois il en existe plus de vingt dehez le ('gune, par exemple); elles sont tres-mobiles les unes sur les autres, et, par la nature de leurs facettes articulaires 1 ). le cou se ploie en $\mathrm{S}$, de faren a se raceourcir ou sial-

(1) ('es surfaces articulaires sont concaves daus un sens et convexes dans l'autre, de facon a s'emboitur mutueìement. A la partie supérieure du rou elles permettent librement la flexion en avant, tandis quà la patrtic moyenne elles sont, an 
longer, suivant que ses courbures augmentent ou s'effacent. Cette disposition est surtout remarquable chez les oiseaux de rivage, tels que les cigognes, qui, pour saisir leur proie, ont besoin de darder leur bec avec une grande rapidité à une distance considérable. L'action des muscles destinés à mouvoir cette partie est aussi facilitée par l'existence d'apophỵses nombreuses servant à leur insertion.

Chez presque tous les oiseaux les vertèbres du dos sont au contraire tout à fait immobiles : et on comprend facilement la nécessité de cette disposition chez les animaux conformés pour le vol ; car cette portion de la colonne épinière, servant à soutenir les còtes et fournissant par conséquent un point d'appui aux ailes, doit avoir une grande solidité En général, ces vertebres sont mème soudées entre elles; mais, chez les oiseaux qui ne volent pas, comme le casoar et l'autruche (fig. 136), elles conservent de la mobilité. Les vertebres lombaires et sacrées se réunissent toutes en un seul os, ayant les mèmes usages que le sacrum de l'homme. Enfin, les vertebres coccygiennes sont petites et mubiles; la dernière, qui supporte les grandes plumes de la queve, est ordinairement plus grande que les autres, et relevée d'une crète saillante (fig. 205).

$\$ 430$. Les cótes des oiseaux présentent aussi quelques particularités de structure qui tendent encore à donner de la solidité au thorax. Le cartilage qui, chez les mammiferes, les fixe au sternum, est remplacé ici par un 0 ; et chacune d'elles porte à sa partie moyenne une apophyse aplatie qui se dirige obliquement en arrière au-dessus de la còte suivante, de façon que tous ces os prennent des points d'appui les uns sur les autres.

Mais la partic la plus remarquable de la charpente osseuse du thorax est le sternum ( $f(g .207)$, qui, servant à donner insertion aux muscles du vol, prend chez les oiseaux un développement extrème et constitue un grand bouclier convexe, et ordinairement carré, yui recourre le thoras et une grande partie de l'abdomen. Chez le casoar et l'autruche (fig. 136), qui ne peuvent pas s'élever dans les airs et qui n'ont que des ailes rudimentaires, le sternum ne présente point de crìte à sa face externe, mais chez les autres oiseaux un y remarque une espece de carène saillante et longitudinale nommée le bréchet $(b, f i g .207)$, qui sert à donner plus de force aux muscles abaisseurs de l'aile.

contraire, dispusées de façon ì ne permettre que le renversement en arrière; enfu a la base du cou elles changent encore de structure et redeviennent propres aux mouvements de flexion en avant. 
$\$ 434$. Les os de l'épaule sont également disposés de la manière la plus favorable à la puissance des ailes. L'omoplate (o) est étroite, maistrès-allongée dans le sens 0 qui est parallèle à l'épine, et s'appuie sur le sternum nonseulement par l'intermédiaire de la clavicule ou fourchette ( $f)$, maisaussià l'aide d'unautre os qui remplit les fonctions d'une seconde clavicule et qui est appelé os coracoüdien $(c)$, parce qu'il paraìt ètre l'analogue de l'apophyse coracoïde de l'omoplate humaine. Les clavicules des deux côtés se soudent presque toujours par

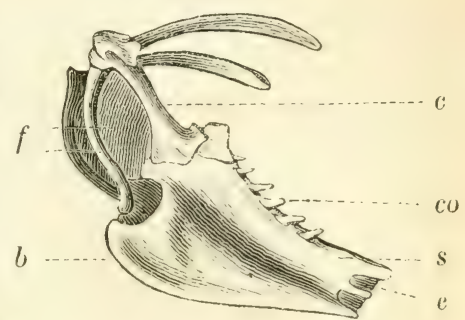

$S$

Fig. 207. Os de l'épaule et sternum (1). leur extrémité antérieure en forme de $\mathrm{V}$ dorıt la pointe est dirigée en bas et attachée au bréchet; et les os coracoïdiens constituent des ares-boutants qui, avec la fourchette, maintiennent les épaules écartées et ofirent à l'humérus un point d'appui d'autant plus solide que l'animal est meilleur voilier. Chez les oiseaux qui ne volent que peu ou point, les clavicules n'offrent, au contraire, qu'un faible développement. Ainsi, dans certains perroquets terrestres de l'Australasie, ces os sont réduits à un état tout a fait rudimentaire; chez les casoars et l'autruche d'Amérique, ils ne sont représentés que par de petils stylets; chez l'autruche d'Afrique et les toucans, il atteignent presque le sternum, mais ne se réunissent pas entre eux inférieurement; enfin, chez quelques hiboux ils son! unis par un cartilage, tandis que chez les oiseaux ordinaires leur soudure est complèe, et que souvent mème ils vont s'appuyer directenent sur le sternum, au moyen d'une prolongement médian qui nait de cette soudure.

Les membres antérieurs des oiseaux ne servent jamais ni à la marche, ni à la préhension ni au toucher, mais forment des espèces de rames tres-étendues, nommées ailes. En parlant des chaures-souris, nous avons déja vu un exemple de la transformationdes membres thoraciques en un organe de locomotion aérienne: chez ces animaux cest un repli de la peau qui sert à frapper l'air, et pour la soutenir les doigrts prennent une longrue extrémité; mais

(1) s sternum; - e échancrure du sternum; - co origine des cites sternales ; 1, brechet; - f fourchette ou clavicules furculatires ; - c us coraroillien ; - " omoplate; $-m$ membrane fibreuse qui sétend de la fourehette au sternum. 
chez les oiseaux ces larges rames sont d'une autre nature : elles sont formées de plumes roides qui nont besoin d'ètre fixées que par leur base, et la main, par conséquent, ne présente plus les divisions digritales, yui nuiraient a sa solidité et ne seraient d'aucume utilité; elle a la forme d'une espece de moignon aplati et presque immobile (fig. 90, 20:3). La conformation des bras et de l'avant-bras ne different que peu de celle de l'homme; l'humérus ne présente rien de particulier; le radius et le cubitus ne peuvent tourner l'un sur l'autre, et sont en général d'autant plus longrs que le vol est plus puissant. Le carpe se compose de deux petits os placés sur le mème rang et suivis du métacarpe, qui présente deux branches soudées par leurs extrémités; au còté radial de la base de cette dernière partie de la main, s'insere un pouce rudimentaire: enfin à son extrémité se trouve un doist médium composé de deux phalanges, et un petit stylet représentant un doigt externe.

\$ 132. Les pennes ou grandes plumes des ailes sont appelées

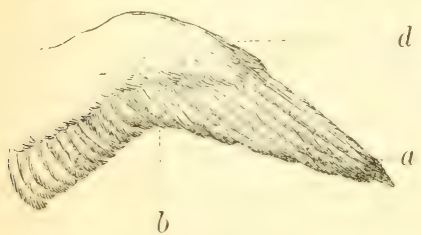

Fig. 208. Aile de Faucon (1). rémiges, et c'est de leur longueur d plus encore que de celle des os du bras, de l'avant-bras ou de la main que dépendent l'étendue des ailes et la puissance du vol. Chaque fois que l'oiseau veut frapper l'air, il élève l'humérus et avec lui l'aile encore ployée; puis il la déploie en étendant l'arant-bras, aussi que la main, ef l'abaisse subitement; l'air qui résiste à ce mouvement lui fournit alors un point d'appui, sur lequel il se souleve: il se lance ainsi comme un projectile, et, une fois l'impulsion donnée à son corps, il incline ou reploie l'aile pour diminuer autant que possible la résistance nouvelle que le fluide ambiant oppose à sa course. Celte résistance et la gravitation qui tend a faire tomber tous les corps vers le centre de la terre diminuent graduellement la vitesse que loisean a acquise par cette pereusion de l'air, et s'il ne fait pas de nouveaux mouvements il ne tardera pas a deseendre: mais si, avant que la vitesse acequise par le premier coup d'aile soit anéantie, il en donne un second, il ajoutera une vitesese nouvelle à celle qu il avait encore, et se déplacera par un mourement accéléré. Tel est, en effet, le mécanisme du rol.

Pendant que l'oisean est ainsi suspendu dansl'air, ce sont ses ailes qui supportent tout le poids de son corps; et pour qu il puisse con-

11 a rémiges primaires ou pennes de la main; - b rémiges secondaires ou pennes de l'avant-bras; $-d$ pennes batardes ou pennes du pouce.. 
server dans cette position son équilibre, il faut que son eentre de gravite $(\$ 280$ ) soit placé à peu près sous les épaules et aussi bas que possible; c'est pour cela que, pendant le vol, il porte en général sa tète en avant en tendant le cou, et que son tronc, au lieu d'ètre allongé comme celui des mammifères, est toujours ramassé et ovalaire.

II est évident que la résistance de l'air est d'autant plus grande que la masse de ce fluide frappée à la fois par les ailes est plus considérable, et par conséquent que, plus les ailes seront étendues, plus aussi, toutes choses égales d'ailleurs, la vitesse acquise par l'abaissement de ces rames sera grande; il en resulte que nonseulement les oiseaux à longues ailes pourront voler plus vite que ceux a ailes courtes, mais aussi pourront se soutenir plus longtemps dans l'air, car ils ne seront pas obligés de répéter aussi souvent les mouvements de ces organes, et par conséfuent anssi se fatigueront moins vite. Et, en effet, tous les oiseaux reinarquables par leur rol rapide et sontenu ont de grandes ailes, tandis que ceux dont les ailes sont courtes ou médiocres, comparativement au voIume du corps, volent avec bien moins de vitesse ef sont condamnés à des repos plus fréquents.

Parmi les oiseaux remarquables par la puissance de leur rol, nous citerons le condor et les frégrates (fig. 209). Le condor ou grand

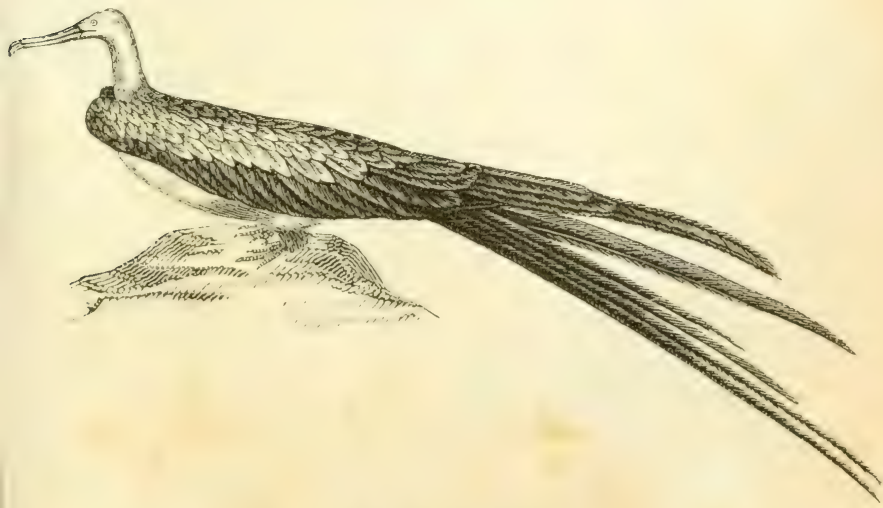

Fig. 209. La Frégale.

vautour des Andes a plus de quatre metres d'onveroure of sioleve plus haut qua aucun oiscau: on le voit tanteit all bord de la mere, tantot planant au-dessus du Chimborazo, e'est-a-dire a un niveau 
de près de sept mille mètres au-dessus du premier point. Sa demeure habituelle est sur la crête des rochers de la Cordillière des Andes, immédiatement au-dessous de la limite des neiges perpétuelles, à un niveau de trois mille trois cents à quatre mille huit cents mètres au-dessus du niveau de la mer; c'est de ces pitons escarpés qu'il descend dans les vallons et dans la plaine pour chercher sa nourriture, qui consiste principalement en cadavres de grands mammifères; on prétend mème que, réunis plusieurs ensembles, ils peuvent tuer facilement des boufs, et qu'ils sont assez puissants pour enlever dans leurs serres des moutons et des lamas, et les transporter ainsi jusqu'à la cime du Chimborazo et des autres montagnes les plus élerées de la chaine des Andes. Les frégates, qui ont les ailes encore plus longues proportionnellement à leur taille et qui habitent les mers tropicales, ont le vol si puissant qu'elles peuvent s'éloigner de terre à des distances de plus de quatre cents lieues.

Pour s'élever verticalement, il faut que les ailes de l'oiseau soient entierement horizontales; mais ce n'est pas ordinairement le cas: en général, elles sont inclinées d'avant en arrière de façon à imprimer à l'animal un mourement ascensionnel oblique; quelquefois mime cette inclinaison est telle que pour monter à peu près verticalement dans l'atmosphère l'oiseau est obligé de voler contre le vent. La longueur relative des rémiges influe sur la facilité avec: laquelle il peut s'élever dans un air calme; les oiseaux dont les rémiges antérieures sont les plus longues et les plus résistantes a leur extrémité, ont le vol plus oblique que ceux dont l'aile est tronquée au bout.

Ainsi, les faucons, qui ont les ailes pointues (fig. 208), ne peu-

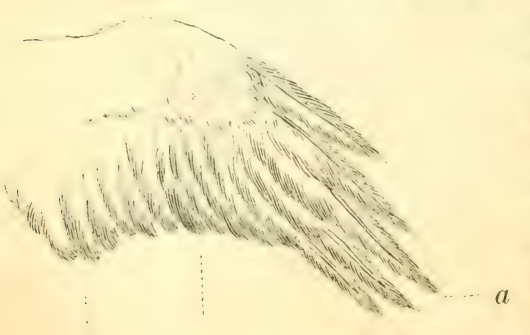

b a

Fig. 210, Aile d'un Épervier (1). vent s'élever qu'en zigzag, comme un vaisseau qui court des bordées, ou bien en volant contre le vent; tandis que les éperviers, les aigles et les autres oiseaux de proie dits ignobles, dont les ailes : ont tronquées au bout ( $f i g .240)$, peuvent s'élever verticalement.

(1) $a, a$ rémiges primaires; $-b$ rémiges secondaires. 
Lorsque l'oiseau veut s'élever de terre, il prend son premer clan en sautant sur ses pieds et en étendant ses ailes de façon à pouvoir frapper l'air avant de retomber sur le sol; ceux qui ont les ailes très-longues ont besoin de plus d'espace pour les ahaisser ; et il en résulte que si leurs pieds sont en mème temps trop courts pour leur permettre de sauter très-haut, ils ne peurent que difficilement prendre leur essor. Les martinets sont dans ce cas.

Les pennes de la queue servent aussi aux oiseaux pour se diriger dans leur vol ; ils les étalent et les relevent ou les abaissent comme un gouvernail pour augmenter ou diminuer l'obliquité de leur course, et, en les inclinant, s'en aident aussi lorsqu'ils veulent changer leur direction.

$\$$ 433. Lorsque l'oiseau pose, ce sont ses membres postéricurs qui seuls lui servent de soritien; c'est donc un animal réellement bipède, et, comme tel, il doit avoir le bassin large et fixé solidement à la colonne vertébrale. Les os des hanches, en effet, sont extrèmement développés chez les oiseaux, et ils ne forment, avec les vertèbres sacrées et lombaires, qu'une seule pièce (fig. 20:3). En général, cette ceinture osseuse est incomplète en arant; les pubis ne se réunissent pas entre eux, et la portion ischiatique, au lieu d'ètre séparée du sacrum par une large échancrure, se soude a cet os par sa partie postérieure, et transforme l'échancrure en un trou. Lios de la cuisse est court et droit, et la jambe se compose, comme chez la plupart des mammifères, d'un tibia, d'un péroné et d'une rotule; seulement le péroné se soude au premier avant d'arriver à sa partie inférieure. Un seul os, qui fail suite a la jambe, représente le tarse et le métatarse, et porte à son extrémité inférieure les doigts qui sont ordinairement au nombre de quatre; il n'en existe jamais davantage; mais quelquefois le doigt, externe ou l'interne, que l'on désigne sous le nom de pouce, ou mème tous les deux disparaissent, de manière qu'il n'en existe plus que trois, ou seulement deux ( $f i g$. 215). Le nombre des phalanges va presque toujours en auggmentant régulierement depuis deux jusqu'à cinq, du pouce au doigt externe qui en a foujours le plus. Entin de ces quatre Fig. 211. T'ie moyen ifeicher. doigts trois seulement sont ordinairement dirises on alsant, lamlis 
que le pouce est dirigé en arriere; quelquefois le doigt externe se porte aussi en arriere, el cette disposition est surtout remarquable chez les oiseaux grimpeurs, tels que les perroquets, les toucans et les pics ( $\mathrm{fig}$. 211).

Nous arons dit, il y a un instant, que, pendant le vol, le centre le gravité du corps de loiseau doit se trouver sous les épaules; pour (qu’il reste en équilibre sur ses pattes, qui sont situées à l'arrière du tronc, il faut que ces organes puissent se ployer assez en avant, et que les doigh soient assez longs pour avancer au delà du point ou tomberait une ligne verticale passant par le centre de gravité, ou bien que ce centre lui-meme se porte en arriere, de facon à se trouver au-dessus de la base de sustentation. Cela explique l'utilité de la grande flexion de la cuisse et de l'obliquité du larse sur la jambe; lorsque le pied est grand et que le cou peut se reployer de façon à porter la tète en arrière, l'équilibre s'établit ainsi, sans que le corps séloigne beaucoup de la position horizontale ( $f(y .212)$; mais lorsque le cou est court, la tìte grosse et les doigts de longueur médiocre, l'animal est obligé de prendre, pendant la station ou la marche, une position presque verticale (fig. 213). Ciest pour conserver

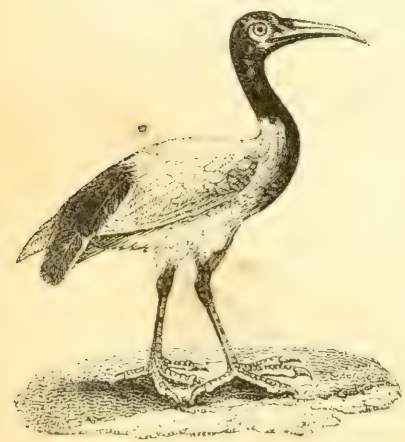

Fig. 212. Ibis.

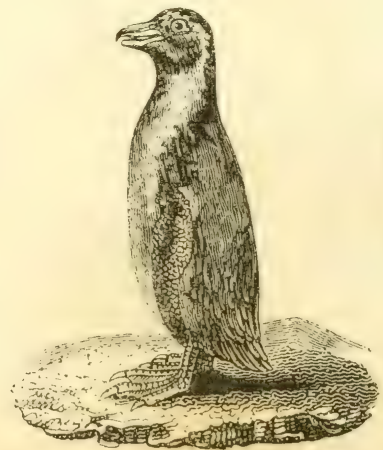

Fig. 213. Manchol.

plus facilement l'équilibre que les oiseaux placent en général leur tète sous leur aile pendant qu'ils dorment perchés sur ine seule patte. Chez plusieurs de ces animaux, cette position est rendue singulièrement commode par une jarticularité dans la structure de l'arficulation du genou. Chez l'homme el la plupart des animaux, les membres fléchissent sous le poids du corps des que leurs muscles 
extérieurs cessent de se contracter, et e'est la nécessité de la contraction permanente de ces organes qui rend la station si fatigante: mais, chez la cigogne et les autres oiseaux a longues pattes, il en est tout autrement : l'extrémité inférieure du fémur présente un creux où s'emboite, pendant l'extension du membre, une saillie du tibia, laquelle ne peut en sortir que par un effort musculaire; la patte une fois redressée reste par conséquent étendue sans que l'animal ait besoin de contracter les muscles et sans qu'il en résulte aucune fatigue.

Il est toujours plus difficile à un oiseau de prendre son vol lorsqu'il est à terre que lorsquil peut se lancer d'un point élevé : nous en arons déja vu la raison, et chacm sait que la plupart de ces animaux perchent bien plus souvent qu'ils ne se posent a terre. Pour se maintenir en équilibre sur une branche, il faut qu'ils l'embrassent arec leurs doigts et la serrent fortement; s il leur avait fallu déployer pour cela une force musculaire considérable, une telle position aurait été promptement fatigante; mais ici encore un mécanisme très-simple rend tout effort presque inutile, et permet aux oiseaux de serrer la branche qui les soutient, mème quand ils dorment; les muscles fléchisseurs des doigts passent sur les articulations du genou et du talon, de facon que lorsque celles-ci se fléchissent, elles tirent nécessairement sur les tendons de ses muscles et font fléchir les doigrts; le poids du corps. en affaissant les cuisses et les jambes, détermine done ce mouvement, et il en résulte que

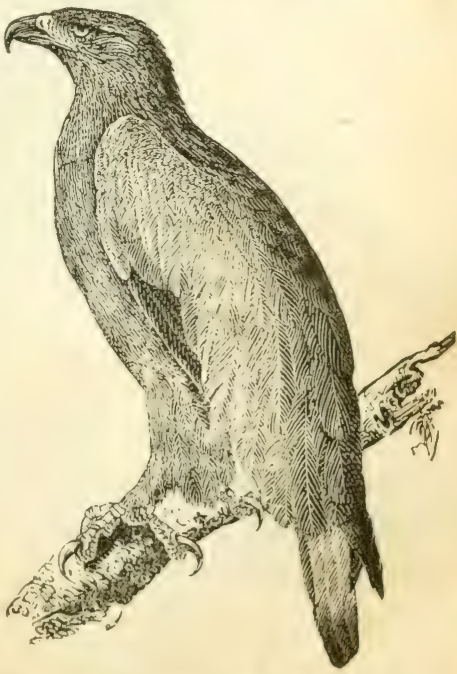

Fig. 21. Aigle royal. limimal sorre, sans exereer ancun effort, la branche sur latpuelle il est perché et s'y maintient fixé.

Il esiste des differenees asser orandes dans la ronformation des

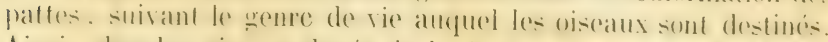

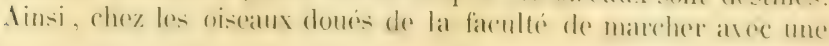


grande vitesse, les pattes sont non-seulement robustes, mais trèslongues, et le pied comparativement petit; chez le casoar (fig. 20.4) et l'autruche (fig. 213 ), dont la course est aussi rapide que celle du cheval, cette disposition est très-remarquable; et elle s'observe aussi chez le messager, qui marche à grands pas en poursuivant les serpentsdont il fait sa principale nourriture. Chez l'aigle (fig. 214), le faucon, le vautour, ete., ces organes sont également robustes, mais courts, et les doigts sont armés de grands ongles crochus et aigus, à l'aide desquels ces oiseaux saisissent leur proie, soit pour la déchirer sur place, soit pour l'emporter avec eux; chez les oiseaux conformés pour vivre sur les bords des eaux el y chercher à zué les vers et les poissons dont ils font leur pàiure, les pattes sont grèles, diune longueur extrime, et nues jusqu'au-dessus du genou (fig. 216), disposition qui est tresi-

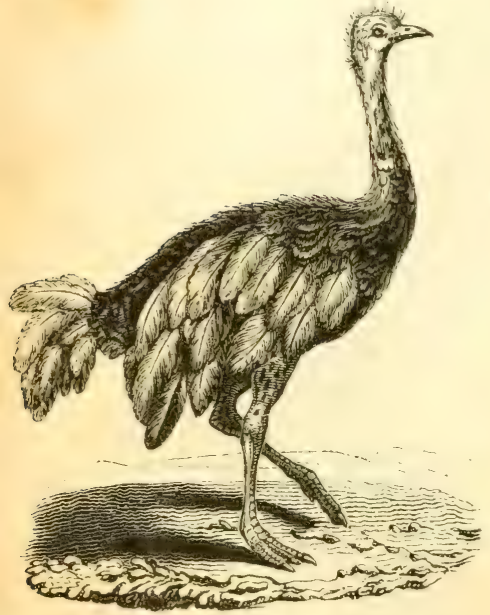

Fig. 215. Aulruche d'A frique.

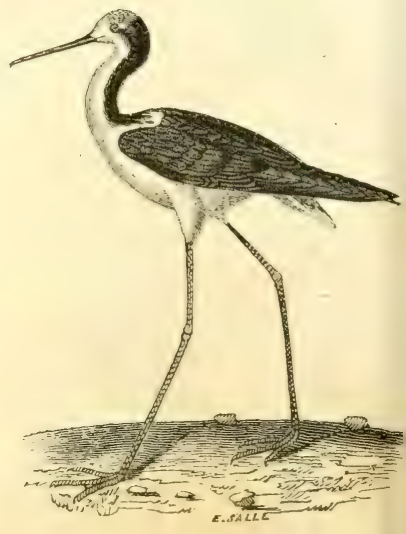

Fig. 216. L'Échasse d'Europe.

favorable a ce cremre d'existence, et qui a valu aux oiseaus de rivage le nom d'échassiers; enfin, chez les espèces destinées à vive sur une eau plus profonde, les pattes sont palmées, c'est-àdire transformées en nageoires par l'addition d'une membrane qui s'étendentre les doigts sans les empècher de s'écarter, caractere qui se roit chez les canards (foy. 217), les eygnes of un yrand nombre d'oiseaux aquatiques. 
$\$$ 434. La sensibilité tactile est peu développée chez les oiseaux: les plumes qui revètent toute la surface de leur corps opposent de grands obstacles a l'exercice de cette faculté, et le mode de con-

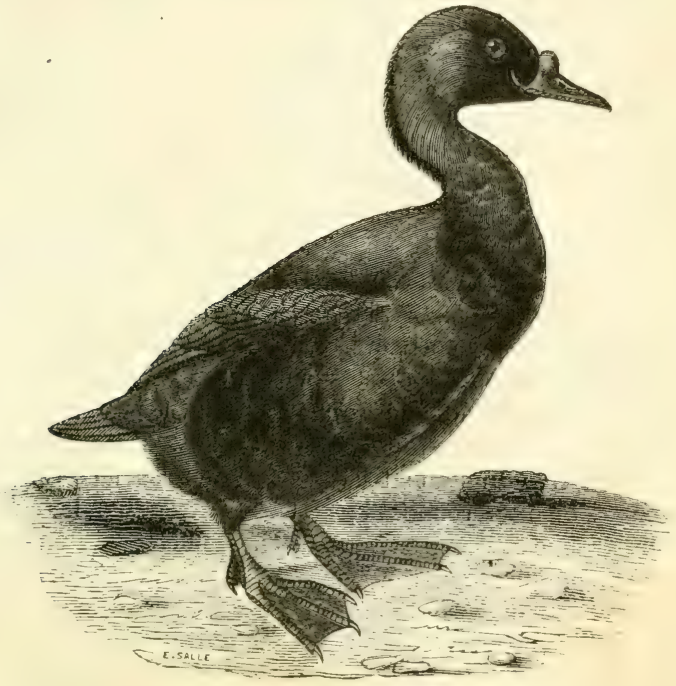

Fig. 217. Le Cunard Macreuse.

formation rles oryanes de préhension y est exalement défarorable. Le goùt est plus ou moins obtus chez ces animaux; leur langue (fig. 230) est, en général, cartilaquineuse et dépourrue de papilles nerveuses, et ils paraissent presque toujours avaler leurs aliments sans les déguster. L'appareil de l'odorat est plus parfait, sans offrir cependant tout le développement qu’on y trouve dans la classe des mammiferes. Les fosses nasales sont creusées a la base de la mandibule supérieure (fig. 206), et ne communiquent pas arec des sinus: leur surface est tapisiée par une membrane piluilaire tres-vasculaire, ef est augnentée par trois lames eartilagineuses (ou cormets) contournées sur elles-mèmes et appliqués contre leur paroi. Enfin, les arriere-narines se réunissent vers lo milieu de la voute palatine, de maniere a y former une fente lonqritudinale. Les oiseaux carnassiers, surtout cenx qui vivent de charogne, ont lappareil de l'odorat plus devoloppé que les 
oiseaux granirores ou insectirores : et la plupart des auteurs assurent que chez les premiers la finesse de ce sens est telle quelle leur fait décourrir leur proie, lors mème quils en sont à des distaners tres-considérables: mais les expériences de quelques savants tendent à prouver que, chez ces amimaux. l'odorat est presque nul, et que cest la rue qui les wuide presque uniquement.

Lappareil de louie est moins compliqué que chez les mammiferes: le parillon de loreille manque ehez les oiseaus, ot le conduit auriculaire ne consiste snere quen un tube membraneux placé entre los carré et une partie saillante de loccipital.

Lappareil de la vue parait ètre, au contraire. plus parfait que dans la classe précédente : les yeux des oiseaux sont plus grands comparativement au volume de la tète. et on y trouve des parties nouvelles. La rétine est trés-épaisse et il en part une membrane noire. plissée en éventail ou à la maniere diune bourse, unu šavance rers le cristallin: les physioloristes ne sont pas daceord sur la nature de cet appendice, nommé peigne : snivant les uns, ce serait une dépendance de la choroide, et. suivant d'autres, un prolongement nerveux destiné à augrmenter l'éteudue de la surface visuelle. La pupille est toujours ronde. l'iris tres-contractile, la cornée transparente, grande et convexe, et la sclérotique fortiliée en arant par un cercle de playues osseuses logées dans son épaisseur. L'appareil palpébral se compose de deux paupieres horizontales, dont. linférieure est la plus grande el la plus mobile el d'une troisième paupiere verticale et semi-transparente qui occupe l'angle interne de lowil et peut recourrir toute la surface de cet organe. Enfin, il existe toujours des glandes lacrymales.

Che\% quelques oiseaux. la portée de la rue est extremement longue; on en roit qui, élerés dans l’air à des hauteurs telles que, malgré leur volume, nous ne les apercerons qu'à peine, distinguent nettement les petits animaux dont ils se nourrissent, et fondent sur cette proie éloignée sans la moindre indécision. Chez eux, le cristallin est beaucoup moins hombé el moins dense que chez les oiscaux qui ne séloignent que peu de la surface de la terre, et il paraitrait que l'oeil pent sadapter à ces grandes différences de portée dans la vision a laade de contractions de ses muscles moteurs qui, en agrissant sur le cercle osseux de la sclérotique, compriment les humeurs dont l’oranane est rempli, déterminent aussi la distension de la corncé, et en augmentent par conséquent la courbure lorsque lanimal a besoin de devenir momentanement presque myope pour distingure nettement les objets tres-rapprochés. 
Le systeme nerveux, qui préside aux fonctions dont nous renons de passer en revue les organes, présente ausi dans sa structure des particularités remarquables. Liencéphale est moins développé que chez les mammiferes: les hémispheres cérébraux $(f y .218, c)$ en sont encore les parties les plus volumineuses; mais ils n'offrent pas de circonyolutions, et ils ne sont pas réunis d'une manière anssi complete, car la grande commissure, dont nous avons parlé précédemment sous le nom de corps calleux, manque dans cette classe. Les lobes optiques $(o)$, qui chez les mammiferes sont petits t restent cachés entre le cerreau et le cervelet, prennent, au contraire, ici un grand

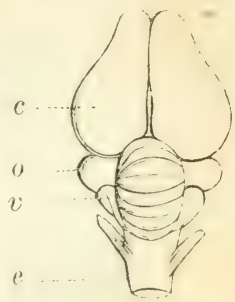

Fiig. 21s. Cerrealu "'Aulrueler développement et se montrent toujours à découvert en arriere et en dehors des lobes cérébraus ; enfin, au lieu d'ètre solides, ils sont. creux, comme les lobes cérébraux. Le cervelet (v) est sillonné tramsversalement par des rainures paralleles et conver.yntes; il est formé presque en entier par le lobe médian, qui chez les mammiferes est petit comparativement aux lobes latéraux (ou hémispheres du cervelet), et ceux-ci restent dans un état plus ou moins rudimentaire, surtout chez les oiseaux mauvais voiliers; quant a la protubérance annulaire, qui dans la classe précédente réunit entre eux les hémisphères du cervelet, en passant autour de la moelle allongés, elle marque ici de mème que chez les reptiles et les poissons. Enfin la moelle épiniere des oiseaux (e) est, en général, treslongue et présente deux renflements correspondant a lorigine des nerfs des ailes ot des pattes: chez ceux qui volent le mieux, le renflement supérieur est plus développé que l’inférieur, el cenx qui se servent de leurs paltes plus que de leurs ailes présentent mo disposition inverse.

43:3. Le régime des oiseatux est tries-rarié les uns se nourrisient exclusivement de sranes, dautres dönsectes, d'antres de joisons, dautres encore de la chatie des mammiferes on des oi-

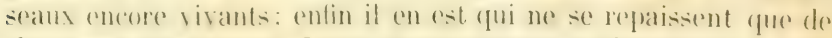

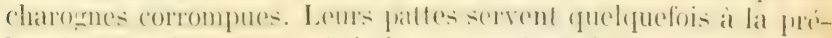
hension des aliments, mats le bee est fomjoms le principal organe emplose a red usares a forme varie suivant la nature des aliments ef suivant le calactere plus ou moins carnatsice de ces ani-

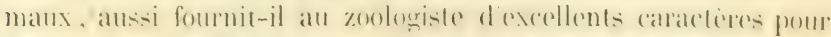

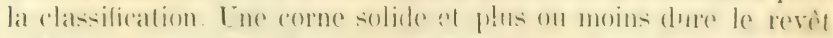

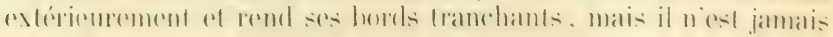


armé de véritables dents; aussi la mastication est-elle très-incomplete et en général entierement nulle. Chez les oiseaux qui vivent de chair et qui ont besoin de déchirer leur proie, les faucons (fig. 220), les aigles $(f i g .214)$, les vautours (fig. 222), par exemple, la mandibule supérieure est très-courte, très-forte, crochue vers le bout f't terminée par une pointe aigue: quelquefois mème ses bords sont

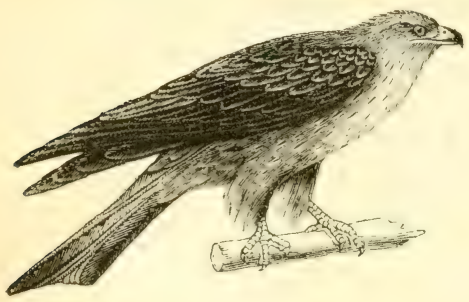

Fig. 219. Milan.

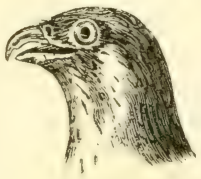

Fïg. 2ะ0. Têle de Fuusoir.

plus ou moins dentelés, ce qui en fait une arme plus puissante. et on peut juger des habitudes plus ou moins sanguinaires de ces animaux par le derré auquel leur bec offre ces divers caracteres. Ainsi le faucon (fig. 220) est de tous les oiseaux de proie celui dont le bec est le plus courbé. le plus court, le mieux dentelé et le plus robuste proportionmellement à sa taille: aussi est-il le chasseur le plus intrépide; tandis que le milan (fig. 219), qui ne ditfere guere du faucon que par son bee plus faible, moins crochu et non dentelé sur les bords, ainsi que

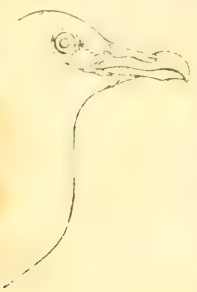

1.2y. 2:21. par ses serres moins robustes, est d'un naturel liche; et le vautour(fig. 222 ), dont le bec est encore plus allongé, et par conséquent moins fort, ne s'attaque mème pas aux animaux vivants et se repait de cadavres. Les oiseaux de mer, qui se nourrissent de la chair des poissons trop volumineux pour ètre avalés d'une bouchée, se font également remarquer par leur bec gros et crochu au bout (fig. 221); mais cet organe est beaucoup plus allongé que chez les oiseaux de proie et par conséquent moins puissant. Lorsque les oiseaux piscirores ne recherchent que des poissons ou des reptiles assez petils pour itre saisis et arales avec facilité, le bee devient dreit, sallonge eneore davantage of ressemble à une 
pince à longues branches; les martins-picheurs (fig. 226), les cigognes (fig. 223), ete., nous en offrent des exemples. Les oiseaux qui

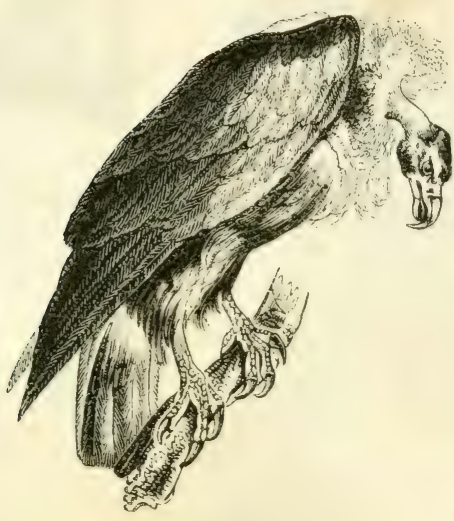

Fig. 22:. V'сu'our fauve.

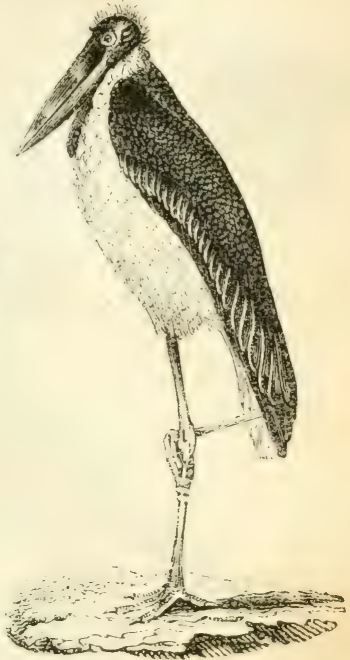

Fig. 223. Cigogne ì sac.

vivent d'insectes, de vers, de sraines ou de fruits, ne présentent rien de semblable : les premiers ont, en général, le bec très-grèle, trèsallongé et droit ou faiblement arqué (fig. 22:4);

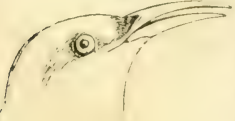
a moins toutefois que ce ne soit au vol quils prement les petits insectes dont ils se nourrissent, car alors le bec est court, très-élargi, et profondément fendu: disposition quise voitchez les hirondelles, lesengoulevents (fig. 22\%), ete.

Fig. 22.t. Guipier. et qui leur permet d'engrloutir facilement leur proie dans leur large grueule. Les granivores, au contraire, ont le bec court, épais, bombéendessus ou conique, et en çénéral droit (fig. 227).

Une modification de cet organe plus remarquable encore nous est offerte par les pélicans (fig. 228), oiscaus ayuati(pues qui portent entre les deux branches de la màchoire inférieure une grande poche cutanée tres-extensible, dans lauguelle ils accumulent le produit de leur pèche pour le degorger ensuite et s'en repaitre à loisir. 

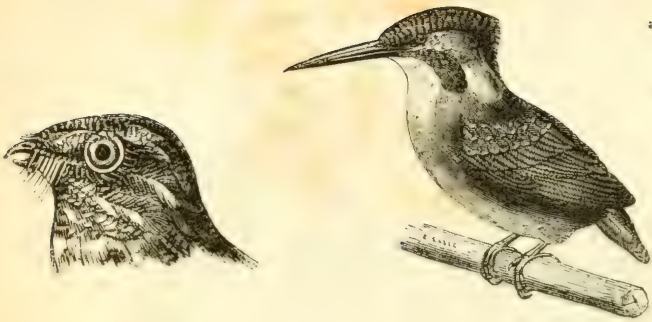

Fig. 226. Marlin-pécheur.

Fig. 225. Engoulevent.

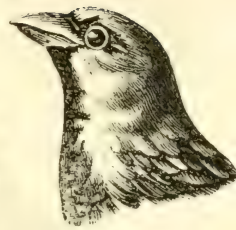

Fig. 227. Moincun.

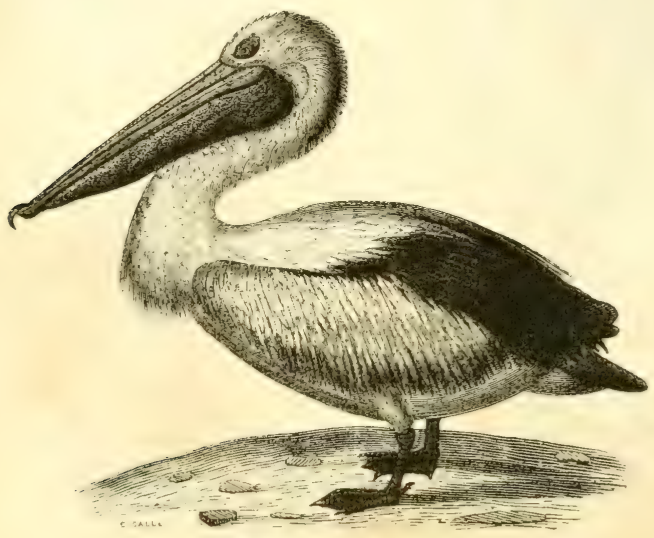

Fig. 228. Pelican.

Enfin il est aussi à noter que le bec des oiseaux offre quelquefois des bizarreries de forme dont l'utilité ne nous est pas connue; telle est, par exemple, l'espèce de casque qui surmonte cet organe chez les calaos (fig. 229), et qui acquiert des dimensions monstrueuses.

$\S$ 436. La langue sert quelquefois à la préhension des aliments aussi bien cju'à la déglutition, et présente des particularités de structure remarquables. L'os liyö̈le $(h, f i g$. 230), sur lequel elle est portée, se prolonge en arrière sous la forme de deux longues corne: sui remontent rlerriene la tète, et qui donnent attache par leur ex- 


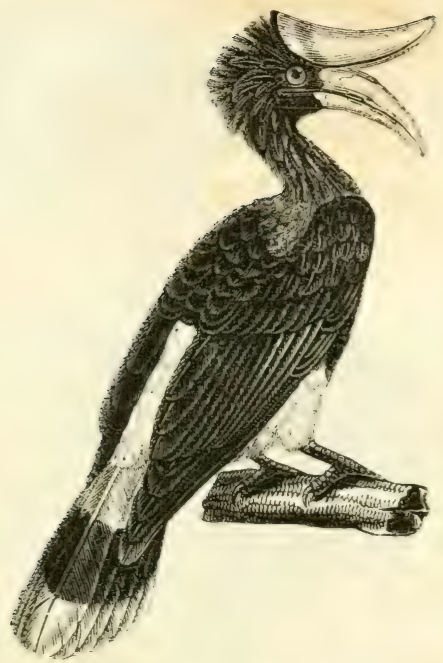

Fig. 229. Calao à casqque en croissanl.

Irémité à des muscles $(m)$ fixés antérieurement à la màchoire inférieure; lorsque ces muscles se contractent, ils ramènent en has

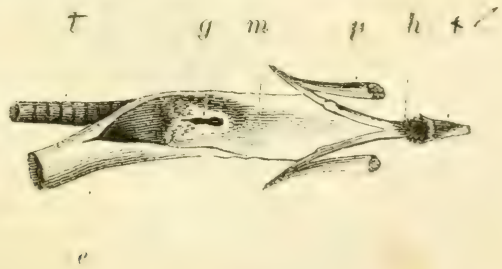

Fig. 230. (1).

et en arant ces cornes, et poussent par conséquent la langue hors de la bouche. Ce mécanisme est surtout curieux chez les pics (fig. 231) et chez quelques autres oiscaux qui dardent leur langue avec une

(1) Langue, glotte, etc. $-l$ langue; $-h$ hyoüde; $-m$ muscles de lhỵüle; $p$ pharynx; $-g$ glotte; $-t$ trachée; $-e$ œsophage. 
l. zngue.

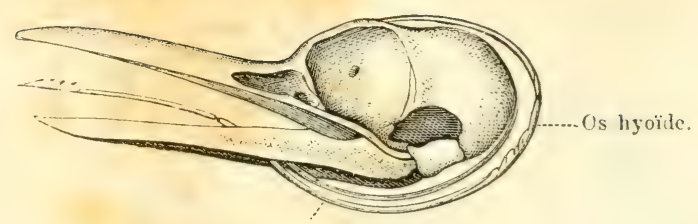

Fig. 231. Téle de Pic.

vitesse extrème, et à des distances considérables, sur les insectes dont ils se nourrissent. Cet organe présente aussi dans sa forme des différences importantes à noter. Chez les perroquets, qui mâchent jusquà un certain point leur nourriture, la langue est épaisse et charnue; chez les oiseaux de proie, clle est encore large et assez molle; chez la plupart des granivores (fig. 230), elle est sèche, triangulaire, et hérissée, vers la base, de petites pointes cartilagineuses; enfin, chez certains insectivores, son extrémité est armée de crochets ou de dentelures.

Les glandes salivaires sont placées sous la langue et consistent en des amas de petits follicules arrondis. La salive est ordinairement épaisse; quelquefois elle est tout à fait gluante.

$\$ 437$. L'arrière-bouche ou pharynx n'est pas séparée de la bouche par un voile mobile, comme chez les mammifères, et ne présente rien de remarquable. L'cesophage (fig. 232), parvenu vers la partie inférieure du cou, communique avec une première poche digestive, nommée jabot, dont les parois sont membraneuses. Les aliments séjournent pendant une certain temps dans cc premier estomac, dont la forme et la grandeur varient. C'est chez les granivores que le jabot est le plus développé; on le trouve aussi chez les oiseaux de proie; mais il manque chez l'autruche et chez la plupart des piscirores. Au-dessous de cette partie, l'œsophage se resserre de nouveau, et présente à quelque distance une seconrle dilatation appelée ventricule succenturié, dont la surface interne est criblée par un nombre considérable de petits pores communiquant avec des follicules, destinés à sécréter le suc gastrique; en général, le volume de ce second estomac est peu considérable; mais, chez les oiseaux qui manquent de jabot, il est beaucoup plus grand que de coutume, et paraît en tenir lieu. Enfin le ventricule succenturié s'ouvre inférieurement dans un troisième estomac nommé gésier, où la chymification s'achève; sa capacité varie beaucoup, mais c'est surtout dans sa structure qu'il présente des 


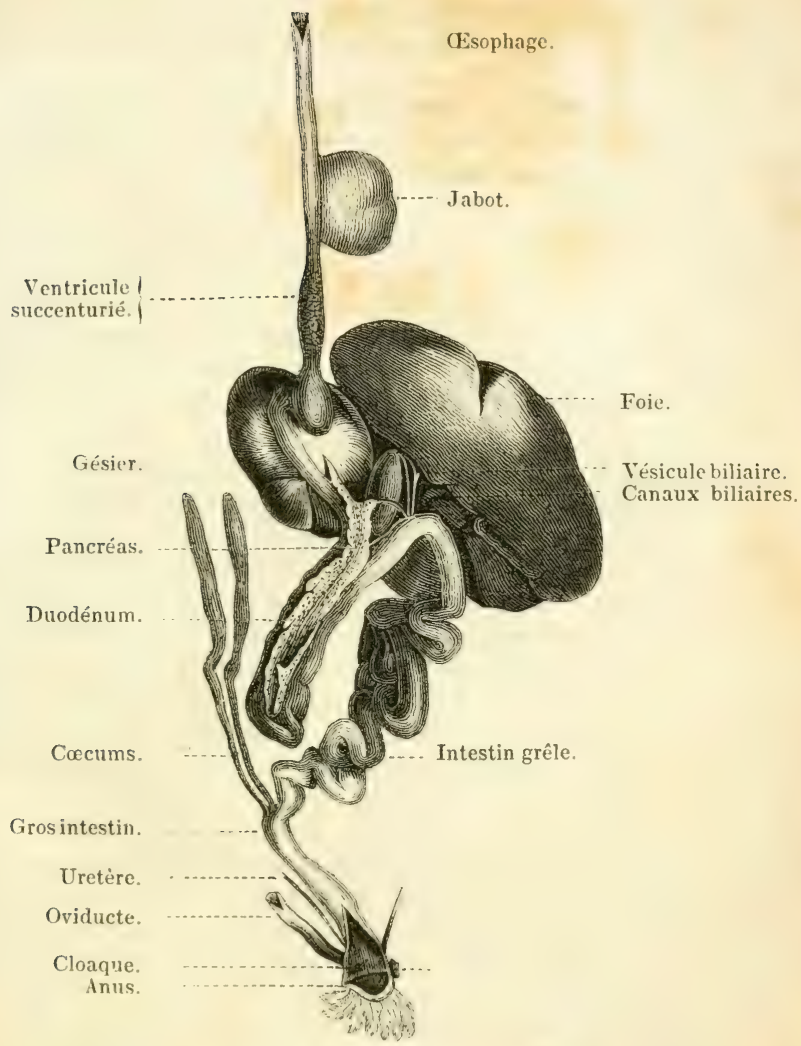

Fig 232. Appareil digeslif de la Poule.

différences importantes. Chez les oiseaux qui se nourrissent uniquement de chair, les parois du gésier sont minces et membraneuses; mais chez ceux (qui avalent des aliments plus durs et plus difficiles à digérer, il est garni de muscles puissants, destinés a comprimer ces matieres et a les broyer. C'est chez les granivores que cet organe est le plus musculaire: l'épaisseur de ses parois charnues est tres-considérable, et sa surface interne est revètuc d'une espeece d'épiderme prespue cartilagineux; sil force est im- 
mense . chez l'autruche, par exemple, on a vu les corps les plus durs ètre broyés par ses contractions, et il tient évidemment lieu d'un appareil masticateur.

L'intestin, qui fait suite à cette série d'estomacs, est beaucoup moins long que chez la plupart des mammifères, mais se compose aussi de deux portions : l'intestin grèle et le gros intestin. Le premier, après avoir formé une première anse, se contourne diversement; le second n'en diffère que peu et n'est pas boursouflé, mais en général s'en distingue facilement par l'existence dans leur point de jonction de deux appendices tubiformes, et terminés en cul-desac, que l'on appelle des cocums. Ces appendices manquent ou du moins sont très-petits chez la plupart des oiseaux de proie, mais sont généralement longs et assez gros chez les oiseaux granivores et omnivores.

Le foie est tres-rolumineux et remplit une grande partie du thorax, aussi bien que de la portion supérieure de labdomen : car ces deux cavités ne sont pas séparées, le muscle diaphragme étant réfluit à l'état rudimentaire. Cette glande est divisée en deux lobes à peu près égaux, et donne en général naissance à deux canaux hépatiques qui, après s'ètre réunis, débouchent dans l'intestin. Enfin, il existe presque toujours une vésicule du fiel qui ne reçoit. qu'une portion de la bile et la verse dans l'intestin par un canal particulier. Le pancréas est logé dans la première anse de l'intestin grèle; il est généralement long, étroit et plus ou moins divisé.

La rate, organe dont les usages ne sont pas bien connus. est petite. Les reins, qui sécrètent l'urine, sont au contraire très-volumineux et de forme irrégulière; ils sont logés derrière le péritoine, dans plusieurs fossettes creusées le long de la partie supérieure du bassin, et ne présentent pas, comme chez les mammifères, une substance corticale distincte. Les uretères aboutissent, de mème que les oviductes, près de l'anus, dans une partie dilatée de l'intestin rectum nommée cloaque (fig. 232); il n'existe point de vessie, et l'urine est évacuée arec les excréments. Ainsi que nous l'avons déjà dit, elle se compose presque entièrement d'acide urique, qui est très-peu soluble, et qui, en se desséchant, forme une masse blanchâtre.

$\$$ 438. Les produits nutritifs de la digestion passent de l'intestin dans le torrent de la circulation par des vaisseaux lymphatiques qui, en se remissant, forment deux canaux thoraciques; ces conduits souverent dans les reines jugulaires de change coté de la base dil cour. 
$\S$ 439. Le sang des oiseaux est plus riche en globules que celui des mammifères; et ces corpuscules, au lieu d'ètre circulaires, sont elliptiques (fig. 28). La manière dont ce liquide circule ne présente rien de particulier, et la route qu'il suit est la mème que chez les mammifères. En effet, le sang se rend du ventricule gauche du cœur aux artères, qui sont chargées de le distribuer à tous les organes; revient dans l'oreillelte droite du cœur; descend ensuite dans le ventricule droit, qui l'envoie aux poumons par l'intermédiaire des artères pulmonaires; revient de nouveau au cœur, puis descend dans l'oreillette gauche du cœur, et achève enfin le cercle circulatoire en entrant dans le ventricule gauche, d'où nous l'avons vu partir (fig. 37). Le cœur a la mème forme, la mème structure, la mème position et les mèmes enveloppes que chez les mammifères; les parois du ventricule gauche sont extrèmement épaisses, et le ventricule droit enveloppe le premier à droite et en dessous sans se prolonger jusqu'à la pointe de cet organe; les oreillettes n'ont pas d'appendice bien distinct à l'extérieur; enfin, l'aorte, dès sa naissance, se divise en trois grosses branches (fig. 233), dont les deux premières portent le sang à la tête, aux ailes, et aux muscles de la poitrine; et la troisième se recourbe en bas autour de la bronche droite, et constitue l'aorte descendante. Il existe aussi quelques particularités dans le mode de distribution des artères, mais elles sont peu importantes, et il est seulement à noter que, dans divers points du corps, ces vaisseaux constituent des plexus remarquables en s'anastomosant fréquemment entre eux. Le système veineux se termine par trois gros trones, dont l'un est l'analogue de la veine cave inférieure des mammifères, et les deux autres correspondent à peu près aux deux veines sous-clavières, qui ne se réunissent pas pour constituer un canal commun (ou veine cave supérieure), comme chez ces derniers animaux. 


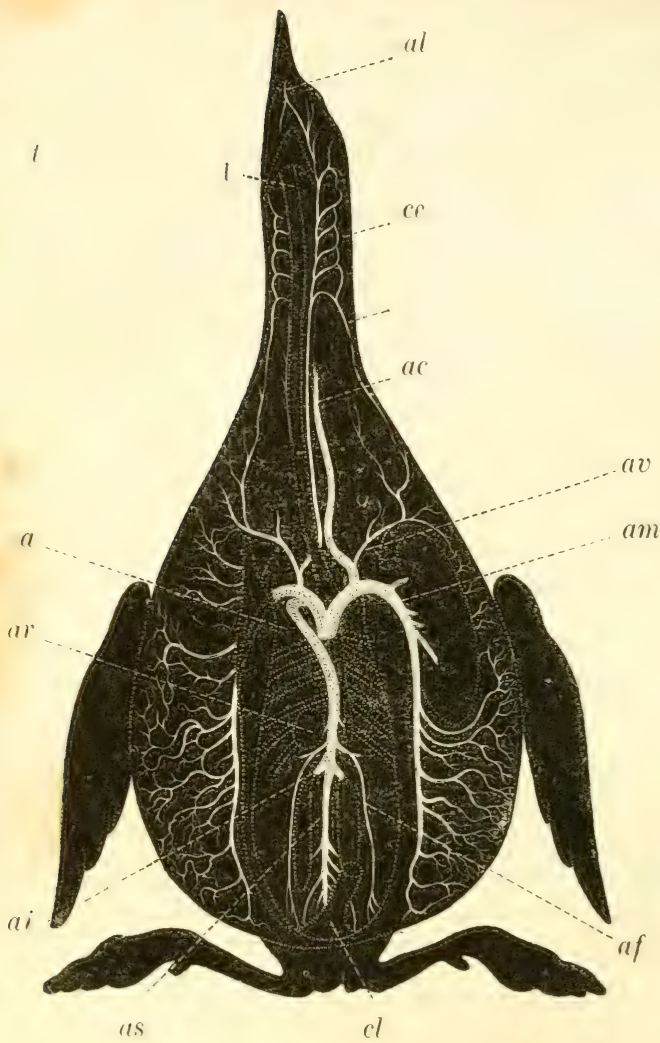

Fig. 233 Système arlériel d'un oiscau (1).

(1) Artìres de la grèbe : - $a$ artère aorte; - am l'une des grosses artères qui naissent de la crosse de l'aorte, laquelle, après avoir fourni l'artère carotide $(\alpha c)$ et l'artère sous-clavière, va se distribuer aux muscles de la poitrine et correspond à lartère mammaire des animaux mammifères; - $u v$ l'une des branches de l'artère vertébrale se rendant aix muscles de l'épanle; - ce anses artérielles formées par des branches de la carotide externe ; $-a l$ artère linguale; $-\ell$ la trachée-artère ; (1) artères rénales; - af artères fémorales; $-n i$ artère ischiatique allant aux membres inférieurs: - as artère sacrée faisant suite à l'aorte et donnant naissance à l'artère mésentérique inférieure, etc. ; $-c l$ le cloaque. 
$\$$ 4.40. L'appareil de la respiration offre des particularités plus importantes que celui de la circulation. Les poumons, comme nous l'avons déjà dit, communiquent avec de grandes cellules creusées dans le tissu cellulaire, et transmettent ainsi l'air dans toutes les parties du corps, de facon que la respiration est en quelque sorte double, le sang veineux se trouvant en contact avec l'oxygène, lors de son passage à travers les vaisseaux capillaires de tous les organes, aussi bien que lorsqu'il traverse les capillaires pulmonaires.

Les poumons ne sont pas divisés en lobes comme ceux des mammifères et sont loin de remplir le thorax, ils sont accolés aux còtes et présentent à leur surface inférieure plusieurs aurertures (fig. 234)

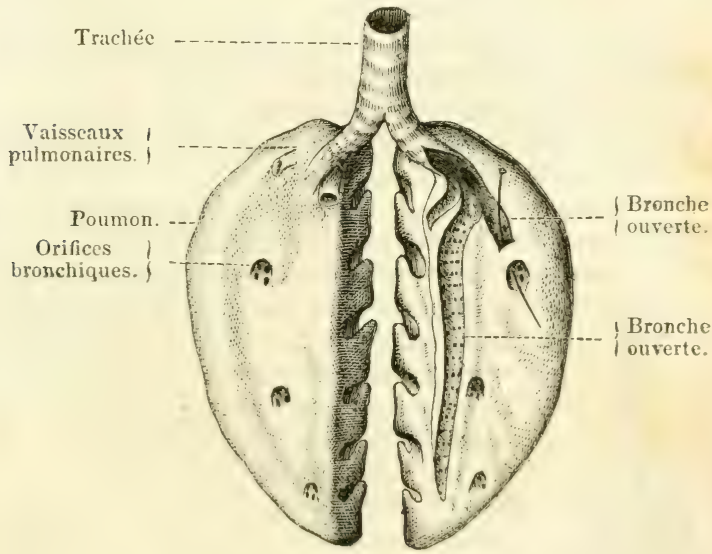

Fig. 234. Poumons d'un oiseau.

appartenant à des bronches qui les traversent de part en part et servent à porter l'air dans les cellules pneumatiques placées entre les divers organes de l'animal. Ces cavités sont formées par des cloisons membraneuses ou par des lames de tissu cellulaire, et communiquent les unes avec tes autres; on en roit dans le trone qui présentent des dimensions très-considérables, et d'autres qui se prolongent vers la tète et entre des muscles des membres : l'air se répand ainsi dans toutes les parties du corps, et, en général, pénètre jusque dans la substance des os.

L'examen des cellules aériennes, chez différents oiseaux, montre 
que la quantité d'air distribuée ainsi aux diverses partıes du corps est, toutes choses égales d'ailleurs, en rapport avec l'énergie et la continuité des mouvements de l'animal : ainsi chez les aigles, les éperviers et d'autres oiseaux grands voiliers, ce fluide pénètre dans tous les os; tandis que, chez ceux qui n'ont pas la faculté de voler, et qui ne marchent que lentement, comme les pingouins, etc., il est exclu de la plus grande partic ou mème de la totalité du squelette. En général, l'air se trouve en plus grande abondance dans les os des membres les plus employés dans la locomotion: dans l'autruche, par exemple, les cellules aériennes présentent dans le fémur un développement remarquable.

Les oiseaux sont de tous les animaux ceux dont la respiration est le plus active ; ils consomment proportionnellement plus d'oxygène que les mammifères, et ils résistent moins long-temps à l'asphyxie. Ce sont aussi les animaux qui produisent le plus de chaleur; la température de leur corps s'élève à $41^{\circ}, 42^{\circ}, 43^{\circ}$ et même 4.40 centigrades, et les plumes dont ils sont recouverts leur sont tresutiles pour empècher leur refroidissement lorsqu'ils s'élèvent dans l'atmosphère à des hauteurs considérables.

$\$$ 441. De mème que chez les mammifères, l'organe de la voix est une dépendance de l'appareil de la respiration, Le larynx supérieur est d'une structure très-simple et ne sert que peu ou point

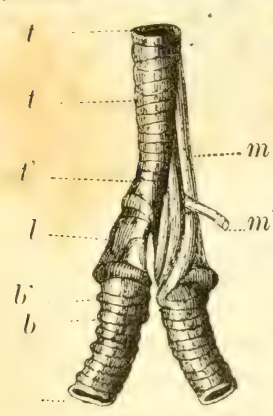

Fig. 235. (1). à la production des sons. Son ouverture a la forme d'une fente $(g, f i g .230, p .375)$ dont les bords ne peurent ni s'étendre ni se relâcher; et il ne s'y trouve ni ventricules, ni cordes vocales, ni épiglotte. Mais à l'extrémité inférieure de la trachée, il existe un second larynx dont le jeu est très-remarquable, et dont la structure est d'autant plus compliquée que I'oiseau module mieux son chant. Chez les oiseaux chanteurs, ce petit appareil se compose d'une espèce de tambour osseux ( fig. 235, l), dont l'intérieur est divisé inférieurement par une traverse de même nature que surmonte une membrane mince de forme semi-lunaire $(c, f i g$. 236). Ce tambour communique

(1) Larynx inférieur de la corneille : $-t$ trachée-artère; $-l$ ' tambour formé par l'extrémité inférieure de la trachée; $-l$ osselet moyen de la trachée; $-l$ ' premier arceau des bronches, séparé du troisième osselet du larynx par un espace membraneux; $-b$ bronches; $-m$ muscles propres du larynx - ces muscles ont été enlevés du côté opposé; - m' muscle abaisseur de la trachée. 
inférieurement avec deux glottes formées par la terminaison des bronches et pourvues chacune de deux lèrres ou cordes vocales; enfin des muscles dont le nombre varie suivant les espèces s'étendent entre les divers anneaux dont se composent ces parties, et les meuvent de manière à tendre plus ou moins fortement les membranes qu'elles soutiennent. Chez les oiseaux qui sont privés de la faculté de moduler les sons d'une manière compliquée, la cloison membraneuse dont nous avons parlé ci-dessus manque; et chez ceux qui ne chantent pas, il n'existe pas de muscles propres du larynx inférieur,

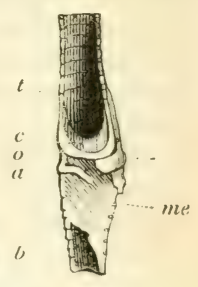

Fig. 236. (1). et l'état de la glotte ne peut ètre modifié que par ceux qui élèvent ou abaissent la trachée.

$\$$ 442. Les oiseaux sont ovipares et n'ont pas, comme les animaux de la classe précédente, des mamelles pour allaiter leurs petits. La durée de l'incubation (ou du temps que lo jeune oiseau met à se développer dans l'intérieur de l'œuf) varie dans les différentes espèces, mais elle est à peu près constante pour chacune de celles-ci ; pour l'oiseau-mouche, le plus petit des animaux de cette classe, elle est de douze jours seulement; pour les serins que nous élerons en domesticité, elle est de quinze à dix-huit jours, de vingt et un jours pour les poules, de vingt-cinq jours pour les canards, et quarante à quarante-cinq jours pour les cygnes. Un certain degré de chaleur est nécessaire à ce phénomène; celle dı soleil sufiit pour faire éclore les œufs de quelques oiseaux des régions intertropicales: mais, en général, il en est tout autrement, et, pour maintenir les œufs à la température convenable, la mère les recouvre de son corps et les dépose dans un lit propre à les abriter.

Quelques oiseaux se contentent, pour cela, de creuser dans la terre ou dans le sable une cavité arrondie; mais la plupart déploient, dans la construction de cette espèce de berceau, une adresse et un art remarquables; et une chose non moins surprenante, c'est la régularité avec laquelle toutes les générations suc'essives exécutent les mèmes travaux ot bailissent des nids exactenent semblables, lors mème que les circoustances ou ces animaux

11. Coupe verticale du larynx : $-\ell$ purtion inférieure de la trachée fendue par moitié; - c membrane semi-lunaire située au-dessus du point de réunion dés deux gluttes et fixée à une traverse osseuse $\langle\emptyset\rangle ;-a$ bourrelet que forme la livre interne de la glotte droite; - me face interne de la bronche droite formée par une membrane tympaniforme ; - b portion de la cavité de la bronche droite mise i nu par la section dune partie de cette membrane. 
ont été placés ne leur ont jamais permis d'en voir et de prendre des lecons de leurs parents; un instinct admirable les guide et les porte a prendre une foule de précautions dont ils ne connaissent pas d'avance toute l'utilité. Les parois du nid sont ordinairement bàties avec de petites tiges flexibles et quelquefois mastiquées avec de la terre délayée dans la salive gluante de l'animal; mais leur forme et leur disposition varient beaucoup, comme nous avons déjà eu l'occasion de le voir $(\$ 328)$. Presque tous en garnissent l'intérieur avec des substances molles qu'ils ramassent avec soin, ou mème

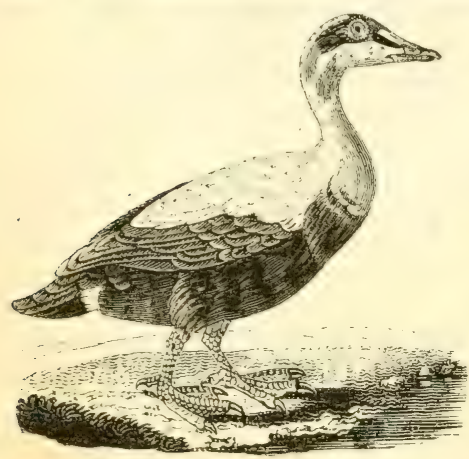

Fig. 237. L'Eider.

avec un duvet moelleux qu'ils arrachent de leur poitrine. La substance chaude et légère employée dans l'économie domestique sous le nom d'édredon n'a pas d'autre origine; elle pro vient d'une espèce de canard appelé eider (fig. 237), qui habite les îles des mers arctiques et qui a l'habitude de se dépouiller de la sorte pour garnir son nid avec le duvet arraché à sa poitrine et à son ventre.

La ponte a lieu, en général, une fois par an, quelquefois deux; et, dans l'état de domesticité, la fécondité devient encore plus grande. Le nombre des œufs est plus considérable chez les petites espèces que chez les grandes; les aigles n'en pondent qu'un ou deux; la mésange et le roitelet, quinze à vingt.

La constance avec laquelle ces oiseaux couvent leurs œufs est admirable; quelquefois les deux parents se partagent ce soin; d'autres fois le màle se borne à veiller aux besoins de la femelle pendant que celle-ci reste accroupie sur ses œufs; ct dans d'autres espèces, c'est la mère qui s'occupe seule de l'incubation. En ggénéral, ce n'est qu'à regret et poussée par la faim qu'elle quilte pour quelques instants sa progéniture; et lorsque ses petits sont éclos, son instinct maternel la porte à leur prodiguer les soins les plus tendres: elle les recouvre de ses ailes pour les príserver du froid, et leur apporte une nourriture choisie, que souvent elle dégorge dans leur gosier après l'avoir à moitié digéréc pour la rendre plus appropriée à leur estomac délicat. On la voit aussi guider leurs premiers pas, leur apprendre a se servir de leurs ailes, et, 
lorsqu'un danger les menace, déployer pour les sauver autant de courage que de dévouement, et on pourrait presque dire d'intelligence. Il est cependant quelques oiseaux qui déposent leurs œufs dans des nids qui ne leur appartiennent pas, afin de les faire couver par des nourrices étrangères : tel est le coucou, qui pond ses œufs un à un dans des nids de fauvettes, de bruants, de merles ou de quelque autre oiseau insectivore ayant l'habitude de nourrir ses petits avec des aliments convenables aussi pour les jeunes coucous; et, chose remarquable, la couveuse qui s'y trouve devient pour ces intrus une mère tendre et infatigable, quorqu'ils la privent de sa propre progéniture. Suivant quelques naturalistes, les vieux coucous ont le soin de détruire les œufs qu'ils trouvent dans le nid auquel ils confient le leur; mais d'autres observateurs assurent que c'est le jeune coucou lui-mème qui se charge de les rejeter de sa demeure ou d'en expulser, aussitòt après leur naissance, les petits dont il usurpe la place. L'illustre Jenner, médecin anglais, à qui on doit la découverte de la vaccine, nous dit avoir vu bien des fois le manége au moyen duquel ce petit intrus se débarrasse de ses faibles compagnons; le jeune coucou se glisse sous l'un des petits oiseaux dont il partage le berceau, et parvient bientòt à le placer sur son dos où il le retient à l'aide de ses ailes; ensuite, se trainant à reculons jusqu'au bord du nid, il le jette par-dessus ; puis il recommence les mèmes mouvements pour un second et ainsi de suite jusqu'à ce qu'il reste maitre de sa demeure. On ne connait pas bien la cause qui détermine les coucous à abandonner ainsi à d'autres oiseaux le soin de l'incubation. Ils restent souvent par paires dans le voisinage de l'endroit où les œufs ont été dépo. sés; et leurs petits, quand ils sont assez forts pour voler, quittent leurs premiers pourvoyeurs, et rejoignent leurs parents naturels, qui se chargent de compléter leur éducation.

L'instinct qui porte l'oiseau à couver ses œufs est, en général, des plus puissants; et cependant cette impulsion, en quelque sorte aveugle, est susceptible d'ètre, jusqu'it un certain point, modifiée par les circorstances extérieures. Ainsi les autruche's couvent leurs œufs lorsqu'elles lrabitent les climats tempérés, mais en abandonnent l'incubation a la chaleur des rayons solaires lorsqu'elles vivent sous la zone torride. Il paraitrait aussi que souvent plusieurs de ces grands oiseaux réunissent leurs $\propto u f s$ dans un mème trou et se relayent à tour de ròle pour les couver.

$\$$ 413. Les soins que les oiseaux donnent à leur progéniture sont un sujet d'observation plein d'interèt; mais un instinct plus singulier, et par conséquent plus remarquable encore, est celui qui purte 
certaines especes a changer de climat suivant les saisons, et a faire, à des époques déterminées de l'année, des royages plus ou moins longs (royez $\$ 323)$. Quelques espèces émigrent ainsi pour fuir le froid ou pour chercher une température moins élevée, et vont dans le midi ou dans le nord pour pondre ou pour y passer le temps de la mue; d'autres changent de pays pour se procurer plus facilement des moyens de subsistance : la plupart des insectivores sont dans ce cas; mais il est des oiseaux qui exécutent des voyages réguliers sans y ètre sollicités par aucune cause appréciable et sans que leur déplacement paraisse porter aucun changement bien notable dans les conditions où ils se trouvent. Du reste, quelle que soit la circonstance qui rende la migration périodique des oiseaux utile à eux-mèmes ou à leur progéniture, il est bien évident que ce n'est pas elle qui en est ordinairement la cause déterminante; les oiseaux voyageurs éprourent, à certaines époques de l'année, le besoin de changer de place, comme ils épronvent dans d'autres moments le désir de construire leur nid sans y ètre portés par un calcul intellectuel ou par la prévision des avan tages qu'ils en recueilleront. C'est un instinct aveugle qui, en général, les pousse, et qui se développe quelquefois indépendamment de tout ce qui peut influer dans le moment sur le bien-ètre de l'animal. Ainsi. dans des expériences faites sur quelques oiseaux voyageurs de nos pays, on a vu ce besoin se manifester avec force à l'époque ordinaire, bien qu'on eùt le soin de maintenir autour de ces animaux une température constante, de leur donner une nourriture convenable, et qu'on eùt eu la précaution de choisir de jeunes individus qui n'avasent pas encore pu contracter l'habitude des migrations. Lorsqu'ils changent de climat, ils n'attendent pas pour partir que le froid leur soit devenu insupportable, et ils ne sont pas repoussés peu à peu vers le midi par les empiétements de l'hiver; mais ils les précèdent et se transportent de suite et presque tout d'un trait dans les régions tropicales; souvent on les voit revenir au printemps, lorsque la température est encore audessous de ce qu'elle était au moment de leur départ; et, pour certaines espeeces, nous le répétons, les migrations ne coincident avec aucune circonstance extéricure appréciable. Ce phénomène est, par conséquent, inexplicable; mais en cela il ne diffère pas de tous ceux que détermine l'instinct, el à mesure que nous arancerons dans l'étude des animaux, nous aurons l'oceasion d'en voir un grand nombre qui ne sont ni moins intéressants ni moins incompréhensibles.

Mais de ce yue les migraltions dépendent d mone impulsion instine- 
tive et aveugle, il ne faut pas en conclure que les circonstances extérieures soient sans influence sur le développement du besoin que les oiseaux voyageurs éprouvent de changer d'habitation; on remarque, au contraire, que ce phénomène coïncide, en général, avec des variations atmosphériques, et que le moment de l'arrivée et du départ est souvent avancé ou retardé, suivant que la saison froide se prolonge plus ou moins.

L'époque à laquelle les oiseaux voyageurs arrivent dans nos pays, ou les quittent, varie suivant les espèces; ceux qui sont originaires de régions les plus septentrionales de l'Europe nous viennent à la fin de l'automne ou au commencement de l'hiver, et, dès les premiers beaux jours, fuyant la chaleur comme ils avaient fui l'excès du froid, retournent vers le nord pour y faire leur ponte; d'autres oiseaux qui naissent toujours dans nos contrées, et qui doivent par conséquent ètre considérés comme étant essentiellement indigènes, nous quittent en automne, et, après avoir passé l'hiver dans les climats chauds, reparaissent parmi nous au printemps, ou bien, évitant au contraire la chaleur modérée de notre été, émigrent alors vers les régions arctiques; il en est d'autres encore 'qui, natifs des pays méridionaux, s'élèvent vers le nord pour échapper à l'ardeur du soleil d'été, et nous arrivent au milieu de la belle saison. Enfin, on en voit aussi qui ne séjournent jamais dans nos contrées, et qui dans leurs migrations annuelles ne font qu'y passer. L'époque de l'arrivée et du départ de ces voyageurs est, en général, déterminée d'une manière très-précise pour chaque espèce, et l'expérience a appris que dans certaines localités les chasseurs pouvaient compter sur l'arrivée de tels ou tels oiseaux, comme sur une rente dont les termes écherraient à jour fixe. L âge y apporte cependant quelque différence : on voit ordinairement les jeunes ne se mettre en route que quelque temps après les adultes; et cela paraît dépendre de ce que, la mue ayant lieu plus tard chez eux que chez ces derniers, ils ne sont pas encore rétablis de l'espèce de maladie qui accompagne ce phénomène au moment où ceux-ci sont déjà en état de supporter les fatigues du voyage.

$\$$ 44. Un autre fait non moins curieux dans l'histoire des oiseaux est la faculté à l'aide de laquelle ces animaux s'orientent dans un pays inconnu et savent reconnaitre à des distances immenses la route à suivre pour regagner leur nid. Les pigeons voyageurs nous ont déjà offert un exemple remarquable de cel instinct ou sens incompréhensible pour l'homme $(\$ 339)$; les hirondelles nous en fourniront également. Ces petits oiseaux font, 
comme nous l'avons déjà dit $(\$ 323)$, des voyages bien longs; et cependant, par un instinct singulier, ils savent au printemps suivant retrouver les lieux où ils ont déjà niché et ils y reviennent toujours. On s'est assuré de ce fait en attachant à la patte de plusieurs hirondelles de petits cordons de soie pour constater leur identité. Elles construisent leur premier nid dans le voisinage de celui où elles sont nées; l'hirondelle de cheminée bâtit chaque année le sien au-dessus de celui de l'année précédente, el l'hirondelle de fenètre s'établit dans celui qu'elle avait quitté à l'automne. Un célèbre physiologiste italien du siècle dernier, Spallanzani, a vu, pendant dix-huit années consécutives, les mèmes couples revenir à leurs anciens nids sans presque s'occuper de les réparer. Les hirondelles montrent aussi dans d'autres occasions la singulière faculté de se diriger vers un lieu déterminé dont elles sont éloignées d'une distance considérable; si on transporte au loin une couveuse renfermée dans une cage et qu'on lui donne sa liberté, elle s'élève d'abord très-haut comme pour examiner le pays, puis se dirige en ligne droite vers l'endroit où elle a laissé sa couvée. Spallanzani a répété avec succès cette expérience à diverses reprises, et a vu un couple d'hirondelles de rivière, qu'il avait transporté à Milan, se rendre en treize minutes auprès de ses petits laissés à Pavie.

$\S 4$ 40. L'instinct de la sociabilité est aussi très-développé chez certains oiseaux : nous avons déjà eu l'occasion de parler de la manière dont plusieurs de ces animaux se réunissent par légrions innombrables pour voyager de concert, et des secours mutuels qu'ils se prêtent quelquefois $(\$ 329,331,338)$; mais il est à noter que cet instinct ne se développe guère que chez les espèces destinées à se nourrir d'insectes ou de substances végétales, et que les oiseaux de proie vivent presque toujours solitaires ou réunis seulement par paires.

$\$ 446$. Les oiseaux, de mème que les mammifères, varient aussi entre eux par la manière dont ils se procurent leur nourriture; la plupart ne la cherchent que de jour, mais on en connaît aussi qui sont nocturnes ou qui ne prennent le vol que pendant le crépuscule, et il est digne de remarque que tous ces derniers ont en général des couleurs sombres et le plumage moelleux, de façon que leurs ailes frappent l'air sans bruit, comme si le Créateur, dans sa prévoyance infinie, avait voulu favoriser ainsi la chasse à laquelle ces animaux se livrent au milieu de l'obscurité. Les diverses espèces de la famille des hiboux, les engoulevents, etc., nous offrent des exemples de cette coïncidence entre les mœurs de l'oiseau et la nature de son plumage. 
$\$ 447$. Le nombre d'espèces d'oiseaux connues des naturalistes est d'environ cinq mille; et comme l'organisation de ces animaux présente une grande uniformité, leur classification offre des difficultés considérables ; les caractères dont on se sert pour les diviser en ordres, en familles et en genres sont fournis principalement par la conformation du bec et des pattes, organes dont la structure est en rapport avec le régime de ces animaux. Cuvier, dont nous suivons ici la méthode, les partage ainsi en six ordres, savoir : les Rapaces, les Passereaux, les Grimpeurs, les Gallinacés, les Echassiers et les Palmipèdes.

$\$ 448$. Les Rapaces ou orseaux de proie se reconnaissent à la puissance de leurs serres et de leur bec : la mandibule supéricure est robuste, recourbée vers le bout et terminée en une pointe aiguiè propre à déchirer la chair des animaux dont ils se nourrissent; et les doigts, également vigoureux, sont garnis d'ongles crochus ef puissants, à l'aide desquels ils saisissent leur proie. En çénéral, toutes les parties de leur corps indiquent une force considérable, et leur aspect dénote leur caractère farouche. Les uns sont diurnes, et se reconnaissent à leur plumage serré et à leurs yeux dirigés latéralement : ce sont les vautours (fig. 222), les gypaètes (fig. 238), les faucons, les aigles ( fig. 214), les éperviers, les milans (fig. 219),

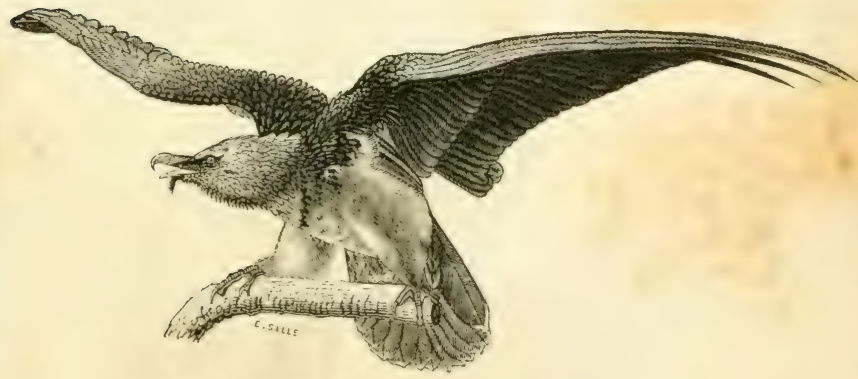

Fig. 238. Gypaìte ou Vaulour des agneaux.

les buses, etc. ; les autres sont nocturnes, et constituent la famille des hiboux (fig. 239), caractérisée par un plumage lìche ef par la direction antérieure des yeux. 


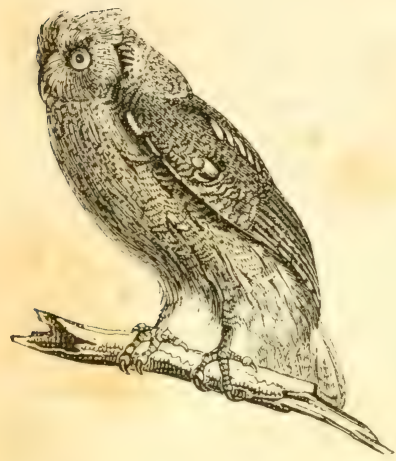

Fig. 239. Hibou (Scops rulgare).

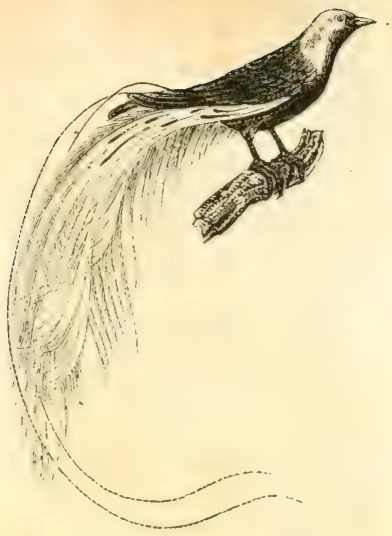

Fig. 210. Oiscau du Paradis.

$\$ 49$. Les Passereaux ont les pattes grèles, faibles et conformées de la manière ordinaire, c'est-a-dire ni palmées, ni armées d'ongles crochus et puissants, ni allongées en forme d'échasses, et ayant un seul doigt dirigé en arrière. Leur bec est faible (fig. 241), droit et peu ou point crochu (fig. 2.2, 243); leurs ailes

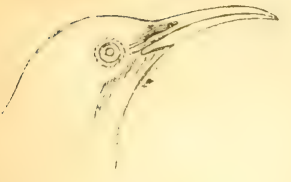

Fig. 241. Silelle

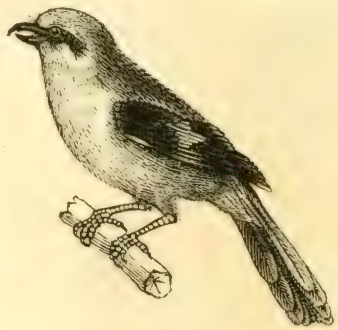

Fig. 242. Pie-grièche.

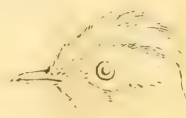

Fig. 213. Roilelel.

assez grandes; enfin, ils sont tous de petite ou de moyenne taille, et ils ont en général des formes sveltes et légères. Les uns sont insectivores, d'antres sont granivores, ot d'autres encore sont omni- 
vores, et c'est dans cet ordre que se rangent tous les oiseaux chanteurs et la plupart des oiseaux de passage. Le nombredes passereaux est immense, et nous nous bornerons à citer comme exemples les pies-grièches (fig. 242), les merles, les fauvettes, les hirondelles, les engoulevents ( $\mathrm{fg} .225)$, les alouettes, les moineaux, les corbeaux, les oiseaux de paradis (fig. 240), les colibris ou oiseaux-mouches (fig. 244), les roitelets (fig.243), les mar-

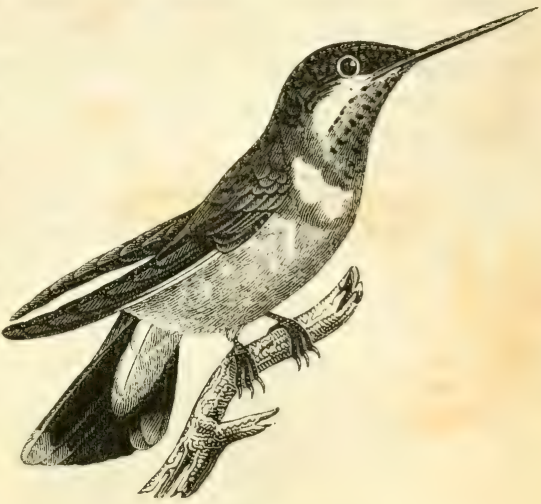

Fig. 244. Collbri. tins-pècheurs ( $\mathrm{fig} .226$ ) et les calaos ( $\mathrm{fig}$. 229).

$\$$ 40. Les Grimpeurs sont des oiseaux qui, avec le régime et

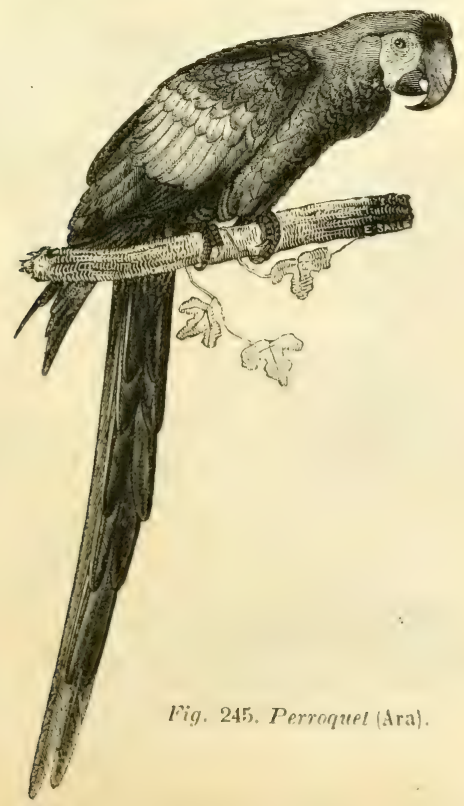


l'organisation ordmaire des passereaux, ont les doigts dirigés deux en avant et deux en arrière, disposition qui leur permet de se mieux cramponner au tronc et aux branches des arbres sur lesquels ils grimpent dans toutes les directions, quelquefois mème en se servant de leur bec pour faciliter leurs mouvements. On range dans cette division les toucans, remarquables par leur énorme bec, les perroquets ( $f g .245)$, les coucous, les pies (fig. 211), etc.

$\S 451$. Les Galdinacés ont le bec médiocre, renflé en dessus et propre seulement à un régime granivore : les ailes courtes, le corps

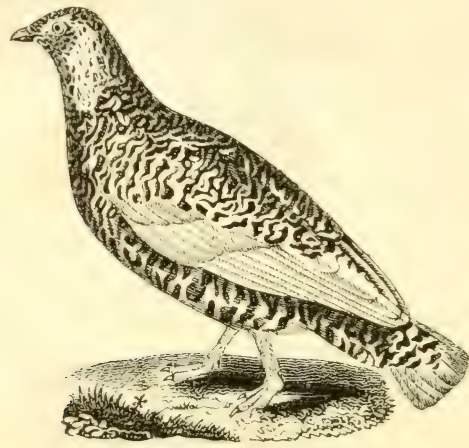

Fig. 246. Lagopìde ordinaire.

lourd, les pattes médiocres et les doigts faibles, mais réunis ordinairement à leur base par un petit repli cutané. La plupart de ces oiseaux

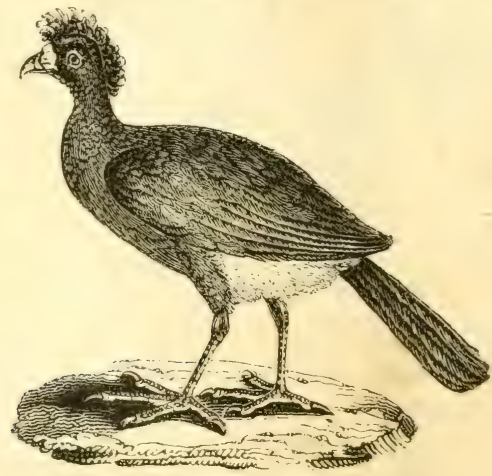

Fig. 247. Le Hocco commun. 
volent mal, ne nichent pas sur les arbreset cherchent leur nourriture à terre. Cet ordre se compose de deux familles bien distinctes, celle des pigeons et celle des gallinacés proprement dits, comprenant le coq, les faisans, les paons, les dindons, les pintades, les hoccos (fiy. 217), les perdrix, les cailles, les lagopèdes ou perdrix de neige (fig. 246), les coqs de bruyère, etc.

$\$ 403$. Les Ecmassiens se reconnaissent à leurs tarses très-élevés et a leurs jambes dénuées de plumes vers le bas, disposition qui les fait paraître comme montés sur des échasses, et qui est très-favorable, soit à la rapidité de la course, soit au passage à gué dans des eaux peu profondes. Leur taille est en général élancée, et la longueur de leur cou est telle que, tant haut montés qu'ils soient sur leurs pattes, ils peuvent, sans se baisser, ramasser à terre leurs aliments. Les uns se nourrissent d'herbes, les autres de reptiles aquatiques, de mollusques, de petits poissons, etc.

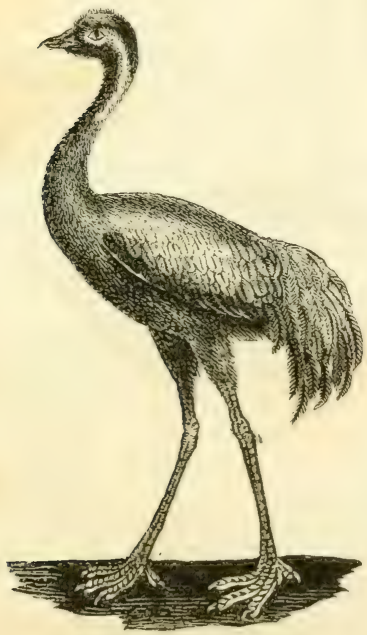

Fig. 248, La Grue.

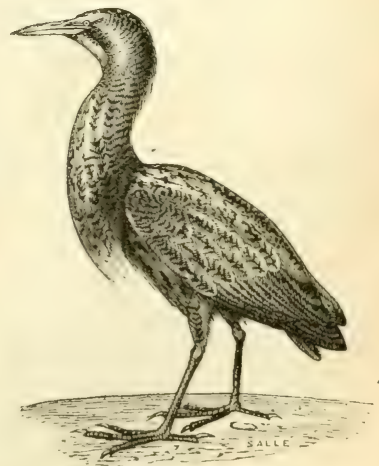

Fig. 249. Butor d'Europe.

On range dans cette division les oiseaux de rivage, tels que les hérons, les grues (fig. 248), les cigognes (fig. 223), les butors (fig. 249). les bécasses, les ibis (fig. 212), les échasses (fig. 216), les poules d'eau, les flamants ( $f i y .2: 30)$, ete., et quelques autres genres qui n'habitent pas dans le voisinage des eaux, mais qui ressemblent. 
aux précédents par leur conformation, les autruches (fiy. 21 i), les casoars (fig. 204) et les outardes, par exemple.

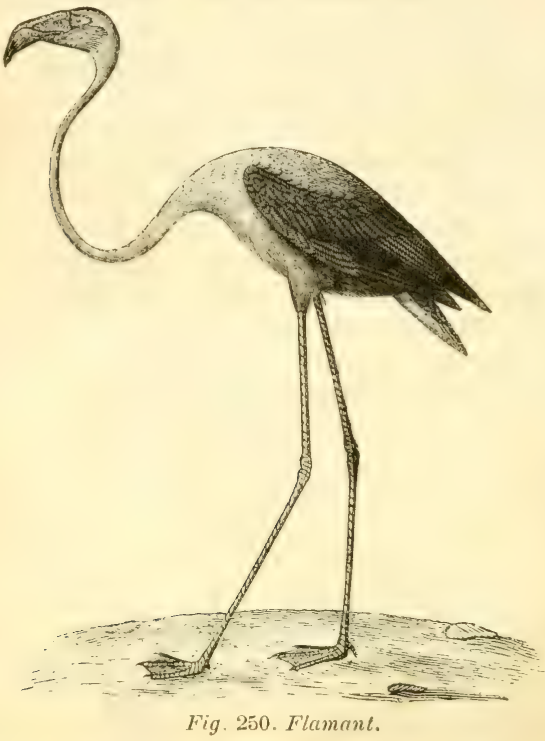

$\$$ 43.3. Enfin, les Palmipèdes, ou orseaux Nagetrs, sont caractérisés par leurs pattes, de longueur médiocre, terminées par une

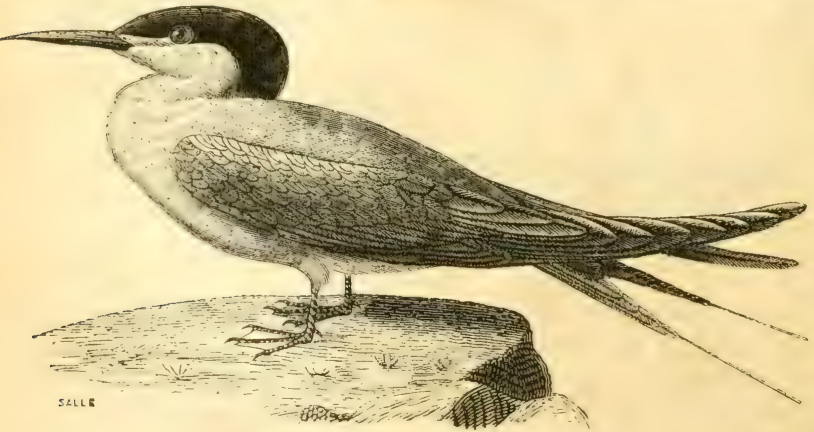

Fig. 251. Hirondelle de mer. 
large nageoire. Ces rames sont formées par les doigts réunis à l'aide d'un repli de la peau, et sont en général placées très-loin en arrière; ce qui est favorable à la nage, mais rend la marche difficile. Nous citerons comme exemples de ce groupe les manchots (fig. 243) et les pingouins, qui ont les ailes si courtes qu'elles ne peuvent servir au vol; les pétrels, les albatros, les mouettes et les sternes ou hirondelles de mer (fig. 2̈̈l), qui ont au contraire les ailes longues et le vol puissant; les pélicans (frg. 228), les frégates (fig. 209) et les fous, qui sont non moins bien organisés pour le vol que les précédents, et se font remarquer par une palmure encore plus complète des pattes; enfin, les cygnes, les oies et les canards ( $f g .217$ ), dont le bec est revètu d'une peau molle, au lieu d'ètre garni de corne.

\section{CLASSE DES REPTILES.}

$\$$ 434. La classe des reptiles comprend tous les animaux vertébrés à sang froid, dont la respiration (à l'état parfait, sinon dans le jeune âge) est aérienne et incomplete. Ils ont des poumons comme les mammifères et les oiseaux; mais leur appareil circulatoire est toujours disposé de manière à ce qu'une partie du sang veineux se mèle au sang artériel sans avoir traversé l'organe respiratoire, et en général ce mélange s'opère dans le cœur, qui ne présente qu'un seul ventricule dans lequel s'ouvrent les deux oreillettes (\$108).

Par leur forme générale, les reptiles se rapprochent des mammifères plus que des orseaux; mais, du reste, ils offrent à cet égard beaucoup de variations, comme on peut le voir en comparant entre eux une tortue (fig. 233$)$, un crocodile (fig. 23:), un serpent

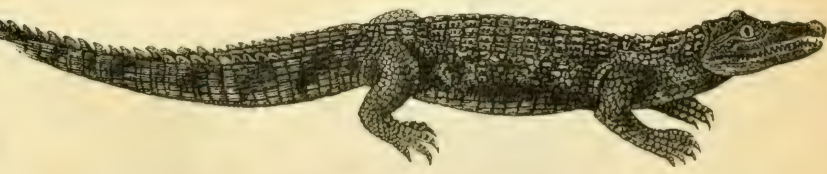

Fig. 252. Crocodile.

lfig. 2:30) et un crapaud (fig. 2:34). Leur tète est presque toujours pelite, et leur corps tres-allongé; quelques-uns, tels que les serpents, manquent complétement de membres ou n'en ont que des vestiges (fiy. 2.̈6); mais la plupart de res animaux, le lérard on

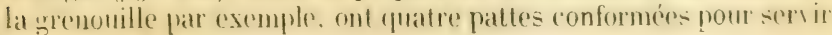


à la marche ou à la nage. Du reste, ces membres sont d'ordinaire trop courts pour empècher le tronc de traìner à terre, et, au lieu

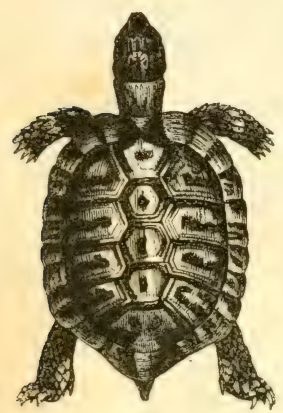

Fig. 253. Torlue grecque.

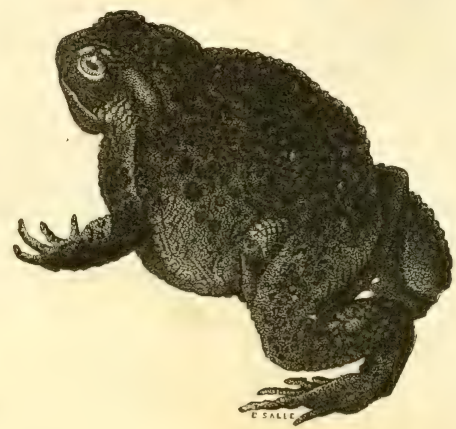

Fig. 254. Crapaud.

d'ètre dirigés parallèlement à l'axe du corps et de se mouvoir dans ce sens, ils se portent en général de còté et se meuvent de dehors en dedans perpendiculairement à cet axe, disposition qui est très-défavorable a la locomotion : aussi la plupart des reptiles

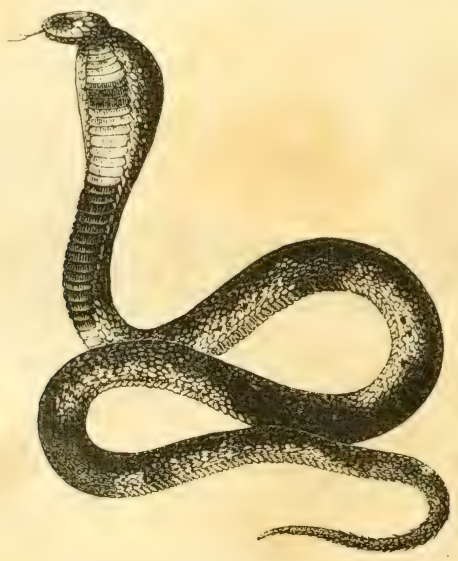

Fig. 255. Naja Aspic. 
ont-ils lair de ramper sur le sol plutòt que de marcher, et c'est de là que leur vient leur nom.

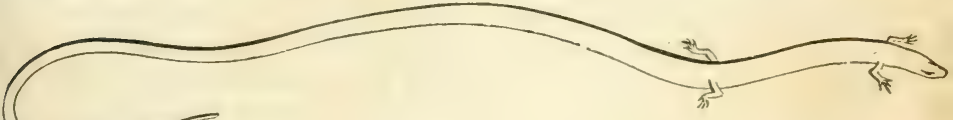

Fig. ¿56. Chalcide.

$\S 40 ̈ 3 ̈$. Leur squelette présente dans sa structure des variations bien plus grandes que celui des animaux vertébrés à sanğ chaud; toutes les parties dont il se compose peuvent tour à tour manquer, si ce n'est la tète et la colonne vertébrale; mais les os qui s'y trouvent conservent toujours une grande ressemblance avec ceux des mammiferes et des oiseaux, et se reconnaissent facilement pour cn ètre les analogues.

$\$$ 456. Le crâne est toujours petit et la face allongée; la màchoire inférieure est composée de plusieurs pièces comme chez les oiseaux et s'articule aussi à un os distinct du temporal (l'os carré ou tympanique); quelquefois mème cet os est à son tour suspendu à un levier mobile (fig. 269), disposition qui augmente beaucoup la dilatabilité de la bouche, comme nous le verrons bientòt en parlant de la déglutition chez les serpents. La màchoire supérieure est en général immobile, mais chez les serpents elle est articulée de façon à exécuter quelques mouvements; chez plusieurs reptiles, les lézards et les tortues, par exemple, les os du cràne se prolongent latéralement au-dessus des tempes, en manière de bouclier, et donnent ainsi à la tòte une longueur considérable. Enfin, la tète est en générał peu mobile, et s articule sur la colonne vertébrale au moyen d'un seul condyle à plusieurs facettes.

$\$$ 4:7. Les os du trone offrent, dans leur disposition et leur nombre, des variations plus considérables. Chez les lézards, les crocodiles et les autres reptiles conformés à peu près de la meme maniere, on n'y remarque, en général, que peu d'anomalies: et il est seulement à noter que les cótes sont plus nombreuses que chez les mammifères ou les oiseaux, et garnissent l'abdomen aussi bien que la portion thoracique du corps. Chez les serpents le sternum manyue ainsi que les os des membres, et les còtes, dont le nombre est très-considérable, sont libres par leur extrémité inférienre; on en compte quelduefois plus de trois cents paires, chez la couleure, par exemple, et elles sont assez mobiles pour fue lamimal puisise 
s'en servir comme d'arcs-boutants dans ses mouvements de reptation ; les vertèbres jouissent aussi d'une grande mobilité et s'articulent entre elles au moyen d'une tubérosité reçue dans une cavité correspondante et maintenue à l'aide de ligaments. Chez les grenouilles le squelette offre une disposition inverse, car les còtes manquent tout à fait, et le sternum est, au contraire, très-développé et réuni aux os de l'épaule pour constituer une sorte de ceinture autour de la poitrine. Mais c'est chez les tortues que la disposition de ces os est le plus remarquable, car ils constituent deux grands boucliers entre lesquels l'animal peut, en général, se retirer tout entier. L'un de ces boucliers occupe le dos et se nomme carapace; l'autr., situé sous le ventre (fig. 2\%7), se nomme plastron, et de chaque còté ils sont unis entre eux de facon à laisser en avant et en arriere une ouverture servant au passage de la tète, des jattes et de la queue. Cette espèce de cuirasse n'est recouverte que par la peau, qui, à son tour, est en grénéral garnie de larges plaques écailleuses : (1 tous les muscles et autres parties molles sont renfermés dans la srande cavité ainsi formée.

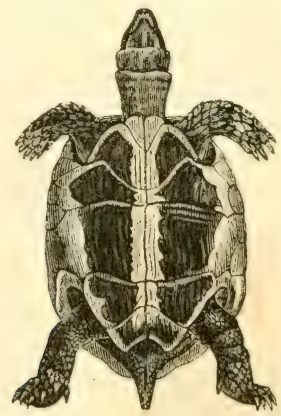

Fig. 257. Toilue grecque (vue en dessous).

\$. 4:8. La charpente osseuse des tortues, pour présenter cette disposition insolite, a dù ère, comme on le pense bien, profondément modifiée : on y retrouve cependant les mèmes pièces constituantes que chez les animaux vertébrés normaux ; seulement, plusieurs de ces piecess ont changé de forme et de volume.

Lorspḷion examine la carapare par sal face superieure, on roit

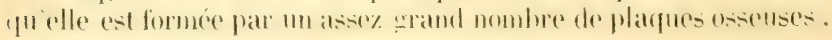


unies entre elles par dies sutures, et dont huit occupent la ligne inédiane; seize constituent de chaque còté de celles-ci une rangée longitudinale, et vingt-cing ou vingt-six entourent le tout comme un cadre ovalaire. Il est alors difficile de reconnaitre la nature de ces os; mais si on examine la carapace par sa face inférieure (fig. 238 ), on voit aussitòt que les pièces médianes dont nous venons de parler ne sont autre chose que des dépendances des ver-

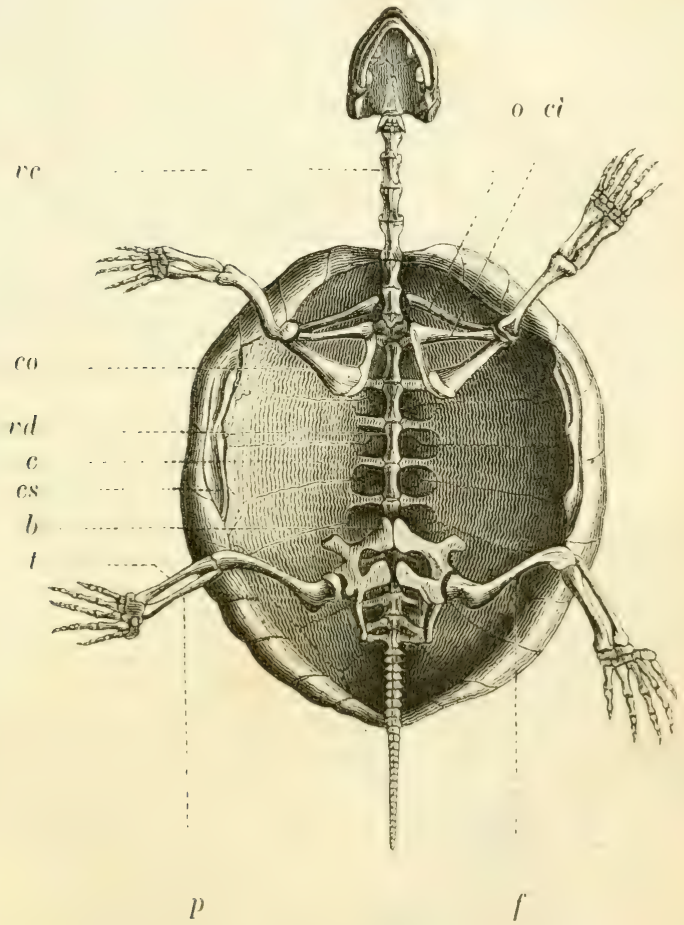

Fig. 258. Squeletle de Torlue (1).

(1) Squelette d'une tortue de terre dont on a en'evé le plastron : - ve vertèbres cervicales; $-v d$ vertebres dorsales; $-c$ cites: $-c s$ cites sternales ou pirces marginales de la carapace: - o omoplate; - cl clavicule; - co os conatcoülien : - $b$ bassin ; $-f$ rémur ; $-\ell$ tibia ; $-p$ péroné. 
tèbres dorsales $(v d)$. En dessous se trouve effectivement le corps de chacun de ces os avec sa forme ordinaire, ainsi que le canal vertébral servant à loger la moelle épinière; mais la portion supérieure des parois de l'anneau qui constitue ce canal, au lieu d'avoir, comme de coutume, la forme d'une bande osseuse transversaie, séparée de ses congénères par un espace vide, et d'ètre surmontée d'une apophyse épineuse, est ici élarơie en manière de disque, et se continue sans interruption avec les plaques analogues appartenant à la vertèbre qui précède et à celle qui suit. Ces vertèbres dorsales, devenues ainsi immobiles, portent chacune une paire de côtes comme chez l'homme et la plupart des autres animaux vertébrés; mais ces côtes $(c)$ s'élargissent au point de se toucher dans toute ou presque toute leur longueur, et de s'articuler entre elles par des sutures; enfin, les pièces marginales (cs) qui s'articulent avec l'extrémité des còtes et qui bordent en quelque sorte la carapace, représentent évidemment la portion sternale de ces os, qui, chez les mammiferes, restent à l'état cartilagineux, mais qui, chez les oiseaux, sont complétement ossifiés. Dans quelques torlues, elles restent mème cartilagineuses, et, chez presque tous ces animaux, plusieurs d'entre elles s'appuient latéralement sur les bordś du plastron.

Le plastron est formé par le sternum, qui présente un développement extraordinaire et s'étend depuis la base du cou jusqu'à l'origine de la queue (fig. 257). Les pièces qui entrent dans sa composition sont au nombre de neuf, et, au lieu d'ètre placées toutes à la file les unes des autres comme chez les mammifères, elles sont, à l'exception d'une seule, rangées par paires, et soudées ou articulées entre elles, de façon à former une grande plaque ovalaire. Tantòt ce bouclier est entier et solide dans toute son étendue ; tantòt il est divisé en trois portions, dont l'antérieure et la postérieure sont un peu mobiles, et d'autres fois encore il est évidé au centre en manière de cadre ; enfin, de chaque còté, il est fixé à la carapace, soit par un large prolongement osseux, soit par des cartilages, et, en avant comme en arrière, il en reste écarté pour laisser passer la tète, les membres et la queue.

La carapace et le plastron, ainsi que nous l'avons déjà dit, ne sont recouverts que par la peau; aucun muscle ne s'insère à leur stirface extérieure, et c'est par conséquent dans l'intérieur du tronc que vont se fixer ceux du cou et des membres. L'épaule, au lieu de s'appuyer sur la face externe des parois du thorax, se loge également dans l'intéricur de cette cavité, et le bassin est, pour ainsi dire, rentré dans l'intérieur de l'abdomen. 
Les os de l'épaule $(o, c l, c o)$ s'articulent avec la colonne vertébrale, d'une part, et avec le sternum, de l'autre, de facon à former une sorte d'anneau entre la carapace et le plastron. On y distingue trois branches qui souvent se soudent ensemble de bonne heure et qui convergent vers la cavité articulaire de l'humérus, qu'elles forment en se réunissant. L'un de ces os (o), suspendu à la colonne vertébrale, est évidemment l'omoplate; le second, qui se dirige en arrière $(c o)$, est l'analogue de l'os coracoïdien des oiseaux; et le troisième $(c l)$, qui descend se joindre au plastron, est le représentant de la clavicule, ou du moins de l'apophyse acromion de l'omoplate, avec laquelle cet os s'articule d'ordinaire.

Le bassin (b) ressemble beaucoup à la ceinture formée par les os de l'épaule. Il se compose de trois paires de pièces distinctes : un os iliaque, qui s'attache aux apophyse's transverses des vertèbres postérieures de la carapace; un pubis et un ischion, qui l'un ef l'autre se dirigent vers le plastron et se réunissent à leurs congénères.

$\$ 4: 39$. Chez d'autres reptiles, les os de l'épaule ressemblent davantage à ce que nous avons déjà vu chez les oiseaux. Les membres ne présentent en général rien de bien remarquable; tantòt ils sont comme tronqués au bout, et ne peuvent servir qu'à pousser l'animal en avant: chez les tortues de terre, par exemple; tantôt ils sont terminés par des doigts déliés et garnis d'ongles, qui permettent à l'animal de s'accrocher aux inégalités du sol et de grimper avec facilité : les pattes du lézard sont conformées de la sorte; d'autres fois il existe à l'extrémité des doigts une disposition particulière qui est singulièrement favorable à ce genre de mouvement : ainsi, chez les grenouilles d'arbre ou rainettes (fig. 259), onvoita l'extrémitéde chacun de ces organes une espèce de pelote arrondie et visqueuse qui permet à l'animal de se fixer contre les corps sur

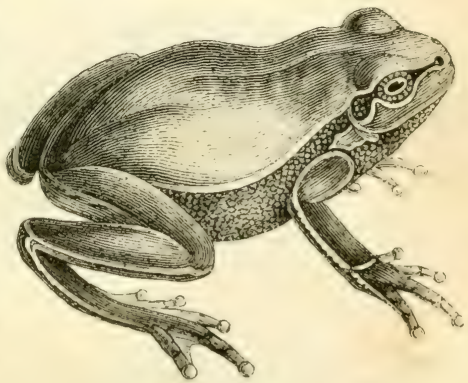

Fig. 259. Rainelle. lesquels il grimpe, meme lorsque la surface de ceux-ci est trèslisse; et chez les geckos, dont une espece habite le midi de la France, et y est connue sous le nom vulgaire de Tarente (fig. 260),

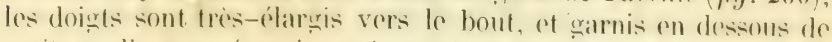

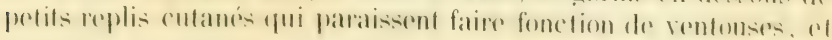


qui permettent à ces reptiles hideux de monter le long des murs le: plus unis. et mème de marcher suspendus aux plafonds.

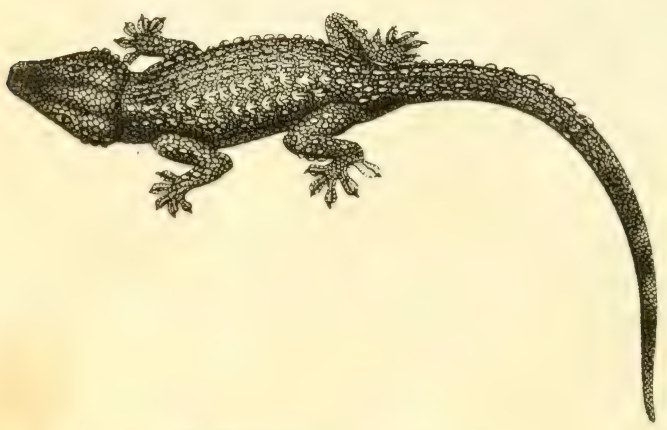

Fig. 260. Gecko des murailles.

Il est aussi des reptiles dont les doigts sont opposables à peu pres comme ì la main de l'homme; en effet, chez les caméléons (fig. 261).

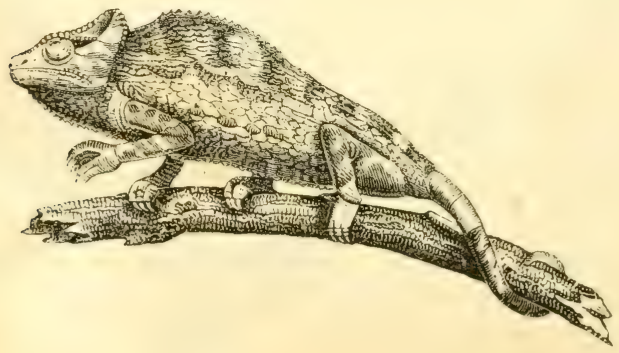

Fig. 261. Cuméléon commun.

ils sont réunis en deux paquets qui s'écartent et se rapprochen comme les branches d'une pince, et qui servent à ces animaux pour saisir les brariches sur lesquelles ils se tiennent; les caméléons ont aussi la queue préhensile. ce qui en fait des animaux essentiellement grimpeurs. 
On connait aussi des reptiles ailés. Les dragons (fig. 263), animaux assez voisins des lézards, sont dans ce cas. Ils se distinguent de tous les autres animaux de la mème classe par l'existence d'espèces de voiles formées par un grand repli de la peau situé le long des flanes, et assez semblables aux ailes des chauves-souris, mais qui, au lieu d'ètre soutenues et mises en mouvement par les membres, en sont tout à fait indépendantes, et sont soutenues par les six premières fausses còtes étendues horizontalement en ligne droite. L'animal s'en sert comme d'un parachute pour se soutenir en l'air lorsqu'il saute de branche en branche; mais il ne peut les mouvoir avec assez de force pour voler comme une chauve-souris ou un oiseau. Ces singuliers reptiles, qui habitent l'Inde, réalisent donc, jusqu'à un certain point, la fable des lézards ou serpents volants, dont quelques écrivans de l'antiquité ont parlé; mais les dragons des zoologistes, au lieu r'ètre des animaux redoutables, comme ceux des poetes. sont de très-petite taille, et n'attaquent que les insectes.

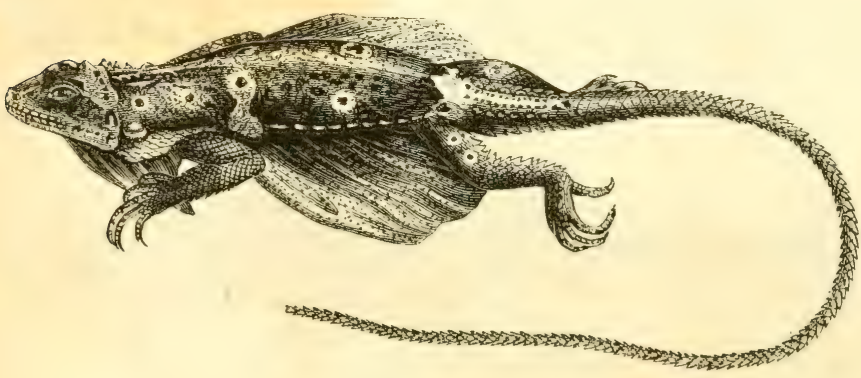

Fig. 265. Dragon

A l'époque ou vivaient les ichthyosaures et les plésiosaures dont nous avons parlé il y a quelques iustants, il existait aussi un reptile volant encore plus singulier que le dragon. D'après la structure de sa charpente osseuse, on voit que, de même que nos chatvessouris, il devait pouvoir marcher sur la terre et voler; car ses pattes postérieures et tous les doigts de ses pattes de devant, un seul excepté, sont conformés de la manière ordinaire ; mais le second doigt des membres antérieurs est plus de deux fois aussi long que le trone, et servait probablement a soutenir un repli de 
la peau propre à remplir les fonctions d'ailes. Pour rappeler cette conformation singulière, on a donné à ces sauriens fossiles le nom générique de PTÉrodActYLES.

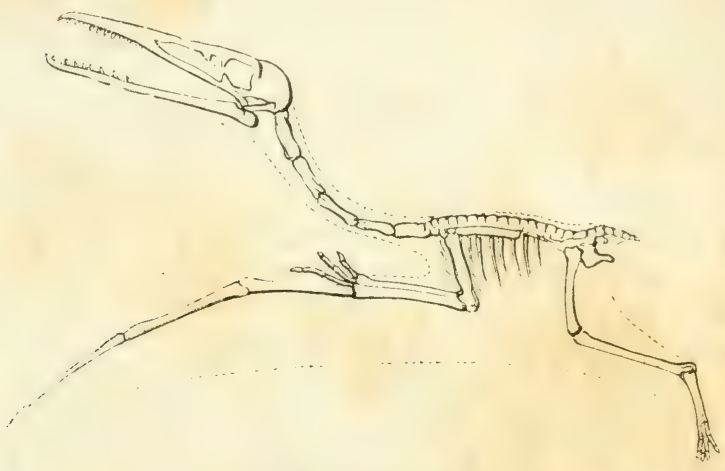

Fig. 266. Plérodactyle (1).

$\$ 460$. Les mouvements des reptiles sont en général moins vifs et moins soutenus que ceux des mammiferes et des oiseaux, comme, du reste, on pouvait le prévoir d'après l'étendue plus bornée de leur respiration; car il existe toujours, ainsi que nous l'arons déjà vu, un rapport intime entre l'énergie de ces deux fonctions. Les muscles recoivent moins de sang et présentent une teinte blanchàtre ; enfin, il est également à remarquer que ces organes conservent plus long-temps leur irritabilité après qu'on les a soustraits à l'influence du système nerveux. Chez les animaux à sang chaud, la destruction du corveau et de la moelle épiniere ou la section d'un nerf détermine immédiatement une paralysie complète, soit générale, soit locale, et, peu de temps après que ce phénomène s'est déclaré, il devient impossible d'exciter des contractions musculaires en piquant ou en stimulant autrement les parties affectées. Chez les reptiles, au contraire, la faculté d'exécuter les mouvements sous l'influence de ces stimulants se conserve dans des circonstances analogues pendant fort long-temps : ainsi la queue d’un lézard, détachée du corps, continue à se mouvoir pendant plusieurs heures, et il arrive souvent de voir une

(1) La ligne ponctuée indique le contour présumé de la peau. 
tortue morte depuis plusieurs jours acriter ses membres lorsquion en stimule les muscles par des piqueres. On peut en conclure que, chez ces animaux, la division du travail physiologique et la localisation des diverses fonctions du systeme nerveux sont portées moins loin que chez les mammifères et les oiseaux, d'où résulte une dépendance mutuelle moins intime entre les différentes parties de l'économie.

$\$$ 461. L'encéphale des reptiles est peu développé; la surface dı cerveau est lisse et sans circonvolutions (fig. 267). Les deux hémisphères sont ovalaires, plus ou moins allongés et creusés

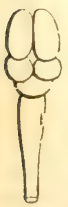
intérieurement d'un ventricule; de mème que chez les oiseaux, il n'y a point de corps strié; enfin à leur partie antérieure on remarque souvent des lobules olfactifs assez gros, situés à l'origine des nerfs de la première paire. Les lobes optiques sont en général assez grands et placés en arrière des hémisphères, sur le mème niveau. Le cerFig. 267 . velet est au contraire très-petit, et, de mème que chez les autres animaux vertébrés ovipares, il n'envoie pas sous la moelle allongée un prolongement transversal, de manière à y former une sorte d'anneau, comme chez les mammiferes. La moelle ípinière, comparée au cerveau, est très-développée, et on remarque aussi que les nerfs sont plus gros proportionnellement au volume des parties centrales du systeme nerveux que chez les animaux supérieurs.

$\$$ 462. La plupart des reptiles n'ont pas d'organe spécial pour lo toucher, et en général la sensibilité tactile ne peut ètre très-développée a raison de la nature de leurs téguments. Quelques-uns ont. il est vrai, la peau complétement nue et l'épiderme à peine distinct: mais, chez la plupart, elle est recouverte par une couche épidermique épaisse et formée par des lames plus ou moins dures de matière cornée ou mème osseuse. La substance connue sous le nom d'écaille, et employée à des usages si variés en tabletterie, n'esı autre chose que les plaques cornées qui garnissent la carapace. d'une espèce particulière de tortue marine appelée le caret (fig. 262). Chez les reptiles à peau nue, l'épiderme, de consistance moyenne, se détache et se renouvelle très-souvent, et, chez les animaux de cette classe où il offre plus de consistance, il se détache aussi at différentes éporques de l'année, pour faire place à un épiderme nouveau; tantòt cette espece de mue est partielle, ou du moins l'épiderme ne tombe que par lambeaux; mais d'autres fois il se détache en entier et conserve la forme de l'animal dont il provient. Les serpents se dépouillent ainsi plusieurs fois par an. 
Les yeux des reptiles ne présentent rien de bien remarquable: leur disposition est en général à peu pròs la mème que chez les oiseaux; mais on n'y trouve que rarement un prolongement ayant de l'analogie avec le peigne. Les paupieres sont ordinairement au nombre de trois, mais quelquefois elles manquent complétement; (hez les serpents, par exemple, la peau se continue sans interruption au-devant des yeux et présente seulement dans ce point assez de transparence pour ne pas opposer d'obstacle au passage de la lumière, disposition qui donne à ces animaux une fixité remarquable dans le regard.

L'appareil auditif est bien moins complet que chez les mammifères ou mème les oiseaux. L'oreille externe manque presque toujours complétement : il n'y a jamais de conque auditive, et le tympan est à fleur de tète et à nu, ou caché sous la peau, quelquefois mème il n'en existe aucune trace; la caisse n'est d'ordinaire que très-imparfaitement cloisonnée par les os du crâne et communique par une large fente avec l'arrière-bouche, dont elle semble (quelquefois n'ètre qu'une dépendance : les osselets de l'ouï manquent pour la plupart; entin le limaçon est souvent rudimentaire.

Les fosses nasales sont peu développées et le sens du gout parait ètre très-obtus chez tous ces animaux; la langue est quelquefois épaissie et charnue, mais en général elle est mince, sèche, très-protractile et bifide vers le bout; les serpents et les lézards ( fig. 268) nous en offrent des exemples. La langue des grenouilles présente

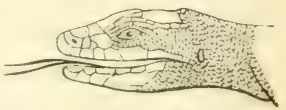

Fig. 268. une particularité singulière : elle est charnue et fixée à la mâchoire par son extrémité antérieure, tandis que sa pointe dirigée en arriere. est libre et peut se renverser au dehors. Entin, chez le caméléon cet or rame devient un instrument de préhension très-remarquable. car l'animal peut la darder à une distance qui dépasso la longueur de son corps, et elle se termine par une espece de pelote visqueuse a lacuelle sattachent facilement les mouches el autres insectes dont se repait re reptile a mourements lents ef gauches.

\$163. Il est peu de reptiles qui virent unipuement de matlieres vourétales. Presigue tous sont carnivores, et, à queldues exceptions pres, ne recherchent qu une proie vivante, quils avalent. en général, sans la diviser : ausio le choix des animaux dont ils se nourrisient est-il, pour ainsi dire, régré par le calibre de lener bonche. Elle est loujours larerement fendur: mais cost che\% les

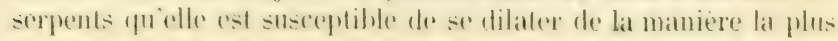


remarquable: aussi ces reptiles peuvent-ils avaler des animaux plus gros qu'eux. Les deux branches de la mâchoire inférieure

n

c $m a$

m

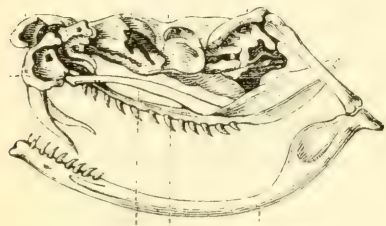

p $p \quad m i$

Fig. 263. Téle de Crolale.
( $m i$ fig. 269) ne sont pas unies, et l'espècede pédoncule $(t)$ quiles soutient (l'os tympanique) est non-seulement mobile lui-mème, mais est comme suspendu à une autre portion du temporal, appelée os mastoïdien $(m a)$, qui est également séparée du crâne, (c) et attachée à cette boite

osseuse par des ligaments et des muscles seulement; les branches de la màchoire supérieure $(m)$ ne sont fixées à l'os intermaxillaire que par des ligaments qui leur permettent de s'écarter plus ou moins; et les arcades palatines $(p)$ participent aussi à cette mobilité. Ce mode de structure est en rapport arec les moeurs de ces reptiles essentiellement carnassiers. En effet, ils peuvent supporter pendant long-temps l'abstinence; mais, en général, lorsque l'occasion se présente, ils engloutissent dans leur estomac une si grande masse d'aliments que, pendant leur digestion, ils restent dans un état d'engourdissement plus ou moins profond : ils ne mâchent pas leurs aliments; mais leur gueule est armée de dents crochues, propres à y retenir la proie.

$\$$ 464. Plusieurs serpents, tels que la vipère, l'aspic (fig. 255), le crotale ou serpent à somnettes, et le trigonocéphale, présentent des particularités de structure encore plus remarquables. car la nature les a pourvus d'un appareil venimeux à l'aide duquel ils frappent d'une mort subite, dès qüils les mordent, les animaus dont ils veulent se repaître. Leur venin est sécrété par des glandes qui ressemblent beaucoup aux glandes salivaires, et qui versent ce liquide au dehors par un conduit excréteur aboutissant à l'une des dents maxillaires de la mâchoire supérieure, dont la conformation est modifiée pour ètre en rapport avec les usages auxquels elle est destinée. Cés glandes $(f i g .270, v)$ sont placées sous les muscles temporaux, de manière à ètre comprimées par leur contraction; et cette dent, plus grande que les autres, est tantòt percée d'un canal, et tantôt creusée d'un sillon seulement; mais, dans l'un et l'autre cas, le conduit qu'elle présente est en communication avec le canal excréteur de la glande venimeuse, et sert à verser le venin au fond de la plaie faite par la dent elle-mème. Ce venin est un 
poison des plus violents. Il n'est ni àcre ni brùlant, il ne produit sur la langue qu'une sensation analogue à celle occasionnéc par une matière grasse, et il peut ètre avalé impunément; mais, introduit en quantité suffisante dans une plaie, il donne la mort avec une rapidité effrayante. Son énergie varie suivant les espèces et suivant les circonstances dans lesquelles le serpent se trouve. La mème espèce paraìt être plus dangereuse dans les

$n \quad v \quad m$

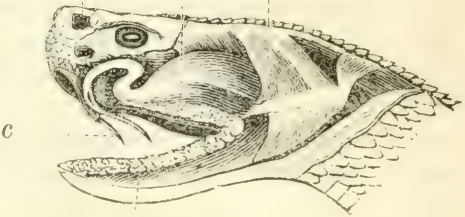

s pars chauds que dans les pays froids ou tempérés, et les accidents déterminés par sa morsure sont d'autant plus sraves que le poison coule plus abondamment dans la plaie : aussi ces animaux sont-ils bien plus redoutables lorsqu'ils ont jeuné quelque temps, et que leur venin s'est amassé en quantité considérable dans les glandes où il est sécrété, que lorsqu'ils viennent de mordre à plusieurs reprises, et qu'il ne leur reste plus qu'une petile quantité de ce liquide. On a remarqué aussi que leur morsure n'agit pas de la mème manière sur tous les animaux. Il paraitrait que, pour les sangsues, les limaces, l'aspic, la couleuvre et l'orvet, le venin de la vipere, par exemple, n'est pas un poison; tandis qu'il pent tuer aver une grande rapidité tous les animaux a sang chaud, les lézards et la vipere elle-mème. En cgénéral, la quantité de venin nécessaire pour donner la mort est, toutes choses égales d'ailleurs, d'autant plus considérahle que l'animal blessé est plus grand : ainsi, lorsqu'un centieme de grain de venin de la vipère suffit pour tuer un moineau, il en faudra six fois davantage pour tuer un pigeon.

Ce poison, pour agir sur l'économie animale, doit ètre absorbé et porté dans le torrent de la circulation; ansisi, dans les cas de morsure de serpents venimeux, faut-il se hiter demplover les moyens les plus propres a ralentir cotte absorption, afin d'avoir le

(1) Appareil venimenx d'un Crofule ou serpent à sonnettes : - $v$ glande venimeuse, dont le conduit excreteur abontit à la grosse dent mobile $c$; $-m$ muscles Gévateurs de la machoire, qui recouvrent en partie la glande et peurent la comprimer; $-s$ glandes salivatres qui garnissent le bord des mâchoires; $-n$ narin au-dessous de layuelle se voit la fossette qui distingue ces serpents et les trigone. céphales des vipères. 
lemps de faire sortir ou de détruire le venin déposé an fond de la pifuure. La compression exercée sur les veines au-dessus du point picqué, et l'application d'une ventouse sur la plaie elle-mème, sont les moyens les plus propres à ralentir l'absorption du poison; mais, pour délivrer complétement le malade du danger qui le menace, il faut en général élargir la plaie et en cautériser le fond, soit avec le fer rouge, soit avec des caustiques énergiques. On a vanté aussi plusieurs remèdes internes, tels que l'ammoniaque, l'arsenic, etc.; mais ces moyens, s'ils sont quelquefois utiles, ne peuvent inspirer une grande confiance. Les Indiens de l'Amérique du sud attribuent des vertus encore plus grandes à une plante de ce pays, connue sous le nom de guaco ou de micania guaco : ils assurent que nonseulement l'application des feuilles de guaco sur la morsure des serpents les plus dangereux prévient tout effet délétère, mais que l'inoculation du suc de cette plante empèche ces animaux de mordre la personne ainsi préparée. On cite à l'appui de cette opinion les observations d'un auteur espagnol, nommé Vergas, et celles de Mutis; enfin, le célèbre et savant voyageur M. de Ilumboldt pense, d'après quelques expériences, que le guaco peut donner a la peau une odeur qui répugne au serpent et l'empeche de mordre.

Quant aux symptomes qui accompagnent l'action du renin, ils different suivant les espèces et suivant les circonstances. En général, la circulation s'affaiblit extrèmement, le sang perd la faculté de se coaguler, et la gangrène envahit la partie blessée.

La disposition de l'appareil venimeux varie chez ces reptiles. Tantòt la dent qui termine le canal excréteur du venin est un crochet mobile, tantòt une dent immobile, simplement sillonnée.

Les serpents à crochets venimeux mobiles sont les plus redoutables. Ces crochets $(c, f i g$. 270), situés sur le devant de la bouche, sont isolés, très-aigus et percés d'un petit canal qui aboulit près de leur extrémilé : ils sont fixés sur des os maxillaires très-petits ( fig. 269), et ces os, portés sur un long pédicule, sont très-mobiles, de sorte que, lorsque l'animal ne veut pas se servir de ses crochets, il les reploie en arrière et les cache dans un repli de sa gencive, tandis que dans le cas contraire il les redresse. On voit une de ces longues dents de chaque còté, et il y a derrière chacune d'elles plusieurs germes destinés à la remplacer si elle se casse Jans une plaie; mais les os maxillaires ne portent pas d'autres dents, et on ne voit dans le haut de la bouche que les deux rangées de dents palatines, au lieu de quatre rangées, comme chez les coulenves. Ces derniers animaux, de même que plusieurs autres 
reptiles, ont le palais garni de dents aussi bien que les màchoires. D'autres reptiles sont, au contraire, complétement dépourvus de dents (les crapauds, par exemple); et chez les tortues, ou ces organes manquent également, les màchoires sont recouvertes d'une lane cornée à bords tranchants comme le bec des oiseaux; mais il n'y a jamais de lèrres charnues et mobiles comme chez les mammifères.

$\$ 46 \ddot{0}$. Les aliments ne devant pas séjourner dans la bouche pour y ètre broyés, le voile du palais aurait été en général inutile, et en effet il n'existe presque jamais. Chez la plupart de ces animaus. le pharynx n'est pas distinct de la bouche, et sourent il n'y a mème aucune ligne de démarcation bien tranchée entre l'vesophage et l'estomac, qui est simple et de forme variée. Les intestins sont courts et dépourvus d'appendice coocal; le wros intestin differe peu de l'intestin grrèle et se termine dans un cloaque où viennent aboutir aussi les canaux urinaires et les or janes de la reproduction.

Les reptiles ont, de mème que les animaux supérieurs, des vaisseaux lymphatiques destinés à pomper les produits de la digestion et à les verser dans le torrent de la circulation.

$\$ 466$. Leur sang est peu riche en matieres solides, et les globules elliptiques qui y nagent sont d'un volume plus considérable que dans aucune autre classe. La disposition cie l'appareil circulatoire varie; mais, ainsi que nous l'avons déjà dit $(\$ 108)$, il y a toujours une communication directe entre le systeme vasculaire à sang rouge et le systeme vasculaire a sang noir, de sorte que ces deux liquides se mèlent et que les organes ne regoivent quiun sang imparfaitement artérialisé par le travail de la respiration. Presque toujours le cocur se compose de denx oreilletles (fig. 27I) souvrant dans un seul ventricule. Il en résulte que le sang artériel venant des poumons, reçu dans l'orrillette saluche, et le sangr reineux arrivant des diverses farties du corps dans l'oreillette opposée, se mèlent dans ce ventricule commun. Une portion de ce mélange retourne par l'artire aorte dans les divers organes qu'il est destiné à nourrir, tandis qu'une autre se rend aux poumons par des vaisseaux rui naissent immédiatement du ventricule commun, ou mème de l'artere aorte. Dans les crocodiles, le coeur (fig. 272) est conforme a peu près de la meme maniere que chez les oiseaux et les mammiferes, et présente une cloison qui sépare le ventricule droit du ventricule gauche : il en résulte que cet organe offre deux ventricules distincts et deux oreillelles. et que le sang artériel ne sy mèle pas an sangr veineux; mais me. 
disposition particulière des artères opere ce mélangre à quelque distance du coeur, et les vaisseaux de toute la moitié postérieure

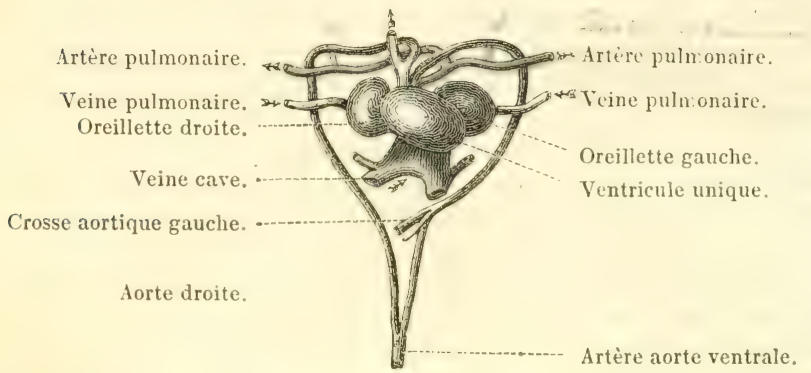

Fig. 271. Cour d'une Torlue.

du corps ne recoivent que du sang imparfaitement artérialisé. En effet, le sang veineux recu dans le ventricule droit ne va pas

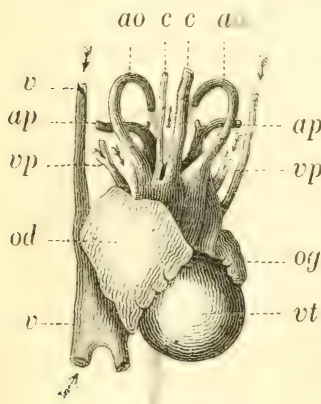

Fig. $272(1)$. en entier aux poumons, comme chez les vertébrés à sang chaud; car, à còté de l'ouverture des artères pulmonaires $(a p)$, se trouve un autre vaisseau $(a)$, qui naît également du ventricule droit, et qui, vp après s'être recourbé derrière le cœur, va aboutir dans l'aorte descendante $(a 0)$. Il en résulte que, à chaque contraction du cour, une portion du sang veineux est envoyée aux poumons et une autre portion va se mèler au sang artériel; mais ce mélange ne se fait dans l'intérieur de l'artère aorte qu'au-dessous de l'origine des branches (cc) que ce vaisseau envoie à la tète et à la partie antérieure du tronc, de manière que ces parties recoivent du sang artériel pur, tandis que toutes

(1) Cour et gros vaisseaux du crocodile : $-v, v$ veines qui rapportent le sang des diverses parties du corps à l'oreillette droite du cœur $(o d)$; $-v \ell$ les deux ventricules, qui intérieurement sont séparés par une cloison; - ap les deux artères pulmonaires qui se rendent du ventricule droit aux poumons; $-a$ vaisseau qui part du même ventricule et se réunit à l'artère aorte descendante; $-v p$ veines pulmonaires qui portent le sang artériel des poumons à l'oreillette gauche $(o g)$, d'où il descend dans le ventricule gauche et pénètre ensuite dans l'artère aorte $(\alpha \circ)$ et dans les deux artères $(c c)$ qui se distribuent à la tête, etc. 
celles dont les arteres naissent en arriere du point de jonction de l'aorte avec le vaisseau venant du ventricule droit, ne recoivent qu'un mélange de sang rouge et de sang noir.

Jusqu'en ces derniers temps on croyait que, chez d'autres animaux de cette classe (les batraciens), il riexistait an contraire qu'un seul ventricule; mais on a démontré qu'il en était autrement. Quant au mode de distribution des arteres chez les reptiles, nous nous bornerons à ajouter quï existe deux ou plusieurs crosses aortiques se recourbant à droite el à gauche, et se réunissant bientòt pour constituer un trone unique (voy. fig. 1.1, page 77).

$\$ 467$. La respiration est peu active chez les reptiles; la plupart de ces animaux ne consomment que peu d'oxygène, et peuvent en ètre long-temps privés sans tomber en asphyxic. Du reste, la tempèrature a la plus grande influence sur ce phénomène, et, dans la saison chaude, le besoin de respirer se fait sentir bien plus vivement qu'en hiver. Une grenouille, par exemple, que l'on prive d'air, périt en moins de deux heures en été, tandis qu'en hiver elle peut continuer à vive pendant plusieurs jours. Chez quelques reptiles, comme nous le verrons bientòt, il existe, dans les premiers temps de la vie, des branchies; mais les poumons ne tardent pas à se développer, et d'ordinaire les branchies se flétrissent alors et disparaissent, de telle sorte que le mème animal a une respiration d'abord aquatique, puis aérienne : il en est mème qui conservent ces organes pendant toute la vie, et qui, ayant en mème temps des poumons, sont complétement amphibies: les protées, les sirénes et les axolotles (fig. 122) sont dans ce cas; mais la plupart des reptiles n'ont jamais que des poumons. Il ne faut pas en conclure cependant que leur respiration soit toujours exclusivement aérienne: car, chez plusieurs de ces animaux, la peau est aussi un organe respiratoire, et peut ag̣ir sur l'air dissous dans l'eau aussi bien que sur l'oxygène sazeux. Chez quelques reptiles, la respiration cutanée est mème si active que, dans certaines circonstances, elle suffit à l'entretien de la vie.

Les poumons sont organisés d une maniere peu fatrorable at une grande activité de la fonction dont ils sont le siéce; car leurs cellules sont tres-grandes, ot par conséupuent la surfare vasculane destinée a receroir le contart de lair est pen étendue. Ils ne sonl pas logés dans une cavité particuliere, le thorax nétant pas séparé de labdomen par un muscle diaphragme, et lair ne se renouselle dans leur intérieur quarec moins de facilite et de régularile yue chez les animaux superiems. (Quelquefois meme, chez les yre-

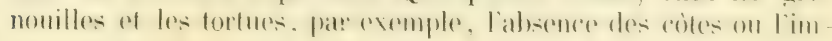


mobilité de ces os rend impossibles les mouvenents inspirateurs ordinaires, et alors c'est par ces phénomènes de déglutition que

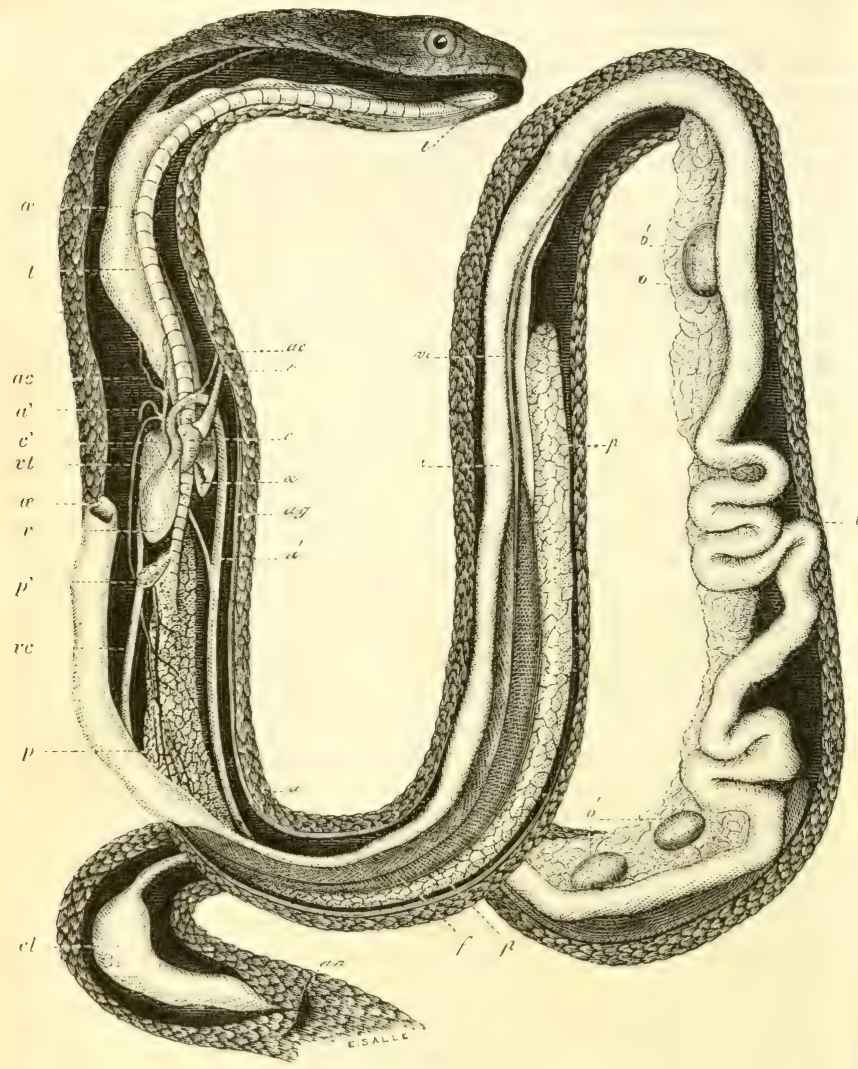

Fig. 273. Analomie de la Couleuvre (1).

(1) - $l$ langue et glutte; $-\alpha$ asophage, coupé en $e^{*}$ pour mettre à découvert le cour, etc. ; $-i$ estomac; $-i$ ' intestin; $-c l$ cloaque; - an anus ; $-f$ foie ; o ovaire; - $\sigma^{\prime}$ œufs ; -1 trachée; $-p$ poumon principal ; $-p$ 'le petit poumon ; - $v \iota$ ventricule du cuur; - $c$ oreillette gauche du cœur; $-c^{\prime}$ oreillette droite; - $a g$ aorte gauche; $-a d$ aorte droite; $-a$ ' aorte ventrale; - $a c$ artères carotides; $-v$ veine cave supérieure; $-v c$ veine cave inférieure; $-v p$ veine pulHanai:e. 
lair est pousse dans les poumons. Il est aussi a noter que lesserpents offrent, dans la disposition de lappareil respiratoire, une anomalie remarquable, l'un de leurs poumons étant tellement rudimentaire que souvent on l'apercoit avec peine, tandis que l'autre acquiert des dimensions très-considérables (fig. 273).

$\$ 468$. Les reptiles sont tous des animaux à sang froid, c'est-àdire qui ne produisent pas assez de chaleur pour avoir une température sensiblement au-dessus de celle de l'atmosphère. Tout leur corps s'échauffe ou se refroidit en mème temps que le milieu ambiant, et les changements de température qu'ils éprouvent ainsi influent puissamment sur toutes leurs fonctions. Une chaleur d'environ quarante à cinquante decrés est promptement funeste à lat plupart de ces animaux, et le froid tend à ralentir chez eux tous les phénomènes vilaux. En hiver, la plupart des reptiles ne peuvent plus digérer les matieres ingérées dans leur estomac et ne prennent pas d'aliments. Leur respiration se ralentit aussi de la manière la plus remarquable. Ainsi pendant la saison froide l'action de l'air sur la pean suffit à l'entretien de la vie d'une grenouille, et on peut extirper les poumons d'un de res animaux sans déterminer l'asphyxie; tandis qu'en été ils ont besoin non-seulement de la respiration pulisonaire, mais encore de la respiration cutanée, et la mort arrive promptement quand l'air n'agit plus sur la peau ou s' troure exclu des poumons. Enfin l'abaissement de la température détermine souvent chez ces animaux un engourdissement léthargrique analogue à celui des animaux hibernants.

$\$$ 469. De mème que les oiseaux, les reptiles n'ont pas de mamelles pour allater leurs petits, et se reproduisent par des ceufs: seulement reux-ci éclosent quelquefois avant la ponte (chez la ripere, par exemple), et on donne le nom d'oroviripares aux animaux chez lesquels ce phénomène sobserve.

Le mode de développement de la plupart des reptiles ne pré sente rien d'anormal; mais les grenouilles, les crapauds, les salamandres et les autres espreces désignées par les zoologistes sous le nom commun de batraciens, ne naisient pas avec la forme qu ils doivent conserver, ot subisient dans le jeme àre des métaniorphoses remarquables. Ils ressemblent d'abord a des poissons par leur forme exterienre ansi bien que par lem structure intérieure. et rest peu a peu qu'ils acquicent les caracteres properes a la clasie des reptiles. Lorsqu ils sont dans cet chat transituire on leme dome le nom de tétards, ef les métamorphoses qüils subsisont sont pluson moins considérables suivant lesespeces. Less spenouilles,

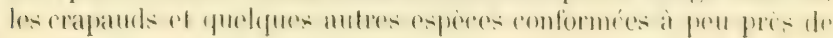


mème sont, de tous les batraciens, ceux dont les métamorphoses sont les plus complètes. Au moment où le jeune tètard de grenouille sort de l'œuf, il ressemble beaucoup à un petit poisson, et il ne peut vivre que dans l'eau. Sa tète est très-grosse, son ventre renflé, et son corps, dépourvu de membres, se termine par une queue longue el comprimée; sa bouche n'est encore qu'un petit trou, à peine perceptible, et ses branchies ne consistent qu'en un tubercule placé de chaque còté à la partie postérieure de la tète. Bientòt ces appendices s'allongent et se divisent en lanières ; les yeux se dessinent à travers la peau, et une fente transversale se montre sous le cou, de manère à y former une espèce dopercule membraneux. Un peu plus tard, les branchies $(f g .274, b$ ) se ramifient et les lèvres se recourrent d'une sorte de bec corné, a l'aide duquel l'animal se fixe aux végétaux dont il fait sa principale nourriture; mais cet état ne dure que peu. Au bout de quelques jours, les franges branchiales qui flottaient de chaque còté du con disparaissent (fig. 27\%), et la respiration se fait à l'aide de petiles houppes vasculaires, fixées le long̣ de quatre ares cartilagineux, situés sous la gorge et appartenant à l'hyoïle. Une tunique membraneuse, recouverte par la peau, enveloppe ces branchies internes, auxquelles l'eau arrive par la bouche, en passant
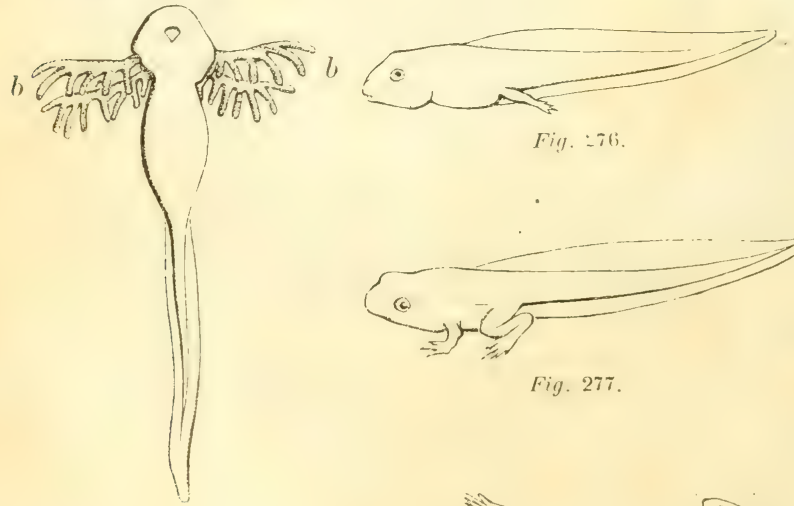

Fig. 274.

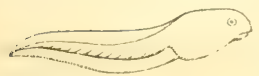

Fin 275 .

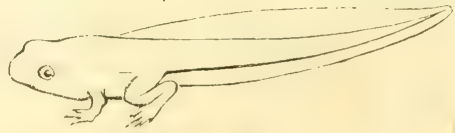

Fig. 277 .

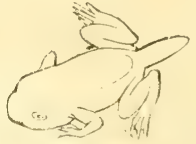

Fill. 278

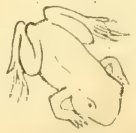

Fig. 779. 
par les intervalles des arceaux de l'hyoide; enfin, apres avoir baigné ces organes, ce liquide sort par une ou deux fentes extérieures, dont la position varie un peu, suivant les espèces. L'appareil respiratoire présente alors, comme on le voit, la plus exacte ressemblance avec celui des poissons. Quelque temps apres, les pattes postérieures du tètard se montrent et se développent petit à petit (fig. 276); leur longueur est déjà assez grande qu'on ne roit pas encore les pattes antérieures. Celles-ci se développent sous la peau, qu'elles percent plus tard (fig. 277). Vers la mème époque, le bec corné tombe et laisse à nu les màchoires; la queue commence à s'atrophier (fig. 27s), les poumons se déreloppent, et, à mesure que ces organes deviennent plus exclusirement le siége de la respiration, les branchies se flétrissent et disparaissent : les arceaux cartilaggineux qui les portaient sent aussi en partie absorbés : enfin la queue disparait complétement: le petit animal prend la forme qu il doit toujours conserver (fig. 279), et change complétement de réxime. Herbivore d'abord, il devient peu à peu exclusivement carnivore, et à mesure que les métamorphoses s'achèrent, son canal intestinal, de long et contourné en spirale qu'il était, devient court, presque droit, et renflé dans les points correspondants à l'estomac et au colon.

L'appareil de la circulation subit des changements correspondants à ceux quéprourent les organes de la respiration. Le cueur des batraciens adultes se compose, comme celui de la plupart des reptiles, de deux oreillettes et d'un seul rentricule; d'ou nait une grosse artiere, qui, à sa base, est renflée en bulbe contractile, et qui hientòt se bifurque pour former les deux crosses de l'aorte; mais lorsque le jeune animal respire par des branchies seulement, le sang, chassé du ventricule, se distribue à ces oryanes, et de la se rend en majeure partie dans une artere dorsale dont les branches se ramilient dans les divers organes f fig. 280). Nous arons déjà ru que, chez les poissons, le sany suit le mime trajet (\$ 109); mais lorsque les poumons se developpent, la disposition de l'ap)pareil vasculaire change; il s'établit lne communication directe entre les arteres qui portent le sang aux branchies et celles qui le recoirent de ces organes, de surte que le liquide nomricier n'est plus obligé de traverser an appareil de respiration aquattique pour arriver dans l'artere dorsale, et de la dans les diverses parties du corps. Liartere (a) qui nait du ventricule, et que lion pourrait eomparer d'abord à une artere branchiale, devient allors l'origine du vaisseau dorsal, et constitue avee lui une reritable artere aorte, dont rertaines branches. qui se rendent aus pou- 
mons, se développent en mème temps et établissent la circulation pulmonaire. Enfin, les vaisseaux branchiaux s'oblitèrent, et alors

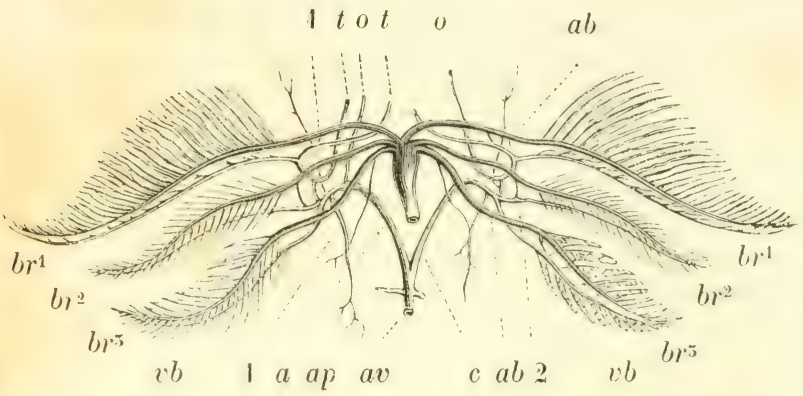

Fig. 280. Vaisseaux sanguins du Têlard de la Salamandre (1).

la circulation se fait à peu près de mème que chez les autres reptiles. Le sang veineux, revenant de toutes les parties du corps, est versé dans le rentricule par l'une des oreillettes, et s'y mèle avec le sang artériel venant des poumons et poussé dans le mème ventricule par l'autre oreillette. Ce mélan ze pénètre dans l'aorte, et se rend en petite partie aux poumons et en majeure partie aux livers organes de l'animal.

(1) Fig. 280. a artère qui part du ventricule unique du cœur et se divise en six branches $\langle a b\rangle$, qui se rendent aux trois paires de branchies et s'y ramifient (on les appelle arlires branchiales); - br les branchies, dans lesque'les on roit se distribuer les artères branchiales et naitre ies veines branchiales $(v b)$ qui reçoivent le sang après son passage à travers les lamelles des branchies; celles des deux dernières paires de branchies se réunissent pour fournir de chaque côté un vaisseau $|c|$ qui, en s'anastomosant à son tour avec celui du côté opposé, forme l'artère aorte ventrale ou artère dorsale $(a v)$, laquelle se dirige en arrière et distribue le sang à la plus grande partie du corps; la veine branchiale de la pren ière paire de branchies se recourbe en avant et porte le sang vers la tête $(\ell \ell) ;-1$ petite branche anastomotique extrêmement fine qui unit l'artère et la veine branchiales entre elles à la base de la première branchie, et qui, en s'élargissant plus tard, permettra au sang de passer du premier de ces vaisseaux dans le second sans traverser la branchie; -2 petite branche anastomotique qui établit le passage de la même manière entre l'artère et la veine des branchies de la seconde paire; -3 vaisseau qui, en se réunissant avec un filet situé plus en dedans, joint égillement l'artère et la veine des branchies postérieures; - $o$ artère orbitaire; - ap artères pulmonaires rudimentaires. 


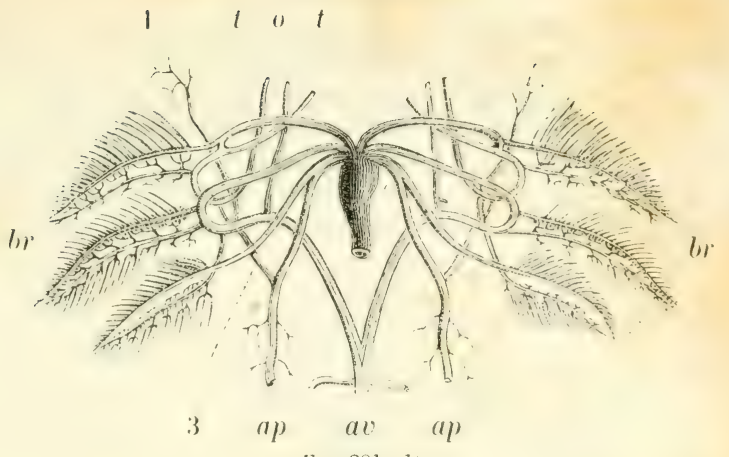

Fig. 281. (1).

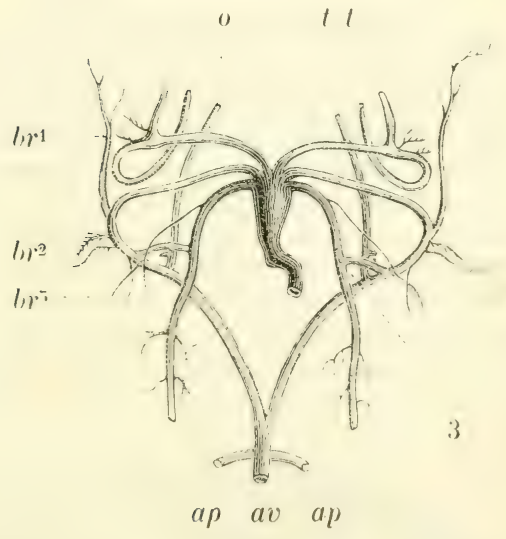

Fig. 282 (1).

(1) Fig. 281. Les mêmes parties chez un têtard dont les branchies commencent à perdre de leur importance dans la respiration et dont une partie du sang va du cour aux diverses parties du corps sans traverser ces organes. Les mêmes lettres indiguent les mêmes vaisseaux que dans la figure précédente, et on remarquera que les branches anastomotiques $(1,2,3)$, lesquelles, dans le têtard précédent, étaient capillaires et ne pouvaient pas laisser passer une quantité notable de sang, sont ici assez grosses, et que c'est avec elles plutit qu'avec les vaisseaux branchiaux que les arteres venant du coetur s:mblent se continuer. Les artères pulmonaires se sont aussi heaucoup développées. - Fig. 282. Les mêmes parties chez l'animal parfitit indiquies par les mêmes lettres; les vaisseaux qui dans le têtard se rendaient à deux branchies de la seconde paire se continuent maintenant aver laorte par lintermédiaire des branchies anastomotigues $1 N^{\prime \prime 21, ~ c o t ~ c o n s t i t u e n t ~ a i n s i ~ l e s ~}$ d. ux crosses aortiques. 
$\$$ 470. Certains batraciens subissent des métamorphoses moins completes. Ainsi, les salamandres (fig. 283) acquièrent, comme les grenouilles, des membres par le progres et l'age, et perdent leurs branchies, mais conservent toujours leur longue queue, et, comme nous laavons déjà dit, il est aussi quelques-uns de ces reptiles qui, sous le rapport de leur mode de respiration. restent toujours a l'état de tètard. car leurs branchies persistent pendant toute la vie.

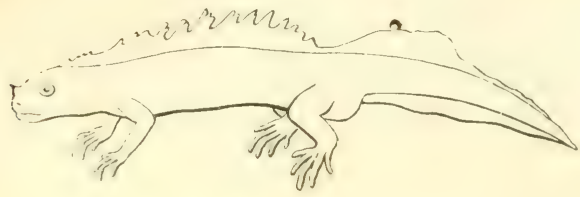

Fig. 283. Salamanule aqualique.

\$71. En général; les reptiles abandonnent leurs oeufs aussitòt apres la ponte, et l'incubation s'en fait à l'airle de la chaleur atmosphérique seulement; mais il est à cet érard une exception remarquable : un grand serpent de l'Inde, roisin des boas et des couleures, conmu sous le nom de python, couve ses nufs, et, pendlant qüil reste enroulé autour de sa progéniture, il développe une quantité de chaleur si considérable que la température de son corps séleve quelquefois à plus de 40 degrés. Un autre reptile voisin des crapauds, le pipa (fig. 281), présente aussi une particu-

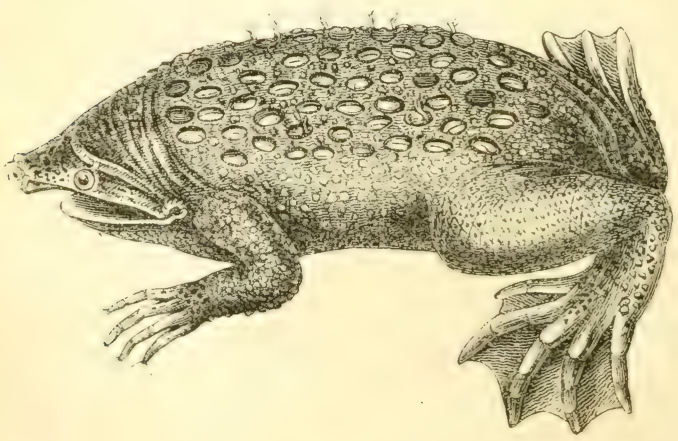

Fig. 284. P'ipu 
larité de mocurs qui mérite d'ètre signalée ici : cet animal, à l'état adulte, vit à terre, mais naît sous la forme d'un tètard, et a besoin d'ètre alors plongé dans l'eau: aussi, au moment de la ponte, le màle place les oufs sur le dos de la femelle, et la peau de celle-ci. irritée par le contact de res corps, se grontle et forme des cellules dans lesquelles les petits éclosent ; la mère, ainsi chargée, se rend a l'eau et y demeure jusqu'à ce que ses petits aient achevó leurs métamorphoses : c'est alor's seulement que les jeunes pipas quittent leurs loges, et que la mère revient à terre.

$\$ 472$. Les reptiles présentent, comme nous venons de le voir, des différences anatomiques et physiologiques tres-considérables; et pour que la classification de ces animaux soit en quelque sorte la traduction des divers degrrés de ressemblance ou de dissemblance qu'ils offrent entre eux, il faut les diviser d'abord en deux groupes ou deux sous-classes, savoir :

$1^{\circ}$ Les Reptlles ordix.mes, qui, à toutes les époques de la vie, sont pourvus de poumons, ne sont jamais conformés pour respirer dims l'eau, et ne subisent pas de métamorphoses;

$2^{\circ}$ Les Reptiles ampinbies, qui dans le jeune àge respirent à l'aide de branchies, et sont conformés pour vivre dans l'eau; mais qui subissent des métamorphoses et possèdent des poumons lorsqu'ils sont à l'état adulte.

Les reptiles ordinaires se subdivisent en trois ordres : les Chéloniens, les Sauriens et les Ophidiens.

$\$$ 773. Les Cheloniexs ou tortues ont les còtes immobiles et réunies aux vertebres dorsales pour constituer une carapace (fig. 2:;8) : leur corps est également cuirassé en dessous par un plastron (fig. 2:33); leur bouche est dópourvue de dents et garnie d'un bec corné : enfin leur peau est presque toujours recouverte de grandes plaques écailleuses, et leurs membres sont au nombre de deux paires et asiez semblables entre elles.

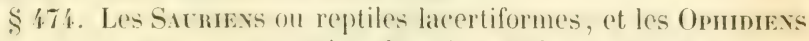
ou serpents, ont, au contraire, les cotes el les vertebres dorsales mobiles, et ils ne présentent jamais ni caraparee ni plastron: ils n'ont pas de bece corné, leur bonche est fortement dentée et leur peau psl ceaillense. Ils defferent done considérablement des tortues, mais ils se ressemblent beaucoup entre eux, car on les distingue surtont par labsence ou la présence des pattes, of ces organes disparaissent graduellement de fateon yuion en troure des restiges meme chez certains reptiles pui ne perosent plus sen servir pour la locomotion. Quoi quil en soit, on donne crencealement le nom dephli-

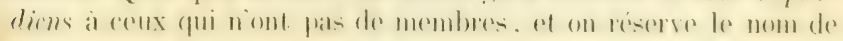


sauriens pour ceux qui en possèdent (fig. 283), et qui ressemblent ainsi à nos lézards. Comme exemple d'ophidiens, nous citerons les

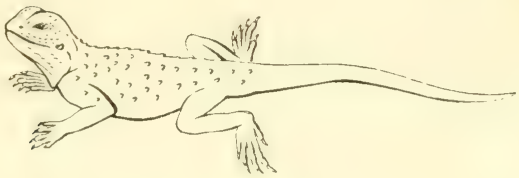

Fig. 285. Agame.

viperes, les crotales (fig. 286), les najas (fig. 2:3:3), parmi les serpents venimeux; ef les couleures, les boas et les pythons parmi

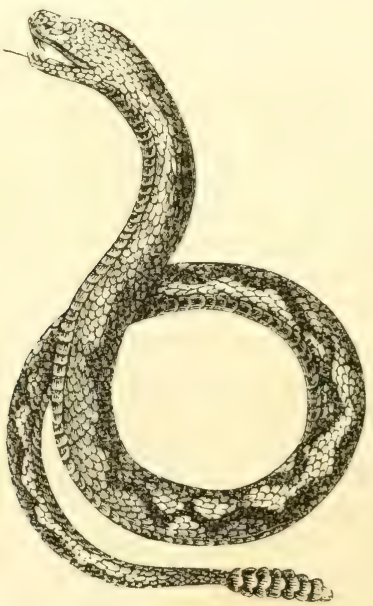

Fig. 285. Crolale ou Serpent ì sonnelles.

les serpents non venimeux. L'ordre des Sauriens comprend les crocodiles (fig. 2:2), les lézards, les caméléons (fig. 261), les geckos (fig. 260). les acames (fig. 28:i), les iquanes (fig. 257), ete. 


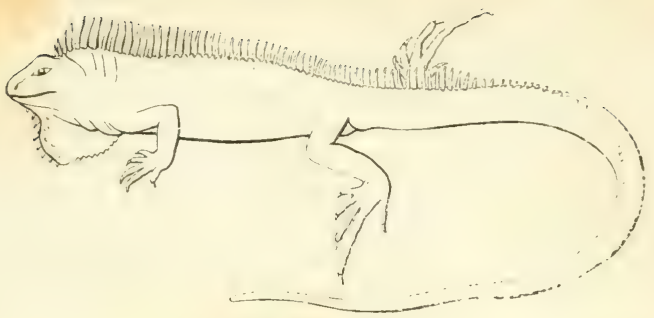

Fig. 287. Iguane.

$\$ 475$. Enfin la division des reptiles amphibies ne se compose que d'un seul ordre, celui des batraciens, qui, en général, sont faciles à reconnaitre a la nudité de leur peau. On range dans ce groupe les grenouilles, les rainettes (fig. 2:39), les crapauds (fig. 234), les pipas ( fig. 281), les salamandres terrestres, les tritons ou salamandres aquatiques (fig. 283), les protées, les axolotles (fig. 122), etc., ainsi que les cécilies, qui par la forme générale de leur corps ressemblent à des serpents.

\section{CLASSE DES POISSONS.}

$\$$ 476. Lal quatrième et derniere classe de l'embranchement des animaux vertébrés comprend les poissons.

Ces animaux, ainsi que chacun le sait, sont destinés a vivre sous l'ean, et cette circonstance a imprimé à toute leur organisation un cachet particulier; mais les différences les plus importantes qu'ils présentent, lorsqu'on lés compare aux autres vertébrés, consistent dans la conformation des appareils de la respiration et de la circulation. Ils n'ont des poumons a aucune époque de la vie et ils respirent par des b:anchies seulement. Leur coeur ne renferme que deux cavités et ne reçoit que du sang veineux; ce liquide, apres avoir subi le contact de l'oxygene, passe dans un vaisseau dorsal, où aucune nouvelle force motrice n'accélère sa course vers les diverses parties du corps (royez \$ 109). Leur circulation ne peut done etre aussi active (fue chez les animaux supéricurs, et leur sang est froid comme celui des reptiles. La peau est nue et couverte d'écailles seulement : ils n'ont pas de mamelles comme les mammi- 
fères, et ils se reproduisent au moyen d'œufs; enfin leurs membres ont la forme de nageoires.

$\$ 477$. La forme extérieure des porssons varie; mais leur corps est en général tout d'une venue. Leur tète, aussi grosse que le tronc, n'en est pas séparée par un rétrécissement semblable au cou des vertébrés supérieurs; et leur queue, par sa grosseur vers sa base, ne se distingue pas du reste du corps. Quelques-uns de ces animaux manquent tout a fait de nageoires; mais, chez presque tous, on voit un nombre considérable de ces organes placés, les uns sur la ligne médiane du dos ou du ventre, et par conséquent impairs, les autres sur le còté et disposés par paires (fig. 288). Ces derniers

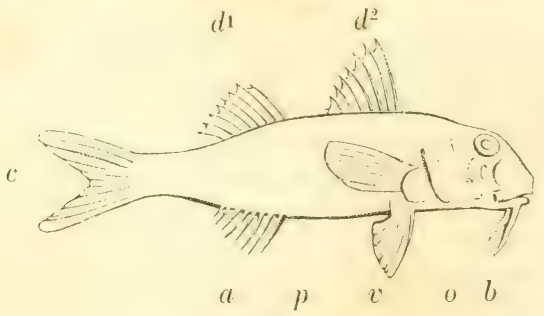

Fig. 288 (1).

représentent les quatre membres des autres animaux vertébrés; les membres antérieurs, qui correspondent au bras de l'homme et à l'aile de l'oiseau, sont fixés, de chaque còté du trone, immédiatement derriere la tète, et sont appelés nageoires pectorales. Les membres abdominaux (v), moins ćloignés les uns des autres, occupent en général la face inférieure du corps et peurent ètre placés plus ou moins en avant ou en arriere depuis le dessous de la gorge jusqu'à l'origine de la queue : on les nomme nageoires ventrales. Les nageoires impaires occupent, comme nous l'avons déjà dit, la ligne mérliane du corps et se distinguent en nageoires dorsales $(d)$, nageoires anales $(a)$ et nageoires caudales $(c)$, suivant qu'elles sont placées sous le dos, sous la yueue ou à son extrémité. Du reste, les unes et les autres ont à peu près la mème structure, et consistent presque toujours en un repli de la peau, soutenu par des rayons osseux ou cartilagrineux, à peu près de la mème manière que les

(1) Le rouget (mullus barbalus), pour montrer les diverses nageoires, etc. : $p$ nageoire pectorale; $-v$ nageoire ventrale; $-d^{\mathrm{x}}$ première dorsale; $-d^{2}$ deuxième dorsale ; $-c$ caudale ; $-a$ anale; $-o$ ouverture des ouies; $-\downarrow$ barbillons de la mâchoire inférieure. 
meure absolument membraneuse : certaines lamproies sont dans re cas, et, sous ce rapport, elles établissent le passage entre les vertébrés et les invertébrés.

$\$ 480$. Les os ne présentent jamais de canal médullaire, et le cartilage qui en fait la base n'est pas semblable à celui des mammiferes et des oiseaux; car, lorsqu'on le fait bouillir dans l'eau il ne donne pas de gélatine.

Le squelette se compose de la trite, à laquelle est joint un appareil hyö̈dien très-développé et servant à la respiration; du trone et des membres.

$\$ 481$. La structure de la tète est très-compliquée: on y remarque d'abord une portion médiane, composée d'un grand nombre d'os articulés entre eux par des sutures et formant une espece de carène immobile, a laquelle sont suspendus les os des mâchoires,

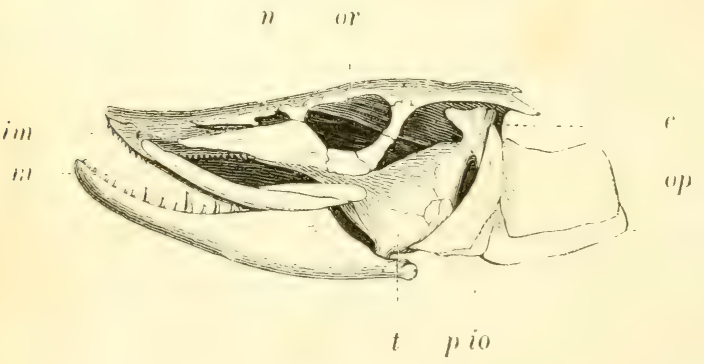

Fig. 290. Os de lu léle du Brochel (1).

c'es jones, ete. Celte portion médiane, dont la forme ordinaire est a peu pres celle d'une pyramide à trois faces, ayant son sommet dirigé en avant, présente en arrière la boìte crânienne $(c)$, où se loge l'appareil de l'ouie aussi bien que l'encéphale. Sa partie mogenne est évidée pour former les cavités orbitaires (or), et cI

(1) $c$ crâne; - or orbite ; $-n$ fosses nasales; $-i m$ os intermaxillaire; $-m$ os maxillarre supérieur; $-\ell$ espéce de cloison latérale qui sépare la joue de la bouche, et qui s'articule cn avant au vomer par l'intermédiaire des arcades palatines, dont on aperçoit une portion au-dessus de l'os maxillaire, en haut avec le crâne $(c)$, en bas avec la mâchoire inférieure, et en arrière avec le préopercule ( $\left.p^{\prime}\right)$,

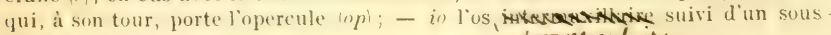
ope: rovalatire

interoperculairc 
avant on y remarque des fossettes appartenant a l'appareil olfactif $(n)$, et une espèce de gros bouton formé par l'os vomer et servant a porter la màchoire supérieure (fig. 291,v). On y distingue: les analogues de l'occipital, des temporaux, des sphénoïdes, des pariétaux, du frontal, d'un ethmoïle et d'un vomer; mais la plupart de ces parties sont composres de plusieur's pièces qui ne se soudent jamais, comme cela arrive de bonne heure pour les mammifères et les oiseaux.

A l'extrémité antérieure de cette portion crânienne de la tète se trouve la mâchoire supérieure, qui y est quelquefois fixée d'une manière immobile, mais qui, en général, conserve une grande mobilité : on y distingue, de chaque coté, un os intermaxillaire (im), placé près de la ligne méliane, et un os maxillaire ( $m$ ), qui s'étend latéralement et qui est mobile sur le premier.

Une chaine de patites pieces osseuses s'étend, de chaque còté de l'angle antéricur de la fosse orbitaire, à son angle postérieur, et complète airisi le cercle orbitaire. Plus en dedans, on voit aussi de chayue còté une sorte de cloison verticale qui est suspendue au cràne et qui sépare les orbites et les jones de la bouche. Elle est formée par les analogues des os palatins, ptérygoüdien, tympanique, etc., et s'articule avec le crane par deux points (sur le vomer et sur les tempes). A sa partie inférieure elle donne attache a la màchoire inférieure, et en arrière elle se prolonge de manière a constituer une sorte de couvercle mobile qui protége l'appareil respiratoire et qui est appelé opercule. Trois pieces de chaque cóté forment la màchoire inférieure, qui s'arlicule par une surface roneave avec l'appareil jugal, dont nous venons de parler. Enfin, en dedans de ces cloisons latérales et an fond de la bouche se trouve une charpente très-compliquée dans sa structure, qui sert a l'insertion des branchies on à les protéger, et qui parait formée par l'analogne de l'hyö̈le parrenu à un développement extrème (fig. 291). L’os de la langrue (l) se continue en arriere avec une série de pièces médianes, et s'articule de chaque coté avec une branche latérale tres-longue et trés-grosse (b), qui, par son extrémité opposée, est comme suspendue a la face interne de la cloison latérale de la tète, dont il a été déja question. Ces branches latérales, formées de plusieurs os, portent à leur bord inférieur une série de rayons aplatis et recourbés $(r)$, qui concourent arec les opereules a compléter les parois des cavités branchiales et sont connus sous le nom de rayons branchiostéges. En arriere de ces branches, il part de la portion médiane de l'appareil hyoüdien puatre paires

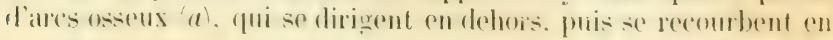


haut et en dedans, et vont se fixer à la base du crâne par l'intermédiaire de quelques petits os nommés pharyngiens supérieurs (ph). Ces arceaux portent les branchies et sont appelés pour cette raison arcs branchiaux. Enfin, en arrière de ceux de la derniere paire, à l'entrée de l'œsophage, se voient deux os pharyngiens inférieurs, disposés ordinairement de manière à pouvoir s'appliquer contre les os pharygiens supérieurs dont il vient d'ètre question.

$$
\text { phars or v }
$$

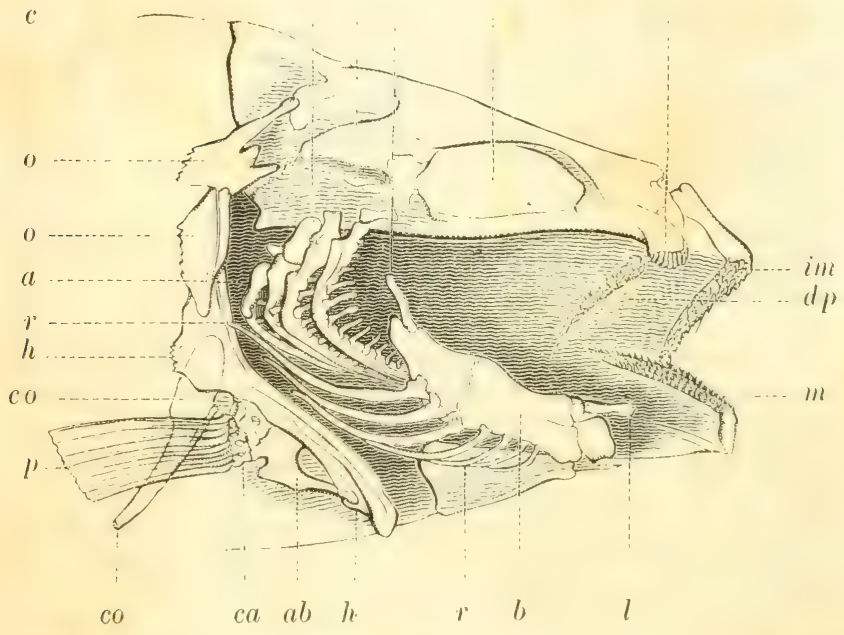

Fig. 291. Têle é appareil respiraloire d'un poisson (1).

(1) Fig. 291. Tête osseuse de la perche, dont on a enlẹvé, d'un côté, les mâchoires, la cloison jugale et lopercule, pour montrer l'intérieur de la bouche et l'appareil hyoüdien; $-c$ crâne ; - or orbite; $-v$ vomer (armé de dents); - im mâchoire supérieure; - dl) dents implantées sur l'arcade palatine; - mi mâchoire inférieure ; $-l$ os lingual; - $-b$ branches latérales de l'appareil hyoüdien; - $s$ stylet servant à suspendre ces branches à la face interne des cloisons jugales; - r rayons branchiosteges; - $a$ arceaux branchiaux; $-p / h$ os pharyngiens supérieurs; - ar surface articulaire de la cloison déjà mentionnée; - 0 à $h$ ceintıre osseuse supportant la nageoire pectorale $(p)$; - o et $o^{\prime}$ omoplate divisée en deux pièces; - $h$ humérus; $-a b$ os de l'avant-bras; - ca os du carpe; - $c o$ os coracoïdien. 
Telle est en crénéral la structure compliquée de la tète osseuse des poissons. Quelquefois on y remarque des anomalies : ainsi, chez les espadons et quelques autres especes voisines des thons, la mâchoire supérieure se prolonge de façon à constituer une espèce de bec semblable à une broche ou à une lamed'épée, dont

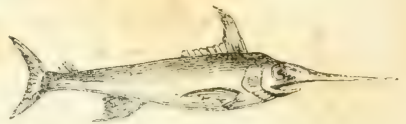

Fig. 292. Espadon. ces poissons se servent comme d'une arme puissante pour attaquer les plus grands animaux marins. Quant à la comparaison des diverses pièces dont elle se compose avec les os de la tète des mammifères, nous ne nous y arrèterons pas, car il règne encore à cet égard beaucoup d'incertitude.

$\$$ \$82. La colonne vertébrale, qui fail suite à la tìte, ne présente (pue deux portions distinctes, l'une dorsale, l'autre caudale (fig. 289); car ici il n'y a ni cou ni sacrum. Le corps des vertebres a une forme particuliere : il est creusé en avant et en arrière d'une cavité conique; ces deux espaces vides se joignent quelquefois de maniere a les transformer en un trou, et la double cavité conique résultant de la juxta-position des deux vertebres voisines est remplie par une substance molle. L'anneau destiné au passigge de la moelle épinière est surmonté d'une apophyse épineuse, et de chanue còté on voit en général une apophyse transverse plus ou moins distincte, qui, au-dessus de la cavitó abdominale, se porte en dehors ef s'articule d'ordinaire avec la còte correspondante; mais qui, dans la prortion caudale de la colonne, se dirige ('n bas, el forme souvent avec celle du còté opposé un anneau de la partie inférieure duquel nait une longrue apophỵse épineuse, semblable a celle qui est située à la face dorsale de la vertèbre.

Les cotes manquent quelquefois; d'autres fois elles enceignent tout l'abdomen, et, chez un petit nombre de poissons, elles viennent se fixer à une sírie d'os imprairs, que l'on doit considérer comme un sternum. Sourent elles portent un ou deux stylets, qui se dirigent en dehors et pénetrent dans les chairs. Il y a quelquefois aussi des stylets semblables qui partent du corps des vertebres : et c'est ainsi que, dans quelyues enenres, tels que celui des harengse les arètes des poistons deviennent tres-nombreuses.

Enfin on tromse encore, sur la ligne médiane du corps, un cortain nombre dos, appelés inter-ipineux (fiy. 29:3, i), qui, en wrinéral, s'appuient contre le bout des apophyses épineuses des vertebres, et (qui s’articulent par leur extrémité opposée allece les rayons des nayeoires médianes $(r)$. Ces rayons sont tantòt des os 
pointus, nommés aiguillons ou épines; tantòt des tıges ossifiées à

$r$

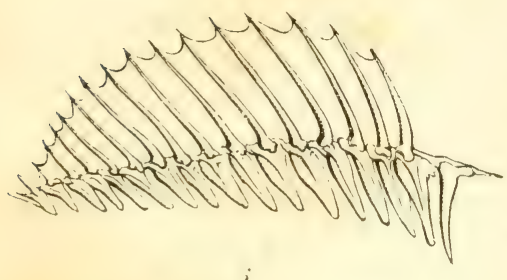

Fig. 293. Nageoire dorsale. leur base seulement, formées ensuite d'une multitude de petites articulations et souvent ramifiées vers le bout. Ces derniers appendices sont appelés rayons mous ou articulés : ils forment toujours la nageoire caudale ( $\mathrm{fg} .289$ ), et quelquefois il n'en existe pas d'autres.

$\$$ 483. Les nageoires latérales, qui représentent les membres, sont terminées par des rayons semblables à ceux des nageoires verticales et analogues aux doigts. A la nageoire pectorale on tronve, a la base de ses appendices, une série transversale de quatre à cinq petits os plats (ca, fig. 291), comparables aux os du carpe, qui, à leur tour, sont fixés à deux os plats $(a b)$, qui semblent ètre le radius et le cubitus élargris. Cet appareil est porté sur une espèce de ceinture osseuse, située immédiatement derrière les ouies, et sur laquelle l'opercule vient s'appliquer comme sur un chambranle : il se compose d'une série de trois os, s'étendant depuis le crâne jusqu'à l'appareil hyoüdien, et porte en arrière un long stylet. La pièce principale qui entre dans sa composition est celle qui porte l'avant-bras et qu'on peut par conséquent comparer à l'humérus $(h)$ : elle se réunit inférieurement avec celle du còté opposé et avec un prolongement médian de l'appareil hyoïdien, et tient au cràne par l'intermédiaire de deux os, que Cuvier considère comme les analogrues de l'omoplate $\left(o^{\prime}\right)$; enfin le stylet, qui en part et se prolonge en arrière sur les còtés du corps, est d'ordinaire formé de deux pieces et peut ètre comparé à un os coracö̈dien (co).

Le membre postérieur (fig. 283̈) est moins compliqué; les rayons de la nageoire ventrale ne sont portés que par un seul os, en général triangulaire, qui souvent vient s'attacher en avant à la symphyse médiane de la ceinture osseuse du membre pectoral, et qui d'autres fois reste suspendu dans les chairs.

$\$ 484$. Dans les poissons cartilagineux, tels que les raies et les squales, appelés vulgairement chiens de mer, la disposition du squelette diffère de ce que nous venons de décrire, et offre une ressemblance très-grande avec le squelette encore cartilagineux des lètards. Le crâne n'est pas divisé par des sutures et ne se compose 
que d'une seule pièce, modelée d'ailleurs et percée à peu près comme le crâne d'un poisson ordinaire. La mâchoire supérieure est formée par des pièces analogues aux os palatins ou au vomer ; les maxillaires et les intermaxillaires n'exi-tent pas ou ne se trouvent qu'à l'état de vestige, cachés sous la peau. La mâchoire inférieure n'a également qu'une pièce de chaque côté, et l'appareil operrulaire manque en général complétement. La colonne vertébrale est quelquefois formée en grande partie d'un seul tube, percé de chaque còté pour le passage des nerfs, mais point divisé en vertèbres distinctes; souvent aussi le corps des vertèbres est percé de part en part, de façon que la substance gélatineuse qui remplit les intervalles de ces os forme un cordon continu. Quant à la disposition des os de l'épaule, du bassin et des nageoires, elle varie. Enfin, l'appareil hyö̈dien, qui supporte les branchies, est en général conformé à peu près de mème que chez les poissons ordinaires: mais, dans les deruiers degrés de cette série (chez les lamproies, par exemple), les ares branchiaux manquent.

$\$ 4803$. La plupart des poissons nagent avec une grande agilité ; on assure que le saumon, par exemple, avance quelquefois avec une vitesse de huit mètres par seconde et parcourt en une heure l'espace de trois ou quatre myriamètres. En général c'est en frappant latéralement l'eau par des flexions alternatives de la quene et du trone qu'ils se meurent de la sorte : aussi les muscles destinés à courber latéralement la colonne verlébrale sont-ils si développés qu'ils constituent ordinairement à eux seuls la majeure partie de la masse du corps. Les nageoires médranes, c'est-à-dire la caudale, la dorsale et l'anale, servent à augmenter l'étendue de cette espèce de rame; mass les nageoires latérales, c'est-à-dire les pectorales et les ventrales, ne concourent que peu à la progression, et ont en général pour usage principal d'influer sur la direction de la course et surtout de maintenir l'animal en équilibre.

$\$ 486$. Une particularité de l'organisation des poissons, qui leur est d'un grand secours dans la natation, est l'existence d'une espèce de poche remplie d'air et disposée de manière à pouvoir ètre comprimée à volonté. Cette vessie natatoire, placée dans l'abdomen, sous l'épine dorsale, communique d'ordinaire avec l'oesophage ou avec l'estomac par un canal à travers lequel l'air contenu dans son intérieur peut s'échapper ; mais ce fluide ne parait pas y pénétrer par cette voie : il est le produit d'une sécrétion ayant son siére dans une portion glandulaire des parois du reservoir lui-mème. et quelquefois celui-ci est complétement fermé. Par les mouvements descotes, cette vessie élastique est plus on moins compriméo. 
et, suivant le volume qu'elle occupe, elle donne au corps du poisson une pesanteur spécifipue égale, supérieure ou inférieure à celle de l'eau, et le fait ainsi rester en équilibre, descendre ou monter dans ce liquide. On a remarqué qu'elle manque souvent et que généralement elle est très-petite dans les espèces destinées à nager au fond des eaux ou mème à s'enfouir dans la vase, telles que les raies, les soles, les turbots et les anguilies.

Chez un petit nombre de poissons, les nageoires pectorales prennent un développement extrème et permettent à l'animal de se soutenir pendant quel(pues instants dans l'air, lorsqu'il s'élance hors de l'eau. Le dactyloptere $(f i g .8 \%$ ) nous en a déjà offert un exemple. Il en est aussi quelques-uns qui, en rampant ou par des sauts répétés, parviemnent à avancer sur la terre. On en cite meme qui grimpent sur les arbres; mais ces exemples sont bien rares.

En traitant des oryanes du mouvement chez les poissons, nous ne pouvons omettre de signaler un appareil très-singulier qui se voit chez quelques-uns de ces animaux et qui leur permet d'adhérer avec une grande force aux corps étrangers : c'est un disque aplati qui recouvre le dessus de la tète, et qui se compose d'un certain nombre de lames cartilagineuses dirigées obliquement en arriere et mobiles (fig. 291). Les poissons du genre Echénéis sont les seuls qui offrent ce mode d'organisation, et l'un d'eux, qui vit dans la Méditerranée et dans l'Océan, est depuis long-temps rélebre sons

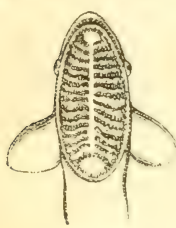

Fiig. 294.

le nom de Remora (fig. 29:3): du reste son histoire a été chargée de fables. On a prétendu que ce petit poisson se nourrissait par l'espèce de succion qu'il exerce avec le disque dont nous venons de parler, et on lui a attribué le pouvoir d'arrèter subitement la course du vaisseau le plus rapide. Une espèce, rossine de la précédente, est très-commune dans les eaux de l'ile de France, et il paraît que, sur les còtes de la Cafrerie, on l'emploie à la pèche, en le lâchant à la poursuite des poissons et en le ramenant à l'aide d'une ligne attachée à sa queue aussitòt qu'il s'est fixé sur sa proie.

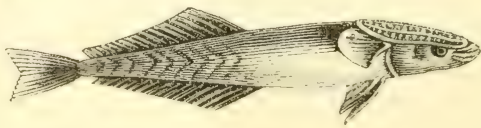

Fig. 295. Le Remor". 
$\$ 487$. La vie d'un poisson se passe presque entièrement à pourvoir à sa subsistance of à fuir ses ennemis; ses sens extérieur's ne paraissent lui donner que des impressions obtuses et ses facultés sont des plus bornées; on ne lui comnait aucune industrie, aucun instinct remar(uable: anissi son cerveau est-il peu développé, et ses organes des sens bien imparfaits.

La cavité du crâne est petite relativement à la masse du corps, et l'encéphale ne la remplit pas à beaucoup près. Entre ses parois et le cerveau, on trouve une masse spongieuse et grasse, d'un volume considérable, surtout chez les individus adultes. Les lobes qui composent l'encéphale sont placés à la file les uns des autres et représentent souvent une espece de double chapelet. On y distingue un cervelet, des hémisphères cérébraux, des lobes optiques, des lobes olfactifs et, en arrière de toutes ces parties, des lobes appartenant à la moelle allongée.

La nature des téguments des poissons doit leur rendre le tact bien imparfait; et, dénués, comme ils le sont, de membres prolongés et surtout de doigts flexibles et propres a envelopper les objets, ce n'est qu'au moyen de leurs levres que ces animaux peuvent exercer le sens du toucher. Les barbillons gu'on leur voit autour de la bouche $(b$, fig. 288) paraissent servir à les avertir du contact des corps. Le goùt est aussi à peu près nul ; car leur langue, à peine mobile, n'est pas charnue, et ne recoit que peu de nerfs, et les aliments ne séjournent jamais dans la bouche. L'appareil de l'orlorat est de structure plus compliquée, mais n'est pas disposé de facon à ètre traversé par l'air ou par l'eau servant à la respiration. Les fosses nasales ne consistent qu'en deux cavités terminées en cul-de-sac, s'ouvrant en général an dehors chacune par deux narines, et tapissées par une membrane pituitaire plissée d'une manière très-remarquable. L'oreille est presipue toujours logée tout entiere dans la cavité du cràne, sur les cótés du cerveau, et ne consiste gruère qu'en un restibule surmonté de trois canaux semi-circulaires, auxquels les ondes sonores n’arrivent qu'après avoir mis en vibration les téguments communs et les os du crane. En crénéral on ne voit rien qui puisse ètre comparé a l'oreille externe, an tympan ou a la caisse. Enfin les yeux sont tres-sands et peu mobiles : ils nont pas de veritables paupieres ni d’appareil lacrymal. La peau passe alldevant de l'eril et se latise traverser par la lumiere. La cornée est presque plane, la pupille tres-large et peu ou point contractile; enfin, le eristallin est sphérigue. En exenceal ces organes nofleent rien de particulier quant a lexr position; mais ehez quelepues pois-

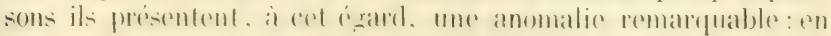




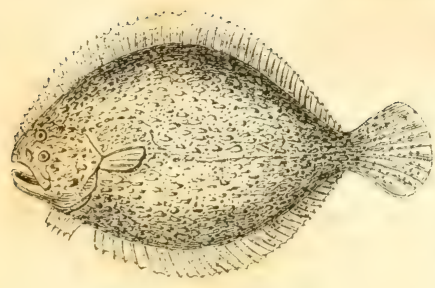

Fig. 295. Le Turbol.

effet, chez les soles, les plies, les turbots et les autres poissons plats (fig. 296), ils ne sont pas logés, comme d'ordinaire, des deux còtés de la tèle, mais sont dirigés l'un et l'autre du même côté, ct cette espèce de monstruosité coïncide avec un défaut de symétrie dans d'autres parties du corps.

$\$$ 488. Les poissons sont tres-roraces : il n'en est qu'un trespetit nombre qui vivent principalement de matières végétales, ef, en général, ils avalent sans chois tous les petits animaux qui sont a leur portée. Quelques especes sont dépourvues de dents, mais chez la plupart il en existe meme plusieurs rancées, comme dans la grueule du requin, par exemple (fig. 297 ; et le plus ordinairement on en trouve non-seulement aux deux mâchoires, mais au

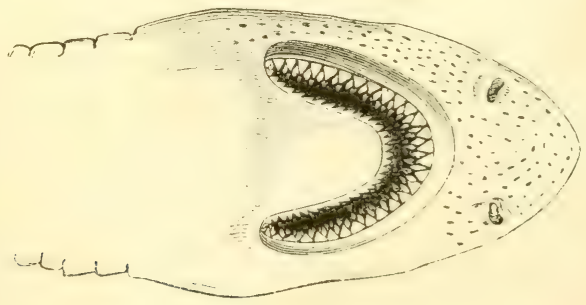

Fig. 297. Têle du Requin

palais, implantées sur le vomer ou sur les os palatins (fig. 291), à la lanque, sur le bord intérieur des ares branchiaux, et enfin jusque dans l'arrière-bouche, sur les os pharyngiens qui entourent l'entrée de l'œesophage. Elles n'ont jamais de racines, mais se soudent avee l'os qui les porte : elles tombent néanmoins, probablement par un mécanisme analogue à celui de la chute du bois des cerfs, et sont remplacées par de nouvelles dents, qui naissent tantòt dessous, tantùt à còté des anciennes. Les dents dont les mâchoires sont armées ne servent en général qu’à retenir ou à briser la proie; celles situées au fond de la bouche sont rarement disposées de manière à la broyer. Du reste leur forme varie beaucoup; tantòt elles sont si fimes et si serrées gu'olles offrent l'aspect du velours; of 
d'autres fois elles constituent des crochets robustes, des lames à bords tranchants ou des tubercules arrondis.

$\$$ 489. Quelques poissons ne se nourrissent pas de matières solıdes et vivent en suçant seulement les liquides quils puisent dans les corps d'autres animaux : les lamproies sont dans ce cas, et leur bouche, au lieu d'avoir la disposition ordinaire, offre une structure tres-singulière, mais bien en rapport avec ses fonctions : en effet, les cartilages qui, chez les raies, ete., forment les màchoires, sont ici soudés en anneaux et soutiennent un disque charnu dont la surface est garnie de dents et dont le milieu est occupé par la bouche; enfin, la langue, également armée de dents, se meut en avant et en arrière en marière de piston, et permet à l'animal de se servir de cet appareil, comme d'une ventouse, soit pour se fixer aux corps étrangers, soit pour pomper les corps dont il se nourrit.

La bouche n'est entourée d'aucune glande salivaire. L'ossophage est court; l'estomac et les intestins varient pour la forme et les dimensions. Le foie est généralement grand et d'un tissu mou; presque toujours le pancréas est remplacé par des cœecums d'un tissu parliculier, placés autour du pylore; eufin, la position de l'anus varie beaucoup : quelquefois il se trouve sous la gorge, d'autres fois à la base de la queue. Les reins sont extrèmement volumineux et s'étendent des deux còtés de la colonne vertébrale dans toute la longueur de l'abdomen. Leurs conduits excréteurs aboutissent à une espèce de vessie, dont l'ouverture externe est placée immédiatement derrière l'anus et l'orifice des organes reproducteurs.

La digestion parait se faire très-rapidement, et le chyle est absorbé par de nombreux vaisseaux lymphatiques, qui aboutissent par plusieurs trones dans le systeme veineux, pres du cour.

$\$$ 490. Le sang des poissons, comme nous l'arons déji dit, est rouge, et les grlobules ont une forme elliptique et des dimensions considérables $(\$ 81$, fig. $28, c)$.

Le cour (fig. 12) est placé sous la grorge, dans une cavité séparée de l'abdomen par une especé de diaphragme, et protégé par les os pharyngiens en dessus, les ares branchiaux sur les cótés, et en général par la ceinture humérale en arrière. Il se compose, comme nous l'avons déja vu $(\$ 109)$, d'une oreillette, qui recoit le sang veineux rassemblé dans un vaste sinus situé auprès, et d'un ventricule placé en dessous et donnant naissance, par son extrémité antérieure, à une artere pulmonaire, dont la base est renflée et constitue un bulbe contractile. Ce vaisseau se divise bientot en branches latérales, qui se distribuent aux branchies, et le sangy, après avoir traversé ces organes, remonte vers la tète par un autre 
vaisseau qui longe également le bord des ares branchiaux. Là, ces canaux envoient quelques branches aux parties voisines et se réunissent pour former une grande artère dorsale, laquelle se dirige en arrière au-dessous de la colonne vertébrale, et donne des rameaux à toutes les autres parties du corps (fig. 42). Enfin tout le sang veineux ne se rend pas directement dans le sinus que nous avons déjà mentionné; celui des intestins et de quelques autres parties, avant que de relourner au cœur, se répand par la veine porte dans le foie.

On voit done que le sang, en parcourant le cercle circulatoire. traverse en entier l'appareil de la respiration, comme chez les mammiferes et les oiseaux, mais ne passe qu'une seule fois dans le cour, ce qui doit rendie sa marche plus lente. Enfin le cœur lui-mème correspond par ses fonctions à la moitié droite du mème organe chez les vertébrés supérieurs (voyez fig. 39).

$\$$ 491. La respiration se fait au moyen de l'air dissous dans l'eau et a lieu à la surface d'une multitude de lamelles saillantes et trèsvasculaires, fixées au bord externe des aucs branchiaux, dont nous avons déjà indiqué la position. En général on compte, de chaque còté, quatre branchies, composées chacune de deux rangées de lamelles allongées. Dans la plupart des poissons cartilagineux il y en a cind, et dans la lamproie on en trouve sept. Chez presque tous les poissons osseux, ces lamelles sont simples et fixées par la

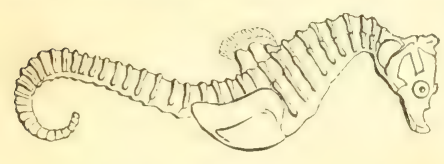

Fig. 298. Hippocampe. base seulement; chez un petit nombre, tels que les hippocampes appelés vulgairement chevaux marins (fig. 298), elles sont au contraire ramifiées et en forme de panaches ; enfin, chez la plupart des poissons cartilagineux, tels que les raies et les requins, elles sont fixées à la peau par leur bord externe aussi bien qu'aux ares branchiaux par leur bord interne.

L'eau nécessaire à la respiration entre dans la bouche, et, par un mouvement de déglutition, passe par les fentes que les ares branchiaux laissent entre eux, et arrive de la sorte aux branchies, dont elle baigne la surface, puis elle s'échappe au dehors par les ouvertures des ouïes. On voit, en effet, l'animal ouvrir la bouche et soulever son opereule alternativement. Chez les poissons dont les branchies sont lihres a leur bord extérieur, il suffit d'une seule de ces ouvertures de chaque coté; mais, lorsque les branchies sont fixes, il faut, pour la sortie de l'eau, autant d'ouvertures qu'il y a 
d'espaces interbranchiaux. Aussi, chez le requin (fig. 299), on cn compte cinq paires, et chez la lamproie (fig. 31:3) sept paires. On peut par conséquent connaitre la disposition de l'appareil respiratoire par la seule inspection de ses ourertures extérieures. Il est aussi à noter que chez quelques poissons l'eau ne passe pas directement de la bonche dans la cavité respiratoire par les fentes situées entre les ares branchianx, mais y arrive par un canal situé au-dessous de l'œsophage à peu près comme la trachée des animaus supérieurs; les lamproies offrent ce mode de structure

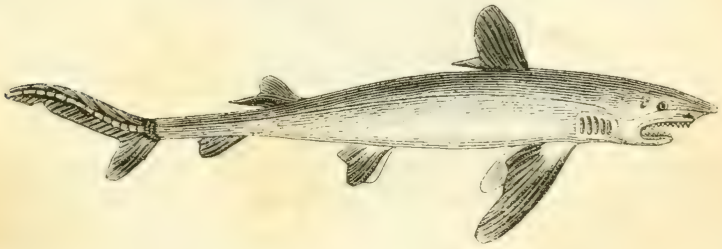

Fig. 299. Requin

Les poissons ne consomment qu'une quantité assez faible d'osygene; quelques-uns cependant ne se contentent pas de celle qui est dissoute dans l'eau, et viennent de temps en temps a la surface respirer l'air. Il en est mème qui en avalent et qui convertisient l'oxycrene en acide carbonique, en le faisant passer an travers de leur intestin : la loche des étangs nous oflere, en eflet, un exemple de ce singulier phénomeno. Lorspue les poissons demeurent hors de l'au, ils périssent en crénéral promptement par aspleysie; non pas que loxygene leur manque, mais parce que. les lamelles branchiales n'étant plus soutenues par l'eau, s'affacisent et ne se laissent pas lraverser aussi facilement par le sang, ef paree que ers orsames, en se desséchant, deviennent improperes a remplir leurs fonclions : aussi les poissons qui périssent le plus promplement par lexposition a l'air ont-ils des oü̈es tres-fendues, ce qui facilite lévaporation à la surface des branchies: tandis que ceux qui résistent le micus ont ces ouvertures tress-étroites ou possident meme quelque rérephatede oil is pervent censerver de l'eau peur humerfer ces organes. Iese divers poisions qui composent la latmille des Pharyngrens laberiblhiformes sont tres-remarquables 
sous ce rapport et doivent leur nom aux cellules aquifères placées au-desssus de leurs branchies.

Ces cellules (fig. 300), renfermées sous l'opercule et formées par des lamelles des os pharyngiens, servent effectivement à retenir une

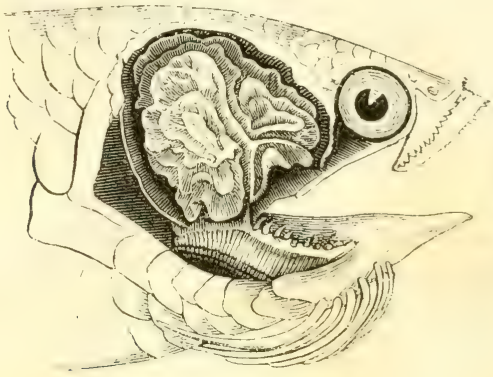

Fig. 300. Appareil respiralorre de linabas.

rertaine quantité d'eau, laquelle maintient les branchies humides lorsque l'animal est à l'air, et lui permet d'y vivre assez long-temps : aussi ces poissons ont-ils l'habitude de sortir des rivières et des étangs, qui sont leur séjour ordinaire, et de se porter à d'assez grandes distances, en rampant dans l'herbe ou sur la terre. Ceux qui présentent cet appareil labyrinthiforme, porté au plus haut degré de complication, et qui ont recu le nom d'Anabas, nonseulement restent très-long-temps hors de l'eau, mais encore, à ce que l'on assure, grimpent sur les arbres. La plupart des poissens de cette famille habitent les Indes, la Chine et les Moluques. Une espèce, le Gourami, qui est originaire de la Chine et qui est trèsestimé pour sa chair savoureuse, a élé acclimaté dans les étangs de l'île de France et de Cayenne.

$\$ 492$. Ainsi que nous l'avons déjà dit, les poissons ne produisent presque pas de chaleur; mais quelques-uns d'entre eux ont la singuliere faculté de développer de l'électricité et de donner ainsi des commotions très-fortes aux animaux qui les touchent. La torpille, le silure ou malaptérure et une espèce de gymnote sont dans ce cas, et, chose remarquable, l'organe électrique présente une ronformation toute différente chez chacun d'eux. 
C'est la grmnote ou anguille électrique (fig. 301) qui possède au plus haut degré cette faculté curieuse ; elle habite l'Amérique méridionale et ressemble beaucoup aux anguilles ordinaires, si ce n'est qu'eile manque de nageoires au bout de la queue et que sa peau est sans écailles bien visibles. Ce poisson atteint deux mètres de long: son corps est allongé et tout d'une venue, et sa peau est enduite d'une matière gluante : il est très-commun dans les petits ruisseaux et les mares que l'on rencontre cà et là dans les plaines immenses situées entre la Cordillière, l'Orénoque et la Bande-Orientale; et on le

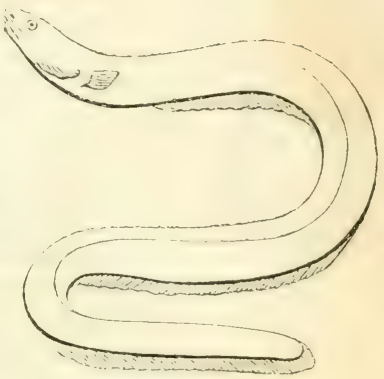

Fig. 301. Gymnole. trouve aussi dans le Méta, l'Apure, l'Orénoque, elc. Les commotions électriques qu'il donne à volonté et dans la direction qu'il choisit suffisent pour abattre les hommes et leschevaux, et la grmnote a recours à ce moyen pour se défendre contre ses ennemis, et jour tuer de loin les poissons dont elle veut se repaitre; car l'eau, ainsi que les métaux, transmet le choc engourdissant de ce singulier animal de la mème manière que les paratonnerres conduisent, de l'atmosphère dans la terre, l'électricité des nuages. Ses premières décharges sont en général faibles; mais quand il est irrité et agité. elles deviennent de plus en plus vives et sont alors terribles. Lorsqu'il a frappé ainsi à coups redoublés, il s'épuise et a besoin d'un repos plus ou moins prolongé avant que de pouvoir donner de nouveaux choes. On dirait qu'il emploie ce temps a charger ses organes électriques, et les Américains profitent de cette circonstance pour le prendre sans danger. Pour faire la pèche des gymnotes, ils font entrer de force, dans les étangrs habités par ces poissuns, des chevaux sauvages, qui, recevant les premiers choes, sont bientòt étourdis et abattus ou mime tués; ensuite ils s'eniparent des grmnotes épuisées avec des filets ou avec le harpon.

L'appareil a l'aide duyuel la symnote produit ces commotions électriques règne tout le longr du dos et de la queue, et consiste en quatre faisceaux longitudinaus, composés d'un grand nombre de lames membraneuses paralleles et très-rapprochées entre elles, qui sont à peu près horizontales et unies par une infinité d’autres lamelles plus petites, placées verticalement en travers; les petites rellules prismatiques of transtersales, formeres par la remion des 
ces lames, sont remplies d'une matiere gélatineuse; enfin tout l'appareil reçoit des nerfs très-gros.

La torpille ( $f g .302$ ) est un poisson cartilagineux et aplati qui ressemble beaucoup aux raies ordinaires. Son corps est lisse et représente un disque à peu près circulaire, Iont le bord antérieur est formé par

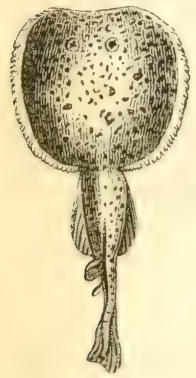

Firg. 302. Torpille commune. deux prolongements du museau, qui, de chaque còté, vont rejoindre les nageoires pectorales et laissent entre ces organes, la tète et les branchies, un espace ovaliare servant à loger l'appareil électrique de ces poisions. Cet appareil (fig. 301) se compose d'une multitude de tubes membraneux verticaus, serrés les uns contre les autres, comme des rayons d'abeilles, subdivisés par des cloisons horizontales en petites cellules remplies de mucosités et animées par plusieurs branches très-grosses des nerfs pneumo-gastriques. C'est dans ces singuliers organes que se produit l'électricité à l'aide de laquelle les torpilles peuvent donner, à ceux qui les touchent, des commotions violentes, et produire tous les phénomènes qui, dans les expériences de physique, résultent d'un courantélectrique ordinaire, tels que des étincelles, des décompositions chimiques, etc. Ces poissons sont moins puissants que les gymnotes, mais peuvent néanmoins frapper d'engourdissement le bras de celui qui les touche, et ils se servent probablement de ce moyen pour s'emparer de leur proie. On a constaté dernièrement que cette propriété est sous la dépendance du lobe postérieur de l'encéphale, et qu'en détruisant ce lobe ou en coupant les nerfs qui en partent, on anciantit la faculté de produire des commotions. Nous en arons dans nos mers plusieurs especes qui fréquentent les còtes de la Vendée et de la Provence.

Enlin la silure électrique ou malaptérure (fig. 303) habite le Nil ef le Sénécal ; sa longueur est d'environ trois a quatre décimètres. et elle parait devoir la faculté de donner des commotions électri-

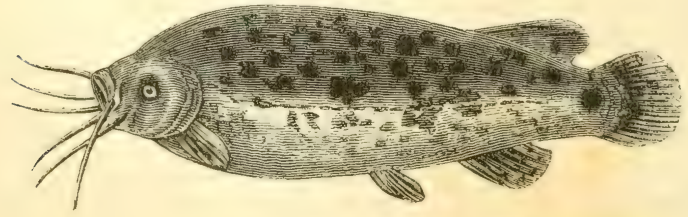

Fig. 303. Malıptérure électriךue. 
ques à un tissu particulier situé entre la peau des flancs et les muscles et ayant l'apparence d'un tissu cellulaire feuilleté. Les Arabes donnent à ce poisson le nom de raasch, qui signifie tonnerre.

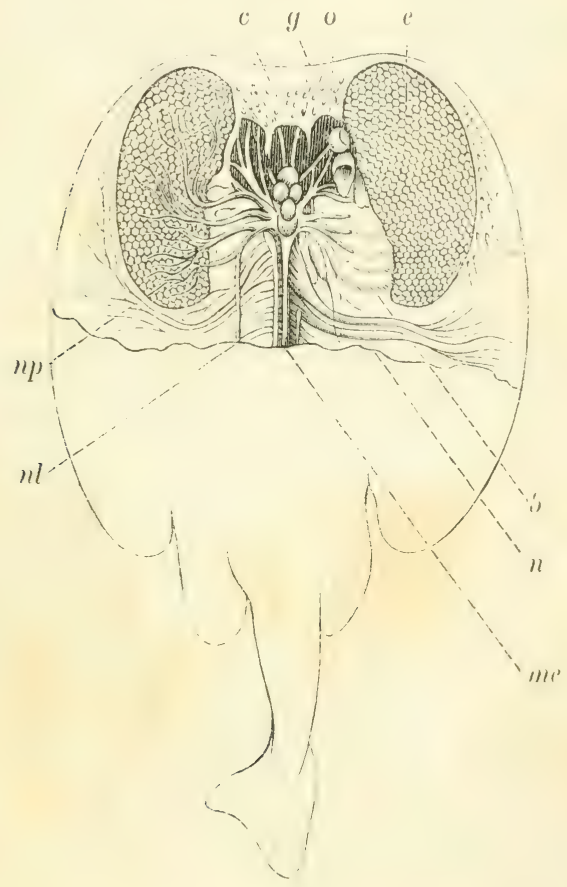

Fig. 304. Appareil électrique de la Torpille (1).

\$ 493. Les poissons se multiplient au moyen d'oufs, of le nombre de cenx-ci est quelquefois immense : il peut s'élever, pour une seule ponte, à des centaines de mille. En grénéral, ils n'ont quine enveloppe mucilagineuse et sont fécondés apress la ponte. Quelpues-uns

(1) $c$ le cerveau; - me la moelle épiniere; - o weil et nerf optiyue; - $c$ organes électriques; $-n p$ nerfs pneumogastriques se renclant à l'organe électrique ; $-n$ l branche du précédent constituant le nerf latéral; $-n$ nerfs spinaux. 
de ces animaux sont au contraire ovovivipares ; mas quelle que soit la manière dont les jeunes poissons sont amenés à la vie, ils sont, du moment de leur naissance, abandonnés complétement à eux-mèmes, et dans le premier âge il en périt beaucoup.

C'est au développement simultané d'un nombre incalculable d'œufs déposés dans un mème lieu et à l'instinct qui pousse divers poissons à se suivre entre eux, que l'on doit attribuer la réunion de certaines espèces en légions immenses et serrées, appelées par les pècheurs des bancs de poissons. En effet, on ne peut guère appeler ces réunions des sociétés; les individus dont elles se composent ne s'aident pas entre eux; les mèmes besoins à satisfaire les retiennent dans la mème localité ou les en éloignent, et si on les voit quelquefois suivre l'un d'entre eux conme un guide, c'est probablement par suite d'une tendance à l'imitation qui accompagne toujours les premières lueurs de l'intelligence.

$\$$ 49. Quoi qu'il en soit, ces animaux, ainsi réunis en troupes, font souvent de longs voyages, tantòt pour gagner la mer, tantòt pour remonter les rivieres ou pour changer de parages. Certains poissons mènent une vie presque sédentaire et restent toujours dans la localité qui les a vus naitre; d'autres sont toujours errants, et un grand nombre de ces animaux font périodiquenent des voyages plus ou moins longs. A l'époque du frai, ils se rapprochent ordinairement des cotes, ou entrent dans les rivières et font quelquefois de la sorte un trajet extrèmement long. Chaque année, vers la mème époque, des bandes de poissons voyageurs arrivent dans les mèmes parages, et l'on croit généralement que plusieurs de ces espèces émigrent régulierement du nord vers le sud et du sud vers le nord, en suivant une route déterminée; mais peut-ètre serait-il plus exact de croire que lorsqu'ils disparaissent du littoral ils se retirent seulement dans les grandes profondeurs de la mer. Le hareng est un des poissons les plus remarquables sous ce rapport, et le plus célèbre par l'importance des pèches dont al est l'objet. II habite les mers du nord et arrive chaque année en légrions innombrables sur diverses parties des còtes de l'Europe, de l'Asie et de l'Amérique, mais ne descend guère au-dessous du quarantecinquième degré de latitude nord. Quelques naturalistes pensent que tous ces bancs de harengs se retirent périodiquement sous les glaces des mers polaires, et partent de cette retraite commune en une immense colonne, qui, en se subdivisant, se répandrait sur presque toutes les còtes situées au-dessus du parrallèle que nous venons d'indiquer. On a été mème jusqu'à tracer sur la carte l'itinéraire de ces poissons ; mais cette longue émigration et ce rendez- 
rous commun dans les régions arctiques sont loin d'etre démontrés, et il y a lieu de croire que les choses ne se passent pas de la sorte. C'est près de nos còtes que les harengs déposent leurs œufs, et il est probable que les jeunes se retirent bientòt dans les grandes profondeurs de la mer et s'y dirigent vers le nord, ou ils doivent rencontrer en plus grande abondance les petits crustacés et les autres animalcules propres à leur servir d'aliments. Au printemps, d'autres besoins les rapprochent du rivage et leur font rechercher des eaux moins profondes et plus chaudes : ils se montrent alors 'n légions innombrables et descendent vers le sud. mais, après itre arrivés dans la Baltique, sur les còtes de la Hollande et jusque dans la Manche, on ne les voit pas reprendre la route du nord pour passer l'hiver sous les glaces du pòle, et recommencer au printemps suivant leur prétendu vorage périodique.

Quoi qu'il en soit, aux mois d'avril et de mai, les harengs commencent à se montrer dans les eaux des îles Shetland, et, vers la fin de juin ou en juillet, ils y arrivent en nombre incalculable et en formant de vastes banes serrés, qui courrent quelquefois la surfice de la mer dans une étendue de plusieurs lieues et ont plusieurs centaines de pieds d'épaisseur. Peu après ces poissons se répandent sur les còtes de l'Écosse et de l'Angleterre. Pendant les mois de septembre et d'octobre, ils y donnent lieu à de grandes pèches; et, depuis la mi-octobre jusque vers la fin de l'année, ils abondent dans la Manche, principalement depuis le détroit de Calais jusqu'à l'embouchure de la Seine. En juillet et aoùt, ils restent d'ordinaire en pleine mer; mais cnsuite ils entrent dans les eaux peu profondes, et cherchent un endroit convenable pour y déposer leurs neufs, où ils séjournent jusque vers le mois de février. Les harengs les plus vieux fraient les premiers et les jeunes plus tard; mais la lempérature et d'autres rirconstances paraissent influer aussi sur ce phénomene; car dans certaines localités on en trouve d'cuvés pendant presque toute l'année. Après la ponte, ils sont maigres et peu estimés; les pècheurs les appellent alors des harengs gais. Leur multiplication est prodigieuse : on a trouvé plus de soixante mille œufs dans le ventre d'une seule femelle de moyenne grardeur. On assure que leur frai recouvre quelquefois la surface de la mer dans une grande étendue, et resiemble de loin à de la sciure de bois qui y serait répandue. Du reste, on ne sait yue fort peu de chose sur le jeune âge de ces poissons (1).

(1) La pêche du hareng est une des plus importantes : elle occupe chaque annéc des flottes entières, et jadis elle était poursuivie avec encore plus d'activité. Vers le milieu du dix-septitme siecle, les Hollandais n'y employaient pas moins de 
$\$ 49: 3$. Les sardines, les maquereaux, les thons et les anchois sont aussi des poissons de passage qui visitent périodiquement nos cotes et y donnent lieu à des pèches importantes. Le saumon est également remarquable par ses voyages; il habite toutes les mers arctiques, et chaque printemps il entre en grandes troupes dans les rivieres pour les remonter jusque près de leurs sources. Dans ces émigrations, les saumons suivent un ordre régulier, en formant deux longues files réunies en avant et conduites par la plus grosse femelle qui ouvre la marche, tandis que les plus petits mâles sont à l'arrière-garde. Ces troupes nagent en général avec grand bruit, au milieu des fleuves et pres de la surface de l'eau si la température est donce, plus prés du fond si la chaleur est forte. D'ordinaire les saumons arancent lentement et en se jouant; mais, si quelque danger parait les menacer, la rapidité de leur natation devient telle que l'œil peut à peine les suivre. Si une digue ou une rascade s'oppose à leur marche, ils font les plus grands efforts pour la franchir. En s'appuyant sur quelque rocher et en redressant tout a coup avec violence leur corps courbé en are, ils s'élancent hors de l'eau el sautent quelquefois de la sorte à une hauteur de quatre a cing mètres dans l'atmosphère pour aller tomber au delà de l'obstacle qui les arrètait. Les saumons remontent ainsi les fleuves jusque vers leur source, et vont chercher dans les petits ruisseaux et les endroits tranquilles un fond de sable et de gravier propre à y déposer leurs œufs; puis, maigres et affaiblis par tant de fatigues,

deux mille bâtiments, et on a évalıé à huit cent mille le nombre de personnes que cette branche d'industrie faisait vivre dans les deux provinces de la Hollande et de la Frise occidentale. Les Norwégiens, les Américains, les Écossais, les Anglais, ct même nos pêcheurs, s'y adonnent aussi en grand nombre; et aujourd'hui encore, bien que son importance soit moindre, elle est néanmoins une grande source de richesses pour tout le littoral des mers du nord. Dans nos divers ports situés entre Dunkerque et l'embouchure de la Seine, on compte chaque année trois à quatre cents hâtiments montés par environ cinq mille marins qui s'occupent de la pêche du hareng, et on évalue à près de 4 millions les produits qu'ils en obtiennent.

Cette pêche se fait d'ordinaire avec des filets de cinq à six cents toises de long dont le bord inférieur est alourdi par des pierres, tandis que le bord supérieur est maintenu à flut au moyen de barils vides, et dont les mailles sont juste assez grandes pour permettre au hareng d'y enfoncer la tête jusqu'au delà des ouïes, mais ne laissent pas passer les nageoires pectorales. Je poisson, en cherchant à vaincre l'obstacle que cette grande clois'n rerticale oppose à son passage, s'emmaille ainsi, et ne pouvant pius, à cause de ses nageoires et de ses ouïes, ni avancer ni reculer, il reste prisonnier jusqu à ce que les pêcheurs retirent leur filet à bord. Le nombre des harengs qui se prennent de la sorte est quelquelois si considérable qu'en peu d'instants tout le filet s'en trouve garni et rompt sous leur poids. En général, cette pêche se fait luin du port, et pour conserver le poisson on le sale à bord. 
ils redescendent en automne vers l'embouchure des fleuves et vont passer l'hiver dans la mer. Les oufs sont déposés dans un enfoncement que la femelle creuse dans le sable. Le mâle vient ensuite les féconder. Les jeunes saumons grandissent très-promptement, et, lorsqu'ils ont atteint la longueur d'environ un pied, ils abandonnent le haut des rivières pour gagner la mer, qu'ils quittent à son tour, pour rentrer dans les fleuves lorsqu'ils sont longs de quatre à cinq décimètres, c'est-à-dire vers le nilieu de l'été qui a suivi leur naissance. Nous avons déjà vu que les hirondelles, qui, à l'approche de la saison froide, émigrent vers le sud, reviennent chaque année dans les mèmes lieux. Il parait que les saumons ont le mème instinct. Pour s'en assurer, un naturaliste, nommé Deslandes, mit un anneau de cuivre à la queue de douze de ces poissons et leur rendit la liberté dans la riviere d'Auzou, en Bretagne. Bientòt après ils disparurent tous, mais l'année suivante on reprit dans le mème lieu cinq de ces saumons; la seconde année, trois; et l'année d'après, trois encore.

$\$$ 496. Les mœurs des poissons n'offrent que peu de particularités curieuses; mais l'histoire de ces animaux doit néanmoins nous intéresser, ne füt-ce qu'à raison de l'importance des pèches dont ils sont l’objet. A une époque qui n'est pas bien éloignée de la nòtı, cette branche d'industrie occupait un cinquieme de la population totale de la Hollande, et pour la pèche du harong seulement ce pays couvrait de ses bàtiments les mers du nord. En Angleterre, clle fait subsister aussi un nombre considérable de bons et hardis matelots; et mème en France, où elle a moins d'importance, on compte de trente à quarante mille pècheurs, dont près du liers s'aventure chargue année jusque sur les còtes de l'Islande et de Terre-Neuve à la recherche de la morne (fig. 30:3), grand el excellent poisson qui abonde clans ces parage's et qui se montre aussi, mais en petit nombre, dans nos mers.

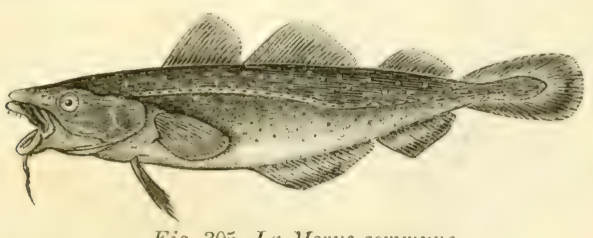

Fig. 305. La Horue commune.

$\$$ 697. Classification. - Les poissons constituent une des clatsons

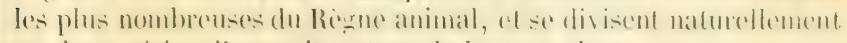

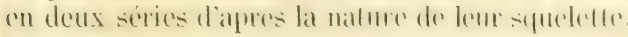


Le groupe ou sous-classe des porssoxs ossevx est de beaucoup le plus nombreux en genres ct en espèces. Il se compose de tous les poissons ordinaires et se subdivise, d'après des caractères en général peu importants, en six ordres, désignés sous les noms d'acanthoptérygiens, de malacoptérygiens abdominaux, de malacoptérygiens subbranchiens, de malacoptérygiens apodes, de lophobranches et de plectognathes.

$\$ 498$. Les Plectognatines se distinguent de tous les autres poissons à squelette osseux, par la conformation de la bouche; car leur màchoire supésieure, au lieu d'ètre mobile comme d'ordinaire, est soudée ou engrenée au cràne. On range dans ce petit groupe : les coffres (fig. 306), qui sont remarquables par l'espèce de cuirasse à compartiments osseux dont ils sont revètus. Les diodons et les tétrodons, qui ont la faculté de se gonfler comme des ballons en aralant de l'air et en distendant ainsi un peu leur estomac, appartiennent aussi à rette division.

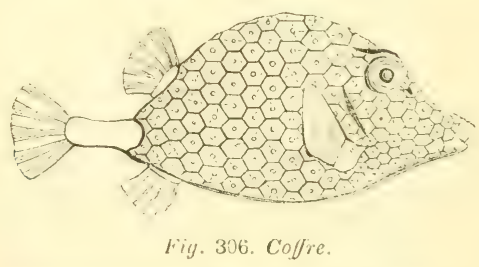

$\$$ 199. L'ordre des Lophobnaxcues ne présente rien de particulier dans la disposition des màchoires, mais est caractérisé par la structure des branchies; en effet, ces organes, au lieu d'avoir la forme des dents de peigne, se divisent en petites houppes rondes fixées par paires le long des arcs branchiaux. On y range les sygnathes, les hippocampes ( $f i g .298)$, etc.

$\$ 500$. L'ordre des Acaxtnopténygiexs comprend tous les pois-sons osseux à màchoire supérieure mobile et à branchıes pectinées.

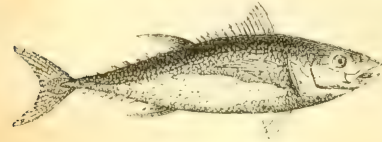

Fig, 307. Thon dont la première nageoire dorsale est soutenue par des rayons osseux etspiniformes (fig.293). Cette division comprend les trois quarts des poissons connus, et se subdivise en un grand nombre de familles. On y range: les perches, les matuereaux, les thons, les espadons, ete.

501 . Lorde des MaL.coptenyguess aboosuxarx se distingue da précédent par la nature des rạons qui constiluent lat premiere 
nageoire dorsale, et qui, au lieu d'ètre épineux, sont cartilagineus, articulés vers le bout et, en général, divisés en plusieurs branches (fig. 308). Ce caractère lui est commun avec les deux groupes de poissons osseux dontil nous reste à parler, et pour l'en distinguer il faut ajouter que les nageoires ventrales

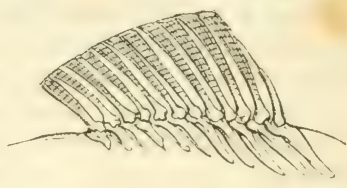

Fig. 308. sont situées sous l'abdomen, en arriere des pectorales et non attachées aux os de l'épaule. Nous citerons comme exemple de cet ordre : les carpes, les brochets (fiy. 309), les silures (fig. 303), les saumons, les harengs, les sardines et les anchois.

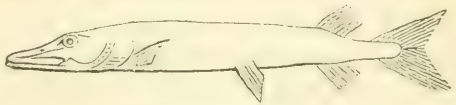

Fig. 309. Brochet.

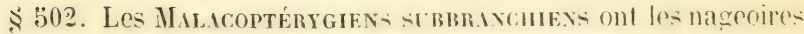
conformées de la mème manière que dans l'ordre prérédent, mais leurs nageoires sont placées sous les pectorales et suspendues aux os de l'épaule. Cette division comprend : la morue ( $\mathrm{fig} .305$ ), le merlan, le remora ( fig. 295), et la famille des pleuronectes ou poissons plats, composéc des plies (fig. 309), des turbots (fig. 296), des soles, etc

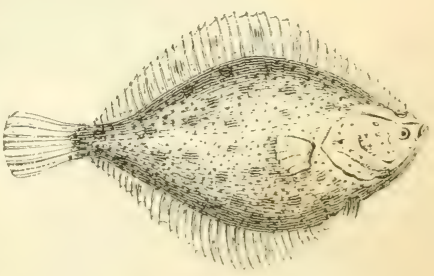

Fig. 310. Plie.

$\$$ ö03. Enfin, lordre des M.ulacoptérygiexs apones est surtont caractérisé par le défaut de rayons épineux à la nagreoire dorsale et le manque absolu de nageoires ventrales. Les poissons qui oflrenl ce mode de structure ont tous une forme allongée et une pean épaisse, molle et peu écailleuse; ce sont les anguilles, les rrymnotes (fiy. 301), etc.

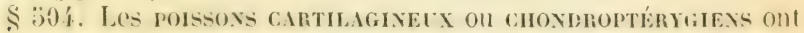
le squelette ordinairement cartilagineux; quelquefois cette charpente intérieure est mème presque membraneuse, mais jamais elle n'est osseuse, la matiore ealcaire qui en durcit la surface ne sy déposant que par petits grains. On y remargue ansi une resiem- 
blanee tris-grande avee le squelette encore cartilagineux des fidards. Il est seulement à noter que les pieces qui représentent los os maxillaires supérieurs et intermaxillaires sont rudimentaires, et que la màchoire supérieure est formée essenliellement par les analogues des os palatins. Tantòt les branchies sont libres a leur bori externe, comme chez les poissons osseux; tantòt, au contraire, elles sont atlachées par ce bord aussi bien que par leur hord interne, el cette différence sert de base à la division des poissons cartilagineux en deux groupes, savoir : les chondroptérygiens (i) branchies libres, qui constituent un seul ordre, et les chondropherygiens a branches fixes, qui en forment deux, les sélaciens et les cyclostomes.

\$ $30 \%$. L ordre des Choxdroptérgatexs a branchues libres est désigné ausit sous le nom des sturiomiens, parce qu'il a pour type lesturgeon (sturio). Il se compose de poissons dont la forme ne présente rion dianormal (fig. 311) et qui ont pour la plupart la peau crarnie de srandes plaques ossenses disposées par rangées, et la bouche dépourvue de dents.

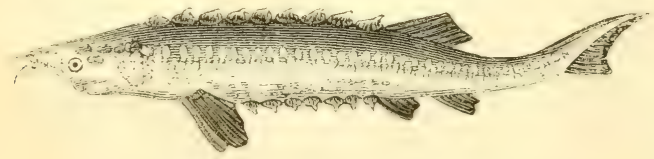

Fig. 311. Es/urgcon

$\$ 306$. Les Chondropténgaiexs a Brixcmes fixes présentent un caractère commun très-remarquable dans la disposition de l'apparcil respiratoire. Les branchies au lieu d'ètre libres par leur bord externe et suspendues dans une cavité commune, d'où l'eau s'échappe au dehors par une seule ouverture, sont, au contraire, adhérentes aux téguments, de sorte que, pour la sortie de l'eau qui les a baignées, il faut autant d'ourertures qu'il y a d'intervalles entre elles. Ces ouvertures sont presque toujours extérieures; quelquefois cependant elles débouchent dans un canal commun, servant à transmettre l'eau au dehors; enfin, des ares cartilagineux, souvent suspendus dans les chairs, sont placés vis-à-vis des bords extérieurs des branchies. Du reste, ces poissons diffèrent beaucoup entre eux et constituent, ainsi que nous l'arons déjà dit, deux ordres, les Sélaciens et les Cyclostomes.

$\$ 307$. Lordre des Séc.rexs comprend tous les poissons cartilagineux a branchies fixes, dont les machoires sont mohiles et 
disposées pour la mastication. On y range la famille des squales, composée de's requins (fig. 299), des squales proprement dits, des marteaux (fig. 313), des scies, etc. ; et la famille des raies, dans laquelle les torpilles prennent place aussi bien que les raies proprement dites (fig. 312). Tous ces poissons ont, de chaque còté du cou ou à

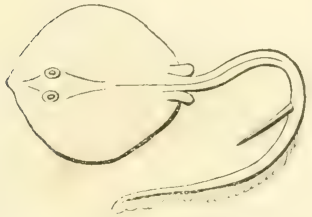

Fig. 312. Raie.

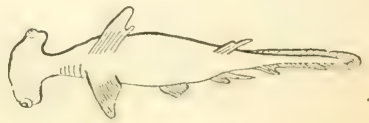

Fig. 3I3. Marteau.

sa face inférieure, cinq ouvertures branchiales en forme de fentes, et plusieurs portent à la partie supérieure de la tète denx ouvertures, appeléesévents, qui conduisent aux branchies et qui servent à y porter l'eau nécessaire à la respiration lorsque la gueule de lanimal est remplie par une proie trop volumineuse. Ces animaux sont très-roraces et sont souvent remarquables par la force et la multiplicité de leurs dents, le requin, par exemple ( $f g$. 299). Les uns sont ovo-vivipares, les autres font des œufs revètus d'une coque dure et cornée.

$\$ 308$. L'ordre des Crccostoues est caractérisé par la conformation singulière de la bouche, qui n'est propre qu'à la succion,

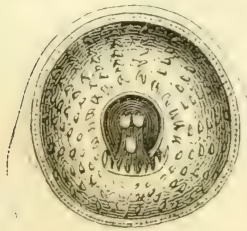

Fig.314. Bouche de lamproie. et qui se compose d'une sorte de ventouse formée par les mâchoires soudées en anneaux (fig. 344). Ces poissons sont les plus imparfaits de tous les vertébrés. Leur squelette est quelquefois membraneux (chez les ammocètes ou lamprillons) et offre toujours bien moins de complications que chez les autres poissons; le système nerveux est très-peu développé et les branchies ont la forme de petites bourses. Les lamproies (fig. 31:3) constituent le type principal de ce groupe. 
DEUXILME EMBRANCIEMENT.

\section{ANIMAUX ANNELÉS ou ARTICULÉS.}

$\$ \ddot{009}$. Les animaux qui composent enlle șande division présentent non-seulement une structure extérieure essentiellement différente de celle qui est propre aux trois autres embranchements du Règne animal; mais aussi des caractères extérieurs, en général, si tranchés et si évidents, qu'il est presque toujours facile de les reconnaitre au premier coup d'œil. Tout leur corps, en effet, est dirisé en tronçons et semble composé d'une suite d'anneaux placés a la file les uns des autres. Chez les uns, cette disposition annulaire résulte seulement de l'existence d'un certain nombre de plis fransversaux qui sillonnent la peau et ceignent le corjs: mais, chez la plupart, l'animal est renfermé dans une sorte d'armure solide, composée d'une série d'anneaux soudés entre eux ou réunis de manière à permettre des mouvements. Cette armure a des usages analogues à ceux de la charpente intérieure des animaux vertébrés: car elle détermine la forme générale du corps, elle protége les parties molles, elle donne des points d'attache aux muscles, et elle fournit à ces organes des leviers propres à assurer la précision et la rapidité des mouvements . aussi l'appelle-t-on souvent un squelette cxtérieur; mais ce serait à tort que l'on voudrait y voir le représentant ou l'analogue du squelette des rertébrés, car, dans la réalité, elle n'est autre chose que la peau devenue dure et rigide, ou mème encroùtée par une sorte d'épiderme calcaire de consistance pierreuse. Pour donner une idée rraie de ses usag̣es aussi bien que de sa nature, il serait par conséquent préférable de la nommer un squelette tégumentaire.

\$: 310. Les divers amneaux ou troncons du corps d'un animal arti('ulé ont toujours beaucoup de ressemblance entre eux; quelquefois. rhez la scolopendre par exemple (fig. 139), ils sont presque tous la répétition exacte les uns des autres, et toujours ils montrent une iendance remarcuable vers cette uniformité de structure. Chacpur 
anneau peut porter deux paires d'appendices ou de membres, l'une appartenant à son arceau dorsal ou portion supérieure (fig. 316), l'autre à son arceau ventral; et, lorsque ces appendices sont peu développés, et que la division du travail physiologique est peu

Arceau dorsal. Rame dorsale.

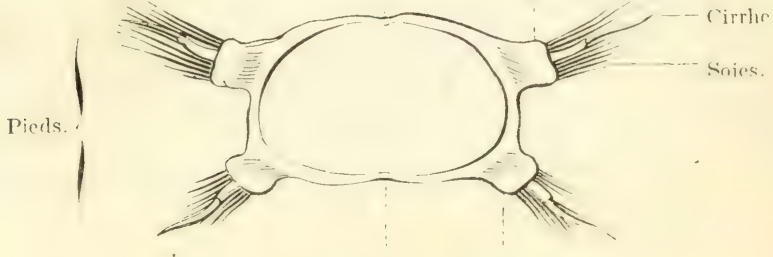

Arceau ventral. Rame ventrale.

Fig. 316. Coupe verlicale d'un areneau du corps d'un anvélide du genre amphinome.

avancée, tous les anneaux en sont effectivement pourvus: aussi Ie nombre de ces organes est-il quelquefois extrèmement considérable; mais, en général, les appendices de certains anneaux acquièrent un grand développement, et, pas une sorte de compensation ou de balancement organique, les autres restent rudimentaires nu ne se montrent mème pas. Presque toujours les appendices de larceau inférieur sont les seuls qui se développent, et ils prennent des formes d'autant plus variées que l'animal est plus élevé dans la série des ìtres. Ce sont enx qui, diversement modifién, constiment les filaments semblables a des cornes qui ornent la tète des insectes et des crustacés, et qu'on nomme antennes; les divers oryanes de mastication, les pattes, les nageoires, ote. (fi!y. 120, 121). Queluuefois les appendices de l'arceau supérieur existent partout et remplissent, comme ceux de l'arceau inférieur, les fonctions de pattes : divers annélides noms en offent des exemples; mais dordinaire ils n'existent tout au plus que sur deux des ammeaux situres vers la partie moyenne du eorpes ef ils constituent alors des ailes on des organes analogues, comme nous le verrons bientot en parlant des insectes. Les pattes sont, en général, au nombre de trois quatre. ring ou sept paires: quelquefois on en compte plusieurs centaines, et d'autres fois elles mancuent rompletement : mais alors elles sont souvent représentés, pour ainsi dire, par des faceseaux de srice raides; comme dans le ver de terre, par exemple. 
\$:11. La tendance que montrent les anneaux du corps à se répéter les uns les autres est remarquable dans la disposition des muscles et mème du systeme nerreux, aussi bien que dans la conformation du squelette tégumentaire. En général, dans cet embranchement, chaque anneau, dans son état complet, possède une paire de ganglions nerveux; et tous ces ganglions, réunis entre eux par des cordons de communication, constituent une double chaine qui occupe la ligne médiane du corps près de sa face ventrale ( fig. 58). Chez la plupart des animaux articulés inférieurs, comme chez ceux plus élevés dans la série, mais dont le développenent n'est pas terminé, ces ganglions sont tous à peu pres égaux et forment avec leurs cordons de communication deux chaines semblables à des cordons garnis de noeuds étendus diun bout du corps à l'autre (fog. 317); mais,

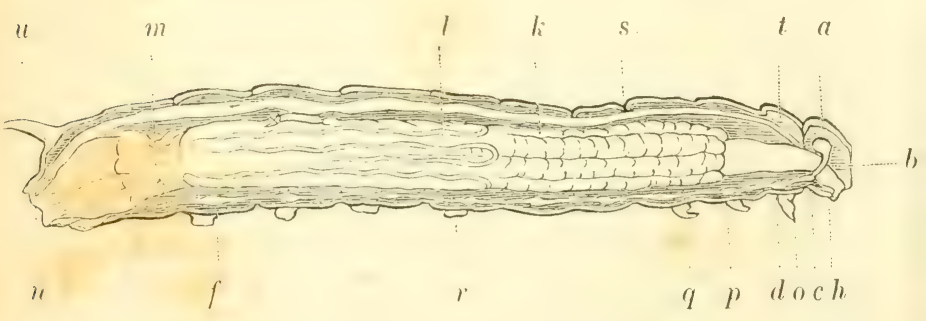

Fig. 317. Analomic de la chenille du Sphinx $\{1\}$.

à mesure que l'on s'élère à des ètres plus parfaits, on voit ces mèmes ganglious se rapprocher entre eux, soit latéralement de manière à se confondre sur la ligne médiane en une seule série, soit dans le sens longitudinal, de façon à déterminer la réunion de plusieurs paires

(1) Fig. 317 et 318. Sphinx du troêne : $-a$ ganglions céphaliques ou cerveau' situés au-devant de l'œsophage et donnant naissance aux nerfs des yeux, etc. ; $b$ cordons qui unissent ces ganglions à ceux de la seconde paire, en passant de chaque cité de l'œsophage, et formant ainsi un collier autour de ce canal; $-c$ première paire de ganglions post-œsophagiens situés derrière la bouche; $-d$ ganglions du premier anneau du thorax ; $-c$ masse nerveuse formée par les ganglions du deuxième et du troisième anneaux thoraciques; $-f$ sixième paire de ganglions abdominaux; $-h$ la bouche; $-i$ la trompe; $-j$ œsophage; $-k$ estomac; $l$ intestin et vaisseaux biliaires; $-m$ gros intestin; $-n$ anus; $-o$ pattes de la première paire; - $p$ pattes de la seconde paire; - $-q$ pattes de la troisième paire -..r première paire de pattes memhraneuses de la chenille; $-s$ vaisseau dorsal; - I premier anneau du thorax: - u corne qui surmonte l'extrémité de l'abdomen de la chenille. 
en une seule masse (fig. 318). Cette centralisation est quelquefois portée si loin (dans certains crabes, par exemple), qu'il n'existe jour tous les anneaux du corps que deux masses nerveuses, l'une située dans la tète, l'autre dans le thorax; mais il est impossible

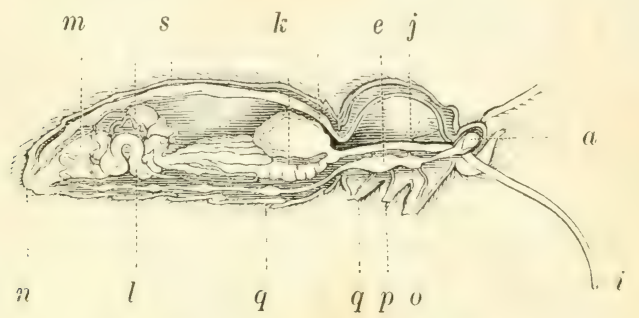

Fig. 318. Anatomie du Papillon Sphinx (1).

(qu'elle aille au dela : car les cordons qui réunissent entre eux ces deux centres nerveux passent de chaque còté de l'oesophage, et les ganglions céphaliques sont placés au-devant ou au-dessus de ce lube; tandis que les ganglions du reste du corps sont situés en arriere de l'cesophage, au-dessous du canal digestif. Cette portion du système nerveux forme en effet une espèce de collier autour de l'oesophage, disposition que nous retrouverons chez les mollusques; mais la portion post-cesophagienne ou ventrale du système ganglionaire ne se compose chez ceux-ci que d'une ou de deux paires de ganglions situés sur la ligne médiane du corps: tandis que, chez les animaux articulés, on trouve d'ordinaire une longue suite de ganglions ventraux; et, lorsqu il n'existe dans cette partie du corps qu'une seule masse nerveuse, on reconnail facilement qu'elle résulte du rapprochement de plusieurs paires de ganglions.

Les anatomistes désignent en grénéral les ganglions réphaliques de tous ces animaux sous le nom de cerveau, et quelques-uns veulent voir dans la chaine ventrale le représentant de la moelle épiniere; mais ces rappochements ne paraissent pas fondés, et, s’il fallait chercher les analogues de ces divers centres médullaires chez les animaux vertéhrés, ce serait plutot aux petits ganglions situés sur le trajet des racines antérieures des nerfs spinaux quon pourrait les comparer.

(1) Les diverses parties sont indiquées par les mêmes lettres que dans la figure précédente. 
$\$ 512$. Les animaux annelés ayant en général un svstème nerveux plus développé que les mollusques, des inembres pour la locomotion, et une espèce de squelette tégumentaire, doivent nécessairement leur ètre supérieurs dans tout ce qui caractérise essentiellement l'animalité, c'est-à-dire dans les fonctions de relations; mais, sous le rapport des fonctions de la vie végétative, ils sont moins bien partagés, car leur appareil circulatoire est moins complet et manque quelquefois entièrement. En général, ils ont le sang blane ; mais tous ne sont pas dans ce cas, et du reste cette différence ne parait pas avoir chez eux une grande importance. Leur mode de respiration varie: leur tube digestif s'étend d'un bout du corps a l'autre; la bouche est placée a la tète, et l'anus à l'extrémité opposée. Enfin il existe presque toujours des mâchoires ou du moins des instruments particuliers pour la préhension des aliments, et ces orqanes sont toujours disposés latéralement par paires; au lieu d'ètre placés l'un au-devant de l'autre, comme chez les animaux vertébrés.

Cet embranchement se divise, comme nous l'arons déjà dit, en deux groupes principaux formés, l'un, par les animaux articulés proprement dits, qui se reconnaissent à leurs membres articulés; l'autre par les vers, chez lesquels les membres n'existent plus ou ne sont représentés que par des tubercules garnis de soies et chez. lesquels presque toutes les parties de l'organisation se degradent en quelque sorte de façon a ne soffrir sourent que dans un état d'imperfection fort grande.

SOUS-EMBRANCHEMENT

\section{DES ANIMAUX ARTICUIÉS}

PROPREMENT DITS.

$\$ 513$. Les animaux articulés, proprement dits, ne doivent pas leur supériorité à leurs organes de locomotion seulement, ils ont aussi le système nerveux bien plus développé que celui des vers, et la localisation des fonctions est portée beaucoup plus loin dans leur organisation que chez ces derniers; nous avons déjà signalé quelques-unes des différences qui distinguent entre eux ces ètres et qui servent de base à leur division en classes $(\$ 380)$, il est, par conséquent, inutile d'y revenir en ce moment. et il suffit de reproduire 
sous la forme d'un tableau synoptique quelques caracteres pro-.. pres à ces divers groupes. Respiration tuant a seffecde trachées ou de poches pulmonaires.
A N I A U X articulés proprement dits.

A Nima $\cup x \mid \begin{gathered}\text { Respiration } \\ \text { aérienne s'effec- } \\ \text { tuant à l'aide } \\ \text { de trachées ou } \\ \text { de poches pul- } \\ \text { monaires. } \\ \text { proprement }\end{gathered}$
branchies.

\begin{abstract}
Une tête distincte du thorax et garnie d'antemnes.

Le corps composé de trois portions distinctes: tête, thorax et abdomen; trois paires de pattes; Insecles. en général des ailes.

Point de distinction entre le thorax et l'abdomen; vingt-quatre pai- Myriapodes. res de pattes on davantage; ja-
mais d'ailes.

Point de tête distincte du thorax ; i quatre paires de pattes, point d'an- $\{$ Arachnides.
tennes.

En général, cinq ou sept pairesde
pattes; sexes séparés.

Point de pattes servant à la locomution chez l'adulte; hermaphro - Cirrhipèle's.
disme.
\end{abstract}

\section{CLASSE DES INSECTES.}

$\$ 014$. La classe des insectes se compose de lous les animaus articulés ayant le corps composé : d'une tète, d'un thorax et d'un abdomen distincts, et les pattes au nombre de trois paires; à ces caracteres extérieurs on peut ajouter que leur respiration se fait a l'aide de trachées aériferes, qu'ils sont dépourvus d'un système vasculaire proprement dit, et que presque toujours ils subissent des métamorphoses dans le jeune àge. Enfin, il est encore à noter que presque tous sont pourvus dailes et que ce sont les seuls animaux invertébrés qui soient conformés pour le vol.

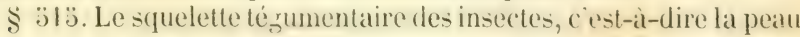
endurcie de ces animaux, conserve quelquefois une certaine llexibilité, mais présente en général une consistance analogne a celle de la corne. Il ne faut pas croire cependant que son tissu soit réellement de nature cornée. La chimie nous apprend qu il est compose de matieres tres-difiérentes, et qu une suistance particuliere, nommée chitine, en forme la base. (In y voit un stand nombre dre

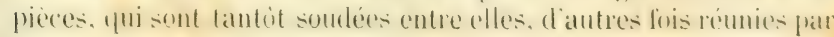


des portions molles de la peau, et jouissent ainsi d'une mobilité plus ou moins grande.

Le corps de l'insecte, comme nous l'avons déjà ru, se divise en un certain nombre d'anneaux placés bout à bout, et, dans cette série de serments, on distingue, avons-nous dit, trois portions, auxquelles on a donné les noms de tête, de thorax et d'abdumen.

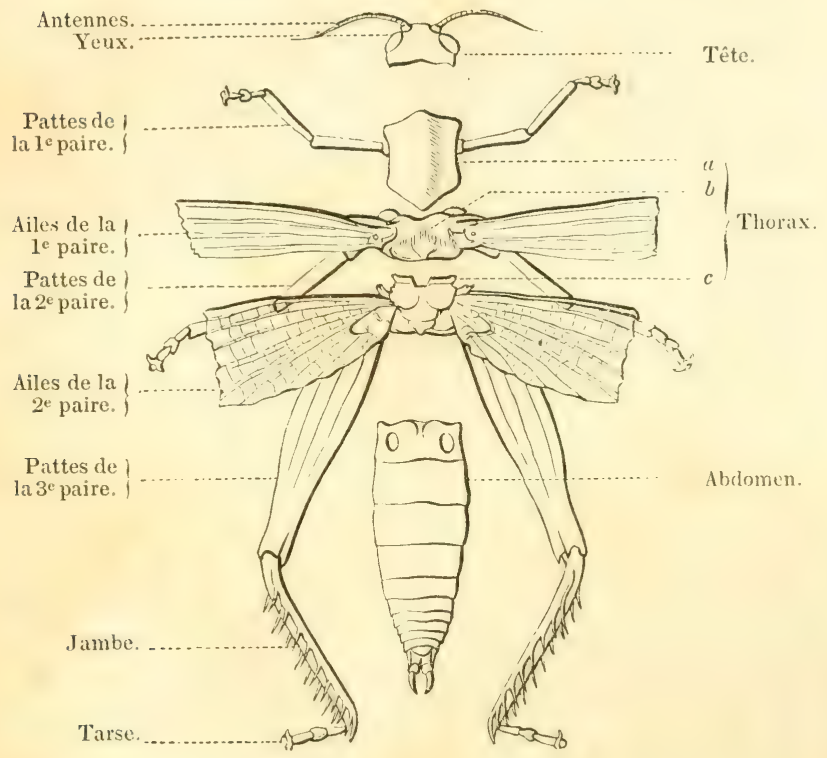

Fig. 319. Anatomie du squelelle légumenleux l'une Sauterelle.

Les membres ou appendices qui naissent de ces divers animaus ont une structure analogue à celle du trone de l'animal : ils se composent, en effet, de tubes solides ou de lames creuses, placés hout a bout et renfermant dans leur intérieur les muscles et les nerfs destinés à les faire mouvoir.

La tète n'est forméc que d'un seul tronçon et porte les yeus, es antennes et les appendiees de la bouche. Les antennes constituent la premiere paire de membres ou appendices des insectes, a se composent d'un nombre censiderable de pedits anticles plater 
bout à bout. Elles naissent de la partie antérieure ou supérieure de la tète, et affectent en général la forme de cornes grèles et flexibles (a fig. 320); mais leur conformation varie beaucoup, chez les mâles surtout : ainsi, tantòt elles ressemblent à des plumes (fig. 322), tantòt à des scies, d'autres fois à de petites massues (fig. 321), et

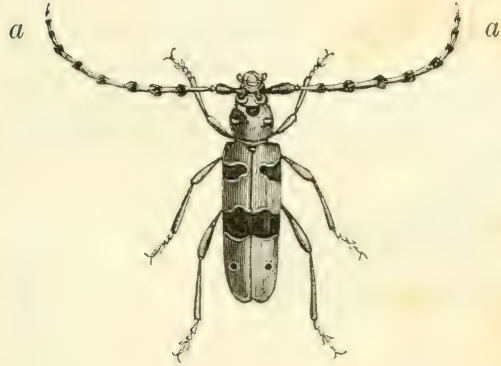

Fig. 320. Capricorne des Alpes.

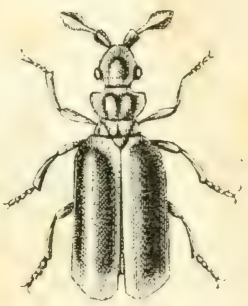

Fig. 321. Paussus cornu.

d'autres fois encore elles se terminent par une partie élaryie, composée de lamelles superposées comme les feuillets d'un livre (fig. 338); leur longueur e'st quelquefois très-considérable. Quant à leur usage, on ne sait rien de positif; mais il est à présumer que ce sont des organes de tact et peut-ètre aussi d'audition.

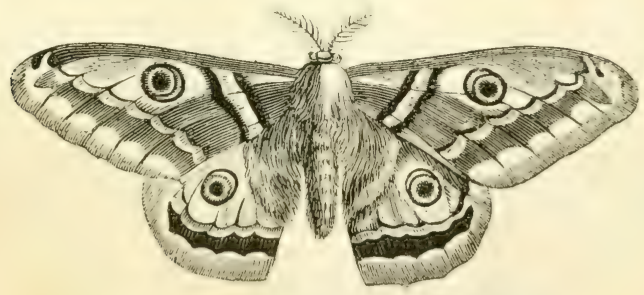

Fig. 322. Bombyx pelit paon de nuil.

D'autres appendices au nombre de trois paires naissent de la partie inférieure de la tìte et constituent les organes de matstieation ou de succion; nous y reviendrons en parlant de la diquestion (\$:32:3).

$\$ 516$. Le thorax des msectes oecupe la patie moyenne de leur rorps et porte les paltes et les ailes. Il se compose toujours de frois 
anneaux, nommés prothorax, mésothorax et métathorax $(a, b, c$, fig. 319), et c'est à l'arceau ventral de chacun de ces téguments que se fixe l'une des paires de pattes. Les ailes naissent, au contraire, de l'arceau dorsal des anneaux thoraciques, mais le prothorax (a) n'en porte jamais, et jamais aussi il n'existe plus d'une paire de ces appendices sur chacun des deux anneaux suivants, de sorte que leur nombre ne peut dépasser deux paires.

$\$ 317$. On distingue dans les pattes des insectes une hanche composée de deux articles, une cuisse, une jambe et une espèce de doigt.

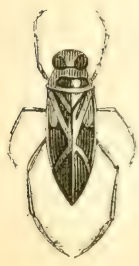

Fig. 323. Notonecte.

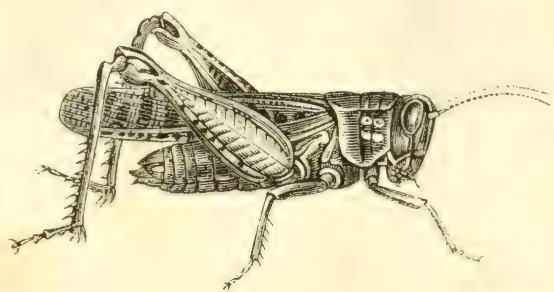

Fig. 324. Criquel.

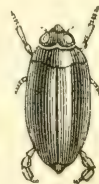

Fig. 325. Gyril

nommé tarse, qui est divise en plusieurs articles, dont le nombre varie de deux à ciny, et terminé par des ongles. Leur conformation varie, mais, comme on le pense bien, est toujours en rapport avec les mours de ces animaux. Ainsi les insectes dont les pattes postérieures présentent une grande longueur (fig. 324) sautent, en général, plutòt qu'ils ne marchent; chez les insectes nageurs, tels que les Dytisques, les Notonectes (fig. 323) et les Gyrins, appelés vulgairement tourniquets (fig. 323 ), les tarses sont ordinairement aplatis, ciliés et disposés comme des rames, et chez ceux qui peuvent marcher suspendus à des surfaces lisses on troure, sous le dernier arlicle de ces organes, une espèce de pelote ou de ventouse propre à les faire adhérer aux corps qu'ils touchent. (Quel-

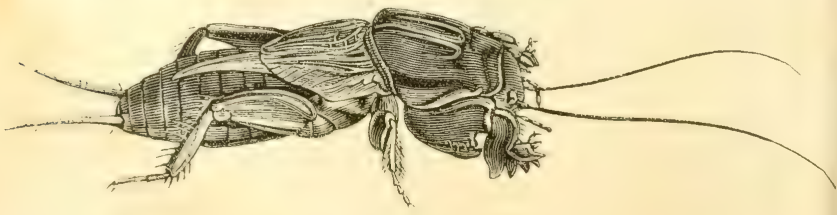

Fing 326. Courtilière. 
quefois, aussi, les pattes antérieures sont élargies, comme celles des taupes, afin de servir à creuser la terre; la courtilière (fig. 326), qui occasionne souvent dans nos campragnes des dégàts considérables en coupant les racines qui se trouvent sur son passage, nous offre un exemple remarquable de ce mode de structure. Il existe

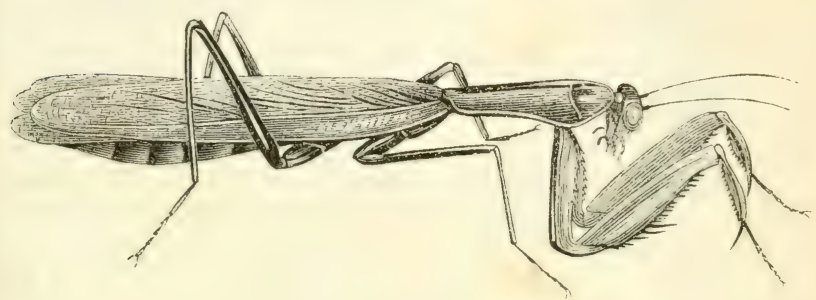

Fig. 327. Mante religieuse.

aussi des espèces chez lesquelles ces mèmes pattes constituent des organes de préhension, la jambe étant disposéc en manière de çrifìe et pouvant se reployer contre l'article précérlent, dont le bord est armé d'épines; un grand insecte du midi de la France, la Nante religieuse (fig. 327 ), est conformée de la sorte. Enfin on connait aussi des insectes chez lesquels les pattes antérieures, réduites à un état rudimentaire et reployées contre la poitrine, ne servent plus aux mouvements et échappent facilement à la vue, de facon qu'au premier abord on croirait ces animaux pourvus de quatre pattes seulement: plusieurs papillons diurnes sont dans ce cas ( fig. 328).

$\S 58$. Les ailes des insectes sont des appendices lamelleux, composés d'une double membrane, soutenus à l'intérieur par des nervures plus solides. Lorsurielles sont encore à peine

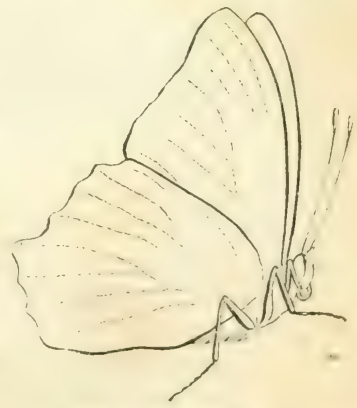

Fig. 328. Worphe. déreloppées, elles sont molles et flexibles; mais bientot elles se dessèchent et demeurent roides et élastiques. En général, il en existe deux paires: on n'en roit jamais un plus grand nombre; mais quelquefois l'une ou l'autre de ces paires manquent: ef rest toujours sur les deux derniers anneaux du thorax qu'elles naissent. 
Leur forme varic ; lor'squ'elles servent réellement au vol, elles sont minces ef transparentes ou recouvertes par une sorte de poussiere colorée formée par des écailles d'une petitesse micrescopique : comme cela se voit che\% les papillons; mais souvent celles

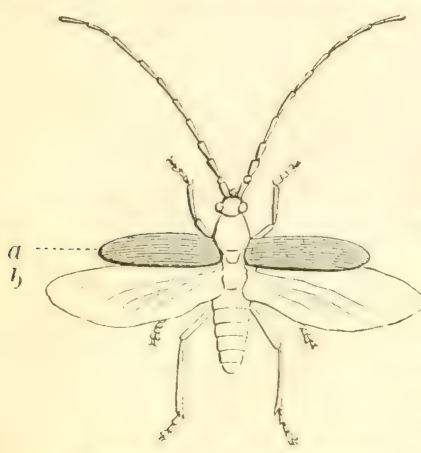

Fig. 329. Capricorne charpentier. de la première deviennentépaisses, dures et opaques, et constituent des espèces de boucliers ou d'étuis, nommés élytres ( $a$, (fig. 329), qui dans le repos recouvrent les ailes membraneuses $(b)$ et servent à les protéger : dautres fois ces mèmes ailes, encore membraneuses vers leur extrémité, deviennent dures et opaques vers, leur base, et sont alors désignées sous le nom de demi-étuis ou hémélytres. On connaît aussi des insectes chez lesquels les ailes, au lieu d'avoir une structure lamelleuse, sont fendues en une nultitude de membranes barbues

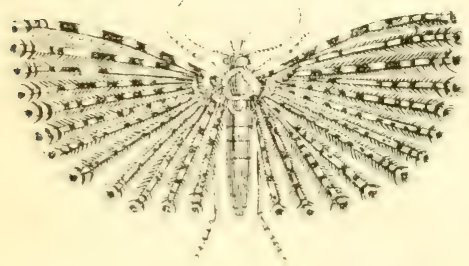

Fig. 330. Orníode.

sur les bords, semblables à des plumes disposées en éventail; cela se voit dans un genre voisin des papillons, et désigné sous les noms de ptérophore et d'ornéode $(f g .330)$. Enfin, lorsque les ailes postérieures manquent, elles sont d'ordinaire remplacées par deux petits filets mobiles terminés en massue que l'on nomme balanciers (fig. 331).

$\$ 319$. L'abdomen des insectes est composé d'un nombre considérable d'anneaux mobiles les uns sur les autres, souvent on en compte jusyu'à neuf ; mais d'autres fois on n'en distingue pas autant, ce qui parait dépendre de la soudure de deux on plusieurs de ces segments entre eux. Chez l'insecte parfait, ces anneaux ne portent jamais ni pattes ni ailes; mais ceux qui occupent l'extrémité postírieure du corps donnent souvent naissance à des appendices dont les formes et les usages varient beaucoup. Tantòt ce sont de simples soies ou des stylets dont les fonctions ne sont pas bien connues; 


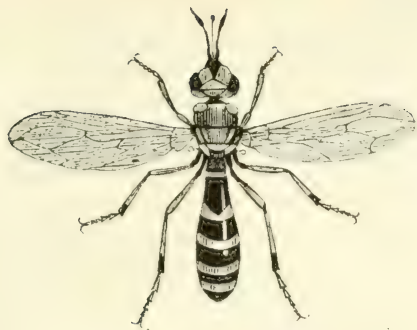

Fig. 331. Conops.

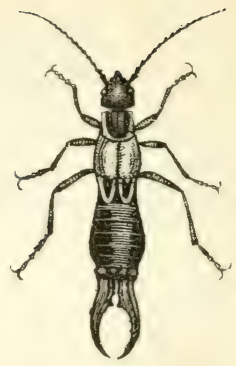

Fig. 332. Forficule.

chez les íphémères, par exemple (fig. 3388). Tantòt ces organes affectent la forme de crochets et constituent une pince plus ou moins puissante, comme chez les forficules ou perce-oreilles (fig. 332).

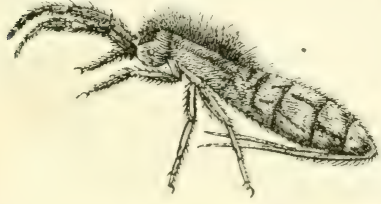

Fig. 333. Podurelle.

D'autres fois ils sont disposés de facon à agir comme un ressort et à servir à l'animal pour se lancer cnavant; les podurelles (fig. 333), petits.insectes qui, dans nos climats, se cachent sous les pierres ou se tiennent à la surface des eaux dormantes, et qui habitent quelquefois aussi dans la neige des régions les plus froides du grlobe, offrent ce mode d'organisation. Enfin, d'autres fois encore, ces appendices abdominaux ont une structure plus compliquée et constituent une arme offensive ou un appareil destiné à effectuer le dépòt des nufs pondus par l'animal dans un lieu propre au développement de ses jeunes; comme exemples de ces ororanes, nous pouvons citer l'aiguillon rétractile des gucpes et des abeilles et la tariere des tentrides. Le premier se compose d'un dard formé de deux stylets aigrus logrés dans une tige cornée ou étui, et présentant chacun en dedans un sillon par lequel s'écoule le venın sécrété dans une petite glande siluée tout aupres: dans l'état de repos toutes res pieces sont retirées dans lintérieur du corps de l'animal ; mais, quand l'insecte veut son servir, il fait sortir l'étui, et l'enfonee, ainsi que son dard, dans la peau de son ennemi. Quelyuefois il lui est meme impossihle de le 
retirer; l'aiguillon tout entier se sépare alors de son corps, et reste implanté dans la plaie. La déchirure qui en résulte détermine promptement la mort de l'insecte. Le mâle est toujours privé de cette arme : aussi peut-on le saisir sans danger; mais les femelles et souvent les individus stériles, appelés ouvriers, en sont pourvus, et sa piqùre détermine une inflammation très-douloureuse.

La tarière des cigales, des foenes (fig. 334), des ichneumons et de beaucoup d'autres insectes offre une disposition assez analogur,

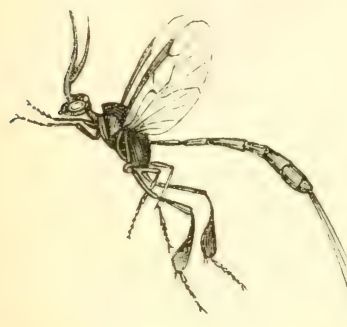

Fig. 334. Fone-lancicr. et on y remarque, en général, une espèce de petite scie à l'aide de laquelle l'insecte entaille les tissus végétaux ou animaux dans lesquels il doit déposer ses œufs; c'est en piquant de la sorte une espèce de chêne du Levant que le petit insecte, connu sous le nom de cynips, détermine la formation des noix de galle, dont on fait un si grand usage pour la fabrication de l'encre et la préparation des teintures noires : la petite entaille, pratiquée par la tariere, détermine un épanchement des sucs du végétal, et il en résulte bientòt une excroissance au centre de laquelle se trouvent les aufs des cynips.

\$: :20. Les insectes sont pourvus de sens très développés; ils jouissent évidemment de l'ouie et de l'odorat, aussi bien que du lact, du croùt et de la rue; mais jusqu'ici on n'a pas découvert le siécre de lolfaction et, chez la plupart de ces animaux, on n'apercoit aucun organe spécial d’audition. Les antennes et les appendices de la houche semblent ètre les principaux instruments du toucher, et les premiers servent peut-ètre aussi à la perception des sons. Nous ne savons aussi que peu de chose sur l'appareil du goùt: mais les organes de la vue ont été mieux étudiés.

La structure des yeux est très-différente de ce que nous avons vu chez les animaux supérieurs. En général, l’organe qui, au premier abort, parait ètre un oeil unique, est dans la réalité formé par l'agslomération d'une multitude de petits youx, ayant chacun une cornée, un corps vitré de forme conique, un enduit de matière colorante ot un filament nerveux particuliers. Chez le hanneton. par exemple. on en comple près de neuf mille, et on connaît des insertes qui en ont plus de vinut-rimg mille. Toutes ees petites 
cornées sont hexagonales, et sont soudées entre elles de façon a constituer une espèce de cornée commune, dont la surface présente une multitude de divisions semblables aux mailles d'un filet, visibles seulement à l'aide d'une loupe; et c'est à raison de cette disposition que l'on donne souvent à res yeux composés le nom d'yeux à réseau ou d'yeux à facettes. Du reste, chacun des petits appareils constituants de ces organes multiples est parfaitement distinct de ceux qui l'entourent et forme avee eux un faisceau de tubes terminés chacun par un filet nerveux provenant du renflement terminal d'un mème nerf optique. Presque tous les insectes sont pourvus de deux de ces yeux composés, situés d'ordinaire sur les còtés de la tète; mais quelquefois ils sont remplacés par des yeux simples, et d'autres fois ces deux sortes d'organes existent en mème temps. Quant à la structure des yeux simples, que l'on désigne aussi sous les noms de stemmates ou d'ocelles, elle a la plus grande analogie avec celle de chacun des éléments des yeux composés. En général, les yeux simples sont réunis en groupe, all nombre de trois, vers le sommet de la tète. On ne sait rien de précis sur la manière dont ces appareils agissent sur la lımière qui les frappe ni sur le mécanisme de la vision chez les insectes.

$\$ 321$. Plusieurs insectes possèdent, de mème que les animanx supérieurs, la faculté de produire des sons; mais, en général. leur chant ne se lie pas aux mouvements de l'air dans l'appareil respiratoire, comme chez les premiers, et dépend du froltement de certaines parties du corps les unes sur les autres, ou des mourements imprimés à ces instruments spéciaux par la contraction des muscles. Ainsi le bruit monotone et assourdissant de la cigale résulte: de la tension et du relàchement alternatifs d'une membrane élastique disposée comme la peau d'un tambour de basque sur la base de l'abilomen; chez les criquets ce sont certaines parlies des ailes qui, en frottant l'une contre l'autre, vibrent avee intensité et qui offrent à cet effet une structure très-curieuse; mais le bourdonnement des mouches parait dépendre de la sortie rapide de l'air par les stigmates thoraciques pendant les mouvements violents du vol. Enfin, il est d'autres insectes encore qui produisent une espèce de cri dont le mode de production n'est pas encore bien connu, tel est le papillon de nuit connu sous le nom de Sphinx tête de mort.

\$.32. Le systeme norveux des insectes présente la disposition geinérale et la plupart des modifications que nous avons déja signaléeen tratant de l'embranchement auguel ess animaus apparliement 
(voyez \$\$11). Il se compose principalement d'une double série de ganglions qui sont réunis entre eux par des cordons longitudinaux $(f i g .333)$ : le nombre de ces ganglions correspond à celui des an-

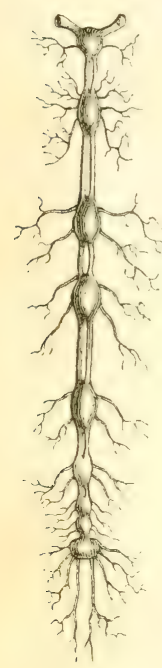

Fig. 335. neaux; et tantòt ils sont à peu près également espacés et s'étendent d'un bout du corps à l'autre, tandis que d'autres fois plusieurs d'entre eux sont rapprochés de manière à constituer une masse unique. Les ganglions céphaliques présentent un développement assez grand et donnent naissance aux nerfs des antennes, des yeux, etc. La première paire de ganglions post-osophagiens fournit les nerfs de la bouche; et les cordons qui unissent ces noyaux médullaires aux ganglions céphaliques et qui embrassent l'osophage donnent de chaque còté un nerf qui remonte sur l'estomac, et qui, en s'unissant aver celui du còté opposé, constitue un nerf médian situé au-dessus du canal digestif, et présentant sur son trajet deus ganglions. Les trois paires de ganglions situées à la suite de ceux placés immédiatement derriere l'osophage appartiennent aux trois anneaux du thorax, et sont le point de départ des nerfs des pattes et des ailes; en général, elles sont trés-rapprochées entre elles et beaucoup plus grosses que les paires suivantes qui appartiennent à l'abdomen.

$\$ 323$. La maniere dont les insectes se nourrissent varie beaucoup : les uns ne vivent que du suc des plantes ou des animaux, les autres se repaissent d'aliments solides et sont ou carnivores ou pliytophages; et à ces différences correspondent des modifications remaryuables dans la conformation de la bouche.

Chez les insectes broyeurs, tels que les scarabées, les hannetons, les blattes (fig. 336) ou les sauterelles, cette ouverture est carnie en avant d'une pièce médiane, nommée lève supérieure ou labre ( $a$, fig. 337), et présente de chaque còté une espèce de grosse dent, mobile et très-dure, appelée mandibule ( $b, f g .337$ ), qui sert à diviser les aliments. Immédiatement en arrière des mandibules se trouve une seconde paire d'appendices, dont la structure est plus compliquée : ce sont les mâchoires (c, fig. 337). Chacun de ces derniers organes offre au dedans une lame ou un cylindre plus ou moins dur et ordinairement armé de dentelures ou de poils, et porte du còté externe une ou deux petites tiges composées de plusieurs arlicles et appetées palpes maxillaires. Enfin, derrière les màchoires 


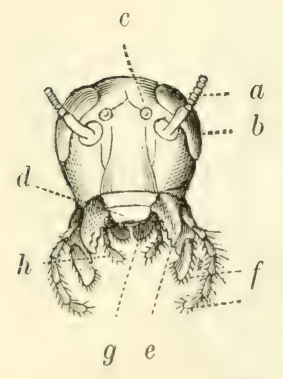

Fig. 336. Têle de Blalte vue par-devan $\ell$ (l).

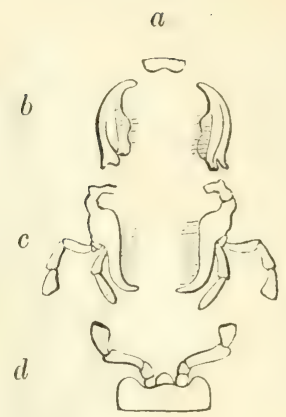

Fig. 337. Appendices buccaux d'un Carabe.

se trouve une seconde paire d'appendices, dont la base est supporté par une pièce cornée médiane, nommée menton $(d)$. Ces appendices constituent la languette. Ils sont appliqués contre les màchoires, comme ces organes sont eux-mèmes appliqués contre les mandiluules; et on leur distingue aussi une paire de filaments articulés et mobiles, appelés palpes labiaux : parce qu'on donne ordinairement le nom de lèvre inférieure aumenton réuni à la languette. Quant à la forme de ces diverses parties, elle varie suivant la nature et la consistance des aliments. Les palpes servent principalement à saisir les aliments et à les maintenir entre les mandibules pendant que celles-ci les divisent.

Quelquefois les màchoires prennent un développement énorme et constituent au-devant de la tète une sorte de pince; disposition qui est très-remarquable chez les cerfs-rolants (fig. 338) et les autres espèces du genre lucane, par exemple :

(1) $a$ antennes; $-b$ yeux composés; $-c$ ocelles; $-d$ labre; $-c$ mandibules; - $f$ mâchoires; $-g$ languette ; $-h$ palpes labiaux. 


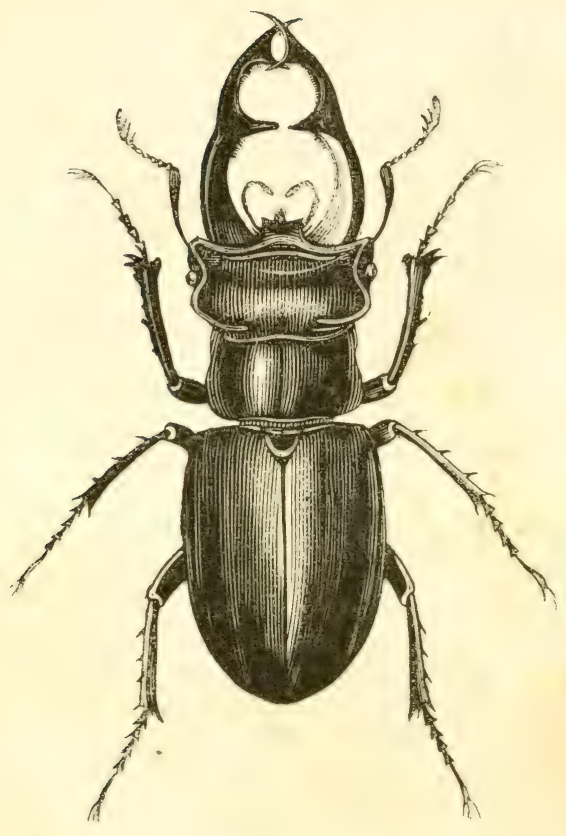

Fig. 338. Lucane mélallique.

\$ 524. Chez les insectes suceurs, les mâchoires ou le labre s'allongent de manière à constituer une espèce de trompe tubulaire, dans l'intérieur de laquelle on tronve souvent des filaments déliés, remplissant les fonctions de petites lancettes, et formés par les mandibules et les màchoires modifiées au point d'ètre souvent à peine remarquables.

Chez les abeilles, les anthophores (fig. 339), les bourdons, ef les autres insectes désignés par les zoologistes sous le nom commun d'hyménoptères, l'appareil buccal offre une disposition qui est en quelque sorte intermédiaire à ces deux états extrèmes. 


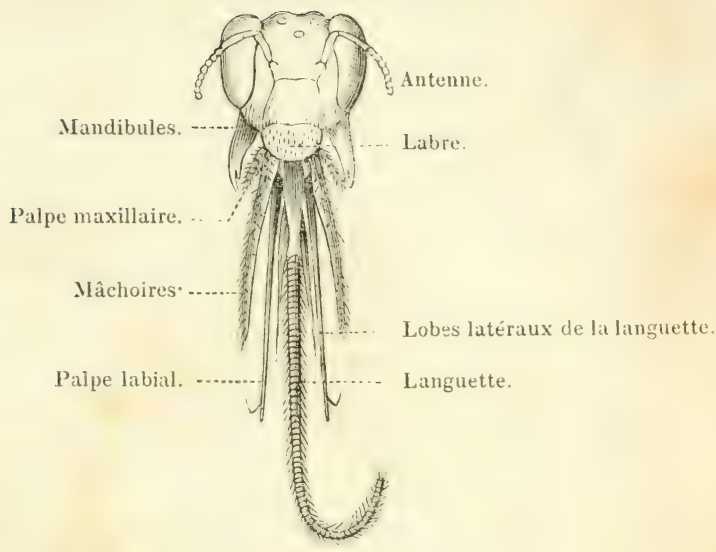

Fig. 339. Téte d'un Anthophore.

La lère supérieure $(a, f i g .340)$ et les mandibules $(b)$ ressemblent beaucoup a celles des insectes broyeurs, et la levre et les mandibules ne présentent mème rien de très-particulier; mais les màchoires $(c)$ et la languette $(d)$ se sont excessivement allongées, et les premières prennent une forme tubulaire etengaînent longitudinalement lescòtés de la languette: de facon que ces organes, réunis en faisceaux, constituent une trompe, qui sert de conduit aux aliments, toujours mous ou liquides, dont ces insectes se nourrissent. Cette trompe est mobile à sa base et llexible dans le reste de son étendue, mais ne s'enroule jamais comme nous le verrons chez les papillons. Quant aus mandibules, elles servent principalement à découper les matières dont les hyménoptères font leur nid ou bien à saisir et à mettre à mort la proie dont

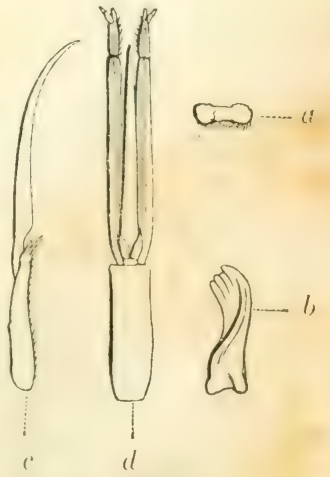

Fig. 310.

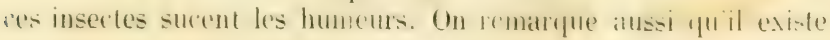


dans l'intérieur de la cavité buccale d'autres pièces solides qui manquent chez les insectes broyeurs, et qui constituent des valvules destinées à fermer le pharynx toutes les fois que le mouvement de la déglutition ne s'effectue pas.

$\$ 523$. Chez les punaises des bois, les cigales, les pucerons et les autres insectes de l'ordre des hémipteres, l'appareil de succion se

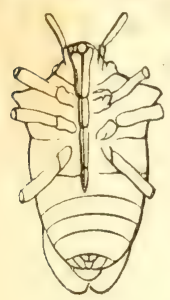

Fig. 341 . compose des mèmes éléments; mais ceux-ci affectent une disposition un peu différente. La bouche est armée d'un bec tubulaire et cylindrique, dirigée en bas et en arrière (fig. 341), et composée d'une gaine renfermant quatre stylets; la gaine ( $a$, fig. 34z) est à son tour formée de quatre articles placés bout à bout, et représente la lèvre inférieure; à sa base on aperçoit une pièce conique et allongée qui est l'analogue du labre; enfin, les stylets $(b, c)$, qui ont la forme de filets grèles, roides et dentelés à Punaise des bois. leur sommet, pour pouvoir percer la peau des animaux ou les raisseaux des plantes, sont les représentants des mandibules et des màchoires excessivement allongées. Dans les

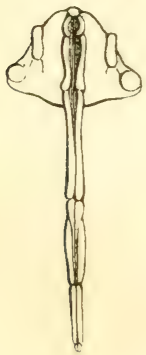

$a$

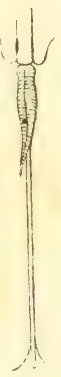

b

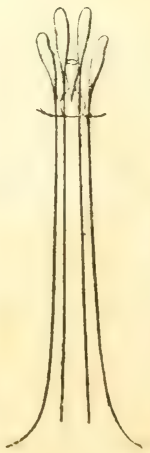

$c$

Fig. 342. Appareil buccal d'un Hémiptère.

hémiptères qui vivent aux dépens des animaux, le bec est en général très-robuste et replié en demi-cercle sous la tète. Chez ceux qui se nourrisent du sue des végétaux il est au contraire presque toujeurs grèle et appliqué dans le repos contre la face inférieure 
du thorax, entre les pattes. Sa longueur est quelquefois si considérable qu'il dépasse en arrière l'extrémité postérieure de l'abdomen.

Chez les mouches, la trompe, tantòt molle et rétractile, tantòt cornée et allongée, représente aussi la lèrre inférieure, et porte souvent à sa base des palpes; un sillon longitudinal en occupe la face supérieure et loge des stylets dont le nombre varie de deux à six, et dont les analogues chez les insectes broyeurs sont les mandibules, les màchoires et la languette. Quelquefois cette trompe acquiert une longueur énorme (fig. 343), quelquefois au contraire elle est a peine visible.

$\S 526$. Enfin, chez les papillons (fig. 345), qui se nourrissent aussi de substances liquides, mais qui les trouvent au fond des fleurs et n'ont pas besoin d'instruments vulnérants pour se les procurer, il n'existe plus de stylets faisant fonctions de lancettes, comme chez les précédents, et la bouche est garnie d'une longue trompe $(b, f i g .344)$ roulée en spirale et composée de deux filets creusés en gouttière à leur partie interne, qui ne sont autre chose que les mâchoires excessivement allongées et modifiées dans leur forme. I la

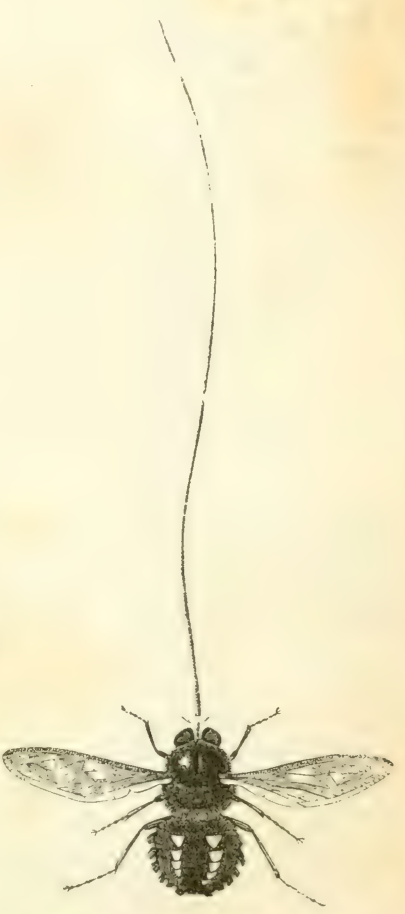

Fig. 313. Nimestrine longirostre. base de cette trompe on distingue en avant une petite piese membraneuse, qui est le représentant du labre, et, de chaque coté, un petit tubereule, dernier vestigro des mandibules. ()n y apereoit aussi des rudiments de palpes maxillaires, et en arriere se troure une

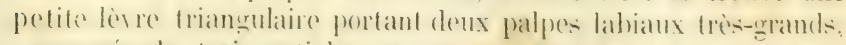
composés de trois ardieles of prespue toujours velus of warnis d'écailles $(d)$. 
$\$ 327$. Le canal alimentaire présente en général une structure aissez compliquée. Quelquefois il est droit et présente à peu près le mème diamètre dans toute sa longueur; mais d'ordinaire il est plus on moins flexueux, et offre plusieurs renflements et rétrécissements

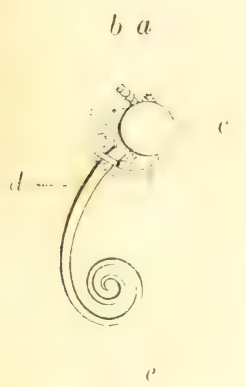

Fig. 34. Timmpe d'un papillon (1).

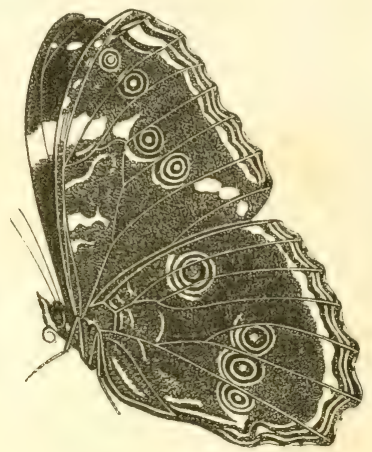

Fig. 345. Morphe hélénor.

successifs. On y distingrue alors (fig. 346) un pharynx, un wesophage, un premier estomac ou jabot, un second estomac ou gésier. dont les parois sont musculaires et sourent armées de pieces cornées propres à triturer les aliments; un troisieme estomac, nommé eentricule chylifique, dont la texture cst molle et délicate; un intestin gròle, un coecum et un rectum. De mème que chez les animaux supérieurs, on remarque un rapport entre la nature des aliments ef le développement quacquiert ce canal; chez les insectes carnassiers il est, en général, trés-court, tandis que chez les insectes qui se nourrissent de substances végétales il est ordinairement fort long. Les aliments qui y arrivent sont d'abord imbibés de salive; l'appareil qui sécrete ce liquide consiste en un certain nombre de tubes flottants, terminés quelquefois par des espèces d'utricules et communiquant avec le pharyns par des camaux escréteurs. Une multitude de villosités dont le ventricule chylifique est ordinairement garni paraissent servir a lat sécrétion d’un suc grastrique, et c'est éralement dans cette cavité qu'est versée la bile. Il n'existe pas de foie proprement dit chez les insectes; mais ret organe est remplacé par des lubes longrs ef délicis, qui llottent 
dans l'intérieur de l'abdomon et débouchent supériemrement dans le ventricule chylifique $(c$, fig. 346). Ces vaisseaux biliaires tiennent aussi lieu de glandes urinaires, car il s'y forme de l'acide urique. Par un de leurs bouts ils débouchent toujours dans le ventricule chylifique, et l'autre extrémité est tantôt libre, tantôt fixée à l'intestin soit auprès de la première ouverture, soit dans le voisinage du rectum. Enfin, on trouve encore, vers l'extrémité postérieure du canal intestinal, d'autres organes sécréteurs ( $e$ ) qui servent à élaborer les liquides particuliers (tels que le venin de l'abeille) que plusieurs insectes font sortir de l'extrémité de leur abdomen lorsqu'on les inquiète.

$\$ 523$. Il paraitrait que c'est par une simple imbibition que le chyle traverse les parois du tube digestif et se mèle au sang. Ce dernier liquide est aqueux ef incolore; il n'est pas renfermé dans des vaisseaux, et se trouve répandu dans les interstices que les organes laissent entre eux ou présentent dans la substance de

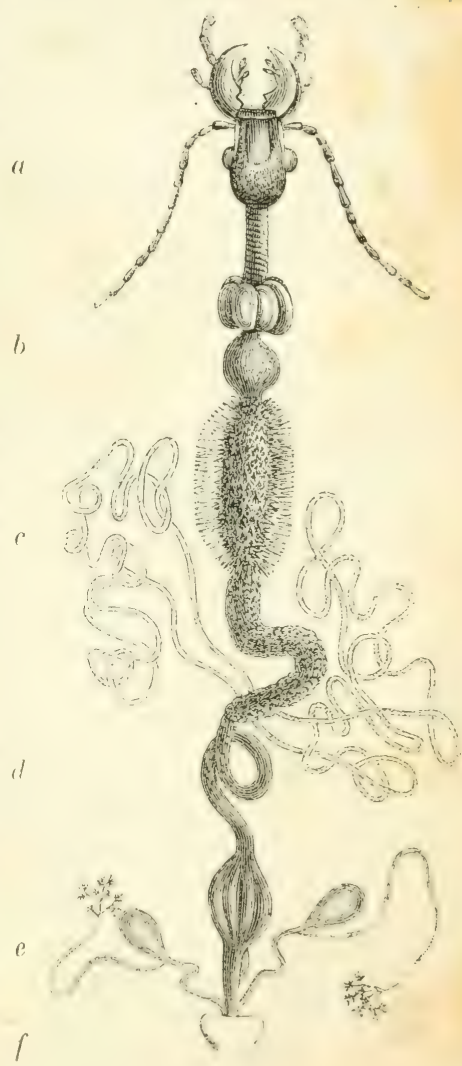

Fig. 316. Appareil digestif (1).

leur tissu. Les insertes manquent aussi dune circulation réguliere. On distingue bien, dans certaines parties du corps, des courants mème assez rapides: mais le liquide nourricier ne pareourt pas un

(1) a tête portant les antennes, les mandihules, ete. ; - l, jabot et gésier, suiris du ventricule chylifique: - $c$ vaisseaux biliaires; $-i$ intestins: - - organes si créteurs; $-f$ anus. 
cercle de manière à revenir constamment vers son point de départ . Il n'existe effectivement chez ces animaux que des vestiges d'un appareil circulatoire (royez $\$ 113$ ). On voit près de la surface dorsale du corps un tube long̣itudinal (fig. 317 et 318 ) qui exécute des mouvements alternatifs de contraction et de dilatation analogues à ceux du coeur chez les animaux supérieurs; mais ce vaisseau dorsal ne parait fournir aucune branche. Le liquide nourricier y pénètre par des ouvertures latérales, garnies de valvules pour empècher le reflux, et on ignore comment il s’en échappe. Du reste, le mouvement du sang ne dépend pas uniquement de cet. orqane; car on a découvert récemment dans plusieurs insectes des valvules mobiles dont les battements déterminent dans ce liquide des courants rapides, et, chose singulière, c'est dans les pattes que cet appareil est logé.

$\$ 329$. Le sang, devenu veineux par son action sur les divers tissus de l'économie, ne peut done venir, dans un point déterminé du corps, so mettre en contact avec l'oxygène et reprendre ainsi ses qualités vivifiantes. Si la respiration s'était faite de la manière ordinaire à l'aide de poumons ou de la surface extérieure du corps, elle aurait été par conséquent extrèmement incomplète; mais le désavantaģe qui paraitrait devoir résulter de cette grande imperfection dans la fonction si importante de la circulation n'existe réellement pas. La nature a suppléé au transport du sang en conduisant l'air luimème dans toutes les parties du corps, à l'aide d'une multitude de canaux qui communiquent avec l'extérieur et se ramifient à l'infini dans la substance de ces or wanes (fig. i7). Ces tubes aćrifères, désignés, comme nous l'avons déjà dit $(\$ 133)$, sous le nom de trachées, présentent une structure compliquée : on y distingue d'ordinaire trois tuniques, dont la moyenne est composée d'un filament cartilagineux, enroulé en spirale comme un élastique de bretelles Tantòt ils sont simples; mais d'autres fois ils présentent un certain nombre de grands renflements en forme de vésicules molles, qui remplissent les fonctions de réservoir à air $(h, f i g .46)$. Les ouvertures par lesquelles l'air pénetre dans les trachees sont nommées stigmates : elles ressemblent en général à une petite boutonnière, mais présentent quelquefois deux valves qui s'ouvrent et se ferment comme les battants d'une porte. On en voit d'ordinaire une paire sur les parties latérales et supérieures de chaque anneau; mais elles manquent souvent aux deux derniers segments du thorax.

Quant au mécanisme par lequel l'air se renouvelle dans l'intérieur de cet appareil respiratoire, il ne parait consister en général que dans les mouvements de contraction ef de dilatation de l'abdo- 
men. Linsi que nous lavons déjà dit ailleurs, la respiration est trèsactive chez ces animaux. Ils consomment une quantité considérable d'air comparativement à leur volume, et s'aspliysient promptement lorsquion les prive d'oxygène; mais, quand ils sont dans cet clat. de mort apparente, ils peuvent y rester tres-longtemps sans perder la faculté de revenir à la vie.

$\$ 330$. La plupart des insectes ne produisent que très-peu do chaleur; mais quelques-uns de ces animaux en dégagent dans certaines circonstances une quantité assez considérable pour élever notablement leur température. Les abeilles sont dans ce cas, surtout lorsqu'elles s'agritent beaucoup dans leur ruche, et il est a noter que la respiration devient alors très-active.

$\$ 531$. Un autre phénomène plus remar(uable, et dont on ne connait pas encore la cause, est la production de lumière qui s'observe rhez quelques insectes. Le lampyre ou ver luisant nous en offre un exemple bien connu de toutes les personnes qui frépuentent nos campagnes : le mâle (fig. 347 ) est ailé et n'est pas lumineux; mais la femelle ifig. 3is), qui est privée d'ailes, of yui se trouve tres-souvent

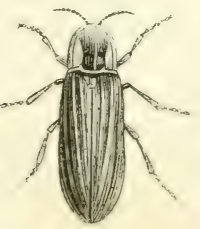

Fig. 317. Lampyre mâle.

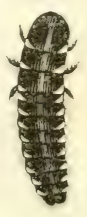

Fig. 318. Lamprye femelie.

sur les buissons pendant les nuits chaudes de l'été, répand une lueur phosphorescente tres-vive. Chez une autre espece de lampyre qu habite Italie, les individus des deux sexes sont en mème temps ailés et lumineux; mais celte proprićté singuliere est surtout remarquable chez certains laupins (qui habitent les régrons chaules de l'Amérique, et qui produisent, en voltiggant dems l'obseurité, une illumination naturelle du plus bel offet : les femmes les placent. souvent dans leurs cheveux comme ornement, et on assure que les Indens sien servent pour s'éclairer quand ils royagent de nuit. Che\% nos lampyres, la lumiere provient de queleques laches silueses sur le destus des deux ou trois derniers amneaux de l'abdomen.

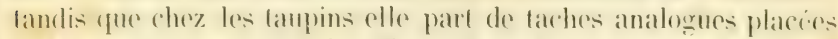

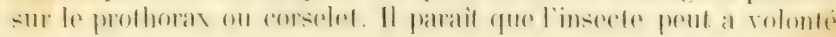


faire varier l'intensité de cette lueur phosphorique, et qu'elle persiste pendant un certain temps lorsqu'on place l'animal dans un gaz impropre à la respiration, ou même dans le vide, mais qu'elle s'éteint dans l'eau froide.

$\$ 532$. Les sexes sont distincts chez ces animaux, et souvent il existe des différences très-grandes entre le mâle et la femelle : le lampyre commun nous en a déjà offert un exemple (fig. 347, 348). Presque tous les insectes pondent des œufs; quelques-uns cependant sont vivipares. Souvent il existe à l'extrémité de l'abdomen de la femelle un dard, une tarière ou quelque autre organe destiné à pratiquer des trous propres à recevoir les neufs; et, par un instinct admirable, la mère déposo toujours ceux-ci dans un endroit ou les jeunes trouveront à proximité les aliments dont ils auront besoin. bien que, dans la plupart des cas, ces aliments ne soient pas de la nature de ceux qu'elle recherche elle-mème.

Dans lo jeune àge. les insectes changent plusicurs fois de peau et présentent presque toujours un phénomène des plus singuliers, dont, au reste, nous avons déja vu un exemple chez les batraciens. La plupart d'entre eux, en sortant de l'cuf, ne ressemblent ni à leurs parents, ni à ec qu'ils deviendront plus tar.l, et subissent, avant que d'arriver a l'état parfait, des changements si considérables qu'on ne peut mieux les désigner que sous le nom de métamorphoses.

En général, les insectes passent par trois états bien distincts, yu'on désione sous les noms d'état de larve (fig. 3łö), d'état de mymphe (fig. 3\%0) et d'etat parfait ( fig. 3:31); mais les changements up’ils subissent ne sont pas toujours éqalement grands : tantòt ces changements rendent l'aumal tout a fait méconnaissable; d'autres fois ils ne consistent guere que daus le développement des ailes, ef on désione ces degrés divers de transformation sous les noms de métamornhoses completes et de demi-métamorphoses.

$\$$ 333. Les insectes a métamorphoses completes sont toujours plus ou moins vermiformes lorsqu'ils sortent de l'oeuf et qu'ils sont a l'état de larve (fig. 399); leur corps est allongéé, presque entiè-

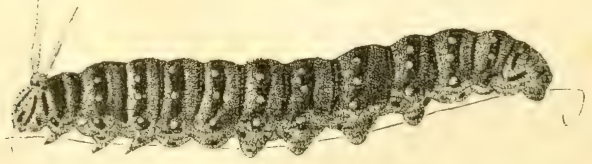

Fig. 319. Chenille du Papillon Machaon. 
rement mou, et divise en anneaux mobiles dont le nombre normal est de 13 : tantòt ils sont complétement privés de pattes; d'autres fois ils sont pourvus d'un nombre variable de ces or wanes, mais dont la conformation ne rappelle en rien celle des mèmes parties chez l'animal adulte. Presque toujours ils n'ont que des yeux simples, et en sont quelquefois completement privés; enfin leur bouche est presque toujours armée de mandibules et de màchoires quelle que soit la conformation qu'elle doit prendre par la suite, et on voit souvent les premiers de ces or wanes servir a la locomotion aussi bien qu'à la préhension des aliments. Ces larves varient du reste dans leur forme et sont connues tantot sous le nom de chenilles. tantòt sous celui de vers.

Apres ètre restés dans cet état pendant un temps plus ou moin: long et avoir éprouvé plusieurs mues, leurs ailes se forment sous la peau et ils se changent en mymphes. Pendant toute la durée de cette seconde période de leur existence, ces singuliers animaux cessent de prendre de la nourriture et restent immobiles. Tantòt la peau dont ils viennent de se déponiller se dessèche et constitue une espèce de coque oviforme dans lintéricur de laquelle ils demeurent renfermés; tantòt ils ne sont recouverts que par une pellicule mince, qui, appliquéc sur les or wanes extérieurs, en suit tous les contours et ressemble à des langes dans lesquels l'insecte serait emmaillotté. Cette dernière disposition, qui se voit chez les nymphes des papillons ou chrysalides ( frg. 330$)$, leur a fait donner aussi les noms de pupe et de maillot.

Avant d'éprouver celle métamorphose, la larvese pripare

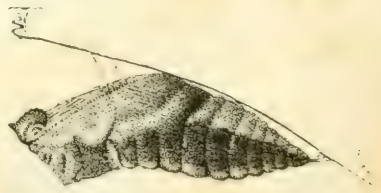

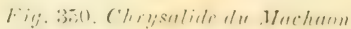
souvent un abri et se renferme

dans une coque yu'elle fabrigue aree de la sole sécrétéc par les shandes salivaires ef préparée à l'airle de filieres creusées dans les levres. D’autres fois olle se suspend au moyen de filaments (fig. 3:̈0) ou se cache dans quel que trou. C"est pendaunt que l insecte est dansect etat de repos apparent qu il so fait dans l’intérieur de son corps un travail aclif. dont le resullat est le developpement complet de toute son orzansation. Ses parties intérieures se ramollisiont et prennent peu à peru la forme qu'elles doivent conserver; les divers organes dont lanimal ardulte doit itre pourvu se déreloppent sous: lenveloppe qu les cache, et, quand eofle érolution est acherés.

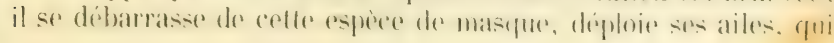


ne Lardent pas à acequérir de la consistance, et derient un insecte parfait.

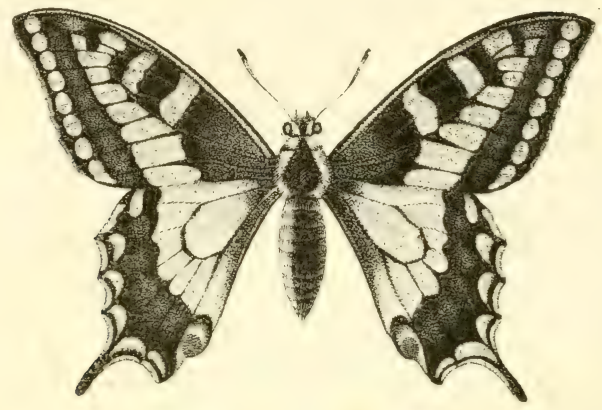

Fig. 351. Papillon Machaon.

\$334. Comme exemple de ces métamorphoses complites, nous ne pouvons mieux choisir qu'en prenant le bombyx du mûrier; car cet insecte à l'état de larve est pour nous d'un immense intérit, cest le rere a soie dont léducation eontribue si puissamment à la prospérité agricole de nos provinees méridionales et dont les produits alimentent tant de riches industries.

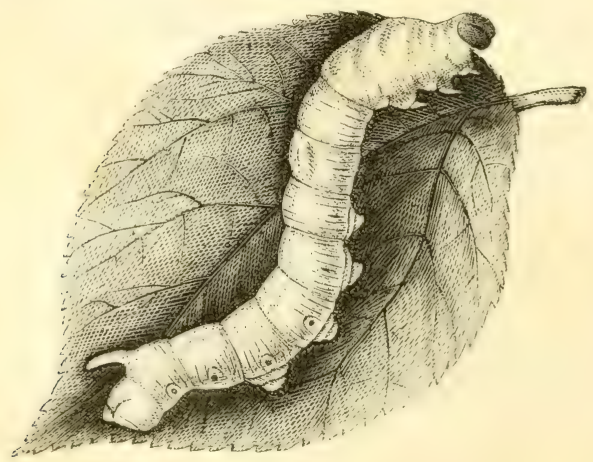

Fig. 352. Her à soir. 
Cet insecte est originaire des provinces septentrionales de la Chine et ne fut introduit en Europe que dans le sixième siecle. Des missionnaires gree's en apporterent des oufs à Constantinople sous le règne de Justinien, et, à l'époque des premières croisades, sá culture se répandit en Sicile et en Italie; mais ce ne fut guère que du temps de Henri IV que cefte branche d'industrie agricole acquit quelque importance dans nos provinces méridionales, dont elle forme aujourd'hui l'une des principales richesses.

Les œufs du bombyx du mùrier sont désignés par les agriculteurs sous le nom de graine de ver à soie. Quand ils ont été desséchés, ils ont une teinte gris-cendré; et, avec quelques soins, on peut les conserver ainsi pendant assez long-temps sans les détériorer. Pour que le travail de l'incubation commence et que les larves éclosent, il faut que les oetifs éprouvent pendant quelque temps une température d'au moins $15^{\circ}$ à $16^{\circ}$ centigrades. Après aroir éprouvé huit ou dix jours de chaleur croissante, ils deviennent blanchàtres; et, bientòt après, les larves commencent à en sortir. Ces petits animaux, au moment de la naissance, n'ont qu'environ une ligne et un quart de long. Leur corps est allongé, cylindrique, annelé, ras et ordinairement de couleur grisâtre; à son extrémité antérieure on distingue une tète, formée par deux espéces de calottes dures et écailleuses, sur lesquelles on remarque des points noirs, qui sont des yeux; la bouche occupe la partie antérieure de cette tète, et est armée de fortes mâchoires; les trois anneaus suivants portent chacun une paire de petites pattes icailleuses, et représentent le thoras; cnfin l'abdomen est tresdéreloppé et ne porte pas de membres sur les deux premiers segments, mais est garni postérieurement de cinq paires de tubercules charnus qui ressemblent à des moignons et qui constituent autant de pattes.

Dans le milli de la Franee on appelle les vers a soie des magnans, et de là le nom de magnanerie quion donne aux ćlablissements dans lespuels on les élieve. Le premier soin qu'ils réclament apres leur naissance est de les séparer do leurs copues et de les places sur des claies ou ils trouvent une nourriture appropriée at leurs hesoins. P'our cela on a l'habitude de recouvrir les oeufs d'une feuille de papier criblée de trons, à travers lesquels les vers montent pour arriver jusquaux fenilles de murier placés au-dessus: et e'est lorsu ils sont sur les rameaux garnis de ces feuilles quion les transporte sur les claies préparés pour leur sorvir de demenre. La nourriture du ver a sole consiste en feuilles de mùrier (fig. 3:3.2). re ést par conséfuent de la culture de eette plante que dépend la 
possibilité d'élever ces insectes. Le nuturier blane est l'espèce la plus généralement employée à cet usage ; c'est un arbre qui s’élève à quarante ou cinquante pieds, el qui donne quatre ou cinq quintaux de feuilles, quelquefois mème dix ou douze. Il s'accommode assez bien de tous les terrains, et on le cultive avec succès jusque dans le nord de l'Europe; mais il n'y croìt nulle part sauvage. En effet, ce mùrier est originaire de la Chine. Deux moines grees l'introduisirent en Europe vers le milieu du sixiène siecle en mème temps que les vers à soie. Sa culture se répandit hientòt dans le Péloponèse, et fit donner a rette partie de la Grèce son nom moderne de Morée. De la les mùriers et les vers à soie passèrent en Sicile par les soins du roi Roger, et prirent dans la Calabre une extension rapide. Quelques grentılshommes qui araient accompag̣é Charles VIII en Italie pendant la gruerre de 1494, ayant connu tous les avantages que ce pays retirait de cette branche d'agrieulture, voulurent en doter leur patrie et firent apporter de Naples des mùriers, qu'on planta dans la Provence d dans le Dauphiné. Il y a une trentaine d'aunces, on voyait encore à Mllan, près de Nontélimart, le premier de ces arbres planté en France : il y fut apporté par Guy Pope de Saint-Auban, seiqneur d'Allan. Aujourd'hui les mùriers courrent une grande partie du midi de la France et se cultivent mème dans le nord.

Les vers à soie vivent à l'état de larve environ trente-quatre jours, et, pendant ce temps, changent quatre fois de peau ; le temp: compris chtre ces mues successives constitue ce que les agriculteurs appellent les divers áges de ces petits animaux. A l'approche de chaque mue, ils s'engrourdissent et cessent de manger; mais, apres avoir changé de peau, leur faim redouble. On appelle petite fièze le moment de grand appétit qui précède chacune des quatre premières mues, et grande frèze celui qui se remarque durant Io cinquieme àge du ver. La quantité de nourriture qu'ils consomment augmente rapidement. On compte que, pour les larves provenant d'une once de graine il faul ordinairement environ sept livres de feuilles pendant le premier àye, dont la durée est de cinc jours: vingt et une livres pendant le second àze, qui dure seulement quatre jours; soixante-dix lirres dans le troisieme àge, qui dure sept jours; deux cent dix livres pendant le quatrieme àge, dont la durée est égale à celle du troisieme à ze, et douze à treize cents lives pendant le cinquieme àze. C'est le sixième jour du dernier àge qua lieu la grande freze. Les vers dévorent alors deux à trois cents lirres de feuilles, et font, en mangeant, un bruit yui ressemble a celui d'une forte averse. Le dixieme jour, ils cessent de mangrer el 
s'apprètent à subir leur première mélamorphose. On les voit alors chercher à grimper sur les branches des petits fagrous yu'on a soin de placer au-dessus des claies oi jusqu'alors ils sont restés. Leur corps devient mou, et il sort de leur bouche un fil de soie qu'ils trainent après eux. Bientòt ils se fixent, jeftent autour d'eux une multitude de fils d'une finesse extrène, qu'on appelle banc ou banne. et, suspendus au milieu de ce lacis, filent leur cocon, fu'ils construisent en tournant continuellement sur eux-mèmes en divers sens e't en enroulant ainsi autour de leur corps le fil qu'ils font sortir de la filière dont leur levre est percée. La soie ainsi formée se produit dans des glandes qui ont beaucoup d'analogie avec les grlandes salivaires des autres animaux, el la matiere dont elle est composéc est molle et gluante au moment de sa sortie, mais ne tarde pas a se durcir a l'air. Il en résulte que les divers tours de ce fil unique s'agglutinent entre eux et constituent une enveloppe dont le tissu est ferme el dont la forme est ovoïde. La couleur de cette suie varie : tantòt elle est jaune, tantòt d'un blanc éclatant, suivant la variété du ver qui l'a produite, et la longueur de chayue fil rlépasse souvent trois cents mètres, mais varie beaucoup ainsi que le poids des cocons. Les vers nés d'une once de graine peuvent en donner jusqu'à cent trente livres; mais une telle ricolte est rare, et sonvent un n'en retire que soixante-dix a quatre-vingrts liveres de cocon.

En général trois jours et demi à quatre jours suffisent aux larves pour achever leur cocon, et si on ourre ensuite cette espexe de cellule on voit gue l'animal (fig. 3:5) n'offre plus le mème aspect quavant sa réclusion : il a pris une couleur lrune, sa peau ressemble à du vieux cuir, et sa forme est ovoidde, un peu pointue à son extrémité postćrieure. On n’y distinģue plus ni tète ni màchoires ; mais sa portion postérieure est oecupre par des anneanx mobiles, fandis qu'en arant on remarque une bande oblique, disposée en écharpe
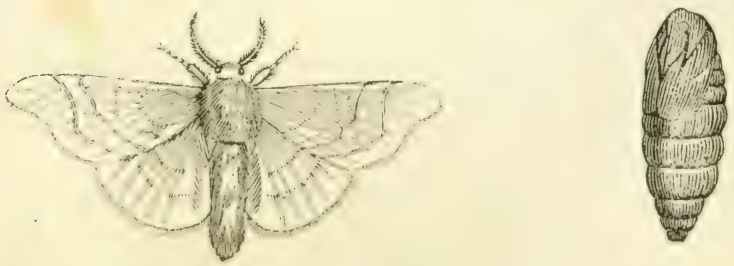

Fig. 353. Bombyx du múrier. 
et représentant les ailes futures de l'animal parfait. Le temps pendant lequel les bombyx restent ainsi renfermés à l'état de chrysalide varie suirant la température. Si la chaleur est de $15^{\circ}$ à $18^{\circ}$. ils en sortent à l'état parfait du dix-huitieme au vingtiène jour. Pour percer leur cocon, ils en humectent une extrémité avec une liqueur particulière qu'ils dégorgent; et ensuite ils heurtent avec violence leur tète contre le point ainsi ramolli. Lorsque le bombrx a de la sorte achevé ses métamorphoses, il se présente sous la forme d'un papillon a ailes blanchàtres (fig. $3: 33)$ : sa bouche n'est plus armée de màchoires comme dans le jeune àtre, mais se prolonge en une trompe roulée en spirale; ses pattes sont grèles et allongées, et sa conformation intérieure differe autant de celles de la larve que sa forme extérieure. Presque aussitòt après leur naissance, les papillons se recherchent entre eux; ensuite les femelles pondent leurs œufs, dont le nombre s'élere à plus de cinq cents pour chacun de ces insectes; enfin, apress avoir vécu à létat parfait pendant dix a vingt jours, ils meurent.

\$ 333 . Les abeilles, dont nous arons déjà eu l'occasion de parler (\$332), éprouvent des changements plus grands encore, puisqu'a l'état de larve elles manquent complétement de pattes et ressemblent à de petits vers. Il en est de mème des mouches, des cousins et d'un grand nombre d'autres insectes: ainsi les anmaux vermiformes qui fourmillent dans les charognes en putréfaction, et qui sont connus sous le nom d'asticots, ne sont autre chose que les larves de la mouche dorée. Les cousins ou moustiques qui, le soir. voltigent en troupes nombreuses et qui se rendent si incommodes à l'homme par leurs piqûres enrenimées, vivent dans l'eau lorsqu'ils sont à l'état de larve. Ils sont alors remiformes, privés de pattes, et ont l'abdomen terminé par des soies et des appendices disposés en rayons (fig. $3 \ddot{3} 6)$; enfin leur avant-dernier anneau donne naissance à un tube assez long $(t)$ à l'aide duquel l'animal puise dans l'atmosphère l'air dont il a besoin. Pour respirer ainsi, il se pend en quelque sorte à la surface de l'eau la tète en bas; et on le roit à de courts intervalles renouveler ce manége. La nymphe continue à virre dans l'eau et à s'y mouroir; mais, au licu de respirer comme la larve, elle puise lair dont elle a besoin au moyen de deux tuyaux placés sur le thorax. Elle flotte à la surface du liquide, et, apres avoir achevé sa métamorphose, l'insecte parfait (fig. 33̈7) se sert de sa dépouille de nymphe comme d'un bateau jusqu à ce que ses longrues jambes et ses ailes aient aequis assez de solidité pour lui permettre de marcher sur la surface de l'eau ou de s'envoler; car si son corpis renait à ctre submergé, comme cela 
arrive souvent quand le vent renverse ces frèles embarcations, il se noierait infailliblement.

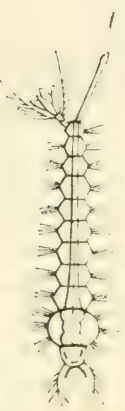

Fig. 356. Larve de Cousin.

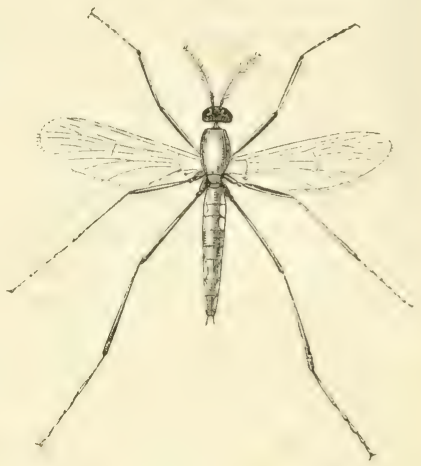

Fig. 357. Cousin (grossi).

§536. Les insectes à demi-métamorphoses passent aussi par l'état de larve et de nymphe avant que d'arriver à l'état parfait; mais ici la larve ne diffère guère de l'insecte parfait que par l'absence d'ailes, et l'état de nymphe n'est caractérisé que par la croissance de ce's organes, qui, d'abord reployés et cachés sous la peau, sont alors libres, mais n’acquièrent tout leur développement qu'à l'époque de la dernière mue.

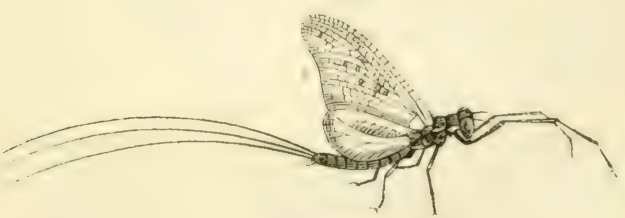

Fig. 358. Éphemire.

Nous citerous comme expmples d insectesoffrant er genre de mé-

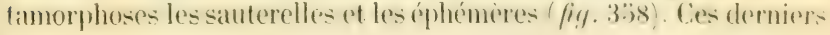




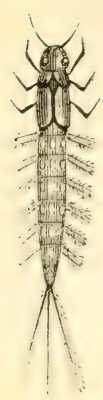

Fig. 359.

présentent mème une particularité remarquable; car d'ordinaire les insectes changent de peau pour la dernière fois lorsyu'ils passent de l'état de nymphe à l'état parfait, tandis que l'éphémère éprouve encore une mue avant que d'ètre complétement adulte, bien qu'elle ne vive ainsi que l'espace de quelques heures. La larve de ces éphémères vit dans l'eau et ne ditfère que peu de l'adulte, si ce n'est par la brièveté de ses paltes, par l'absence d'ailes et par la rangée de lames ou de feuillets qu'elle porte de chaque còté de son abdomen, et qu'elle emploie comme organes de respiration et de natation. La nymphe (fig. $3 \ddot{3} 9$ ) ne differe de la larve que par la présence des fourreaux renfermant les ailes. Au moment l'eau, et, après avoir voltigé pendant quelques minutes, va se poser sur un oljet élevé ot s'y livre bientòt à des mouvements violents au moyen desquels il se dépouille de sa membrane tégumentaire: c'est alors seulement que ses pattes acquierent toute leur longueur, et son corps les couleurs qu'il doit conserver.

$\$$ 337. Quelques insectes, tout en subissant des changements considérables dans le jeune âgge, ne passent point par la série complète de transformations dont nous venons de parler; ils semblent, pour ainsi dire, s'arrèter en route, et n'arrivent jamais à posséder les ailes. Les puces sont dans ce cas. En sortant de l'œuf, elles sont privées de pieds et ont la forme de petits vers de couleur blanchàtre. Ces larves sont très-vives et se roulent en cercle ou en spirale. Bientòt elles deviennent rougeâtres, et, après avoir vécu dans cet état pendant une douzaine de jours, elles se renferment dans une petite coque soyeuse, d'une finesse extrème, pour s'y transformer en nymphes; enfin, au bout de douze jours environ de réclusion, si le temps est chaud, elles sortent de leur enve'oppe à l'état parfait.

$\S$ 3338. Enfin, il est aussi des insectes qui ne subissent pas de métamorphose et qui naissent avec tous les organes dont ils doivent ètre pourvius, mais ce sont toujours des insectes aptères qui nous offrent ce mode de développement. Le podurelle ( fig. 333), dont il a été déjà question, et les poux sont dans ce cas.

$\$ 539$. Les insectes, si remarquables par leur organisation, le sont encore davantage par leurs mœurs et par l'instinct admirable dont la nature a doué un grand nombre d'entre eux. Les ruses ıfu'ils omploient pour se procurer leur nouriture ou pour se sous- 
traire à leurs ennemis, et l'industrie qu'ils déploient dans leur's travaux, étonnent tous ceux qui en sont témoins; et, lorsqu'on les voit se réunir en sociétés nombreuses pour suppléer à leur faiblesse individuelle, s'aider entre eux, se partager les travaux nécessaires à la prospérité de la communauté, jourvoir à leurs besoins futurs, et souvent mème régler leurs actions d'après les circonstances accidentelles où ils se trouvent, on reste ronfondu de trouver chez des ètres si petits, et en apparence si imparfaits, des instincts si variés et si puissantz, et des comhinaisons intellectuelles qui ressemblent tant à du raisonnement. Le sujet ne tarirait pas si nous voulions rapporter ici des exemples de ces phénomènes curieux; mais les limites étroites de ces lecons ne nous permettent pas d'y consacrer en ce moment plus de temps, et nons ne pouvons que renvoyer nos lecteurs à ce que nous en avons déjà dit en traitant d'une manière générale des actions des animaux. (Voyez § 317 à \$339.)

$\$ \ddot{40}$. Classification des insectes. - Si nous cherchions maintenant à résumer en peu de mots les différences les plus importantes que les insectes offrent entre eux, nous verrions que ces différences dépendent surtout de la structure de l'appareil buccal, qui règle le régime de ces animaux; de la disposition des organes servant à la locomotion aérienne, fonction qui donne à la classe tout entière un de ses traits les plus saillants; enfin, du genre de métamorphoses que ces ètres subissent dans le jeune âge. Or, d'après ce que nous avons dit ailleurs sur l'essence des classifications naturelles, il est évident que ce doit ètre par conséquent dan. les modifications de l'appareil buccal, des ails et du morle de développement, que le zoologiste cherchera les bases de la distribution méthodique de ces animaux. En effet, c’est de la sorte quion est parvenu a les diviser en $u$ certain nombre d'ordres, auxquels on a donné les noms de coléopteres, orthopteres, névroptères, hyménoptères, lépidoptères, hemipteres, rhipipteres, diptères, parasites et thysanoures.

$\$$ 541. Les Coléoptines, de mème que les orthopteres et les névroptères, sont conformés pour se nourrir de substances solides. soit animales, soit vérétales, et sont pourvus à cet effet de mandibules et de màchoires propres a opérer la division de ces aliments (fig. 337 ). Ils sont pourvus de deux paires d'ailes, mais celles de la premiere paire ne sont pas propres au vol, et constituent des especes de boucliers durs et cornés que l'on nomme élytres (fig. 329). Les ailes de la seconde paire sont, an contrairo. 
membraneuses, transparentes, et trop longues pour se cacher sous les ólytres sans se reployer en travers; quelquefois elles manquent, et alors l'insecte est dans l'impossibilité de voler : c'est le cas du charançon, qui ravage nos greniers à blé, et se fait remarquer par sa tête prolongée en façon de bec.

Les coléoptères subissent des métamorphoses complètes. La larve ressemble à un ver dont la tète est cornée, tandis que le reste du corps est presque toujours mou (fig. 360$)$; sa bouche

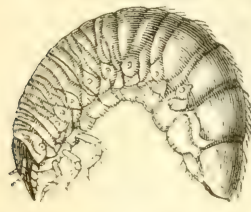

Fig. 360. Larve de Hannelon. est conformée de mème que celle de l'insecte parfait, et il n'y a pas toujours d'ocelles; les trois anneaux qui suivent la tète sont presque toujours pourvus chacun d'une paire de pattes, ordinairement très-courtes; enfin, il existe chez un grand nombre de ces animaux une paire de fausses pattes, attachée au der. nier segrment de l'abdomen. La nymphe est. inactive et ne prend pas de nourriture; elle rst recouverte d'une peau membraneuse qui s'applique exactement. aux parties situees au-dessous et les laisse aperceroir.

La plupart de ces insectes se font remarquer par la dureté de leurs téruments et le brillant de leurs couleurs; les uns sont carnassiers : le carabe doré ou jardinier $(f i g .6)$, si commun dans les allées sablées. par exemple; d'autres, tels que le hanneton, se nourrissent de matieres végétales. Leur nombre est immense, on en connaît. plus de trente mille especes; mais nous nous bornerons à citer ici

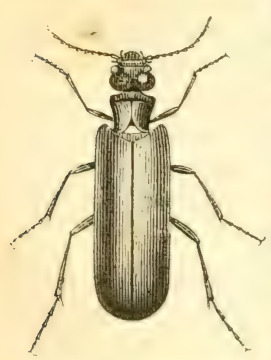

Fig. 361. Cantharide v'e-

les scarabées, dont une espèce ( $f i g .363$ ) est célèbre à cause du respect dont elle était l'objet chez les anciens Égyptiens; les cantharides ou mouches d'Espagne (fig. 361), qui, dans le midi de la France et en Espagne, vivent sur le frêne et le lilas, et fournissent à la médecine une substance vésicante trèsénergique; les calandres ou charançons, qui vivent dans le blé; les vrillettes ( $f$ g. 362 ), et les limebois, qui, à l'état de larve, perforent. les bois des vieux meubles et des charpentes; les dermestes (fig. 36 i), dont les larves se sicante (grossie).

nourrissent des dépouilles d'autres animaux et sourent détruisent de la sorte les fourrures et les collections zoologiques; enfin, les coccinelles ou bétes à Dieu: les cicindeles, les carabes (fig. 6), etc. 


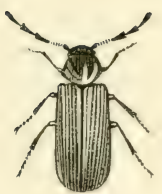

Fig. 362.

Vrilletle.

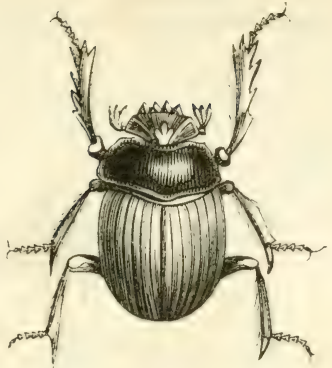

Fig. 363. Scarabée (ou Aleuchus) des Égyptiens.

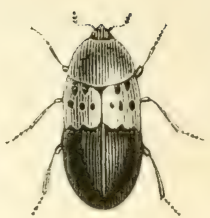

Fig. 364.

Dermeste du lart.

$\$ 342$. Les Ortuoptenes ressemblent aux précédents par la disposition générale des organes de la mastication, ainsi que par le nombre et la consistance de leurs ailes; mais s'en distinguent par lo morle de plissement des ailes postérieures et par la nature de leurs métamorphoses. Leurs ély tres sont moins dures que chez les coléoptères, et les ailes membraneuses ( $f i g .36 .5)$, lorsqu'elles sont dans lo repos, ne se déploient pas pas transrersalement, mais se plissent

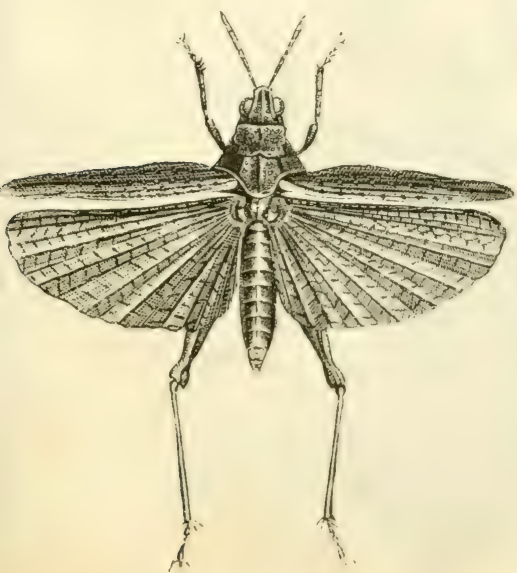

Fig. 365. Saulerelle.

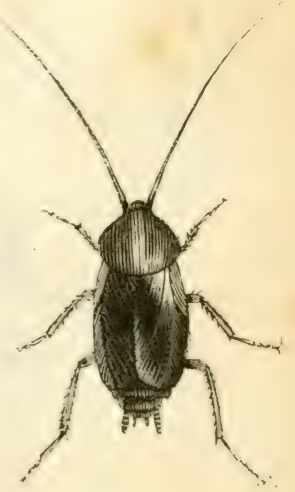

Fig. 366. Blalle. 
seulement dans le sens longitudinal, à la manière d'un éventail. Ils ne subissent que des demi-métamorphoses, ef la larve ainsi que
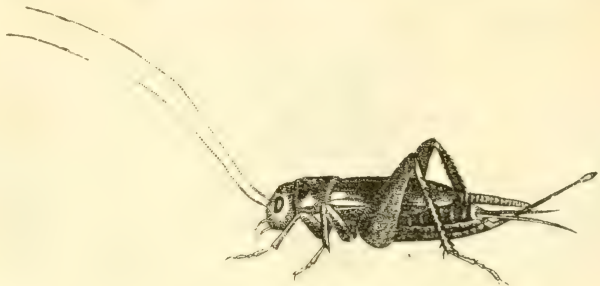

Fig. 367. Grillon domestique.

la nymphe ressemblent à l'insecte parfait, si ce n'est quant aux ailes. Enfin, tous sont terrestres, et la plupart sont remarquables far l'allongement de leur corps et le développement extrême des pattes postérieures, ce qui en fait des animaux sauteurs.

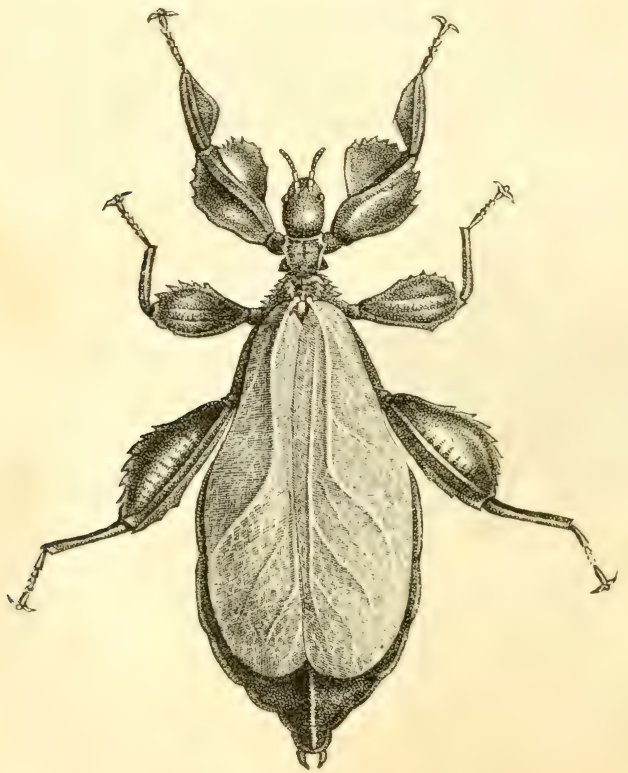

Fig. 368. Pluyllie feuille-siche. 
Les sauterelles et les criquets (fig. 32.1) sont les représentants principaux de ce groupe; mais on y range aussi les mantes (fig. 327), les phyllies (fig. 368), les grillons (fig. 367), les courtilières (fig. 326), les blattes (fig. 366) et les forticules (fig. 332).

\$ 343 . Les Névroptères se distinguent des autres insectes masticateurs par la contexture de leurs ailes, qui, an nombre de quatre, sont toutes membraneuses, transparentes, diune délicatesse extrème et également utiles pour le vol. Le corps do ces insectes est en général mou et très-allongé ; enfin, les uns subissont

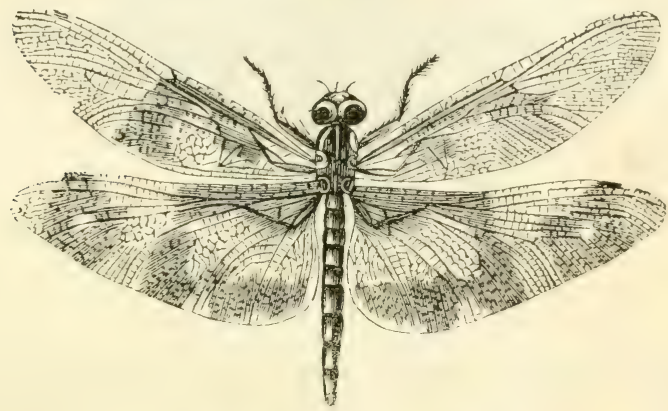

Fig. 369. Libellule indienne

des métamorphoses complètes, les autres des demi-métamorphoses seulement. Cet ordre comprend les libetlules (fig. 369), les agrion(fig. 14:3), les éphémeres (fig. 3:3s). les fomrmilions (fig. 370). Ies termites, les friganes, elc.

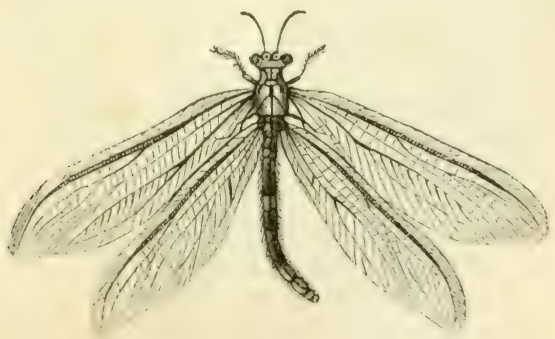

Fig. 370. Fourmilion ordinaire. 
\$ \$4. Les Hruéxoptìnes établissent en quelque sorte le patsage entre les insectes masticateurs et les suceurs: ils sont, en effet. pourvus de mandibules conformées à peu près de mème que chez. les premiers, mais ne s'en servent pas pour la mastication et se nourrissent de matières molles ou liquides gu'ils pompent à l'aiule

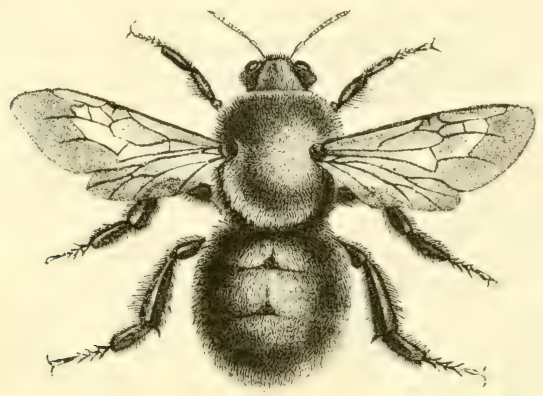

Fig. 371. Bourdon.

d'une trompe mobile et flexible, composée des màchoires et de la languette, excessivement allongée (fig. 339). Ils ont, comme les névropteres, quatre ailes membraneuses et transparentes; mais res ailes, au lieu d'ètre réticulées comme une dentelle, sont divisées en un certain nombre de cellules assez grandes par des nervures cornées, et elles se croisent horizontalement sur le corps pendant le repos. Leurs téguments n'offrent que peu de dureté, et labdomen des femelles est terminé par une tarière ou par un aiguillon.

Ces insectes subissent une métamorphose complète. La larve, tantót privée de pattes, ressemble à un ver; d'autres fois, pourvue de six pieds à crochets et sourent aussi de douze à seize pieds membraneux, ressemble darantage à des chenilles: dans l'un et l'autre cas, elle a une tète écailleuse avec des mandibules, des màchoires, et une lève à l'extrémité de laquelle est une filière four le passage de la matière soyeuse dont sa coque doit ètre construite. Le régime de ces larves varie beaucoup. Plusieurs ne peuvent se passer de secours étrangers ef sont élevées en commun par des individus stériles, réunis en société, ainsi que nous l'avons cléjai vu en parlant des abeilles (\$332). La nymphe reste sans nourliture of dans un repos complet. Enfin, dans leur élat parfait. 
les hyménoptères vivent presque tous sur les fleurs ef meurent au bout de la première année de leur existence.

Cet ordre comprend la plupart des insectes les plus remarquables par leurs instincts, tels que les fourmis, les abeilles (fig. 111) et les guèpes. On y range aussi les bourdons (fig. 371), les xylocopes ( fig. 103), les tentredes, les sirex (fig. 372), les ichneumons, les cynips, etc.

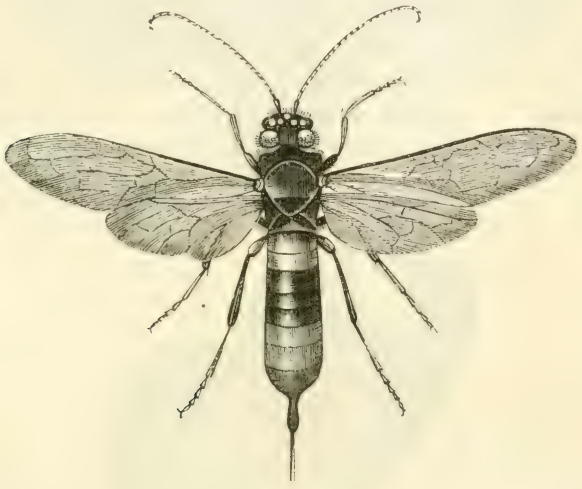

Fig. 372. Sirex géant.

\$: :":). L'ordre des Lépinoptères se compose d'insectes dont la bouche (fig. 344) est conformée de manière à n'ètre propre quà

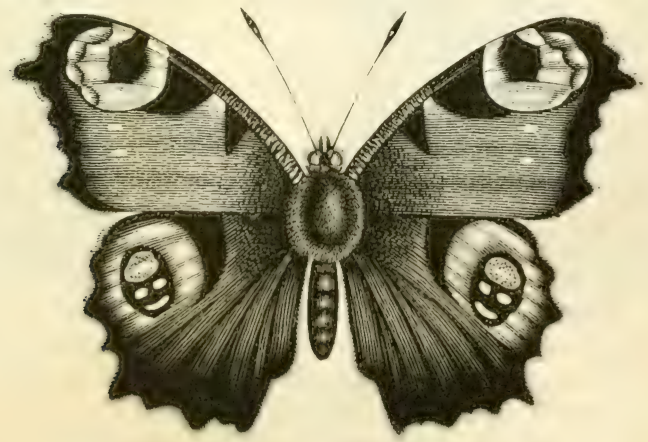

Fig. 373. Venesse paon du jour. 
l'aspiration des sucs déposés sur la surface des plantes, et dont les ailes, au nombre de quatre et membraneuses comme dans les deux groupes précédents, sont opaques et diversement coloriées par la présence d'une sorte de poussiere écailleuse fixée à leur surface. La bouche, comme nous l'avons déjà dit, a la forme d'une longue trompe roulée en spirale. Enfin, ces insectes subissent des métamorphoses completes, et leurs larves $(f g .319$ et $377,4 b)$, connues sous le nom de chenilles, sont pourvues de pattes vers les deux extrémités de leurs corps, et vivent en général de feuilles : les unes s'enveloppent d'un cocon soyeux pour y achever leur transformation; d'autres se roulent dans des feuilles, ou se suspendent à quelque corps étranger au moyen d'un fil de soie.

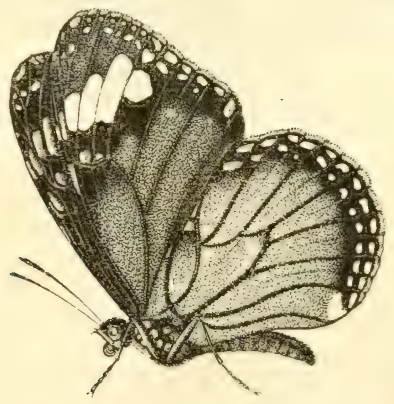

Fig. 3-4. Danä̈de plexippe.

Parmi les lépidoptères, les uns volent de jour, les autres ne se montrent qu'à la brune, et d'autres encore restent comme engourdis durant le jour et ne sortent que la nuit. Les Diurnes se reconnaissent à leurs ailes élevées verticalement pendant le repos ( $f y .374)$, et sont remarquables par la variété et la vivacité de leurs couleurs; on les désigne généralement sous le nom de papillons, mais les zoologistes les distinguent en vanesses (fig. 373), papillons proprement dits ( $f g .331$ ), danaïdes ( fig. 374), etc. Les Crépusculaires et les Noclurnes ont les ailes horizontales pendant le repos, et ont en général des couleurs plùs ternes que les précédents. Ce sont les sphinx (fig.373̈), les bombyces (fig. 376), les phalènes, les teignes, etc. La pyrale (fig. 377), qui occasionne souvent de grands dégâts dans les vignobles, appartient aussi à ce groupe. 
$\$ 346$. Les Hémiptènes ont aussi la bouche disposée pour la succion, mais elle ne consiste pas en une simple trompe et a la forme d'un bec, dans l'intérieur duquel se trouvent des stylets aigus, propres a perforer les tissus animaux ou végétaux dans

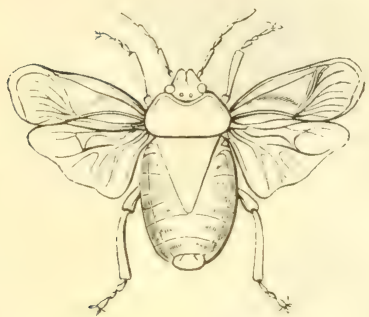

Fig. 378. Pentalome.

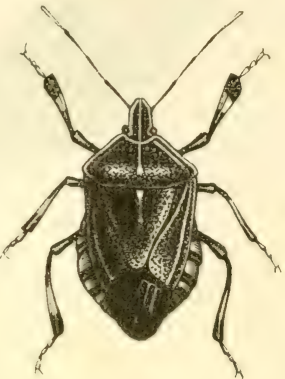

Fig. 379. Halys.

lesquels l'animal doit puiser les liquides dont it se nourrit (voyez $\$ 323)$. Ces insectes ont ordinairement quatre ailes comme tous les précédents; mais, en général, celles de la première paire ne sont membraneuses que vers le bout, et constituent des demi-

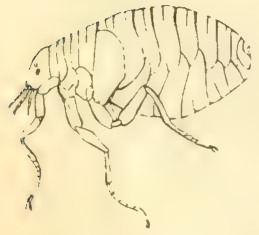

Fig. 380. Puce.

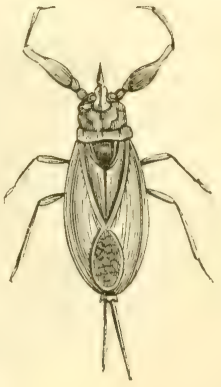

Fig. 381. Nèpe.

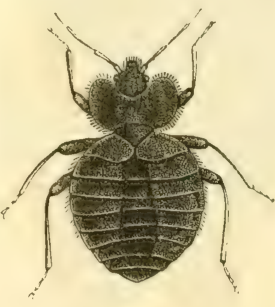

Fig. 382. Punaise.

ilytres; entin les métamorphoses sont incomplètes, et l'insecte en wandisiant ne change ni le forme ni d'habitude, seulement il arquiert. en général, des ailes dont il élail dabord privé; quel- 


\section{CLASSE DES MYRIAPODES.}

$\S$ 5äl. Les Myriapodes respirent l'air au moyen de trachées comme les insectes, mais ils different considérablement de ces animaux ainsi que des arachnides par leur conformation générale. Non-seulement ils n'ont jamais d'ailes, mais leur corps, très-allongé et divisé en un grand nombre d'anneaux, porte sur chacun de ses segments au moins une paire de pattes : aussi le nombre de ces organes s'élève-t-il toujours à vingt-quatre ou davantage, et n'existe-t-il aucune ligne de démarcation entre le thorax et l'abdomen. Ils ressemblent un peu à des serpents ou à des vers qui seraient munis de pieds; mais leur organisation intéricure les rapproche des insectes ordinaires.

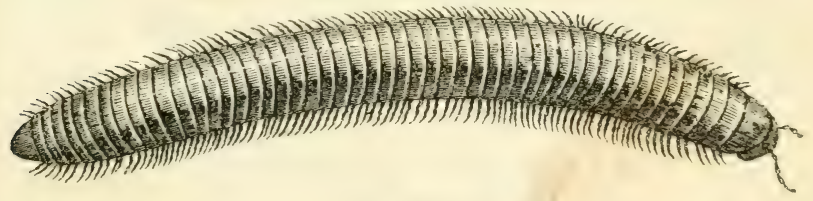

Fig. 389. Iule.

La tète des myriapodes est garnie de deux petites antennes el de deux yeux formés ordinairement d'une réunion d'ocelles. Leur bouche est conformée pour la mastication et présente une paire do mandibules biarticulées suivies d'une espece de lèvre à quatro divisions, et deux paires d'appendices semblables à de petits pirds. Le nombre des anneaux de leur corps varie, ot quelquefois ces segments paraissent réunis deux à deux, de telle sorte que chaque tronçon mobile porte deux paires de pattes (fig. 360). Ces derniers oryanes ne se terminent que par un seul crochet. Enfin il existe de chaque còté du corps une série de stigmates en communication: avec des trachées conformées de la mème manière que chez les insectes ordinaires. Les myriapodes éprouvent dans le jeune àye des métamorphoses, mais ces changements ne sont pas analogue: à ceux que nous avons vus chez les insectes proprement dits, of consistent seulement dans la formation de nouveaux anneaux of dans une augmentation correspondante du nombre des pattes.

$\$ 5: 32$. Deux groupes naturels, faciles a distinguer par la forme 
des antennes, composent cette petite classe, savoir les Curuognatues ou Iules, et les Curlopodes ou Scolopendres.

Les Chllognathes ont le corps cylindrique, et se nourrissent de matières organiques plus ou moins décomposées; leur marche est lente, et ils se roulent souvent en spirale ou en boule. On les distingue sous les noms d'iules (fig. 389), de polydesmes (fig. 390) et de gloméris.

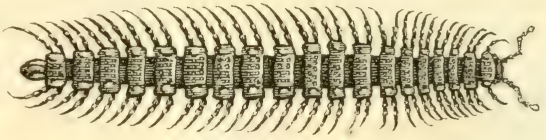

Fig. 390. Polydesme.

Les Curlopodes ont le corps déprimé et plus membraneux que les précédents; ils sont carnassiers et courent très-vite. Trois genres principaux constituent groupe : les scolopendres (fig. 1399), les lithobies et les scutigères.

\section{CLASSE DES ARACHNIDES.}

$\$$ J̈33. La classe des arachnides se compose d'animaux articulés qui ont beaucoup d'analogie avec les insectes, et qui sont également organisés pour vivre dans l'air; mais qui s'en distinguent, au premier coup d'oeil, par la forme générale du corps et par le nombre des pattes, et qui diffèrent aussi de ces animaux par plusieurs particularités importantes dans leur structure intérieure. En effet, les arachnides ont tous la tête confondue avec le thorax et dépourvue d'antennes; ils ont quatre paires de pattes et jamais d'ailes; enfin, ils respirent en général à l'aide de cavités pulmonaires, et ont presque tous un appareil circulatoire assez complet.

\$ 534 . Le squelette tégımentaire de ces animaux est en général moins solide que celui des insectes, et leur corps se compose de deux parties principales, presque toujours distinctes: l'une appelée céphalothorax, parce qu'elle est formée par la tète et le thorax confondus en un seul tronçon; l'autre nommée abdomen, et composée tantòt d'unc suite d'anneaux distincts (comme cela se voit chez les scorpions (fig. 3:3̈), tantòt d'une masse molle, globuleuse et sans divisions (chez les araignées, par exemple, fig. 146). 
Les organes de la locomotion sont tous fixés au céphalothorax, et consistent en huit pattes trèssemblables à celles des insectes et presque toujours terminées par deux crochets; en général, leur longueur est considérable, et elles se cassent facilement; mais, de même que chez les crustacés, le moignon, après s'ètre cicatrisé, reproduit une nouvelle patte qui croît peu à peu, et finit par être semblable à celle dont l'animal avait été privé. Jamais les arachnides ne présentent des vestiges d'ailes, et leur abdomen est toujours complétement dépourvu d'appendices locomoteurs.

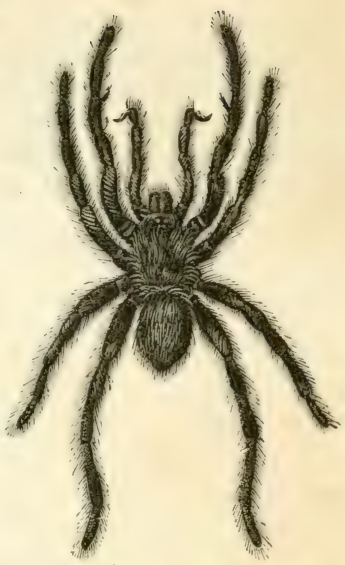

Fig. 391. Mygale.

$\$ 3: 3 \%$. C'est sur la partie antérieure du céphalothorax que se trouvent la bouche et les yeux. Ces derniers organes sont toujours simples et en nombre assez considérable : on en compte ordinairement huit ( $\mathrm{rg} .392)$, et on distingue dans chacun d'eux une cornée transparente, derrière laquelle se trouvent un cristallin ot une humeur vitrée, puis une rétine formée par la termi-

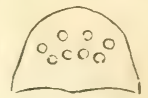

Fig. 392. naison d'un nerf optique et une enveloppe de matiere colorante. On ne sait rien relativement aux instruments a l'aide desquels s'exerce l'audition chez les arachnides; mais on a des preuves multipliées de l'existence de ce sens chez ces animaux, et il paraitrait mème que certains d'entre eux sont sensibles au charme de la musique. Le toucher s'exerce principalement par l'extrémité des pattes et par les appendices dont la bouche est garnie.

$\$ 536$. Le système nerveux des arachnides présente des différences assez grandes; tantòt (chez les scorpione, par exemple) il se compose d'une série de huit masses ganglionaires réunies entre olles par de doubles cordons de communication et formant une chaìne étendue, d'un bout du corps a l'autre, d'une maniere presque uniforme: d'autres fois (chez les araignées, ete.) on trouve tous les ganglions du thorax réunis en une seule masse ( $t$, fiy. 393 et fig. 396), d'où partent en arriere deux cordons (c) qui vont aboutir à un ganglion abdominal unique $(a$, fig. 396 $)$. Du reste. la disposition gémémale de ces parlies est toujoura la mème: les aran- 
glions antérieurs $(c)$, situés au-devant ou au-dessus de l'œsophage, et considérés plus ordinairement comme représentant le cerveau de ces animaux, donnent naissance aux nerfs optiques en avant, et se continuent en arrière avec le collier œsophagien; les autres ganglions sont situés au-dessous du tube alimentaire, et envoient des nerfs aux pattes, aux appendices de l'abdomen, etc.

$$
\text { ct } \quad e \quad c \text { no } \quad y
$$

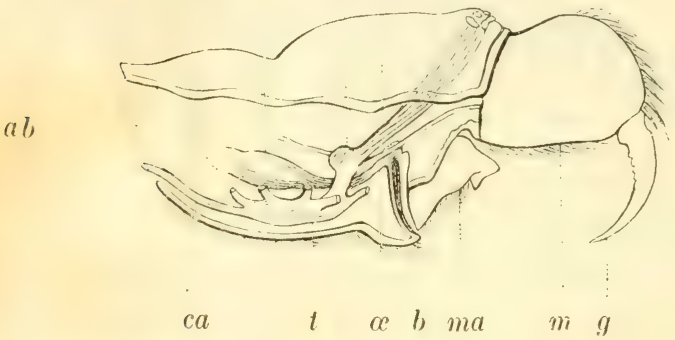

Fig. 393. Système nerreux, etc. (1).

\$:37. Les arachnides sont carnassiers, mais se bornent en général à sucer les humeurs contenues dans le cadavre de leur victime, et, afin de leur rendre plus facile la capture d'animaux dont

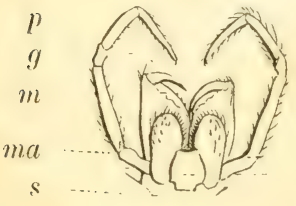

Fig. $394(2)$. ils pourraient redouter la force, la nature a pourvu un grand nombre d'entre eux d'un appareil venimeux. La plupart se nourrissent d'insectes qu'ils saisissent virants; quelques-uns cependant sont $l$ parasites. Chez les premiers la bouche (fig. 394) est garnie d'une paire de mandibules armées de crochets mobiles, ou

(1) Section du céphalothorax d'une mygale, montrant la disposition du système nerveux : - cl céphalothorax; $-m$ mandibule; $-g$ griffe ou crochet mobile qui la termine; $-l$ bouche: $-a$ osophage; $-c$ estomac; $-a b$ origine de l'abdomen; $-c$ cerveau ou ganglion céphalique; $-t$ masse ganglionaire du thorax; - ca cordons qui s'unissent aux ganglions abdominaux; - no nerf optique; $y$ yeux.

(2) Appareil buceal d'une araignée : - s sternum; - llèvre; - mu mâchnires; - $p$ palpes des mâchoires; $-m$ mandibules; $-g$ crochet ou griffe des mandibules. 
conformées en manière de pinces, d'une paire de mâchoires lamelleuses portant chacune un grand palpe plus ou moins pédiforme, et d'une lère inférieure; chez les arachnides parasites, la bouche a la forme d'une petite trompe d'où sort une espece de lancette formée par les mâchoires.

Le crochet mobile des mandibules présente près de son extrémité une petite onverture qui est l'orifice du canal excréteur de la glande venimeuse dont nous avons déjà parlé, et la liqueur qu'elle verse au fond des plaies détermine presque aussitòt l'engourdissement des insectes auxquels ces animaux font la chasse, mais est trop faible pour nuire à l'homme, et c'est sans aucune raison que le vulgaire attribue souvent à la morsure des araignées les boutons et les rougeurs qui se développent quelquefois sur notre peau.

Certains arachnides sont pourvus d'un autre appareil venimeux destiné au mème usage et servant en même temps conme arme défensive : tel est le crochet qui termine l'abdomen des scorpions (fig. 393). Ce dard présente au-dessous de la pointe plusieurs ou-

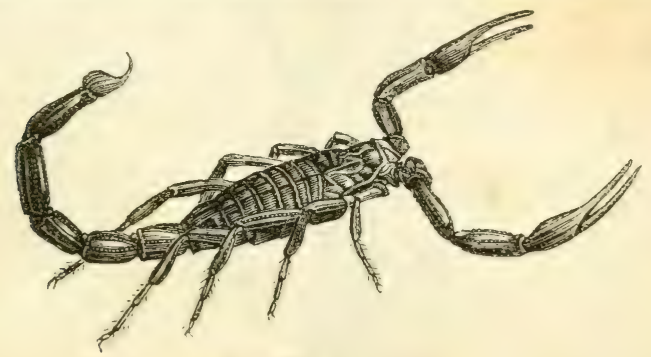

Fig: 395. Scorpion.

vertures qui communiquent avec une glande venimeuse, et la piqùre de ces arachnides est souvent mortelle pour les animaux mème assez gros, tels que les chiens. Les grands scorpions des pays chauds sont aussi très-redoutables pour l'homme, mais la piqùre des espèces qui habitent l'Europe ne parait pas ètre jamais mortelle; il en résulte ordinairement une inflammation locale plus ou moins vive, accompagnée de fievre et d'engourdissement, ef quelquefois de vomissements, de dotileurs dans tout le corps et de tremblement. Pour combattre ces accidents, les médecins conseillent l'usage de l'ammoniaque (ou alcali volatil) administré i l'intérieur aussi bien qu'à l'extérieur, et l'application de substances émollientes sur la plaie.

Le canal infestinal est en cénéral asser simple, mais offie yuel- 
quefois des appendices cœcaux qui pénètrent jusque dans l'intérieur des pattes. En genéral, des tubes analogues aux vaisseaux biliaires des insectes s'ouvrent à l'intestin près de l'anus; mais chez quelques arachnides, tels que les scorpions, il existe un foie composé de quatre grappes glanduleuses.

C'est aussi autour de l'ouverture anale que se trouvent les glandes sécrétoires de la matière soveuse et les filières à l'aide desquelles plusieurs arachnides se construisent des toiles sourent très-étendues et d'une délicatesse extrême (f, fig. 396).

$m$

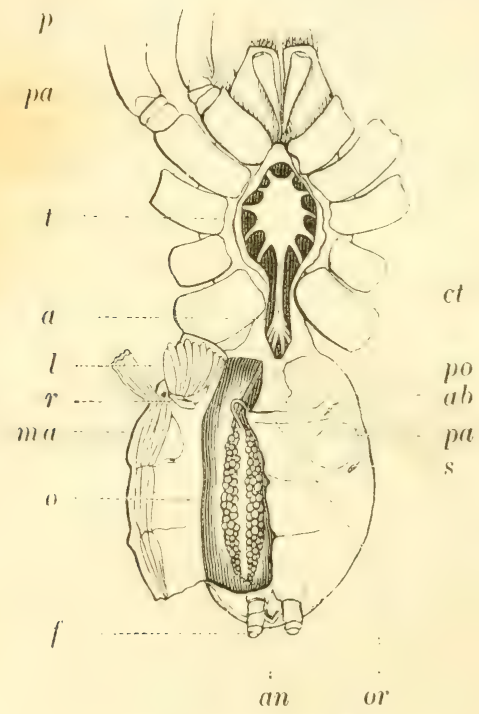

Fig. 396. Anatomie d'une Mygale (1).

$\$ 3: 5$. La respiration des arachnides est aérienne comme colle des insectes, et se fait quelquefois au moyen de trachées; mais chez la plupart de ces animaux, et notamment chez les araignées

(1) $\mathrm{cl}$ céphalothorax ouvert en dessous et donnant attache aux pattes dont la hase est en place; - pa patte de la première paire; $-p$ palpe; $-m$ mandibules: - $a b$ abdomen; - 1 masse ganglionaire thoracique; - $a$ ganglions abdominaux; - po poches pulmonaires; $-s$ stigmates; $-l$ lamelles respiratoires d'une de ces cavités ouverte; - o ovaires; - or orifice des oriductes ; - ma muscles de l'abdomen; $-a n$ anus; $-f$ filières. 
et les scorpions, elle est concentrée dans des poches logées dans l'abdomen et appelées poumons. Ces derniers organes présentent dans leur intérieur une multitude de lamelles membraneuses ( $l$, fig. 396) disposées comme les feuillets d'un livre; aussi ressemblentils bien plus à des branchies intérieures qu'à de véritables poumons. Chaque poumon reçoit l'air par une ouverture située à la face inférieure de l'abdomen $(s)$, et on en compte tantôt deux, tantôt quatre ou mème huit.

Certaines araignées possèdent en mème temps des poumons et des trachées, les segestries sont dans ce cas; et d'autres, telles que les faucheurs et les mites, sont pourvues de trachées seulement. Ces tubes ont la mème structure que chez les insectes, et l'air y pénètre par deux stigmates très-petits situés à la partie inférieure de l'abdomen.

Le sang est blanc chez tous les animaux de cetteclasse. Les arachnides pulmonaires sont pourvus d'un appareil circulatoire assez. complet. Leur cœur ( $f g .397)$, situé sur le dos, a la forme d'un vaisseau allongé, et donne naissance à diverses artères; le sang, après avoir traversé les organes, se rend aux poumons, et de là arrive au cour, en suivant une marche semblable à celle que nous avons déjà vue chez les crustacés (\$111). Chez les arachnides $a r$ dont la respiration s'effectue uniquement à l'aide de trachées, l'appareil de la circulation est rudimentaire. Il ne parait y avoir qu'un simple vaisseau dorsal, sans artères ni veines.

$\S 539$. Les arachnides pondent des nufs comme les insectes, et le mâle diffère en, général, de la femelle par la

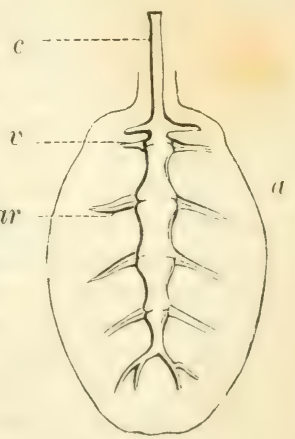

Fig. 397 (1). forme des palpes maxillaires, dont les usages paraissent c̀tre trèsimportants. Un grand nombre de ces animaux enveloppent leurs oeufs dans un cocon de soie, et quelquefois la mère demeure avec sa jeune famille pour la protécrer, et porte mème les petits sur son dos lorsqu'ils sont encore trop faibles pour marcher. Tous ces animaux subissent plusieurs mues avant que d'arriver à l'àge adulte, et quelques-uns éprouvent une sorte de mélamorphose, car il en est dont les pattes ne sont d'abord qu'au nombre de trois paires et qui en acquierent une quatrième à un âge plus ou moins avancé.

1) Abdomen et cour dune araignéc: - abdomen; - c curur: - ar artere céphalique; $-v$ canaux veineux. 
$\$ 560$. Les arachnides sont doués d'instincts variés qui sont quelquefois non moins remarquables que ceux des insectes; et on serait mème porté à leur accorder des facultés plus développées, car on a vu des animaux de cette classe se prêter à une espèce d'éducation et donner des signes d'une sorte d'intelligence. Plusieurs ont recours à des ruses particulières pour s'emparer de leur proie, et d'autres déploient dans la construction de leur demeure une industrie singulière : nous avons déjà eu l'occasion de parler du nid si remarquable de la mygale $(f g .100)$; les toiles que nos araignées de jardin tendent avec une régularité admirable sont également curieuses. La soie avec laquelle ces animaux se construisent ainsi des retraites, tendent des piéges à leur proie et forment descocons pour leurs oufs, est sécrétée par un appareil logé dans la partie postéricure de l'abdomen. Cet appareil consiste en plusieurs paquets de raisseaux contournés sur eux-mèmes et aboulissant à des pores percés au sommet de quatre ou de six mamelons coniques ou cylindriques appelés filières et situés audessous de l'anus (fig. 396). La matière gluante expulsée à travers ces pores prend de la consistance par le contact de l'air, et constitue des fils d'une ténuité extrème et d'une longueur trèsgrande. A l'aide de ses pattes, l'animal réunit en une seule corde une multitude de ces fils; et chaque fois qu'en se balancant les filières viennent à toucher le corps sur lequel il pose, il y attache le bout d'un de ces fils, dont l'extrémité opposée est encore renfermée dans l'appareil sécréteur, et dont il peut par conséquent augmenter à volonté la longueur. La couleur et le diamètre des fils varient braucoup : une araignée du Mexique se construit une toile composée de fils rouges, jaunes et noirs entrelacés avec un art qui étonne; et on a calculé que dix mille fils sortant des pores d'une des filieres de quelques-unes de nos araignées communes n'égalent pas en grosseur un de nos cheveux, tandis que d'autres espèces propres aux pays chauds forment des trames si fortes qu'elles suffisent pour arreter de petits oiseaux, et que l'homme mème a besoin de faire un effort pour les rompre. La manière dont les aranéides mettent leur soie en œurre ne varie pas moins: les unes se bornent à tendre des fils irréguliers, d'autres tissent une toile dont les mailles sont d'une régularité extrème. Quelquefois on les roit immobiles au milieu de leur trame, guettant leur proie; d'autres fois ils se cachent dans une retraite qu'ils se construisent tout auprès, et qui a tantòt l'apparence d'un tube soyeux. tantòt celle d'une petite coupe.

$\$ 561$. Les arachnides se divisent en deux sortes, dapros la structure des organes de la respiration et de la circulation. 


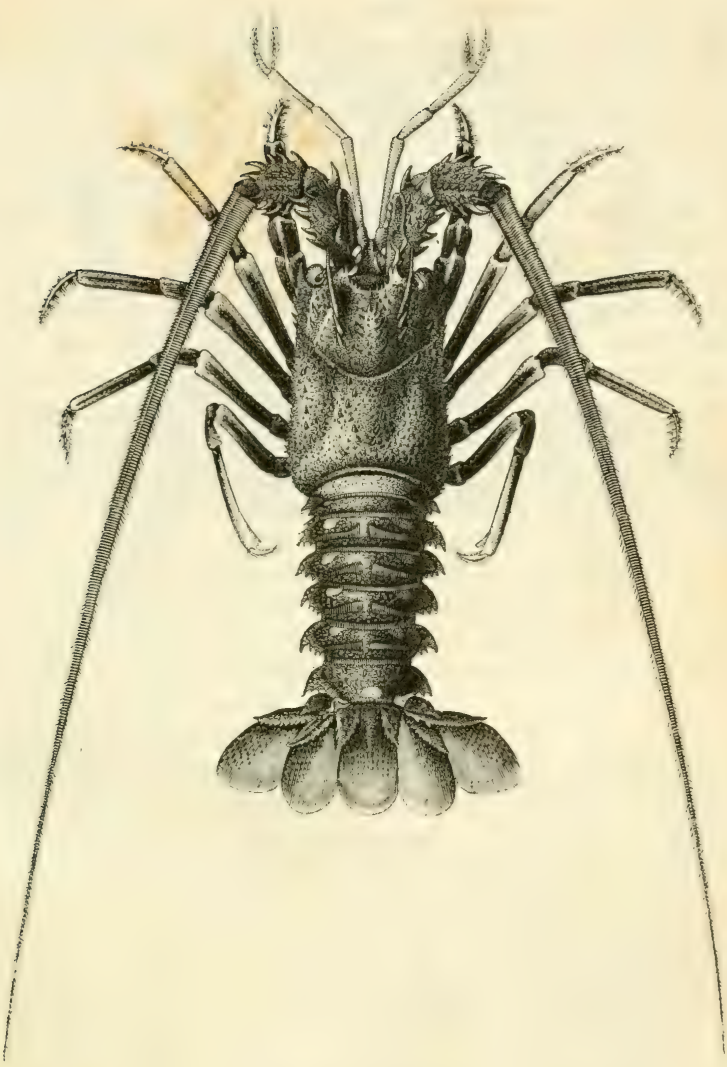

Fig. 400. Langouste.

tégumentaire des larves des insectes se renouveler à plusieurs reprises. On comprend facilement la nécessité de ces mues che\% des animaux dont tout le corps est renfermé dans une gaine solide, qui, ne pouvant croitre comme les parties intérieures, opposerait a leui développement des obstacles invincibles si elle ne tombait pas du moment yu elle est devenue trop petite pour les loger commodement; ausi les crustacés changent-ils de peau 
pendant tout le temps que dure leur croissance, et il paraitrait que la plupart de ces animaux grandissent pendant presque toute leur vie. La manière dont ils se dépouillent de leur ancienne enveloppe est très-singulière; en général, ils parviennent à en sortir sans y occasionner la moindre déformation, et, lorsqu'ils la quittent, toute la surface de leur corps est déjà revètue de sa nouvelle gaine; mais celle-ci est encore molle et n'acquiert la solidité qu'elle doil avoir qu'au bout de quelques jours.

Le corps des crustacés se compose d'une série d’anneaux plus ou moins distincts. Tantút la plupart de ces segments sont simplement articulés entre eux et jouissent d'une mobilité assez grande; tantòt ils sont presque tous soudés ensemble et ne se distinguent que par des sillons situés à leur point de jonction; enfin d'autres fois leur union est encore plus intime, et c'est par analogie seulement qu'on est conduit à considérer le tronçon résultant de leur fusion comme composé de plusieurs anneaux plutòt que d'un seul. Il en résulte, comme on le pense bien, des différences très-grandes dans la forme générale de ces animaux; et si l'on compare entre eux un cloporte (fig. 401) ou un lalitre (fig. 14.4) et un crabe (fig. 402$)$, par exemple, on sera porté au premier abord à les croire conformés d'après des types entièrement dissemblables; mais une étude plus

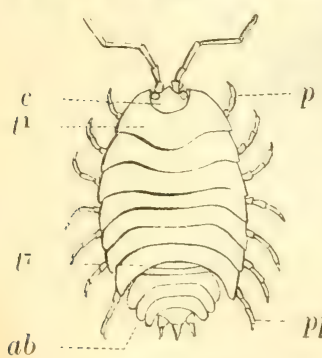

Fig. 401. Cloporle. approfondie de leur structure fait voir que la composition de leur squelette tégumentaire est essentiellement la même, et que les différences tiennent presque entièrement à ce que la plupart des anneaux, complétement distincts et mobiles chez les cloportes, sont soudés entre eux chez les crabes, et à ce que certaines parties analogues ne présentent pas chez ces deux animaux les mèmes proportions. Ainsi, chez le cloporte (fig. 40I) ou chez le talitre (fig. 144), on trouvera une tète distincte $(c)$ suivie d'un thorax composé de sept anneaux semblables entre eux $\left(t^{1}, t^{7}\right)$ et portant chacun une paire de pattes $(p, p p)$; enfin, à la partie postérieure du ('orps, on verra un abdomen (as) formé également de sept segments, dont la grandeur diminue rapidement, mais dont la forme est à peu près la mème que dans le thorax. Chez un crabe, au contraire (fig. 402 ), la tète n'est pas séparée du thorax et ne forme, avec toute celte partie moyenne du corps, quin seul froncon recouvert far un srand bouclier solide, nommé carapace: 


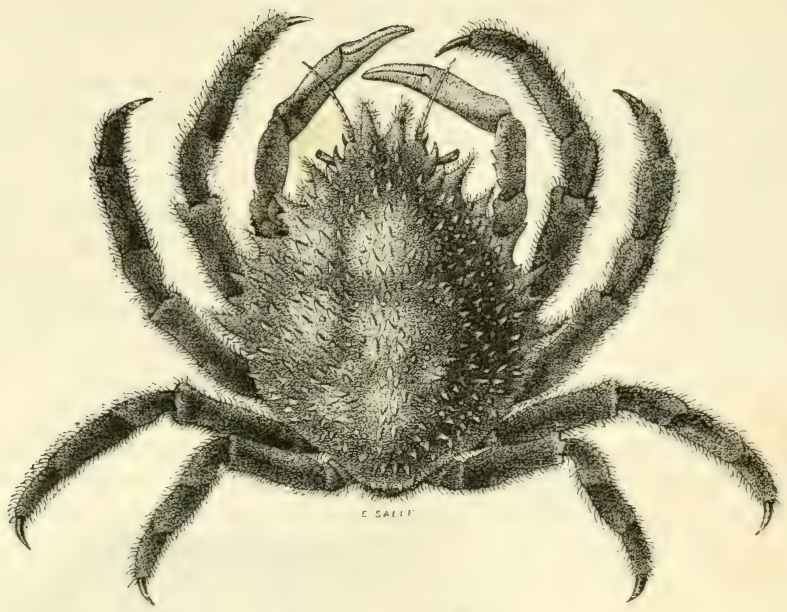

Fig. 402. Crabe-Mä̈а.

enfin l'abdomen échappe d'abord à l'œil, car il est reployé en dessous du thorax et n'offre que peu de volume: cependant il est. facile de démontrer que, chez le crabe comme chez le cloporte, il existe en arrière de la tète sept anneaux thoraciques bien reconnaissables, et que la carapace n'est pas un organe nouveau créé pour les premiers, mais seulement la portion dorsale de l'un des anneaux de la tète, qui a pris un développement extrème et a chevauché sur tous les anneaux voisins. Chez d'autres animaux de la mème classe. la forme générale du corps s'éloigne encore davantage de celles dont nous venons de parler. Ainsi, les limnadies sont renfermées entre deux boucliers ovalaires, réunis comme les valves d'une huilre, et c'est apresaroir enlevé cette cuirasse mobile qu'on reconnait la structure annulaire de leur corps (fig. $4.1: 3)$; les cypris, qui abondent dans les eaux stagnantes, offrent une disposition analogue; seulement les anneaux dont leur corps se compose sont encore plus difficiles à reconnaitre. Enfin, nous citerons encore les lernées, qui, à l'àge adulte, offrent les formes les plus bizarres (fig.130, 131); mais qui, dans la première période de leur existence, ont une structure annulaire bien réçulière (roy. \$366). Cette étude comparative du squelette tégumentaire des cruslacés 
offre un grand intérèt pour l'anatomie philosophique, dont une des branches les plus importantes a trait aux modifications que la nature fait subir aux mèmes éléments organiques, pour les adapter a des usages variés et pour créer avec des matériaux analogues des instruments dissemblables: mais les limites que nous arons assignćes à ces lecons ne nous permettent pas de nous arrèter plus long-temps sur ce sujet.

S 56:3. Les appendices latéraux des divers anneaux constitutifs du corps sont en général très-nombreux, et offrent aussi des différences considérables dans leur conformation et dans leurs usages, soit qu'on les considere dans les diverses parties d'un mème indivirlu, soit qu'on les compare chez des espèces distinctes. Coux des
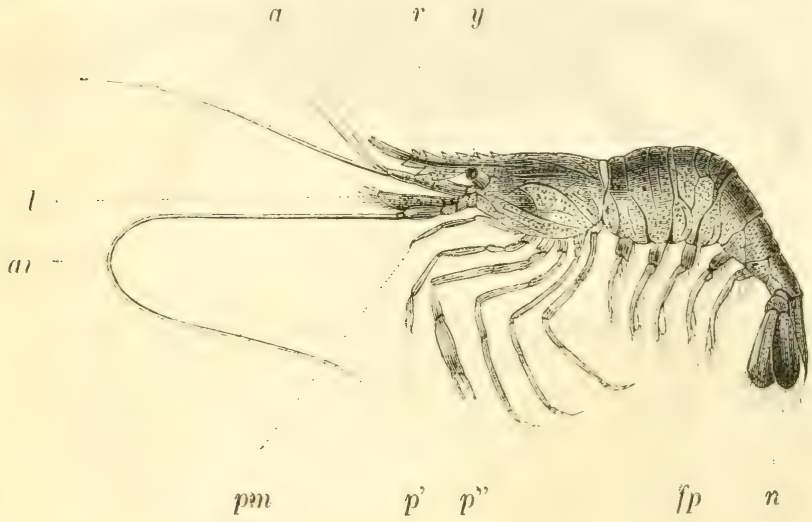

Fig. 403. Palémon (1).

premicrs anneaux sont, en général, affectés aux fonctions de relation et portent les yeux ou constituent des antennes; les suivants entourent la bouche et servent à la préhension ou à la division des aliments ( fig. 120, 121); ceux de la portion moyenne du corps constituent des paltes pour la locomotion, et ceux qui sont placés plus en arrière ont des usages très-variables, mais servent, en général, soit à la respiration, soit à la repreduction; enfin, cette longue sćrie

(1) $a$ antennes de la première paire ; - $a$ i antennes de la seconde paire ou antennes inférieures; $-l$ appendice lamelleux qui en recouvre la base; $-r$ rostre ou prolongement frontal de la carapace; $-y$ yeux; $-p m$ patte-mâchoire externe ; - p' patte thoracique de la première paire; - p'" patte thoracique de la seconde paire; $-f p$ fausses pattes natatoires de l'abdomen; $-n$ nageoire caudale. 
se termine ordinairement par une ou plusieurs paires de membres disposés pour servir de nageoires.

La tète, ou plutòt la portion céphalinue du corps, porte les reux. les antennes et les appendices buccaux : quelquefois clle est divisé on plusieurs anneaux distincts (chez les squilles, par exemple) $(f i g .411)$; mais, en général, elle noffre point de séparation semblable et n'est formée que d'un seul troncon qui parait représenter sept de ces anneaux confondus entre cux. Tantòt elle est mobile et distincte du thoras (fig. 400); tantìt, an contraire, sondée a rette seconde portion du corps, qui, à son tour, se compose d'anneaux articulés entre eux chez certaines especes. soudés en une seule masse chez d'autres.

Les antennes sont presque toujours au nombre de deux paires, et constituent, en général, des espèces de cornes filiformes très-allongées. Les pattes naissent par paires des divers anneaux thoraciques; sourent on en compte sept paires : chez les cloportes (fig. 401), les crevettes des ruisseaux et les talitres, par exemple; mais, d'autres fois, comme cela se voit chez les crabes (fig. 402) et les écrevisses (fig. 120$)$, leur nombre est réduit à cinq paires; seulement les appendices qui, dans le premier cas, formaient les quatre pattes antérieures, sont affectés à d'autres usages et transformés en organes de mastication. Il existe aussi des différences tres-grandes dans leur structure : chez quelques crustacés, elles sont toutes foliacées, membraneuses, et propres à la natation seulement ( $\mathrm{fg}$. 415$)$; chez d'autres, elles ont la forme de petites colonnes coudées, articulées et disposées pour la marche seulement; chez d'autres encore, tout en restant propres à ce dernier genre de locomotion, elles doivent servir en même temps comme autant de petites bêches pour fouir la terre, et alors elles sont élargies et lamellaires vers le bout (fig:"404); enfin, chez d'autres encore, elles se terminent en pince et deviennent alors des instruments de préhension en mème temps qu'elles remplissent encore leurs fonctions ordinaires dans la locomotion (fig. 120, 121). Chez les crustacés nageurs, tels que les écrevisses, les langoustes (fig. 400), lespalímons (fig. 10.3), ete.

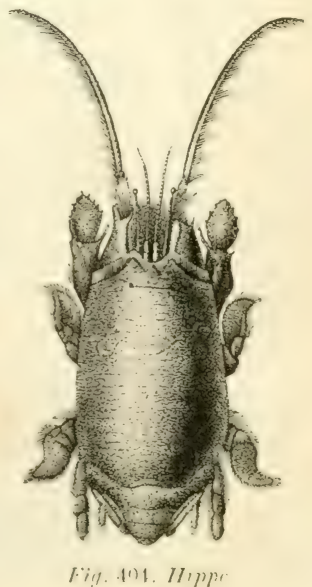

43 
l'abdomen offre, en général, un développement considérable, et se termine par une large nageoire, de facon à devenir le principal agent locomoteur; mais, chez cenx qui doivent marcher plus qu'ils ne nagent, il est, en général, très-petit et replové sur le thorax : chez les crabes, par exemple, cette portion du corps est réduite presque à rien, et constitue l'espèce de tablier mobile qu'on apercoil a la face inférieure du corps entre les pattes.

$\$ 566$. Le systeme nerveux se compose d'une double série de ganglions situés sur la face ventrale du corps, près de la ligne médiane. En général, leur nombre correspond à celui des segments distincts dont le corps se compose; et toujours ceux de la première paire sont logés dans la tète, au-devant de l'oesophage, où ils constituent une espèce de cerveau (fig. $40 \ddot{z}, c)$; mais la disposition des ganglions du thorax et de l'abdomen varie beaucoup : tantòt ils sont également espacés entre eux, et forment avec leurs cordons de communication une chaine étendue d'un bout du corps à l'autre ; tantòt ils sont plus ou moins rapprochés entre eux, et quelquefois ils sont tous réunis en une seule masse, située vers le milieu du thorax $(f i g .403, t)$. Il est à noter que cette centralisation du

c na

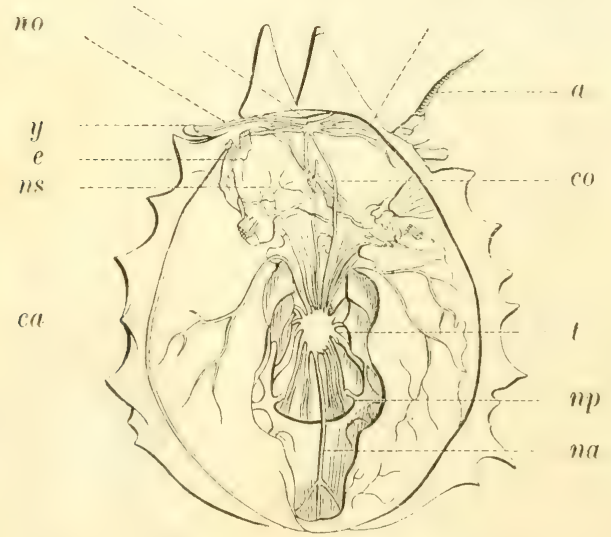

Fig. 405. Système nerveux d'un Crabe, le Mä̈a (1).

(1) ca carapace ouverte; - $a$ antennes extéricures; $-y$ yeux ; $-c$ estomac ; - $c$ cerveau; - no nerfs optiques; - co collier œsophagien; - ns nerfs stomatogastriques; - $\ell$ masse ganglionaire thoracique; - np nerfs des pattes; na nerf abdo:minal. 
systeme nerveux devient de plus en plus complète à mesure que l'animal acquiert une organisation plus élevée. Du reste, les crustacés n'ont tous que des facultés très-bornées, et aucun d'entre eux ne présente beaucoup d'intérèt sous le rapport de ses møurs. Les yeux sont conformés à peu près de mème que chez les insectes. Quelquefois ils sont simples; mais, en général, ils sont composés, et, chez tous les crustacés les plus parfaits, ces organes sont portés sur des pédoncules mobiles $(f i g .406)$, disposition qui ne se voit dans

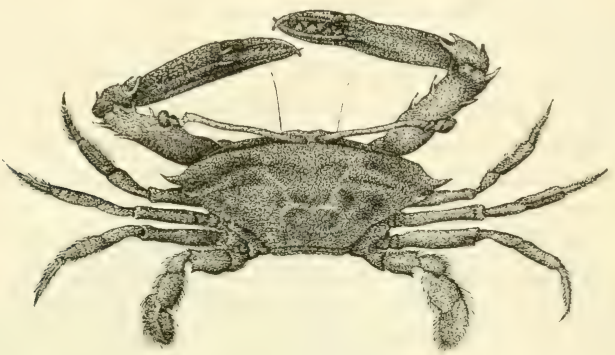

Fig. 406. Podopththatme.

aucune des autres divisions de l'embranchement des animaus arliculés. Chez un grand nombre de crustacés, il existe aussi un appareil de l'ouie, qui est situé à la base des antennes externes, et qui se compose d'une petite membrane semblableà un tympan (fig.407), au-dessus de laquelle se trouve une espèce de vestibule rempli de liquide et $m$ renfermant la terminaison d'un nerf particulier. On ne sait rien de positif touchant l'odorat et le goût ehez ces arimaux.

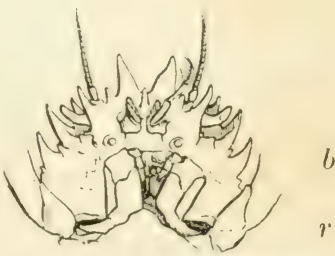

Fig. 407 (1).

$\$ 867$. La plupart des crustares vivent de substances animales; matis ils présentent de sandes différenees dans leur régime : les

1) Portion anterieure de la face in érieure du corps d'un crabe le maïal : ai antennes internes; $-a$ antennes externes; $-y$ yeux; - o organe auditif; $m$ pattes-mâchoires; $-b$ bouche; $-p$ base des pattes antérieures; $-r$ ouverture afférente de la cavité respiratoire; $-s$ sternum. 
uns ne se nourrissent que de matieres liquides; les autres se repaissent d'aliments solides, et on remarque dans la conformation de leur bouche des différences correspondantes. Chez les crustacés masticateurs, il existe an-devant de cette ouverture une lève courte et transversale, suivie d'une paire de mandibules, d'une levre inférieure, d'une ou deux paires de mâchoires proprement dites, et en général d'une ou de trois paires de mâchoires auxiliaires ou pattes-mâchoires, qui servent principalement à la préhension des alments (voy fig. 121). Chez les crustacés suceurs, au contraire, la bouche se prolonge en une espere de bec ou de trompe, semhlable à ce que nous avons déjà vu chez les insectes, dont les mours sont analogues. Dans l'intérieur de ce tube se trouvent des appendices grêles et pointus, qui font l'office de petites lancettes, et, de chaque còté, on voit d'ordinaire des organes analognes aux mârhoires auxiliaires des crustacés broyeurs, mais qui sont conformés pour servir à fixer l'animal sur sa proie.

\$ 368. Le canal dig̣estif s'étend de la tète à l'extrémité postérieure de l'ablomen, et se compose d'un osophage très-court, d'un estomac grand (e, fig. 409) et en général arme intérieurement de dents puissantes, d'un intestin gròle et d'un rectum. Chez quelques crustacés, la bile est sécrétée par des vaisseaux biliaires assez semblables à ceux des insectes; mais, en sénéral, il existe un foie tresvolumineux $(f o)$, divisé en plusieurs lobes et conprosé d'une multitude de petits tubes terminés en cul-de-sac et groupés autour l'un canal excrétcur ramifié, dont l'extrémilé débouche de chaque còté dans l'intestin, près du pylore.

$\$$ \$69. On ne sait rien sur la maniere dont le chyle passe de l'intestin dans l’appareil circulatoire. Le sang est incolore ou légrirement teint en blen ou en lilas, et se coagule facilement. C. liyuide est mis en mouvement par un cour situé sur la ligne médiane du dos (c. fig. 409) et composé d'une seule carité. Sa forme varie, et ses contractions chassent le sang dans les arteres, qui le distribuent a toutes les parties du corps. Les veines sont très-incompletes et sont formées principalement par les lacunes que les divers organes laissent entre eux et que tapisse une conche minee de tissu collulaire; elles aboutisient à de vastes sinus situés près de la base des palles (s, fig. 408), et de ces eavitís le sang se rend aux organes respiratoires, puis revient au cour par des canaux bien distincts nommés branchiocardiaques $(v b)$.

$\$ 870$. Les crustacés sont presque tous des animaux essentiollement aquatiques; aussi leur respiration se fait-elle presque toujours a l'aide de branchies, ol, Iorsque ces organes mancquent. 


\section{CRUSTACÉS.}

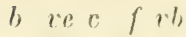

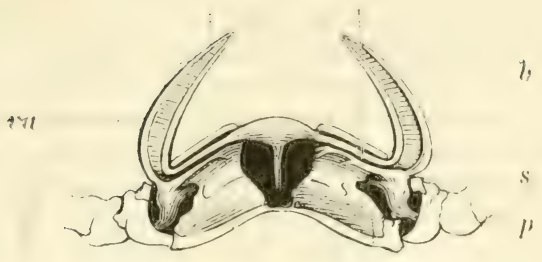

sl $\quad c e$

Fïg. 408. Appreil irculatore d'un Crabe (1).

fis

e $m$

ao

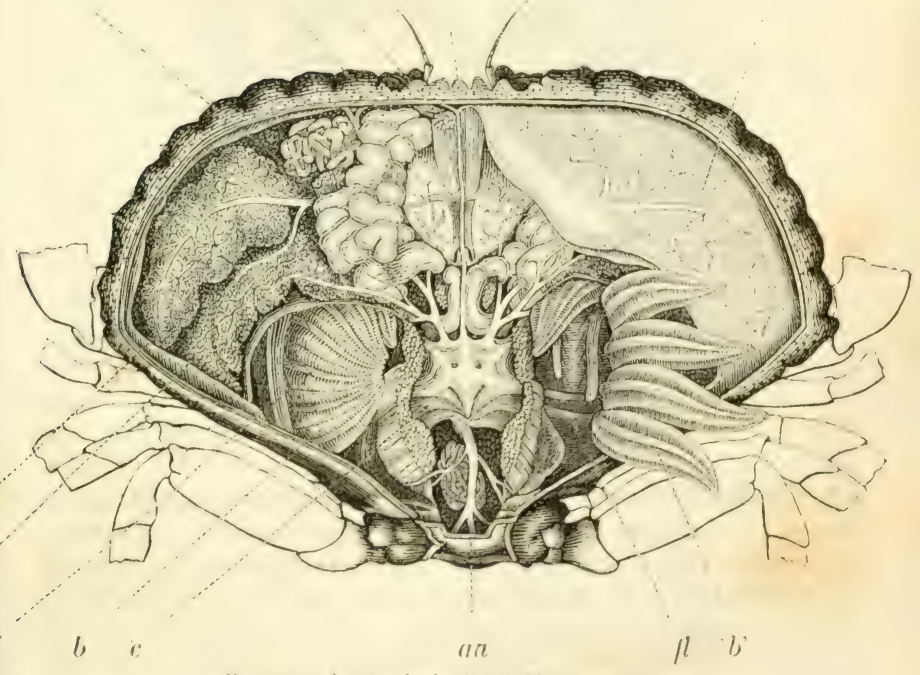

Fig. 409. Anatomie clu Crabe Toartern (2).

11. Coupe verticale du thorax d'un crustare, montrant la marclie suivie par le sang; $-c$ cœur ; $-s$ sinus veineux; $-b$ branchies ; $-v a$ vaisseau qui porte le sang veineux allx branchies; - te vaissean yui reroit le sang apri's son passage a travers le reseatu capillaire des branchies. - $r$ l) vaisseatux branchio-rarrliagues: - $f$ voute des flancs; - st sternum; - ce cellule des flancs; - $p$ base des pattes.

(2) La majeure partie de la carapace a été enlevée : - $t$ portion de la mem-

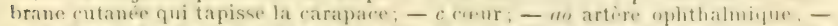
on artiere abtominale: - b branchies dans leur position naturelle: - li hranchies renversees en dehors pour montrer leurs vaisseaux ellerents: - $l$ voute des

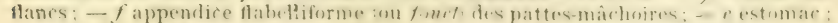
- m muscles de l'estomac; - fo foie. 
rest la peau de certaines parties du corps (le plus souvent des patles) yui en tient lien. Du reste, la disposition de l'appareil res.piratoire varie beaucoup. Ainsi, chez les crabes, les écrevisses et tous les autres crustacés d'une orqanisation analogue, les branchies consistent en un nombre considérable de pyramides composées chacune diune multitude de petits cylindres disposés comme les poils d'une brosse, ou de petites lamelles empilées les unes sur les autres comme les feuillets d'un livre. Ces organes sont fixés par leur extrémité au bord inférieur de la voùte des flanes (fig. 408 et 40 ), et sont renfermés dans deux grandes carités situées sur

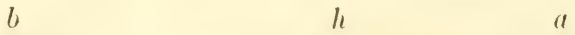

1

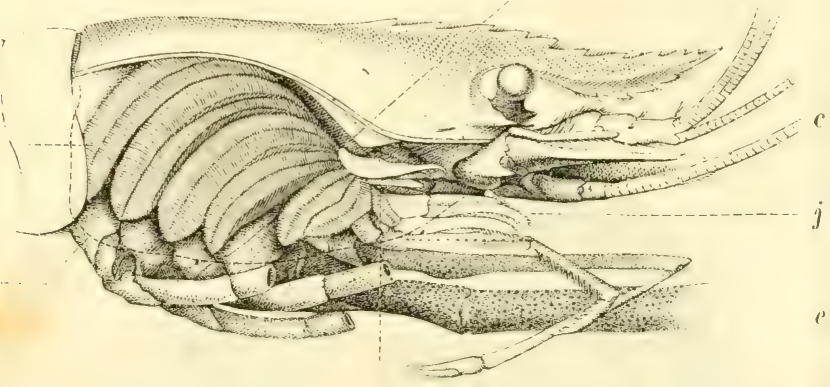

Fig. 410. Appareil respiratoire d'un Palémon (1).

les còtés du thorax et comprises entre la carapace et la voùte dont nous venons de parler, disposition qui ne se retrouve dans aucun autre animal de cette classe. La cavité respiratoire communique au dehors par deux ouvertures : l'une, servant à l'entrée de l'eau, est presque toujours située entre la base des pattes et le bord de la carapace $(r, f i g .407)$; l'autre, destinée à la sortie de ce liquide, est placée sur les còtés de la bouche. Enfin le renouvellement de l'eau à la surface des branchies est déterminé par les mouvements d'une grande valvule située près de cette dernière ouverture et formée par un appendice lamelleux des màchoires de la seconde

(1) $a$ rostre ; $-l$ carapace ; $-c$ base des antennes; $-d$ base de l'abdomen ; $\rho$ base des pattes; $-f$ branchies; $-g$ ligne ponctuée indiquant le bord inférieur de la portion de la carapace qui recouvre les branchies et qui a été enlevée dans cette préparation; $-h$ canal efférent de la respiration; $-i$ valvule ; $-j$ extrémité du canal efférent. 
paire (c, fig. 121, et $i, 410)$. Chez d'autres crustacés, less suilles, par exemple (fig. \$11), les branchies ont la forme de panaches, et, au lieu d'ètre renfermées dans le thorax, flottent librement a l'extérieur, et sont fixées aux membres abdominaux; chez d'autres encore, tels. que les crevettes des ruisseaux et les talitres, ce sont des vésicules membraneuses fixées à la base des palles, sous le thorax, (qui tiennent lieu de branchies; enfin, chez les crustacés isopodes, la respiration s'effectue à l'aide des fausses pattes abdominales qui sont devenues foliacées et membraneuses.

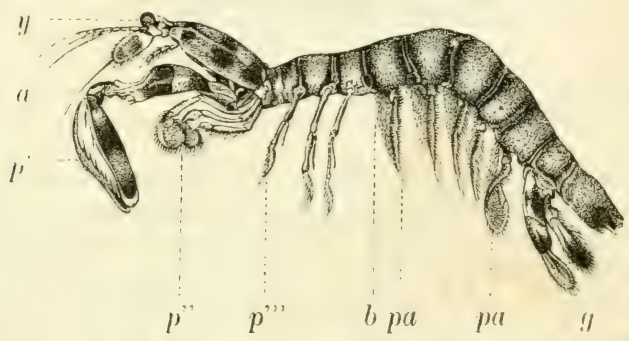

Fiy. 411. Squille (?)

$\$$ 37. Il existe un trés-petit nombre de ces animaux qui vivent a lair; mais ils font exception à ce que nous arons dit relativement aux différences de structure de l'appareil respiratoire chez les animaux aquatiques et terrestres, car, au lien d'ètre pourvus de poumons ou de trachées, ils respirent par des branchies, comme les premiers; seulement ces organes sont disposés de manière a si maintenir dans un état d'humidité nécessaire à l'exercice de leurs fonctions. Les gécarcins ou crabes de terre ( $f \mathrm{~g}$. 412) qu'on rencontre dans diverses régions du grobe, mais qui abondent surlout aux Antilles, ou on les connait sous le nom de fourlomroux, nous offrent un exemple remar(puable de ceile anomalie. Iu lieu de vivre dans l'eau, comme les crustacés ordinaires, ils sont terrestres, et, quoiqu'ils soient pourvus de branchies, quelques-uns d'entre eux s'asphysient promptement par la submersion. Leur respiration est en effet trop actwe pour que la petite quantité d’oxróne dissoute dans l'eau puisse suffire à leurs hesoms, tandis que dans l aur

(1) y yeux ; - $a$ antennes ; $-p$ ' pattes de la première paire; $-p$ " pattes des trois paires suivantes : - $\psi^{\prime \prime \prime}$ pattes thoraciques de's trois dernieres paires: pe fausses pattes abdominales; $-b$ branchies; $-g$ nageoire catrdale. 
ils troment ce watz an abondance: et une disposition analogue a celle que nous avons déja rencontrée chez quelques poissons fig. 300 leur permet de rester hors de l'eau sans que leurs bran-

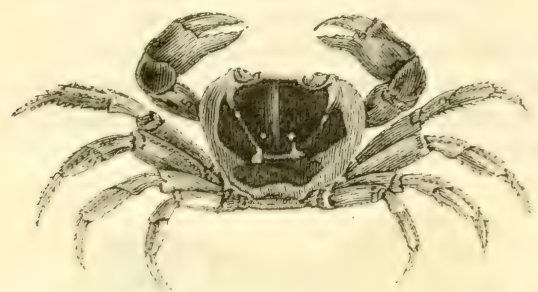

Fig. 4l2. Gecarcin ou Crabe de terre.

"hices desiechent au point de devenir impropres a remplir leurs fonctions : tantot il existe au fond de la cavité respiratoire une espèce d angere destinée a servir de réservoir pour l'eau nécessaire au maintien do lhumidité antour des branchies: d'antres fois on trouve a lat voùte de cette cavité une membrane spongreuse qui parait servir aux memes lisages. La plupart de ces crabes de terre se tiennent d'ordinaire dans les bois humides, et s'y cachent dans des trons qu’ils creusent dans le sol; mais les localités qu’ils préfèrent varient suivant les e-peces : les unes vivent dans les terrains bas et marecageux qui avoisinent la mer; d'autres se tiennent sur les rollines boisces lom du littoral, et a certaines époques ces dernières 'puittent leur demeure habituelle pour gagner la mer.

Les cloportes (fy. 401) sont aussi des crustacés terrestres dont la respiration aérienre s'effectue a l'aide de lames foliacées qui sont situées sous l'abdomen, et qui, chez d'autres animaux conformes a peu pres de la meme maniere, romplissent les fonctions de branchies.

$\$ 372$. Les crustacés sont tous ovipares : la femelle se distingue en crinéral du male par la forme plus élargie de son abdomen, et, apres avoir pondu ses orufs, elle les porte pendant un certain temps suspendus sous cette partie du corps ou mème renfermés dans une espece de poche forméc par des appendices appartenant aux pattes; quelquefois les petits naissent dans cette poche et y restent jusqua ce quils airnt subi leur premiere mue. En général les jeunes n'éprouvent pas de véritables métamorphoses; quelquefois cependant ils arefuierent par les progres de làge un plus grand nombre de patteri, et il en est pui changent completement de forme pendant 
les premiers temps de la vie: les lernées nous ont déja offert un exemple de ces transformations voy. fiy. 130).

$\$ 374$. La classe des crustacés peut se diviser en trois groupes principaux ou sous-classes, caractérisés par la conformation de la bouche, savoir :

10 Les Conesticés misticiteurs, dont la bouche est armée de machoires et de mandibules propres a la mastication;

20 Les Crostacés sccecrs, dont la bouche est composéc d'un bee tubulaire armé de suçoirs;

$3^{0}$ Les Crostacés mprostres, dont la bouche ne présente pas dappentices qui lui appartiennent en propre, mais est entourécéce pattes dont la base fait office de mâchoires.

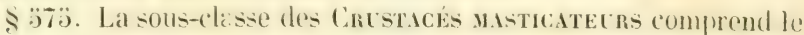
plus grand nombre de ces animaux, et se compose de tous ceus dont loromisation est la plus compliquee et la plus parfate. Elle se subdivise en plusieurs ordres, dont les plus importants sont les décapodes, les stomapodes, les amphipodes, les isopodes, les branchiopodes et les entomostracés,

$\$ 376$. Lordre des Décapones comprend les crabes, les écrevisses et tous les autres crustacés dont les branchies sont intérieures et dont les pattes sont au nombre de ciny paires. La tide et le thoras de ces animaux sont confondus en une sente matson fue rexemre mene wrande carapace (fiy. Alis) : re bouclier dorsal savance en crínéal

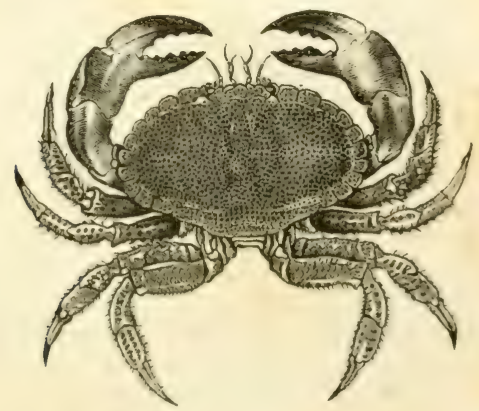

Fïg. 11:3. Cirabe-Tonertenu.

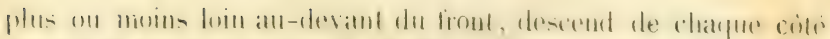

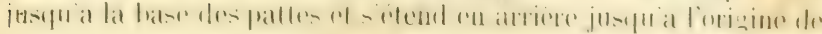


l'abdomen $(f i g .400,403)$. Il en résulte qu'en dessus on ne peut distinguer dans toute cette partie du corps aucune trace de division annulaire; mais en dessous la plupart des arneaux, quoique soudés entre eux, sont encore reconnaissables et laissent dars leurs points de jonction des lignes de sutures plus ou moins distinctes. Les yeux sont toujours portés à l'extrémité d'une paire d'appendices mobiles qui naissent du premier segment de la tète; quelquefois la lungueur de leur pédoncule est très-consilérable (fig. 406), et, en général, ils peuvent se reployer dans les cavités qui remplissent les fonctions d'orbites et qui sont formées par le bord antérieur de la carapace. Les or zanes de la locomotion sont également très-développés chez ces crustacés; plusieurs courent arec une rapidité extrème, et d'autres nagent avec encore plus de vitesse. Leurs pattes, comme nous l'avons déjà dit, sont an nombre de cinc paires et sont fixées aux cing derniers anneaux du thorax; mais, en rénéral, celles des quatre dernières paires seules servent a la locomotion, et celles de la première paire, terminées par une pince plus ou moins parfaite, deviennent des organes de préhension (fiy. 413). Chez les décapodes les mieux conformés pour la nage (tels que les écrevisses, les homards, les langoustes et les palémons), le corps est.allongé et l'abdomen se termine par une large nageoire transwersale (fig. 400); tandis que chez cenx qui sont conformés pour courir, les crabes, par exemple, l'abdomen est très-court, ne présente pas de nageoire terminale, et se recourbe sous le thorax.

$\$ 577$. Les Stompodes ont également les yeux portés sur des pédoncules mobiles, le thorax recouvert en tolalité ou en partie par une carapace, et les pattes cylindriques; mais leurs branchies ne sont pas renfermées dans des cavités du thorax, et flottent sous l'abdomen ou manquent complétement. La squille (fig. 4.11), dont nous avons déjà parlé, appartient à cet ordre.

$\$ 378$. Les Aupurpodes n'ont pas les yeux pédonculés et manquent de carapace: leurs pattes, disposées à peu près comme dans les ordres précédents, sont au nombre de sept paires; leur abdomen est très-développé, et leur respiration s'effectue a l'aide de vésicules membraneuses suspendues à la base des pattes. Les (revettes des ruisseaux ef ies talitres (fig. 144) nous offrent ces caractères.

$\$$ :79. Les Isopones ressemblent aux amphipodes par la conformation des yeus et des pattes, mais respirent au moyen d'appendices foliacés cachés sous l'abdomen. Les cloportes, les sphéromes, les

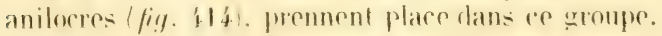




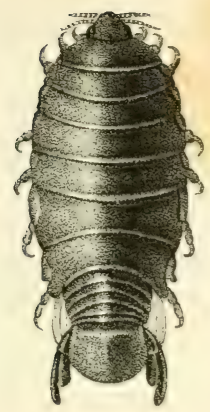

Fig. 414. Anilocre.

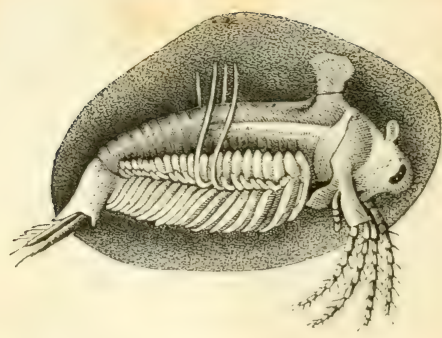

Fig. 4l:. Limnadie (1).

$\$$ 380. Les Braxcmopodes sont de petits crustacés dont les pattes ne peurent plus servir à la marche, mais affectent la forme de lames foliacées, et constituent en mème temps des organes de natation et de respiration. Tels sont : les limnarlies, dont il a déjà été question (fig. 41:3); les apus, les branchippes, les daphnies, etc.

$\$ 581$. Les Extomostr.icés sont aussi conformés pour la nage seulement; mais leurs pattes rigides et biramées ne semblent pas ètre propres à tenir lieu de branchies, et c'est par la surface générale du corps que la respiration parait s'effectuer. Les cyclops (fig. 416) font partie de ce groupe.

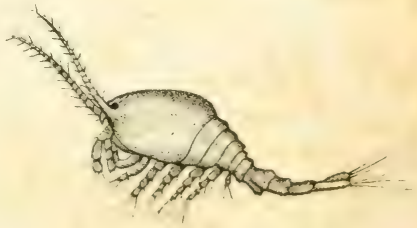

Fig. 416 Cyclops.

\$ 382 . Les Crustucés stcecns vivent en parasites sur daulres: animaus, et ont la bouche en forme de bee ou de trompe cylindrique renfermant des appendices styliformes propres à percer les téguments des animaux dont ils sucent les humenrs. La structure de ces amimaux varie beancoup, et la plupart éprouvent dams le jeune àge des métamorphoses considérables : quelques-uns peuvent toujours marcher ou nager; mais d'autres, apress setre fixes sur leur proie, prennent un accroissement monstrueux qui les prive de la faculté de se mouroir; leurs membres deviennent rudimentaires, tandis que leur corps crossit beaucoup et prend souvent les formes les plus bizarres. Ils vivent en général sur des poissons.

(1) L'une des valves de la carapace a été enlevée. 
I hans la classification naturelle des crustacés, les suceurs doivent ilre répartis en tross ordres distincts; mais ces petits ères

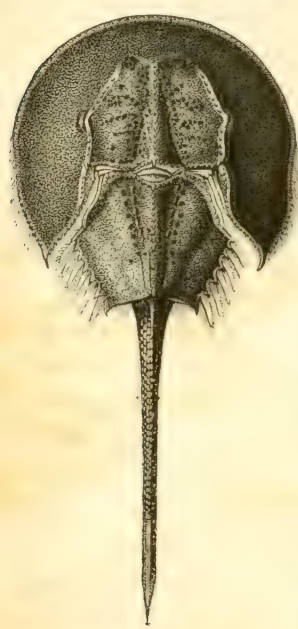

Fig. 417. Limule. n'offrent pas assez d'intérèt pour que nous nous y arrêtions davantage, et nous nous bornerons à ajouter que la plupart de ceux qui vivent immobiles et sont dépourvus d'organes locomoteurs rentrent dans la division des Lernées ( fig. 130); tandis que le groupe principal, formé par les suceurs pourvus de pattes natatoires, est celui des Caligues.

$\$ 583$. La division des Crustacés $\mathbf{X Y -}$ phosures ne se compose que d'un seul genre, celui des Linumes ( $\mathrm{fig}$. 417 ), dont la structure est des plus anomales. Ce sont de grands crustacés dont le corps est divisé en deux parties : la première, recouverte par un grand bouclier demi-circulaire, porte les yeux, les antennes et six paires de pieds qui entourent la bouche et qui servent en mème temps à la marche et a la mastication (roy. fig. 119 , page 271 ): la seconde portion du corps, recourerte par un autre bouclier presque trianqulaire, porte en dessous cinq paires de pattes natatoires, dont la paire postérieure est grarnie de branchies; et elle se termine par une longue quene styliforme. Ces singuliers amimanx habitent l'océan Indien et les còtes d'Amérique : on les connait sous le nom vulgaire de crabes des Moluques.

\section{CLASSE DES CIRRIIPIDES.}

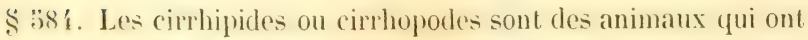
en mème tenips de grands rapports avec les mollusques et arec les crustacés, mais qui se rapprochent davantage de ces derniers, ot qui appartiennent a l'embranchement des animaux articulés. bans les premiers temps de lat vie, ces petils c̀tres, qui sont tous marins, nagent librement, et ressemblent extremement a certains crustacés inférieurs, tels que les jeunes ryclops (fig. 133) ; mais bientòt apres ils se fixent pour toujours sur queique corps sousmarin, et changent complétement de forme. C'és par le dos quils 
adherent ainsi, et leur corps, plus ou moins piriforme ot recourbé sur lui-mème, est renfermé en totalití ou en majeure partie dans une espèce de coquille composie de plusieurs pieces (fig. 418). Ils n'ont point d'yeux, et leur bouche est garnie de mandibules et de mâchoires ayant la plus srande ressemblance avec celle de certains crustacés; la face ab) lominale de leur corps est occup pe par deux rangées de lobes charnus portaut chacun de lonğs appendices cornés zrarnis de cils et composés d'um grand nombre d'articles (fig. 119). Ces esperes de bras on cirrhes, dont te nombre est de douze paires, sont recourbés sur eux-mèmes. et l'animal les fait constamment sortir et rentrer par l'ourerture de sa waine. A l'extrémité de cette série d'or ranes se trouve une espere de queue ayant la forme d'un long tentacule charnu, a la base de laquelle se troure lanus. Leur srsteme nerveux se compose diune double chaine de ganglions disposés exactement comme chez les autres animaux articulés. Ils ont un coeur lozé dans la partie dorsale de leur corps. et ils respirent par des branchies dont la forme varie.

Les cirrhipides se divisent en deus familles: les anatifes of les balanes.

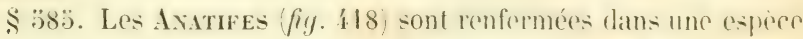
de manteau comprimé, ouvert d'un còté et suspendu à un long pédoncule charnu t tantôt ce manteau est presque entièrement cartilagineux; d'autres fois il est recouvert par cing lames testacées, dont les deux principales ressemblent assez à celles d'une moule. L'anatife commune habite dans nos mers et se trouve fréquemment attachée aux rochers, à la quille des navires ou à des morceaux de bois flottants. Elle a été le sujet des fables les plus absurdes : quelque ressemblance grossic̀re de sa co puille avec un oiseau a fait dire qu'elle donnait naissance à l'espèce d'oie qu'on nomme bernache.

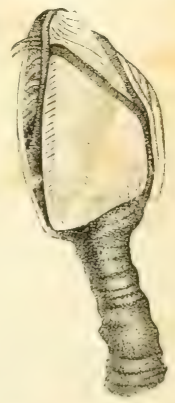

Fig 418. Analife.

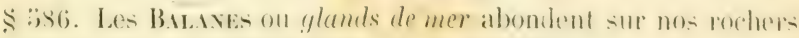
et sont contenus en entier dans une espece de coquille ordinairement conique et très-courte. qui est fixée par la base et qui se compose de plusieurs pans articulés entre eux : l'ouverture de ce tube est occupée par deux on quatre valves mobiles, entre lesquelles se trouve une fente destinée a liverer passage aux cirrhes.

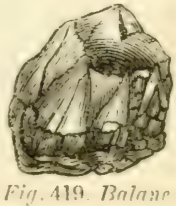

i i. 
SECONDE SERIE

\section{DES ANIMAUX ANMELÉS.}

\section{ES VERS.}

$\$ 587$. Chez ces animaux, la division annulaire du corps devient de moins en moins marquée; il n'existe point de membres articulés pour la locomotion; le systeme nerveux perd de son importance, et l'organisation générale se simplifie de plus en plus à mesure que l'on descend de ceux qui ressemblent le plus aux animaux articulés proprement dits à ceux qui se rapprochent davantage des zoophytes. lls sont, en général, remarquables par l'allongement considérable

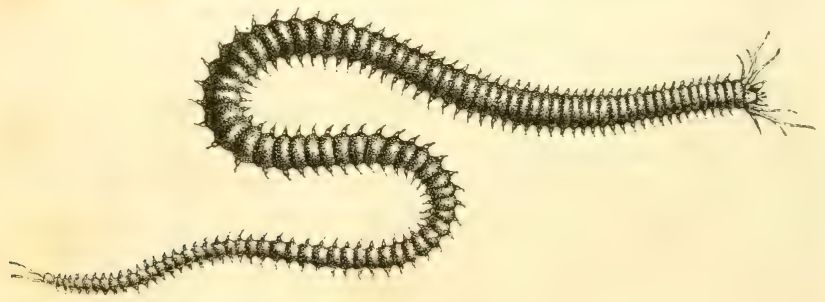

Fig. 420. Néréide.

de leur corps, et ils forment, comme nous l'avons déjà dit, trois classes; savoir: les annélides, les infusoires rotateurs ou systolides, et les helminthes ou vers intestinaux.

\section{CLASSE DES ANNELIDES.}

$\$ 588$. La classe des annélides se compose de vers qui sont pourvus d'un systeme nerveux multiganglionaire et d'un appareil vasculaire pour la circulation.

Le corps des annélides est toujours très-allongé, mou, et divisé par des repris circulaires en un grand nombre d'anneaux; tantòt ils 
ont une tète distincte: d'autres fois ils en manquent, et, d'ordinaire, on leur voit, de chaque côté du corps, une longue série de faisceaux de soies portés sur des tubercules charnus et tenant lieu de pieds $(f i g .420)$. Souvent il existe deux de ces organes placés l'un au-dessus de l'autre, de chaque còté des divers anneaux du corps ( $f g .316)$; d'autres fois ces deux tubercules sétifères sont réunis, et presque toujours il existe à la base de chacun un long appendice mou et cylindrique, nommé cirrhe (c, fig. 421); quelquefois la place

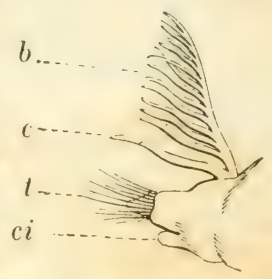

Fig. 421 (1). des pieds est indiquée seulement par quelques poils roides, et d'autres fois il n'existe sur tout le corps aucune trace de membres. Ces soies servent aux annélides pour ramper et leur fournissent aussi des armes pour leur défense; car, en général, elles sont très-acérées et conformées de manière à s'implanter avec force dans les corps mous contre lesquels elles frappent. Chez les annélides dépourvus de soies, tels que les sangsues (fig. 150), il existe aux extrémités du corps des ventouses qui sont également des instruments de locomotion.

$\$$ 589. Le système nerveux de ces animaux est peu développé. et consiste dans une chaine simple ou double de très-petits ganglions étendus d'un bout du corps à l'autre. La plupart sont pourvus d'un certain nombre de petites taches qui paraissent ètre des yeux, et d'ordinaire leur tète est garnie de plusieurs filaments analogues aux cirrhes des pieds, et appelés antennes et cirrhes tentaculaires $(f y .423)$, qui paraissent ètre des organes de tact. La bouche occupe la face inférieure de la tète, ou l'extrémité antérieure du corps lorsutulil n'y a pas de tète distincte; elle est souvent armée d'une trompe protractile (fig. 42.2) et de màchoires ayant la forme de crochets cornés. L'intestin est droit, tantòt simple. lantòt garni d'un nombre plus ou moins considérable de coecums situés de chaque còté. Enfin, l'anus occupe l'exúcémité postérieure du corps.

Le sangr est presque toujours rouge; quelquefois cependant il est vert, et d'autres fois encore à peine coloré. Ce liquide circule dans un systeme trè-compliqué de vaisseaux, dont les uns sont contractiles et tiennent lieu de cour, et d'autres remplissent les fonc-

(I) Patte d'un amnélide du genre cunice: $-t$ tubercule setifere; $-i$ cirrle dorsal; - ci cirrhe inféricur ou ventral ; -4 branchie. 
tions d'arteres et de reines. Du reste, la disposition de cet appareil circulatoire varie d'un annélide à un autre.

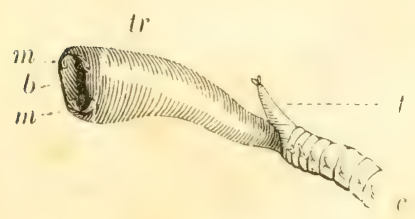

Fig. 422. Têle el trompe de Glycère (1).

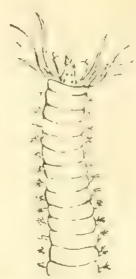

F'g. 4:3. Têle, etc., d'une Néréirle.

La respiration de ces animaux est quelyuefois aérienne, mais en général aquatique, et, dans ce dernier eas, elle s'opère ordinairement au moyen de branchies extérieures, dont la forme et la disposition varient beaucoup : lantòt ces or:anes ressemblent a des feuil-

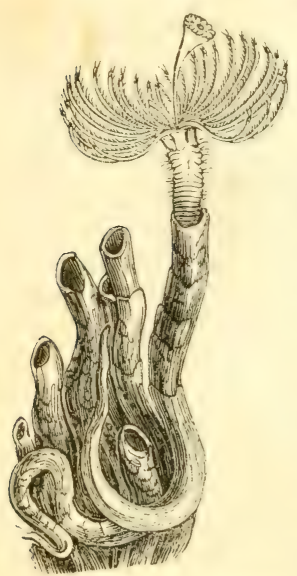

Fig. 424. Groupe de sirpules. les ou à des arbuscules, et sont fixés audessus des pattes, de chaque còté du dos. comme chez l'arénicole (fig. 46); tantòt ils ont l'aspect de panaches et sont réunis cn couronne autour de l'extrémité antérieure du corps, disposition dont les serpules (fig.424) nous offrent un exemple.

$\$ 590$. La plupart des annélides habitent dans la mer, et plusieurs de ces animaux s'y construisent pour demeure un long tube, formé tantòt de matières calcaires sécrétées par la peau de l'animal (fig. 124), tantôt de sable ou de fraggments de coquilles agglutinés par une substance gélatincuse ; plusieurs s'enfouissent profondément dans le sable, l'arénicole, par exemple ( $\mathrm{fg} .46$ ); d'autres se cachent sous les pierres. Il est aussi des annélides marquer par les ventouses dont les deux extrémités de leur corps sont garnies, vivent dans les ruisseaux; et il en est de mème des naï, qui ressemblent davantage aux vers de terre; enfin, ces derniers, que les zoologistes désignent sous le nom de lombries, sont des animaux terrestres.

(1) $c$ portion antérieure du corps; -1 tête: $-\ell r$ trompe; $-U$ ouverture buccale; $-m$ mâchoires. 


\section{CLASSE DES INFUSOIRES ROTATLERS OU STSTOIIDES.}

$\$ 591$. Ces ètres, que l'on confond souvent, mais à tort, avec Ies animalcules infusoires proprement dits, sont d'une petitesse telle, quavant la découverte du mieroscope leur existence n'était mème pas soupconnée ; et néanmoins leur structure paraît ètre presque aussi compliquée que celle des annélides. Tant que les instruments à l'aide desquels on les observait ne les faisaient paraître qu'une centaine de fois plus gros qu'ils ne le sont réellement, on n'a pu apercevoir dans leur inlérieur aucun organe distinct, et pendant fort long-temps on les a cités comnie des exemples d'ètres composés seulement d'une sorte de gelée animée et se nourrissant par imbibition. Mais les recherches de quelques naturalistes modernes, et surtout d'un professeur de Berlin, M. Ehrenber⿳亠口冋. ont fait voir combien on s'était trompé à l'égard de ces animalcules; et anjourd 'hui ce n'est pas leur simplicité de structure qui nous étonne, nais

$a$

(1)

b

$b$

$c$

f

!

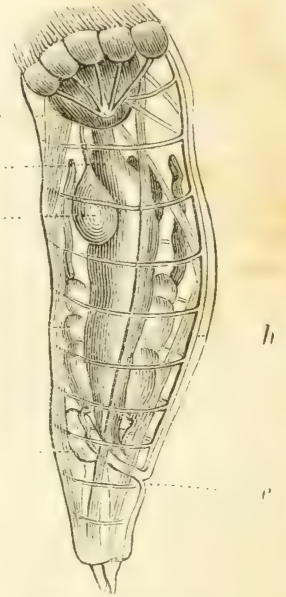

Fig. 425. Hydalime 11'. bien la complication de leur organisation toute microscopique.

Ces animalcules se reneontrent dans les eaux stagnantes. Leur corps est semi-transparent et présente des traces assez distinctes de divisions annulaires. La bouche en oceupe l'extrémité antérieure. et, de chaque coté ou mime tout autour de cet orifice, so roient, en général, des cils vibratiles, dont les momvements rotateurs sont tres-remarquables. Presque toujours l'arriere-bouche est garnie de muscles puissants at armés de màchoires laterales. Ice canal digestif est droit : il s'étend d'un bout du corps à l'autre el présente d'ordinaire, vers le milieu, un renflement qui constitue l'estomac de ces

(11) Inatomic de lhydatine, animalcule microscopique, voisin du rotifire : " cils vibratile's; $-b$ masse charnue qui entoure la bouche et met en mouvement les mâchoires ; $-c$ estomac ; $-d$ cloaque ; $-c$ anus ; $-f$ glandes salivaires ; $g$ ovaires; $-h$ inuscles. 
petils ètres; souvent on voit, de chaque còté de ce tube, des corps d'apparence grlandulaire, et, à son extrémité postérieure, une sorte de cloaque dans lequel viennent déboucher les oviductes. On a découvert aussi dans ces animalcules un grand nombre de muscles. et mème un système nerveux ganglionaire.

$\$ 592$. Les Rotifìres ( $/ \mathrm{g} g .132$ ), dont une espèce est devenue célèbre par les expériences de Spallanzani sur la suspension de la vie qu'entraine le desséchement, peuvent ètre pris pour type de cette classe. Leur corps est allongré et se termine antérieurement par deux petites couronnes de cils qui, au gré de l'animal, rentrent. dans l'intérieur ou se déploient en dehors, et qui, par leurs vibrations, produisent l'image de deux petites roues tournant avec rapidité sur leur axe. Une queue bifurquée et articulée les termine en arrière et leur sert pour se fixer aux corjs sur lesquels, ils veulent reposer; enfin, on leur remarque encore deux petits points rotiges qui paraissent ètre des yeux. Ces animaleules nagent avec une vivacité extrème et pondent des oufs oralaires.

$\$ 593$. D'autres animalcules, auxquels on a donné le nom de Bracuoxs, ressemblent aux rotifères par le mode général de leur organisation, mais méritent dètre signalés à raison de l'espèce de carapace dont leur corps est recouvert. Chez plusieurs de ces petits ètres, le test est mème bivalve et rappelle tout à fait celui de certains crustacés, tels que les cypris et les daphnies.

$\$ 594$. Eufin, on doit rapprocher aussi de ces infusoires rotateurs les tardigrades, qui sont dépourvus de cils vibratiles autour de la bouche, et qui ont un système nerveux très-semblable à celui des animaux articulés. Il est à noter qu'ils possèdent aussi, comme les rotiferes, la faculté de revenir à la vie après avoir été desséchés ot morts en apparence pendant un temps très-considérable.

\section{CLASSE DES HELMINTHES.}

$\$ 59:$. Cette division comprend les vers intestinaux et les autres animaux inférieurs d'une organisation analogue. Quelques naturalistes, à l'exemple de Cuvier, les rangent dans l'embranchement des animaux rayonnés ou zoophytes; mais ils n'offrent rien de radiaire dans leur structure et se lient de la manière la plus naturelle aux annélides. La plupart de ces ètres singuliers ne peuvent vivre que dans l'intérieur d'autres animaux, et se logent dans la substance du foie, dans les yeux, dans le tissu cellulaire, dans les muscles, 
et mème dans le cerveau, aussi bien que dans le canal digestif. On sait qu'ils se multiplient au moyen d'cufs, ou mème qu'ils donnent quelquefois naissance à des petits vivants; mais on ne comprend pas bien comment ils peuvent se transmettre d'un animal à un autre, ni comment ils peuvent pénétrer dans la profondeur des organes dans l'intérieur desquels ils se développent. Presque tous ont une grande analogie avec les lombrics terrestres ou avec les sangsues; mais ils se distinguent des annélides par l'absence d'une chaine de ganglions nerveux; leur sang n'est pas rouge, et ils n'ont pas de membres sétifères comme la plupart des premiers. En général, leur corps est très-allongé et cylindrique ou déprimé, et présente des traces plus ou moins distinctes de divisions annulaires (fig. 1:33); on ne leur roit rien qui ressemble aux conronnes de cils vibratiles dont sont pourvus les animalcules que nous venons de décrire; mais leur bouche est souvent garnie de crochets ou conformée en manière de ventouse. Plusieurs présentent des vaisseamx bien distincts, et chez quelques-uns on trouve des vestiges d'un systeme nerveux; mais il n'en est pas qui paraissent pourvus d'organes spéciaux pour la respiration.

Nous citerons comme exemples de ce groupe les linguatules, les ascarides, les strongles, les douves et les tænias.

$\$ 596$. Les linguatules (fig. 1333 ) ont le corps déprimé, atténué postérieurement et fortement annelé; leur bouche est armée de crochets, leur canal alimentaire étendu d'un bout du corps à l'autre; ils ont un système nerveux composé d'un seul ganglion et de deux longs cordons; enfin on leur trouve encore d'autres organes d'une structure compliquée. On les rencontre souvent dans les sinus frontaux du cheval et du chien.

$\$ 597$. Les ascarides et les strongles ont le corps cylindrique et atténué aux deux bouts; on ne leur voit pas de divisions annulaires, mais leur structure intérieure ne differe que peu de celle des vers dont nous venons de parler.

Les douves se rapprochent davantage des sangsues: leur corps est aplati et garni de ventouses, a l'aide descyuelles clles se fixent pour sucer; leur canal dignestif se ramifie plus ou moins, et leur organisation, en général, offre moins de complication que chez les annélides. Du reste, elles ont une crande analogie de structure avee d'autres vers qü habitent les caus douces ou salées, et qui sont désignés par les naturalistes sous lo nom de planaires.

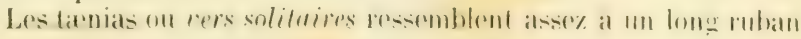


plissé en travers; ils ont le corps aplati, très-allongé et divisé en un grand nombre d'articles qui renferment chacun un ovaire, et présent in ou deux pores; le canal intestinal parait ètre remplacé par deux vaisseaux longitudinaux qui communiquent au dehors par ces orifices latéraux, et la tète ne présente pas de bouche bien distincte.

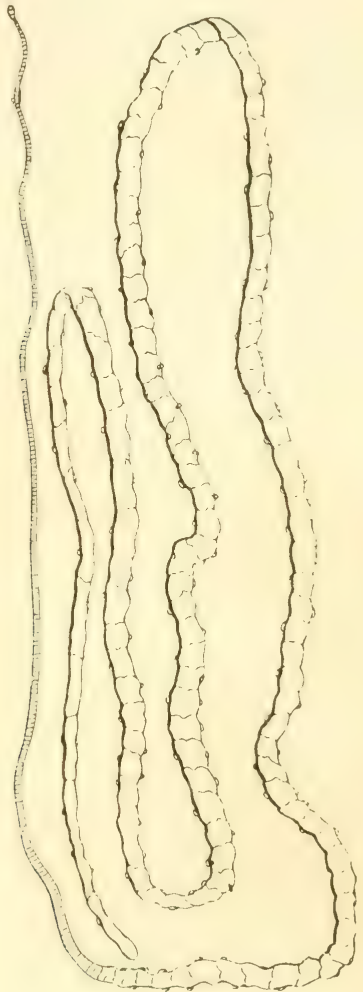

Fig 426. Treniu. 


\section{EMBRANCHEMENT DES MOLLUSQUES}

OU MALA COZOA I RES.

$\$$ :398. L'embranchement des mollusques se compose, romme nous l'arons déjà dit, d’un nombre considérable d'animaux dépotrrus d'un systeme cérébro-spinal et d'un squelette intérieur, comme les animaux articulés, mais nayant pas, comme ceux-ci, le corps divisé en anneaus, ni les samglions réunis en une longrue chaine mediane à la face ventrale du corps. Its se distinguent allssi des zoophytes par la disposition paire de leurs oryanes de relation, et ont en grénéral la bouche et l'anus plus ou moins rapprochés l'un de lautre. Du reste, ils diflerent beaucoup entre eus, et se divisent en deux series principales, savoir : les mollusques proprement dits. et les molluscoïdes ou tuniciens.

\section{SOUS-EMBRANCHEMENI}

\section{DES IMOLLUSQUES}

PROPREMENT DITS.

\$:99. Dans ce grompe, le systeme nerveux se compose tonjours de plusieurs granglions réunis par des cordons médullaires, de facon a former une sorte de collier plus ou moins serré autour de l'osephage, mais à ne pas se prolonger postéreurement en maniere dre chaine sous-intestinale, comme chez les animaux annelés.

La forme grénérale de ces mollusques est exlrèmement variable. Leur corpls est toujours mou, ct ce n'est meme que chez un trespetit nombre d'entre enx la sciche, par exemple) quil existe a l’intérieur quelfues pièces solides non articulées el servant à protéger les visceres plutòt qua fournir à l'appareil locomoteur des levirers et des points diapmi. Les muscles se tixent directement aux téruments, et nagrisent gruere que sur le point meme ou ils sinserent; aussi les monsements ne sont-ils que lents et en gréneral mal détermines. Chez un petit nombre de ces ètres (les poulpes, efe.). il existe des appendiees flexibles et allongés destines a la locomotion fig. 1:39, jage $30: 3)$ : mais, dans la plupart descrals. l'animal ne peut se déplatere que par les contractions suceessises des divers points de ha surface inférieure de son eorps, ef lors meme qu il existe des membres, res orgämes sont rémis on groupe

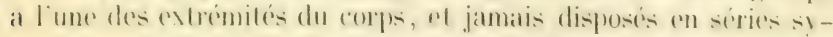

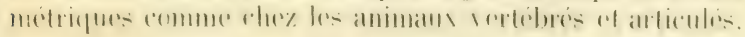


La peau des mollusques, toujours molle et visqueuse, forme souvent des replis qui enveloppent plus ou moins complétement le corps, et cette disposition a fait donner le nom de manteau à la portion de tégument qui fournit d'ordinaire ces expansions. Souvent ce manteau est presque entierement libre, ct constitue deux grandes voiles qui cachent tout le reste de l'animal, ou bien ces deux lames se réunissent de manière à former un tube ; mais d'autres fois il ne consiste qu'en une espèce de disque dorsal dont les bords seuls sont libres ou entourent plus exactement le corps sous la forme d'un sac.

$\$ 600$. En général, cette peau molle est protégée par une espèce de cuirasse pierreuse nommée coquille. Ciest une sécrétion ayant quelque analogie avec celle de l'epiderme qui produit celte enveloppe. Les follicules, loxés d'ordinaire dans les bords du manteau, déposent a sa surface une matière semi-cornée mèlée à une proportion plus ou moins forle de carbonate calcaire qui se moule sur les parties sous-jarentes, et se solidifie. La lame ainsi formée s'épaissit et s’accroit par le dépòt successif de matieres nouvelles. Sa superficie n'est pas pierreuse, mais ressemble à une espèce d'épiderme, et porte le nom de drap marin. Quelquefois elle conserve une consistance cornée dans toute son épaisseur; en général cependant la proportion de carbonate de chaux qu'elle renferme augmente rapidement et lui donne une dureté pierreuse. Souvent sa surface interne est mème plus dense que le reste, et présente une structure particuliere qui la rend vitreuse ou chatoyante et nacrée. Quelquefois la coquille reste toujours renfermée dans l'épaisseur de la peau des mollusques; mais, en général, elle est extérieure, et dépasse mème les bords du manteau, de façon à fournir à l'animal un abri parfait. On donne communément le nom de mollusques nus à cerx qui sont dépourvus de coquilles ou qui n'ont qu'une coquille intérieure, et le nom de conchiféres à ceux dont la coquille est visible au dehors.

La manière dont la coquille s'accroit est facile à comprendre. Si on examine une coquille d huitre, par exemple, on voit qu'elle se compose d'une multitude de lames superposées dont on peut mème déterminer la séparation à l'aide de la chaleur. Ces lames ont été formées successivement par le manteau de l'animal, qu'elles recouvrent, et par conséquent c'est la plus extéricure qui doit ctre la plus ancienne; cest elle aussi qui est la plus petite, et chaque nourelle lame yui vient sy ajouter dépasse la lame située an-desius, de facen que da coguille, en meme temps quedle aug-

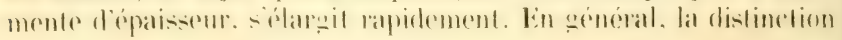


des lames composantes est moins marquée, et souvent les matieres nouvelles se déposent sur le bord de la coquille seulement et de manière à ce que leurs molécules correspondent exactement aux molécules de la partie déjà consolidée; ce qui donne au tout une structure fibreuse.

Les couleurs les plus variées et les plus agréablement disposées ornent les coquilles, et varient souverit avec l'âge. Presque toujours elles sont tout à fait superficielles et semblent dépendre d'une sorte de teinture opérée par la peau de l'animal, qui est peint d'une manière correspondante à celle de son enveloppe. La matière colorante parait ètre réposée sur la coquille au moment de sa formation; aussi est-elle d'autant plus vive que cette derniere est plus jeune. C'est le bord du manteau qui la produit. En effet, si une coquille vient à ètre cassée et que l'animal parvienne à réparer cet accident, la partie nouvellement formée est toujours blanche lorsqu'elle n'a pas été en contact avec le bord du manteau; et si elle correspond a ce bord, on la voit prendre la couleur que celui-ci présente dans le point qu'elle touche. Ainsi, lorsque ce bord est tachetí, il en résulte, sur le bord de la coquille, des taches correspondantes; et, à mesure que celui-ci s'allonge, ces taches se confondent avec celles précédemment formées, et produisent des lignes perpendiculaires aux stries d'accroissement, ou bien ne se joignent pas à celles-ci et restent isolées, suivant que le manteau demeure immobile et conserve avec le pourtour de la coquille les mèmes rapports, ou bien que par les mouvements de l'animal il change souvent de position. Quelquefois la sécrétion de la matière colorante varie aussi avec l'âge, et des circonstances accidentelles peuvent également la modifier. La lumière, par exemple, exerce sur ce phénomène une influence très-remarquable, et non-seulement les coquilles les plus exposées à l'action de cet agent physique sont d'ordinaire les plus vivement colorées; mais, lorsqu'un mollusque vit fixé sur un rocher ou en partie caché sous une éponge ou quelque autre corps opaque, la portion de la coquille ainsi placée dans l'obscurité est toujours plus pàle et plus terne que celle exposée au contact des rayons solaires.

$\$ 601$. L'appareil digestif de ces animaux est très-développé. Il existe toujours un foie volumineux, et souvent on trouve aussi des glandes salivaires et des orçanes de mastication; mais les intestins ne sont jamais retenus à l'aide d'un mésentère. Leur sang est incolore ou légèrement bleuâtre, ct circule dans un appareil vasculaire tréscompliqué, composé d'arteres et de veines. Un cour, formé d'un ventricule $(v)$ et d'une ou deux oreillettes $(o)$, se trouve sur le tra- 
jet du sang artériel, et envoie ce liquide dans toutes les parties du corps, d'où il revient à l'organe de la respiration. Quelquefois on rencontre aussi, à la base des vaisseaux qui pénètrent dans ce dernier appareil, des réservoirs veineus nommés cœurs pulmonaires.

Quant à la dispositıon des organes de la respiration, elle varie trop pour que nous puissions en parler ici. Nous dirons seulement que tantòt ils ont la forme de poumons, d'autres fois celle de branchies.

$\$ 602$. Nous ne pouvons dire non plus rien de général sur la structure des organes des sens, qui, du reste, sont toujours moins complets que chez les animaux vertébrés. Certains mollusques ne paraissent loués que du sens du toucher et du sens dı gout; mais chez un grand nombre on trouve des yeux, dont la structure varie, et, chez quelques-uns de ces animaxi, il existe mème un appareil de l'ouie; mais on n'en connait pas qui soit pourvu d'un organe particulier pour l'odorat.

Les mollusques naissent d'œufs et ne se multiplient jamais par bourceons, comme cela a lieu pour la plupart des molluscö̈des; mais lantòt ces $\alpha$ ufs éclosent au dehors, tantòt dans l'intérieur du corps de leur mère, et alors les petits naissent vivants. Dams tous les cas, ces animaux viennent au jour ayant déjà à peu prè la forme qu'ils doivent conserver, et n'éprourent pas de métamurphoses.

$\$ 603$. Le sous-embranchement des mollusques proprement dits se compose, comme uous l'avons déjà vu, de quatre groupes principaux ou classes, auxquelles on a donné les noms de céphalopodes, de gastéropodes, de ptéropudes et d'acéphales. Nous allons en faire connaitre les caractères les plus saillants.

\section{CLASSE DES CÉPHALOPODES.}

$\$ 604$. Cette classe se compose de mollusques dont la forme est Ires-bizarre; car leur tète est placée entre le tronc et les pieds ou lentacules servant à la locomotion, et, lorsqu'ils marchent, c'est le rorps en haut et la tète en bas qu'ils se trainent sur le sol (fig. 19:3). En effet, c'est sur la tète, autour de la bouche, que s'insèrent leurs pieds, et c'est de lì que leur vient le nom de céphalopodes.

Le trone de ces animams est recourert par le manteau, qui a la forme d'un sac, tantòt presque sphérique, tantòt plus ou moins allongé, qui renferme tous les viscères et qui est ouvert en avant seulement (fig. 398, o). La lìte sort de cette ouverture : elle est. ronde et pourvue, en cénéral, de deux gros yeux (fig. 8) d'une 
structure très-analogue à celle des yeux des animaux vertélorís. La bouche en oceupe le milien; elle est armée de deux mâchoires. Enfin, autour de eette ouverture, se troure une couronne d'appendices flexibles et charnus (fig. 427). yui sont dósirnés indifféremment sous les noms de pieds ou de bras. ol qui méritent cralement bien ces dénominations, car ils servent en mème temps d'or zanes de préhension et de locomotion.

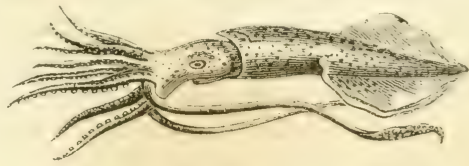

Fig. 4ㄴ.7. Calmar commun.

$\$ 60:$. Lescephalopodes sont des amimaux essentiellement aquatiques, et, par conséquent, e est à l'aide de branchies quils respirent. Ces organes se trouvent eachés dans le manteau, sous une eavite particuliere fig. 128), dont les parois se dibatent of se con-

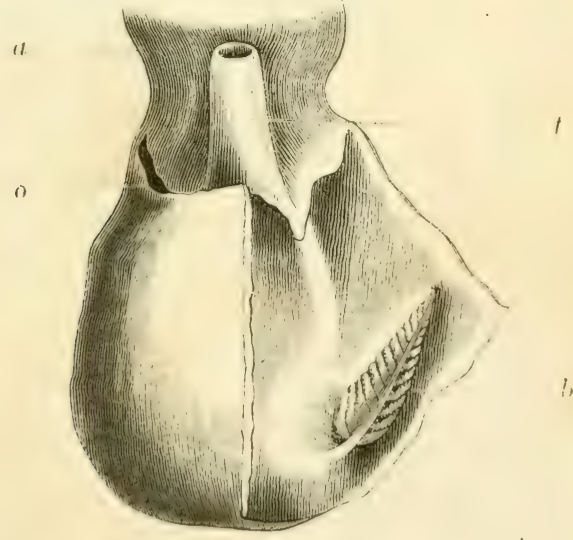

Fig. 4.8. Branclies du Poulpe (1).

(1) Corps d'un poulpe ru par la face inferieure le manteau est fen \}u sur la ligne. médiane, et, d'un cêté, rejeté en dehors pour montrer l'intérieur de la cavité respiratoire : - $a$ base de la tête : - $t$ le tube par lequel l'ean sort de la masité res-

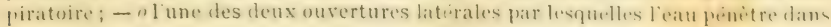
cette carité; - blune des branches. 
tractent alternativement, et dont l'intérieur communique avec lo dehors par deux ouvertures : l'une $(0)$, en facon de fente, servant à l'entrée de l'eau; l'autre, prolongée en tube ou entonnoir $(t)$, et servant à la sortie de l'eau et des excréments. Chaque branchie $(b)$ a la forme d'une pyramide allongée, et se compose d'un grand nombre de lamelles membraneuses, placées transversalement et fixées des deux còtés d'une tige médiane. Le nombre des branchies varie, et cette différence est caractéristique des deux grandes divisions naturelles dont cette classe se compose. Chez les poulpes, les seiches et les calmars, il n'en existe qu'une seule paire; mais chez les nautiles on en trouve deux paires.

$\$ 606$. Le cœur est situé entre les branchies, sur la ligne médiane du corps, et n'est formé que par un seul ventricule $(c, f i g .429)$; le

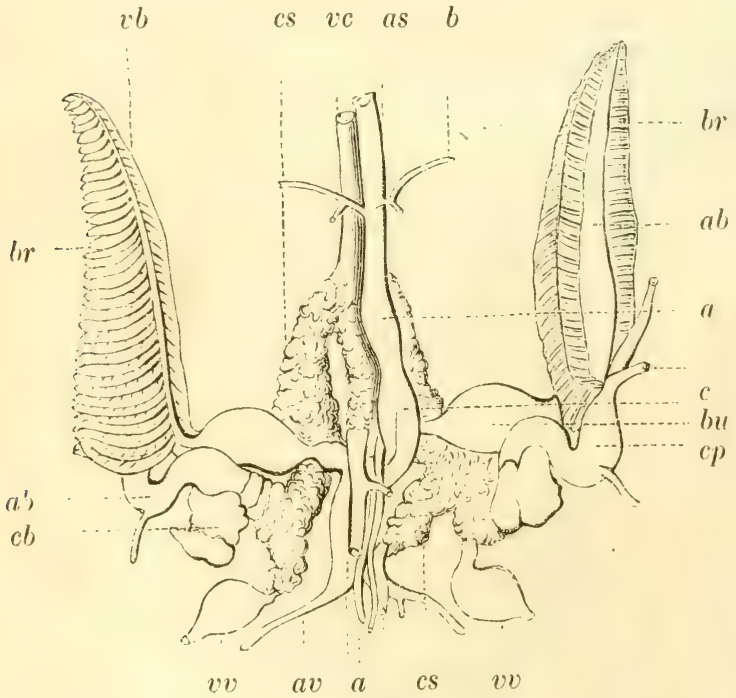

Fig. 429. Organes de la circulation el de la respiration (1).

11) $c$ le cour aortique, dont l'extrémité supérieure se continue avec l'aorte supérieure, qui distribue le sang à la tête, etc.; $-l$ des branches de ce vaisseau; - a l'aorte inférieure, qui présente un bulbe à son origine, et se divise bientôt en deux branches $\left(\tau v^{*}\right) ;-v^{*}$ veine cave, dont les parois sont recouvertes par des corps spongieux $l e s\} ;-v$ reines des viscires allant déboucher dans les deux branches 
sang $\mathrm{y}$ arrive des branchies par des veines branchiales $(v b)$ dont les ouvertures sont garnies de valvules, et pénètre ensuite dans les artères qui naissent de cet organe et qui se distribuent dans le corps. Ce liquide revient ensuite dans une grosse veine cave qui, parvenue auprès du coeur, se divise en deux branches pour se rendre aux branchies; enfin, ces derniers vaisseaux, parvenus a la base des organes respiratoires, présentent, en général, une dilatation remarquable et se garnissent de fibres musculaires, de facon à constituer deux réservoirs contractiles faisant les fonctions de cours pulmonaires $(c p)$. Cette disposition se remarque chez tous les céphalopodes à deux branchies, mais n'existe pas chez ceux qui sont pourvus de quatre branchies.

$\$ 607$. L'appareil de la digestion est très-compliqué. La bouche est entourée d'une lèvre circulaire et armée de deux mandibules verticales, qui ressemblent beaucoup à un bec de perroquet et qui sont mises en mourement par des muscles puissants. Il existe des glandes salivaires tres-développées, plusieurs estomacs et un foie volumineux; lintestin va déboucher dans la cavité branchiale, à la base de l'eutonnoir par lequel l'eau est expirée, et communique avec un or gave sécréteur très-singulier qui, chez les céphalopodes a deux branchies, produit en abondance une liqueur noiràtre, à laquelle on a donné le nom d'encre; le conduit excréteur de cette glande s'ouvre près de l'anus, et, lorsque cet animal est en dangrer, il lance au dehors, par l'entonnoir, ce liquide en quantité assez grande pour teindre l eau qui l'entoure et pour se cacher ainsi a la vue de ses ennemis. C'est l'encre d'un de ces céphalopodes, la seiche. qui est employée en peinture sous le nom de sépia, et plusieurs auteurs pensent que l'encre de Chine est une substance analosuc (1). Les céphalopodes tétrabranchiaux ne présentent ritn de semblable.

$\S 608$. Nous avons dit plus haut que les mollusques ne présentent pas dams l'intérieur de leur corps une charpente solide articulée ct comparable au squelette des animaux vertébrés. Chez les céphaloporles, cependant, on retrouve encore des vestiges de quelque chose d'analogue; car il existe dans la tète un cartilage qui nonseulement protége le cerveau, mais ausisi sélargit dans diverses

de la veine cave; $-c p$ sinus veineux ou cours branchiaux; $-s$ renflement de la base des artires branchiales; $-U$. branchies; $-a b$ artere branchiale; $-r l$ veine branchiale; - lu bulbe des veines branchiales, situé près de la terminaison de ces vaisseaux dans le cour.

(1) Il paraitrait cependant que la matière ordinairement employée pour la fabrication de l'encre de: Chine n'est autre chose que le charbon très-divisé. 
directions, pour fournir des points dinsertion aux principaux muscles rle l'animal. Il est aussi a noter que l'abromen de ces animaux est, en général, soutenu par une sorte de coquille interne qui, che\% les calmars, est cornée; mais qui, chez les seiches. est do mature calcaire et est appelée l'os de ces animaux.

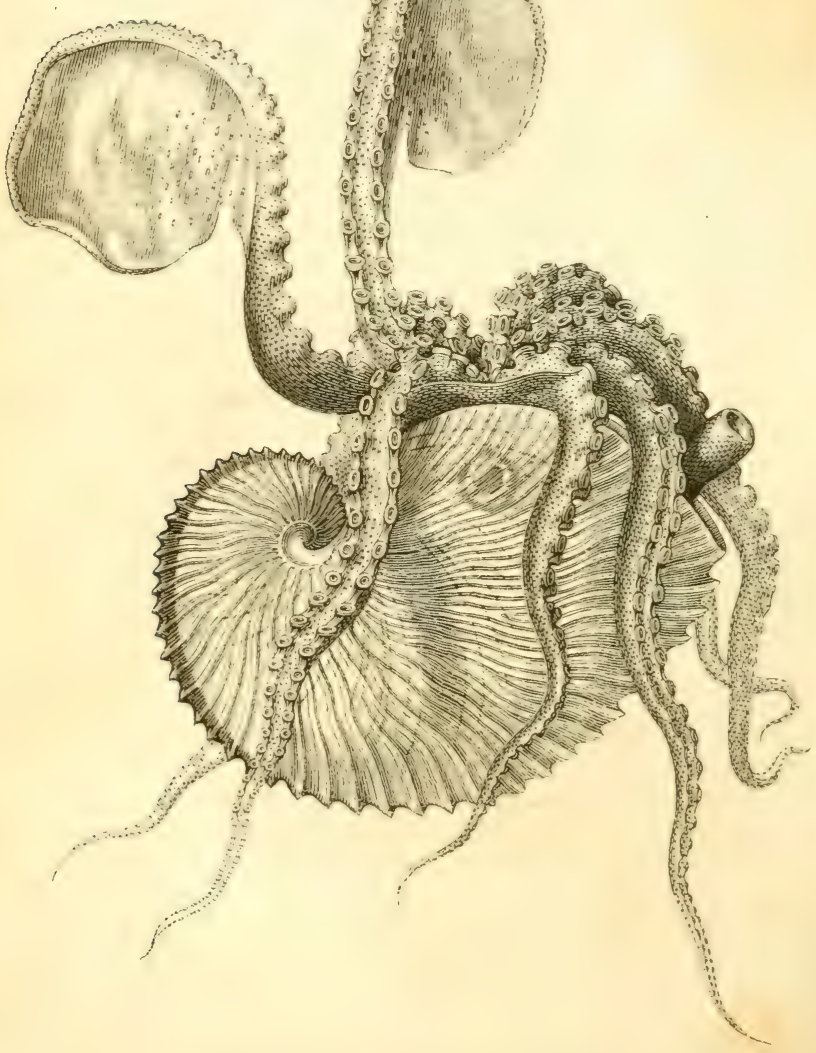


$\$ 609$. La disposition des organes de la locomotion et de la préhension fixés autour de la bouche varie chez ces mollusques. Che\% les céphalopodes dibranchiaux, il existe une couronne de gros tentacules charnus, dont la surface interne est garnie de suçoirs ou rentouses, il l'aide desquels ils se fixent arec beaucoup de force aus corps qu'ils embrassent (voyez fig. 1:39, page 303̈) Chez les poulpes on compte huit de ces appendices, et chez les seiches dix : quelquefois deux d'entre eux s'élarwissent en forme de rames ou de voiles membraneuses, comme chez l'argonaute (fig. 4.30), ou s'allonsrent de facon à devenir filiformes, comme dans les calmars (fig. 427) et surtout dans les calmarets ( fig. 8). Chez les céphalopodes tétrabranchiaux. ces appendices sont tous grèles et répourvus de sucoirs. mais extrèmement nombreux (fig. 4.31).

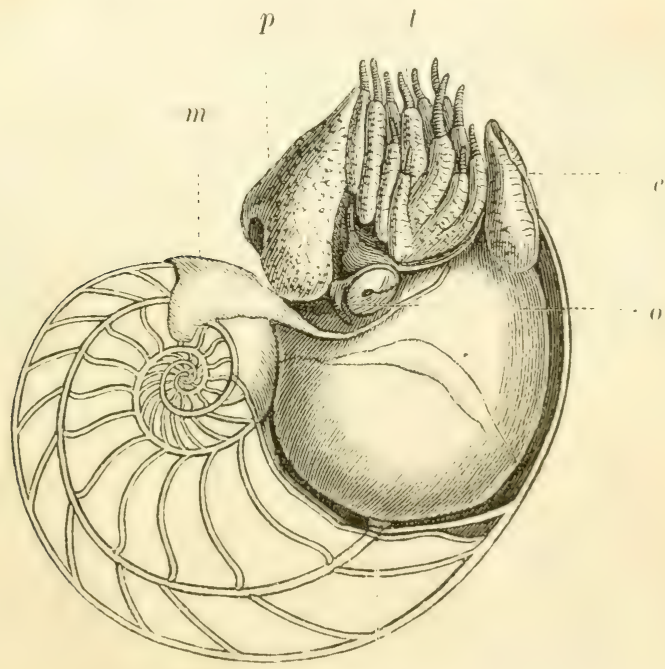

s

Fig. 431. Nrulile (1).

\$ 610. La phupart desmollusques de cette classo sont remaryuables par le déreloppement el la preffection de leurs yeux, qui res-

(1) Dans cette figure on a reprisenté la coquille ouverte : - / les tentacules; $c$ l'entonnoir; $-p$ le pied; $-m$ portion du manteau; $-o$ (eil ; $--s$ siphon. 
semblent extrèmement à ceux des animaux vertébrés. Plusieurs possèdent aussi un appareil auditif, mais cet organe se trouve réduit à un pelit sac membraneux représentant le vestibule et recevant un nerf. Entin, le systeme nerveux de ces animaux est plus compliqué que celui des autres mollusques, et les divers ganglions

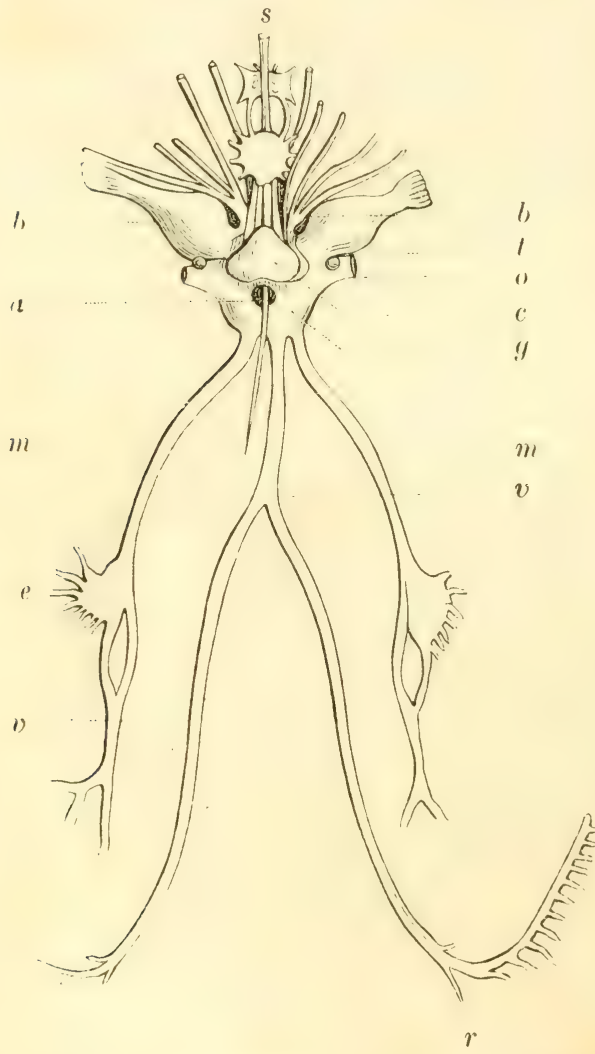

Fig. 432. Systime nerveux de la Seiche (1).

1) "le collier nerveux qui mbrasse l'osophage, dont le trajet est indiqué par une soie Isi: - $-c$ la masse nerveuse, située au-devant de l'cesophage et nommée 
groupés autour de l'œsophage tendent davantage à se confondre en une seule masse. Le collier médullaire ainsi formé se compose d'une paire de ganglions céphaliques, d'où naissent les nerfs optiques, etc.; d'une paire de ganglions situés plus en avant, mais sous l'œsophage, et fournissant les nerfs des tentacules; enfin, d'une paire de ganglions thoraciques donnant naissance aux nerfs du manteau, et à deux cordons qui se portent en arrière, et forment de chaque còté de l'abdomen un gançlion dont partent des branches destinées an coeur, aux branchies, etc.

$\$ 611$. Tous les céphalopodes sont marins : ils sont très-voraces. et se nourrissent principalement de crustacés et de poissons, dont ils s'emparent à l'aide de leurs bras souples et vigoureux, et dont ils dévorent facilement la chair au moyen de leurs mandibules acérées. Quelques-uns de ces animaux se logent dans des coquilles contournées sur elleś-mèmes : l'argonaute et le nautile, par exemple; mais quelques naturalistes pensent que le premier ne forme pas lui-mème cette loge calcaire, et vit en parasite dans la coquille d'un autre mollusque.

Cette classe comprend les poulpes $(f i g .159)$, les argonautes $(f i g .430)$, les seiches, les calmars (fig. 427), les calmarets $(f g .8)$, les nautiles

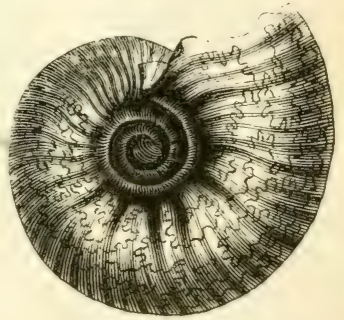

Fig. 433. Amm (m) " (fig. 431), ete. On y range aussi les ammonites (fig. 4.33), corpulles yui ont de l'analogie arec celles des nautiles et qui ne se trouvent (qu'à l'état fossile.

communément le cerveau : sa surface supérieure est surmontée d"un tubercule cordiforme tres-gros, et il part de sa partie anterieure deux nerfs qui bientit se terminent dans un ganglion cirsulaire, qui, à son tour, donne naissance a une autre paire de nerfs, lesquels descendent sous la bouche de maniere à embrasser de n-uveau l'œesophage, et y forment un petit ganglion antérieur d'ou naissent les nerls labiaux; - $b$ ganglions tentaculaires, dou naissent les nerís dı bras; - oneris optiques qui naissent des parties laterales du cerveau, et bientot se renflent en un gros ganglion; $-\ell$ petits tubercules nerveux, situes sur lorigine des merfs optiques; $-g$ ganglion sous-resophagien ou ventral; $-v$ grand nerf des viscares, dout l'une des branches présente un ganglion allongé ;r), et pénètre dans la branchie; $-m$ nerfs qui naissent également des ganglions postaesophagiens et qui présentent sur leur trajet un gros ganglion étoilé fe dont les branches se distribuent au inanteau. 


\section{CLASSE DES GASTEROPODES.}

$\$ 612$. Le's gastéropodes sont des mollusques qui sont pourvus d'une tète et qui se meuvent à laide d'un disque charnu ou picd

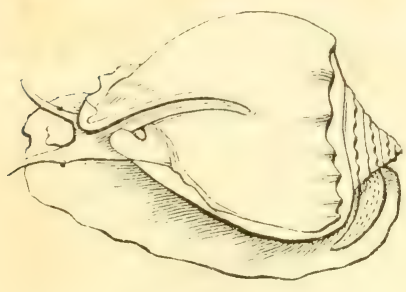

Fig. 434. Casque. placé sous le ventre (fig. 434), ou d'une nageoire formée par la mème partie dı corps (fig. 438). Cette classe, qui a pour type le colimacon, est extrèmement nombreuse, et se compose principalement d'animaux logés dans tine coquille d'une seule pièce, le plus ordinairement en forme de còne et enroulée en spirale ; quelques espèces sont au contraire absolument nues: la limace, par exemple. Le corps est allongé et se termine en avant par une tète plus ou moins développée, qui porte la bouche, ot qui est garnie de tentacules charnues, dont le nombre varie de deux a six ; le dos est tevelu d'un manteau qui se prolonge plus ou moins en arriere, sous forme d'un sac membraneux, et sécrete la coquilie; enfin le ventre est couvert en dessous par la masse charnue du pied. Les viscères logés sur le dos occupent la partie supérieure du bouclier ou du còne formé par la coquille, et y restent toujours renfermés; mais la tète et le pied saillent au dehors quand l'animal se déploie pour marcher, et rentrent dans le dernier tour de spire lorsquil se contracte : aussi la grosseur de cette derniere partie de la coquille et la forme de son ouverture sont-elles en rapport avec la grosseur du pied. Chez la plupart des mollusques gastéropodes aquatiques dont la coquille est spirale, il existe un disque corné ou calcaire, nommé opercule (fig. $43 \ddot{3}, 0)$, qui est fisé a la partie postérieure du pied, et qui ferme l'entrée de sa coquille lorsque l'animal s'y retire.

$\$ 613$. Le coeur est toujours aortique et se compose presque toujours d'un ventricule et d'me oreillette : il se trouve près du dos de l'animal, du còté opposé à celui occupé par les organes reproducteurs.

Les oryanes de la respriration sont conformés lantót pour la respiration aćreme. Lantit prour lat vie aguatique. Dans le premies 
(ats, ils consistent en une cavite sur les parois de latpuelle les vaisseaux sangruins forment un réseau compliqué, ct dans l'intérieur de laquelle l'air pénetre du dehors par un orifice pratiqué sous le bord externe du manteau. Cette espece de poumon (fig. 1.2.2) est situr sur le dos de lanimal, et se troure logé dans le dernier tour die spire de sa coquille, lorsque le mollusque est pourvu d'une enveloppe semblable. Chez les gastéroporles destinés à respirer dans l'eau, la disposition des branchies varie : souvent ces organes sont renfermés dans line cavité analogue à celle qui constitue le poumon des précidents (fig. 4:3:) : mais d'autres fois ilsont logés entre le mantean

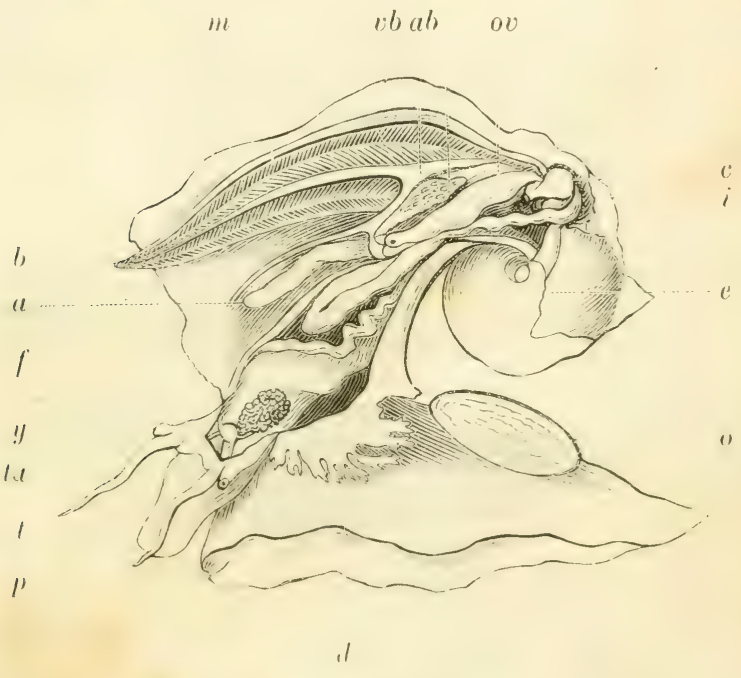

Fig. 435. Anntomie d'un gastéropole pectinibranche (1).

(1) Fig. 433. Anatomie du lurbn picr, pour montrer la disposition de la cavité respiratoire : $-p$ le pied de l'animal; - o l'opercule; $-\ell$ la trompe; - la les tentacules; $-y$ les yeux; - m le manteau fendu longitudinalement, de maniere à ouvrir la cavité respirature: - f bord anterieur du mantean qui, dans la position naturelle, recuure le dos de lanimal et y laisse une onverture on grande fente par laquelle l'eau arrive à lat branchie; - l, la branchie : - el la reine branchiale qui se rend au coeur $(c)$; - ab l'artère branchiale; - a l'anus; - illintestin : e l'estomac et le foie; - ov l'oviducte. Au-dessus de la nuque on voit le ganglion

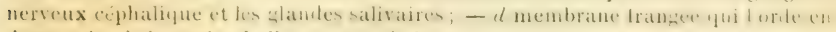
dessous le còté gatuche de l'ouverture de la cavité respiratuire. 
(t le pied, ou mème sur le dos de l'animal, de facon à flotter librement dans le liquide ambiant. Comme exemple des gastéropodes pulmonaires, nous citerons le colimaçon et la limace, qui vivent à terre; les lymnées (fig. 141), les planorbes et les physes; qui se tiennent dans les eaux dormantes et viennent à la surface du liquide prendre l'air nécessaire à leur respiration. Parmi les gastéropodes pourvus de branchies renfermées dans une cavité dorsale, on remarque les rolutes, les buccins, les porcelains (fig 1:37), les haliotides ou ormiers, elc. Les patelles et les pleurobranches (fig. 436)

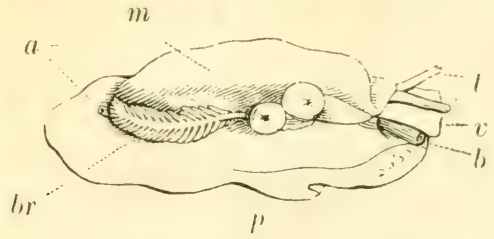

Fig. 43;. Pleurobranche (1).

prortent ces organes dans le sillon qui sépare le pied du manteau, et, chez les doris (fig. 43), et les éolides (fig. 437), ete., ils consistent en panaches ou en lanières fixées sur la face dorsale du corps.

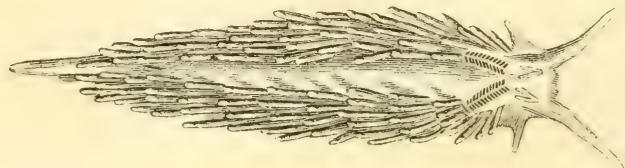

Fig. 437. Eolide.

$\$ 61 \%$. La bouche des gastéropodes est entourée de lèrres contractiles, et quelquefois armée de dents cornées qui occupent le palais. Chez plusieurs autres animaux de cette classe, la partie antérieure de l'oesophage est très-charnue, et a la faculté de se porter au dehors de manière à constituer une trompe. Quelquefois l'estomac est aussi garni de pieces cartilagineuses ou osseuses propres à diviser les aliments; lintestin est contourné sur lui-mème et logé entre les lobes du foie et l'ovaire; enfin l'anus $(a$, fig. 4:36) est presque toujours situé du còté droit du corps, et se trouve souvent a peu de distance de la tète.

(1) $m$ le manteau releré pour montrer la branchie $(b r)$; $-\ell$ l'anus ; $-l$ la bouche et la trompe; $-v$ le roile; $-l$ les tentacules; $-p$ le pied. 
$\$ 61 \%$. Dans cette classe, les organes de la sensibilité sont moins développés que chez les céphalopodes; les tentacules, que la plupart des gastéropodes portent sur le front, ne servent guère qu'au tact et peut-ètre à l'odorat. On ne leur connait pas d'organe auditif, el leurs yeux, qui manquent quelquefois, sont très-petits et d'une structure très-simple: ils sont tantòt adhérents à la tète, tantòt portés sur la base, le còté ou la pointe des tentacules. Enfin le système nerveux est moins développé que dans la classe précédente, et se compose principalement d'un ganglion céphalique et d'un ganglion thoracique réunis en collier autour de l'œesophage. Parmi ces animaux, les uns sont terrestres, et d'autres habitent les caux ciouces; mais la plupart d'entre eux vivent dans la mer. En général, ils sont conformés pour ramper, comme les colimaçons, la lymnée ( $f g .141)$, la porcelaine (fig. 137), etc.; mais quelquefois ils sont destinés à nager seulement : les carinaires, par exemple.

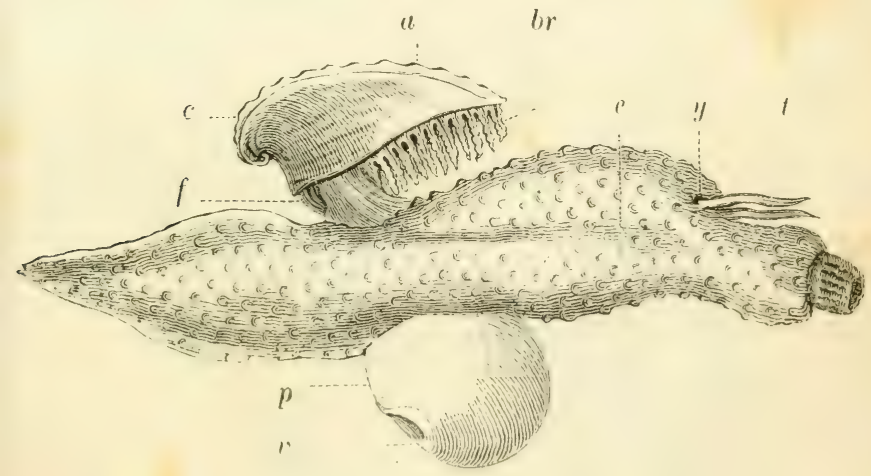

Fig. 438 Ca inaire.

(1) $b$ bouche; $-\boldsymbol{t}$ tentacules; $-y$ yeux; $-e$ estomac; $-f$ foie $;-a$ anus; $c$ coquille ; $-b r$ branchies; $-p$ pied; $-v$ petite ventouse située sur le bord du pied. 


\section{CLASSE DES PTÉROPODES.}

$\$$ 616. Les ptéroporles, ainsi que nous l'arons déjà dit, sont de petits mollusques pourrus d'une tète distincte et conformés pour llotter dans l'eau et y nager a l'aide de deus nagroires placées. comme des ailes, de chaque còté du cou fig. 160). Les uns sont nus. les autres pourvus d'une coyuille. Du reste, leur histoire n'offre pas assez de particularités intéressantes pour nous y arrèter plus longtemps.

\section{CLASSE DES ACEPHALES.}

$\$ 617$. Les mollusifues dont nous nous sommes occupés jusqu ici ont tous une tite distincte; ceux dont il nous reste a parler en sont dépolarvus. et montrent dans loute leur organisation une simplicite

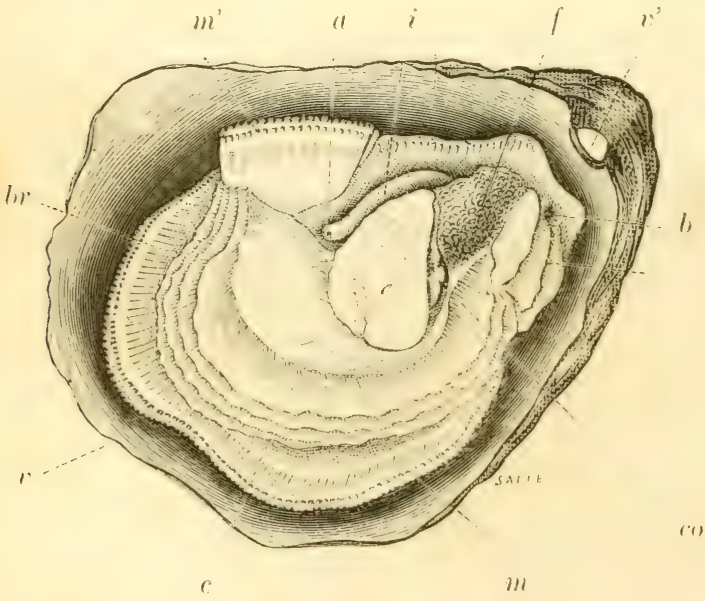

Fig. 439. Analomie de l'Huîlre (1).

(1) $v$ l'une des valves de la coquille; $-v$ sa charnière; $-m$ l'un des lobes du manteau ; $-m$ ' portion de l'autre lobe reployée en dessus; $-i$ inuscles de la coquille; $-b r$ branchies $;-b$ bouche; $-i$ tentacules labiaux $;-f$ foie ; $-i$ intestin: - " anus: - co coeur. 
plus grande. Leur corps est enve'oppo tout entier par le manteau. romme un livre dans sa couverture ; la peau du dos, en effet, n'est adhérente que vers le milieu, et forme de changue còté un grand repli on voile qui recouvre toutes les autres parties de lanimal (fig. 439), et quclquefois mème se joint a son congénère de facon at ne laisser d'ourertures qu"en araut et en arriere, et à constituer deux longs tubes pour le passage de l'eau necessaire a la respiration (fig. 440). Une coquille compozio de de!s batlants ou valses recouvre ce manteau en totalité ou en partie, et présente à sa partie supérieure une charnière garnie d'un ligament élastique, dont le jeu fait bâiller les valves toutes les fois que

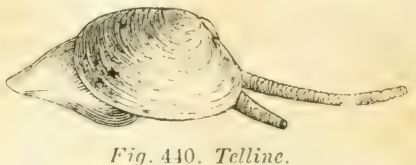

les muscies, étendus de l'une a l'autre, ne se contractent pas pou les naintenir fermées. Les viscères sont réunis en une petite masse sous la partie dorsale du manteau, et la portion rentrale du corps se prolonge en général de façon à former un pied charnu ayant quelque analogie avec celui des vastéropodes, mais beaucoup moinbien conformé pour la locomotion. Quelquefois cest la face interne du manteau qui tient lieu d'organe respiratoire, et qui offre a cel effet un réseau vasculaire très-developpé (chez les térébralules, par exemple); mais, en général, il existe un appareil branchial trèsdéveloppé et composé de deux paires de grandes lames membraneuses fixement striées et flottantes entre le pied et le manteat (fig. 439). La bonche est éralement cachée entre les plis du manteau, et se trouve à l'une des extrémités de la hase de laabdomen; elle n'est jamais armée de lents, mais olle est parnie latéralenent de deux paires de prolongemerts labiaux qui constituent des tentacules lamelleux. Liestoma est asicez décoloppé, et l'intestin forme autour du foie plusieurs rireonvolutions avant que de gagner lo bord postérieur de la base de l'abdomen, oil est situe lanus. Id rour est en général situé au-dessus de la masse viscélale ainsi formée (fig. fïi), et se compose d'un ventricule aortique et d'unc ou deux oreillettes destineses a receroir le sang yui arrive des branchies. En crenéral, ce rentricule cet fusiformer, ot prósente une particularité remarquable, sa cavité étant traversée par löntestin rectum. Enfin le ststemo nerveux consiste principalement on dext

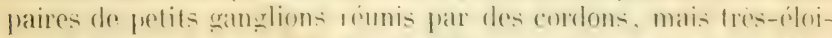

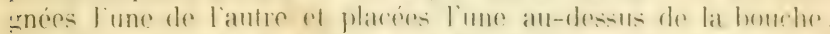

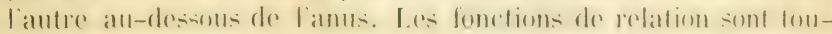

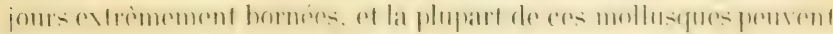


it peine se dipplacer en se poussant avec le pied ou en fermant bruscuement leur coquille pour lancer au dehors l'eau renfermés entre les valves, ce qui imprime à leur corps un choc en retour; en grénéral, ils vivent presque immobiles au fond de l'eau ou enfouis dans le sable, et quelques-uns se fixent mème aux rochers à l'aide d'un faisceau de filaments cornés ou soyeux qui nait du pied, et qui est appelé le byssus de ces animaux.

$\$ 618$. Cette classe se divise, d'apres la présence ou l'absence de branchies lamelleuses, en deux ordres : les Lanelabraxcies, comprenant les huitres, les moules, les arondes ou huitres perlipres (fig. 4.1), les peetens on corquilles de Saint-Jacques, les

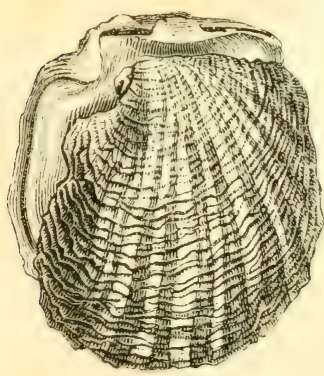

Fiig. 141. Aronde perlière.

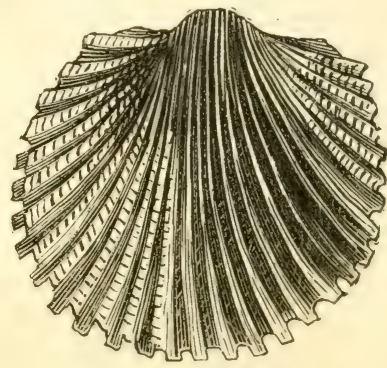

Fig. 442. Buccarde.

mactres (fig. 13\%), les buccardes ou coques (fig. 442), les solens on manches-de-couteau, les tarets, ete. Les Bu.nchopodes doivent leur nom à deux espeeces de bras charnus qui remplacent le pied : Irstérébratules (fiy. 443 et 4.4 ) offrent ce mode de structure.

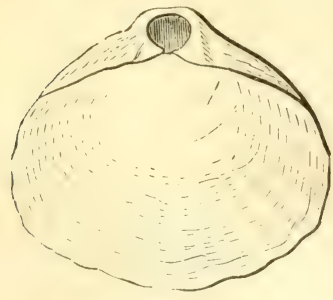

Fig. 413. Coquicle de Téríbralule.

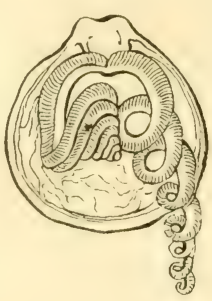

Fig. 444. Animal de la Térébralule 
SOUS-EMBRANCIIEMENT

\section{DES MOLLUSCOIDES OU TUNICIENS.}

$\$$ 619. Les animaux que nous réunissons ici sont considérés par la plupart des zoologistes comme devant ètre rangés, les uns parmi les mollusques proprement dits, et les autres parmi les zoophytes: mais cette opinion parait tenir a l'imperfection des connaissance: que l'on arait sur la structure de ces ètres, et maintenant que leur anatomic et leur physiologrie ont été mieux étudićes, on voit qu'ils sont tous conformés sur le mème plan général, et qu'ils établissen en quelque sorte le passage entre les mollusques proprement dits et les zoophytes. Ils sont tous pourvus d'un tube digestif distinct contourné sur lui-mème et ouvert à ses deux bouts, et d'un appareil branchial très-développé ( fig. \$4⿱艹) ; la plupart offrent encore

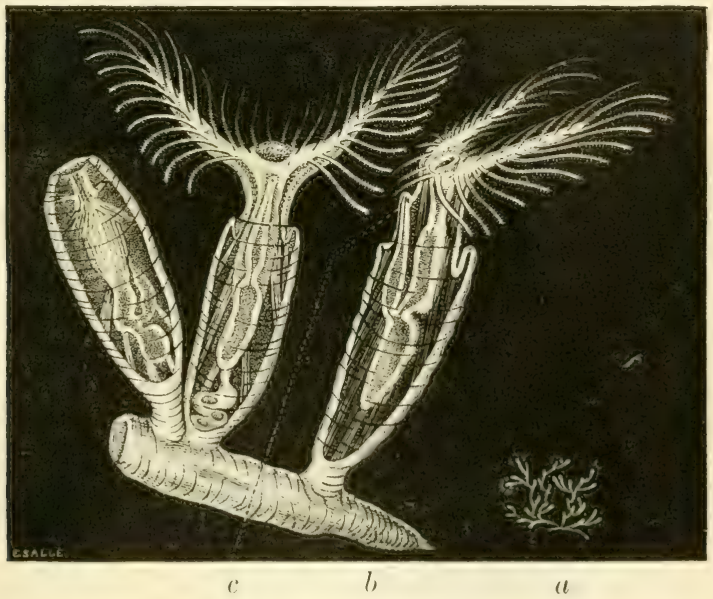

Fig. 4.15. P'lumatelle (1).

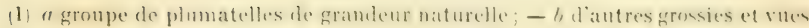
dans diverses positions; $-c$ anus 
$\$ 621$. Les Bryozonres, qui, jusquen ces dernières amnés. avaient été confondus arec les polypes les plus simples, ont le manteau moins développé et les branchies à nu; ees or cranes consistent dans une couronne de tentacules qui entourent la bouche ot qui sont garnis latéralement de cils vibratiles (fig. 4qu); l'anus est situé à peu de distance de la bouche, ef le liquide nourricier arrive entre les visceres et le manteau, ainsi que dans l'interieur des tentacules, mais n'est pas mis en mourement par un cour: enfin la portion inférieure du manteau se durcit en grénéral de facon a constituer une sorte de tube ou de cellule tantòt cornée, tantèt calcaire, dans lequel lanimal peut se retirer tout entier. En général, ces ètres, d'une petitesse presque microscopique, vivent réunis en masses plus ou moins considérables. La plupart habitent la mer, mais on en trouve aussi dans les eaux douces. Parmi ces derniers, nous citerons les aleyonelles et les plumatelles (fig. 4tö, assez communs dans nos étangs; et, parni les promiers. les flustres, les rétépores et les vésiculaires.

\author{
EMBRIXCHEMENT
}

\title{
DES ZOOPHYTE
}

5 622. Dans ce quatrieme et dernier embranchement du Rione animal, lorganisation est beaucoup moins complete yue chez la plupart des autres animanx, et les diverses parties de lóconomie, au lieu d'etre disposées par paires de chanue coté doun plan longitudinal, se grompent autour d'un axe ou d'un point central, de facon a donner a l'ensemble du corps une forme rayonnée ou sphérigue. Le systeme nerveux est rudimentaire ou nul, ef il n'existe point d'organes spéciaux des sens, si er n'est quelquefois de petites laches colorées qui paraisient ère quelque chose dianalog̣e ans yeux des mollusques.

Il existe, eomme nous larons déjia dit, des variations tres-errandes dans la structure de ces animanx, dont plusiours resemblent, far leur aspect extérieur, at desplantes plutot quat des colres anmes : et cest en raison de ces differences quion diviso les zoephlives en ring clasises : les échinodermes, les aralephes. les polypes les infusoires polygastriques et les spongiaires. 


\section{CLASSE DES ECHINODERMES.}

$\$ 623$. Les échinodermes (fig. 134 et 161) sont des animaux rayonnés dont la peau est épaisse et sourent soutenue par une sorte de squelette solide ( $f y .4 \%$ ), el dont la structure intérieure est très-compliquée. Its sont conformés pour ramper au fond de l'eau, el sont en général pourvus à cet effet d'une multitude de petits tentacules rétractiles qui passent à travers des pores dont leurs tég̣uments sont percés, et agrissent par leur extrémité à la manière de

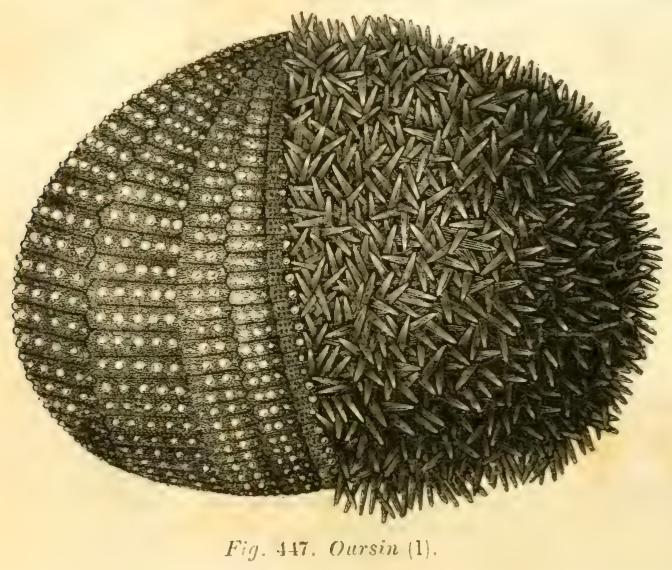

ventouses. Chez la plupart de ces zoophytes (les hulothuries et les oursins. par exemple), la cavité digestive a la forme d'un tube ourert à ses deux extrémités ; mais chez d'autres (les astéries) elle ne consiste que dans un sac garni tout autour d'appendices plus ou moins rameux et communiquant au dehors par une seule ouverture qui remplit la double fonction d'une bouche et d'un anus. Les échinodermes possèdent un appareil circulatoire assez développé, +t sont de tous les zoophytes ceux dont l'organisation est la plus compliquée et la plus parfaite. Ils vivent dans la mer, et ils forment trois groupes principaux : les holothuries (fig. 161), les oursins (fig. 17i) et les astéries ou étoiles de mer (fig. 134).

(1) Du côté gauche on a enlevé les épines pour montrer le test. 
Les holothuries sont remarquables par la disposition de leur appareil respiratoire, composé de tubes membraneus ramifiés comme un arbre, et recevant l'eau dans son interieur par l'intermédıaire d'un cloaque et de l'anus.

\section{CLASSE DES ACALEPIIES.}

$\$ 624$. Les acalephes sont des animaux mous, d'une consistance gélatineuse, qui llottent toujours dans la mer et sont essentiellement organisés pour la nage. Ils nont pas, comme les échinodermes. une peau bien distincte des parties sous-jacentes of une cavité intérieure logeant les visceres : leur organisation est tris-simple, et leurs oraanes intérieur's se réduisent presigue a un estomac communiquant en général directement au dehors par une bouche seulement, et donnant naissance à des canaux qui se rendent dans les diverses parties du corps et qui s'y ramifient souvent de façon à y donner naissance à un système vasculaire.

La famille la mieux connue de cette classe est celle des méduses ( $\mathrm{fg}$. \$48), parmi lesquelles on range les rhizostomes (fig. 162), qui abondent sur nos còtes, et qui sont remarquables par la disposition singulière de leur appareil digestif. En effet, l'estomac ne communique pas au dehors, comme d'ordinaire, au moyen d'une bouche centrale placée entre la base des tentacules, mais a l'aide d'un grand nom-

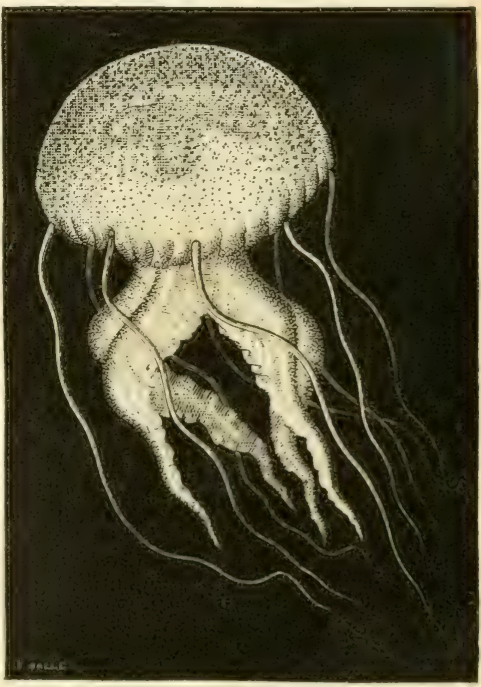

Fig. 448. Médluse (pélagie). bre de peits canaux termines par des pores a l'extremité libre de

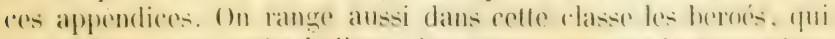
ressemblent a de potils ballons: les cestes, qui and la forme diun 


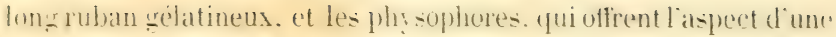
gurlande charçée de fleurs et de fruits.

\section{CLASSE DES POLYPES.}

\$6:3. On reunit en general sousce nom les bry vavaires, dont nous

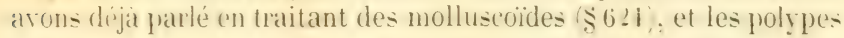

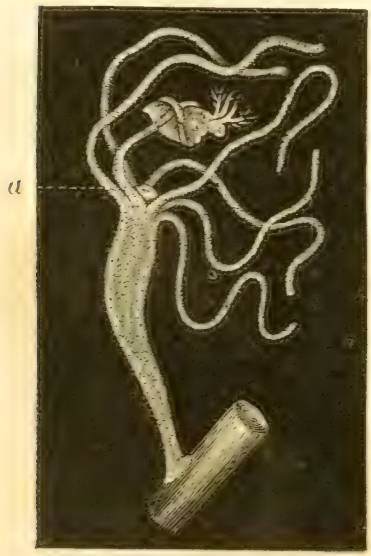

Fig. 419. Hydre. proprement dits, qui ont une structure toute différente et bien moins complète. Ce sont des animaux dont le corps esl cylindrique, mou et percé à l'une de ses extrémités par une bouche centrale qu'entourent des tentacules plus ou moins nombreux et dépourvus de cils vibratiles ( $a$, fig. \$49). Cet orifice tient également lieu d'anus, et conduit, directement ou par l'intermédiaire d'un tube membraneux, daus une grande cavité qui occupe tout le corps, qui se continue superieurement dans l'intérieur des tentacules et qui loge les ovaires suspendus à ses parois. L'extrémité inférieure du polype est disposée de façon a adhérer aux corps étrangers sur lesquels l animal est destine a virre tixé; et sat peau se durcit en ginéral en warde partie, de maniere a lui constituer une enveloppe cornece ou calcaire analogrue aux cellules dont nous avons déjà parlé m derrivant les bryozoaires. Les polypes proprenent dits ressemblent aus-i aux molluscoïdes par leur mode de multiplication; car la plupart dientre eus se reproduisent non-seulement par des ceufs, mais aus-i au moven de bourgeons qui naissent sur diverses parlirs de la surface de leur corps et ne s'en séparent jamais : de surte que les rliserses générations restent greffées en quelque sorte les unes sur les antres, et forment des masses plus ou moins considerables dans lesquelles tous les individus d une mème race so liement et virent, jusqua un certain point, dune vie commune.

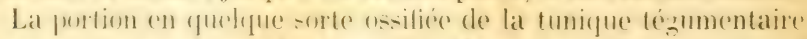

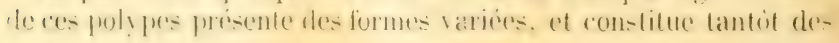


tubes, tantot des especes de cellules. Pendant long-temps on l'a considérée comme étant seulement la demeure des jolypes qui la forment, et c'est elle qu'on désigne sous le nom de polypier. Quelquefois chaque polype possede un polypier distinct; mais d'ordinaire c'est la portion commune d'une masse de polypes agrégés qui présente les caractères propres à ces corps, et il se forme ainsi des polypiers agrégés dont le volume peut devenir extrèmement considérable, quoique chacune de ses parties constituantes n'ait que des dimensions fort petites.

$\$ 626$. C'est de la sorte que des polypes dont le corps n'a que quelques pouces de long élèvent dans les mers voisines des tropiques des récifs et des îles. Lorsqu'ils sont placés dans des circonstances favorables à leur développement, certains animaux de cette classe pullulent au point de recouvrir des chaines de rachers ou d'immenses banes sous-marins, et de former avec les masses pierreuses de leurs polypiers, amoncelés les uns au-dessus des autres, des amas dont l'é-

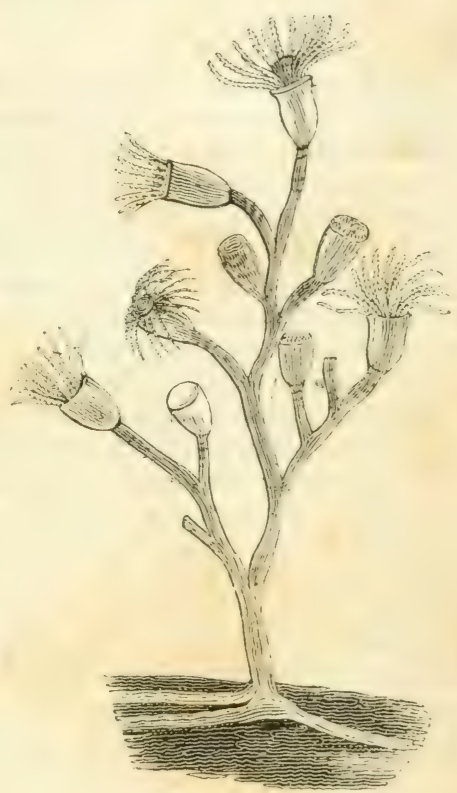

Fig. 450. Serlulaire. tendue saccroit sans cesse par la naisiance de nomveaux individus au-dessus de ceux déja existants. Lal dépouille solide de chanue colonie de polypes reste intatele apres que ces frèles architectes ont péri, et sert de base pour le développement diatres polypiers jusqu'à ce que ces récifs vivants alteignent la surface de l'eaus car alors ces animaux ne pearent plus y rivre, ot le sol forme par leurs débris cesse de sélever Mais bientot la surface de ces amat: de polypiers, exposée a l'action de latmosphere, devient le sicire d'une nonvelle série de phénomènes : des grames déposéses far les rents ou apportées par les vagues y germent ef la courent diune. 
riche végétation, jusqu'à ce qu'enfin ces vastes charniers de zoophytes presque microscopiques deviennent des iles habitables. Dans l'océan Pacifique, on rencontre une foule de récifs et d'ìles qui n'ont pas d'autre origine. En général, ils semblent avoir pour base quelque cratère de volcan éteint, car presque toujours ils on t une forme circulaire, et présentent au centre une lagune communiquant au dehors par un seul chenal : on en connait qui ont plus de dix lienes de diamètre.

$\$ 627$. Presque tous les polypes habitent la mer; on en trouve cependant dans les eaux douces. Ceux dont le polypier est simplemeut charnu ou corné sont répandus dans toutes les latitudes, mais ce n'est guère que dans les mers des climals chauds qu'on trouve en abondance des polypes à polypier pierreux.

Quelquefois les polypes agréçés déposent dans l'intérieur du tissu commun par lequel ils sont unis une matière cornée ou calcaire qui constitue une sorte de tige intérieure et qui se ramifie comme un arbre à mesure que la masse animće pousse de nouvelles branches. C'est de la sorte que se forme la matière pierreuse nommée corail (fig. 164), dont on fait un grand emploi comme ornement, et dont la pèche est active sur les còtes de l'Algérie.

On doit ranger dans cette division du Regue animal les actinies ou anémones de mer (fig. 143), (qui ont le corps charnu et qui se voient en si grand nombre sur les rochers de nos còles; les carophyllies of les astéries, qui concourent plus que tous les autres ¿ la formation des récifs de corail, le corail lui-mème (fig. 161), les sertulaires (fig. 4:30), qui n’ont qu'une gaine cornée, les verelilles (fig. 4:51), qui n'adhèrent pas au sol, mais sont simplement cnfoncés dans le sable par une des extrémités de leur tige commune, et les hydres, dont nous avons déjà eu à nous occuper (\$347).

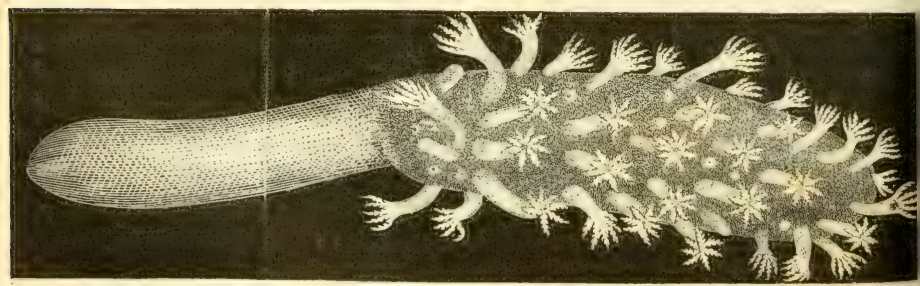

Fig. 451. Polypes (Verelilles). 


\title{
CI ASSE DES INEUSOIRES
}

\author{
PROPREMENT DITS.
}

$\$ 628$. Ces animalcules, qui ne s'aperçoivent qu'au moren du microscope et qui se développent en abondance dans l'eau contenant des débris de corps organisés, ont été, jusqu'en ces derniers temps. confondus avec les rotateurs $(\$ 991)$, dont la structure est trèsdifférente. Leur corps, tantòt arrondi, tantòt allongé, est souvent couvert de petits cils, et offre dans son intéricur un nombre ordinairement très-considérable de petites cavités qui paraissent remplir les fonctions d'autant d'estomacs. Chez quelques-uns, ces sortes d'ampoules semblent ètre groupées autour d'un canal qui s'ourre au dehors par ses deux extrémités (fig. 167); mais d'autres fois elles paraissent ètre tout à fait isolées, et les personnes qui ont fait de ces petits ètres l'objet d'une étude spéciale ne s'accordent pas sur l'existence d'une communication directe entre leur cavité et le dehors. La maniere dont ces infusoires se propagent a été l'objet de beaucoup de recherches, et un srand nombre de naturalistes pensent qüils peuvent se former directement par la désagrération des matieres dont les fenilles, la chair musculaire et autres corps oryanisés se composent; mais cette génération spontanée est loin d'ètre suffisamment démontrée, et l'on sait que, dans certains cas au moins. ils naissent les uns des autres. Du reste, leur mode de propacration est bien d'aceord avec la simplicité de leur structure : c'est par la division spontanée de leur corps en deux on plusieurs framents, dont chacun continue de visre ef devient bientòt un nouvel individu semblable au promier, que ces êtres singuliers se multiplient.

Leurs formes sont tres-variées, et on les a divisés en plusieurs genres, parmi lesquels nous citerons les Excuéunes (ur, fig. 167\%), dont le cerps est oblong; les Vordoces, yui sont ylobuleux et fournent continuellement sur eux-memes, et les Moxubes (I, fig. I67). qui ressemblent a de petils points tourbillonnant dans l'eau ou ofles nagent. C'est a la presence de myriades d'une espece particuliere de ces petites monarles. dont le corps est roloré en rougere. que l'eau des étangs salés doit la couleur sanguinolente quiolle offre quelquefois. 


\section{CLASSE DES SPONGIAIRES.}

$\$ 629$. Les éponges $(f i g .166)$ et les autres corps d'urie structure analogue n'ofrent les caractères les plus saillants de l'animalité que pendant les premiers temps de la vie, et ressemblent plus tard à des végretaux informes plutòt qu'à des animaux ordinaires. Lors de la naissance, ces singuliers d̀tres ressemblent assez à certains infusoires; leur corps est ovalaire et garni partout de cils vibratiles à l'aide desquels ils narent dans l'eau : sous ce rapport, ils ressemblent aussi aux larves de divers pulypes au moment ou elles sortent de l'weuf; mais bientòt les jeunes spongiaires se fixent contre quelque corps étrangurer, deviennent complétement immobiles; ne donnent plus aucun sigrne de sensibilité ni de contractilité, et en grandissant se déforment complétement. La substance gélatineuse de leur corps se crible de trous et de canaux traversés sans cesse par l'eau, et il se développe dans leur intérieur une multitude de filaments cornés et de spicules, tantòt calcaires, tantòt siliceux, qui, disposés en faisceaux entre-croisés, constituent une espece de charpente solide. Enfin, à certaines époques de l'année, on voit se développer, dans la substance de ces masses informes, des corpuscules ovoides ou sphériques qui tombent dans les canaux dont il vient d'ère question, et qui, entrainés en dehors par les courants dont l'éponge est sans cesse traversée, constituent les espèces de larves ou corps reproducteurs doués de la faculté locomotive mentionnée plus haut.

On connait un grand nombre de spongiaires; la plupart sont propres aux mers des rénions chaudes, mais plusieurs habitent les rochers de nos cotes. Celles dont on fait un si grand usage dans l'écunomic domestique se distinguent par la nature purement cornée et par l'élasticité des filaments dont leur charpente solide se compose: l'une de ces espèces, l'éponge commune, se trouve en grande abondance dans la Méditerranée; l'autre, appelée éponge usuelle, est propre aux mers d'Amérique. Ces corps sont l'objet d'un commerce important, et, pour les préparer aux usages auxquels on les destine, il suffit de les bien laver pour détacher de leur squelette corné la matiere animale dont il est naturellement recouvert. 


\section{DE LA DISTRIBCTION GEOGRAPHIUEE}

\section{DES ANIIIUX.}

$\$ 630$. Pour nous former une idée gênérale du Regne animal, il ne nous suffit pas de connaitre les principaux phénomenes par lesquels la vie se manifeste chez les ètres animés et d'avoir étudić la structure de leur corps et le mécanisme de leur's fonctions; il nous faut aussi jeter un coup d'oil sur la manière dont les animaux sont répartis à la surface du grlobe, et chercher à apprécier l'influence que peuvent exercer sur eux les circonstances diverses au milieu desquelles ils sont appelés à vivre.

$\$ 631$. Lorsqu'on porte son attention sur la manière dont les animaux sont distribués autour de nous sur le globe, on est d'abord frappé par la différence des milieus dans lésquels ils habitent. Les uns, comme chacun le sait, vivent toujours sous l'eau et meurent promptement quand on les retire de ce liquide; les antres ne peuvent exister que dans l'air et périssent presque aussitòt s'ils viennent à ètre submergés. Les uns, en effet, sont destinés à peupler les eaux, les autres à vivre sur la terre; et, lors(qu'on compare, sous le rapport physiologique et anatomique, ces animaux aquatiques et terrestres, on découvre, du moins en partie, les causes de ces différences dans leur mode d'existence.

En étudiant la respiration, nous avons sionalé un rapport constant entre l'intensité de cette fonction et l'énergie vitale. Les animaux, avons-nous dit, consomment dans un temps donné une quantité d'oxygène d'autant plus considérable que leurs mouvements sont plus vifs et leur nutrition plus rapide : or ils ne peurent prendre cet oxygene que dans les fluides dont leur corps dist baigné, et dans un litre d'air il existe 208 centimetres cubes de ce principe vivifiant, tandis que dans un litre d'eau il ne sen est trouvé ordinairement en dissolution qu'environ 13 centimetres. II est donc évident que le degré d'activité dans la fonction répiratoire, indispensable a l'exercice des facultés properes aux animaus supérieurs, doit ètre bien plus facile a alleindre dans l'air que daus

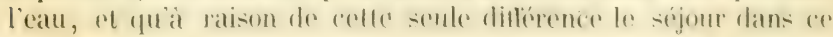


dernier fluide doit ètre interlit à tous les ètres les plus élevés dans la série animale. On comprend, en effet, qu'un animal qui, pour vivre, a besoin de s'approprier à chaque instant ure quantite considérable d'oxygene, n'en trouve pas en proportion suffisante lorsqu il est plongé sous l'eau, et qualors il périsse asphyxié. Mais, au premier abord, on s'explique moins facilement les raisons pour lesquelles un animal aquatique ne puisse continuer à vive lorsqu'on le retire de l'eau pour le placer dans l'air, car on lui fournit alors un fluide plus riche en oxygène que ne l'élait le liquide rlont laction vivifiante suffisait à tous ses besoins. Il est cependant diverses circonstances qui nous rendent, jusqu'à un certain point, compte de ce phénomene. Ainsi, la physique nous apprend qu'un corps, pesé scrupuleusement dans l'air et dans l'eau, est plus léwer dans ce dernier cas que dans le premier, et que, pour le soutenir en équilibre, il suffit alors d'un poids équivalent a celui qui représentait sa pesanteur dans l’air, diminué de celui de la masse d'eau quil a déplacée. Il en résulte que des animaux dont les tissus sonl trop mous pour se soutenit par eux-mèmes dans l'air, et sy affaisient au point de devenir inaptes a remplir leurs fonctions dans lorganisme, peuvent cependant vivre tres-bien dans le sein des eaux, ou ces mèmes tissus, n’etant guère plus denses que le fluide ambiant, n'ont besoin d'offrir qu'ume bien faible résistance pour conserver leurs formes et pour empècher les diverses parties du corps de retomber sur elles-mèmes. Cette seule considération suffirait pour nous expliquer pourquoi des animaux gélatineus, tels que les infusoires ou les méduses, sont nécessairement confinés dans les eaux: car, lorsqu'on observe un de ces etres délicats encore plongé dans ce liquicle, on voil que toutes ses parties, mème les plus ténues, se soutiennent dans leur position normale et flottent avec aisance dans le milieu ambiant; mais dès qu'on les en retire, leur corps tout entier s'affaisse et n'offre plus à l'œil qu'une masse informe et confuse. L'influence de la densité du milieu ambiant sur le jeu mécanique de ces instruments de la vie se fait aussi sentir chez des animaux dont la structure est plus parfaite, mais chez lespuels cependant la respiration s'exerce encore par des appendices membraneux ramifiés, comme des arbuscules ou des panaches. Ainsi, chez les annélides ou mème chez les poissons, les branchies se composent de filaments flexibles, qui se soutiennent facilement au milieu de l'au, et qui permettent de la sorte an fluide respirable d'arriver et de se renouveler sur tous les points de leur surface; mais, a l'air, ces memes filaments membraneux safficsont par l'efled de lesur propere poids, refombent les uns sur 
les autres, et, par cela seul, excluent l'oxygine de la plus grande partie de l'appareil respiratoire. Il en résulte que cette fonction est alors entravée, et que l'animal peut mourir asphyxié dans l'air, tandis qu'il trourait dans l'eau tout ce dont il avait besoin pour respirer librement. Pour se convaincre de l'importance de ces variations dans l'état phỵsique des organes placés dans l'air ou dans l'eau, il suffit de se rappeler ce qui se passe dans nos laboratoires de dissection : un anatomiste qui voudrait étudier la structure d'une partie délicate, n'y arriverait que difficilement s’il faisait sa dissection à l'air; mais en plaçant dans l'eau l'objet de son étude, il parvient bien plus aisément à en distinguer toutes les parties; car ces parties, soutenues en quelque sorte par ce liquide, conservent alors leurs rapports naturels comme si elles étaient d'un tissu consistant et rigide. Une autre circonstance qui influe également sur la possibilité de la vie dans l'air ou dans l'eau, est l'évaporation qui se fait toujours a la surface des corps organisés placés dans l'air, mais aui n'a point lieu au milieu de l'eau. Un certain degré de dessiccation fait perdre à tous les tissus organiques les propriétés physiques qui les distinguent, et l'on voit toujours les pertes par évaporation entrainer la mort des animaux lorsqu'elles dépassent certaines limites. Il en résulte que les ètres dont l'organisation n'est pas calculée de façon à les préserver des effets nuisibles d'une pareille évaporation, ne peuvent vivre que dans l'eau et périssent promptement dans l'air. Or, léconomie animale ne peut satisfaire à cette exigence qu à la condition d'une complicaton très-grande dans sa structure. En effet, si la respiration doit ètre active, il faut que la surface respiratoire soit alors logée profondément dans quelque cavité intérieure où l'air ne se renouvellera que dans la mesure nécessaire a l'entretien de la vie. Pour assurer ce renourellement, il faudra que l'appareil de la respiration se complique d'orwanes moteurs propres a l'assurer; pour prévenir la dessiccation d'une portion quelconque de la surface du corps, il faudra aussi que la répartition des liquides dans les diverses parties du corps se fasse aisément el yu il esiste une circulation active, ou bien que catte surface soit revetue d'une tunique à peine perméable. Cola est si vrai, que meme chez les poissons, ou la circulation est bien complete. mais na lien que lentement, et ou le réseau capillaire n'est pas tres-serré, la mort arrive promptement, far suite de la dessiceation d'une partie du corps, de la portion postérienre, par esemple; lors mème que cette portion seulement est exposée a lair el que tout le reste de lamimal demeure plongé dans l'eau. 
Nous pourrions ajouter encore que, dans l'eau, l'alimentation est possible arue des instruments de préhension et de mouvements moins parfaits que dans l'air, ou le transport des matières étrangreres dont l'animal a besoin est plus difficile à opérer. Ainsi, sous tous les rapports les plus essentiels, la vie est, en quelque sorte, plus facile a entretenir dans le sein des eaux qua la surface de la terre : elle nécessite, dans l'atmosphere, des instruments physiologiques plus compliqués et plus parfaits; aussi les eaux sont-elles l'élément naturel des animaix les plus inférieurs dans la série zoologique; et, si les productions de la création se sont succédé dans le mème ordre que les états transitoires par lesquels chaque animal passe durant la période de son développement, on en peut conclure que c'est aussi au milieu des eaux qu'auront paru d'abord les ètres animés, résultat qui śaccorde arec les observations des géologues et avec les récits de l'Écriture.

Le phrsiologiste peut de la sorte se rendre compte du mode actuel de répartition des animaux entre les deux éléments géolocriques qui se partagent la surface du globe, l'eau et la terre; mais ces différences fondamentales ne sont pas les seules que lon observe dans la distribution réographique des ètres animés. Si un naturaliste, familier avec la faune de son pays, visite des régions lointaines, il voit, a mesure qu il avance, la terre se peupler danimaux nouveaux à se's yeux, puis ces especes disparaitre a leur tour pour faire place à d'autres espèces également inconnues.

Si, quittant la France, il aborde dans le sud de l'Afrique, il n'y trouvera (qu'un petit nombre d'animaux semblables à ceux qu'il avait rus en Europe, et il remarquera surtout l'éléphant aux grandes oreilles. l'hippopotame, le rhinocéros à deax cornes, la girafe. des troupeaux innombrables d'antilopes, le zèbre; le buffle du Cap, dont les cornes recouvrent par leur base élargie tout le front; le liou à criniere noire; le chimpanzé, (qui, de tous les animaux, ressemble le plus à l'homme; le crnocéphale, ou singe à face de chien : les vautours d'especes particulières; une multitude d'olseaux à flumage brillant, étrangers à l'Europe ; des insectes également différents de ceus du nord, par exemple le termite fatul, qui vit en sociétés nombreuses, et élère avec de la terre des habitations communes d'une disposition tres-curieuse et d'une hauteur considérable.

$\$ 632$. Si notre zoologiste quitte le cap de Bonne-Espérance of pénète dans l’intérieur de la srrande île de Madagascar, il y trouvera encore une faune différente. La il ne verra aucun des grands quadrupedes qu'il avaut remarqués en Ifrique. ot la famille des 
singeses seia remplacée par d'autres mammiferes également bien conformés pour grimper aux arbres, mais ressemblant davantage aux carnassiers, et désignés par les naturalistes sous le nom de malis; il rencontrera l'aye-aye, un animal des plus singuliers, qui parait ètre l'objed d'une sorte de vénération de la part des habitants, et qui tient en mème temps du singe et de l'écureuil; des tenrecs, petits mammiferes insectivores, qui ont le dos épineux comme celui de nos hérissons, mais qui ne se roulent pas en boule; le caméléon à nez fourchu, et plusieurs reptiles curieux qu'on ne trouve pais ailleurs, ainsi que des insectes non moins caractéristiques de cette région.

$\$ 633$. Poursuivant encore sa route el arrivant dans l'Inde, notre voyageur y verra un éléphant distinct de celui d'Afrique; des bøufs, des ours, des rhinocéros, des antilopes, des cerfs, écalemient différents de ceux de l'Europe ou de l'Afrique; l'orang-outang et une foule d'autres singes particuliers à ces cortrées; le tigre royal, l'aryus, le paon, des faisans et une multitude presque innombrable d'oiseaux, de reptiles et d'insectes inconnus ailleurs.

$\$ 634$. Si ensuite il visite la Nouvelle-Hollande, tout y sera encore nouveau pour lui, et l'aspect de cette faune lui paraîtra encore plus étrangre que celle des diverses populations zoologiques qu'il avait déja passees en revue. Il n'y trouvera plus d'especes analosues à nos boufs, à nos chevaux, à nos ours et à nos grands carnassiers; les quadrupèdes de grande taille manqueront mème entierement, et il découvrira dés kanguroos, des phalanyers volants et des ornithorhingues.

$\$ 63 \ddot{3}$. Enfin si notre voyageur, pour revenir dans sa patrie, traverse le vaste continent de l'Amérique, il y découvrira une faune ayant de l'analogie arec celle de l'ancien monde, mais composée presque entierement d'espeeces différentes; il y rerra des singes à queue prenante, de grands camasiers assez semblables à nos lions et a nos tigres, des bisons, des lamas, des tatous: enfin des oiseaux, des reptiles et des insectes également remarquables et également nouveaux pour lui.

$\$ 636$. Des diflérences non moins grandes dans les especes ammales, propres aux diverses rérions du globe, śobservent lorsejuan lieu de s'en tenir a lobservation des habitants de la terre on examine les myriades dètres animés qui vivent an milien des eaux. En passant des còtes de l'Europe dans l'oeean indien, de de ce dernier dans les mers de l'Amérique, on rencontre des poisions, des mollusques, des crustateris ef des zoophy tes particuliers a chateun de res parages. Ce cantonnement des esperees, soit alquatiques, soit 
terrestres, est si marqué, qu'un naturaliste un peu exercé ne peut méconnaìtre, au premier coup d'ocil, l'origine des collections zoologiques quion aura recueillies dans l'une ou l'autre des grandes diviśions géographiques du globe, et qu'on solimettra à son examen. La faune de chacune de ces divisions offre un aspect particulier et peut ètre facilemeni caractírisée par la présence de certaines especes plus ou moins remarquables.

$\$ 637$. Les naturalistes ont imag̣iné plusienrs hypotheses pour se rendre compte de ce mode de distribution des animaux a la surface du globe; mais. dans l'ćtat actuel de la science, il est inpossible d'en donner une explication satisfaisante, à moins d'admettre que, dans l'origine des choses, les diverses especes ont pris naissance dans des régions différentes, et que peu à peu elles se sont ensuite répandues au loin pour occuper une portion plus ou moins considérable de la surface de la terre: En effet, la présence d'un animal particulier dans un point restreint du globe suppose nécessairement, lorsfue cet animal ne se rencontre pas ailleurs, qu'il est oriquaire de ce point ou bien qu'il y est arrivé par émigration d'une rézion plus ou moins éloignée, el qu'ensuite il aura été complétement détruit là où était le berceau de sa race; c'est-àdire précisément là ou, suivant toute probabilité, devaient se frourer réunies toutes les conditions les plus farorables à son existence. Rien ne milite en faveur de cette derniere hypothèse, et il répugne au sens commun de croire que, daus le principe, le mème pays a vu naitre le cheval, la girafe, le bison et le kanguroo, far exemple, mais que ces animaux lon! ensuite quitté sans y laisser de traces de leur passage, pour aller se cantonner, l'un dans les steppes de l'Asie centrale, l'autre dans l'intérieur de l'Afrique, Im troisieme dans le Noureau-Monde, et un autre encore dans les srandes iles de l'Australie. Il est bien plus naturel de supposer que chaque espèce a été, dès l'origine, placée par l auteur de toutes choses dans la réxion qu'elle était drstinée à habiter d'une maniere permanente, et que c'est en partant d'un certain nombre de ces centres de créations distinctes que les divers animaux se sont répandus dans toute l'étendue de la portion du globe qui forme aujourd'hui le domaine de chacun d'enx. Dans l'état actuel du globe, il nous est impossible de reconnaitre tous ces foyers zoologiques : car on conçoit la possibilité d'échanges si multipliés entre deux régions dont les faunes étaient primitivement distinctes, qu'elles puissent n'offrir aujourd'hui que des espèces communes à l'une et à l'autre, el alors rien ne décèlera aux yeux du maturaliste leur séparation originelle; mais lorsqu'ume contrés sera peuplée d'un 
nombre considérable d'espèces qui ne se roient pas ailleur's, mème là où les circonstances locales sont les plus semblables, on sera autorisé à penser que cette région a été le théatre d'une création zoologique particulière, et on devra la considérer comme une région distincte.

Ce que le naturaliste doit se demander, ce n'est donc pas comment il se fait que les divers points du globe soient habités aujourd'hui par des espèces différentes, mais bien comment les animaux ont pu se répandre au loin sur la surface du globe et comment la nature a posé à cette dissémination des bornes variables suivant les especes. Celte dernière question se présente surtout a l'esprit lorsqu'on voit combien est inégale l'étendue du domaine occupé aujourd'hui par tel ou tel ètre animé : l'orang-outang, par exemple, se trouve confiné dans l'ile de Bornéo et dans les terres roisines; le bouf musqué est cantonné dans la partir la plus septentrionale de l'Amérique, et le lama dans les rérions élevées du Pérou et du Chili; tandis que le canard saurage se montre partout, depuis la Laponie jusquau cap de Bonne-Espérance, et depuis les États-Unis d'Amérique jusquen Chine et du Japon.

Les circonstanees qui farorisent la diseémination des especes sont de deux ordres : les unes tiennent a la nature de l'animal luimème, les autres à des causes qui lui sont étrangèes. Au nombre des premieres, nons devons signaler d'abord le développenient de la puissance locomotive, toutes choses cogales dailleurs: les especes qui vivent fixées au sol ou qui ne possedent que des instruments imparfaits pour la locomotion noccupent qu'une portion bien restreinte de la surface du grlobe, comparées aux especes dont les mouvements de translation sont rapides et énergiques : aussi, parmi les animaux terrestres, sont-ce les oiseaus yui nous offrent le plus d'exemples d'espereseosmopmlites, et, parmi les animanx aquatiques, les rétacés et les poissons. Les reptiles, au contraire, sont pour la plupart cantonnés dans des limites étroites, of il on elet de mème pour la plupart des molluspues ot des crustaces. Läinstinct qui porte rertains animaus a chamger périodiquement de climat

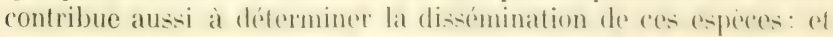
ret instinct, comme nous l'arons dejai vol, existe che\% un mand nombre de ces ètres.

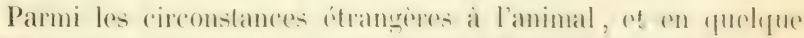
sorte accilentelles, qui eoncourent a amener le mème résultal, nous

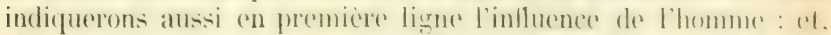

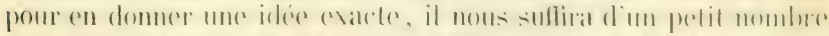

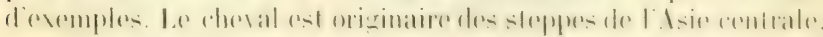


et, à l'époque de la découverte de l'Amérique, il n'esistait dans le Nouveau-Monde aucun animal de cette espèce; les Espagnols l'y ont transporté avec eux à une époque qui ne remonte pas au delà de trois siècles, et aujourd'hui, non-seulement les habitants de ce vaste continent, depuis la baie d'IIudson jusqu'a la Terrede-Feu, possedent des chevaux en abondance, mais ces animaux y out repris la vie sauvage, et s'y rencontrent par troupes presque innombrables. Il en est de mème de notre bouf domestique: transporté de l'Ancien dans le Nouveau-Nonde, il y a pullulé au point que, dans quelques parties de l'Amérique du sud, on en fait une chasse active dans le seul but de se procurer des peaux destinées à la fabrication du cuir. Le chien a été aussi partout le compagnon de l'homme, et nous pouvons ajouter encore au nombre des animaux, derenus cosmopolites à notre suite, le rat, qui parait originaire de l'Amérique, qui a envahi l'Europe durant le moyen âge, et qui se trouve maintenant jusque dans les iles de l'Océanie.

Dans quelques cas, les animaux ont pu franchir des barrières naturelles en apparence insurmontables, et se répandre sur un espace plus ou moins considérable de la surface du crlobe, à l'aide de circonstances dont l'importance semble d'abord bien minime. telles que le mouvement d'un fragment de glace ou d'un morceau de bois entrainé par les comants à des distances souvent trèsconsidérables; ainsi rien n'est plus commun que de rencontrer en mer, à des centaines de lieues de ioute terre, des fucus flottant à la surface de l'eau et servant d'appui à de petits crustacés incapables par eux-mèmes de se transporter à la nage loin des côtes où ils ont pris naissance. Le grand courant maritime qui, sortant du golfe du Mexique, còtoie l'Amérique septentrionale jusqu'à la hauteur de Terre-Neuve, puis se dirige vers l'Islande, l'Irlande, ef redescend vers les Açores, entraîne souvent jusque sur les còtes de l'Europe des trones d'arbres que le Mississipi avait arrachés dans les parties les plus reculées du Nouseau-Nonde et avait charriés jusquà la mer; or, ces bois sont fréquemment taraudés par des larves d'insectes et peuvent dommer attache à des geufs de mollusques ou de poissons, etc. Enfin il n'est pas jusqu'aus oiseaux qui ne contribuent à la dispersion des ètres virants à la surface du globe, et cela de la manière la plus singulière : souvent ces animaux ne digerent pas les œufs qu'ils avalent, et. les éracuant à des distances considérables du point où ils les avaient trouvés, transportent au loin les germes d'une race inconnue jusqu'alors dans les contrées où ils les déposent. 
Nalgré tous ces moyens de transport et d'autres circonstances propres à favoriser également la dissémination des espèces, il n'est que bien peu d'animaux réellement cosmopolites, et la plupart de ces ètres sont cantonnés dans des régrions assez limitées. Du reste, on comprend qu'il doit en ètre ainsi lorsquion étudie les circonstances qui peuvent s'opposer à leur progrès. Mais cette étude est loin de nous fournir une explication satisfaisante de tous les cas de circonscription limitée d'une espece, et il nous est souvent impossıble de deviner pourquoi certains animaux restent confinés dans une localité lorsque rien ne semble devoir s'opposer à leur propagation dans les localités voisines.

$\$$ 638. Quoi qu'il en soit, les obstacles à la dissémination géographique des espèces sont tantót tout mécaniques, d'autres foị physiologiques; et parmi les premiers on doit citer d'abord les mers et les hautes chaines de montagnes. Pour les animaux terrestres, en effet, les mers d'une certaine élendue sont en général une barrière infranchissable, et on roit que, toutes choses égales d'ailleurs, le mélange de deux faunes distinctes est toujours d'aulant plus intime que les régions auxquelles elles appartiennent sont plus rapprochées gréographiquement ou sont mises en communication par des terres intermédiaires. Ainsi l'océanie Atlantique empèche les espèces propres à l'Amérique tropicale de se répandre en Afrique, en Europe ou dans l'Asie; et la faune du Nouveau-Nonde est complétement distincte de celle de l'ancien continent, si ce n'est dans les latitudes les plus élevées, vers le pòle boréal; mais la les terres se rapprochent, l'Amérique n'est plus séparée de l'Asie que par le détroit de Berings, et se trouve liée au nord de l'Europe par le Groënland et l'Islande : aussi les échanges zoolowiques ont-ils pu seffectuer plus facilement, et on y trouve effectivement des espeers communes aux deux mondes : tels sont l'ours blane, le renne. le astor, l'hermine, le faucon pèlerin, laigle à tète blanche, ete. Les hautes chaines de montagnes constituent aussi des barrieres naturelles qui arròtent sourent la dispersion des esperes ef empredhent la fusion des faunes propres à des régions zoologriques voisines. Ainsi les deux versants de la Cordilliere des Indes sont habités par des esperes qui, pour la plupart, sont differentes; et les insectes de la rézion brésilienne, far exemple, sont presefue tous distincts de ceux qur l'on reneontre au Pérou ou dans la Nouvelle-Grenale.

La dispersion des animaux marins vivant pres des coites est entravée de la meme maniere par la configuration géographloigue du globe : mais ici ceses tantit une longue continuite de terres, tanteit une vaste étendue de haute mer gui sopposent a lat discéminalion 
des especes. Ainsi la plupart des animaux de la Méditerranée se retrouvent aussi dans la portion européenne de l'Itlantique, mais n'ont pu parvenir jusque dans les mers de l'Inde, dont la Méditerranée est séparée par le détroit de Suez, et n'ont pu traverser davantage l'Océan pour se répandre sur les còtes du NoureauMonde.

$\$$ 639. Les circonstances physiologiques qui tendent a limiter les diverses faunes sont plus nombreuses; mais celle qui se présente en première ligne est sans contredit la température inégale des diverses régions du globe. Il est des especes qui peuvent supporter également bien un froid intense et les chaleurs tropicales : l'homme et le chien, par exemple; mais il en est d'autres qui, sous ce rapport, sont moins favorisées de la nature et qui ne prospèrent ou mème ne peuvent exister que sous l'influence d'une température déterminée. Ainsi les singes, qui pullulent dans les régions tropicales, meurent presque toujours de phthisie lorsqu'ils se trouvent exposés au froid et à l'humidité de nos climats; tandis que le renne, conformé pour supporter les rigueurs du long et rude hiver de la Laponie, souffre de la chaleur à Saint-Pétersbourg, et succombe en sénéral assez promptement à l'influence d'un climat tempéré. Il en resulte que, dans un grand nombre de cas, les différences de climat sulfisent à elles seules pour arrèter les especes dans leur marche des latitudes élevées vers la ligne, ou des régrious équatoriales vers les poiles. L'influence de la lempérature sur l'économie animale nous explique aussi pourquoi certaines especes restent cantonnées dans une chaine de montagnes sans pouvoir se répandre au lom dans des localitŕs analogues. Nous savons en effet que la température décroit en raison de l'élévation du sol, et par conséquent les animaux qui vivent à des hauteurs considérables ne pourraient dearendre dans les plaines basses pour gagner d'autres montagnes sans trarerser des pays où la température est bien supérieure a celle de leur habitation ordinaire. Le lama, par exemple, abonde dans les herbag̣es du Pérou et du Chili situés à une élévation d'environ quatre ou cinq mille metres au-dessus du niveau de la mer, et s'étend au sud jusqu'a l'extrémité de la Patagonie; mais ne se montre ni an Brésil ni au Mexique, parce qu’il n'aurait pu y arriver sans descendre dans des régions trop chaudes pour sal constitution.

La nalure de la vérétation et de la faune préexistantes dans une région du grlobe influe également sur son envahissement par des repeeces exotiques. Ainsi la dispersion du ver a soie est limitée par la disparition du murier an-desius d'un certain degré do latitule: 
la cochenille ne peut se répandre au dela de la zone où croissent les cactus; et les grands carnassiers, à moins qu'ils ne vivent de poissons, ne peuvent exister dans les régions polaires, où les productions végétales sont trop appauvries pour nourrir un nombre considérable de quadrupèdes herbivores.

$\$ 640$. Il nous serait facile de multiplier les exemples de ces rapports nécessaires entre l'existence d'une espèce animale dans un lieu quelconque et l'existence de certaines conditions climatériques, phytologiques ou zoologiques; mais l'espace nous mantue pour ces détails, et les considérations que nous venons de présenter nous paraissent pouroir suffire pour donner une idée de la manière dont la nature a effectué la répartition des espèces animales sur les divers points de la surface du globe; et, pour atteindre le but que nous nous étions proposé en abordant ce sujet, il ne nous reste plus qu'à jeter un coup d’œil sur les résultals amenés par les diverses rireonstances dont nous renons de parler, c'est-a-dire sur l'état actuel de la distribution géographique des ètres animés.

Lorsuu'on compare entre elles les diverses récrions du globe sous le rapport de leur population zoologique, on est frappé d'abord par l'inégalité extrème qui s'y remarque dans le nombre des espèces. Dans telle contrée on rencontre une diversité extrème dans les formes et la structure des animaus dont sa faune est composée, tandis qu'ailleurs il règne à cet égard une grande uniformité; et il est facile de saisir une certaine relation entre les différents degres de richesse zoologrique et l'élévation plus ou moins considérable de la température. Effectivement, le nombre desespeces, tant marines que terrestres, augrmente en ggénéral à mesure que lon descend des poiles vers l'équateur. Le's terres polaires les plus reculies noffrent guere au voyageur que quelques insectes, et dans ces mers glacées les poissons et les mollusques mème sont peu variés; dans les climats tempérés, la faune devient plus nombreuse en especes: mais c'est dans les régions tropicales que la nature sest montrée le plus prodigue a cet égard, el le zoologiste ne peut roir sans élonnement la diversité sans fin des animatux qui sy trouvent accumulés.

On remarque aussi qu il existe une singuliere coüneidence entre l'élévation de la température dams les diflérentes régrions zoologriques et le degré de perfection organique des animax qui les habitent. C'est dans les climats les plus chauds que visent les animanx les plus voisins de lhomme et ceux qui dans chaque srande division zoologique possedent liorganisation la plus complipune of les facultés les plus développées. tandis que dans les rougons polaries 
on ne rencontre guère que des êtres occupant un rang peu élevé dans la série zoologique. Les singes, par exemple, se trouvent confinés dans les parties les plus chaudes des deux continents; il en est de mème des perroquets parmi les oiseaux, des crocodiles et des tortues parmi les reptiles, et des crabes de terre parmi les crustacés, animaux qui tous sont des plus parfaits de leurs classes respectives.

C'est encore dans les pays chauds qu'on trouve les animaux les plus remarquables par la beauté de leurs couleurs, la grandeur de leur corps et la bizarrerie de leurs formes.

Enfin il semble exister un certain rapport entre le climat et la tendance de la nature à produire telle ou telle forme animale. Ainsi on observe une ressemblance très-grande entre la plupart des animaux qui habitent les régions boréale et australe; les faunes des régions tempérées de l'Europe, de l'Asie et de l'Amérique septentrionale, offrent une grande analogie dans leur aspect général, et dans les contrées tropicales des deux mondes on voit prédominer des formes semblables. Ce ne sont pas des espèces identiques que l'on rencontre dans des régions distinctes et à peu près isothermes, mais des especes plus ou moins voisine's et qui semblent ètre des représentants d'un seul et mème trpe. Ainsi les singres de l'Inde et de l'Afrique centrale sont représcntés dans l'Amérique tropicale par d'autres singes faciles à distinguer des premiers; au lion, au tigre et a la panthere de l'ancien continent correspondent dans le Nouveau-Monde le conguar, le jaguar et l'oneclot. Les montạnes de l'Europe, de l'Asie et de l'Amérique septentrionale nourrissent des ours d'especes distinctes, mais n'offrant entre eux que des différences légères. Les phoques abondent surtout dans le voisinage des deux cercles polaires; et si l'on voulait chercher des prenves de cette tendance, non dans les classes les plus élevées du rèone animal, mais parmi les ètres inférieurs, on en trouverait de non moins évidentes : les écrevisses, par exenple, paraissent ètre confinées aux régrions tempérées du ylobe, et se trouvent répandues dans la plus grande partie de l'Europe par l'espece si commune dans nos ruisseaux; dans le midi de la Russie par une espèce différente, dans l'Amérique septentrionale par deux autres especes également distinctes des précédentes, au Chili par une quatrieme espeece. au sud de la Nouvelle-Ilollande par une cinquieme espece, a Nadagascar par une sixieme, et au rap de Bonne-Espérance par une septième.

La comparaison des faunes propres aux diverses régions zoologriques du globe conduit a d'autres résultats dont il est plus dificile 
de se rendre raison. Ainsi, lorsqu'on examine successivement l'ensemble des espèces qui habitent l'Asie ou l'Afrique et l'Amérique, on remarque dans la faune du Nouveau-Monde un caractère d'infériorité qui n'avait pas échappé au célebre Buffon. Effectivement, ii n'existe pas dans le Nouveau-Monde des mammiferes aussigrands yue dans l'ancien continent: on voit, il est vrai, dans l'Amérique septentrionale un nombre considérable de singes, mais parmi ces animaux il n'en est aucun qui soit l'égal de l'orang ou du chimpanzé; et ce soni des rongeurs et des édentés qui y abondent le plus, c'est-à-dire de tous les mammiferes ordinaires les moins intelligents. Enfin c'est clans l'Amérique qu'on rencontre les sarigues, animaux qui appartiennent it un type inférieur aux mammiferes ordinaires, et qui n'ont de représentant ni en Europe, ni en Asie, ni en Afrique. Si l'on passe ensuite du Nouveau-Monde dans une région plus nouvelle encore, dans l'Australie, on y trouvera une faune dont linfériorité se prononce davantage, car la classe des mammifères n'y est guère représentée que par des marsupiaux et des monothrèmes.

Quant à la délimitation des diverses régrions zoologiques qui se partagent le globe et a la composition de la faune propre a chacune d'elles, nous ne pouvons en traiter ici sans sortir du cadre tracé pour ce cours, et nous regrettons d'autant moins cette nécessité que dans l'état actuel de la science ces questions sont loin d'ètre résolues.

Nous terminerons mème ici nos études zoologiques, car le but que nous nous sommes proposé n'était pas la description particuliere de chacue animal ni l'énumération des caracteres propres a les faire reconnaitre ou à les grouper méthodiquement; nous voulions seulement donner dans ce cours des notions sur la nature ef sur les propriétés de ces ètres, esquuisser rapidement les traits principaus de leur histoire et fournir a nos jeunes lecteurs les connatissances généra!es les plus utiles a tous et indispensables a

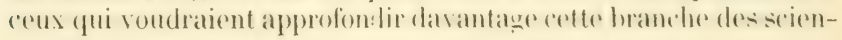
ces-d'observation. 



\section{TABLE DES MATIERES.}

NOTIONS PRÉLIMINAIRES. . . . . . . . . . . . . . . 3

Division des corps naturels en trois règnes. . . . . . . . . . . 5

Rapports sous lesquels on étudie les êtres virants. . . . . . . . . 10

Caractères généraux des animaux. . . . . . . . . . . . . . . 12

Tissus organiques des animaux et organes. . . . . . . . . . 13

Classification des fonctions. . . . . . . . . . . . . . 15

HISTOIRE DES PRINCIP.ILES FOYCTIONS DES INIMIIX.

Fonctions de xutrition. . . . . . . . . . . . . 17

Absorption. . . . . . . . . . . . . . 19

Digestion. . . . . . . . . . . . . . . . 25

Sang. . . . . . . . . . . . . 83

Circulation. . . . . . . . . . . . . . . . . t(0)

Respiration. . . . . . . . . . . . . . . . 81

Exhalation. . . . . . . . . . . . . . . . 97

Sécrétions. . . . . . . . . . . . . . 101

Assimilation et décomposition nutritive. . . . . . . . . . 110

Chaleur animale. . . . . . . . . . . . . . 116

Fonctions de relation. . . . . . . . . . . . . . . . 12l

Système nerreux. . . . . . . . . . . . . . . . . . . 123

Sensibilite. . . . . . . . . . . . . . . . . 1333

Toucher. . . . . . . . . . . . . . . . 141

Goût. . . . . . . . . . . . . . . . 141

Odorat. . . . . . . . . . . . . . . . . 116

Onïe. . . . . . . . . . . . . . . 144

Vue. . . . . . . . . . . . . . . 157

Mourcments . . . . . . . . . . . . . 171

Voix. . . . . . . . . . . . . . . 211

Intellyence et instinct. . . . . . . . . . . . . . . 220 
CONFORMATION ET CLASSIFICITION DES ANIMILX.

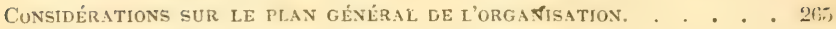

Classifications zoologiques. . . . . . . . . . . . . . . 281

Division du Règne aniınal en embranchoments et en classes. . • . . . 291

ANima ux vertébrés. . . . . . . . . . . . . . . . . . . 310

Mammifères: . . . . . . . . . . . . . . . . 313

Oiseaux. . . . . . . . . . . . . . . . . . 355

Reptiles. . . . . . . . . . . . . . . . . . . 395

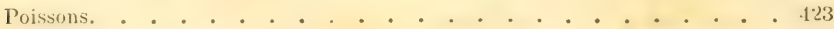

Animaux anvelés. . . . . . . . . . . . . . . . 450

ANimaux articulés. . , . . . . . . . . . . , . 45t

Insectes. . . . . . . . . . . . . . . . . . . . 455

Myriapodes. . . . . . . . . . . . . . . . . . 495

Arachnides. . . . . . . . . . . . . . . . . 493

Crustacés. . . . . . . . . . . . . . . . . 501

Cirrhipèdes. . . . . . . . . . . . . . . . . . 520

VERS. . . . . . . . . . . . . . . . . . 522

Annélides. . . . . . . . . . . . . . . . . . Ib.

Rotateurs. . . . . . . . . . . . . . . . . . 525

Helminthes, . . . . . . . . . . . . . . . . . 526

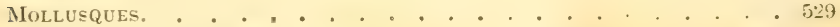

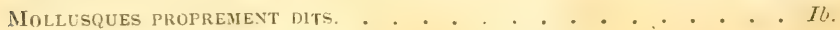

Céphalopodes. . . . . . . . . . . . . . . . 532

Gastéropodes, . . . . . . . . . . . . . . . 510

Ptérnpodes. . . . . . . . . . . . . . . . . . 514

Acéphales. . . . . . . . . . . . . . . . . . Il).

Molluscoides, . . . . . . . . . . . . . . . . 517

Tuniciers proprement dits. . . . . . . . . . . . . . 545

Bryozoaires. . . . . . . . . . . . . . . . . 549

Zuofhites. . . . . . . . . . . . . . . . . . Il.

Echinodermes. . . . . . . . . . . . . . . . 550

Acalèphes. . . . . . . . . . . . . . . . . 551

Polypes. . . . . . . . . . . . . . . . . . . 552

Infusoires. . . . . . . . . . . . . . . . . . . . 555

Spongiaires. . . . . . . . . . . . . . . . . . . 556

Distribution gÉograpitique des anjMAUX, . . . . . . . . . . 55: 




